\title{
La producción novelística de la "generación ausente" en el contexto de las memorias del pasado reciente argentino (1973-1983)
}

\author{
Autor: María Virginia Castro \\ Grado académico: Doctora en Letras -- Universidad Nacional de La Plata. Facultad de \\ Humanidades y Ciencias de la Educación -- Año aprobación 2015. \\ Director: Miguel Ángel Dalmaroni \\ Jurado: De Diego, José Luis; Franco, Marina; Kohan, Martín
}

\section{RESUMEN}

Ansgar Nünning y Astrid Erll (2003; 2005) y Astrid Erll (2005) han desarrollado las relaciones entre memoria y literatura introduciendo los conceptos de "memoria en la literatura: puestas en escena", "memoria de la literatura I: topoi e intertextualidad", "memoria de la literatura II: canon e historia de la literatura" y "literatura como medio de la memoria colectiva". Adoptando esta cuádruple distinción, la presente tesis doctoral se propone dar cuenta de la producción narrativa de la auto denominada "generación ausente" -conformada por autores nacidos alrededor del año 1960-, que tuvo entre sus preocupaciones principales tematizar el decenio 1973-1983, eligiendo para hacerlo la forma novela. Algunos de los escritores del corpus son: Carlos Gamerro, Matilde Sánchez, Daniel Guebel, Luis Chitarroni, Alan Pauls, Sergio Chejfec, Miguel Vitagliano, Gustavo Nielsen, Juan Forn, Carlos E. Feiling, Sergio Bizzio, Daniel Link, Martín Kohan, Damián Tabarovsky, Marcelo Figueras, Rodrigo Fresán y Ricardo Strafacce.

Al respecto, el primer capítulo de este trabajo está dedicado a debatir las diversas utilizaciones del concepto de "generación" en la sociología de la literatura argentina, concepto que, a partir de la década del ochenta cayera en general descrédito. En efecto: luego del triunfo de lo que Miguel Dalmaroni entiende como la " operación Raymond Williams' en Punto de Vista", se privilegiaron los conceptos de "grupo cultural" o "formación" de Raymond Williams para pensar colectivos culturales frente al de "generación". En nuestro trabajo, redefinimos "generación" como "construcción identitaria" (Cf. Jureit/ Wildt 2005) y "categoría de memoria" (Cf. Weigel 2005), esto es: entendida siempre como un constructo y en clave memorial, y en las antípodas de las formulaciones de matriz biologicista o embebidas de un afán matemático cercanas a la primitiva definición del concepto dada por José Ortega y Gasset.

En un contexto de publicación de sus primeras novelas donde las llamadas "narrativas sobre los años setenta" comienzan a proliferar y con un marco de "crisis del mercado editorial" (1976-1989) y “concentración y polarización de la industrial editorial" (19902000), los escritores estudiados se proponen volver a narrar la última dictadura, cuando la literatura ya no llenaría -como sí lo habría hecho en 1980- "un vacío de discurso" (Cf. Sarlo 2006). Sobre dicho contexto de publicación y numerosos análisis de la "memoria en la literatura" y la "memoria de la literatura I" observables en las novelas reseñadas versan los capítulos dos y tres de la presente tesis.

Una de las hipótesis fundamentales de nuestro trabajo es que los novelistas del corpus no sólo intervinieron en el campo literario en calidad de escritores, sino que fueron "críticos-estrategas" (en el sentido de Walter Benjamin) y "productores culturales" (en el sentido de Raymond Williams). Así, fueron miembros del staff de diversas revistas 
literarias, empleados de sellos ya existentes y/ o fundadores de las llamadas "editoriales independientes" y "editoriales artesanales", firmantes de textos de intervención -tanto en la prensa como en las dos últimas "historias de la literatura argentina" dirigidas, respectivamente, por Noé Jitrik y David Viñas-, pero también autores únicos de ambiciosos ensayos interpretativos donde se propone una determinada política de la literatura (en términos de Jacques Rancière), o bien un nuevo "canon" argentino. Por lo mismo, el capítulo cuatro de la presente tesis reseña estas intervenciones y las pone en diálogo con, por un lado, la producción estrictamente literaria de los novelistas del corpus, y, por el otro, con los que hemos hipotetizado como "cuatro grandes ciclos de canonización" ocurridos a partir de 1985, una vez mitigada la angustia de las influencias suscitada por Jorge Luis Borges.

El recorrido planteado en esta tesis doctoral permite arribar a la conclusión general de que los autores del corpus, a partir de una muy acertada lectura del estado del campo literario argentino de fines de la década del ochenta del siglo XX (momento de triunfo de la operación crítica que hiciera de Juan José Saer, Manuel Puig y Ricardo Piglia los tres "nombres del consenso"), lograron en tiempo récord revertir su lugar inicial de carencia. Lo hicieron percibiendo el lugar central que, tanto en términos de memoria colectiva como de "memoria en la literatura", "memoria de la literatura I" y "memoria de la literatura II" ostentaba el decenio 1973-1983, con un alto nivel de consciencia del potencial estratégico que tenía el comparecer como "generación ausente", y haciendo un uso deliberadamente ambiguo de la etiqueta de la "nueva narrativa", que continua circulando hasta el día de hoy como contraseña en nuestro alicaído mercado de libros.

\section{Palabras clave}

MEMORIA - PASADO RECIENTE ARGENTINO - NOVELA ARGENTINA "GENERACIÓN AUSENTE" 


\section{ÍNDICE GENERAL}

\section{AGRADECIMIENTOS [pág. 6] \\ INTRODUCCIÓN [pp. 7-35]}

\section{Capítulo 1. La "generación ausente" [pp. 36-90]}

1.1. La "generación ausente" según Lucas Rubinich (1985) y como tópico polémico en Los días del viaje

1.2. El concepto de "generación" en la sociología de la literatura argentina

1.3. Generación como "construcción identitaria" (Jureit/ Wildt 2005) y "categoría de memoria" (Weigel 2005)

1.4. Lecturas de las memorias del pasado reciente en la novela argentina: Sarlo (1987), Reati (1992), Piña (1993), Avellaneda (1997), Gramuglio (2002) y Dalmaroni ([2003] 2004)

1.5. Tres intentos de periodización de las memorias del pasado reciente en la novela argentina dependientes del "factor generacional": Ruiz (2005), Gundermann (2007) y Drucaroff (2011)

CODA. "Memoria en la literatura" y "memoria de la literatura I": la "generación ausente" en modo autoficcional

Conclusiones del capítulo

Capítulo 2. "Nosotros, los del ochenta": por una política de la literatura [pp. 91162]

2.1. El "Grupo Shangai” y el surgimiento de Babel, revista de libros ( $\mathrm{n}^{\circ} 1$ : abril de 1988 - $\mathrm{n}^{\circ}$ 22: marzo de 1991)

2.2. Tres notas metodológicas sobre el trabajo con publicaciones periódicas

2.3. Por una política de la literatura: "Rodolfo Walsh - Manuel Puig - Osvaldo Lamborghini” (Link 1989) ¿Una amalgama imposible?

2.4. Un contexto de publicación adverso y común: la crisis del mercado editorial (19761989) y el "alejamiento del lector nativo de la ficción" (1985-1990)

2.5. Escribir, publicar y editar en un contexto de "concentración y polarización de la industria editorial" (1990-2000)

2.6. Diversas acepciones de "lo nuevo". La experiencia cooperativa de Ediciones Tantalia en el contexto del surgimiento de las "nuevas editoriales independientes" de los años noventa

2.7. Con V de Vian contra Babel, revista de libros. Tres herederas disímiles de Babel: La Giralda, el perseguidor/ revista de letras y Magazín Literario

CODA. Ni "babélicos", ni "planetarios". Memoria en la literatura de la "Operación Raymond Williams"

Conclusiones del capítulo

\section{Capítulo 3. Las novelas [pp. 163-233]}

3.1. Los militantes populares como "víctimas absolutas" en Los planetas, de Sergio Chejfec 
3.2. ¿Quién de nosotros escribirá el "Deutsches Requiem" de la dictadura? Dos veces junio, de Martín Kohan

3.3. Volver a contar la guerra de Malvinas: Las Islas, de Carlos Gamerro como "memoria de la literatura I" de Los pichiciegos y "Los pasajeros del tren de la noche"

3.4. Tomar la voz de los "hijos tempranos" de los detenidos-desaparecidos

3.5. Carlos Gamerro, "crítico-estratega": su novelística como confluencia y desvío respecto a las tesis expuestas en "Argentine Literature and its Monsters" y El nacimiento de la literatura argentina y otros ensayos

3.6. Memoria del lector y "sobreinterpretación" en El coloquio, de Alan Pauls; Los ojos así, de Miguel Vitagliano; La perla del emperador, El terrorista y El perseguido, de Daniel Guebel

3.7. Politizar a César Aira: Auschwitz, de Gustavo Nielsen y Gerardo y Mercedes, de Ricardo Strafacce

3.8. La hipótesis de "la tensión literatura-mercado" (Caparrós 1991) usada a favor del trabajo de la memoria

3.9. Memoria y bestsellerismo: Jorge Asís y Jorge Lanata

CODA. Memoria y Premios. Algunos notas sobre el Apéndice 1

Conclusiones del capítulo

Apéndice 1: Ganadores de los premios Clarín de Novela, Planeta de Argentina, Herralde de Novela y Alfaguara de novela

Capítulo 4. "Memorias de la literatura II": la formulación de un canon [pp. 234332]

4.1. "Canon de mercado", "canon" y "contra-canon". A modo de mapa: cuatro grandes "ciclos de canonización" de 1985 a hoy

4.2. Divergentes "memorias de la literatura II": tres historias recientes de la literatura

4.3. Por una Literatura de izquierda: un contra-canon sin Juan José Saer. La polémica por el canon (2005)

4.4. Algunas notas sobre el canon argentino en La tierra elegida, de Juan Forn; El punto vacilante, de Sergio Chejfec; Con toda intención, de Carlos E. Feiling; Leyenda, de Daniel Link; Mil tazas de té, de Luis Chitarroni; Temas lentos, de Alan Pauls y Fuga de materiales, de Martín Kohan

4.5. "Críticos-estrategas": editores, exégetas y plagiarios

4.6. "Nueva encuesta a la literatura argentina (2000-2009)". "200 años, 200 libros. Recorridos por la cultura argentina": ingreso de tres miembros de la "generación ausente" en el "Canon del Bicentenario"

CODA. Crisis de 2001: "nuevas editoriales artesanales" y "primavera editorial" (20022004). Surgimiento de los "pequeños sellos editoriales" alrededor de la crisis económica de 2008

Conclusiones del capítulo

Apéndice 2: Nómina de las novelas escritas por la "generación ausente" reseñadas en el marco de la presente tesis con sus primeras ediciones y reediciones

Apéndice 3: Traducciones a lenguas extranjeras de las novelas escritas por la "generación ausente" reseñadas en el marco de la presente tesis 
BIBLIOGRAFÍA GENERAL

מם

Fuentes Primarias [pp. 343-353]

Fuentes Secundarias [pp. 354-384] 


\section{AGRADECIMIENTOS}

Las páginas que siguen, adjudicadas por entero a mi responsabilidad, se enriquecieron gracias a los diversos aportes que recibí a lo largo de la investigación, iniciada en el año 2006. Quisiera dejar expresado en primer lugar mi agradecimiento hacia Miguel Ángel Dalmaroni: su nivel de compromiso y generosidad al momento de supervisar mi trabajo llevan el concepto de "director de tesis" a otra dimensión. Mi gratitud para Julio Schvartzman y Daniel Balderston, que en invierno de 2007 corrigieron los primeros borradores de lo que luego sería mi Plan de Tesis. También para Nora Domínguez, Beatriz Sarlo, Régula Rohland, Miguel Vedda y Aníbal Jarkowski, de la UBA; Graciela Goldchluk, María Cristina Tortti, Verónica Delgado y Laura Juárez, de la UNLP; María Luisa Siguán Boehmer, de la Universidad de Barcelona; los profesores alemanes Helmut Galle, Marcel Lepper y Johannes Kabathek; Vera Carnovale, Eugenia Sik y Lucas Domínguez Rubio, del CeDInCI; Josefina Mallo, de la Biblioteca de Humanidades "Profesor Guillermo Obiols", y Guillermo Korn y Ariel Bermani, del Instituto de Literatura Argentina "Ricardo Rojas". Mi agradecimiento especialísimo para Martín Greco, Miguel Vitagliano y Horacio Tarcus, lectores y maestros apasionados. Gracias a Rodolfo Biscia, Marcos Guntín y Malena Chinski: por el diálogo siempre exigente y el tesoro de su amistad. Hago expreso mi reconocimiento hacia las autoridades del Instituto de Investigaciones en Humanidades y Ciencias Sociales (FaHCE-UNLP) -donde estuvo radicada mi investigación entre los años 2009 y 2014- y del Consejo Nacional de Investigaciones Científicas y Técnicas, que la financiaron. Gracias a Mara Ruth Glozman, por todo y ad eternum. A Viviana Lysyj: por compartir conmigo su colección de revistas. A Martín Koval, Verónica S. Luna, Valeria Sager, Juan Augusto Gianella, Paulo Ricci, María Paula Salerno, Ana Bugnone y Giselle Rodas, compañeros de tesis. A Maren Ahlzweig, por el asesoramiento lingüístico y, sobre todo, su enorme corazón. A los queridos amigos de tantos años, Marianela Cuzzani, Bibiana Beglau y Félix Busso: por la alegría y la visión anti academicista del mundo. A mi hermana Eugenia, que nunca necesitó leer para ser la más inteligente. Y, por último, muchas, infinitas gracias (otra vez) a mis padres, Graciela Tarchini y Oscar Castro, por los constantes intercambios de ideas, las críticas siempre constructivas y su apoyo incondicional durante todo el proceso de investigación y escritura de este trabajo.

Dedico la presente tesis doctoral a la memoria de mi abuelo Rubén, lector omnívoro y único viajero de la familia. 


\section{INTRODUCCIÓN}

Hablar hoy de narrativas sobre el pasado reciente es aludir a una considerable cantidad de discursos que desde hace casi cuarenta años participan de las "luchas por las representaciones del pasado" y las cambiantes políticas de la memoria en nuestro país. ${ }^{1}$ Habría - por lo menos- tres instancias en que el pasado cercano se transforma en objeto de asedio: durante los primeros cuatro años del gobierno alfonsinista (bajo la forma del llamado "show del horror", VER González Bombal/ Landi 1995 y Feld 2010), y alrededor del vigésimo (1996) y trigésimo (2006) aniversarios del golpe militar del 24 de marzo de 1976, ya que como señala Elizabeth Jelin, las "fechas redondas" son coyunturas de activación de la memoria y tienen el poder de interpelar tanto a la comunidad científica como a la sociedad en general, transformándose en momentos de intenso debate sobre las interpretaciones aparentemente ya consolidadas sobre una experiencia histórica para el otorgamiento de nuevos sentidos (Cf. 2000: 6-13).

Este trabajo se propone analizar cierta zona de la producción literaria argentina que apuesta a volver a narrar lo ocurrido en Argentina entre los años 1973-1983, contribuyendo a estatuir dicho período histórico en privilegiada "memoria en la literatura". 2 Más precisamente: las novelas escritas por narradores, que, habiendo nacido alrededor de 1960, comenzaron a publicar en un contexto-entre 1985 y 1990- de crisis del mercado editorial, bajo la discutida coyuntura del "alejamiento del lector nativo de la ficción", y -entre 1990 y 2000- de quiebra de editoriales locales y/o desnacionalización de las principales para la formación de grandes Grupos, proceso que, tanto en los años noventa como alrededor de las crisis económicas de los años $2001 \mathrm{y}$ 2008, se vio acompañado del surgimiento de las llamadas “editoriales independientes" y "editoriales artesanales".

Algunos de los nombres sobresalientes de este grupo de narradores son: Carlos Gamerro, Matilde Sánchez, Daniel Guebel, Luis Chitarroni, Alan Pauls, Sergio Chejfec,

\footnotetext{
${ }^{1}$ Las "luchas por las representaciones del pasado", como las define Elizabeth Jelin, "implican, por parte de los diversos actores, estrategias para 'oficializar' o 'institucionalizar' una $(s u)$ narrativa del pasado. Lograr posiciones de autoridad, o lograr que quienes las ocupan acepten y hagan propia la narrativa que se intenta difundir [...] implica una estrategia para 'ganar adeptos', ampliar el círculo que acepta y legitima una narrativa, que la incorpora como propia, identificándose con ella..." (2002: 36).

${ }^{2}$ Los conceptos de "memoria en la literatura"; "memoria de la literatura I"; "memoria de la literatura II"; y "literatura como medio de la memoria colectiva" que proponen Ansgar Nünning, Marion Gymnich y Astrid Erll (2003); Ansgar Nünning y Astrid Erll (2003; 2005) y Astrid Erll (2005) serán desarrollados en el marco de esta Introducción y utilizados a lo largo de nuestro trabajo. En todos los casos y a menos que se especifique lo contrario, las traducciones del alemán al castellano son propias.
} 
Miguel Vitagliano, Gustavo Nielsen, Carlos E. Feiling, Sergio Bizzio, Daniel Link, Martín Kohan, Juan Forn, Marcelo Figueras, Rodrigo Fresán y Ricardo Strafacce.

En un momento en el que claramente la literatura ya no operaba en una suerte de "vacío de discurso" si se acepta que aquel había sido el caso en el año 1980, cuando se publican las novelas Nadie nada nunca, de Juan José Saer; Respiración artificial, de Ricardo Piglia; Flores robadas en los jardines de Quilmes, de Jorge Asís; Soy paciente, de Ana María Shua (Cf. Sarlo 2006), los narradores de nuestro corpus buscaron legitimarse a partir de la construcción de una autoimagen de escritor colectiva de tipo generacional específica, esto es, la transformación de un mero dato biológico -el haber nacido alrededor de 1960: la formulación vuelve a ser deliberadamente laxa- en marca identitaria y prerrogativa para ser escuchados. ${ }^{3}$

En un contexto de publicación de sus primeras novelas (fines de la década del ochenta, comienzos de la década siguiente) en el que Juan José Saer y Ricardo Piglia eran percibidos de manera prácticamente unánime como los "nombres del consenso", se postularon a sí mismos como la "nueva literatura [política]". ${ }^{4} \mathrm{Y}$, desde un lugar de enunciación autoconstruido en términos generacionales, intervinieron en cuatro importantes debates sobre el pasado reciente.

\footnotetext{
${ }^{3}$ En 1988, María Teresa Gramuglio publica "La construcción de la imagen" en el $\mathrm{n}^{\circ} 4$ de la Revista de Lengua y Literatura que publica la Universidad Nacional de Comahue, donde señala que sería posible "leer un conjunto variado y variable de cuestiones: cómo el escritor representa, en la dimensión imaginaria, la constitución de su subjetividad en tanto escritor, y también, más allá de lo estrictamente subjetivo, cuál es el lugar que piensa para sí en la literatura y la sociedad" (1988: 3). Cuatro años más tarde, en "La construcción de la imagen" incluido en La escritura argentina editado por la Universidad del Litoral de Santa Fe, desarrolla el concepto y afirma que "los escritores, con gran frecuencia, construyen en sus textos figuras de escritor [...] imágenes que son proyecciones, autoimágenes y también anti-imágenes o contrafiguras de sí mismos" (Gramuglio 1992: 37). De los textos de cualquier escritor sería posible desprender una imagen: una idea de sí mismo en tanto escritor (una ideología literaria) y una idea de lo que la literatura es, o debería ser (una ética de la escritura). Y -siempre según Gramuglio- de dicha imagen parcial sería posible inferir un estado del campo literario, y sus conflictos. El concepto es retomado por María Alejandra Minelli en Con el aura al margen (Cultura argentina en los años '80/ '90), donde analiza las figuras de escritor de Manuel Puig, Copi, Osvaldo Lamborghini y César Aira en términos de los "condenaditos". Retomando a Gilles Deleuze y Félix Guattari en Mil mesetas. Capitalismo y esquizofrenia (1980), donde se afirma que el condenado dibuja la figura simétrica e invertida del rey, Minelli adjudica esta figura a los escritores nombrados, en tanto "la figura del condenado está pregnada por caracteres que enfatizan el desafío estético que lanzan y acentúa la visibilidad de este grupo que por aquellos tiempos pugnaba por el reconocimiento y el prestigio en el campo literario argentino" (2006: 94). También Julio Premat, en Héroes sin atributos. Figuras de autor en la literatura argentina (2007), analiza las "figuras" de Macedonio Fernández, Jorge Luis Borges, Antonio Di Benedetto, Osvaldo Lamborghini, Juan José Saer, Ricardo Piglia y César Aira. La hipótesis subyacente es que "la literatura moderna en Argentina [...] supondría, en paralelo con la producción de una obra, la construcción de una figura de autor. Una figura de autor, tanto en el plano tradicional y conocido de los medios culturales, académicos y editoriales, como, lo que es menos previsible, un personaje de autor, una ficción de autor en los textos" (2007: 15). Premat señala que la figura de autor es una "representación oximorónica". Esto es: "ser un gran escritor es no ser nada o nadie" (Ibid.).

${ }^{4}$ De cuánto esta percepción tiene de parcial y construida (por los mismos agentes del campo), volveremos en los capítulos dos y cuatro. La expresión "nombres del consenso" es de Matilde Sánchez (2000).
} 
El primero versó sobre la responsabilidad que les cupo a las propias organizaciones armadas en el proceso de su aniquilación, debido al "quiebre" de algunos militantes caídos en manos de las fuerzas represivas que, bajo tortura, pasaron a colaborar con los servicios de inteligencia. En este sentido, la novela El fin de la historia (1996) de Liliana Heker, que tematiza por medio de las convenciones de la roman à clef el "quiebre" de la oficial montonera real Mercedes Carazo y la relación que establece con su torturador, el ex marino perteneciente al grupo de tareas 3.3.2 Antonio Pernías durante su cautiverio en la Escuela de Mecánica de la Armada, constituiría la instancia de intervención más fuerte por parte de la literatura en dicho debate, que a nivel político -y en el seno de las organizaciones político-militares- había comenzado dos décadas atrás, a raíz del secuestro de Roberto Quieto en diciembre de $1975 .^{5}$

La virulencia de la polémica que rodeó la aparición de la novela de Heker se vuelve comprensible si recabamos en su fecha de publicación, dado que es también a mediados de la década del noventa del siglo XX cuando toma lugar el rescate del pasado militante de los detenidos-desaparecidos, en cuya imagen pública hasta el momento había prevalecido el carácter de víctimas del Estado terrorista. ${ }^{6}$

En esta resignificación de "víctimas" a "combatientes", coincidimos con Alejandra Oberti y Roberto Pittaluga (2006) en señalar el rol central que tuvo la publicación de los tres tomos de La Voluntad (1997/98), de Martín Caparrós y Eduardo Anguita, sin olvidar el lugar que le cupo al documental Cazadores de utopías (1996), de David Blaustein. Si bien, por razones que desarrollaremos en el capítulo uno (y a pesar de lo que podría deducirse de sus fechas de nacimiento), ni Caparrós ni Anguita se entienden a sí mismos como miembros de la "generación ausente" (y tanto en sus intervenciones públicas como en el alter ego presente en su novela, Liliana Heker se

\footnotetext{
${ }^{5}$ Roberto Quieto, miembro de la conducción nacional de Montoneros, es secuestrado el 28 de diciembre de 1975. Inmediatamente luego de su captura, se produce una seguidilla de secuestros, detenciones, desapariciones y pérdidas de infraestructura que permiten inferir que Quieto se ha "quebrado" y entregado información a las llamadas "fuerzas de seguridad". En febrero de 1976, un Tribunal Revolucionario acusa en ausencia a Quieto de traición, y lo condena a muerte, lo que suscita una enorme conmoción en el seno militante (Gillespie [1982] 1997: 266ss). El n 12 de Evita Montonera de febreromarzo de 1976 dedica el artículo "Juicio revolucionario Roberto Quieto" y la contratapa "La conducta revolucionaria" a analizar este caso. Asimismo, el editorial del $n^{\circ} 13$, que expresa la necesidad de, frente a la "delación de Quieto", abrir "un proceso de crítica y autocrítica dentro de Montoneros, que trate de encontrar las tendencias negativas que la hicieron posible" (Evita Montonera 13 1976: 2).

${ }^{6}$ Para una antología comentada de las intervenciones que conformaron la polémica que acompañó la publicación de El fin de la historia de Liliana Heker, VER Demarchi 2003.
} 
autoconstruye identitariamente como perteneciente a la generación de los militantes populares), creemos que tanto El fin de la historia como el texto firmado por Anguita y Caparrós resultan indispensables para contextualizar la publicación de Los planetas (1999), de Sergio Chejfec, autor que sí se coloca dentro de dicha generación.

Entre los sentidos que Los planetas propone, sería posible leer una toma de posición personalísima frente al debate que rodeó la reivindicación de la llamada "generación del setenta", ocurrida a partir de mediados de los años noventa hasta hoy.

Es indudable que las confesiones del ex capitán de marina Rodolfo Scilingo sobre su participación en los llamados "vuelos de la muerte" en febrero de 1995 (Verbitsky 1995) resultaron un hito en lo que hace a la autocrítica y asunción de responsabilidades castrenses (Canelo 2011). No obstante, la creación en abril de 1995 de la agrupación Hijos por la Identidad y la Justicia Contra el Olvido y el Silencio se revelaría en retrospectiva como el acontecimiento de la década. Desde su constitución como red con alcance nacional en octubre de 1995, H.I.J.O.S. se propuso intervenir activamente en el "trabajo de memoria", asumiendo un doble desafío. ${ }^{7}$

Por un lado, el deber de no traicionar las lealtades familiares y políticas que los unen a Abuelas y ex compañeros de militancia de sus padres asesinados. Por otro lado, el de no renunciar por ello a proponer narrativas subversivas, que apuesten conscientemente a hacer estallar los relatos familiares meramente luctuosos, censurados o incompletos, o bien artificiosamente montados sobre la figura de la "víctima inocente" o el "militante ejemplar" que otros familiares, ex compañeros de militancia de sus padres y demás agentes históricos han ido construyendo sobre los detenidosdesaparecidos.

\footnotetext{
${ }^{7}$ En Los trabajos de la memoria, Elizabeth Jelin explica que la noción de "trabajo de [la] memoria" remite a los conceptos freudianos de "trabajo de duelo" y "trabajo de elaboración", pero extendidos al plano social. Interesa que Jelin coloque el concepto de "trabajo" en el centro de su planteo, dado que con esto -y tal como ella misma se encarga de explicar- la capacidad de agencia del colectivo social es puesta en primer plano En palabras de Jelin: "El trabajo como rasgo distintivo de la condición humana pone a la persona y a la sociedad en un lugar activo y productivo. Uno es agente de transformación, y en el proceso se transforma a sí mismo y al mundo. La actividad agrega valor. Referirse entonces a que la memoria implica 'trabajo' es incorporarla al quehacer que genera y transforma el mundo social" (2002: 14). Sobre el concepto de "trabajo de memoria", Hugo Vezzetti escribe lo siguiente: "Desde mi óptica, significa resaltar que la memoria es una práctica social y que, en tanto trabajo, requiere de materiales, de instrumentos, de soportes [...] Antes que en la mente de las personas, la memoria social reside en artefactos materiales y públicos: ceremonias, libros, filmes, monumentos, aniversarios, lugares. Y la idea de trabajo debe ser tomada también en un sentido bien concreto: ese trabajo de la memoria tiene como condición para su desarrollo el hecho de que existan actores, iniciativas, esfuerzos, tiempo y recursos..." (2000: 19).
} 
En este sentido, la polémica alrededor de Los rubios (2003), de Albertina Carri, documental sobre la desaparición de sus padres Roberto Carri y Ana María Caruso (Legajo n. 1761 y 1771), detenidos-desaparecidos el 24 de febrero de 1977, sería la más visible de las suscitados por las narrativas de la posmemoria de H.I.J.O.S., aunque no la única. $^{8}$ Las remisiones al cine de Jean-Luc Godard y John Waters, el uso de la animación con muñecos Playmobil para hacer un docudrama del secuestro y la (ya tan comentada) escena de Los rubios donde la actriz Analía Couceyro - en quien desdobla la directora- aparece dándole la espalda al monitor desde el cual una ex compañera de militancia de su madre desaparecida da testimonio, fueron los mojones de la controversia que rodeó el estreno de este documental, y que se extendió hasta el BAFICI en su edición 2007, donde la directora presentó el libro Los rubios. Cartografía de una película, suerte de respuesta demorada a sus críticos.

Si traemos Los rubios aquí, es porque dos de los más activos defensores de Albertina Carri son autores de novelas que resultaron altamente significativas para pensar nuestro corpus: Martín Kohan y Alan Pauls. En el caso de Alan Pauls, no se limitó a defender la propuesta de Los rubios frente a sus detractores, sino que participó en la película en calidad de asesor de guión. Y todavía más: escribió y publicó la novela Historia del pelo (2010), segunda entrega de su "trilogía sobre los setenta", en la estela de lo que él entendió como la propuesta más novedosa de la realización de Carri: la “politización de lo trivial” (Pauls [2007] 2009).

\footnotetext{
${ }^{8}$ Con el término "posmemoria", Marianne Hirsch designa por primera vez en su artículo "Family Pictures: Maus, Mourning and Post-Memory" la memoria de la generación siguiente a la que padeció o protagonizó los acontecimientos. Mediante el comic Maus. Historia de un sobreviviente de Art Spiegelman (en dos partes: Maus I. Mi padre sangra historia de 1973 y Maus II. Y aquí comenzaron mis problemas, cuya primera edición es de 1986), Hirsch ejemplifica el concepto de "posmemoria", que define como "la del hijo del superviviente cuya vida está dominada por las memorias de aquello que precedió su nacimiento" (1992/ 93: 8). El prefijo "post" no implica que estemos más allá de la memoria, sino que es utilizado por Hirsch para distinguir esta "posmemoria" de la otra memoria (fruto de una experiencia directa). Son sus caracterísitcas el carácter ineludiblemente mediado de los recuerdos y el distinguirse de la Historia por la conexión emocional que mantiene con los hechos. El 1997, Hirsch publica el estudio Family Frames. Photography, Narrative and Postmemory, cuyo primer capítulo repite casi textualmente los conceptos desplegados cinco años antes. A la definición original de "posmemoria", se agrega ahora la siguiente precisión: a diferencia de la memoria, "está conectada a su objeto o fuente no mediante el recuerdo, sino mediante una investidura imaginaria y la creación" (Hirsch 1997: 22). Para una conceptualización de toda memoria en términos de "posmemoria", VER Sarlo (2005). Sobre la recepción de Los rubios, VER: Kohan (2004a; 2004b) y Macón (2004). Otras realizaciones cinematográficas de hijos sobre sus padres detenidos/ desaparecidos, tanto en registro documental como ficcional: Papá Iván (2000), de María Inés Roqué; Encontrando a Víctor (2004), de Natalia Bruchstein; El tiempo y la sangre (2003), de Alejandra Almirón; (H) Historias cotidianas (2001), de Andrés Habegger; $M$ (2007), de Martín Prividera; El premio (2012), de Paula Markovitch e Infancia clandestina (2012), de Benjamín Ávila.
} 
Pero Pauls no fue el único, ni el primero entre los autores de la "generación ausente" en hacer memoria en la literatura sobre el pasado reciente argentino desde la peculiar perspectiva generacional de los hijos de los detenidos-desaparecidos: también lo hicieron Rodrigo Fresán en Historia Argentina (1990), Carlos Gamerro en El secreto y las voces (2002) y Marcelo Figueras en Kamchatka (2003). ${ }^{9}$ En estas novelas, se apuesta a subvertir muy conscientemente los sentidos arrojados hasta el momento por el "trabajo de la memoria", aunque con un importante matiz: los que toman la palabra son hijos tempranos de los militantes populares, por lo que su reconstrucción de la vida y desaparición de sus progenitores no sólo discrepa, sino que -dada su capacidad de recordar por sí mismos- es también autónoma respecto a aquella que les ha sido transmitida por abuelas, tíos y compañeros de militancia sobrevivientes. ${ }^{10}$

El cuarto de los debates sobre el pasado reciente argentino, considerado por Horacio Tarcus (2006/2007) como el más importante entre los surgidos alrededor del trigésimo aniversario del golpe militar, fue iniciado en diciembre de 2004 desde las páginas de la revista cordobesa La Intemperie y tuvo como voces privilegiadas (aunque no excluyentes) las pertenecientes a algunos ex miembros del Ejército Guerrillero del Pueblo, liderado por Jorge Ricardo Masetti con apoyo de Ernesto "Che" Guevara, y activo en la provincia Salta entre los meses de junio de 1963 y abril de $1964 .^{11}$ Motivado por el testimonio de Héctor Jouvé sobre los fusilamientos internos de dos militantes del EGP, Adolfo "Pupi" Rotblat y Bernardo "Nardo" Groswald, acusados de “degradación física y moral” y ultimados en consecuencia por sus propios compañeros, el debate giró sobre las relaciones entre la violencia política y las prácticas que se pretenden emancipatorias, para luego tomar la inflexión más específica de los efectos que el uso de la violencia tuvo sobre las prácticas y valores sostenidos por las organizaciones político-militares de los años '60 y ' 70 .

\footnotetext{
${ }^{9}$ También Cristina Feijóo, ex presa política, asume en La casa operativa (2007) la perspectiva de un "hijo" para narrar la caída en 1972 de un grupo de militantes. Seis años antes, en Memorias del río inmóvil, la autora ya había hecho mimesis de la voz de un "hijo" para aproximarse al fenómeno de la apropiación de bebés y el robo de identidades. También lo hace Elsa Osorio en su novela $A$ veinte años $l u z$ (2006), que tuvo un año antes una primera versión como guión cinematográfico (Cautiva, con dirección de Gustavo Biraben). Por último, María Teresa Andruetto construye una tercera persona cercanísima a "Julieta", protagonista e "hija" de una militante-popular en Lengua madre (2010).

${ }^{10}$ Con el adjetivo "tempranos" se hace referencia a aquellos hijos de militantes populares nacidos unos quince años antes del Golpe de Estado de 1976, que perdieron durante la adolescencia a sus padres víctimas del terrorismo de Estado, o debieron exiliarse con ellos. Recordemos que en su página web, la agrupación Abuelas de Plaza de Mayo interpela en su búsqueda de nietos apropiados a aquellos nacidos entre 1975 y 1980.

${ }^{11}$ Para un estudio documentado y crítico sobre el Ejército Guerrillero del Pueblo, VER Rot [2000] 2010.
} 
Diversos textos (entre ellos, incluso algunos pertenecientes al género lírico, publicados como homenaje a los combatienes abatidos por la Gendarmería en el n ${ }^{\circ} 4$ de marzo de 1965 de La Rosa Blindada) hicieron "memoria en la literatura" de la experiencia foquista liderada por Masetti, utilizando diversos grados de ciframiento y alusión. Entre los pertenecientes al género narrativo: los cuentos "La guerrilla", de Raúl Damonte Taborda y "Los ojos del tigre", de Germán Rozenmacher (ambos publicados en 1967, dentro de sus respectivos volúmenes homónimos), y la novela Los guerrilleros (1968), de Iverna Codina. También hay menciones al EGP en Los cuadernos de Praga (1998), de Abel Posse y Los pasajeros del Anna C. (2012), de Laura Alcoba. No obstante, el texto de ficción que obtuvo mayor visibilidad fue el best-seller Muertos de amor, del periodista Jorge Lanata, que publicó Alfaguara (parte en ese entonces del grupo Santillana) en 2007, suscitando una considerable polémica entre los ex militantes del Ejército Guerrillero del Pueblo sobrevivientes y el autor, a quien los primeros acusaron de mala fe, simplificación histórica y oportunismo. Al respecto, su carácter de "mejor vendido" alerta sobre la necesidad de revisar otras cuestiones.

2012 fue el año en el que se cumplieron treinta años de años del conflicto bélico en el Atlántico Sur. Esta "fecha redonda" tuvo como principal efecto la revitalización a nivel diplomático del reclamo por la soberanía. ${ }^{12}$ Entre los eventos alusivos, se destacan por su carácter institucional las mesas redondas de discusión en torno a la cuestión Malvinas y la importante exposición de documentos relativos al reclamo, acompañados por textos historiográficos, periodísticos, testimoniales y literarios llevadas a cabo de abril a junio de 2012 en la Biblioteca Nacional ("Malvinas: archipiélago de la memoria"). En el contexto de dicha "fecha redonda", no parece fortuito que el Premio Clarín de Novela Edición 2012 le haya sido otorgado a Fernando Monacelli por Sobrevivientes, cuya trama se inicia con la aparición, tras permanecer casi 25 años cubiertos por la masa antártica, de los cadáveres congelados de tres héroes del Crucero General Belgrano.

Tanto el carácter de best-seller de Muertos de amor como la premiación de Sobrevivientes en la "fecha redonda" del conflicto bélico en el Atlántico Sur, nos conduce a la reconsideración de una hipótesis de trabajo por demás incómoda, enunciada a comienzos de la década del noventa por Martín Caparrós: la idea de que "la

\footnotetext{
${ }^{12}$ El 14 de junio de 2012, la presidente Cristina Kirchner lleva por primera vez el planteo de la soberanía argentina en las Islas ante el Comité de Descolonización de la ONU. Sobre la importancia de esta gestión, VER Ginzberg 2012.
} 
tensión de la literatura con el mercado reemplaza a la tensión con la política" (1991: 7). La formulación de Caparrós no es inocente, sino que entraría en diálogo polémico con aquella que postula que la tensión entre literatura y política fue la que predominó durante la década del setenta (tensión que se resolvería, incluso, con la disolución de la primera en la segunda, VER Sigal 1991: 249 y Gilman 2003: 158-187). Contra esto, Caparrós postula el surgimiento de una nueva tensión: "literatura-mercado", que persistiría hasta la actualidad.

De tomarse la hipótesis para su indagación, nuestro trabajo debería analizar las relaciones que las novelas del corpus establecen con el mercado editorial y el best sellerismo, en un contexto que determinados autores han caracterizado como de "proliferación" de materiales sobre la última dictadura y los llamados "años setenta" (Cf. Romero 1997; Lorenz 2001; Cerrutti 2004; Levín 2005; Basualdo 2006/ 2007).

El antecedente más evidente de esta problemática es el "caso Jorge Asís", cuya novela Flores robadas en los jardines de Quilmes fue un verdadero éxito de ventas, alcanzado en 1984 los 100.000 ejemplares vendidos en catorce ediciones por la editorial Losada, a los que se le sumaron los 80.000 ejemplares de la edición de bolsillo que lanzó la revista La Semana (Cf. Burgos 2003). En este contexto, la impugnación de Asís por parte de cierta zona de la crítica académica durante la década del ochenta (Avellaneda 1983; Marimón 1982; Sarlo 1987) y la polémica suscitada por su tardío rescate como el "maldito total de nuestra literatura" (Ludmer 2001) deberían ser leídas no sólo en términos literarios (se atacaría a Asís por ser un "mimético", un "populista"), sino también políticos: se atacaría a Asís por ser un ejemplo pionero de la mercantilización de la memoria.

A su vez, el debate alrededor del "caso Asís" nos alerta sobre la necesidad de difereciar en nuestro análisis entre "consagración literaria" y "éxito editoral", retomando para ello el espesor conceptual que despliega Nora Catelli en "Circuitos de la consagración en castellano: mercado y valor” ([2009] 2010).

En su aporte, Catelli define "valor literario" como "una categoría permeable, huidiza [...] una exigencia [...] en relación [...] con los ascensos y caídas de la close reading" (Catelli [2009] 2010: 5). En efecto: "sólo puede haber close reading si el texo soporta, sin ser destruido, que la lectura persiga [...] algún grado de experiencia estética" (Ibid.). Para Catelli, en los mecanismos de consagración ("ese espacio casi bélico para los diversos sectores que disputan el capital simbólico en el campo 
cultural") entrarían a jugar dos "principios de jerarquización": el dominante desde el punto de vista del mercado y el dominante desde el punto de vista de la autonomía (literaria).

En términos de Pierre Bourdieu, lo señalado explicaría la frecuente asimetría entre el valor cultural y el valor económico ostentado por determinados "bienes simbólicos". 13

Si bien coincidimos con Catelli en que "el mercado" no debe ser entendido como monolítico, sino que dejaría "zonas anárquicas fuera de él y también dentro", es importante no soslayar en nuestro análisis las nuevas condiciones en las que los autores estudiados publican, las que "aparentemente disuelven la cuestión del valor y también atenúan o neutralizan las posibilidades de una jerarquización no ligada al mercado" (Op. Cit. Catelli [2009] 2010: 6).

Por lo mismo, cabría hacer una evaluación matizada del rol que les cabe en la promoción de determinadas "memorias en la literatura" para la novela argentina (entre ellas y de forma acusada: la última dictadura militar) a los premios literarios, tanto a los organizados a nivel local (Premio Clarín de Novela y Planeta de Argentina) como a aquellos gestionados por editoriales españolas (Premio Herralde) y los grandes holdings (Premio Alfaguara de Novela).

Lo señalado hasta ahora exige explicitar algunas cuestiones, que pasamos a enumerar. Primera pregunta: ¿cuál sería la legitimidad de conformar un corpus de novelas? Segunda pregunta: ¿en qué nos basamos para titular nuestro trabajo "La producción novelística de la 'generación ausente' en el contexto de las memorias sobre el pasado reciente argentino (1973-1983)" por sobre otros sintagmas ya utilizados para remitir al mismo objeto de estudio en términos de la "novelística que representa la 'guerra sucia"” (Reati 1992), "narrativas de la guerra sucia" (Corbatta 1999), "novelas de la dictadura militar" (Gramuglio 2002) y "novelas argentinas sobre la dictadura"

\footnotetext{
${ }^{13}$ Sobre el concepto de "bienes simbólicos": la propuesta de Bourdieu desplegada en "El mercado de los bienes simbólicos" (1971) fue retomada en La distinción (1979) y en Las reglas del arte, cuya primera edición francesa está fechada en 1992, extenso trabajo que revisa y amplía algunos de los conceptos mencionados en "Campo intelectual y proyecto creador" (1966). Uno de los planteos centrales de Bourdieu en esta serie de ensayos puede reducirse a una formulación matemática: libro (bien simbólico) = valor cultural + valor comercial. Según Bourdieu, el libro es un bien simbólico que circula en nuestra sociedad y que es susceptible de recibir dos valores -las más de las veces- absolutamente divergentes: un "capital cultural" (obtenido a partir de buenas críticas en los medios, evaluaciones positivas por parte de otros escritores o figuras respetadas dentro del campo literario, otorgamiento de algún premio importante, inscripción en un catálogo editorial de prestigio), y un "capital comercial" (obtenido a partir de las cifras de venta, posición del libro en el ranking de los "más vendidos", reediciones, etc.).
} 
(Dalmaroni [2003] 2004)? Tercera pregunta: ¿cuál es exactamente la articulación "literatura-política" que nuestra tesis tiene como sustrato (articulación que, por otra parte, nos remite al viejo y problemático concepto de "literatura política")? Cuarta pregunta: ¿por qué pensar los narradores de nuestro corpus bajo el concepto de "generación ausente" cuando gran parte de los mismos ya han sido estudiados en términos de dos "grupos culturales" enfrentados (Berg 1996; Saítta 2004 y 2005; Botto 2006; Patiño 2006; Sager 2007)? Quinta pregunta: ¿por qué en nuestro trabajo damos una importancia crucial a la participación de los escritores estudiados en los procesos de formulación de determinadas "tradiciones selectivas" y/ o procesos de canonización de determinados autores de 1985 a hoy, y cómo se vincularía dicha participación respecto a las características peculiares que asumiría la producción novelística escrita por la "generación ausente" que hace "memoria en la literatura" del decenio 1973-1983? Sexta pregunta: ¿por qué poner en duda la pretensión de los narradores de nuestro corpus de encarnar la "nueva narrativa [política]"?

Respecto a la primera pregunta (“¿cuál sería la legitimidad de conformar un corpus de novelas?”), se adhiere al diagnóstico que hace José Luis de Diego en ¿Quién de nosotros escribirá el Facundo? Intelectuales y escritores en la Argentina (19701983) sobre "el lugar dominante que el género novela tuvo y tiene desde los setenta hasta hoy" (2001: 57) y en que sería posible postular una lectura "del campo literario en la posdictadura sub specie de novela", dado que "es [...] en los debates sobre el género donde se va reconfigurando el campo literario, con la emergencia de sus referentes más fuertes y el retroceso de las figuras que dominaron las décadas anteriores" (2001: 243). En un marco más general y retomando la definición ya canónica de "novela" de Mijail Bajtín en Estética y teoría de la novela (1975) y Problemas de la poética de Dostoievski (1978): si la novela se constituye a partir de un diálogo que es el entrecruzamiento, las alianzas, mezclas y pugnas de las ideologías, ella se constituiría en el medio privilegiado de comunicar la experiencia (cuya naturaleza continúa aún hoy en disputa) del pasado reciente argentino.

La segunda pregunta ("¿en qué nos basamos para titular nuestro trabajo en términos de 'La producción novelística de la generación ausente en el contexto de las memorias sobre el pasado reciente argentino (1973-1983)' por sobre otros sintagmas ya utilizados para remitir al mismo objeto de estudio?") se responde en dos partes. Por un lado, la pretensión de utilizar el decenio 1973-1983 en tanto "memoria en la literatura" 
en vez de "la dictadura" (esto es: los años 1976-1983) se funda en el consenso al día de hoy casi total entre los historiadores que se ocupan del pasado reciente argentino de que "la dictadura" no habría comenzado ex nihil con el golpe del 24 de marzo de $1976 .{ }^{14}$ Desde el concepto de "estado de excepción" que Giorgio Agamben toma de Carl Schmitt (Agamben 2006), la historiadora Marina Franco ha redefinido el período 19731976 como "parte de un continuo" que arrancaría como mínimo con la dictadura de la autodenominada "Revolución Argentina" (1966-1973), “dejando a la vista hasta qué punto la dictadura militar de 1976 se inscribió en una temporalidad fluida de la que fue un producto posible" (2012: 18).

Franco se ocupa de rastrear todas las leyes de índole represiva promulgadas por el último gobierno peronista que -aún antes del llamado "Operativo Independencia"colocó la solución del "problema subversivo" como objetivo de Estado. La clásica matriz de análisis basada en la alternancia "democracia-autoritarismo" (Cavarozzi 1983) se volvería por lo tanto inválida para conceptualizar el decenio 1973-1983, como ya lo ha señalado, entre otros, Roberto Pittaluga (2010). Por todo lo dicho, sería necesario proceder con cautela al momento de construir sintagmas con pretensión explicativa tales como "novelas de/ sobre la dictadura". 15

De todas formas, esto no es óbice para que la mayoría de los textos históricos de divulgación continúen usando hasta hoy la palabra "dictadura" en sus títulos, dada la gran circulación del término por fuera de la Academia, en otras palabras, en términos de memoria social. Por otra parte, si bien Marina Franco habla de "temporalidad fluida" o "continuidad relativa" (pensando el período 1973/76 desde el concepto de "estado de excepción", que Giorgio Agamben, retomando a Carl Schmitt, despliega en Estado de excepción. Homo saccer, II, 1), señala enfáticamente "el corte abrupto" que significó el golpe militar del 24 de marzo de 1976, considerado desde tres aspectos: la implantación por parte de las FFAA de un sistema concentracionario sistematizado a escala nacional; la metodología de la desaparición forzada de personas, junto con crímenes asociados

\footnotetext{
${ }^{14}$ Coincidimos con Cecilia N. Lesgart en que "1976-1983 ya no parece ser la temporalidad con la cual revisitar el pasado reciente en la Argentina. Ni 1976 significa el único y/ o primer momento de instalación de la violencia política, y 1983 se desvanece como gran línea inaugural de la política" (2006: 195).

15 Jorgelina Corbatta, al hablar de "narrativas de la guerra sucia" adoptaría inadvertidamente la perspectiva de los perpetradores. Mientras las FFAA utilizan el sintagma de la "guerra sucia", las diferentes agrupaciones político-militares en sus documentos internos y publicaciones refieren a una "guerra revolucionaria" (PRT-ERP), "guerra del pueblo" (FAR), o bien "guerra popular" (Montoneros). Ya para 1978, los Organismos de DDHH tabuizaron el uso de la palabra "guerra" para aludir a lo sucedido, y lo plantearon en términos de "genocidio". Sobre los debates acerca de la pertinencia o no de utilizar el término "genocidio", VER Sigal 2001. En términos estrictamente jurídicos, el uso del término "genocidio" ha sido desestimado por Rafecas (2011).
} 
como el robo de niños e identidades, y el afán refundador de la dictadura (con su importante faceta económica). ${ }^{16}$

Por otra parte, la pregunta “¿en qué nos basamos para titular nuestra indagación bajo los términos de 'La producción novelística de la generación ausente en el contexto de las memorias sobre el pasado reciente argentino (1973-1983)' ?" lleva implícito en su interior los desarrollos teóricos que proponen Ansgar Nünning, Marion Gymnich y Astrid Erll (2003); Ansgar Nünning y Astrid Erll (2003; 2005) y Astrid Erll (2005) para plantear de manera no mecánica la relación entre memoria y ficción. A saber: los conceptos de la "memoria de la literatura I: topoi e intertextualidad"; la "memoria de la literatura II: canon e historia de la literatura"; la "memoria en la literatura: puestas en escena" y la "literatura como medio de la memoria colectiva".

En el prólogo a una compilación de ensayos publicada en 2003, LiteraturErinnerung-Identität: Theoriekonzeptionen und Fallstudien [Literatura-RecuerdoIdentidad: Concepciones teóricas y estudios de caso], Erll, Gymnich y Nünning explican las líneas generales de su propuesta: ampliar la estrecha interrelación entre "recuerdo" e "identidad" a una tríada: "literatura", "recuerdo" e "identidad". La pregunta a responder es "qué rol juega la literatura en los procesos de interpretación individuales y sociales, cómo se alimenta de los fenómenos mentales, materiales y sociales de la cultura y cómo puede por su parte volver a surtir efecto sobre éstos" [2003: iii). Más suscintamente: “qué rol les corresponde a las obras literarias en el juego recíproco entre recuerdo e identidad" (Erll/ Gymnich/ Nünning 2003: iv). Los autores se apoyan en el modelo de la triple mimesis de Paul Ricoeur (1983/85) para dar la siguiente respuesta:

En primer lugar, la literatura está referida a y es preformada por una realidad extraliteraria precedente (prefiguración): las obras literarias surgen en el contexto de las culturas, en cuyos órdenes simbólicos circulan ya determinadas versiones y conceptos de memoria e identidad (objetivados en la interacción social, en textos de la tradición literaria y en los medios de otros sistemas simbólicos). En segundo lugar, los textos literarios pueden representar [darstellen] memorias e identidades (configuración): determinados contenidos pertenecientes a memorias individuales y colectivas, estereotipos de lo propio y de Lo Otro, pero también memorias y autoimágenes no sancionadas socialmente, excluidas y reprimidas son tomadas en consideración de manera modélica y tentativa dentro de un espacio marcado como ficcional y por medio de una serie de procedimientos estéticos específicos. Tales puestas en escena [Inszenierungen] literarias de la memoria y la identidad poseen -en tercer lugar- la capacidad de volver a actuar sobre la realidad extraliteraria (refiguración): la literatura ha tomado y

${ }^{16}$ Cf. Franco 2012: 316ss. Para un análisis de la faceta económica del autodenominado "Proceso de Reorganización Nacional”, VER Basualdo 2005; Damill 2005 y Morresi 2007. 
toma parte en la formación y reflexión de memorias e identidades de manera considerable. Las obras literarias -siempre y cuando encuentren lectores- modelan de manera conjunta y activa las versiones del pasado y las auto imágenes (tanto de tipo individual como colectivo). (Erll/ Gymnich/ Nünning 2003: iv-v)

En esta definición no queda explicitado qué se entiende por "realidad extraliteraria precedente", ni en cuáles términos ésta preformaría la literatura. Además, hay una utilización aproblemática del concepto de "representación" al momento de afirmar que "los textos literarios pueden representar [darstellen] memorias e identidades" durante la fase de la configuración. Si bien inmediatamente después se habla de las "puestas en escena [Inszenierungen] literarias de la memoria y la identidad", casi podría pensarse la utilización de este término, propio del arte teatral, como un desvío deliberado para evitar la discusión sobre el concepto de "representación", que el mismo desarrollo de la argumentación volvería por otra parte deseable.

El planteo de Paul Ricoeur aparece simplificado en exceso, especialmente en lo que hace a su lectura del concepto de mimesis aristotélica en términos de "mimesis creadora”. ${ }^{17}$ No obstante, en el trabajo „Gedächtniskonzepte der Literaturwissenschaft. Ein Überblick“ [Conceptos de memoria de la teoría literaria. Una mirada general”], que firman para el mismo volumen, Erll y Nünning recuperan en parte la densidad del concepto ricoeuriano de "mimesis creadora", y redefinen la dudosa categoría de "realidad extratextual" en términos de "orden simbólico". ${ }^{18}$

Como última crítica, se percibe una excesiva confianza en "los poderes" de la literatura en el marco de la fase de la refiguración. Lo dicho sobre esta instancia ("[las obras literarias] poseen la capacidad de volver a actuar sobre la realidad extraliteraria";

\footnotetext{
${ }^{17}$ En su artículo "Para una teoría del discurso narrativo" (1980), que adelanta las tesis que serán desarrolladas en los tres tomos de Tiempo y narración (1983/ 85), Ricoeur señalaba un importante malentendido: "tendemos a traducir mimesis por 'imitación', en el sentido de copia de un modelo preexistente. Pero Aristóteles tenía en mente un tipo de imitación completamente diferente, pensaba en una imitación creadora" ([1980] 1999: 140). Para apoyar esta afirmación, se recuerda al lector que la tragedia -según la define Aristóteles- "trata de representar a los hombres mejores (belíones) de los que son en realidad", por lo que "la mimesis no es un mera reduplicación de la realidad" (Op. Cit. Ricoeur 1980] 1999: 140).

18 "El proceso literario aparece entonces como un suceso activo y constructivo, del cual participan en la misma medida sistemas culturales dadores de sentido, procedimientos literarios y prácticas de recepción y en el cual la realidad no es simplemente reflejada, sino primero 'creada poiéticamente' y luego 'enriquecida icónicamente' [...] El orden simbólico de la realidad extratextual y los mundos creados en el medio de la ficción entran en una relación de influencia e intercambio mutuos. El modelo de la triple mimesis de Ricoeur puede contribuir a una diferenciación de los diferentes niveles de la relación entre literatura y memoria: las obras literarias refieren en primer lugar a la memoria extraliteraria, representan en segundo lugar sus contenidos y funciones en el medio de la ficción y pueden, en tercer lugar, marcar las memorias individuales y las culturas de la memoria.” (Erll/ Nünning 2003: 17)
} 
"la literatura ha tomado y toma parte en la formación y reflexión de memorias e identidades de manera considerable": nuestro énfasis) se volvería prácticamente insostenible ya a comienzos del siglo $\mathrm{XX}$, donde la literatura -frente a las narrativas que proponen los mass media y el cine- se constituiría como un discurso de efectos más bien limitados.

Este modelo inicial será condensado en el volumen Gedächtniskonzepte der Literaturwissenschaft. Theoretische Grundlegung und Anwendungsperspektiven [Conceptos de memoria de la teoría literaria. Fundamentación teórica y perspectivas de uso], que Astrid Erll y Ansgar Nünning compilan dos años más tarde, donde la relación entre literatura y memoria es explicada mediante cuatro conceptos-núcleo: la "memoria de la literatura I: topoi e intertextualidad"; la "memoria de la literatura II: canon e historia de la literatura"; la "memoria en la literatura: puestas en escena" y la "literatura como medio de la memoria".

Erll y Nünning entienden el concepto de "memoria de la literatura I" en el sentido de un genitivus subjectivus. Para el mismo, retoman el aporte de Renate Lachmann en Gedächtnis und Literatur [Memoria y literatura] (1990), donde ésta afirma que "la memoria del texto es su intertextualidad" (Lachmann 1990: 35). Lachmann define la intertextualidad como "espacio mnemotécnico que se despliega entre los textos, y [...] espacio de memoria al interior de textos concretos, que es construido por los intertextos inscriptos en ellos" (Op. Cit. 1990: 11). ${ }^{19}$ La literatura es considerada aquí un sistema simbólico.

En en caso de la "literatura de la memoria II" se trata de un genitivus objectivus. Los autores señalan que la "memoria de la literatura II" se efectúa en un marco institucional, a través de la construcción de cánones literarios e historias de la literatura. En este sentido, la literatura es considerada un sistema social. ${ }^{20}$

Con la "memoria en la literatura: puestas en escena" los autores se refieren a la "representación del recuerdo y la memoria en los textos literarios" (Erll/ Nünning 2005: 4). La cuestión a responder es "con qué procedimientos son tematizados y escenificados los contenidos y funciones de la memoria" (Ibid.).

\footnotetext{
${ }^{19}$ Si bien Lachmann reconsidera el fenómeno de la intertextualidad dentro de un marco teórico de tipo memorial, su formulación es deudora del concepto de dialogización de Mijail Bajtín en el ensayo "La palabra en la poesía y en la novela" incluido en Teoría y estética de la novela [1978] (1989) y de la lectura que Julia Kristeva realiza de él en términos de "intertextualidad" (Cf. Kristeva [1969] 1981; [1970] 1974), algo que se vuelve explícito en „Kultursemiotischer Prospekt“ ["Prospecto semióticocultural"], cuando Lachmann define la literatura y la cultura como un proceso continuo de "de- y resemantización" (Lachmann 1993: XVIII).

${ }^{20}$ Para la diferenciación entre orden simbólico y orden social, VER Schmidt 2000.
} 
El cuarto y último concepto-núcleo (la "literatura como medio de la memoria") remite a la pregunta de qué función puede cumplir la literatura en el seno de una cultura de la memoria. (Cf. Op. Cit. Erll/ Nünning 2005: 5). Se trata de un fenómeno de la recepción. A dicho fenómeno dedica Erll su aporte individual al tomo, bajo el título de „Literatur als Medium des kollektiven Gedächtnisses“ [“Literatura como medio de la memoria colectiva"].

Según Erll, la literatura cumpliría tres funciones: "almacenamiento" (guardar contenidos de la memoria colectiva y mantenerlos en disponibilidad a lo largo del tiempo), "circulación" (hacer circular y propagar versiones y contra-versiones del pasado, imágenes de la Historia y conceptos identitarios en una cultura de la memoria), y cue (ejemplificada por Erll mediante la cadena de asociaciones con la tradición alemana y la literatura nacional que se dispara al escuchar "Fausto" o "Wilhelm Meister", de manera independiente a si estos textos literarios han sido efectivamente leídos).

De las tres funciones adjudicadas a los textos literarios, nos interesa exclusivamente la de "circulación", puesto que ninguna de las novelas escritas por la "generación ausente" detenta el estatuto de "texto cultural" (canónico), necesario para la función de almacenamiento y/ o cue. ${ }^{21}$ Por otra parte, el único texto de nuestra tradición literaria que podría ser pensado en términos de cue, es el Martín Fierro, algo que resulta totalmente irrelevante en relación a la problemática abordada en nuestro trabajo, en cuya constelación conceptual la "memoria" es siempre de tipo colectiva, quedando fuera de nuestro planteo el concepto de "memoria cultural". ${ }^{22}$

\footnotetext{
${ }^{21}$ En su ensayo „Was sind kulturelle Texte?“ [“¿Qué son los textos culturales?”] publicado en 1995, Aleida Assmann diferencia entre "dos marcos de recepción [...] dentro de los cuales los textos se constituyen o bien como 'literarios,' o bien como 'culturales'" (1995: 234). Se trata de "maneras diferentes de ingreso a textos que bien pueden ser idénticos" (Ibid.). El otorgarle status de "cultural" o "literario" a un determinado texto se basa en el "acto decisionista" del receptor. De los tantos textos literarios que una sociedad produce y conserva, sólo a algunos se les otorga el status de "textos canónicos" (y esto significa para los Assmann "status de textos culturales"). Los textos culturales se distinguen de los textos literarios por medio de una forma diferenciada de aproximación y exégesis textual: en vez de la lectura privada, la distancia estética y la demanda de novedad propias de los textos literarios, la recepción de los textos culturales se caracteriza por "la veneración, el estudio repetido y la emoción" (Op. Cit. A. Assmann 1995: 242). La Biblia es para Aleida Assmann el "paradigma del texto cultural" (1995: 237).

${ }^{22}$ En 1992, Jan Assmann publica Das kulturelle Gedächtnis. Schrift, Erinnerung und politische Identität in frühen Hochkulturen [La memoria cultural. Escritura, recuerdo e identidad politica en culturas desarrolladas de la Antigüedad] dedicado a fundamentar la pertinencia del concepto de "memoria cultural", que aplica al análisis de tres culturas de la Antigüedad: Egipto, Israel y Grecia. El concepto de "memoria cultural" es expuesto en contraposición con un segundo concepto: el de "memoria comunicativa", que se apoya -aunque con una importante diferencia- en el de "memoria colectiva" de Maurice Halbwachs ([1925] 1992). Mientras que para Halbwachs es central el concepto de "marco" (familia, religión, clase social) para establecer la matriz social dentro de la cual se insertan los recuerdos
} 
Mientras los conceptos de "memoria de la literatura I: topoi e intertextualidad", "memoria en la literatura: puestas en escena" y "la literatura como medio de la memoria colectiva" son centrales para el desarrollo expositivo del capítulo tres (que se destina por entero al análisis de las novelas), el concepto de "memoria de la literatura II: canon e historia de la literatura" lo es para el capítulo cuatro (donde se da cuenta de determinados procesos de canonización de narradores discernibles de 1985 a hoy, en los cuales los escritores estudiados han tenido un rol principal, tanto como agentes de canonización, como, en algunos casos puntuales, objeto de la misma dentro de la nómina del llamado "canon del Bicentenario").

Para contestar la tercera pregunta (“¿cuál es exactamente la articulación "literatura-política" que nuestra tesis tiene como sustrato -articulación que, por otra parte, nos remite al viejo y problemático concepto de "literatura política-?”) retomamos el concepto de "política de la estética" en La política de la estética, ([2003] 2006), de Jacques Rancière, aunque circunscribiéndolo al objeto literario (lo que da como resultado el sintagma "política de la literatura", que es precisamente el título de un libro publicado por el teórico franco-argelino en 2007). Como señala Rancière en La política de la estética:

No es que el arte sea político a causa de los mensajes y sentimientos que comunica sobre el estado de la sociedad y la política. Tampoco por la manera en que representa las estructuras, los conflictos o las identidades sociales. Es político en virtud de la distancia misma que toma respecto de esas funciones.

(Op. Cit. Rancière [2003] 2006: 1)

individuales, la "memoria comunicativa" que proponen los Assmann se relaciona con las prácticas del recuerdo y la memoria individual, que circulan mediante la interacción de tipo cara-a-cara y que, por lo tanto, no se remontan más allá del miembro más anciano de la comunidad. El primer capítulo de Das kulturelle Gedächtnis. Schrift, Erinnerung und politische Identität in frühen Hochkulturen [La memoria cultural. Escritura, recuerdo e identidad politica en culturas desarrolladas de la Antigüedad] se destina a contraponer "memoria comunicativa" a "memoria cultural", explicitándose sus respectivas características: (1) mientras la "memoria comunicativa" refiere experiencias históricas contenidas en el contexto de una biografía individual, la "memoria cultural" tiene como contenido historias de tipo mítico, o acontecimientos de un pasado remoto; (2) mientras la "memoria comunicativa" se transmite mediante la interacción entre individuos, de manera informal y espontánea en el seno de una comunidad viva, la "memoria cultural" lo hace con un alto grado de formalismo mediante objetivaciones, rituales, escenificaciones, danzas o secuencias de acciones de tipo simbólico; (3) mientras la "memoria comunicativa" se remonta unos ochenta, máximo cien años atrás (dentro del horizonte temporal de tres o cuatro generaciones), la "memoria cultural" remite a un pasado remoto, una temporalidad mítica; (4) mientras la "memoria comunicativa" es detentada por testigos directos pertenecientes a una comunidad determinada, la "memoria cultural" lo es por especialistas en la transmisión cultural, que se encargan de promover determinados "textos" -el término debe entenderse en sentido amplio- a la categoría de "texto cultural" (Cf. Assmann 1992: 48-86). Existe traducción al castellano del artículo de Jan Assmann "¿Qué es la 'memoria cultural' ?" en el n 21 de Pensamiento de los Confines (diciembre de 2007). 
El concepto de "política de la literatura" es desarrollado in extenso en un artículo homónimo incluido en el ya mencionado volumen. Allí, Rancière explica que supone la existencia de un "lazo esencial" entre la política como forma específica de la práctica colectiva (en tanto "reconfigura el reparto de lo sensible", "hace audibles cual seres parlantes a quellos que no eran oídos sino como animales ruidosos") y la literatura como práctica definida del arte de escribir. La literatura "en tanto literatura" también haría política, pues participaría del reparto de lo sensible al intervenir -siempre según Rancière- "en la relación entre prácticas, entre formas de visibilidad y modos de decir que recortan uno o varios mundos comunes" (Cf. Rancière [2007] 2010: 16-17).

En el marco de nuestro trabajo, se articula el concepto de Rancière de la "política de la literatura" con lo propuesto por la llamada "generación Literal", que, desde una matriz teórica diferente, persiguió en los años setenta la consecución de una revolución en la literatura (desestimando por lo mismo la factibilidad de una "literatura revolucionaria" y/ o una "literatura política", que tendría por objetivo suscitar consciencia de las formas de dominación y aumentar así las energías revolucionarias). Es importante enfatizar el hecho de que la llamada "generación Literal" planteó dicha revolución en la literatura en términos de una "lectura activa de la tradición". ${ }^{23}$

El vínculo que los autores de la "generación ausente" plantean entre literatura y política aparecería por lo mismo tan próximo a la formulación de Rancière de la "política de la estética" como a la de los literalistas de una "lectura activa de la tradición literaria", aunque con una importante salvedad: se trata aquí de "políticas de la literatura" en plural, las más de las veces construidas por medio de la aleación (ligeramente transgresiva) de diferentes "poéticas" -en el sentido de Gianni Vattimo-, que ya estaban en disponibilidad. ${ }^{24}$

La cuarta pregunta (¿por qué pensar los narradores de nuestro corpus bajo el concepto de "generación ausente"?) se responde en el capítulo uno a partir de la

\footnotetext{
${ }^{23}$ Como señala Héctor Libertella en Nueva escritura en Latinoamérica (1977), remitiéndose a Edoardo Sanguineti (1969) el proceso de museificación de las vanguardias da un golpe irreversible a la creencia en la factibilidad de una "revolución en el arte" (y en el lenguaje). Para los autores de Literal y los representantes continentales del Neobarroco, se trata ahora de la consecución de una "vanguardia en el caballo de Troya": "hacer cosas nuevas con cosas viejas". En una formulación que confluye con ésta, Giorgio Agamben redefinió a "la vanguardia consciente" en términos de "un esfuerzo extremo por recuperar una relación con el pasado" ([1978] 2007: 201). Volveremos sobre estas definiciones en el capítulo cuatro.

${ }^{24}$ En Poesía y ontología (1993), Vattimo define "poética" como los "programas de arte propuestos, discutidos o combatidos por los artistas no sólo en sus obras de arte, sino con escritos y tomas de posición teóricas" (1993: 47). El siglo XX es según Vattimo el "siglo de las poéticas": la enunciación programática ha prevalecido sobre la producción de obras, de modo que las obras son ilustraciones provisorias de las poéticas.
} 
constatación de que la cohorte de nacimiento no asegura la univocidad de la construcción identitaria en términos generacionales, puesto que habiendo nacido alrededor de 1960, es posible autoconstruirse identitariamente como ex combatiente de Malvinas, temprano militante popular, activista cultural (éste es el caso de, por ejemplo, Salvador Walter "Batato" Barea, nacido en 1961), o miembro de la "generación ausente".

Desnaturalizando el general descrédito que aqueja hoy al concepto "generación literaria" como herramienta heurística, el capítulo inicial de este trabajo plantea un recorrido bibliográfico por diferentes textos, tanto por los que definimos como "de intervención" (manifiestos, entrevistas, editoriales de publicaciones periódicas), como por aquellos que se enmarcan disciplinariamente dentro la sociología de la literatura. En el recorrido, diferenciamos tres usos del concepto de "generación".

En primer lugar, un uso que podría pensarse en términos antropológicos como "nativo" (o visión emic), esto es, utilizado los propios agentes para autodefinirse, y, en el caso de la "generación ausente", con voluntad polémica, observable en, por ejemplo, el artículo "La generación ausente", de Lucas Rubinich publicado en el n 23 de Punto de Vista (1985) y la concomitante discusión suscitada alrededor de él en el número único de Los días del viaje, publicado en otoño de 1988 y dedicado en su totalidad al tópico de la "generación ausente".

En segundo lugar, un uso que se pretende analítico, deudor de las formulaciones de la "teoría de la generaciones" de José Ortega y Gasset ([1923] 2003; [1933] 1958) y del cual se reconocen en la sociología de la literatura vernácula una minoría de herederos: Emilio Carilla (1954), Adolfo Prieto (1954), Noé Jitrik (1959), Adolfo Arrieta (1958/ 60), Arturo Cambours Ocampo (1963) y Luis Gregorich (1968), entre los más destacados.

En tercer lugar, un uso meramente denominativo, que adopta el término de manera aproblemática en tanto ha cristalizado como modo de referir a, por antonomasia, la "generación del '80" del siglo XIX (presente tanto en la Historia de la Literatura Argentina que publica Ricardo Rojas entre 1917 y 1922, como en la que dirigen Adolfo Prieto y Susana Zanetti en las dos versiones de CAPÍTULO, lanzadas por CEAL en 1967 y 1979 como fascículos).

Dentro de la sociología alemana, la vigencia del discurso generacional para la asimilación del pasado alemán post 1945 ha hecho de él una "construcción identitaria" 
(Jureit/ Wildt 2005) y una "categoría de memoria" (Weigel 2005), conceptualizaciones que se apartan de manera considerable de la primitiva definición del concepto en clave histórico-cultural dada por Karl Mannheim en su clásico ensayo "El problema de de las generaciones" (1928) y Julius Petersen en "Las generaciones literarias" (1930). Sin plantear por ello ningún tipo de analogía historiográfica entre la Shoah y el Terrorismo de Estado, nos focalizamos en aquellas reformulaciones del concepto en la sociología de la cultura alemana que resulten operativas para el abordaje de nuestro propio objeto de estudio.

Entre los principales rasgos de la "generación ausente" (entendiéndola siempre no como un dato objetivo, sino como una "construcción identitaria", realizada por los propios agentes), se contarían el sostener no haber tenido ningún tipo de militancia durante los llamados "años setenta" y el plantearse la relación con la generación precedente en términos de "hermanos mayores" (Rubinich 1985) y bajo la figura del "coloquio" (Pauls 1983), esto es, apartándose del "modelo de conflicto" y del gesto parricida prototípicos de los que se autoproclaman la "joven generación”.

La "generación ausente" sería, por lejos, la autoconstrucción identitaria menos presente en la escena pública, y la más inestable. Por lo mismo, los escritores estudiados habrían procedido a hacer memoria en la literatura de su generación en novelas tales como Posdata para las flores (1991), de Miguel Vitagliano, Historia del llanto, de Alan Pauls y El desperdicio, de Matilde Sánchez (ambas de 2007). Al hacerlo, adherirían a la práctica de un subgénero novelístico particular: la novela que escenifica una generación literaria efectivamente existente mediante las convenciones de la roman à clef, la novela autobiográfica y el modo autoficcional (Fowler 1982), del cual existe un ejemplo célebre: Adán Buenosayres (1948), de Leopoldo Marechal. ${ }^{25}$ Todo lo señalado es tema de la coda correspondiente al capítulo uno.

Para responder la quinta pregunta ("¿por qué en nuestro trabajo damos una importancia crucial a la participación de los escritores estudiados en los procesos de formulación de determinadas "tradiciones selectivas" y/ o procesos de canonización de determinados autores de 1985 a hoy, y cómo se vincularía dicha participación respecto a

\footnotetext{
${ }^{25}$ Habida cuenta de que la bibliografía secundaria que estudió el período lo hizo dividiendo los agentes en dos "grupos culturales" antagónicos ("babélicos" VS. "planetarios") utilizando Babel, revista de libros como un polo, y la colección dirigida por Juan Forn como su opuesto (VER Berg 1996; Saítta 2004 y 2005; Botto 2006; Patiño 2006; Sager 2007), en la coda correspondiente al capítulo dos analizaremos cómo algunas novelas hicieron memoria en la literatura de este supuesto conflicto, lo que habría dado pábulo - desde la ficción- a dicha visión del campo literario.
} 
las características que asume la producción novelística escrita por la "generación ausente" que hace memoria en la literatura del decenio 1973-1983?") se comienza reponiendo la centralidad que tiene para nuestro trabajo el planteo que aparece en una de las secciones titulada "La técnica del crítico en trece tesis", incluida en el libro Dirección única, de Walter Benjamin, donde éste presenta una concepción esencialmente agonística del quehacer del crítico. Según ella, el crítico es fundamentalmente un "estratega en el combate literario". Ricardo Piglia retoma esta caracterización para circunscribirla a los agentes que también se desempeñan como escritores. Según su formulación en "Borges como crítico": "un escritor define primero lo que llamaría una lectura estratégica, intenta [por medio de su actividad como crítico] crear un espacio de lectura para sus propios textos" (Piglia [1997] 2000: 159).

Un hito en este sentido es la definición de cuál sería exactamente la "tradición de literatura [política]" reivindicada por varios de los agentes estudiados, que enuncia Daniel Link en enero de 1989 desde las páginas del nº 6 de Babel, revista de libros: una amalgama de las poéticas de Rodolfo Walsh, Osvaldo Lamborghini y Manuel Puig, cuestión sobre la cual nos extendemos en el capítulo dos.

La intervención de Link pide leída dentro del conjunto de autores que conforman la "tradición selectiva" que se dejaría inferir de la lectura de Babel, revista de libros ( $n^{\circ} 1$ : abril de 1988 - n 22: marzo de 1991): Juan José Saer, Ricardo Piglia, César Aira, Rodolfo Fogwill, Alberto Laiseca, Raúl Damonte Botana (“Copi”) y Marcelo Cohen (y también, aunque de manera no tan relevante para nuestro trabajo: Arturo Carrera y Héctor Libertella). ${ }^{26}$

A los fines de dilucidar qué grado de novedad entrañaba la postulación de dicha "política de la literatura" y tomando siempre Babel, revista de libros como eje, en el capítulo dos se recogen juicios de valor sobre estos autores publicados en las revistas Los libros ( $\mathrm{n}^{\circ}$ 1: julio de 1969 - $\mathrm{n}^{\circ}$ 44: enero/ febrero de 1976) y Punto de Vista $\left(\mathrm{n}^{\circ} 1\right.$ : marzo de 1978 - n 90: abril de 2008), señaladas por la bibliografía secundaria como antecedentes directas de Babel (Warley 1993; Avellaneda 1995; Bosteels/ Rodríguez Carranza 1995; Delgado 1996 y De Diego 2001).

\footnotetext{
26 En la definición clásica de Raymond Williams: la "tradición selectiva" es "una versión intencionalmente selectiva de un pasado configurativo y de un presente preconfigurado, que resulta entonces poderosamente operativa en el proceso de definición e identificación cultural y social" ([1977] 2009: 159).
} 
Asimismo, se revisa qué tradiciones selectivas proponen otras publicaciones periódicas más cercanas en el tiempo a Babel: Sitio $\left(\mathrm{n}^{\circ}\right.$ 1: diciembre de $1981-\mathrm{n}^{\circ}$ 6: mayo de 1987); El Porteño (n ${ }^{\circ}$ 1: febrero de 1982 - no 134: febrero de 1993); Pie de Página ( $\mathrm{n}^{\circ}$ 1: Primavera 1982 - n 3: Verano 1984/85); Diario de Poesía (nº 1: julio 1986 - no 83: 2011) y el suplemento “Culturas” de Páginal 12 (años 1987-1989, mientras Martín Caparrós y Jorge Dorio fueron sus directores). En este marco se hacen menciones específicas al $\mathrm{n}^{\circ} 51$ de la revista Vigencia (editada en el año 1981 por la Universidad de Belgrano) y a la sección "Literatura Argentina", firmada por Juan Sasturain durante todo el año 1981 para Humor registrado. ${ }^{27}$

El capítulo dos tiene además como segundo objetivo el relevamiento y análisis de datos sobre el contexto de "crisis del mercado editorial" (1976-1989) y el "alejamiento del lector nativo de la ficción" (1985-1990) publicados en el primer número de Pie de Página (Primavera de 1982), los números 30 y 81 de El periodista de Buenos Aires $\left(\mathrm{n}^{\circ}\right.$ 1: 15 de septiembre de $1984-\mathrm{n}^{\circ}$ 140: 15 de mayo de 1987); el $\mathrm{n}^{\circ} 8$ de Vuelta (marzo de 1987), el suplemento "Culturas" de Página/ 12 correspondiente al 27 de diciembre de 1987 y el suplemento "Cultura y Nación" de Clarín correspondiente al 15 de abril de 1988. Dos trabajos de referencia contextualizan las coyunturas mencionadas: “Apogeo y crisis de la industria del libro: 1945-1970”, de Jorge B. Rivera (1986) y El capital de la cultura. Las industrias culturales en la Argentina (2008), de Octavio Getino.

Asimismo, en el capítulo dos se releva el proceso de "concentración y polarización de la industria editorial" (1990-2000) mediante datos presentes en el Informe del Centro de Estudios para la Producción "La industria del libro en la Argentina" (que abarca los años 1990-2004) y artículos publicados en La Maga (n 1: septiembre de 1991- n 249: septiembre de 1998), contextualizándolos dentro de las descripciones más generales de

\footnotetext{
${ }^{27}$ Una revista surgida en los '90 pareció querer colocarse "en la vereda de enfrente" de Babel, revista de libros, reivindicando por lo mismo Libro de Manuel (1972), de Julio Cortázar y desestimando la propuesta de César Aira: Con V de Vian ( ${ }^{\circ}$ 1: diciembre de $1991-\mathrm{n}^{\circ} 42$ : noviembre/ diciembre de 1999). Por último, Babel tuvo como "continuadoras" tres revistas de muy diferente tenor: La Giralda (número único publicado en abril de 1995), el perseguidor/ revista de letras ( ${ }^{\circ} 1$ : mayo $1995-\mathrm{n}^{\circ} 12$ : Primavera/ Verano 2005) y Magazín Literario. Mapa mensual de cultura $\left(\mathrm{n}^{\circ} 1\right.$ : julio $1997-\mathrm{n}^{\circ} 6$ : diciembre de 1997). Muchos de los integrantes de las publicaciones mencionadas coincidieron tempranamente en los staff del suplemento literario de Página/12, llamado inicialmente "Culturas" del diario Página/12, luego "Primer Plano", más tarde "Radar", y, por último "Radarlibros" (n 1: 16 de noviembre de 1997 - hoy, con un cambio de formato en el n ${ }^{\circ} 358$ correspondiente al 12 de septiembre de 2004; entre 1998 y 2004 Daniel Link asume las funciones de editor, manteniéndose Juan Forn en la dirección hasta el año 2002).
} 
dicho contexto en Alatriste (1999), Schavelzon (2002), Rama (2003), y nuevamente Getino (2008).

Los años noventa fueron también ocasión del surgimiento de las llamadas "editoriales independientes", en un arco temporal que va de la rosarina Beatriz Viterbo (surgida en 1990, sus editoras son Adriana Astutti, Sandra Contreras y Marcela Zanín) a Adriana Hidalgo (surgida en 1999, sus editora general es Adriana Hidalgo y sus directores editoriales, Edgardo Russo y Fabián Lebenglik). Al respecto, cabe enfatizar que uno de los espacios privilegiados para la formulación de una "tradición selectiva", es la construcción de un catálogo editorial.

Por todo lo señalado, interesan en su doble rol de novelistas, editores (y, en un único caso, también albacea y plagiario) los miembros de la "generación ausente" Juan Forn, Luis Chitarroni, Miguel Vitagliano, Rubén Mira, Aníbal Jarkovski, Martín Kohan, Daniel Link y Ricardo Strafacce, que son tomados como "casos testigo" y contextualizados dentro de las cuatro grandes coyunturas editoriales ocurridas durante los últimos treinta y ocho años en nuestro país: la crisis del mercado editorial (19761989) y el "alejamieno del escritor nativo de la ficción" (1985-1990); la concentración editorial y el surgimiento de las llamadas "editoriales independientes" en la década del noventa; la aparición de las llamadas "editoriales artesanales" alrededor de la crisis de 2001 y la aparición de una segunda camada de "pequeños sellos independientes" alrededor de la crisis de 2008 en simultáneo con lo que podría pensarse el pico máximo de concentración editorial, reflejado en la compra el 19 de marzo 2014 de de los sellos comerciales de España, Portugal y Brasil de Santillana por parte de Penguim Random House (grupo Bertelsmann) por 72 millones de euros (las dos últimas coyunturas mencionadas, en la coda correspondiente al capítulo cuatro).

Ahora bien: la cuestión de qué características peculiares asumiría la producción novelística escrita por la "generación ausente" que hace memoria en la literatura del decenio 1973-1983 es desarrollada en el capítulo tres, donde se indaga la posible cualidad diferencial de las novelas de nuestro corpus en relación a la "tradición selectiva" a la que sus autores adhirieron en tanto "críticos-estrategas", para problematizar la hipótesis de partida de que estas adhesiones habrían mantenido una correspondencia directa con la propia producción narrativa.

En el marco acotado de esta Introducción, ejemplificamos lo dicho con la excepcional memoria en la literatura de la militancia de los "jóvenes menores" 
entendiéndolos como "víctimas absolutas" presente en Los planetas (1999), de Sergio Chejfec en un contexto de unánime reivindicación de la misma alrededor del vigésimo aniversario del Golpe; la memoria en y de la literatura de la figura del "segundón" afectado a tareas represivas en los centros clandestinos de detención, tortura y exterminio en la novela Dos veces junio (2002), de Martín Kohan; el intento por parte de Carlos Gamerro de emular en Las Islas (1998) a Los pichiciegos (1983), considerada hasta el momento la "gran novela" sobre Malvinas (Kohan 1994 y 1999; López 2010) y la asunción de la voz de los "hijos tempranos" de los militantes populares asesinados como una manera de apropiarse del novedoso espacio discursivo de H.I.J.O.S. en Calle de las escuelas $N^{\circ} 13$ (1999), de Martín Prieto; El secreto y las voces (2002), de Carlos Gamerro e Historia del pelo (2010), de Alan Pauls.

Si uno de los riesgos que corren las novelas que eligen narrar "el presente dictatorial en clave de pasado remoto" (Op. Cit. Avellaneda 1997: 153) es que un lector no avisado lea una mera narración ficcional de tipo histórico donde en verdad se le está proponiendo la recuperación de una memoria tanto más acuciante, el riesgo opuesto sería el de la sobreinterpretación. ${ }^{28}$ Precisamente, en su columna La Verónica del $n^{\circ} 19$ de Babel, revista de libros de septiembre de 1990, Martín Caparrós señalaba la posibilidad de leer La perla del emperador de Daniel Guebel en clave política (y en la desaparición del personaje de Li Chi, la cifra de la suerte de los detenidosdesaparecidos), al mismo tiempo que alertaba sobre el riesgo de realizar una lectura en dichos términos.

Podría afirmarse que tanto El terrorista (1998) como El perseguido (2001), de Guebel, optan por hacer del riesgo de la sobreinterpretación un procedimiento literario. En ellas, el pasado dictatorial se ve reducido a una serie de ítems léxicos: "los Aparatos de Estado", "el Terror", "la prensa de izquierda”, etc., que no terminan de armar sistema dentro de la trama total. Si el título, tal como también señaló Umberto Eco (1986), es la primera clave del contenido del libro y el disparador de las primeras conjeturas, para el caso de las novelas de Guebel, operaría como catalizador de la sobreinterpretación del lector. ${ }^{29}$ Por la contraria, tanto El coloquio (1991), de Alan Pauls como Los ojos así

\footnotetext{
${ }^{28}$ La sobreinterpretación es definida por Umberto Eco como: "la sobreestimación de la importancia de los indicios que nace con frecuencia de una propensión a considerar significativos los elementos más inmediatamente aparentes, cuando el mismo hecho de que son aparentes nos permitiría reconocer que son explicables en términos mucho más económicos" (Eco [1992] 1995: 52-53).

29 "Por desgracia, un título ya es una clave interpretativa. Es imposible sustraerse a las sugerencias que generan Rojo y negro o La guerra y la paz. Los títulos que más respetan al lector son aquellos que se reducen al nombre del héroe epónimo, como David Copperfield o Robinson Crusoe, pero incluso esa
} 
(1996), de Miguel Vitagliano apelan a los saberes del lector aprendidos en, para dar un ejemplo paradigmático, la lectura de Respiración artificial.

Por último, la indagación de la supuesta cualidad diferencias de las novelas escritas por "la generación ausente" se cierra en el capítulo tres con algunas notas sobre la articulación "memoria y bestsellerismo" y "memoria y sistema de premios".

Sobre el primer punto -y más allá de la calidad o disvalor de su prosa- se procede a indagar la condición de "mejor vendida" de la novela Muertos de amor (2007) del periodista-escritor Jorge Lanata. Asimismo, qué podría inferirse de la publicación en la colección Narrativas Históricas de Sudamericana de Los cautivos. El exilio de Echeverría (2000), de Martín Kohan. Este último escritor aprovecharía el auge de la novela histórica bestsellerista para usar la hipótesis de Martín Caparrós (Op. Cit. 1991) a favor del trabajo de memoria. Por último, el capítulo tres incluye algunas notas sobre el "Apéndice 1: Nombres de la 'generación ausente' dentro la nómina de ganadores de los premios Clarín de Novela, Planeta de Argentina, Herralde de Novela y Alfaguara de novela". Dado el carácter parcial de la muestra (porque sólo se compilan datos sobre cuatro premios de novela de los tantos existentes), no aspiramos aquí más que hacer algunos aportes preliminares a la problemática "memoria y sistema de premios".

Sobre el cambio de siglo, habida cuenta del capital simbólico acumulado por nuestros "críticos-estrategas", éstos apuntarán a imponer una "memoria de la literatura II" específica, con su concomitante y férreo sistema de exclusiones. En otras palabras: no ya una "tradición selectiva" determinada, sino un canon. ${ }^{30}$

Por lo mismo, el capítulo cuatro tiene como eje la memoria de la literatura II: "canon e historia de la literatura" desde la perspectiva y agencia de la "generación ausente". Asimismo, se introduce el concepto de "canon de mercado", que Marcos Mayer en su trabajo “¿Qué es el canon?” publicado en el $\mathrm{n}^{\circ} 189$ de $\tilde{N}$. Revista de Cultura del 12 de mayo de 2007 define como "la contra-cara del canon académico [...]

mención puede constituir una injerencia indebida por parte del autor. Papá Goriot centra la atención del lector en la figura del viejo padre, mientras que la novela también es la epopeya de Rastignac o de Vautrin, alias Collin. Quizás habría que ser honestamente deshonestos, como Dumas, porque es evidente que Los tres mosqueteros es, de hecho, la historia del cuarto." (Eco 1986: 10)

${ }^{30}$ Mientras el canon se propone como un modelo definitivo y supone procesos de selección, atribución de propiedades y modelización, que transforman a los textos en modélicos, esto es, en "obras sublimes y representativas" que conviven en el seno de la institución literaria como modelos positivos y patrimonio de la Humanidad (VER Bloom [1994] 2005: 11-14), la "tradición selectiva" es menos universalista y un poco más polémica. Supone zonas de fricción con otras tradiciones, exclusiones y/ o alianzas tácticas. Cuando un escritor mira hacia atrás y elige una tradición, esa tradición marca el camino que él mismo habrá de seguir. 
se conjuga inevitablemente en tiempo presente [...] forman parte de esa selección los autores que son muy leídos" (2007: 8), ejemplificándolo por medio de Osvaldo Soriano.

Para contextualizar las intervenciones de los autores estudiados, se despliega un mapa tentativo de cuatro grandes ciclos en los procesos de canonización, discernibles desde 1985 a la actualidad, que no se darían de manera consecutiva, sino por adición y superposición temporal. Durante el primer ciclo, aproximadamente en el decenio que va de 1985 a 1995, entrarían al canon argentino Ricardo Piglia, Manuel Puig y Juan José Saer (de su mano, Antonio Di Benedetto, cuya obra reedita Adriana Hidalgo a partir del año 2000). ${ }^{31}$ En el segundo ciclo, Osvaldo Lamborghini y Rodolfo Walsh (en tanto "maestro de estilo"). En un tercer momento (alrededor del año 2000) César Aira, Alberto Laiseca, Luis Gusmán y Copi. En un cuarto ciclo, se percibiría el ingreso inminente en el canon de Héctor Libertella y Rodolfo Fogwill (2009-hoy).

Hipotetizamos estos "cuatro ciclos de canonización" apoyándonos en cinco elementos, que ejemplificamos entre paréntesis. Uno: "hitos editoriales" (para el caso de Rodolfo Fogwill: la aparición en el año 2009 de sus Cuentos Completos en Alfaguara). Dos: la fijación de las "obras completas" y/ o reedición de obra que estaba descatalogada (la edición en 1988 de Novelas y cuentos de Osvaldo Lamborghini en Ediciones del Serbal de Barcelona, al cuidado de César Aira). Tres: la consagración internacional (el coloquio internacional César Aira: un episodio de la literatura argentina, celebrado en Francia entre el 14 y 17 de mayo de 2004). Cuatro: la aparición de un volumen de trabajos crítico-académicos firmado por agentes con alto capital simbólico que tenga a determinado autor como objeto exclusivo (la publicación en el año 2010 en Beatriz Viterbo de la colección de ensayos El efecto Libertella, al cuidado de Marcelo Damiani). Cinco: la traducción a lenguas extranjeras (la traducción en 2013 de Aventuras de un novelista atonal y el lanzamiento de la traducción colectiva de Los Sorias el francés por la editorial Le nouvel Attila).

En el capítulo cuatro se analizan asimismo las intervenciones contenidas en el onceavo tomo compilado por Elsa Drucaroff de la Historia crítica de la literatura argentina dirigida por Noé Jitrik (año 2000). El tomo es considerado en su totalidad

\footnotetext{
${ }^{31}$ También entre 1985 y 1990 Abelardo Castillo reinscribe a Leopoldo Marechal y Ricardo Piglia suma a Macedonio Fernández. De todas formas, estos dos nombres no tienen especial relevancia en el marco de nuestro trabajo, que focaliza en las "políticas de la literatura" en relación a la memoria del pasado reciente argentino. Sí la tienen los nombres de Andrés Rivera, Juan Carlos Martini y Héctor Tizón: aunque no ostentan el estatuto de "escritores canónicos", fueron repetidas veces mencionados en relación a las poéticas de la negatividad de Ricardo Piglia y Juan José Saer.
} 
como un "estado de la cuestión" en lo que hace a cuáles son los "nombres del consenso" sobre el cambio de siglo. Al respecto, no es casual que tanto la obra de Juan José Saer como la de Ricardo Piglia y Manuel Puig sean merecedoras de artículos extensos que las toman como objeto de análisis exclusivo (mientras que Rodolfo Walsh había detentado el mismo espacio en el tomo publicado en 1999, La irrupción de la crítica, compilado por Susana Cella). En el marco del análisis del onceavo tomo de esta Historia..., se pone especial atención a dos aportes firmados por miembros de la "generación ausente": Luis Chitarroni ("Continuidad de las partes, relato de los límites") y Martín Kohan ("Historia y literatura: la verdad de la narración”), y a la manera en que dichos aportes críticos articularían con sus propios proyectos literarios.

Como contraste, se indaga qué tipo intervención supondría la publicación en 2006 de una Breve historia de la literatura argentina en un único volumen, firmada por el poeta (aunque también novelista ocasional) Martín Prieto. Por último, se analiza De Alfonsín al menemato (1983-2001), séptimo tomo en el plan general y cierre por el momento de la accidentada Literatura Argentina del siglo $X X$, cuyo director fue David Viñas. Concebida no como mera "historia de la literatura" sino como "historia crítica", imbrincada en su contexto socio-político (en su contorno, para usar un término caro a su director), el volumen publicado en 2010 está nuevamente construido como mosaico de voces e intervenciones, y en él también se plasma una posible respuesta a la pregunta de cuáles son los nombres del canon, que tiene puntos de contacto pero también de divergencia con la respuesta dada diez años antes en el onceavo tomo de la Historia crítica de la literatura argentina, compilado por Drucaroff.

Una doble polémica sobre "canon" y "mercado" signa los primeros años del siglo XXI, que tuvo como disparador el ensayo Literatura de izquierda (2004), de Damián Tabarovsky. La tríada Libertella-Fogwill-Aira es subrayada dentro de un "contracanon" que incluye a Osvaldo Lamborghini, Néstor Sánchez, Puig, Copi, Zelarayán, Perlongher, Viel Temperley, Saer ("con mucha buena voluntad") y "a la desdichada Pizarnik" (Cf. Op. Cit. Tabarovsky 2004: 26). De esta nómina, por lejos lo más sorpresivo es la relativa poca importancia otorgada a la poética saeriana.

Guillermo Martínez, uno de los autores impugnados en Literatura de izquierda en tanto representante de "los jóvenes serios" (VER Tabarovsky 2004: 32-33), responde en su ensayo "Un ejercicio de esgrima", incluido en La fórmula de la inmortalidad (2005). En el marco de la polémica también interviene Martín Kohan. Cinco años más tarde, en 
su aporte para el tomo El efecto Libertella, compilado por Marcelo Damiani en 2010, Tabarovsky alerta que el principal problema al que se enfrentaría el "contra-canon" no es ya "la reacción" (como lo había señalado seis años antes en Literatura de izquierda), sino su neutralización por medio de un dispositivo consagratorio. ${ }^{32}$

Continuando con el tema de los "críticos-estrategas", se focaliza en algunas operaciones sobre el canon presentes en La tierra elegida (2005), de Juan Forn; El punto vacilante (2005), de Sergio Chejfec; Con toda intención (2005), de Carlos E. Feiling; Literatura argentina. Cuatro cortes (2006), de Daniel Link; Mil tazas de té (2008), de Luis Chitarroni; Temas lentos (2011), de Alan Pauls y Fuga de materiales (2013), de Martín Kohan. Importa recalcar el gesto de todos ellos de, luego del cambio de siglo, "hacer libro" de materiales que inicialmente habían sido pensados para soportes menos duraderos (prensa periódica, conferencias, ponencias en congresos, intervenciones en blogs). La excepción a lo señalado es la publicación post mortem de Con toda intención (2005), de Carlos E. Feiling, pensada por sus amigos como homenaje póstumo, lo mismo que la edición en 2007 de sus tres novelas éditas en un volumen único.

Durante 2009, en el marco de la finalización inminente del primer decenio del siglo XXI, la Ñ. Revista de Cultura lanzó una encuesta sobre "los libros de la década", que arrojó resultados cuyo análisis interesa para continuar perfilando la consolidación de una determinada "memoria de la literatura II", a nueve años de comenzado el segundo milenio.

El Bicentenario de la Revolución de Mayo fue motivo del lanzamiento de las colecciones Libros del Bicentenario (dirigida por Ezequiel Grimson: coedición de la Biblioteca Nacional con Ediciones del Zorzal) y la Serie de los Dos Siglos (dirigida por José Luis de Diego y Sylvia Saítta y editada por EUDEBA), y de la exposición "200 años, 200 libros. Recorridos por la cultura argentina" (20 de octubre de 2011 - 20 de enero de 2012) en el Centro Cultural Haroldo Conti, coorganizada por la Biblioteca Nacional. La zona literaria del catálogo de la exposición, creado a partir del voto de veintitrés notables de la cultura, interesa en tanto "estado de la cuestión" y para la discusión sobre qué nuevos escritores habrían ingresado al "canon" a diez años de

\footnotetext{
${ }^{32}$ En el tomo Dominios de la literatura. Acerca del canon (1998), compilado por Susana Cella, se revisa de manera independiente al desarrollo de Harold Bloom la productividad crítica del concepto de "canon". Uno de las hipótesis que recoge nuestro trabajo es la contenida en el artículo "Canónica, regulatoria y transgresiva", de Noé Jitrik, donde éste afirma que no es posible pensar "lo canónico" independientemente de "lo marginal" (Cf. Jitrik 1998: 19-41).
} 
comenzado el siglo XXI. En marzo de 2012, se lanza la Serie del Recienvenido (en Fondo de Cultura Económica: dirigida por Ricardo Piglia). En las tres Colecciones nombradas se destaca la presencia de determinados miembros de la "generación ausente", sobre cuya inclusión hipotetizamos algunas razones en el último capítulo de nuestro trabajo. Para la fundamentación de las mismas, se incluyen datos vertidos en los Apéndices 2 y 3.

Para responder la sexta pregunta (“¿por qué poner en duda la pretensión de los narradores de nuestro corpus de encarnar 'la nueva literatura [política]' y qué podría entenderse bajo este rótulo?") se vuelve imperioso señalar que prácticamente todos los autores analizados pretendieron nimbar su producción literaria con la etiqueta de "nueva narrativa", algo que por lo mismo debe ser objeto de cuidadoso análisis, para no confundir expresiones de los propios agentes con puntos de partida válidos para la investigación.

Dado que desde el inicio hemos puesto entre signos de pregunta el sintagma de "nueva narrativa", ya es momento de adelantar que la especificidad de las novelas del corpus residiría en que en ellas se deja traslucir una muy acertada lectura de las estrategias de reconfiguración del canon que se estaban dando de manera contemporánea a su escritura y publicación. Por lo mismo, las "aleaciones de poéticas" presentes en las novelas estudiadas deberían repensarse como parte de la creación de espacios transversales en el medio de los espacios que distribuyen e imponen las políticas mayores ("[micro]políticas de la literatura", en el sentido que le da al término Félix Guattari). Asimismo, la aspiración a "lo nuevo" se vincularía, más que con una cualidad textual constatable, con el afán de activar una lógica propia del "mercado de los bienes simbólicos", precisamente en momentos en que éste se encontraba sumido en una profunda crisis.

Por todo lo dicho, los autores estudiados elegirían presentarse como "generación ausente", con un alto nivel de consciencia de que la construcción de un espacio generacional específico les permitirá no sólo tomar la voz, sino también disputar en mejores condiciones por un lugar en el campo literario. Al hacerlo, operan no sólo como novelistas, sino también como editores, periodistas culturales, expositores en congresos y firmantes de artículos académicos.

En un contexto de publicación de sus primeras novelas (fines de la década del ochenta, primeros años de la década del noventa) económicamente muy adverso y de 
casi naturalización de la operación crítica que había hecho de las "escrituras elusivas" de Juan José Saer y Ricardo Piglia la forma modélica de referir lo ocurrido en Argentina durante la dictadura, los autores estudiados apostaron a la construcción de un lugar generacional específico que les permitiera no sólo tomar la voz, sino también postularse en términos de una (quizá) novedosa "política de la literatura".

La generación ausente salió de un "no lugar", tanto político como literario. Lo hizo con un alto grado de consciencia de las interrelaciones entre la intervención crítica y la producción ficcional. Para ello, sus miembros se autoconstruyeron identitariamente a partir de la negación de las posibilidades que -en términos de franja etaria- les eran perfectamente posibles: "los que no fuimos a Malvinas", "los que no militamos". Frente a otros colectivos poderosos, eligieron el lugar de la carencia. En este sentido, la toma de voz (tanto política como literaria) fue necesariamente colectiva y generacional. 


\section{CAPÍTULO UNO \\ LA “GENERACIÓN AUSENTE"}

\subsection{La "generación ausente" según Lucas Rubinich (1985) y como tópico polémico en Los días del viaje}

Uno de los episodios quizá menos estudiados de la última dictadura militar fue la pretensión de los militares involucrados en el llamado Proceso de Reorganización Nacional de recrear una "nueva generación del ochenta" y el contexto de modernización del país que los hombres de 1880 plasmaron a su imagen y semejanza. El "Proceso" no sólo se planteó como "poder desaparecedor" (Calveiro 1998; 2005), sino también quiso formular las bases de una generación del '80 "nueva", dando por "agotada" la anterior. De estas aspiraciones refundacionales, nos quedan -por lo menos- dos expresiones orgánicas: La segunda fundación de la República (1976), de Ricardo Zinn y Derecho a la esperanza (1978), de Carlos Conrado Helbling. Mientras el primero buscaba inspiración en las ideas de José Ortega y Gasset para anunciar el advenimiento (matemáticamente inevitable) de una nueva generación del '80, el segundo prefiguró esa generación como resultado de la conjunción entre miembros de las Fuerzas Armadas y los sectores más lúcidos de la civilidad, un proyecto en cuyo marco cobraría sentido el programa de "recuperación de prisioneros" llevado a cabo por el ex Almirante Emilio Eduardo Massera en la Escuela de Mecánica de la Armada. ${ }^{33}$

En respuesta, el suplemento cultural del diario La Opinión (dirigido entre agosto de 1975 y julio de 1979 por Luis Gregorich y, más tarde, por Raúl Vera Ocampo) publicó entre diciembre de 1977 y diciembre de 1980 una serie de cinco artículos sobre la generación del '80, denunciando - de manera asordinada a causa de la censura

\footnotetext{
${ }^{33}$ Como se señala en el Informe de la CONADEP, la ESMA era una excepción a la política de las FFAA de no dejar a ningún detenido libre (ni vivo). En este "campo de recuperación" se distinguían tres grupos de prisioneros: (1) la inmensa mayoría, que siguió el destino secuestro - tortura - permanencia en "capucha" - "traslado"; (2) una ínfima minoría de los secuestrados, que fueron seleccionados y aceptaron la oferta de seguir vivos a cambio de convertirse en "fuerza propia" del Grupo de Tareas. Colaboraban directamente con la represión y fueron llamados "mini-staff"; (3) otra insignificante cantidad de secuestrados -en relación al total- que por su historia política, capacidad personal o nivel intelectual cumplieron funciones de diversa utilidad para el GT. Entre ellas: recopilación y traducción de recortes periodísticos de la prensa nacional y extranjera; elaboración de síntesis informativas; realización de trabajos monográficos sobre problemas diplomáticos, limítrofes y políticos; elaboración de documentos de análisis de coyuntura; clasificación y mantenimiento de los objetos robados en los operativos y tareas de mantenimiento del campo (electricidad, plomería, carpintería, etc.). Este tercer grupo, formado a principios de 1977, fue llamado "staff". (Para una distinción más completa entre las funciones del "ministaff" y el "staff", y una sesgada defensa del "staff" como espacio de resistencia dentro de la ESMA, VER Calveiro 1998: 118-124.)
} 
imperante y apostando a que el lector sabría cotejar las dos épocas y sacar sus propias conclusiones- esta apropiación por parte de los militares. A saber: "Estanislao S. Zeballos: el hombre múltiple”; “Joaquín V. González: el activo meditador de Samay Huasi"; "Lucio V. Mansilla: gran señor del '80"; "Eduardo Wilde (positivismo con humor y ternura)" y "García Merou: el joven crítico". En la serie es significativa la ausencia de un trabajo sobre Miguel Cané, el más xenófobo, reaccionario y racista de los miembros de la generación del ' $80 .^{34}$

Ya en democracia, el sintagma "generación del '80" para referir a los jóvenes menores cuando se produjo el golpe de Estado del 24 de marzo de 1976 comenzó a circular de manera aproblemática dentro del periodismo cultural. Al respecto, ya finalizando la década, Claudia Feld y Mariela Govea señalaban humorísticamente lo siguiente:

Hablar de generaciones es un viejo truco de críticos desocupados, editores desesperados o escritores sin texto. Como hace mucho que no había una, últimamente hubo que inventar la del '80. Es bien sabido que Pasteur acabó no sólo con la leche sino también con el mito de la generación espontánea: así que ésta, como cualquier otra, es una trabajosa construcción de la poiesis, una ficción casi detectivesca, un mito innecesario. (Feld/ Govea 1987: 72)

Dos años antes, desde las páginas del $\mathrm{n}^{\circ} 23$ de Punto de Vista, Lucas Rubinich había hecho en "Retrato de la generación ausente" un uso mixto del término: en tanto "categoría analítica" (con pretensión explicativa) y como "categoría nativa" (puesto que él mismo se coloca como "informante" y dentro de la "generación del ochenta" que pretende delimitar).

Según Rubinich, los miembros de la "generación ausente" ostentan las siguientes características: (1) una condición etaria laxamente común, dado que se trata de una generación conformada por los que "hoy tenemos un poco más o poco menos de treinta"; (2) la duda sobre la pertinencia de autoproclamarse y/ o dejarse etiquetar como "los 'nuevos' intelectuales de la década del '80"; (3) la dificultad para ganar la condición de "éditos", en un contexto de crisis del mercado editorial; (4) la condición de "viejos prematuros" (la carencia de "fervor"); (5) la imposibilidad de cometer "parricidio" contra la generación precedente, dada el área de vacancia en el campo intelectual argentino provocada por el exilio de muchos intelectuales y escritores, la desaparición y el silenciamiento de otros, y el desmantelamiento de los cuerpos

\footnotetext{
${ }^{34}$ Para una antología comentada de los artículos publicados en La Opinión, VER Montergous 1985.
} 
docentes universitarios durante el llamado "Proceso"; (6) la figura de "los hermanos mayores" como consecuencia de lo señalado en el punto anterior para pensar el vínculo con la generación precedente; (7) el contar con una formación deficiente, de carácter autodidacta, impartida en el mejor de los casos de manera informal por los "hermanos mayores" (organizadores bajo dictadura de talleres "secretos" de lectura y discusión de textos prohibidos). ${ }^{35}$

El diagnóstico que hace Rubinich sobre su generación es severo: se autoacusa de "contar con una escasa producción y una deficiente formación, de poseer una casi inexistente presencia en el campo intelectual" (1985: 45). Al mismo tiempo, la carencia de un pasado militante a reivindicar es vista como una ventaja: "creo que nosotros podemos ser más serenos [...] revisar más desprejuiciadamente esa cultura de izquierda de los años '60 de la que ellos fueron protagonistas [...] mirarla con cierta distancia..." (Ibid.).

Esta caracterización fue respondida por María Matilde Ollier y Andrés Thompson en el $\mathrm{n}^{\circ} 25$ de Punto de Vista, bajo el título de "Trascendente... intrascendente". En su réplica, Ollier y Thompson atacan la visión "globalizadora y homogeneizante" que presenta Rubinich de la "generación ausente", poniendo el énfasis en el "clima de iniciación” común a la generación del sesenta y la generación que nos ocupa:

Llegamos, nos incorporamos a la política en una época contestataria y convulsiva donde comenzaban a "confirmarse" las profecías que otros, más viejos que nosotros, habían largamente meditado. Como bien dice Lucas, nos presentamos a la hora de la acción, apogeo - no decadencia- de un proceso que combinaba extensas elaboraciones teórico-políticas (que sucedieron a la caída del peronismo) con los vientos revolucionarios que, desde Cuba, recorrían el subcontinente latinoamericano. Compartimos con nuestros predecesores esa cultura política, aunque nuestra tardía incorporación nos llevó a ocupar un lugar diferente: ellos como hacedores político-intelectuales, nosotros como aprendices. El derrumbe posterior al golpe de Estado arrastró a expertos y novatos. La falta de "faros" y la "crisis de modelos teóricos" afectan a unos y otros. (Ollier/ Thompson 1985: 43)

Contra la idea de que la relación de los intelectuales del los años sesenta con la política fue radicalmente diferente a la propia, Ollier y Thompson postulan entonces una cierta continuidad, aunque marcando al mismo tiempo la aparición de un elemento novedoso: "Nuestra identidad sufre pues este doble condicionamiento: marcada por una vivencia

35 Sobre esta cuestión, VER Zubietta 2009 http://conti.derhuman.jus.gov.ar/pdf/seminario209/programa.pdf (consultado el 3.5.2013). 
política colectiva límite $[\ldots]$ y al mismo tiempo atravesada por un intenso proceso de rescate de lo subjetivo" (Op. Cit. Ollier/ Thompson 1985: 44; nuestro énfasis).

El número único de Los días del viaje. Revista de política y cultura se dedica en su mayor parte a discutir el tema de la "generación ausente". ${ }^{36}$ Ya desde el editorial, dirigido al "desocupado lector", su director coloca el tópico en el centro:

Sobre nuestras intenciones. La revista fue pensada alrededor del tema de la generación ausente. Este número de presentación contiene cinco artículos dedicados especialmente al tema, y el conjunto del material, de un modo u otro, también lo toca, aunque más no sea, por la edad de los autores. (Schwarzberg 1988: 1)

Para plantear esta cuestión, se reproduce en Los días del viaje el artículo de Rubinich publicado en el $\mathrm{n}^{\circ} 23$ de abril de 1985 de Punto de Vista. A él le siguen las intervenciones de Sergio Chejfec ("Mirada retrospectiva"); Eduardo Antín ("Progreso") y Lucio Schwarzberg ("Elogio de la prosodia del maestro"). Finalmente, Rubinich tiene la oportunidad de volver a pronunciarse en "Notas grises sobre una esperanza".

Chejfec elabora su respuesta a partir de la ficción de la reproducción (post mortem) de un supuesto reportaje realizado por "Rita Fonseca" al autor "Sergio Chejfec". ${ }^{37}$ La afirmación inicial de que "Mi generación [entendida como generación literaria] no existía, ni ausente ni presente" es matizada cuando Chejfec trae a su argumentación una conversación sostenida con Carlos Mangone y admite -de manera coincidente con aquél- que sí considera válido el concepto de "generación política", entendida como aquella que ha sido marcada por un determinado acontecimiento, que toma las más de las veces la forma de una "cesura histórica". Ya sobre el cierre de su trabajo y de manera contradictoria con la afirmación inicial, Chejfec adjudica tres rasgos a su generación [literaria] de pertenencia: "la libertad con la que nos dirigíamos a

\footnotetext{
${ }^{36}$ El Consejo Editorial de Los días del viaje. Revista de política y cultura, que publica un único número en otoño de 1988, está conformado por Patricia Angel, Laura Aparici, Daniel Bravo, Mariana Carol, Andrés Delich, Analía del Franco, Lucas Luchilo, Rubén Noiosi, Mariana Podetti, María Elena Ques y Cecilia Sagol. Su director, Lucio Schwarzberg, dedica el editorial del primer número a describir (con ironía) el carácter heterogéno del staff no en términos de "pluralismo", sino de "arribismo": "ésta es una revista realizada por un grupo de amigos (el staff es delator) que, a su vez, invitan a otros que podrían ser sus amigos, o de los que quisieran hacerse amigos. Sólo por esto último, la revista, más que una revista pluralista debería sera una revista arribista" (Schwarzberg: 1988: 1). También sorprende que en el mismo editorial se haga mención explícita el origen de los fondos que permitieron la publicación: "Este número fue financiado por FUCADE [Fundación para el cambio en democracia], una fundación vinculada al radicalismo, que, a su vez, recibió el apoyo de la fundación alemana Friedrich Neumann. El Consejo Editorial, entonces, está integrado por radicales. (Alemanes no conseguimos.) Libramos a nuestros colaboradores y amigos de un estigma tan pesado" (Ibid.).

${ }^{37}$ El nombre de la entrevistadora elegido por Chejfec constituye un homenaje a Juan José Saer, en cuya saga novelística "Rita Fonseca" es una de las "figuras de autor" -se trata, en verdad, de una pintora- de mayor relevancia.
} 
los materiales", "el escribir por fuera de los modelos aceptados por el mercado" y "el desprecio por toda idea de epigonalismo y cobijamiento bajo paternidad alguna" (Cf. Op. Cit. Chejfec 1988: 9-10).

En su intervención, Eduardo Antín elige desestimar a Rubinich de manera explícita en tanto lo define como el típico exponente del nuevo intelectual "especialista" del alfonsinismo o, en términos de Horacio González (a quien cita), el "Intelectual Becado de Escritorio" (mayúsculas en el original). ${ }^{38}$

Schwarzberg es el único de los tres polemistas que focaliza su respuesta en ajustar las conclusiones a las que había arribado Rubinich en su artículo para Punto de Vista, habida cuenta de que ya han pasado tres años desde su aparición.

El primer ajuste tiene que ver con la idea misma de "generación ausente", dado que varios sus miembros ya han logrado publicar. Por lo mismo, Schwarzberg propone rebautizarla como "generación emergente".

El segundo ajuste se opone a la idea de que el vínculo planteado con la generación anterior pueda entenderse como una relación de idílica "hermandad" (la figura de "los hermanos mayores"), puesto que éstos, con el advenimiento de la democracia, han copado todos los espacios de poder del campo cultural e ignoran ostentosamente a los miembros de la "generación emergente":

Creo que la metáfora es incierta; y ya que de metáforas genealógicas se trata, preferiría referirme a ellos como padres putativos, padres que han sido elegidos por sus hijos.

Pero, además, tengo la impresión de que ellos no se han enterado, razón por la cual los nuevos serían hijos bastardos. [...]

Los hijos bastardos quedaron acorralados como si fueran enanos del país de Gulliver. Desde esa estatura, los padres putativos, instalados en la totalidad del campo intelectual con la plenitud de sus patas inflamadas, parecen los dueños de la justicia y de la verdad. ¡Qué parricidio ni qué ocho cuartos! Más vale, con astuta negligencia, hacerse el distraído. (Op. Cit. Schwarzberg 1988: 17)

Por último, Schwarzberg propone otra figura de escritor (¿de intelectual?) para oponerla tanto a la del especialista surgida con el alfonsinismo, como a la del

\footnotetext{
${ }^{38}$ De manera más o menos explícita, los tres polemistas coinciden en acusar a Rubinich de ser "becario de CONICET" (al momento de firmar su nota para Punto de Vista y "Notas grises sobre una esperanza" éste era efectivamente becario de CONICET, tal como se especifica en el epígrafe que acompaña la reproducción de "La generación ausente" en Los días del viaje). La "acusación" se vuelve menos anecdótica leída en el contexto del debate alrededor del definitivo ocaso de la figura del "intelectual revolucionario" propia de la década anterior, y el surgimiento en los ochenta de la nueva figura del "intelectual especialista".
} 
“intelectual vano, epígono o mudo": el polígrafo ("el ensayista”), cuyo modelo sería César Aira. ${ }^{39}$

La réplica de Rubinich publicada en Los días del viaje tiene un tono conciliador que parece apuntar a abrir sentidos que en su primera intervención en Punto de Vista aparecían como excesivamente cerrados. Ahora se trata de caracterizar a la "generación ausente" no en tanto "generación intelectual", sino de "proponer [...] el desarrollo de un estilo intelectual [...] una posible voz entre las múltiples que construyen, no sin dificultad, los miembros de esta peculiar franja generacional" (Rubinich 1988: 19; nuestro énfasis).

Rubinich constata para la "generación ausente" tres modos de "encarar la actividad intelectual":

En primer término, el que se expresa a través de discursos donde persisten elementos (no siempre de manera categórica, contundente) de visiones maniqueístas, de un estilo contestario, degradado, arreflexivo. Quizás sea éste un estilo residual, aunque en los últimos años, discursos con estas características pudieron ser fácilmente asociados a el discurso de la izquierda. Un segundo modo, podría ser consistente en la construcción de proyectos intelectuales marcados por una actitud estrictamente profesional, por cierto "tecnicismo" que tiene diversas manifestaciones. [...] Finalmente, sobre todo en el caso de algunos escritores y poetas, es perceptible una actitud por encontrar respuestas a través de su obra, con una preocupación fuerte por conocer y manejar del mejor modo posible sus herramientas de trabajo [...] a la par que ensayan, no en su escritura sino en el discurso público, un estilo irreverente, burlón [...] sostienen una mirada crítica acompañada de un tono humorístico con algún grado de pesimismo. (Op. Cit. Rubinich 1988: 20; énfasis del autor)

La caracterización del primer modo que realiza Rubinich es un tiro por elevación al conjunto de revistas que, surgidas luego de la instauración democrática, se ubicaron dentro de las consignas de una izquierda si se quiere, resiliente: Pie de Página $\left(\mathrm{n}^{\circ} 1\right.$ : Primavera 1982 - $\mathrm{n}^{\circ}$ 3: Verano 1984/ 85); Mascaró. Revista de literatura ( $\mathrm{n}^{\circ}$ 1: diciembre de $1984-\mathrm{n}^{\circ}$ 7: abril de 1987); Praxis. Estudios, debates, documentos (n ${ }^{\circ} 1$ : Primavera $1983-\mathrm{n}^{\circ}$ 6: Verano 1986) y La Bizca $\left(\mathrm{n}^{\circ}\right.$ 1: diciembre $1985-\mathrm{n}^{\circ} 3$ :

\footnotetext{
39 "Oponer el polígrafo al especialista: ensayar. Ensayar sobre todas las cosas.Y no estoy pensando sólo en la escritura. No distingo, en este caso, por oficios. Pienso, más bien, en la mirada. Quien aparece ensayando es César Aira, uno de los más silenciosos escritores argentinos. Lo vi de lejos, una sola vez, en una conferencia. Yo no lo conocía, y me desagradó la impiedad de sus opiniones sobre escritores que a mí me gustan. Monocorde, impolítico, ausente de afectación polémica, Aira rompió los libros expuestos en los anaqueles de las librerías cultas. Días después, con la insidia de romperlo a él, salí a buscar sus libros. No los encontré en ningún lado, y tuve que encargarlos. Arranqué a leer 'La luz argentina' embargado de mala fe. Y ya no dejé de leer a Aira. A él le debo mi convicción de que, desde cualquier oficio de la inteligencia y de la imaginación, se debe proceder como un polígrafo. El oficio provee el punto de fuga, y todo el resto es ensayar." (Schwarzberg 1988: 18)
} 
primavera 1986). ${ }^{40}$ En las antípodas de la reconsideración crítica de la tradición marxista que proponen los intelectuales nucleados alrededor de Punto de Vista como condición indispensable para elaborar una nueva agenda cultural, los firmantes de las cuatro revistas mencionadas percibirán la renuncia a las certezas movilizadoras de "una" verdad histórica como la abjuración de los ideales revolucionarios y como el traspaso oportunista a la ideología si se quiere más reaccionaria de todas: el "posibilismo".

Tomando distancia de esta posición, Rubinich postula la existencia de un (deseable) "tercer modo", que se distancia tanto del "intelectual especialista" como de la caracterización de la "generación ausente" en términos de una generación apolítica y/ o posmoderna, que -en sentido laxo- se volverá prototípica entre sus impugnadores: "un estilo y una actitud disonantes enmarcados en una visión complejizadora, [que] no excluyen el abordaje de cuestiones insertas en una tradición contestataria preocupada por enlazar justicia social y libertad", presentes en las revistas Fahrenheit 450 y (nobleza obliga) Los días del viaje (Op. Cit. Rubinich 1988: 20). ${ }^{41}$

El 12 de julio de 1999, desde el suplemento "Radarlibros", Daniel Link vuelve a elegir el factor generacional para volver inteligible el campo cultural argentino del momento, señalando la intricada relación entre "generación política" y "generación literaria".

El imaginario organiza más o menos así las generaciones argentinas: están los artistas e intelectuales "del setenta", están "los jóvenes" del ochenta y están los viejos baluartes (la generación de Contorno, o Ernesto Sábato). No es sólo la cultura de masas lo que divide las aguas [...] sino, sobre todo, algo del orden de lo puramente existencial. (Link [1999] 2004: 214)

Link llama la atención sobre la centralidad inamovible de los artistas e intelectuales de la década del setenta:

... el mapa de bolsillo con el que trabajan catedráticos, periodistas culturales, críticos y editores es, todavía, el mapa de la literatura de los años setenta. Y mucho más cierto es que mientras los escritores

\footnotetext{
${ }^{40}$ Pie de Página tuvo como director a Alberto Castro y como Secretario de Redacción (se retira para el tercer número) a Lucas Rubinich. El proyecto de Pie de Página verá su continuación en La Bizca. Revista de crítica cultural, dirigida por un "colectivo" conformado por Maite Alvarado, Gustavo Aprea, Roberto Bein, Alberto Castro, Alicia García Tuñón, Laura Mango, Carlos Mangone, Ariana Vacchieri, Graciela Villanueva y Jorge Warley. Mascaró. Revista de Literatura tuvo en su Consejo de Dirección a Ricardo Mariño (figura como director a partir de $\mathrm{n}^{\mathrm{o}}$ 3), Leonor García Hernando, Susana Silvestre y Juano Villafañe. Praxis. Estudios, Debates, Documentos tuvo un Consejo de Redacción conformado por Laura Rossi (seud. de Laura Klein), Gabriel Rot (seud. de Gabriel Miguens) y Horacio Tarcus (seud. de Horacio Paglione). A partir del $\mathrm{n}^{\circ}$ 2, Emilio Caffasi figura como director.

${ }_{41}$ Fahrenheit $450\left(\mathrm{n}^{\circ}\right.$ 1: noviembre-diciembre $1986-\mathrm{n}^{\circ}$ 4: 1987/ 88). Tuvo en su Grupo Editor a A. Lamas, Christian Ferrer, A. Lorenzetti, C. Morillo, R. Calviño, entre otros.
} 
mayores de cuarenta y cinco años tienen una obra de la que se habla y se escribe, casi nadie se atrevería a caracterizar las "obras" de los escritores de cuarenta años. (Op. Cit. Link [1999] 2004: 215)

Entrevistado por Martín de Ambrosio el 12 de septiembre de 2004 para "Radarlibros", Sergio Chejfec se reconoce como parte de una generación de escritores "marcada por Saer y Piglia", dentro de la cual revistarían Charlie Feiling, Alan Pauls, Luis Chitarroni, Osvaldo Pardo y él mismo, señalando además que "la generación, en nuestro caso, pasa por una serie de experiencias comunes en relación con la historia política" (Chejfec [2004] 2010: 147).

En la entrada correspondiente al 31 de enero de 2006 de su blog Linkillo, que titula "Pasado y futuro", Daniel Link vuelve a insistir sobre la imposibilidad del parricidio:

Mi generación (clase 1959) quedó, casi siempre, atrapada entre la espada y la pared: no haber sido suficientemente adultos en los setenta y no ser suficientemente jóvenes en los ochenta nos obligó a penosos titubeos entre el impulso mimético en relación con nuestros mayores o el parricidio, al que la construcción del propio público (los jóvenes) nos habría obligado (Link 2006 http://linkillo.blogspot.com.ar/2006 01_01_archive.html, consultado el 9.12.2012)

Si la CEPAL había caracterizado los años '80 como "la década perdida", en tanto años de parálisis y fuerte contracción económica para Latinoamérica, signados por el alza de las tasas internacionales de interés, la caída de los precios del petróleo, la fuga de capitales nacionales y la creciente dolarización de la economía (con los fenómenos concomitantes de endeudamiento, recesión y reducción del gasto público), desde las páginas de Lucha Armada en la Argentina, Daniel Mundo postula provocativamente la existencia de dos generaciones perdidas: la del setenta y la del ochenta. No se trata meramente de disputar un rótulo, sino más bien (y considerando que Mundo se señala a sí mismo como miembro de la segunda) de construir un lugar de enunciación posible:

Quisiera plantear que tal vez no sea una de las generaciones la que está perdida -la que sacrificó su vida por un ideal o la que aprendió a desconfiar de los ideales-, sino dos [...] como si el nudo de unión y diferencia entre ambas generaciones se hubiera cortado. Los puentes se han roto. Han sido cortados. (Mundo 2008: 44; nuestro énfasis)

Si bien en los usos del término "generación" que hemos reseñado prevalece lo autorrepresentacional, en la sociología de la literatura argentina el concepto ostenta un desarrollo considerable, que será tema del próximo parágrafo. 


\subsection{El concepto de "generación" en la sociología de la literatura argentina}

En sendas visitas a Buenos Aires, realizadas en 1916 y 1928, José Ortega y Gasset introduce en la escena local no sólo el concepto de la "nueva sensibilidad", sino también su "teoría de las generaciones". Esta última tiene una primera formulación en El tema de nuestro tiempo (en el capítulo inaugural "La idea de las generaciones"), publicado en 1923, y su expansión en "La idea de generación" ("lección tres”); "El método de las generaciones en la historia" ("lección cuatro") y "De nuevo, la idea de generación" ("lección cinco"), originalmente un curso de doce lecciones impartidas en la Cátedra Valdecilla de la Universidad Central en 1933, publicadas como libro bajo el título Esquema de la crisis (lecciones cinco a ocho inclusive) en 1942, y en su totalidad como En torno a Galileo (1958), libro reeditado por la madrileña Revista de Occidente en 1965.

Mientras en "La idea de generación” el concepto está reducido al mínimo (“tener la misma edad y tener algún contacto vital"), en "El método de las generaciones en la historia", en una formulación que se dice deudora de Auguste Comte y John Stuart Mill, Ortega señala que la generación tiene una vigencia de treinta años: "quince años de gestación” y “quince años de gestión” o "vigencia” (Ortega y Gasset [1958] 1965: 52 y 69, respectivamente). También en "La idea de generación” agradece a Wilhelm Dilthey la diferenciación entre contemporáneos y coetáneos (esto es: una generación estaría conformada por individuos que no sólo conviven en el mismo tiempo, sino que además tienen una infancia y juventud común). Al respecto, Ortega señala que: "urge distinguir en Historia entre coetaneidad y contemporaneidad", ya que "alojados en un mismo tiempo eterno y cronológico, conviven tres tiempos [tres colectivos generacionales] distintos", aunque "sólo se coincide con los coetáneos" (Op. Cit. Ortega y Gasset [1958] 1965: 51).

Es importante señalar que Ortega encontró discípulos en Hispanoamérica que complejizaron e incluso superaron su planteo, como es el caso paradigmático de Julián Marías. $^{42}$ Contra esto, su influencia en Argentina declinó tempranamente con la

\footnotetext{
${ }^{42}$ Nos referimos al clásico estudio El método histórico de las generaciones (1949), donde Marías señala el error de "interpretar las generaciones desde el punto de vista de la edad, entendiendo ésta de manera biológica, cuando advertimos, aún en ella, una componente histórica decisiva" ([1949] 1967: 15). Otros herederos tardíos de la "teoría de las generaciones" orteguiana son el cubano José Juan Arrom, autor de Esquema generacional de letras hispanoamericanas (1963) y el chileno Cedomil Goic, autor de Historia de la novela hispanoamericana (1972). Éste último, junto a Ortega y Gasset, fue uno de los "teóricos" enseñados bajo dictadura en la Universidad de Buenos Aires, lo que también sería un factor que explicaría el total descrédito del concepto de "generación" ya para la transición democrática. En el mismo sentido, no es un dato irrelevante que Marías resultara el intelectual extranjero más asiduamente citado en diarios
} 
renovación del arsenal teórico que llevó a cabo la llamada Nueva Izquierda, que desechó los aportes de Ortega, tanto por su posición ideológica como por su endeblez conceptual. ${ }^{43}$ No obstante, en 1954 Emilio Carrilla publica Literatura argentina, 18001950 (Esquema generacional), donde, en explícita adhesión al "método de las generaciones", enumera y caracteriza diez generaciones de escritores, que van de 1810 a 1940.

Un ejemplo pionero del desdén hacia la herencia orteguiana es el libro El caso Ortega y Gasset, de Patricio Canto (hermano de Estela Canto, el fallido amor de Borges), que se define a sí mismo como un ex admirador de Ortega (1958: 36). Aquí, a escaso año de su muerte, el madrileño es tomado como emblema de la "figura del intelectual vil", y se alimenta la sospecha sobre su aparente neutralidad frente al franquismo (Canto 1958: 9; 26 y 15). Ortega es comparado con Mussolini, en tanto creador de una "filosofía de balcón" y su obra caracterizada en términos de "miscelánea prescindible" (Op. Cit. Canto 1958: 38 y 28, respectivamente). La impugnación de Ortega y Gasset es total:

La realidad última se encargó de desmentir cualquier semejanza ocasional que hubiera habido entre literatura, política y religión y lo que Ortega nos decía de ellas. Sus puntos de vista parecían falsos a los hombres de la generación anterior a la suya, y vuelven a parecerlo a las nuevas generaciones. (Op. Cit. Canto 1958: 11)

Lo interesante en esta cita es el uso de "generación" en tanto "categoría nativa" (esto es: a los fines de construir un lugar de enunciación colectivo -"las nuevas generaciones"-, que habilite a Canto a polemizar con Ortega y Gasset desde un lugar construido en términos generacionales) y la simultánea impugnación del concepto en tanto categoría analítica válida.

El "uso nativo" con intención polémica ya estaba en el libelo que escribe Adolfo Prieto contra Borges: Borges y la nueva generación (1954), donde el autor toma la voz en tanto representante de esta última para aventurar una hipótesis:

Borges, como Lugones, es más un fenómeno de presencia que el autor de una obra intrínsecamente valiosa [...] Indagar las causas de este desajuste denunciado me llevó, naturalmente, a declarar la perspectiva desde la que se tornaba obvia su existencia. Para un lector de cincuenta años, por ejemplo,

y revistas durante la última dictadura y que Jaime Perriaux -el intelectual con mayor influencia dentro del gobierno dictatorial- fuera no sólo discípulo del pensador madrileño, sino también autor de Las generaciones argentinas (1970), escrito bajo la influencia directa de su maestro.

${ }_{43}$ Sobre la llamada "Nueva Izquierda [cultural]", VER Hilb y Lutzky (1984); Terán (1991) y Tortti (2007). 
tal desajuste no existe [...] Para los lectores de veinte a treinta años la desproporción es evidente y remite a las diferencias de clima que separan una generación de la otra. (Prieto 1954: 14)

Otro ejemplo acabado de este uso lo constituye el libro El juicio de los parricidas. La nueva generación argentina y sus maestros (1956), de Emir Rodríguez Monegal, donde se señala la aparición hacia 1945 de una nueva generación en la literatura argentina, a la que se define a partir de "el modelo de conflicto" (de allí el nombre de "parricidas") respecto a la generación de 1925 (o "martinfierristas"). Serían los "padres" de dicha generación: Ezequiel Martínez Estrada; Jorge Luis Borges, Eduardo Mallea y Leopoldo Marechal. Asimismo, Rodríguez Monegal señala la importancia del peronismo como principal fuerza actuante sobre la generación del ' $45 \mathrm{y}$ su rol de introductora del existencialismo francés: los "parricidas" adhieren a la doctrina del compromiso según Jean-Paul Sartre. ${ }^{44}$

De 1958 a 1960, Rafael Alberto Arrieta dirige y publica una Historia de la Literatura Argentina en seis tomos (el último contiene un índice analítico de los cinco tomos precedentes). La Historia tiene como colaboradores a Julio Caillet-Bois, Roberto F. Giusti, Ricardo Saénz-Hayes, Ezequiel Martínez Estrada, Ángel J. Battistessa, Juan P. Ramos; Julio Noé, Luis Emilio Soto, Carmelo Bonet, César Fernández Moreno, Augusto Raúl Cortázar, Luis Franco y Domingo Buonocuore.

En el "Prefacio del editor" y el "Prólogo" contenidos en el primer volumen, Arrieta explica que su Historia viene a completar el trabajo realizado por Ricardo Rojas, aunque con inclusión de los "autores vivientes" (la Historia avanza hasta 1950). El plan general de la obra (si bien por momentos es traicionado por una organización según géneros discursivos y/ o por la presencia de artículos extensos que dan cuenta de la obra completa de un único autor, $y$, también, por conatos de ordenación geográfica), es principalmente cronológico.

\footnotetext{
${ }^{44}$ Se llamó "parricidas" o "denuncialistas" a los intelectuales agrupados alrededor de la revista Contorno (noviembre de 1955 a abril de 1959; diez números en total, los tres últimos son números dobles). Escriben para Contorno: Ismael y David Viñas, Juan José Sebreli, Adelaida Gigli, Noé Jitrik, Adolfo Prieto, Rodolfo Kusch, Oscar Masotta, Regina Gibaja, León Rozitchner, Ramón Alcalde (los otros nombres que aparecen en la publicación son seudónimos adoptados por sus miembros para dar la impresión de disponer de un staff más numeroso). Hasta el $\mathrm{n}^{\circ} 6$ predominan las consideraciones literarias en torno al género novela (relectura consagratoria de Roberto Arlt; relectura positiva de Leopoldo Marechal; ataques a Eduardo Mallea, "el gran novelista" del grupo nucleado alrededor de la revista Sur; solapada hostilidad hacia el "grupo Martín Fierro" y J. L. Borges), y la reflexión política aparece muy esporádicamente. Esta tendencia se invierte completamente en los dos últimos números, dedicados al peronismo y al frondizismo, respectivamente. Para un estudio de Contorno y los "denuncialistas" que completa el trabajo pionero de Rodríguez Monegal, VER Avaro/ Capdevila 2004.
} 
El primer tomo abarca tres siglos: desde las cartas de conquistadores hasta la poesía de Bartolomé Hidalgo, pasando por los “poetas de la Revolución”. El segundo tomo se inicia con la introducción del Romanticismo por Esteban Echeverría hasta la batalla de Caseros, aunque la temporalidad se extiende en los estudios individuales consagrados a José Mármol, Domingo Faustino Sarmiento, Juan Bautista Alberdi y Juan María Gutiérrez. El tercer tomo abarca desde la segunda mitad del siglo XIX ("el regreso de los proscritos") hasta el Modernismo, dando cuenta de "la prosa" y "la poesía" de la "generación del ochenta" (pero también -en artículos que las tienen como objeto exclusivo- de la biografía y obra de Hilario Ascasubi, Estanislao del Campo y José Hernández).

El cuarto tomo tiene a Leopoldo Lugones como objeto de estudio privilegiado, aunque en su segunda parte -a partir de un ordenamiento genérico- se ofrece un panorama de "los conjuntos paralelos de la poesía, el teatro, el cuento, la novela, la crítica y el ensayo de la mitad del siglo XX [...] las corrientes estéticas posteriores a la primera y segunda de las guerras mundiales" (Arrieta 1958: XXI), con especial énfasis en el género lírico. Los dos últimos tomos son definidos como "cuerpos aislados" respecto al plan general (Ibid.). Si bien el tomo quinto se dedica a "el folklore literario" (según un ordenamiento por regiones geográficas), se cierra con un artículo sobre Guillermo Enrique Hudson (“escritor argentino en lengua inglesa”). El sexto y último tomo es, por lejos, el más heteróclito: además del índice analítico ya mencionado, contiene un estudio sobre los aportes historiográficos de Pedro de Ángelis, Bartolomé Mitre y Fidel López (entre varios otros nombres de menor relevancia), reseñas y comentarios a las colecciones y antologías poéticas disponibles (partiendo de La Lira, de 1824), un capítulo sobre la traducción poética y varios artículos sobre manuscritos, archivos, historia del libro y mundo editorial, que se extienden temporalmente más allá del año 1950. A lo largo de esta Historia, el factor generacional no aparece problematizado, adoptándose las denominaciones ya cristalizadas de "generación de 1830 " y "generación de 1880".

En 1959, Noé Jitrik despliega en Seis novelistas argentinos de la nueva promoción su propia versión del análisis generacional (el planteo está indudablemente influenciado por El juicio de los parricidas. La Nueva Generación Argentina y sus Maestros). Partiendo de un diagnóstico sobre "el extraordinario florecimiento de la literatura de ficción y, en especial, de la novela" (Jitrik 1959: 11), focaliza en la obra de 
seis novelistas: Alberto Rodríguez (h), Antonio di Benedetto, Beatriz Guido, Héctor A. Murena, Juan José Manauta y David Viñas.

Jitrik toma el "modelo de conflicto" para caracterizar la relación que vincula la "nueva promoción" con la generación anterior: "Hay algo casi fatal en el despertar de una nueva promoción: su enemistad con las anteriores, en muchos casos sin reconciliaciones de ningún matiz" (1959: 28).

En todo el volumen Seis novelistas argentinos de la nueva promoción se percibe una oscilación entre el uso del concepto de "generación" y el de "promoción", sobre la cual recién se darán razones en el libro El problema de las generaciones literarias (Esquema de las últimas promociones literarias), escrito y publicado por Arturo Cambours Ocampo en 1963, que tiene como antecedentes los trabajos Indagaciones sobre literatura argentina (1952) y Lugones: el escritor y su lenguaje (1957).

Si bien Cambours Ocampo no se remonta a Ortega, sino a autores de la línea alemana que desarrollaron el concepto (especialmente a Julius Petersen, "leído de mala fe" -según él- por Ortega y Marías), no reniega del autor de la "teoría de las generaciones" ni mucho menos. En El problema de las generaciones literarias se retoman los conceptos orteguianos de "sensibilidad vital" (1963: 7) y de "generaciones beligerantes o pacifistas" (Cambours Ocampo 1963: 21-22). Aunque también podría pensarse esta voluntad de no circunscribirse a Ortega en términos políticos, dado que Cambours Ocampo, por su extracción peronista, estaría más próximo al tipo de sociología de la literatura que practica la llamada "izquierda nacional" de un Juan José Hernández Arregui (e incluso a la teoría del "imperialismo cultural" de un Abelardo Ramos), que a la practicada por Ortega y Gasset.

De todas formas, al momento de intentar una definición "no matemática" del concepto de "generación”, Cambours Ocampo recupera a Hénri Peyre, autor de Les générations Littéraires (1948), que define "generación" en términos de "la manera de ver en conjunto [...] a los hombres nacidos aproximadamente en la misma fecha y que crecen en la misma atmósfera intelectual" (Op. Cit. Cambours Ocampo 1963: 9).

El problema de las generaciones literarias se propone demostrar la existencia de "seis generaciones literarias argentinas":

La de 1810, que inaugura nuestra independencia política y nuestra dependencia cultural. Literatura declamatoria, de cara al Atlántico y de espaldas al país. La de 1830, romántica y política; la de 1880, con el culto del talento, apasionada por el ferrocarril y que asistió al delirio del progreso de nuestro país, según la definición de Rojas Paz (la generación de Cambaceres, Cané, García Mérou, Olegario 
V. Andrade, Calixto Oyuela...); la de 1907, con la voz tutelar de Rubén Darío y el modernismo (la generación de Lugones, Banchs, Carriego, Capdevila, Fernández Moreno, Alfonsina Storni...); la generación de 1922, la del periódico "Martín Fierro", dirigido por Evar Méndez, entre cuyos redactores fundadores figuraron Oliverio Girondo, Luis L. Franco, Nalé Roxlo y Ernesto Palacio; y por último, la generación de 1930, a la que pertenecemos. (Op. Cit. Cambours Ocampo 1963: 13)

A lo largo del estudio, se observa que Cambours Ocampo oscila entre un uso que se quiere analítico del concepto de "generación" y un uso de tipo autorrepresentacional, especialmente, cuando defiende la existencia de la también llamada "novísima generación" o "generación del treinta", a la cual él mismo pertenecería en tanto poeta (Cf. Op. Cit. Cambours Ocampo 1963: 18; 35-42 y 53ss).

El uso pretendidamente analítico del concepto de "generación" encuentra su límite cuando el autor-en el marco de lo que había definido en la "Advertencia" como "una literatura crítica de anticipaciones"- intenta postular la existencia de una "generación de 1940", y aclara que se ve obligado a reemplazar el término de "generación" por el de "promoción", dado que faltaría perspectiva histórica para probar fehacientemente la existencia de una "generación de 1940” (Cambours Ocampo 1963: 13 y 43).

Al año siguiente, desde las páginas del n 66 de Cuadernos de Cultura (número publicado inmediatamente después de que varios de sus más jóvenes integrantes abandonaran la revista al romper con el Partido), Berta Perelstein impugna el término orteguiano en tanto "categoría analítica" válida, señalando que las primeras teorizaciones (Comte, Dilthey) sobre la "generación" se dan en un contexto reaccionario. De manera coincidente con Patricio Canto, Perelstein señala para el caso de Ortega y Gasset el montaje de "una verdadera empresa publicitaria, que confundió a muchos" (1964: 99). En su intervención, denuncia que la idea de la generación como agente de la dinámica social escamotea deliberadamente la verdadera clave del cambio: la lucha de clases (Op. Cit. Perelstein 1964: 103-104). Perelstein acusa a los “desertores" del PCA (que para entonces habían sacado el primer número de Pasado y Presente) de adherir a la "historiografía generacional", deudora de las formulaciones orteguianas, caracterizada precisamente "por un subjetivismo extremo y por una actitud irracional que termina por negar explícitamente la posibilidad de conocimiento científico de la Historia" (1964: 112 y 103). ${ }^{45}$

\footnotetext{
${ }^{45}$ Pasado y Presente $\left(\mathrm{n}^{\circ}\right.$ 1: abril/ junio 1963- $\mathrm{n}^{\circ}$ 9: septiembre 1965) fue una revista cordobesa fundada por jóvenes disidentes del PCA y dirigida en su primer año de vida por Oscar del Barco y Aníbal Arcondo, y a partir del segundo, por éstos y José Aricó, Samuel Kieczkovsky, Juan Carlos Torre, Héctor
} 
El término de "generación" continúa circulando a lo largo de la década como clave identitaria y con voluntad polémica. El uso polémico está tanto en la evaluación de la experiencia frondizista que publica David Viñas el 31 de diciembre de 1959 ("Una generación traicionada. A mis camaradas de Contorno") en la revista montevideana Marcha, como en el editorial para el primer número de Pasado y Presente de abril/ junio de 1963 que firma José Aricó (y que daría pábulo a las acusaciones de Perelstein arriba citadas), donde éste señala que "Pasado y Presente intenta iniciar la reconstrucción de la realidad que nos envuelve, partiendo de las exigencias planteadas por una nueva generación con la que nos sentimos identificados...” (Aricó 1963: 2).

Una apuesta similar a la de Cambours Ocampo por "una literatura crítica de anticipaciones" se percibe en el fascículo $\mathrm{n}^{\circ} 55$ de Capítulo. Historia de la Literatura Argentina, publicado en 1968 como volumen autónomo por el Centro Editor de América Latina y titulado, precisamente "Los nuevos. Selección de cuentistas y poetas", que firman Josefina Delgado y Luis Gregorich. En su trabajo, alternan el concepto de "promoción" con el de "generación":

En el caso de los cuentistas, se trata de un intento de dar cuenta de la producción de autores "que han comenzado a publicar después de 1960”, y que, de alguna manera, constituyen una reacción frente al absorbente tono comprometido de la generación de 1955, y también un intento de síntesis que no excluye dicha intención militante. (Delgado/ Gregorich 1968: 5)

Los nombres de la "nueva promoción" de narradores son: Germán Rozenmacher; Juan José Saer, Néstor Sánchez, Daniel Moyano, Abelardo Castillo, Juan José Hernádez y Amalia Jamis. Para el caso de los poetas, los compiladores declaran su deseo de “abarcar un lapso más amplio". Esto es: juntar a los "poetas algo mayores" (Raúl Gustavo Aguirre, Roberto Juarroz, Juan Gelman, Hugo Gola, Francisco Madariaga, Mario Trejo y Francisco Urondo) con otros que "dan prueba de las diferentes tendencias de nuestra poesía más reciente" (Juana Bignozzi, Eduardo Romano, Gianni Siccardi,

Schmucler, César Guiñazú, Carlos Assadourian, Francisco Delich (a los que también se suman Luis J. Prieto y Carlos R. Giordano). Tuvo como rasgos sobresalientes la crítica al partido comunista, la difusión del pensamiento de Antonio Gramsci (que había sido traducido al español por Héctor P. Agosti, figura histórica del PCA), la traducción de numerosos artículos firmados por intelectuales de la izquierda italiana contemporánea, la discusión en torno a la lucha armada y el mundo obrero cordobés y la relación entre cultura y política. A partir de 1968, los miembros de Pasado y Presente publican los Cuadernos de Pasado y Presente, que resultarían fundamentales para la renovación del pensamiento marxista en Latinoamérica. Luego de publicados sus nueve números, Pasado y Presente tiene una breve segunda época ( $\mathrm{n}^{\circ}$ 1: abril/ junio $1973-\mathrm{n}^{\circ}$ 2/ 3: julio/ diciembre 1973), donde se evidencia el acercamiento del grupo a la izquierda peronista. Sobre los llamados "gramscianos argentinos", VER Aricó (1988) y Burgos (2004). 
Alberto Spunzberg, Mario Morales, Susana Thénon, Alejandra Pizarnik y Héctor Miguel Angeli) (Op. Cit. Delgado/ Gregorich 1968: 5).

La Historia de la literatura argentina que publica en 1968 el Centro Editor de América Latina bajo la coordinación general de Adolfo Prieto en tres tomos -Los orígenes (1536-1880); El desarrollo (1880-1940) y Los contemporáneos (1940-...)muestra, como la Historia... de Arrieta, un plan que combina lo cronológico con el ordenamiento genérico y el estudio de autores particulares. El concepto de "generación" es utilizado de manera meramente denominativa en tres trabajos incluidos en el primer tomo: "La segunda generación romántica: Gutiérrez, Andrade", de Beatriz Sarlo, y "La generación del '80: las ideas y el ensayo" y "La generación del '80: la imaginación", ambos firmados por Adolfo Prieto.

El tercer tomo (en cuya la sección "Notas y artículos complementarios" se reproduce un fragmento de El problema de las generaciones literarias) incluye un trabajo de Alfredo Veirabé ("La poesía: la generación del '40”), donde, a cinco años de publicado el libro de Cambours Ocampo, ya no se percibe ninguna prevención respecto a la pertinencia de practicar una "literatura crítica de anticipaciones" (como Cambours Ocampo, Veirabé es simultáneamente investigador y objeto de estudio). No obstante, el concepto de Cambours Ocampo de "promoción" resulta elegido en el trabajo que sigue, "La poesía social después de Boedo" de Carlos R. Giordano, donde éste utiliza el sintagma de "promoción poética del '40" para englobar a "los boedistas después de Boedo".

Luis Gregorich firma dos trabajos: "Desarrollo de la narrativa: la generación intermedia" y "La generación del '55: los narradores". En el primero, vuelve a utilizar el concepto de "generación" para referirse al colectivo de narradores que, en términos etarios, se superpondrían tanto con los nombres de "la poesía de la generación del '40" como con "los boedistas después de Boedo". De manera paradojal (porque con sus reparos pondría en duda la existencia misma del propio objeto de estudio), Gregorich señala que:

... los narradores de esta generación posterior al movimiento de Martín Fierro, y que aquí es llamada “intermedia" por simple comodidad expositiva, no pueden reivindicar para sí la mayor parte de las pautas que hacen que una generación de escritores pueda ser definida como tal [...] Pues esta generación intermedia se recluta entre los novelistas y cuentistas argentinos nacidos entre 1905 y 1920 ( $\sin$ que esos límites cronológicos sean respetados en todos los casos) que, en buena parte, han publicado sus primeros libros durante la década del 40 al 50. No hay para ellos ni un lenguaje generacional común, ni un caudillo generacional que haya influido en todos, ni un suceso generacional 
-pese a la importancia de la revolución de 1930- que los haya marcado indeleblemente a todos. (Gregorich 1968: 1201)

De todas formas, Gregorich defiende la utilización del adjetivo "intermedia" para caracterizar esta generación, en tanto ésta no se perfilaría a partir de determinadas características intrínsecas, sino por su condición de estar entre dos colectivos tanto más poderosos:

El nombre de "intermedia" se aplica a esta generación o grupo de narradores, porque abarca la amplia tierra de nadie que corre entre la actividad y la real vigencia de los grupos de Florida y Boedo (y cuyo término puede fijarse en poco después de 1930) y el estallido de 1955, que, ahora sí, con la caída del peronismo y el violento rebrote de la vida literaria que le sigue, basta para congregar a una generación nueva, más o menos formalmente constituida. (Op. Cit. Gregorich 1968: 1201)

Como único rasgo propio de "esta generación que casi no es una generación", Gregorich da "el mérito de haber fijado la autonomía y la importancia del género novelístico dentro de una literatura nacional no completamente desarrollada [...] que las generaciones posteriores ya han empezado a provechar" (Op. Cit. Gregorich 1968: 1201). A vuelta de página, en el cuadro "Cronología de la novela de la generación intermedia", se dan los siguientes nombres: Adolfo Bioy Casares, José Bianco, Ernesto L. Castro, Alfredo Varela, Roger Pla, Ernesto Sábato, Antonio Di Benedetto, Bernardo Verbitsky, Silvina Bullrich, Joaquín Gómez Bas, Estela Canto, Manuel Mujica Láinez, Enrique Wernicke, Abelardo Arias, Arturo Cerretani y Julio Cortázar.

En el mismo tercer tomo se incluye el trabajo "Teatro: desde la generación intermedia hasta la actualidad", que firma Luis Ordaz, que -como ya es patente desde el título- adopta la nomenclatura y el enfoque de Gregorich. Por último, con algunos agregados y bajo el nuevo título de "Las nuevas promociones: la narrativa y la poesía", se reedita el fascículo 55 co-escrito por Gregorich y Delgado que ya hemos reseñado.

En 1972, Adolfo Prieto publica "Conflictos de generaciones", ensayo teórico donde se sopesan las ventajas y problemas del análisis generacional. Específicamente, sobre el "modelo de conflicto", Prieto alerta que:

El concepto de conflicto generacional no debe sobrevalorarse al extremo de resumir en él la dinámica que moviliza el curso de la historia o de atribuirle el carácter configurador de las más profundas agitaciones sociales. El conflicto generacional a veces acompaña y expresa en su verdadera potencialidad un proceso de cambio; a veces indica, en niveles muy limitados, los desajustes de algunos grupos sociales; a veces materializa, simplemente, la disputa por la imposición o 
mantenimiento de gestos, modas o signos convencionales en el ámbito de un grupo profesional o ideológico, una escuela o una capilla artística. (Prieto 1972: 406)

Prieto apoya la pertinencia del enfoque generacional "cuando se aplica a períodos culturales excepcionalmente densos", de los cuales los "picos generacionales" que derivarían del estallido y fin de la Primera y Segunda Guerra Mundial serían el ejemplo por antonomasia (Cf. 1972: 407-409).

Como tercer acontecimiento que determinaría a la generación de escritores “nacidos luego del año 1940”, Prieto señala la Revolución Cubana. Según el crítico sanjuanino, dicha generación se propondría "la conciliación entre vanguardia artística y vanguardia ideológica" (Op. Cit. Prieto 1972: 415). A ella pertenecerían Mario Vargas Llosa, Severo Sarduy, Reinaldo Arenas y Héctor Libertella. Se advierte sobre los miembros de dicha generación (a la que también se alude como "joven generación” y/ o "poder joven"):

Casi todos ellos [...] pertenecen o se sienten adscritos a las pautas de la clase media urbana: son o han sido estudiantes universitarios o seguido cursos en academias de estudios superiores; se muestran irreverentes ante los vínculos familiares y ante el autoritarismo, en cualquiera de sus manifestaciones; profesan un abierto desprejuicio en materia sexual y no parecen cargar en la diferencia de los sexos ninguno de los tabúes e inhibiciones vigentes aún en el mundo de los adultos; en materia política, recelosos de todo sectarismo ideológico, se conceden un amplio campo de opciones, en el que caben tanto las efusiones anarquistas como las simpatías de principio por el espontaneísmo que suele acompañar a los movimientos de izquierda más radicalizados... (Op. Cit. Prieto 1972: 421)

En mayo de 1977, en el número aniversario de Todo es Historia dedicado a “meditar" sobre el decenio 1967-1977, Andrés Avellaneda publica "Literatura argentina, diez años en el sube y baja", donde afirma que "para ordenar el conjunto de obras publicadas en los últimos diez años, nada mejor que comenzar por una distinción 'generacional'" (1977: 108). Así, se postula la existencia de "la guardia vieja de la literatura argentina" (Avellaneda 1977: 109), conformada tanto por el grupo de autores que habían sido parte de las "escuelas" -las comillas están en el original- de Boedo y Florida, como por "los 'intermedios' " (sic!). Haciendo suya la caracterización de Luis Gregorich (1968), Avellaneda define a "los 'intermedios'" como aquellos "nacidos entre 1907 y 1920, llegados a la literatura con sus primeros libros alrededor de 1940". Su nómina agrega a la dada por Gregorich los nombres de Enrique Anderson Imbert, Valentín Fernando, Syria Poletti, Juan José Manauta y Bernando Kordon. También se 
ocupa de enfatizar que "sin duda el más influyente de todos ellos es Cortázar" (Ibid.). Por último, Avellaneda se dedica a explicar quiénes serían "los nuevos":

... estos narradores propiciaron decididamente la experimentación con el lenguaje y la estructura, y atendieron con mayor asiduidad a lo que de un modo un poco simplista puede resumirse en el concepto de "forma literaria". A la inversa, también desconfiaron de la literatura ante la presión de los hechos político-sociales y tendieron a subordinar o a transformar su expresión en una búsqueda de síntesis entre la historia y la Historia, entre la ficción (la literatura) y la "realidad" (el referente) [...] La vasta producción narrativa de estos autores podría ser ordenada en dos grandes tendencias generales: el realismo y la experimentación. (Op. Cit. Avellaneda 1977: 114)

Si bien Avellaneda matiza el término "realismo" (puesto que "como alguna vez precisara Roman Jakobson, posee más categorías que la acuñada en el siglo XIX”), termina señalando a Daniel Moyano y Manuel Puig como "las dos cumbres de la tendencia "realista'" dentro del colectivo de "los nuevos" (Op. Cit. Avellaneda 1977: 114-115). Asimismo, ejemplifica "la tendencia experimental propiamente dicha" con "los narradores que confluyen en la revista Literal", sobre los cuales señala con acierto la construcción de una voz ininteligible, que desborda la producción literaria y trasvasa al género ensayístico e, incluso, se hace presente cuando son entrevistados. Frente a esta voz, tanto Héctor Libertella como Juan José Saer (entre otros), quedan redefinidos como “experimentalistas 'atenuados' " (Cf. Op. Cit Avellaneda 1977: 116). Germán García queda (inadvertidamente) en ambos grupos: como "realista" con Nanina (1968) y como “experimental propiamente dicho" con Cancha rayada (1973).

Por último, en el parágrafo dedicado a la poesía escrita por "los nuevos y novísimos", Avellaneda prefiere el término de "promoción” y/ o "grupo" para armar el mapa de la producción lírica de aquellos que "comenzaron a publicar a principios de la década del '60 y se caracterizaron por una marcada tendencia hacia el uso de niveles coloquiales de lengua; el tema urbano (Buenos Aires), la preocupación social y la política" (Op. Cit. Avellaneda 1977: 115 y 118, respectivamente), y entre los cuales Leónidas Lamborghini sería el caso más demostrativo. ${ }^{46}$

Con la introducción de las teorías de Raymond Williams y Richard Hoggart que realiza el "grupo Punto de Vista" a partir de 1979, el concepto de "generación literaria" comienza a perder prestigio crítico-teórico frente a los conceptos de "formación” y "grupo", que se vuelven dominantes para pensar colectivos de productores culturales.

\footnotetext{
${ }^{46}$ Si bien lo cita, Avellaneda no adopta la denominación de “generación poética del '60” presente en el libro homónimo de Horacio Salas (1975).
} 
Dos son los trabajos con los que Punto de Vista presenta el materialismo cultural en la Argentina.

El primero ("Raymond Williams y Richard Hoggart: sobre cultura y sociedad"), publicado en julio de 1979, es, en verdad, una mera introducción a las entrevistas realizadas por Beatriz Sarlo a Williams y Hoggart, cuando ninguno de los dos había sido traducido aún al castellano. En el caso de Williams, Sarlo parece estar interesada en facilitarle al lector local la comprensión de una serie de "palabras clave", validando su sentido "correcto" en diálogo con el mismo autor: la "estructura de sentimiento" aparece como la más destacada.

El segundo trabajo ("Raymond Williams: proposiciones para una teoría social de la cultura"), que firma Carlos Altarmirano para el no 11 de Punto de Vista de marzo de 1981, vuelve a insistir sobre los "conceptos clave" del materialismo cultural, pero apoyándose ahora para la exposición en la traducción del libro Cultura y sociedad, publicada el año anterior por la editorial Península, de Barcelona. Por último, es fundamental dentro del temprano proceso de difusión de Williams la publicación en 1980 de Conceptos de sociología literaria, que firman Beatriz Sarlo y Juan Carlos Altamirano, organizado como un "léxico". 47

A partir de 1979, también se publican los fascículos para la reedición (aumentada) de la Historia de la literatura argentina dirigida ahora por Susana Zanetti y que consta, en su formato libro (1980/ 86), de cuatro volúmenes: De la Colonia hasta el Romanticismo; Del Romanticismo al Naturalismo; Las primeras décadas del siglo y Los proyectos de la vanguardia. Mientras en "Panorama de la novela", artículo que firma Josefina Delgado como aporte original para el primer tomo, ésta retoma la caracterización de Luis Gregorich de "generación intermedia" (aunque con un agregado que tiende a precisar la colocación política de dicha generación), en su trabajo "Panorama del teatro" Jorge Lafforgue prefiere utilizar el sintagma "promoción del sesenta"

El proyecto de escribir una "memoria de la literatura II" de corte sociológico tuvo bajo la dirección de David Viñas dos formulaciones. Mientras la primera (bajo el significativo título general de Historia social de la literatura argentina) parecía tener como ambición emular la Historia de la Literatura Argentina de Ricardo Rojas y constaba de catorce tomos que abarcaban un lapso temporal amplísimo (desde la

\footnotetext{
${ }^{47}$ Es llamativo que Sarlo y Altamirano dediquen este trabajo a "El Turco" (Juan José Saer), como una suerte de tardía respuesta a su intervención "La novela y la crítica sociológica", de 1967.
} 
fundación de Buenos Aires en febrero de 1536 por Pedro de Mendoza hasta la restauración democrática), la segunda versión tomó proporciones tanto más modestas (solamente los últimos cuatro años del siglo XIX y todo el siglo XX, hasta el llamado “Argentinazo" del año 2001), y su título general se vio concomitantemente reducido a Literatura Argentina del siglo XX.

En su primera versión, el plan general de la obra constaba de los siguientes catorce títulos (el último de los cuales habría correspondido al índice): Entre las fundaciones y la revolución (1536-1810); Independencia y neoclasicismo (1810-1829); Rosas y el país romántico (1829-1833-1852); Indios, montoneros, paraguayos (1853-1861-1879); La gran aldea: entre entre la invasión y el 90 (1880-1890); Rubén Dario, inmigración y centenarios (1890-1910-1916); Yrigoyen, entre Borges y Arlt (1916-1930); La década infame (1930-1946); 4 de Junio y peronismo clásico (1943-1945-1955); Revolución libertadora-revolución argentina (1955-1966); Neoperonismo y modernidad (19661976); Subversión, proceso y Las Malvinas (1976-1983); Argentina en América Latina y Diccionario de autores, obras y personajes.

El primer volumen en ser publicado (aunque séptimo en el primitivo plan general de la obra), cuya compiladora es Graciela Montaldo, sale en 1989 por la Editorial Contrapunto, y es Yrigoyen, entre Borges y Arlt (1916-1930). Tal como lo explica su director en la "Presentación", ostenta un ordenamiento según "algunos protagonistas, nudos y crispaciones". En el capítulo uno ("Polémicas"), que abarca de 1910 a 1930 y que firma Montaldo, reaparece abundantemente el concepto de "generación", aunque en tanto categoría nativa (esto es: se recupera la nomenclatura que los agentes estudiados utilizaron para referirse a sí mismos): se alude a la "generación vanguardista"; los “escritores de la nueva generación"; la "generación de Nosotros y el Centenario" y la “generación de narradores sociales" (1989: 36; 37; 41 y 43, respectivamente).

El contexto desfavorable del mercado de libros en el que es lanzada esta Historia determina la modificación del primitivo plan general y su reducción a un siglo (el siglo XX), a resolver en la mitad de los tomos. Además, en 1991 quiebra Contrapunto (fundada en 1985 por Eduardo Luis Duhalde), por lo que el proyecto debe salir a buscar otra editorial.

En su segunda versión en siete tomos, el plan de la ahora rebautizada como Literatura Argentina del siglo XX queda así: Crisis de la ciudad señorial: Torre de marfil, teatro nacional y anarquía (1896-1916); Yrigoyen entre Borges y Arlt (1916- 
1930); La década infame y los escritores suicidas (1930-1943); El peronismo clásico (1945-1955). Descamisados, gorilas y contreras; De Frondizi al camporato (19551973); El llamado Proceso (1976-1983) y De Alfonsín al menemato (1983-2001). ${ }^{48}$

La Historia crítica de la literatura argentina que dirige Noé Jitrik, cuyo primer tomo, La irrupción de la crítica compilado por Susana Cella, aparece en 1999, se auto proclama heredera de las dos versiones de Capítulo, lanzadas como fascículos en 1967 y 1979, respectivamente. El criterio que preside la concepción de cada tomo combina el recorte cronológico con lo que se propone como una dominante de orden literario del período considerado. El plan general de esta Historia ..., incluido en la solapa posterior de cada tomo, anuncia los siguientes títulos: Una patria literaria (compiladora Cristina Iglesia); La lucha de los lenguajes (compilador Julio Schvartzman); El brote de los géneros (compiladora Susana Zanetti); Sarmiento (compilador Ricardo Piglia); La crisis de las formas (compilador Alfredo Rubione); El imperio realista (compiladora María Teresa Gramuglio); Rupturas (compiladora Celina Manzoni); Macedonio (compilador Roberto Ferro); El oficio se afirma (compiladora Sylvia Saítta); La irrupción de la crítica (compiladora Susana Cella); La narración gana la partida (compiladora Elsa Drucaroff) y Una literatura en aflicción (compilador Jorge Monteleone). ${ }^{49}$

En el "Epílogo" a La irrupción de la crítica, Noé Jitrik se ocupa de explicar los criterios por detrás de su concepción:

La idea es que toda historia es menos una metodología de la constatación que un relato de hechos que se presumen significativos [...] como relato, lo que importa son los momentos de inflexión, los más dramáticos [...] las situaciones en que lo acumulado se concentra sobre sí mismo y da origen a nuevas estructuras, a nuevas modulaciones. (Jitrik 1999: 501)

También marca la distancia respecto a Capítulo en tanto: "Nuestro intento no retoma categorías que en obras anteriores parecían ser decisivas, por ejemplo la información autoral, bibliográfica y cronológica”, dando como explicación para esta

\footnotetext{
48 Al día de la fecha no han sido publicados De Frondizi al camporato (1955-1973) ni El llamado Proceso (1976-1983), títulos correspondientes a los tomos cinco y seis del plan de obra definitivo. En el capítulo cuatro del presente trabajo, se analiza en detalle De Alfonsín al menemato (1983-2001).

49 Si bien los tomos diez, once y doce tienen como eje diferentes problemáticas observables en un lapso temporal que va aproximadamente desde mediados de la década del sesenta hasta la actualidad, la literatura publicada de la transición democrática a hoy no es objeto de un análisis diferenciado. El último tomo, anunciado para cubrir esta falencia y cuyo compilador es Jorge Monteleone, aún no ha sido publicado.
} 
decisión la alta disponibilidad de este tipo de información en la biblioteca virtual (Op. Cit. Jitrik 1999: 502).

En esta Historia... el concepto de "generación” es utilizado repetidas veces en tanto "categoría cristalizada por el uso" Y aún más: en el "Prólogo" que firma Susana Cella en calidad de compiladora de La irrupción de la crítica, parece adquirir (por única vez) pretensión analítica:

La denominación de "generación del sesenta" y la pertinencia de la misma se entroncan con la aparición de textos en los que se advierte el gesto de ruptura en los niveles compositivos, desde el léxico utilizado hasta las temáticas, y en cuanto a la función que adjudican al relato o a la poesía y, por ende, al poeta o al narrador según la prevalente preocupación por la ligazón entre literatura y sociedad o literatura y política que señalamos como rasgo destacado del período. (Cella 1999: 13)

No obstante lo señalado, en esta Historia ... se observa el definitivo abandono de la perspectiva generacional para abordar el objeto de estudio. En este sentido, no podemos más que coincidir con la caracterización que realiza Miguel Dalmaroni (1997) de la “operación Raymond Williams" en su artículo "La moda y "la trampa del sentido común'. Sobre la operación Raymond Williams en Punto de Vista" cuando señala su importancia para explicar las tendencias que prevalecen en la crítica literaria y cultural argentinas hasta el día de hoy:

Examinar lo que en el título llamo 'la operación Raymond Williams' es examinar un capítulo reciente en la historia de las intervenciones teóricas importadoras de la crítica argentina. Y si acaso la proximidad temporal del episodio podría abrir una discusión tanto acerca del interés que su examen, al proponerse, postula para el episodio mismo, como acerca de la confiabilidad crítica de las conclusiones, otra clase de proximidad debe ser señalada entre las condiciones de posibilidad o de enunciación de un trabajo como éste: no pocos de entre quienes nos incorporamos al debate de la crítica argentina en el curso de los últimos, digamos, quince o veinte años, hemos mantenido un diálogo casi obligado con el programa de crítica de la cultura sostenido por Punto de Vista y por el persistente trabajo crítico de Beatriz Sarlo y Carlos Altamirano, diálogo más o menos constante, más o menos intermitente, que pudo haber oscilado -según los momentos- entre la fascinación y la polémica, el consentimiento y el desacuerdo, el plagio y el rechazo... (Dalmaroni 1997: 13)

En La larga revolución (1961), obra escrita y planificada como continuación de Cultura y sociedad (1958), Williams había colocado el concepto de "generación" en relación directa con el de "estructura de sentimiento", explicando que "una generación puede formar a su sucesora con razonable éxito, en el carácter social o el patrón cultural 
general, pero la nueva generación tendrá su propia estructura de sentimiento, que, en apariencia, no procede de ninguna parte" ([1961] 2003: 57-58).

La única vez que parece rescatarse este señalamiento de Williams, es en el diccionario de Términos críticos de sociología de la cultura (2002), dirigido por Carlos Altamirano. En la entrada al concepto "Generaciones", que firma Marcelo Urresti, se afirma que:

... a través de las generaciones pueden replantearse discusiones vigentes $[\ldots]$ toda vertiente que busque comprender esas vagas pero fundantes estructuras del sentir y del pensar tiene en las generaciones una herramienta casi insoslayable para sus observaciones. (Urresti 2002: 94-95)

En sendos trabajos publicados en 2004 y 2006, Sylvia Saítta ("La narrativa argentina: entre la innovación y el mercado (1983-2003)") y Paulo Ricci ("Narrar la zona. Vanguardias literarias en una ciudad de provincia. Escenas, recorridos y autores en la Santa Fe de la década del sesenta") presentan una "solución de compromiso": el concepto de "grupo generacional". Mientras que en el trabajo de Saítta se alternan inadvertidamente las categorías de "grupo generacional” y "generación sin padres" para designar a los escritores que gravitan alrededor de Babel, revista de libros, en el caso de Ricci la formulación constituye casi una "teoría de los grupos generacionales", que, construída sobre la huella de Ortega, serviría para explicar el cambio literario:

La historia de la literatura [...] está repleta de momentos de agitación, de controversia, de discusiones entre grupos generacionales y de clase que representan posiciones estéticas diversas. Muchos de los acontecimientos del momento histórico en el que se gestan nuevas obras y nuevas concepciones de la literatura, tendrán incidencia en el nacimiento de nuevas voces. Pero no todas las voces, las discusiones y las producciones obtendrán el reconocimiento para erigirse como representativas del “espíritu de su epoca”. (Ricci 2006: 11)

En Alemania el concepto de generación tuvo un desarrollo diferente, que superó el puntos de partida histórico-cultural de los clásicos ensayos de Karl Mannheim (1928) y Julius Petersen (1930) para hacer de él una "construcción identitaria" (Jureit7 Wildt 2005) y una "categoría de memoria" (Weigel 2005). Por lo mismo, sirvió fundamentalmente para pensar la memoria de la Shoah en la literatura, entendiéndola como "cesura histórica" a partir de la cual sería posible reconocer diferentes colectivos generacionales, señalamiento que interesa para nuestro trabajo. 


\subsection{Generación como "construcción identitaria" (Jureit/ Wildt 2005) y "categoría de memoria" (Weigel 2005)}

Como afirman Ulrike Jureit y Michael Wildt en „Generationen. Zur Relevanz eines wissenschaftlichen Grundbegriffs" ["Generaciones. Sobre la relevancia de un concepto científico fundamental"], la "generatividad" [Generativität], la vida en generaciones, es una experiencia cotidiana. El hecho biológico de que cada individuo tenga padres y la mayoría, también hijos (lo que hace que, por regla general, conozca tres generaciones), pertenece a las experiencias personales que anclan como evidente en nuestro lenguaje la "generación" [Generation] en tanto concepto mediador entre la biografía individual y la sociedad. (Cf. Jureit/ Wildt 2005: 7). Mientras en las sociedades preindustriales el concepto queda absorbido por la secuencia genealógica, con la Revolución Francesa, "generación" comienza a señalar una relación de simultaneidad de individuos en una misma conexión socio-histórica. Desde entonces, la relación entre "generatividad" y "generación" es descrita por lo general como una relación de continuidad o discontinuidad, respectivamente (Cf. Op. Cit. Jureit/ Wildt 2005: 15).

Con esta diferenciación entre "generatividad" y "generación", Jureit y Wildt no hacen más que coincidir con el planteo de Reinhart Koselleck en Zeitschichten. Studien zur Historik [Los estratos del tiempo: estudios sobre la historia] (2000), cuando describe la adquisición de la dimensión temporal [Verzeitlichung] como experiencia típicamente moderna. ${ }^{50}$ "Generación”, siguiendo a Koselleck, es por lo tanto un concepto histórico fundamental, o, mejor dicho, un concepto ordenador de tipo temporal. La construcción de "generaciones" está estrechamente relacionada con el nacimiento de la Modernidad europea y con el descubrimiento de la "juventud" como un factor de desarrollo.

El concepto de Jugendgeneration (“joven generación”), surgido en Alemania alrededor de 1900, amalgama definitivamente "juventud" y "generación", transformando el término en un concepto abarcador que remite a ruptura, secesión y predominio. A partir de entonces, las "generaciones" son entendidas crecientemente como actores sociales que poseen una aspiración natural a las posiciones de mando de la sociedad.

\footnotetext{
50 "La inevitable sucesión de generaciones en su concatenación fáctica y temporal que continuamente se engendra a sí misma, conduce siempre a nuevas exclusiones, a determinaciones diacrónicas internas y externas, a lo prematuro o lo tardío respecto a las unidades de experiencia específicas en términos generacionales. Sin estas exclusiones no es pensable ninguna Historia. El cambio generacional y las hornadas de generaciones son, por antonomasia, constitutivas del horizonte temporal finito en términos temporales." (Koselleck 2000: 107; mi traducción)
} 
Con el ensayo del germano-húngaro Karl Mannheim "El problema de las generaciones" (1928), "generación" evoluciona hacia un concepto social de colectividad y su proceso de formación respectivo, que -junto con el de "estamento", "estrato" y “clase"- pretende para sí la categoría de un ordenamiento de tipo socio-cultural. Por lo mismo, no es casual que Mannheim retome explícitamente la metáfora de Karl Marx y Friedrich Engels de que "cada generación está parada sobre los hombros de la otra" en Die deutsche Ideologie. Kritik der neuesten deutschen Philosophie in ihren Repräsentanten Feuerbach, B. Bauer und Stirner und des deutschen Sozialismus in seinen verschiedenen Propheten [La ideología alemana. Crítica a la novísima filosofía alemana en las personas de sus representantes Feuerbach, B. Bauer y Stirner, y del socialismo alemán en sus diferentes profetas]. ${ }^{51}$

Según Mannheim, cada individuo se encuentra en una "posición generacional" [Generationslagerung], que no puede abandonar fácilmente, y que le abre tanto posibilidades específicas como le impone ciertas limitaciones: "la posibilidad [...] de participar en los mismos sucesos, en los mismos contenidos vitales [...] a partir de la misma modalidad de estratificación de la consciencia" (1928: 216). En la constatación de una "posición generacional" determinada, Mannheim ve el potencial para similares formas de comportamiento, sentimiento y pensamiento ("unidad de generación" [Generationseinheit]) como condición necesaria para la construcción de una cohesión de tipo generacional (“conexión generacional" [Generationszusammenhang]), pero no su consecuencia inevitable.

En "Las generaciones literarias" (1930), Julius Petersen enumera sus siete características: (1) la herencia; (2) la fecha de nacimiento (si bien Petersen no le adjudica una importancia decisiva, y contempla el problema de ubicar dentro de una generación determinada a aquellos escritores que son o bien precoces, o bien tardíos); (3) los "elementos educativos": cierta homogeneidad en la educación o formación; (4) las "experiencias de la generación": acontecimientos experimentados por individuos en la misma franja etaria; (5) la "comunidad personal": afinidad por la participación pareja en los mismos; (6) la existencia de un "guía generacional"; y (7) "el lenguaje de la

\footnotetext{
51 "Bienes, conocimiento, características tanto culturales como nacionales son transmitidas en bloque generación tras generación. Cada generación constituye una unidad histórica perfectamente definida y está en condiciones de cambiar su legado. La sociedad no puede ser concebida sino como una manifestación de estas relaciones intergeneracionales -como el 'resultado' de la actividad de una larga serie de generaciones, cada una parada sobre los hombros de la que la precedió." (Marx/ Engels 1969: 43).
} 
generación", definido como "el factor más elemental que provoca la comunidad de generación", puesto que "todo acuerdo sobre metas comunes, requiere el medio del lenguaje" ([1930] 1946: 182-183).

Volviendo a la formulación clásica de Mannheim, "generación” es un concepto que se funda en la experiencia, dado que no sólo describe un "situación" en el espacio social, sino también refiere a una "comunidad" fundada en percibir, interpretar y actuar sucesos y contenidos vitales fundamentales desde el mismo tipo de consciencia. Porque, siguiendo a Mannheim, preguntarse por la "generación" significa también indagar -más allá de lo propio de cada individuo- sobre patrones específicos de la edad y supraindividuales, y con ello marcar un elemento sustancial, para algunos incluso el único relevante, de la relación entre individuo y grupo.

En la sociología alemana, se ha mostrado como productiva la "generación" en tanto categoría diferencial cuando grandes catástrofes históricas justifican la validez de un límite (antes, durante o después de un determinado acontecimiento histórico). Una "generación" formula la propia autocomprensión en base a su vivencia específica por edad de acontecimientos políticos y sociales decisivos, y, por lo mismo, se diferencia tajantemente de las generaciones anteriores y posteriores, que perciben el mismo suceso de otra manera. La Primera Guerra Mundial constituye el ejemplo por antonomasia de la relación entre los sucesos históricos extremos y la formación de generaciones. ${ }^{52}$

Como ninguna otra fase del siglo $\mathrm{XX}$, los años de posguerra fueron marcados por la descripción -mediante el concepto de "generación"- de las diferentes experiencias de los soldados según cuál fuera su edad al momento del conflicto bélico, así también como de aquéllos que eran demasiado jóvenes como para ser llamados a filas, pero vivieron la guerra como niños o adolescentes (de ahí los conceptos de Frontgeneration [generación del frente] y Verlorene Generation [generación perdida]). Por lo tanto, no es ninguna casualidad que precisamente en esa entreguerra, dominada aún por el concepto biologicista de "generación", se haya publicado el todavía hasta hoy influyente ensayo de Karl Mannheim.

En Alemania, "generación" fue y continúa siendo un concepto sociológico fundamental. Prácticamente, casi no pasa una década sin que los cientistas sociales y

\footnotetext{
${ }^{52}$ Con una distancia temporal considerable entre sus intervenciones críticas, tanto Hans Jaeger (1977) como Andreas Schulz (2003) han desestimado consecuentemente el "uso matemático" del concepto de "generación" (esto es: a la manera de Ortega), dado que su valor interpretativo recién se desplegaría con los cortes ocasionados por los sucesos históricos más espectaculares, que abarcan y dividen a toda la sociedad, tales como guerras, revoluciones o colapsos económicos, cuya "periodicidad", claro está, es imposible de predecir.
} 
críticos de la cultura crean haber descubierto una "nueva" generación, en una utilización quizá abusiva del concepto. Como señalan Jureit y Wildt:

El uso entretanto inflacionario de las caracterizaciones generacionales, como la "generación Golf”, la “generación Ally", la generación del 68, la del 89, la "generación Berlín”, la "generación de la guerra del Golfo", muestra la necesidad de reflexionar en el sentido y sinsentido de la investigación de tipo generacional. (Jureit/ Wildt 2005: 8)

En efecto: la investigación de tipo generacional parece no abarcar ningún principio uniforme de análisis. No sólo sociólogos, sino también historiadores y pedagogos, investigadores de la cultura y críticos de literatura, así también psicoanalistas utilizan categorías coetáneas y etarias específicas como categorías pretendidamente analíticas. Este uso múltiple y con frecuencia irreflexivo en términos metodológicos tiene como consecuencia una claridad conceptual escasa, que sólo es superada por la heterogeneidad de los temas trabajados. ${ }^{53}$

En „Familienbande, Phantome und die Vergangenheitspolitik des Generationsdiskurses" ["Vínculos familiares, fantasmas y la política sobre el pasado del discurso generacional"], Sigrid Weigel señala que el concepto de generación se ha transformado post 1945 en una "categoría de memoria" (Cf. Weigel 2005: 125).

Por un lado, a partir de la constatación del regreso del género "novela familiar" y "novela generacional" alrededor del año 2000, Weigel periodiza la memoria de la Shoah en la literatura mediante los conceptos de "literatura de la segunda generación" (prefiriéndolo al término estándar de Väterliteratur [literatura de los padres], utilizado para referir a la narrativa que tematiza la Shoah escrita por los hijos de los perpetradores) y la "literatura de la tercera generación" (esto es: escrita por los nietos de los nazis).

Por otro lado, para el caso específico de la "novela generacional", retoma la doble acepción de "generación" a la que hemos hecho referencia al comienzo de este parágrafo -en tanto "genealogía", pero también como "ruptura"-, dado que precisamente se trataría de la transmisión de la experiencia del "quiebre civilizatorio" (en términos de Norbert Elias) a la próxima generación. Para Weigel, esto significa también "la asunción de una herencia siniestra en una historia, que de lo contrario

\footnotetext{
${ }^{53}$ En su trabajo „Ambivalenz - Eine Annäherung an das Problem der Generationen“ ["Ambivalencia. Una aproximación al problema de las generaciones"], Kurt Lüscher propone diferenciar entre tres tipos de discursos sobre "generación": (1) el genealógico (más específicamente: el de parentesco); (2) el pedagógico; (3) el histórico-cultural. Dentro del tercero, se ubicarían Karl Mannheim y sus herederos críticos (Cf. Lüscher 2005: 53-58).
} 
permanecería abstracta y sería distorsionada por medio de discursos moralizantes sobre víctimas y perpretadores" (2005: 113).

En el capítulo 9 que Stefan Willer escribe para el tratado Das Konzept der Generation [El concepto de generación], publicado en 2008 en coautoría con Ohad Parnes y Ulrike Vedder, se explican los dos modelos posibles según los cuales una generación establecería su vínculo con la generación anterior: el "modelo de continuidad" o el "modelo de conflicto", dentro del cual sería típico el "gesto parricida" de los que se proclaman a sí mismos la "joven generación”. No obstante, Willer se ocupa de caracterizar ambos modelos en tanto prototipos ideales (Cf. 2008: 219 y ss.). Esto es: no modelos "puros", sino ajustables a cada contexto, modelos explicativos dinámicos y siempre tentativos.

Tanto la idea de "generación" como "categoría de memoria" de Weigel, como la observación de Willer de que no hay modelos "puros", han resultado de máxima utilidad para pensar la relación que los narradores de nuestro corpus buscaron establecer con la llamada "generación del sesenta": las figuras de "los hermanos mayores" y "el coloquio" como figura de una interlocución que no reconoce jerarquías ni conflictividades (Cf. Pauls 1983).

También adherimos en nuestro trabajo al señalamiento de que "construcción identitaria, lazo colectivo, comunidad de experiencia y relevancia en términos de actuación [...] caracterizan el discurso sobre las 'generaciones', y caracterizan al mismo tiempo su pretensión explicativa" (Op. Cit. Jureit y Wildt 2005: 9).

Para terminar justificar la pertinencia de un "enfoque generacional” (Jaeger 1977) para el abordaje de nuestro corpus, que mantenga el énfasis en las dimensiones identitaria y autorrepresentacional del concepto de "generación", nos referiremos en los próximos dos parágrafos a otros intentos de periodizar la novelística argentina reciente "de/ sobre" la última dictadura, que se aproximan, dialogan y contrastan con nuestro planteo.

1.4. Lecturas de las memorias del pasado reciente en la novela argentina: Sarlo (1987), Reati (1992), Piña (1993), Avellaneda (1997), Gramuglio (2002) y Dalmaroni ([2003] 2004)

La intervención de Beatriz Sarlo en la reunión organizada por los profesores René Jara y Hernán Vidal a fines de marzo de 1986 en Minneapolis bajo el auspicio del Institute for the Study of Ideologies and Literature y el Department of Spanish and Portuguese de la 
Universidad de Minnesota, fue publicada de forma parcial en abril de 1986 en el $n^{\circ} 26$ de Punto de Vista bajo el título de "El saber del texto". De forma completa, apareció antologizada como "Política, ideología y figuración literaria" en el volumen Ficción y política. La narrativa argentina durante el proceso militar (1987). El trabajo de Sarlo sentó duraderas bases para una posible articulación entre historia reciente, política y ficción (en verdad, el término "ficción” aparece aquí circunscrito al género "novela").

Partiendo de la premisa de que "la literatura puede leerse como discurso crítico aunque adopte (o precisamente porque adopta) la forma de la elipsis, la alusión y la figuración como estrategias para el ejercicio de una perspectiva sobre la diferencia", toda la argumentación se organiza mediante la oposición entre "discurso autoritario" y “discurso del arte y la cultura" (Sarlo 1987: 35 y 40).

Mientras el primero (siguiendo los lineamientos trazados por José Joaquín Brunner en La cultura autoritaria de Chile, publicado en 1981) es caracterizado en términos de "monológico", "excluyente", "modelo comunicacional pobre y unidireccional", y, por mismo, "basado en una relación de poder obviamente prediscursiva", el segundo lo es en los términos opuestos de "dialógico", "práctica de sentidos abiertos, de cadena que no cierra, de figuraciones abundantes" (Op. Cit. Sarlo 1987: 36 y 40).

Si bien la caracterización general de la novelística argentina del período en términos de "ficciones interrogativas de lo real y autoconscientes de los medios y las formas de su interrogación" es matizada en tanto se afirma que "parece difícil [...] caracterizar por un solo rasgo a un corpus que se define, principalmente, por un sistema de diferencias además de líneas de contacto" (1987: 42 y 41, respectivamente), se percibe una lectura tendenciosa del mismo. En efecto: son las novelas que de manera más acusada "trabajan [...] sobre problemas constructivos, de relación intertextual, de procesamiento de citas, de representación de discursos, de relación entre realidad y literatura o de la imposibilidad de esa relación" (Op. Cit. Sarlo 1987: 41) las que finalmente serán más extensamente analizadas y de las cuales se destacará su valor estético: Respiración artificial, de Ricardo Piglia y la "refinadísima" (sic!) Nadie nada nunca, de Juan José Saer (Cf. Op. Cit. Sarlo 1987: 57-58).

En otras palabras: la oposición entre "discurso autoritario" y "discurso literario" es funcional a la operación crítica mediante la cual las poéticas de Piglia y Saer quedan privilegiadas por sobre las “apuestas miméticas” de Jorge Asís y Osvaldo Soriano, algo que ya fue señalado como problema por Miguel Dalmaroni ([2003] 2004). 
En 1992, Sarlo vuelve a estas hipótesis en su trabajo "Strategies of the Literary Imagination" para la antología Fear at the Edge. State Terror and Resistance in Latin America, que compilan Fagen Weiss y Manuel Garretón, aunque reconociendo ahora que "la serie de los Canguros de Jorge Asís sugiere un pacto estable entre la mimesis y su público", lo que explicaría su éxito comercial (1992: 241). De todas formas, el juicio de valor persiste: Nadie nada nunca vuelve a ser la novela que más espacio ostenta dentro de la argumentación.

Muy diferente es el punto de partida de Fernando Reati en su tesis doctoral Narrar lo innombrable. Violencia política y novela argentina: 1975-1985, publicada el mismo año como libro por la editorial Legasa. Reati conforma su corpus novelístico a partir de “obras que mantienen un grado de conexión implícita o explícita entre el referente histórico y su representación bajo la forma de la ficción novelística y en el marco de la violencia política del período reciente" (1992: 20). La principal tesis del libro es que "los escritores proponen soluciones simbólicas a los conflictos sociales, sintetizadas en el caso argentino en la oposición entre autoritarismo y democracia” (Ibid.).

Sin entrar a discutir lo acertado de esta tesis, la tipología que pretende ordenar el corpus deja traslucir un (muy dicutible) criterio temático, que Reati explica en términos de: (1) novelas que se oponen al maniqueísmo del discurso militar (se observa la adopción de la perspectiva de Beatriz Sarlo en "Política, ideología y figuración literaria"); (2) novelas que hacen explícita la fractura de la identidad del yo, del Otro, del país y la realidad; (3) novelas que postulan la memoria como una versión incompleta y no autoritaria de la historia y, por lo tanto, como una alternativa a la historiografía y (4) novelas que codifican en la ambigüedad de las normas sexuales alternativas una reacción contra el autoritarismo político.

Otro de los puntos dudosos del trabajo es el trazado de paralelismos implícitos a los que parecería querer inducir el marco teórico utilizado. Por ejemplo: entre "la voz social" de la literatura surgida luego de la Primera Guerra Mundial y "las representaciones literarias en Argentina" en el período 1975-1985 (Op. Cit. Reati 1992: 22 y 70-71), o bien entre la Shoah y la dictadura argentina (1992: 57-58). Dichos paralelismos (que aparecen aproblematizados) no aportan a la clarificación de la especificidad de la dictadura argentina y/ o las memorias en la literatura de dicha experiencia histórica, y parecen ser producto del contexto de escritura de Nombrar lo innombrable (la Academia norteamericana). 
En 1993, Cristina Piña publica el artículo "La narrativa argentina de los años setenta y ochenta", planteado como un panorama de la producción ficcional de ambas décadas, que giraría alrededor de la pregunta de “¿cómo narrar?”.

Si bien Piña reconoce que la pregunta debe ser situada en un contexto temporal mayor que es "la larga impugnación del realismo" (y cita por lo mismo las hipótesis de Beatriz Sarlo en "Literatura y política", publicado en diciembre de 1983 en Punto de Vista), se percibe en su argumentación una relación cuasi causal entre experiencia histórica y ficción. En esta línea, "los narradores se ven enfrentados [a partir del golpe de Estado de marzo de 1976] con la necesidad de crear nuevas formas de representación literaria para nombrar dicha experiencia devastadora" (Piña 1992: 122) y la condición de exiliados de muchos de ellos "permitió que sus libros articularan, en todo los casos, una denuncia directa de los horrores del autodenominado 'Proceso de Reorganización Nacional' " (1992: 123). También se afirma que "más allá de las impugnaciones del realismo llegadas de Europa, no resultaba posible construir un verosímil literario mimético, en razón de la misma naturaleza abismal que adoptaron las modalidades de la violencia propias de la 'guerra sucia'” (Piña 1992: 125). Para desmentir esta última afirmación, bastaría tomar las novelísticas de Jorge Asís y Enrique Medina, donde no se perciben en ningún momento "estrategias de descentramiento apoyadas en la alusión, el eufemismo, la alegoría, el desplazamiento, la representación paródica; la metaforización en general" (Ibid.).

Contra esto, en su aporte "Lecturas de la historia y lecturas de la literatura en la narrativa argentina de la década del ochenta" para el tomo Lecturas de la historia y lecturas de la literatura en la narrativa argentina de la década del ochenta (1997), Andrés Avellaneda propone realizar una interesante inversión:

Para pensar la narrativa en el marco de la dictadura militar terrorista conviene invertir los términos de la relación entre los textos y la historia: no es ésta un relato maestro que provoque la génesis de aquellos, sino que, por el contrario, es muy posible que de las textualizaciones que llamamos literatura dependa la comprensión de los hechos que denominamos historia. [...] La historia existe, entonces, porque es dicha; porque es narrada y textualizada; porque el lenguaje -también y acaso primordialmente, el de la literatura- abre una comprensión que va a llamarse historia [...] Es de esa lectura que se extraen los lenguajes - las preguntas- que ayudan a elaborar (a crear) los hechos de la historia argentina reciente. (Avellaneda 1997: 141)

Luego de una interesante introducción al tema (donde Avellaneda repite la hipótesis sobre el "quiebre de la ilusión mimética", que fecha a partir de 1955, al mismo 
tiempo que reseña algunos debates sobre la función de la literatura y la figura del intelectual en la década del sesenta, contraponiéndolas a las propias de la del ochenta), el artículo plantea una tipología de "los relatos de la época" (en verdad, se trata exclusivamente de novelas) según los siguientes ítems: (1) "cómo significar y cómo narrar"; (2) "el presente en clave de pasado remoto"; (3) "el presente en clave alusiva"; (4) “mimesis, alegoría, mezclas genéricas" y (5) “escrituras hiperliterarias". Contra el ordenamiento meramente tópico realizado por Reati, se percibe en el caso de Avellaneda una apuesta por ordenar el corpus a partir de los procedimientos y principios constructivos de las novelas que hacen memoria en la literatura de por el llamada "dictadura militar terrorista".

En diciembre de 2002, Gramuglio publica en Punto de Vista el artículo "Políticas del decir y formas de la ficción. Novelas de la dictadura militar", donde hipotetiza que la investigación de la CONADEP y el Juicio a las Juntas son hechos que habrían modificado profundamente las condiciones discursivas de las "novelas que buscan dar forma a aquella experiencia" (2000: 9). En su análisis, señala la aparición en 1984 de la "novela testimonial", que perseguiría "revelar tramos hasta entonces desconocidos, o conocidos sólo a medias, del funcionamiento de las organizaciones guerrilleras y de la experiencia de sus miembros en la lucha, en la clandestinidad o en los campos de concentración" (Gramuglio 2002: 10). ${ }^{54}$

En la segunda parte de su trabajo, Gramuglio se detiene en lo que postula como un cambio de poética en la obra de Luis Gusmán, observable a partir de su novela Villa (1995), que "(de un modo riguroso pero no convencional) trabaja con procedimientos propios de la representación realista" (2002: 12), modo que tendría su continuidad en la novela Dos veces junio (2002), de Martín Kohan.

En Río Gallegos, durante el XII Congreso Nacional de Literatura Argentina celebrado en octubre de 2003, Miguel Dalmaroni señala la emergencia a mediados de los noventa de "una nueva novelística sobre la dictadura", cuya poética contrastaría con los rasgos de oblicuidad, ciframiento alegórico y fragmentación de la novelística escrita bajo dictadura (entre cuyos exponentes más acabados estarían Respiración artificial y Nadie nada nunca). Contra la imposibilidad de "nombrar lo innombrable" de los novelistas del período 1975-1985 que describiera Fernando Reati en Nombrar lo innombrable (y del cual éste desprendía una renuncia lógica a la "simulación mimética

\footnotetext{
${ }^{54}$ Según María Teresa Gramuglio, Recuerdos de la muerte (1984), de Miguel Bonasso sería el primer exponente de la "novela testimonial".
} 
del realismo"), Dalmaroni observa en esta nueva novelística la presencia de cierto impulso "realista o literal", en tanto se opta en las novelas por despojar la representación de toda veleidad experimental o estetizante "para narrar refiriendo por completo, y de modo directo, los sucesos y acciones más atroces" (2004: 159; énfasis del autor).

En su comunicación, si bien recorta un corpus de seis novelas (Villa y Ni muerto has perdido tu nombre, de Luis Gusmán; Dos veces junio, de Martín Kohan; El secreto y las voces, de Carlos Gamerro; Calle de las escuelas $N^{o} 13$, de Martín Prieto y Los planetas, de Sergio Chejfec), Dalmaroni elige concentrar su análisis en "las hablas privadas de los torturadores, asesinos y apropiadores" presentes en las novelas Villa y Dos veces junio. Este intento de la literatura de "dar la voz al otro enemigo" es leído tanto en contrapunto con las confesiones sobre la metodología del exterminio por parte de los genocidas de la ESMA Juan Carlos Rolón y Antonio Pernías, y del ex capitán de corbeta Adolfo Scilingo ocurridas en 1994 y 1995, como en términos de una imposibilidad ética de escribir el "Deutsches Requiem de la dictadura", comprobable en el hecho de que al otro a quien se le da la voz en las novelas mencionadas, no es una figura principal, sino siempre un "segundón" del aparato represivo.

A las dos últimas intervenciones críticas reseñadas podría criticárseles un manejo algo laxo de la categoría de "realismo" y el no desarrollar cómo este supuesto "giro hacia al realismo" dialogaría con: (1) la inexistencia de una "novela realista" a la manera decimonónica europea en la tradición literaria argentina a la cual volver y (2) la coincidencia de este "giro" con la "vuelta a la narración" (Catelli 1983), lo cual, para mediados de los '90, momento en que tanto Gramuglio como Dalmaroni coinciden en fechar dicho "giro", sería ya un dato insoslayable. ${ }^{55}$ Por último, una objeción de tipo metodológico: se percibe cierta tendencia a enunciar hipótesis generales sobre determinados autores a partir de una obra en particular, sin reponer en la argumentación sus respectivas "trayectorias de escritor".

Un ejemplo puntual: creemos que para completar la hipótesis sobre "el cambio de poética a partir de Villa", faltaría considerar cómo esta novela participa de la apuesta

\footnotetext{
${ }^{55}$ En un trabajo publicado en 1983 en el n ${ }^{\circ} 18$ de Punto de Vista ("La vuelta a la narración") Nora Catelli diagnostica el agotamiento de la experimentación y la "vuelta a la narración", cuyos ejemplos por antonomasia serían El nombre de la rosa (traducida al castellano en 1982 y editada por Bruguera), de Umberto Eco y La guerra del fin del mundo (1981), de Mario Vargas Llosa. Catelli se sirve de la parábola bíblica para pergeñar la figura de "el novelista pródigo" como aquel que "vuelve a la narración" (aunque de manera no ingenua: el "novelista pródigo" desconfía de los protocolos de representación realista) y se pregunta si esta vuelta a la narración no podría ser considerada un experimentalismo al revés.
} 
enunciada por Luis Gusmán diez años antes por una "mayor linealidad" en el relato, de la cual la reescritura de En el corazón de junio, vuelta a editar con importantes cambios en 1999, podría considerarse el punto cúlmine. ${ }^{56}$

De todas formas, más allá de las posibles objeciones que hemos explicitado, los aportes reseñados revistan entre los más sugerentes al día de hoy, y constituyen un horizonte ineludible para la indagación de la memoria en y de la literatura que propone la "generación ausente". 57

\subsection{Tres intentos de periodización de las memorias del pasado reciente en la novela argentina dependientes del factor generacional: Ruiz (2005), Gundermann (2007) y Drucaroff (2011)}

En 2007, Christian Gundermann publica Actos melancólicos. Formas de la resistencia en la postdictadura argentina, donde señala lo siguiente:

Alejandro Agresti (1961) pertenece a esa generación "sándwich" de argentinos que les tocó vivir los peores actos de la represión como adolescentes, es decir, sin haber participado activamente de la euforia política juvenil de principios de los setenta $\mathrm{y}$, al mismo tiempo, sin la ventaja de vivir protegida por la inocencia de la infancia. En el momento del golpe de estado de Videla, Agresti tenía quince años. Por lo tanto, la perspectiva de esta generación, la de la "noche de los lápices" se ha considerado particularmente sombría [Nota al pie 1: Según Alejandro Ricagno, la "generación sándwich" está en el medio "entre aquella que masacraron y los que se criaron mansitos al son del fin de la historia"]. (Gundermann 2007: 127)

Esta cita es interesante porque en ella se vuelve explícita la influencia que las opiniones del mismo objeto de estudio ejercen sobre el investigador. En otras palabras: que Agresti o Ricagno elijan autodenominarse como "generación sándwich" no debería hacernos perder de vista las otras poderosas construcciones generacionales que agentes de edades prácticamente idénticas (esto es: coetáneos) hicieron sobre su propia trayectoria vital.

\footnotetext{
${ }^{56}$ Sobre esto, en verano de 1984/ 85 y en el marco de la entrevista que le realizan Alberto Castro con la asistencia de Daniel Link y Carlos Mangone para el $n^{\circ} 3$ de Pie de Página, Luis Gusmán plantea algunas dudas sobre la conveniencia de continuar con la estética "anti populista" o "experimental", cuyo ejemplo paradigmático sería Brillos: "Sucede que empecé de algún modo por el final y no por el principio. Rompí con 'el personaje' cuando aún no lo había creado. Ahora quizá quiero crearlo" (Gusmán [Entrevistado por Castro] 1984/ 85: 17). Asimismo, anuncia que tiene en obra una novela titulada Desierta, según este nuevo patrón. Recién en 2012, con la publicación de La casa del Dios oculto, Gusmán concretará el proyecto de Desierta.

57 En el Apéndice "Aportes para el estudio de la novela (1976-1986). Estado de la cuestión" con que se clausura el libro ¿Quién de nosotros escribirá el Facundo? Intelectuales y escritores en Argentina (19701986), José Luis de Diego reseña otros intentos de dar cuenta de la producción novelística publicada (tanto en el exilio como en nuestro país) entre 1970 y 1986.
} 
Entre las más contrastantes respecto a aquélla: "nosotros: los combatientes de Malvinas" y "nosotros: los (muy jóvenes) cuadros político-militares formados".

Sobre "nosotros: los combatientes de Malvinas": en Las Guerras por Malvinas (2006), el historiador Federico Lorenz explica de la siguiente manera la importancia de no confundir el término de "combatientes" (surgido en la década del ochenta entre los jóvenes conscriptos que habían participado en el conflicto bélico del Atlántico Sur) con el de "veteranos" (elegido por los cuadros de mayor gradación en el Ejército y predominante bajo gobierno menemista en el marco de la estrategia de las relaciones carnales con Gran Bretaña):

A fines de agosto de 1982 un grupo de ex soldados formó el Centro de Ex Soldados Combatientes de Malvinas, que meses más tarde se transformó en la Coordinadora Nacional de Ex Combatientes, que agrupaba a distintas entidades de todo el país. Los miembros de este Centro estaban unidos por la idea de ser una generación identitariamente constituida por el hecho de la guerra y rechazaban específicamente la participación en la agrupación de suboficiales y oficiales. El corte era neto: diferenciarse de las Fuerzas Armadas y recuperar el protagonismo de los civiles bajo bandera. (Lorenz 2006: 206)

Martín Caparrós, que en Cazadores de utopías (1996), de David Blaustein se ubica testimoniando en calidad de ex militante del MAS como uno de los miembros más jóvenes de la "generación setentista", podría ser tomado como ejemplo de la segunda autocontrucción identitaria ("nosotros, los jóvenes menores y cuadros políticomilitares formados"). ${ }^{58}$

No obstante, vale aclarar que unos veinte años antes, en el contexto del alfonsinismo, Caparrós había optado por colocarse en la vereda de enfrente de la "generación militante". Este movimiento de demarcación resulta explícito en su intervención en octubre de 1987 para el suplemento "Culturas" de Página/ 12, que tiene como tópico el treinta aniversario de la captura y asesinato del "Che" Guevara en la Quebrada del Yuro, y que Caparrós titula "Dos, tres, muchos Guevara" (haciendo resonar irónicamente aquella consigna de "Crear dos, tres, muchos Vietnam" en el

\footnotetext{
${ }^{58}$ Para las Naciones Unidas, es “joven” quien tiene entre 15 y 24 años de edad. Dentro de los "jóvenes", se distinguen dos subgrupos: "jóvenes menores" (aquéllos que cuentan entre 15 y 19 años) y "jóvenes mayores" (entre 20 y 24 años). De manera coincidente con Martín Caparrós, en el testimonio que da para el documental Errepé. La historia del PRT-ERP (2000), dirigido por Gabriel Corvi y Gustavo de Jesús, Eduardo Anguita afirma: "Yo ya llevaba tres años de preso, tenía veintitrés años y me consideraba a mí mismo un cuadro. Me consideraba un tipo indestructible. La verdad, en esos años, nada me daba miedo".
} 
"Mensaje a la Tricontinental" del 16 de abril de 1967). ${ }^{59} \mathrm{Su}$ nota constituye una excepción al tono reivindicativo predominante, y es notoria en ella la adopción del "modelo de conflicto" para dirigirse a la generación militante (a la que se acusa de haber inmolado a las jóvenes bases). ${ }^{60}$

Por último, "los chicos de la noche de los lápices" es una construcción de la inmediata posdictadura, cuando aún dominaba la estrategia de victimización de los detenidos-desaparecidos, faltando más de una década para el rescate de su pasado militante. Como señala Sandra Raggio en "La construcción de un relato emblemático de la represión: la 'noche de los lápices' " (2010), en el caso de la militancia de los jóvenes menores, la estrategia fue presentar a los protagonistas como "seres arrastrados por la corriente de los acontecimientos", y poner el reclamo del boleto estudiantil como única explicación de la represión desatada contra los estudiantes secundarios secuestrados entre el 16 y el 17 de septiembre de 1976 en La Plata. ${ }^{61}$

Según Raggio, este relato -en sus tres versiones: la contenida en el Nunca Más; el testimonio del sobreviviente Pablo Díaz en El Diario del Juicio y en su relato para el libro La noche de los lápices, firmado por María Seoane y Héctor Ruiz Núñez- sería un claro ejemplo de cómo la historia reciente narrada en la inmediata postdictadura "ocluyó del relato de las víctimas su adhesión a un proyecto político de izquierda que promovía la transformación radical de la sociedad e incluía como vía posible para lograrlo el ascenso al poder a través de prácticas violentas” (Op. Cit. Raggio 2010: 159). Podría señalarse como hito del contra-relato el testimonio de Héctor Falcone en su autobiografía Memorial de la guerralarga. Un pibe entre cientos de miles (2001) sobre María Claudia, militante de la UES detenida-desaparecida el 16 de septiembre de 1976

\footnotetext{
${ }^{59}$ Los que firman los materiales conmemorativos, englobados bajo el título de tapa "Che y después", son: Osvaldo Soriano, Miguel Briante y Eduardo Galeano. Además, se incluyen el documento histórico "Testimonio de la captura y asesinato del Che" y la historieta La vida del Che (guionista: Héctor Oesterheld; dibujantes: Alberto y Enrique Breccia), publicada originalmente en España en 1968.

${ }^{60}$ Dice Caparrós: "Ernesto Guevara se murió, fue fusilado una mañana, en un pueblito boliviano, después de su derrota y al día siguiente de lo que luego sería su efemérides, y eso parece darle cierta impunidad diplomática. Oh muerte, que todo lo lavas, que todo lo purificas. No me alcanza. Muchos amigos míos también se murieron en las guerras [...] eran -intento pensarlo- gente como yo que, simplemente, se empecinó más, se equivocó más, tuvo menos suerte. [...] ¿Qué culpa, qué parte de culpa tiene Ernesto Guevara en la muerte de ellos? [...] Guevara fue un héroe por inconveniencia, por derrota, por error de cálculo: él se proponía como modelo, y la idea de modelo presupone su imitación, su reproducción [...] Guevara exige sus seguidores la semejanza, el esfuerzo supremo de la similitud, los compele a que sean como él [...] Crear dos, tres, muchos Guevara, ésa fue la consigna" (1987: 6; énfasis del autor).

61 'La explicación ('Desaparecieron por luchar por el boleto escolar') insiste así en la 'inocencia': ¿cuánto de 'subversivo' escondía la reivindicación? Además, convoca a la adhesión mayoritaria: ¿quién podría estar en desacuerdo con tal reclamo? Elude, así, cualquier controversia en torno a las posiciones políticas de las víctimas, lo cual facilita la empatía. En este sentido, la tesis alcanza un alto grado de eficacia en la transmisión de la experiencia a las generaciones que no vivieron la época..." (Op. Cit. Raggio 2010: 159)
} 
en La Plata, donde afirma que efectivamente había un pequeño arsenal perteneciente a la Organización Montoneros en la casa adonde fue secuestrada su hermana.

El trabajo firmado por Gundermann constituye un ejemplo de en qué medida, dada la proximidad temporal con la "generación ausente" y el hecho de que los agentes continúan interviniendo activamente en el campo, se impone la necesidad de mantener la máxima distancia posible con el objeto de estudio, para no confundir determinadas "operaciones críticas estratégicas" con puntos de partida válidos para la investigación (lo que constituiría también el principal problema metodológico de nuestro trabajo).

En 2005, Laura Ruiz publica su tesis doctoral bajo el título de Voces ásperas. Las narrativas argentinas en los '90. En ella se percibe una oscilación entre ceder a los efectos de la "operación Raymond Williams en Punto de Vista" (y optar en consecuencia por privilegiar la categoría de "grupo cultural") y la utilización de un criterio generacional tributario de las formulaciones de Ortega y Petersen para delimitar el objeto de estudio:

Si bien se podría afirmar la presencia de un grupo claramente delimitado que se enmarca en los parámetros mencionados (haberse educado bajo la dictadura militar e iniciar su proyecto creador en los años del neoliberalismo) que recorta un grupo de escritores -aquellos que al momento de publicar sus primeras obras tenían entre treinta y treinta y cinco años-, existe una dificultad teórica para nombrar el grupo en términos clásicos de la historia de la literatura como "generación" o "década", a pesar de la relevancia que el término "generación" ha mantenido en la historia cultural hispánica desde que el escritor Azorín (seud. de José Martínez Ruiz) lo utilizó por primera vez en sus artículos de crítica literaria a principios del s. XX. Pero fue Ortega y Gasset quien en 1923 aportó una discusión filosófica rigurosa sobre el concepto y su utilidad en el campo de la cultura. (Ruiz 2005: 14; nuestro énfasis)

Ruiz caería en el mismo problema metodológico que hemos señalado para Gundermann cuando adopta sin más la caracterización que los autores de su corpus hacen de sí mismos como un punto de partida válido para la investigación (ignorando la existencia de organizaciones de superficie como la UES y la Juventud Guevarista, donde militaban adolescentes):

... al suceder el golpe de Estado los escritores tenían entre nueve y quince años y, por lo tanto, no participaban de la militancia activa, carecían de formación política y muchos de ellos tampoco tenían cabal conciencia de la represión indiscriminada, la censura y la muerte, de ese permanente "clima de cementerio" instalado en el país desde el comienzo de la dictadura, como lo caracterizó Eduardo Muslip en una entrevista personal. (Op. Cit. Ruiz 2005: 50) 
De todas formas, Ruiz finalmente define su corpus en términos de "los autores que nacieron entre 1961 y 1967 " y al momento de dar nombres, cree imprescindible incluir las respectivas fechas de nacimiento entre paréntesis: "los autores considerados en este capítulo [en el capítulo dos] son Raúl Vieytes (1961), Marcelo Figueras (1962), Federico Andahazi (1963), Rodrigo Fresán (1963), Leopoldo Brizuela (1963), Pablo de Santis (1963), Claudio Zeiger (1964), Eduardo Muslip (1965), Marcos Herrera (1966) y Martín Kohan (1967)” (2005: 40 y 43, respectivamente).

La insistencia en la fecha de nacimiento soslayaría precisamente la dimensión entre imaginaria y objetiva que tiene toda "generación", entendida como construcción. A esta tensión (fundamental en nuestro trabajo para delimitar la "generación ausente") pareciera estar haciendo referencia Martín Kohan en "Los ojos de la infancia" ([2009] 2013), cuando pone en (paradójica) relación su edad con la posibilidad de una "memoria oblicua" del pasado reciente:

Cuando Pedro Eugenio Aramburu fue ajusticiado en la Argentina -fue ejecutado por la agrupación Montoneros- yo tenía tres años. Cuando los peronistas se mataron entre sí en el aeropuerto de Ezeiza, yo tenía seis. Siete tenía cuando se murió Perón. Nueve cuando se produjo el último golpe de Estado. Once cuando la selección argentina ganó el mundial de fútbol en tiempo suplementario [...] Interrogada desde el saber y la experiencia cabal, mi presencia en ese mundo lejos estaba de la plenitud de alguna clase de protagonismo. Si se la quisiera resolver, sin embargo, desde la formulación de una ausencia, hay algo que se resiste: el hecho de que yo estaba ahí.

De todo esto se deriva, según lo razono ahora, una especie de oblicuidad. Oblicuidad en la experiencia y oblicuidad en la memoria. El reparto posible de recuerdo y olvido, en las dosis y en los modos que puedan convenir, se produce de manera diferente bajo la marca de lo que visto en diagonal o visto desde un costado, no es menos palpable sino más. Se altera la línea de continuidad entre las causas y las consecuencias y es muy otro el equilibrio de lo que se entiende o se deja de entender. (Kohan [2009] 2013: 238)

De esta cita, interesa destacar que su corta edad no es esgrimida como Kohan como coartada para afirmar - como sí lo hacen otros coetáneos- que "nada podía saber sobre los hechos". Como en el caso de Martín Caparrós (al que volveremos en detalle en el capítulo tres), Kohan es un ejemplo de cómo el factor etario no es el determinante, sino qué tipo de construcción identitaria se realiza a partir de él.

Al respecto, es justo señalar que, ya promediando su exposición, Ruiz relativiza su adhesión inicial a la "teoría de las generaciones" de Ortega: 
Definir a un grupo de escritores en términos de su edad presenta también dificultades teóricas. En la historia de la literatura, la categoría de "generación" ha resultado bastante ineficaz y nunca ha sido suficientemente confiable para periodizar y abarcar zonas literarias. (Ruiz 2005: 47)

Ruiz no ve ninguna "unidad generacional" (en términos de Mannheim), ni "desarrollo de un lenguaje propio de la generación" (en términos de Petersen) en los autores que ella denomina "los escritores jóvenes de los noventa":

La dificultad de aplicar el concepto [de generación] en este estudio reside en que los escritores jóvenes de los '90 no presentan propuestas grupales, no participan en conjunto en instituciones ni manifestaciones culturales (salones o asociaciones literarias, edición de una revista, entre otros) y tampoco se puede afirmar que hubo un ars poetica hegemónica ni concepciones de la literatura o ideas estéticas que les confiriera un carácter de instancia colectiva. (Op. Cit. Ruiz 2005: 15)

Esto último es incorrecto. A los "poetas de los noventa” dedica Marina Yuszczuk su tesis doctoral Lecturas de la tradición en la poesía argentina de los noventa (2011), donde demuestra fehacientemente la emergencia alrededor de 2001 de, por lo menos, dos estéticas poderosas que, por un lado, se plantan frente a las dos líneas (neobarroso y neorromanticismo) dominantes dentro de la llamada "poesía de los ochenta", y, por el otro, al objetivismo poético (al cual adscriben -en una amalgama intergeneracionalDaniel Freidemberg, Jorge Aulicino, Daniel Samoilovich, Daniel García Helder, Jorge Fondebrider y Martín Prieto): la línea “pueril, kitsch y pop" del grupo Belleza y Felicidad (Gabriela Bejerman, Fernanda Laguna y Cecilia Pavón) y la línea "analfabeta, marginal y maldita" (cuyo máximo exponente sería Washington Cucurto, fundador de Eloísa Cartonera).

Si bien Yuszczuk dedica una parte considerable de su trabajo al objetivismo y su órgano de difusión, Diario de Poesía, aclara que coincide con Emiliano Bustos (2000) y Ana Porrúa (2005) en la necesidad de partir la década del noventa, señalando que la "poesía de los noventa en sentido restringido" sería aquella "donde literatura y cultura de masas se nivelan definitivamente" (Yuszczuk 2011: 204).

De la lectura de la descripción del campo a fines de los ochenta y noventa que realiza Yuszczuk, se desprende la conclusión de que el objetivismo poético es precisamente, la "poética bisagra" entre la "poesía de los ochenta" y la "poesía de los noventa propiamente dicha". ${ }^{62}$ En este sentido, su trabajo confluye con el nuestro (lee

\footnotetext{
62 “Tal como se explicitó en la Introducción, el corpus que aquí se trabaja está formado por aquellos poetas cuyos primeros libros surgen en los noventa, por eso si bien Daniel Samoilovich, Daniel Freidemberg y Jorge Aulicino son parte de la formación que estamos analizando, en cuanto a textos
} 
en términos de "poética bisagra" a, por ejemplo, la poesía de Martín Prieto, a quien, en tanto novelista, encuadramos aquí dentro de la "generación ausente").

En 2011, Elsa Drucaroff publica Los prisioneros de la torre. Política, relatos y jóvenes en la postdictadura, volumen de más de quinientas páginas donde se pretende dar cuenta de la narrativa argentina publicada entre 1990 y 2007 mediante un discurso generacional de tipo histórico-cultural (el marco teórico utilizado es fundamentalmente Karl Mannheim) y a partir de una petición de principio: la creencia de que "un trauma que afecta a la sociedad argentina" debe necesariamente engendrar nuevos protocolos de representación que intenten dar cuenta de él (Cf. Drucaroff 2011: 17), algo que -como ya señalamos- ha sido desestimado por autores como Beatriz Sarlo, Andrés Avellaneda y José Luis de Diego. Las citas de trabajo de Drucaroff quizás impresionen como demasiado extensas, pero las creemos necesarias para poder evaluar su planteo con fundamento:

¿A qué llamo "nueva narrativa"? Es una expresión extendida en los suplementos culturales, blogs y artículos especializados, y suele abreviarse como NNA, pero lo que yo llamaré acá NNA es más amplio. Para comenzar a definirlo, digo que también la llamaré, indistintamente, "narrativa de las generaciones de postdictadura". Ambas denominaciones no son sinónimas, como es evidente, pero a mi entender refieren a un mismo fenómeno y dicen de él dos cosas necesarias y complementarias: "NNA" alude a rasgos novedosos que pueden detectarse en la narrativa de escritores y escritoras que nacieron después de 1960 y surgieron a partir de los años 90; "narrativas de las generaciones de postdictadura", por su parte, subraya, en este caso, que esa novedad respecto de la literatura anterior está relacionada con un trauma que afecta a la sociedad argentina y proviene, como todo trauma, de un pasado negado y doloroso.

La denominación NNA hace hincapié en la ruptura, la discontinuidad; la denominación "narrativa de las generaciones de postdictadura", en un factor histórico que, entre otros, determina esa ruptura. Pero ambas denominaciones siempre refieren al mismo corpus de obras: la narrativa que empezaron a escribir, entrada la democracia, y publicaron a partir del menemismo personas que vivieron la dictadura en una edad en la que no habían llegado a la conciencia ciudadana, o que no la vivieron nunca porque nacieron en democracia. Hay, por lo tanto, un componente generacional fundamental en esta definición... (Drucaroff 2005: 17; nuestro énfasis)

poéticos nos centraremos en los de Martín Prieto y Daniel García Helder, que a nuestro juicio tienen continuidad en otras líneas de escritura de la década (el primer libro de Aulicino, Vuelo bajo, es de 1974; el de Freidemberg, Blues del que vuelve solo a casa, es de 1973, y la primera publicación de Samoilovich, Párpado, pertenece a ese mismo año).” (Yuszczuk 2011: 53-54) 
Lo primero que podría objetársele a Drucaroff es la adopción sin más de la etiqueta "nueva narrativa argentina". ${ }^{63}$ En términos de teoría del conocimiento, surge con esto el problema de dar por sentado aquello que, sin embargo, debería ser primero objeto de indagación. ¿Cómo y desde qué teoría sería posible pensar "lo nuevo en la literatura argentina", que parece haber saludado su último "vanguardista" en César Aira (Speranza 2001; 2006)? ¿Quiénes y por qué dicen "NNA"? ¿Esta supuesta novedad estaría planteada respecto a qué, o a quienes? ¿Es legítimo pensar la novedad en términos meramente contenidistas, como parece sugerir el análisis de las "novelas de la NNA" que realiza Drucaroff (que finalmente se concentra en sus "manchas temáticas", a la manera de David Viñas: "lo fantasmal"; "el filicidio"; "el cuerpo como única emanación de las certeza posibles”; “el quiebre de la transmisión generacional”)?

Drucaroff explicita de la siguiente forma su concepto de "generación":

...entiendo a la generación como grupo humano dinámico y coetáneo, particularmente sensible a su tiempo histórico, conjunto de personas que intentan protagonizarlo en algún aspecto, en este caso, el de la producción literaria [...] Una generación es un lugar de pertenencia histórica y, sobre todo, social, en el que lo biológico apenas impone ciertos límites, condiciones de posibilidad [...] Hablaré entonces, en principio, de dos generaciones de postdictadura [...] Planteo los agrupamientos generacionales a partir de ciertos hitos políticos, ciertas efemérides que funcionan como síntesis o puntos de eclosión, entendiendo a cada una como experiencia social ineludible para cualquier ciudadano; en este caso para los escritores y escritoras. (Op. Cit. Drucaroff 2011: 169-170)

En esta definición, el concepto de "efemérides" es central. Drucaroff toma la asunción presidencial de Raúl Alfonsín (19 de diciembre de 1983) como efemérides de la "primera generación de postdictadura" ("contiene a los escritores y escritoras nacidos aproximadamente entre 1961 y 1970”) y los episodios del 19 y 20 de diciembre de 2001 que terminaron con el gobierno de Fernando de la Rúa como efemérides de la "segunda generación de posdictadura" (cuyos miembros, "nacidos entre 1971 y 1989”, según Drucaroff, "son los principales protagonistas del movimiento de la NNA"). Pocas páginas antes, había señalado que, a su vez, estas dos "generaciones de posdictadura" tendrían "dos generaciones militantes como antecesoras". ${ }^{64}$

\footnotetext{
${ }^{63}$ La formulación de Drucaroff sobre "lo nuevo" es llamativamente poco rigurosa: "Cuando hablo de 'nueva' narrativa para la obra de las generaciones de postdictadura me refiero a que encuentro en ella cierta entonación, ciertas 'manchas temáticas' y ciertos procedimientos que en general no aparecen así en otra parte, al menos como tendencia generalizada" (2011: 18).

64 “... creo que hay que entender la existencia de al menos dos [generaciones militantes], integradas por argentinos que tenían, aproximadamente, entre 13 y 45 años al 25 de mayo de 1973, probablemente la efemérides que señala su apogeo generacional, con su potente sensación de inminencia y alegría [...] Si
} 
En la página 179 de Los prisioneros de la torre, el lector encuentra un cuadro de doble entrada donde se explicita qué edad tenían los autores pertenecientes a una u otra generación de la postdictadura al momento de producirse las siguientes efemérides. A saber: (1) la asunción presidencial el 25 de mayo de 1973 de Héctor Cámpora que da inicio a la llamada "primavera camporista"; (2) el golpe del 24 de marzo de 1976; (3) el inicio de la guerra de Malvinas; (4) la renuncia de Alfonsín, y el traspaso del poder seis meses antes del plazo constitucional a Carlos Menem, que se había impuesto en las urnas el 14 de mayo de 1989; (5) las marchas por la Educación de agosto de 1992; (6) el 19 y 20 de diciembre de 2001.

¿Qué podría desprenderse del análisis de este gráfico, que Drucaroff cree indispensable incluir para terminar de bosquejar su planteo generacional?

Lo interesante de este cuadro de doble entrada de "efemérides" y "generaciones de postdictadura" es que -contra su pretensión analítica objetiva- vuelve diáfano el carácter autoconstruido de cualquier "generación" en tanto "construcción identitaria" (Jureit/ Wildt 2005) y/ o "categoría de memoria" (Weigel 2005), más aún considerando el interés que demuestra Drucaroff en señalar que ella misma es parte de la "segunda generación militante" (Cf. Op. Cit. Drucaroff 2011: 148-149).

Por un lado, es notorio el carácter parcial con el que se han elegido determinadas “efemérides”, y no otras. (¿Por qué no elegir el "Cordobazo” en vez del inicio de la “primavera camporista"? ¿Y desde qué criterio se incluye en el cuadro las marchas por la educación de agosto de 1992?) Por otro lado: ¿es legítimo adjudicar análoga importancia -en términos de "cesura histórica"- a la asunción de Alfonsín que a las jornadas del 19 y 20 de diciembre de 2001 (que los historiadores Marcos Novaro Vicente Palermo no ha dudado en analizar como mera "reelaboración de los ideales democráticos de 1983")? ${ }^{65}$

extiendo los dos períodos a treinta y dos años, es porque la fiebre, la pasión y la fiesta que significó el auge de la militancia arrastró a gente muy joven [...]" (Op. Cit. Drucaroff 2011:177)

65 "2001 [...] se presentaba como la oportunidad para lograr aquello que los demócratas de 1983 no habían podido o no habían querido hacer: regenerar las condiciones sociales, económicas y culturales para que la democracia política no fuera puramente "formal' [...] 2001 es la oportunidad para corregir el '83." (Novaro/ Palermo 2004: 15) Tomando el período 1983-1986 en términos de "transición democrática" y caracterizando el 2001 como "setentismo" y "nueva transistología", los autores señalan la existencia de una continuidad ideológica considerable entre 2001 y 1983: "El 'setentismo' y la 'nueva transistología', más que una reivindicación de los años setenta o una superación de los marcos del pensamiento heredado de 1983, consisten, en suma, en esfuerzos por reeditar (redefiniendo) el consenso forjado entonces, en claves que suponen muy poca innovación, y apenas variaciones en la combinación y/ o contraposición de sus mismos elementos republicanos y populistas [...] el setentismo y los nuevos transistólogos mezclan los mismos elementos manipulados por aquellos que critican, incluyendo no sólo el populismo 
Por otra parte, coincidimos con Drucaroff cuando señala repetidas veces que uno de los acontecimientos históricos que significaron en nuestro país una cesura indiscutible, tal como la entendieron Mannheim y Petersen respecto a la primera guerra mundial en Europa, fue la última dictadura militar. Pero con una importante aclaración: la última dictadura se constituyó en "cesura histórica" porque tanto los agentes históricos como los cientistas sociales eligieron construirla en tanto tal. Esto es: en la dinámica entre sus características intrínsecas "objetivas" y sus marcos sociales de recepción (en términos de "memoria colectiva" de Halbwachs). Porque, tal como lo señala Elizabeth Jelin:

Hay un hecho evidente: aún como miembro de un mismo grupo social -desde la familia a la humanidad toda- la vivencia de un acontecimiento histórico es absolutamente diferente según la edad que tiene la persona en cuestión. Vivir una guerra a los cinco, a los veinticinco o a los setenta son fenómenos subjetivos distintos [... La edad, el momento de la vida en que suceden los acontecimientos, deja marcas específicas, porque afecta a las condiciones de vida, experiencias y horizontes futuros. En términos sociales o colectivos, la edad $-\mathrm{O}$ en términos técnicos de la demografía, la cohorte de nacimiento- tiene también otra característica: define un colectivo, que puede ser imaginario, de personas que comparten oportunidades y limitaciones históricas que les deparan un "destino común”. (Op. Cit. Jelin 2002: 119; nuestro énfasis)

\section{CODA. "Memoria en la literatura" y "memoria de la literatura I": la "generación ausente" en modo autoficcional}

En sendos artículos publicados en 2007 y 2008, Alberto Giordano y Graciela Speranza discuten la pertinencia o no de utilizar el neologismo “autoficción” para englobar determinados textos literarios. Por un lado, se preguntan sobre cómo sería posible pensar "el regreso del autor" luego de su muerte proclamada por Barthes en 1968, y cómo deslindar la llamada "autoficción" de la novela autobiográfica y las demás "escrituras del yo". Por otro lado, ensayan razones para explicar el auge del neologismo acuñado por Serge Doubrovsky en 1977, observable tanto en la novelística argentina, como en la producción académica y crítica. A todo esto, cabría sumarle el llamado "giro autobiográfico" (Giordano 2007; 2008; 2011), no sólo en las artes, sino también en las ciencias sociales.

Sobre estos interrogantes también avanza el artículo "Autoficción, una polémica literaria vista desde los márgenes (Borges, Gombrowicz, Copi, Aira)”, de José Amícola, publicado en 2009. De este trabajo, interesa rescatar dos observaciones: el importante 
papel jugado por la literatura escrita en Argentina o relacionada con nuestro país en la discusión del concepto de la "autoficción moderna", y la necesidad de ejercer una sana desconfianza crítica al momento de adoptar sin más nuevas etiquetas. ${ }^{66}$

Lo que es indudable, tal como se desprende de los análisis textuales desplegados por Amícola en Autobiografía como autofiguración. Estrategias discursivas del Yo y cuestiones de género (2007) y "Autoficción, una polémica literaria vista desde los márgenes (Borges, Gombrowicz, Copi, Aira)", es que los llamados "géneros del Yo" son extremadamente populares dentro de la literatura argentina, con exponentes (Borges, Gombrowicz, Copi, Aira) que ya forman parte de nuestra "memoria de la litertura II".

Al respecto, cabría postular como uno de los subgéneros de la novela argentina aquel que elige ficcionalizar una generación literaria efectivamente existente mediante las convenciones de la novela à clef francesa, la llamada "novela biográfica" y/o el modo autoficcional. El ejemplo célebre es Adan Buenosayres (1948), de Leopoldo Marechal, memoria en la literatura de la "generación martinfierrista".

Sobre la llamada "generación parricida" en colisión con la "generación del sesenta", el fresco epocal por lejos más corrosivo es el relato "Sábado de gloria en la capital (socialista) de América Latina", incluido en el volumen Buenos Aires: de la fundación a la angustia, publicado por David Viñas en 1968. Allí aparecen problematizados el exilio de Perón, la herencia intelectual de Jean Paul Sartre (“el maestro de mi generación"), la revolución cubana, EUDEBA, el Boom y "Primera Plana", el Instituto Di Tella con sus happenings, la jerga, las guerrillas de la década (Uturuncos, los focos rurales de inspiración guevarista en el Noroeste argentino), y, fundamentalmente, la revolución sexual. En este relato, la cuidada construcción de una voz en primera (por momentos bastante cínica, pero siempre lúcida) permite escenificar la propia posición generacional del autor.

\footnotetext{
${ }^{66}$ En La batalla de los géneros. Novela gótica versus novela de educación (2003), José Amícola señala el libro Der deutsche Bildungsroman (1992) de Gerhart Mayer como ejemplo claro de un esencialismo crítico que es preciso a evitar en toda aproximación al tema del género que pretenda ser consistente, señalando que Mayer "da por sentada la esencia primordial y atemporal de la novela de aprendizaje, como entelequia libre de cualquier atadura de tiempo y espacio" (Amícola 2003: 151). Similar crítica podría hacérsele al libro de Vincent Colonna, Autofiction et autres mythomanies littéraires (2004). En su libro, Colonna lee escritores pertenecientes a tradiciones literarias y épocas harto diferentes desde una misma etiqueta genérica: la por él llamada "autoficción". Como señala Amícola en su artículo "Autoficción, una polémica literaria vista desde los márgenes (Borges, Gombrowicz, Copi, Aira)" (2009), Colonna olvida contemplar en su análisis que la autoficción necesita del género de la autobiografía (aparecido recién en el siglo XVIII) para existir como tal, dado que "sin verdadera autobiografía no habría posibilidades ni para la novela autobiográfica ni para la autoficción, que dependen de la primera para su constitución" (Amícola 2009: 189 y 184, respectivamente).
} 
De todas formas, Viñas publicará una versión "solemne" de esta colisión generacional apenas un año más tarde: Cosas concretas, novela dedicada nada casualmente "A mis viejos camaradas de Contorno". Nuevamente, como en "Sábado de gloria”, el narrador reivindica para sí una posición lúcida entre dos generaciones: "Me alegro mucho que hayan cambiado los tiempos, y me siento encabalgado entre dos generaciones y con el sexo erguido" (Viñas 1969: 38). Seis años más tarde, Viñas volverá al subgénero novelístico que intentamos precisar aquí con Dar la cara, donde nuevamente lo generacional ostenta un importante rol en la construcción del héroe ("Bernardo Carmán", nacido en 1936). Habiendo cumplido el servicio militar obligatorio, Carmán discute en la pieza de pensión una posible huelga con tres miembros de la llamada "novísima generación", y comprueba con cansancio que "los que venían detrás" eran "despiadados y mucho más implacables de lo que había sido él” (Viñas 1975: 38).

La "serie de los canguros" de Jorge Asís es, sin duda, la saga novelística que se propuso como memoria más completa en la literatura de la "generación del setenta", obteniendo el mayor grado visibilidad. Aunque no es la única: Fuego a discreción (1991), de Antonio Dal Masetto, recoge con sutileza las esquirlas de la "generación literaria de 1970" ${ }^{67}$ Hay alusiones (aunque cifradas) a la "generación setentista" en Tartabul (2006), de David Viñas. En los términos más acotados de la memoria en la literatura de la también llamada "generación militante", cabría por último mencionar las novelas Los compañeros (2000), de Rolando Diez y Los cuerpos y las sombras (2014), de Eduardo Sguiglia.

La "serie de los canguros" consta de Flores robadas en los jardines de Quilmes (1980); Carne picada (1981) y Canguros (1983), con un "insert" en La calle de los caballos muertos (1982) y un primer ensayo en Los reventados (1974). Mientras la novela Flores robadas en los jardines de Quilmes está dedicada a Haroldo Conti, la dedicatoria de Carne picada reza: "a Lucina Álvarez/ a Oscar Barros/ al hijo que deben criar los abuelos". 68

El segundo epígrafe que inaugura Carne picada, cuyo autor es "Oberdam Rocamora" (seudónimo utilizado por Asís para firmar sus notas en Clarín), hace explícito el vínculo entre violencia política y generación de pertenencia: “... que esto es

\footnotetext{
67 "En la biblioteca reconocí la tapa de un libro. Se lo mostré. -¿Dónde está ese tipo? -pregunté-. ¿Escribió algo más? -Lo mataron -me contestó Luis.” (Dal Masetto 1991: 151)

${ }_{68}^{6}$ Lucina Álvarez, poeta y periodista, y su eposo Oscar Barros, periodista y escritor, fueron secuestrados el 7 de mayo de 1976, y desde entonces se encuentran desaparecidos.
} 
una ciudad, una tragona insaciable, una máquina de picar carne, de picar generaciones...". Las alusiones al exterminio de "las mejores cabezas de mi generación" abundan en cada una de las novelas que conforman la serie. Asimismo, las menciones precisas a determinadas figuras del campo literario porteño de la década del setenta.

A mero título de ejemplo: en Carne picada "Rodolfo Zalim", alter ego del autor, se jacta de haber estado en la misma lista de "escritores de la subversión marxista" que Francisco Urondo y Rodolfo Walsh, señalando que "conmigo solamente no cumplieron" (Asís [1981] 2007: 241). Una adivina, Olga, profetiza a Rodolfo "un futuro [literario] espléndido": tendrá mejor estilo que Fogwill y más dinero que Bioy Casares (Op. Cit. Asís [1981] 2007: 254). También se vuelve a hacer mención a la desaparición de "mi amigo Haroldo", que "creía que porque era escritor lo iban a respetar, no se la iban a dar" (Asís [1981] 2007: 284).

El lugar altamente inestable de la generación que nos ocupa explicaría por qué determinados miembros de la "generación ausente" se ocuparon desde muy temprano de crear una memoria en la literatura de su propia generación. Con esto nos referimos a la novela Posdata para las flores, de Miguel Vitagliano, publicada en 1991 por Ediciones Último Reino. También cabría mencionar algunos cuentos incluidos en Nadar de noche (1991), de Juan Forn y La mafia rusa (2008), de Daniel Link. Por último, en 2007, se publican las novelas Historia del llanto, de Alan Pauls y El desperdicio, de Matilde Sánchez.

Antecedente directo de estas memorias sería Con el trapo en la boca. Una cruda indagación de las incertidumbres, conflictos y esperanzas de la juventud de hoy (1983), de Enrique Medina. La novela se abre con una dedicatoria: "A la mujer, a los amigos, entrañablemente". Esto es: los resultados de la "cruda indagación" a la que alude el subtítulo están dedicados a la otra generación (esto es: a la generación anterior, a la que pertenece Medina). La impostación de la voz generacional es no sólo etaria, sino también de género: para mejor acusar a "la juventud de hoy", el autor construye la voz narrativa de "Laura", estudiante secundaria durante la guerra de Malvinas. ${ }^{69}$

\footnotetext{
${ }^{69}$ La ignorancia que Enrique Medina adjudica a Laura sobre el contexto político en el que vive es directamente inverosímil: "En esa época el Macho empezó a usar las camisolas tipo hindú y se rapó la cabeza. No tenía un mango y se tiraba de tener mucha guita. En ese tiempo fue que lo mataron a Pico, que jugaba al jockey en G.E.B.A. Y también mataron a otros dos enfrente de G.E.B.A. Los encontraron atados y cagados a golpes con cadenas, hechos mierda. Siempre se rumoreó en el Normal que el responsable habría sido el Macho. Era peleador nato. Por donde iba dejaba el tendal" (1983: 19).
} 
Miguel Vitagliano dedica su primera novela a su coetánea y amiga Mónica Tamborenea. Mezclando los géneros de la novela epistolar y el diario íntimo, Posdata para las flores se propone dar cuenta de la historia de Alberto, estudiante de Letras en la UBA, poeta inédito y amigo de Carlos, que se ve forzado a exiliarse en España entre los años 1979 y 1981 debido a la militancia de su hermano mayor en la Fede (lo que ocasiona que Alberto se quede en Buenos Aires con Ana, la novia de su amigo). Así como Ana toma a Alberto como sucedáneo de su novio, Alberto advierte con amargura a Carlos que su exilio en en España es, en verdad, un exilio por Ersatz: "Por precaución vivías un exilio que también te tocaba de segunda, que tu hermano se comía y te dejaba las migajas. Vos las disfrutabas como si fueran manjares" (Vitagliano 1991: 31).

No sólo el exilio político es vivido "de segunda mano", sino también la epifanía literaria:

[De mi libro de poemas] lo único que habías rescatado fue el epígrafe de Kerouac: "Nobody knows the other side of my house". Decías que nadie se acordaba de los beatniks y que todos escribían igual, que por eso ni podías soportar la poesía. Después de un tiempo -mucho antes de saber que volvías-, supe que no era cierto, que mi epígrafe había sido citado más de cien veces por los poetas de los setenta. Nosotros éramos chicos, Carlos, cómo lo íbamos a saber, si hasta creíamos que habíamos sido nosotros los que los descubrimos de oferta en las librerías de Corrientes. Estábamos atados a ellos hasta cuando creíamos que no. Siempre llegamos tarde. (Vitagliano 1991: 53)

Carlos arma un colectivo que engloba a su amigo y a su novia Ana: "los que nacimos demasiado viejos", "los condenados a escribir monografías, a no ser nunca protagonistas" que contrasta con un "ellos, que lo habían probado todo, habían estado cerca de tenerlo todo [...] [los que] habían tomado todos los trenes, que se habían mandado por todos los caminos, por todos los desvíos para llegar", esto es, la generación del hermano de Carlos (Op. Cit. Vitagliano 1991: 78 y 107-108). ${ }^{70}$

Se ha explicado el éxito editorial de la antología de cuentos Nadar de noche (que en octubre de 1993 saca la cuarta edición de 11.000 ejemplares, y que será reeditada por Alfaguara en 2002 y por Emecé en 2008,) por la identificación de tipo generacional que fue capaz de suscitar en su momento entre sus lectores. Los relatos -a la manera

\footnotetext{
${ }^{70}$ Apenas un año más tarde, Damián Tabarovsky publica Fotos movidas. Como en el caso de la novela de Vitagliano, una persistente sensación de futilidad signa el destino de los personajes, que ni siquiera detentan nombres propios, sino genéricos (aunque el "escritor" es indudablemente una autoimagen del propio Tabarovsky). Las menciones a ciertos consumos culturales (la telenovela María de nadie), a determinadas marcas de psicofármacos y a la terapia psicoanalítica como solución -por demás fallidapara la angustia existencial, permiten fechar el tiempo narrado de esta enrarecida novela "de iniciación" en los años del gobierno alfonsinista. (Las comillas van a cuenta de que en su primera novela Tabarovsky parece estar empeñado en demostrar la imposibilidad de toda épica y todo aprendizaje.)
} 
sociológica" de Fogwill- contienen un prolijo inventario de los consumos culturales de finales de los años ochenta: películas en VHS, walkmans, sopas chinas en cajas de cartón, "jueguitos electrónicos”, samplers. En "El borde peligroso de las cosas” Forn se autorrepresenta como un escritor que sólo desea escribir "una buena historia de amor", en diálogo con el personaje de "Javier Messen", la "medida" ("messen", en alemán es "medir") opaca y confundida de su generación, incapaz de asumir responsabilidades adultas (la paternidad, un trabajo estable). Durante la larguísima noche de sexo casual, drogas y alcohol en la que el narrador conoce a "Javier", ambos coinciden en que "somos el jamón del sándwich" entre "los pibes" y "los cuarentones clavados en su pasado psicobolche o en la new age" ([1991] 1993: 155).

Llegar tarde, ser un mero testigo, estar entre, no comprender. Las posiciones prototípicas de "la generación ausente" encontrarían una explicación en la cesura histórica que significó la última dictadura militar, que el brevísimo relato "12 de octubre de 1976" firmada por Daniel Link e incluido en La mafia rusa coloca en el centro. El narrador en primera, secretario general del Centro de Estudiantes de su colegio secundario y designado maestro de ceremonias durante el Día de la Raza, incluye la interpretación de la Cantata Sudamericana de Ariel Ramírez y Félix Luna en el programa, lo que desata un escándalo mayúsculo:

La profesora de Literatura [...] me convocó para decirme que todos los que habíamos participado de esa conmemoración corríamos, entre otros riesgos, el de ser expulsados del colegio. Nos habíamos transformado en "rojos" que hacían propaganda "subversiva" [...] Yo era buen alumno y mi beligerancia política se había canalizado hasta entonces en el reclamo de más papel higiénico en los baños y cosas por el estilo. [...] Ese 12 de octubre, mis amigos y yo empezamos a entender lo que había pasado [...] y lentamente nos fue dominando la tristeza de una seudovida vivida a escondidas y el horror de la realidad, que empezaba a atravesarnos. $\mathrm{O}$, mejor dicho: nosotros que abandonábamos el colegio empezábamos a circular a través de una realidad horrible con la tristeza del testigo de algo de lo que nunca podrá hablar con dignidad. (Link 2008: 92-93)

Un año antes, Alan Pauls había publicado Historia del llanto. Un testimonio, primera entrega de su "trilogía sobre los setenta". A la manera de Manuel Puig, el rótulo "un testimonio" de Historia del llanto banaliza e inquieta al mismo tiempo la adscripción genérica. Por un lado, la renuncia ostentosa a la primera persona para el "testimonio" conduce paradójicamente a que éste sea leído en serie con otros relatos de Pauls donde es más obvio el "giro autobiográfico": Wasabi (1994), La vida descalzo, los fragmentos de su diario íntimo en Idea crónica. Literatura de no ficción 
iberoamericana y en Confesionario. Historia de mi vida privada (los tres últimos, publicados en 2006). Por otro lado, el subtítulo pondría a Historia del llanto en contrapunto con el abundante material testimonial que acompañó el vigésimo y trigésimo aniversarios del Golpe. Aunque Historia del llanto presenta un testimonio harto enrarecido, porque el que habla en la novela de Pauls es uno que estuvo, que vio, que supo, pero que fue incapaz de participar (o, mejor dicho, de dejar la pasión de la lectura por la de la acción).

El protagonista sin nombre en Historia del llanto, que lee La causa peronista con el mismo fervor que pocos años antes devoraba las aventuras de Superman, sería un ejemplo (adolescente) de la aberración que Rodolfo Walsh denunció en su "Mensaje a los trabajadores y al pueblo argentino" el $1^{\circ}$ de mayo de 1968, cuando la CGT de los Argentinos presentó su programa en un acto encabezado por Raimundo Ongaro y Agustín Tosco en el Córdoba Sport Club. En el ítem número siete del documento (sin firma), Walsh había dado su definición de intelectual bajo la forma de una admonición: "Un intelectual que no comprende lo que pasa en su tiempo y en su país es una contradicción andante, y el que comprendiendo no actúa, tendrá un lugar en la antología de llanto, no en la historia viva de su tierra" (Walsh [citado en: Anguita/ Caparrós] 2006: 342-343).

Como el autor, el protagonista de Historia del llanto nace en 1959. Con catorce años cuando matan a Allende (e incapaz de llorarlo, o de dimensionar el verdadero significado de esta muerte), un año después sufre una conversión que no es política, sino amorosa: logra llorar por primera vez cuando, en un ejemplar de La causa peronista, reconoce la foto de su vecina montonera, "Silvia", baleada en un enfrentamiento y vejada luego de muerta, la primera mujer desnuda de su vida (Cf. Pauls 2007: 121). Habiendo escuchado durante toda su infancia y adolescencia con partes iguales de deseo y hastío el relato de militancia y exilio que rememoran su padre y su amigo, el "cantautor de protesta", rebautizado por él aviesamente como "Bondad Humana" (en una remisión diáfana a la figura real del artista Piero, hibridada con el film homónimo de Akira Kurosawa), la demarcación generacional se torna estridente:

De ahí en más, todo lo que rodea al cantautor de protesta, no sólo su letrista y sus amigos cercanos, sino sus contemporáneos, sus coetáneos, sus, como se dice en la época, "compañeros de ruta", como también la época que lo encumbra, los valores que defiende, la ropa que usa, todo se le aparece rancio, viciado de la pestilencia singular, tan tóxica, de esos manjares que más allá de cierto umbral de tiempo, cuando se descomponen, irradian una fetidez bestial, difícil aún de concebir en las cosas en 
las que la putrefacción es el único estado de existencia posible. Como es natural, su padre no tarda en caer en la volada... (Pauls 2007: 47)

Como en El beso de la mujer araña (1976), de Manuel Puig, en Historia del llanto los fluidos corporales se politizan. En el extranjero, enamorado de una "erpia" (sic!) que se ha exiliado, el protagonista es incapaz de penetrarla y/ o hacerla gozar. En otras palabras: de dejar de lado su conocimiento libresco sobre la época y poner el cuerpo (Op. Cit. Pauls 2007: 99-100). Al mismo tiempo, la inminencia de leer La causa peronista (comprada de manera clandestina), resulta para él lo más parecido a alcanzar el clímax sexual (Pauls 2007: 118-120).

Por último, la resolución disparatada a la manera de César Aira de la historia del vecino militar a quien su madre solía usar de improvisado niñero (que resulta ser la "Comandante montonera Silvia" arriba mencionada, camuflada bajo ropas de hombre), y la fantasía sexual de tintes lamborghinescos con la que protagonista intenta consolarse de su ignorancia cuando afirma que "no ha sabido lo que había que saber" (pero no aludiendo precisamente a la realidad atroz del terrorismo de Estado, sino a esta identidad femenina secreta), colocarían Historia del llanto en diálogo desafiante con aquella "herencia imposible" que, desde las páginas de Babel, revista de libros, se había propuesto como posible fórmula para continuar escribiendo "literatura política": en la intersección de las poéticas de Rodolfo Walsh, Osvaldo Lamborghini y Manuel Puig (Link 1989), sobre la cual volveremos extensamente en el próximo capítulo.

En ocasión de promocionar Historia del pelo (2010a), segunda entrega de su "trilogía sobre los setenta", Pauls afirma lo siguiente:

Nunca tuve militancia política, nunca tuve relación directa con la práctica política, y a su vez era un consumidor bulímico de toda la literatura política de la época [...] A los trece años ya leía a Althusser. No entendía un carajo, pero había tres cosas que me impresionaban de esos textos y con eso armaba un mapa que me permitía leer al mismo tiempo Estrella Roja o El Combatiente, o La causa peronista, El descamisado o el diario Noticias. (Pauls 2010b: 26)

Pauls realiza un doble movimiento de demarcación: ni perteneciente a la "generación militante", ni perteneciente a los "locos ochenta" del Parakultural:

Los ochenta para mí, y supongo que para muchos de mi generación, fueron una época atroz, tremenda [...] Es la década en la que cambia totalmente de régimen de cultura, para hablar en términos específicos. El momento en que la cultura letrada empieza a ser barrida por la cultura audiovisual, el discurso por la comunicación, etcétera. Los años ochenta son la matriz de muchos de los desalientos de hoy $[\ldots]$ Fue un momento muy inestable: yo me sentía parte de una tradición que estaba medio 
liquidada; veía que la cosa venía mal, pero me sentía bastante más joven que muchos de los que protestaban. Me sentía incómodo. No era un setentista golpeado por la historia y odiaba la fiesta de los ochenta: quedé a mitad de camino en el momento en que empezaba a publicar. (Op. Cit. Pauls 2010b: 27)

También en 2007, Matilde Sánchez publica El desperdicio, elegía generacional a seis años de la muerte de Mónica Tamborenea, la "Elena Arteche" de la novela, en cuya imposibilidad de concretar "la gran obra crítica" se cifre -quizás- el fracaso intelectual de toda una generación. (Sánchez elige el sintagma de "generación desperdiciada" para referirse a la "generación ausente", lo que también explicaría el título de su novela.)

Sobre Arteche/ Tamborenea, Sánchez ya había publicado antes el relato "Pirovano", fechado en 1994 e incluido en La canción de las ciudades (2000), cuyo relato inaugural (“Amsterdam, 79”) se ocupa de separar aguas con la generación setentista, aunque de manera harto sutil: "Somos los únicos [argentinos] que viajan a Europa” (Sánchez 2000: 11). En otras palabras: lo únicos que en el año 1979 han llegado allí por turismo, y no por motivos políticos.

En efecto: en "Amsterdam", la narradora y "C." se cruzan con varios exiliados. Entre ellos, el mismo Fernando Vaca Narvaja, que intenta infructuosamente venderles una camioneta. Los escasos años que separan a la narradora y C. del grupo de "los argentinos del galpón", que "cultivaban la identidad como sólo se hace en el destierro, instalados de lleno en el patetismo [...] desdoblados allí y al otro lado del Océano" (Op. Cit. Sánchez 2000: 31), son decisivos. La diferencia generacional está dada por un hiato temporal mínimo ("hacían bromas cuyo sentido se nos escapaba [...] nos hubieran hecho falta unos años, no más de dos o tres años, para comprender"), pero que define la relación con la experiencia.

La apología libresca de Mario Roberto Santucho que hace C. en el galpón, desencadena una reacción violenta por parte de "los argentinos", que creen descubrir en él un agente de los servicios. Precisamente, porque no pueden creer que C. hable "desde ningún lugar" (desde el lugar irresponsable del turista, del apolítico, o -de manera coincidente con Pauls- del "mero lector"). ${ }^{71}$

\footnotetext{
71 "Ustedes dos en qué andan, preguntó el jefe -quizás dijo a vos quién te manda, no me acuerdo. Qué me venís a mí con Roberto Mario, me venís con la psicopatía, yo estoy jugando tranquilamente al truco y me venís a amargar con el cuento de Robi, o no sabés con quién estás hablando.” (Sánchez 2000: 32)
} 
En su caracterización de la "generación desperdiciada" que Sánchez despliega en El desperdicio, están presentes varios de los elementos que Rubinich (1985) y Pauls (2010b) adjudicaban a dicha generación.

La relación de "hermandad" con la "generación sesentista":

Sólo veíamos películas en blanco y negro. Empezamos a verlas para halagar a Miguel Briante o algún cinéfilo [...] Siempre las mismas películas veíamos, siempre el mismo tipo de cine, ciclos de cine francés, ciclos de películas búlgaras, soviéticas. No se hablaba de cine ruso sino de cine soviético [...] Todo desde los comienzos del cine, nos vimos, siempre los mismos films, machacar y machacar hasta memorizarlos. (Sánchez 2007: 44)

El mito de la "fiesta de los ochenta", contra el que Matilde Sánchez enumera precisos factores materiales para sustentar la hipótesis del empobrecimiento intelectual:

Quienes idealizan los años ochenta llamándolos primavera incurren en la peor mitología. No hubo tal primavera [...] Fue entonces que los lectores empezaron a escasear. [...] La edición empezó a ser sustituida por un circuito de fotocopias vertiginoso. Pocos se preocupaban realmente por la calidad de sus escritos e incluso olvidaban ponerles su nombre, inicialarlos siquiera. Una gran masa de bibliografía pirata se reproducía a tal ritmo que enseguida convertía los textos en corpus anónimos.

(Op. Cit. Sánchez 2007: 44-45)

Sin embargo, "los ochenta" son también el momento de cristalización de una identidad generacional con características propias (no necesariamente negativas):

Nosotros nos juntábamos siempre en algún restaurante del centro al cabo de la presentación de algún libro. Se iba a las presentaciones en masa, a dar aguante al autor que pagaba la edición de su obra. Se iba mucho al teatro en los ochenta también. Eran tiempos de sótanos húmedos y dramaturgia caníbal. [...] Siempre era misterioso cómo después una mesa de tres o cuatro personas se iba poblando de recién llegados [...] Era preciso ganarse una plaza en la mesa y en la conversación y había un placer en ver cómo el otro sorteaba el brete y emergía de sus aciertos o errores. Después se agregaban sillas y nuevas mesas hasta que el barullo era insostenible, una fiesta de desconocidos. (Sánchez 2007: 67-68)

Estas tres citas condensan y anticipan en gran parte lo que se tratará en el próximo capítulo: la relación (no siempre apacible) con Miguel Briante, las adversas condiciones del mercado editorial al momento de publicar las primeras novelas, el impacto que significó en la década del ochenta para el mundo editorial en agonía la aparición de la nueva tecnología de la reprografía ilegal y la facilidad con la que los miembros de la "generación ausente" lograron tejer redes de amistad y colaboración (con sus mayores y entre ellos), que sobrevivieron en el tiempo. 


\section{Conclusiones del capítulo}

Desnaturalizando el general descrédito que aqueja hoy al concepto de "generación literaria" como herramienta heurística, se planteó un recorrido bibliográfico por diferentes textos, tanto por los que definimos como "de intervención" (manifiestos, entrevistas, editoriales de publicaciones periódicas), como por aquellos que se enmarcan disciplinariamente dentro la sociología de la literatura. En los mismos, fueron diferenciados tres usos del concepto de generación: "nativo" (por parte de los propios agentes y con voluntad polémica), "meramente denominativo" o "cristalizado por el uso" (en, por ejemplo, algunos sintagmas que permanecen a lo largo del tiempo en las diferentes Historias de la literatura argentina, a algunas de las cuales volveremos a hacer referencia en el capítulo cuatro) y "analítico" (deudor de las formulaciones de Ortega y Gasset).

Todo lo señalado permitió dimensionar la efectividad y vigencia de la "operación Raymond Willliams" llevada a cabo por Punto de Vista, cuyos principales animadores impusieron a comienzos de la década del ochenta del siglo XX los conceptos williamsianos de "formación" y "grupo cultural" para pensar colectivos culturales (Cf. Op. Cit. Dalmaroni 1997).

El desarrollo más reciente del concepto de "generación" dentro de la sociología y la sociología de la literatura alemanas, que enfatiza la idea de generación en tanto “construcción identiaria” (Jureit/ Wildt 2005) y "categoría de memoria” (Weigel 2005) a partir de la centralidad dada al concepto de "cesura histórica", se reveló operativo para pensar nuestro objeto.

A lo largo del capítulo se arribó a la conclusión principal de que la cohorte de nacimiento no aseguraría la univocidad de la autoconstrucción identitaria en términos generacionales. Habiendo nacido alrededor de 1960, es posible autoconstruirse identitariamente como ex combatiente de Malvinas, temprano militante popular, activista cultural, o miembro de la "generación ausente". Esta última autoconstrucción identitaria sería, por lejos, la menos presente en la escena pública.

Avisados del carácter marginal e inestable de su construcción identitaria en tanto "generación ausente", los narradores de nuestro corpus habrían adoptado diferentes estrategias discursivas para asegurarse la toma de la voz, no sólo en el campo literario, sino también en términos de una "generación política", que sostendría la prerrogativa de estar en mejores condiciones que el resto de la sociedad de volver a hacer memoria en la literatura de lo ocurrido en nuestro país durante el decenio 1973-1983. Por lo mismo, 
algunos de ellos se ocuparon desde muy temprano de dejar asentada en la literatura una memoria de la generación de pertenencia, tanto más débil frente a otros colectivos de coetáneos tales como los "ex combatientes de Malvinas" y -ya alrededor del 2000, dentro de la general reivindicación de los detenidos-desaparecidos en tanto militanteslos “jóvenes cuadros de las organizaciones político-militares". 


\section{CAPÍTULO DOS \\ "NOSOTROS, LOS DEL OCHENTA": POR UNA POLÍTICA DE LA \\ LITERATURA}

\subsection{El "Grupo Shangai" y el surgimiento de Babel, revista de libros $\left(\mathrm{n}^{\circ} 1\right.$ : abril de 1988 - $n^{\circ}$ 22: marzo de 1991)}

¿Hubo un "grupo Shangai”? Si lo hubo, sus miembros jugaron desde el principio a desmentirlo. Sintomático de esto es la entrevista coral que realiza Viviana Gorbato al "grupo Shangai" para el n 181 de El periodista de Buenos Aires en febrero-marzo de 1988, poco antes de que el primer número de Babel, revista de libros ( ${ }^{\circ}$ 1: abril de 1988- $\mathrm{n}^{\circ} 22$ : marzo de 1991) saliera a la calle.

En la entrevista, los entrevistados se encargan de invertir uno por uno los clisés propios de la voluntad de crear "generación literaria": la idea de "marchar adelante de la época" ("No somos una vanguardia, tal vez una retaguardia", afirma Ricardo Ibarlucía); la posibilidad misma de construir un "nosotros" ("Shangai, lo mismo que la Patria o la mujer ideal, es una idea de losotros, esa voz que en argentino clásico nombra al propio grupo de pertenencia", explica Jorge Dorio); el tipo textual "manifiesto" que Jorge Warley y Carlos Mangone (1994) definen como "literatura de combate" ("deploro verecundamente la sarta, la runfla, la retahíla, el batiburrillo de someras sandeces secretadas por un grupúsculo o comité supuestamente autotitulado Shangai en un textículo publicado por alguna de las mejores gacetas porteñas", dice Martín Caparrós). ${ }^{72}$

En verdad, el "grupo Shangai" que se reunía en la confitería Richmond de calle Florida, y después en La Ideal de Suipacha, cuyos miembros enumera Caparrós en 1993 en su testimonio "Mientras Babel" para Cuadernos Hispanoamericanos n. 517-519 ("Daniel Guebel, Luis Chitarroni, Alan Pauls, Ricardo Ibarlucía, Daniel Samoilovich, Diego Bigongiari; Sergio Chejfec, Sergio Bizzio, Jorge Dorio y yo”) era más reducido que el grupo que cuajaría más tarde alrededor de Babel. Revista de libros, dado que faltan en su nómina varias de las figuras que con mayor o menor asiduidad firman

\footnotetext{
${ }^{72}$ El manifiesto del "Grupo Shangai" fue publicado en la contratapa del $\mathrm{n}^{\circ} 6$ de Diario de Poesía de septiembre de 1987 bajo el título "Shangai en Buenos Aires" con el siguiente epígrafe: "Circula por esta ciudad -más específicamente por bares, redacciones y alguna librería- una octavilla redactada con un procesador de palabras, posiblemente con una commodore 64. El panfleto no lleva firma, mas sí título. El título es 'Shangai' y reza así..." (Diario de Poesía 6: 6). Se lo cita casi en su totalidad en el marco del artículo "Nuevos avances y retrocesos de la nueva novela argentina en lo que va del mes de abril", de Martín Caparrós, publicado en la sección "Caprichos" del número 10 de Babel (julio de 1989).
} 
trabajos en la publicación periódica: Daniel Link, Guillermo Saavedra, Christian Ferrer, Matilde Sánchez, Mónica Tamborenea, Graciela Montaldo, Jorge Monteleone, Jorge Warley, Graciela Speranza, Adriana Amante, etc. Al respecto, cabe destacar el carácter heterogéneo y de "amalgama intergeneracional" del staff de Babel, donde trabajan codo a codo ex militantes (como Horacio González y Alejandro Horowicz) con los miembros más jóvenes de la "generación ausente" (Martín Kohan y Miguel Dalmaroni, que colaboran en la publicación como reseñistas).

Babel fue concebida como una revista cultural de gran tiraje (entre 3500 y 5000 ejemplares), apuntando a un público no especializado pero inquieto en materia cultural y ávido de novedades editoriales: su primer número aparece en la Feria del Libro de abril de 1988. Financiada entre los números 1 a 4 inclusive por la Cooperativa de Periodistas Independientes (la misma que a partir del año 1985 edita El Porteño, La Gaceta Porteña y su suplemento - publicado más tarde de manera autónoma como revista- Cerdos y Peces), Babel revista de libros pasa a ser editada a partir del $n^{\circ} 6$ por la editorial Puntosur. Son sus directores Jorge Dorio y Martín Caparrós, y tiene a Guillermo Saavedra como secretario de redacción. En el $n^{\circ} 5$, la revista es coordinada por una secretaría de redacción, que integra María Moreno (seud. de Cristina Forero), que desde el primer número firma la columna "La mujer pública" (números $1 ; 2 ; 5 ; 7 ; 8$; 9; 11 y 12). En el n 9, Salvador Pazos reemplaza a María Moreno en dicha Secretaría. Del $n^{\circ} 9$ al 19 (hasta que abandona la revista), Saavedra se hace cargo de la dirección periodística de la publicación. Del $\mathrm{n}^{\circ} 20 \mathrm{al} \mathrm{n}^{\circ} 22$, el puesto de jefe de redacción es ocupado por Christian Ferrer.

Las principales secciones fijas de Babel son: "El libro del mes" (primera sección de la publicación y espacio per se de promoción de la literatura argentina para la formulación de una "tradición selectiva"); "La esfinge" (consagrada al reportaje central de la revista, que consiste en sesenta y nueve preguntas iguales para cada uno de los entrevistados: escritores ya reconocidos o figuras públicas); "La mesa de luz. Notorios y notables confiesan qué han leído" (escritores, críticos y artistas pertenecientes a la generación de los "hermanos mayores" son consultados sobre lo que leen); "Dossier" (a cargo de un coordinador especialista en el tema en cuestión); "Anticipos" (se adelantan textos de ficción y crítica literaria, de ciencias sociales, etc.); "Bárbaros" (si bien a primera vista pareciera ser un ejercicio de fe exotista, muestra también una inflexión netamente política: para el $\mathrm{n}^{\circ} 2$, narrativa norteamericana de no ficción sobre la guerra de Vietnam; para el n 5, vínculo entre los “bárbaros” Marx y Freud; para el n 10, "Los 
libros del Proceso: ideas de cuando las ideas se mataban", que firma el sociólogo Ricardo Sidicaro).

La publicación destina un gran espacio a dar cuenta de todos los libros publicados en el país: no sólo en las secciones ya mencionadas "El libro del mes"; "La mesa de luz" y "Anticipos", sino también en "Recienvenidos" (micro-reseñas), "Anticipos" y "Narrativas". De todas ellas, quizás "El libro del mes" y "La esfinge” sean los espacios más jerárquicos que cooperan en catapultar al centro del campo literario determinados nombres de la literatura argentina.

Babel, revista de libros contiene ilustraciones en blanco y negro, y también viñetas, que identifican las diferentes secciones (por ejemplo: el elefante hindú que encabeza la sección "Caprichos"). Una de sus particularidades es la presencia de aforismos de disposición vertical al margen de página, que las más de las veces establecen un diálogo polémico con el cuerpo del texto. Por ejemplo: los aforismos "Ya no hay arte popular porque ya no hay pueblo", de André Malraux y "Ningún artista tolera lo real", de Friedrich Nietzsche que arman un interesante contrapunto con lo que se afirma en la nota "Nuevos avances y retrocesos de la nueva novela argentina en lo que va del mes de abril”, firmada por Martín Caparrós para el $n^{\circ} 10$. Las tapas son ilustradas. O bien ostentan retratos fotográficos de desconocidos (la misteriosa mujer de velo negro del primer número), o bien de escritores y artistas (Francis Ponge y Jeanne Moreau, entre otros). El único escritor argentino que obtiene una foto de tapa en Babel es Fogwill (para el n 20).

Sobre la conformación del primitivo grupo "Shangai", nuevamente en palabras de Martín Caparrós para Cuadernos Hispanoamericanos: éste habría sido más una línea defensiva que una fuerza de choque, más un fruto de las circunstancias que de la voluntad. Habrían sido los otros (y no "nosotros") los que habrían provocado el aglutinamiento y forzado, en verdad, su marca identitaria:

Shangai fue un grupo literario que no existió cuando existía; sí antes, y quizás después. Shangai se había formado casi como un acto de defensa, cuando un grupo de escritores jóvenes y ligeramente éditos, un poco amigos, descubrimos que solíamos ser blanco de ataques sorprendentes. Nos tildaban de dandies, posmodernos, exquisitos y/ o trolebuses [...] Como nos ofendían en conjunto supusimos que debíamos defendernos en conjunto. (Caparrós 1993: 526)

¿Quiénes eran los que "nos ofendían"? En esta reconstrucción retrospectiva, Caparrós da por sentada la complicidad de un lector enterado, que puede reponer la 
polémica que en junio de 1984 enfrentó a Sergio Chejfec, Daniel Guebel, Luis Chitarroni, Alan Pauls y él mismo con Miguel Briante, quien -en ocasión de comentar las intervenciones en la mesa redonda "Narradores inéditos de ayer, de hoy y de siempre”, organizada por el Centro Cultural San Martín el 8 de junio del mismo año-había impugnado a los cinco protagonistas desde las páginas del suplemento "Cultura" de Tiempo Argentino. En el contexto del evento, Jorge Dorio (según otras versiones, habría sido Martín Caparrós) desató un pequeño gran escándalo al afirmar que "La sangre derramada sólo sirve para hacer morcillas". ${ }^{73}$ Dicho exabrupto, por supuesto, dio pábulo a la acusación de "posmodernos", que, en sentido más lato, se volvería una constante en años posteriores. ${ }^{74}$

En su nota "Ya no es lo mismo ser inédito que olvidarse", publicada el 13 de junio de 1984, Briante hace una sardónica reseña de lo ocurrido en el Centro Cultural San Martín y afirma que "estos chicos" no hacen más que repetir teorías y modos de entender la literatura que eran típicos de los jóvenes de 18 años en los años sesenta, pero con diez años más de edad.

La respuesta a estas acusaciones, en forma de carta y firmada por los cinco integrantes de la mesa "Narradores inéditos de ayer, de hoy y de siempre" permaneció inédita hasta junio de 2011, cuando fue publicada en el suplemento $\tilde{\mathrm{N}}$ de Clarín, cuya nota de tapa lleva el título de "Últimas noticias de Babel". ${ }^{75}$ En la carta, titulada "Hablando de mi generación", se lee claramente que tanto el ataque de Briante como la defensa por parte de Chejfec, Guebel, Chitarroni, Pauls y Caparrós se realizan en términos generacionales:

Briante define el lugar desde el cual nos mira: el del paternalismo perdonavidas ("estos chicos", suele rezongar en su escrito), el del joven mayor temeroso de la inversión [...] que lo arrancara -junto con sus coetáneos- del dudoso privilegio de ser los últimos escritores jóvenes que nuestras letras han escrito. Curiosamente, nosotros no invocamos la juventud como un atributo [...] Las obsesivas referencias a nuestras edades pertenecen exclusivamente al antaño joven escritor Briante. Él, desde la cuarentena que hoy trajina junto con sus compañeros de la llamada "generación del '60", parece

73 En la definición de Cristophe Charle: "El escándalo, deliberado o no, es un proceso clásico de conquista de notoriedad en el campo intelectual o político" ([1990] 2009: 8).

${ }^{74}$ Con "posmodernismo en sentido más lato" nos referimos a la lectura que cierta zona de la izquierda hace del posmodernismo en tanto arte afirmativo que puede coexistir pacíficamente con el neoconservadurismo cultural y político. Sin embargo, no todo el posmodernismo es afirmativo, ya que como bien señala Andreas Huyssen: "descartar al posmodernismo como síntoma de la cultura capitalista en su etapa de declinación es reduccionista, ahistórico y demasiado parecido al ataque lukacsiano contra el modernismo" (Huyssen [1984] 1987: xx-xxi).

${ }^{75}$ Fueron entrevistados para dar su balance "veinte años después" sobre la experiencia de Babel, revista de libros Martín Caparrós, Luis Chitarroni y Alan Pauls, incluyéndose la misiva a Briante como apéndice documental. 
temer, entre horrorizado y distante, que una nueva generación está tomando el relevo de lo juvenil. (Caparrós/ Chejfec/ Chitarroni/ Guebel/ Pauls [1984] 2011: 9)

El conflicto generacional está planteado, aunque de manera harto enrarecida: se trata de un "nosotros" que no habla en términos de la "joven generación" o la "nueva literatura", pero que sí parece estar atacando a la "vieja generación" (a la que pertenece Briante, a quien no obstante se reconoce su condición de "el más joven de los sesenta"). ${ }^{76}$

Por otra parte, la acusación lanzada por Briante sobre la no originalidad de "los del ochenta" (que no harían más que plagiar las ideas y formas literarias de la generación sesentista) es desestimada por medio de argumentos tomados de "Pierre Menard, autor del Quijote" (1939), de Jorge Luis Borges (que, cuatro años más tarde, será una presencia importante en Babel, revista de libros):

Si nosotros -podríamos llevar nuestra liberalidad hasta convenir en llamarnos "los del ochenta"cristalizamos nuestro discurso en aquello que ya dijeron ellos, "los del sesenta", vendríamos entonces a ser una versión deslucida, anacrónica y una década más vieja de lo que el brillante Briante y sus coetáneos produjeron discursivamente hace veinte años $[\ldots]$ ¿Alcanzará con alegar que -presuntasopiniones similares emitidas en circunstancias diferentes producen efectos diferentes y son, por lo tanto, otra cosa? No- No alcanzará. Sigamos [...] Tal vez una de nuestras diferencias claras con los del sesenta se funde en que nos toca una época en que, a diferencia de los happy sixties, la ideología del progreso atraviesa una crisis regresiva. Nuestras preocupaciones son otras. Nuestros vínculos con los del sesenta no son, entonces, mecánicos. Ni adscripción absoluta, ni plagio involuntario, ni esforzado parricidio. (Caparrós/ Chejfec/ Chitarroni/ Guebel/ Pauls [1984] 2011; nuestro énfasis)

\footnotetext{
${ }^{76}$ Si bien la obra literaria de Miguel Briante no obtuvo un reconocimiento masivo, fue una figura importante del campo cultural. En los años sesenta trabajó como periodista para Confirmado, Primera Plana, Panorama y La Opinión. Su cuento "Kincón" fue premiado por la revista El Escarabajo de Oro y su novela homónima, finalista del premio de la editorial Monte Ávila (que la publicó en 1975). Ocupó el puesto de Jefe de Redacción de El Porteño entre 1982 y 1984 . Entre 1985 y su muerte (25 de enero de 1995) estuvo a cargo de la sección Artes Plásticas de Página/ 12. Se le realizó la muestra-homenaje "El ojo en la palabra" (21 de noviembre de 1996 al 20 de enero de 1997), de la cual participaron Enrique Aguirrezabala, Carlos Alonso, Líbero Baadi, Jacques Bedel, Luis Fernando Benedit, Antonio Berni, Alberto Cedrón, Ignacio Columbres, Jorge de la Vega, Juan Carlos Distéfano, Omar Estela, Roberto Fernández, León Ferrari, Norberto Gómez, Luis Gorriarena, Víctor Grippo, Alberto Heredia, Keneth Kemble, Martín Kovensky, Juan Lecuona, Rómulo Macció, Liliana Maresca, Luis Felipe Noé, Jorge Pietra, Felipe Pino, Jorge Pirozzi, Rogelio Pelesello, Liliana Porter, Víctor Quiroga, Juan Pablo Renzi, Rep, Marcia Schvartz, Oscar Smoje, Oscar Suárez, Pablo Suárez, Clorindo Testa y Luis Wells (damos la nómina completa para demostrar su importancia). La exhibición, de carácter itinerante, inauguró en el Centro Cultural Recoleta de Buenos Aires y viajó a Rosario, San Juan, Mendoza y Mar del Plata. El suplemento "Radar", en su edición del 17 de noviembre de 1996, le dedica a la misma un gran espacio y una separata. Sobre la gravitación de Miguel Briante en el campo intelectual durante las décadas del sesenta, setenta y ochenta, VER Calabrese/ Martínez 2001.
} 
En efecto: la "generación ausente" se va a negar sistemáticamente a asesinar a sus padres, planteando como posibles la coexistencia pacífica (las más de las veces, aunque hubo importantes excepciones a la regla), y la cooperación intergeneracional, todo ello bajo la figura del coloquio. ${ }^{77}$

El coloquio, vale aclarar, también significa hacer de la literatura a escribir y/ o a publicar un espacio heterogéneo de voces, citas y alusiones pertenecientes a los "hermanos mayores", donde ninguna de ellas detente mayor jerarquía que las otras. En este sentido, no parece casual que la segunda novela publicada por Alan Pauls en el año 1990, por la editorial Emecé, se titule, precisamente, El coloquio (la novela será analizada en el capítulo tres). En palabras de Pauls:

La respuesta al paradigma vertical del origen y sus descendencias no es, en mi caso, el parricidio (forma que elige una genealogía para perpetuar su dogmatismo), sino el coloquio. El coloquio cava un túnel (lateral), abre un atajo sobre el borde del imperio edípico y lo burla; no acata sus prescripciones, las elude; no es la condición de una adscripción (¡ubíquese en el árbol genealógico!), sino, para mí, de toda posibilidad de escribir [...] Lo que la figura del coloquio permite no es definir una voz cantante (respecto a la cual yo mediría el éxito de mis tentativas, la fidelidad de mis copias o la insolencia de mis desviaciones personales), sino precisamente todo lo contrario: poner en circulación un conjunto de voces más o menos anacrónicas y heterogéneas entre sí, más o menos discordantes -especie de murmullo literario que convoco cada vez que escribo-. (Pauls 1983: 4)

De todas formas, es indudable que el enfrentamiento con Miguel Briante estuvo en la conformación de aquel "nosotros" (heterogéneo), que cuatro años más tarde sacaría el primer número de Babel, revista de libros. Entrevistados en septiembre de 1990 por Jorge Warley para El Porteño, éste reaparece en las respuestas que dan Alan Pauls, Sergio Chejfec, Matilde Sánchez, Daniel Guebel y Martín Caparrós. El factor convocante es la coincidencia, en el mismo año, de la publicación de las novelas El coloquio, de Pauls; Moral, de Sergio Chejfec; La ingratitud, de Matilde Sánchez; La perla del emperador, de Daniel Guebel y El tercer cuerpo, de Martín Caparrós, dos de las cuales habían sido merecedoras de premios. ${ }^{78}$ Interrogado sobre la supuesta

\footnotetext{
${ }^{77}$ Tampoco podría motejarse de "parricidas" a los críticos de Los libros, tal como lo señala acertadamente José Luis De Diego en su libro "¿Quién de nosotros escribirá el Facundo?" Intelectuales y escritores en Argentina (1970-1986) (Cf. De Diego 2001: 99), ni a los intelectuales y artistas nucleados alrededor de la revista Literal $\left(\mathrm{n}^{\circ} 1\right.$ : noviembre 1973- $\mathrm{n}^{\circ}$ 4/ 5: noviembre 1977).

${ }^{78}$ Mientras El coloquio, de Alan Pauls, recibió como distinción el Premio Antorchas, La perla del emperador, de Daniel Guebel, fue premiada con el Premio Emecé Novela (1989-1990), por el voto unánime de un Jurado integrado por César Aira, Tomás Eloy Martínez y Abel Posse. Dos años más tarde, la edición corregida de La perla del emperador fue además merecedora del Premio Municipal de Literatura (edición 1993).
} 
apoliticidad o aparente falta de compromiso de su producción literaria, Pauls continúa la discusión con Briante de la siguiente manera:

Lo de Briante me parece cómico. Él busca un espacio desde dónde hablar, y lo encuentra en la generación del sesenta que, supuestamente, sería la última que metió la historia en la literatura y tuvo cierta ambición trascendentalista. Yo no asumo ningún tipo de trascendentalismo. ¿Y qué? ¿Por eso Briante va a ser más político que yo? Un carajo. En el país existieron tres grandes escritores que trabajaron la relación literatura/ política al punto de volverlas indiferenciadas: Rodolfo Walsh, Osvaldo Lamborghini y Manuel Puig. Los tres están muertos, pero ésa es la tradición que yo elijo, en la que trato de inscribirme a la hora de pensar tal relación. (Pauls [Entrevistado por Jorge Warley] 1990: 39; nuestro énfasis)

En verdad, sobre esta "tradición de literatura política" se venía insistiendo desde las páginas de Babel, revista de libros (en otras palabras: la propuesta no era privativa de Alan Pauls). Además, contra lo que podría pensarse, no fueron los llamados "babélicos" por la bibliografía secundaria los primeros en proponer estos tres autores como "la (gran) literatura política", sino que éstos ya habían sido "descubiertos" y ensalzados por otras publicaciones periódicas precedentes: desde las páginas de Los libros ( $\mathrm{n}^{\circ}$ 1: julio 1969- $\mathrm{n}^{\circ}$ 44: enero/ febrero 1976); Literal $\left(\mathrm{n}^{\circ} 1\right.$ : noviembre de 1973$\mathrm{n}^{\circ}$ 4/5: noviembre de 1977); Punto de Vista ( ${ }^{\circ}$ 1: marzo de 1978 - $\mathrm{n}^{\circ}$ 90: abril de 2008); Pie de Página ( $\mathrm{n}^{\circ}$ 1: Primavera $1982-\mathrm{n}^{\circ} 3$ Verano 1984/ 85) y Sitio $\left(\mathrm{n}^{\circ} 1\right.$ : dic. de 1981 - n 6: mayo de 1987), donde escribían los "hermanos mayores" César Aira, Josefina Ludmer, Beatriz Sarlo, Rodolfo Enrique Fogwill, Eduardo Grüner, Jorge Jinkis, Héctor Libertella y Ricardo Piglia, entre otros. ${ }^{79}$ Ya para cuando comienza a salir Babel, la exclusión explícita de Julio Cortázar de esta "tradición selectiva" (y las constantes pullas contra Libro de Manuel) podrían pensarse casi un lugar común de cierta crítica autodefinida como "anti-populista" (Gusmán 1984/ 85; Sarlo 2003; Piglia 2011). Sobre lo esbozado aquí versará el parágrafo tres, antecedido por un breve apéndice metodológico.

\footnotetext{
${ }^{79}$ Los libros ( ${ }^{\circ} 1$ : junio de 1969- ${ }^{\circ}$ 44: enero/ febrero de 1976), dirigida por Héctor Schmucler y con un Consejo de Redacción integrado por Beatriz Sarlo, Carlos Altamirano y Ricardo Piglia. Para un análisis de Los libros, VER Panesi (1985) y Warley (1993). Literal ( $\mathrm{n}^{\circ} 1$ : noviembre de 1973- $\mathrm{n}^{\circ} 4 / 5$ noviembre de 1977), con un Consejo de Redacción integrado por Germán García, Luis Gusmán, Osvaldo Lamborghini y Lorenzo Quinteros. Sobre Literal, VER Libertella (2002) e Idez (2010; 2011). Punto de Vista (n ${ }^{\circ}$ 1: marzo de 1978- $\mathrm{n}^{\circ}$ 90: abril de 2008), con la dirección de Beatriz Sarlo y con un Consejo de Dirección integrado por Carlos Altamirano, María Teresa Gramuglio, Hugo Vezetti y Ricardo Piglia (sólo hasta el $n^{\circ}$ 16; al número siguiente se incorpora Hilda Sábato), y en el que durante 1981 participan fugazmente José María Aricó y Juan Carlos Portantiero. Sobre Punto de Vista, VER King (1989) y Warley (1993). Sitio (n ${ }^{\circ} 1$ : diciembre de 1981- $\mathrm{n}^{\circ}$ 6: noviembre 1987), integrada por Eduardo Grüner, Jorge Jinkis, Luis Gusmán y Ramón Alcalde. Pie de Página (n 1: 1982- ${ }^{\circ}$ 3: 1984) tuvo como directores a J. Alberto Castro y Mónica Tamborenea. Sobre Pie de Página y Sitio, VER Patiño (1997).
} 


\subsection{Tres notas metodológicas sobre el trabajo con publicaciones periódicas}

Antes de dar cuenta en qué grado las publicaciones periódicas mencionadas adelantan la "tradición selectiva [de literatura política]" arriba mencionada que, repetimos, no inventan, sino a la que adhieren los escritores agrupados alrededor de Babel, revista de libros, quizá sea necesario hacer tres notas metodológicas.

La primera es una observación respecto a los trabajos disponibles sobre Babel: si bien en la mayoría de ellos se trazan acertadamente líneas de continuidad con Los libros (Bosteels/ Rodríguez Carranza 1995; Delgado 1996; Warley 1993), y también, simultáneamente, con Punto de Vista (Warley 1993; De Diego 2001), los señalamientos no avanzan quizá lo suficiente sobre la considerable red de revistas (anteriores, pero también contemporáneas a la publicación periódica que nos ocupa) donde se va gestando lo que prevalecerá, en la segunda década del ochenta del siglo pasado, como modelo de una "política de la literatura". Al respecto, creemos que analizar una publicación en particular implica la necesidad de desplazarse por la red de publicaciones periódicas inmediatamente precedentes, pero también contemporáneas aparecidas en el país (aunque no solamente, porque es sabido que, por ejemplo, Magazín literario tomó como modelo la francesa Magazine Littéraire, a quien había comprado la franquicia para Latinoamérica). ${ }^{80}$

La segunda observación metodológica tiene que ver con la necesidad de incorporar al análisis el concepto de "sintaxis de revista", que Beatriz Sarlo desarrolla en "Intelecturales y revistas: razones de una práctica" (1992). La hipótesis de Sarlo es que el lugar que un material ocupa en una revista (como nota de tapa, en el medio, en el marco de determinada sección, en las páginas finales) y el tipo y jerarquía de letra utilizados "dicen" algo, y que este plus de significado excede el mero hecho de "haber sido incluido". El ejemplo para explicar el concepto es Sur:

En Sur, por ejemplo, los ensayos de Borges sobre la literatura gauchesca o sobre las inscripciones en los carros aparecieron en cuerpo menor, apretados en las últimas páginas del número, mientras que la distinción de la letra grande y las primeras páginas correspondían a textos sobre el ser latinoamericano de Waldo Frank o Valéry-Larbaud, hoy olvidados. [...] el tipo de letra y el lugar en las páginas de una revista pertenecieron a un conjunto de decisiones tomadas que, básicamente, son la revista misma. [...] Que Waldo Frank pareciera más interesante que Borges, según la disposición que cada uno merece en Sur, tiene que ver con la sintaxis de la forma revista y sus efectos. (Sarlo 1992: 10)

\footnotetext{
${ }^{80}$ Esta pretensión tiene como límite lógico la enseñanza que deja la parábola borgiana (esto es: la diferencia entre dibujar el mapa de China o dibujar China).
} 
La tercera y última nota metodológica persigue recuperar -aunque sea mínimamente- la dimensión material de la publicación periódica en tanto objeto. Esto es: número de tiraje, tipografía, inclusión (o no) de dibujos (blanco y negro o color), viñetas o fotografías y/ o juegos con la distribución del texto en la página.

\subsection{Por una política de la literatura: "Rodolfo Walsh - Manuel Puig - Osvaldo Lamborghini” (Link 1989) ¿Una amalgama imposible?}

En ¿Quién de nosotros escribirá el Facundo? Intelectuales y escritores en Argentina (1970-1986), trabajo que resultó fundamental por su rigurosidad y detalle para armar la red de revistas que intentaremos desplegar aquí, José Luis De Diego señalaba acertadamente que la novelística de Manuel Puig ocupaba en la primera y segunda etapas de la publicación Punto de Vista un lugar marginal, lo que contrastaba con el espacio de privilegio otorgado a Juan José Saer (Cf. Op. Cit. De Diego 2001: 150). En efecto: en la reseña publicada a Pubis angelical en el $n^{\circ} 8$ de Punto de Vista, María Teresa Gramuglio impugna a Puig desde un doble frente. Por un lado, señala la "enajenación" de los personajes de Puig, que son "hablados por los códigos culturales" (1980: 33). Por otro lado, mira a Puig con cierta suspicacia en tanto "pertenece a un jet set de escritores latinoamericanos" que gozan de altos índices de ventas (el éxito comercial, para esta zona de la crítica, siempre es sospechoso). Esta actitud hacia Puig tiene su antecedente directo en Los libros.

Si repasamos los artículos de esta última publicación que refieren a Manuel Puig (a quien se dedican trabajos en los números 4; 25 y 36), se percibe claramente la oscilación entre leer en el autor de La traición de Rita Hayworth una literatura alienada o una literatura de denuncia de dicha alienación, presente de manera paradigmática en la reseña que Héctor Schmucler escribe sobre Boquitas pintadas para el $\mathrm{n}^{\circ} 4$ de Los libros (octubre de 1969), en cuyo desarrollo parece inicialmente adherir a la primera hipótesis ("los personajes no tienen nada para decir: son atravesados por el lenguaje de la sociedad constituida"), para, al recuperar la instancia autoral en tanto instancia crítica, cerrar con la hipótesis exactamente contraria: "Boquitas pintadas denuncia el lenguaje que utiliza (la ideología que comporta) cuando simula creer en él” (Schmucler 1969: 8 y 9 , respectivamente). ${ }^{81}$

\footnotetext{
${ }^{81}$ Esta desconfianza por parte de los críticos de Los libros debería ser considerada en contrapunto con la opinión de los escritores sobre Manuel Puig: en la encuesta incluida en el $n^{\circ} 5$ de la revista, cuya cuarta
} 
En el n 25 de Los libros, Beatriz Sarlo firma una nota titulada "Novela argentina actual: códigos de los verosímil”, donde, apoyándose sobre una definición matizada de dicho concepto, esboza un estado de la cuestión de la novela argentina contemporánea.

Sarlo plantea una tipología: a los textos "que creen en lo verosímil" (que ejemplifica con novelas de David Viñas y Ernesto Sábato, aunque estableciendo una diferencia de calidad a favor del primero) les contrapone aquellos "que se despreocupan del verosímil" y apuestan a "lo real narrativo", ejemplo de lo cual serían las "crónicas" Operación masacre y ¿Quien mató a Rosendo?, de Rodolfo Walsh, definidas como "la propuesta de la década". Esta tipología no incluye la novela Boquitas pintadas, de Manuel Puig, que, si bien merece un elogio inicial (en tanto practicante de "un verosímil de segundo grado [que] consiste en la fijeza con que se repite el juego de lo verosímil cinematográfico, la ética del consejero sentimental, el maniqueísmo obsesivo dentro de cuyos límites se verbaliza"), es finalmente desestimada en tanto "engancha con toda la corriente del revival de los años treinta y cuarenta, vinculada con la devoción hacia el camp, orquestada como una de las varias formas de snobismo de los medios" (Sarlo 1972: 18 y 19, respectivamente).

Al año siguiente, The Buenos Aires Affair es objeto de dos menciones positivas desde el espectro ideológico y estético opuesto al de Los libros. Mientras Enrique Pezzoni firma en el suplemento "Cultura y Nación" de Clarín correspondiente al 27 de noviembre de 1973 su reseña "Tres obras singulares", donde afirma que "Puig, Soriano y Medina invaden el mundo burgués, imitan los productos de que se abastecen, desenmascaran su imbecibilidad..." (Pezzoni 1973: 3), Jorge Di Paola señala en Panorama que el best-seller de Puig es "uno de los textos más fascinantes del año" (Di Paola 1973 [Citado en Anguita/ Caparrós 2006: 376]).

Durante el invierno de 1974, Sarlo vuelve a ocuparse de la novelística de Manuel Puig, aunque esta vez como tema central. En su trabajo, titulado "Cortázar, Sábato y Puig: ¿parodia o reportaje?”, incluido en el n 36 de Los libros, señala el uso acrítico del género policial en The Buenos Aires Affair en tanto "parodia que, en lugar de desconfirmar el género [...] lo confirma por ausencia, al fracasar" (1974: 33). Asimismo, afirma que la inclusión de materiales de prensa en The Buenos Aires Affair que dan cuenta de la violencia paraestatal serían -como en Libro de Manuel- claro 
síntoma de "una mirada que contempla desde afuera" y que "fracasa en su intento de narrar lo político" (Op. Cit. Sarlo 1974: 33; nuestro énfasis). Hay, por último, nuevamente una impugnación del autor desde la demonización del bestsellerismo (y callando por lo mismo que El caso Satanowsky compartió espacio con The Buenos Aires Affair en la lista de best-sellers del año 1973): Puig, como, por otra parte, Cortázar, respondería a la demanda del mercado de "una novedad legible" (Sarlo 1974: 33; énfasis en el original).

Lo expuesto podría llevar a suponer que -siendo Los libros y Punto de Vista antecesoras directas de la propuesta de Babel, revista de libros- el único escritor reivindicado por los llamados "babélicos" de manera impermeable a la prédica negativa de determinados "hermanos mayores", habría sido Manuel Puig. Esta suposición, sin embargo, se revela errónea si recabamos que ya en agosto de 1981, desde las páginas de la revista Vigencia editada por la Universidad de Belgrano, César Aira señala como los mejores entre los novelistas argentinos a Manuel Puig, Nicolás Peyceré, Juan José Saer y Osvaldo Lamborghini (la inclusión de este último, habida cuenta de que deberán pasar catorce años hasta la edición por Ediciones del Serbal de Tadeys -lo más parecido a "una novela" dentro de la escritura lamborghiana- es claramente una provocación).

También Juan Sasturain, con motivo de reseñar Maldición eterna a quien lea estas páginas para la sección "Literatura argentina 1981" de Humor registrado ensalza la propuesta de Manuel Puig: "la descripción [dada por Juan Carlos Onetti de que Puig carece de estilo] es correcta. Pero no describe una carencia sino [...] una modalidad tan ardua como fabricarse un estilo o un gestuario" (Sasturain 1981: 130). Sin embargo, parece adherir a la lectura realizada sobre Manuel Puig en términos de "una literatura alienada" cuando señala "la incapacidad de los personajes de verse y pensarse por fuera de los medios artificiales del radioteatro" (Op. Cit. Sasturain 1981: 132).

En su trabajo "Intelectuales en transición. Las revistas culturales argentinas (19811987)", publicado en 1997 en Cuadernos de Recienvenido de la Universidad de San Pablo, Roxana Patiño señala acertadamente que Pie de Página es la publicación que se planta con mayor virulencia frente al discurso hegemónico de Punto de Vista, poniendo como ejemplo la nota firmada por su director: "Los nuevos tecnócratas (o el círculo de tiza)", que asume los tonos y la disposición gráfica de un editorial clásico. Allí, Castro se pronuncia en contra de "nuestros nuevos demócratas radicalizados" (énfasis en el original: clara alusión al explícito apoyo al alfonsinismo prestado por miembros del 
staff de Punto de Vista), en contra del que también moteja de "liberalismo de izquierda", que "acepta el mandato despolitizador (mientras hace política) y se refugia (o pretende hacerlo) en la zona sagrada del campo intelectual" (Castro 1984/ 85: 4). En este sentido, la introducción por parte de Punto de Vista de los conceptos de "campo" y "habitus" de Pierre Bourdieu son leídas por Castro no como una renovación del arsenal teórico, sino como una defección. El epígrafe de César Vallejo que inaugura el editorial (“¡Oh, campo intelectual de cordillera, con religión, con campo, con patitos! Paquidermos de prosa cuando pasan y en verso cuando párense!") refuerza la desconfianza irónica frente a "esa estrategia [...] que, paradójicamente, otorga un estatuto de lucidez a quien afirme carecer de razones" (Ibid.).

Más allá de esta toma de distancia política, la publicación coincide con Punto de Vista en su formulación de una "tradición selectiva": hay elogiosas referencias a Saer en los tres números de Pie de Página. ${ }^{82}$ También, aunque en menor medida, a Ricardo Piglia. ${ }^{83}$ César Aira, entrevistado para el primer número de Pie de Página por su director Alberto Castro y Gabriela Bogna, vuelve al diagnóstico expresado el año anterior en Vigencia, pero colocando ahora al escritor oriundo de General Villegas en el centro:

\footnotetext{
${ }^{82}$ La sección "Premios" del primer número de Pie de Página denuncia el deliberado silencio por parte de los medios hegemónicos alrededor del premio Boris Vian ("considerado como una mención de repudio a los premios oficiales, y a la política cultural del silencio que se proclama digitando autores y listas negras”), cuya Edición 1982 favoreció a Nadie nada nunca. En el n 2, Sergio Racuzzi y Mónica Tamborenea entrevistan a Juan José Saer, cuya novelística es caracterizada como "una propuesta poética de alternativa que posee y reivindica su espacio natural de ocupación dentro de nuestro sistema literario", dotada de "contundencia política y estética" (1983: 3). En el mismo número, en la sección "Bibliográficas", Jorge Panesi reseña Cicatrices (1969) con motivo de su reedición por el Centro Editor de América Latina, enfatizando la diferencia cualitativa que su autor mantendría con Julio Cortázar y Ernesto Sábado (a quien se acusa de tener una "actitud gazmoña y pequeño burguesa"). Panesi termina este razonamiento (y la reseña) afirmando que "Cicatrices no refracta lo histórico con la facilidad especular de un realismo populista" (1983: 28). Finalmente, en la misma sección del último número de Pie de Página, Daniel Link reseña El entenado, señalando la tentación inevitable de la lectura que, aplicando patrones alegóricos, "revelarían la equivalencia indios/ sociedad civil argentina de determinado periodo" (1984/ 85: 29; nuestro énfasis).

${ }^{83}$ En la misma sección "Premios" mencionada en la nota anterior, se hace referencia a que Respiración artificial ganó el Premio Boris Vian en la edición 1981. El n 2 de Pie de Página incluye la encuesta "Literatura y situación nacional", que son convocados a responder Beatriz Sarlo, Jorge Di Paola, Luis Gusmán, Jorge Lafforgue y Juan Sasturain. Las preguntas planteadas son tres: “¿De qué manera afectó al sector del campo intelectual la situación vivida a partir de 1976?”; “¿Cómo puede leerse la situación vigente en las obras publicadas en el país durante el período?” y “¿Cuáles son sus expectativas ante el proceso de democratización?". En su respuesta, Beatriz Sarlo arma un arco, en cuyos extremos coloca a Jorge Asís y Ricardo Piglia. Mientras el primero "padece la coyuntura de los años setenta con una cercanía a los hechos y las experiencias sociales que da como resultado el efecto de la mimesis absoluta", el segundo "plantea, más bien, cómo la literatura puede interrogar a la historia [...] negándosele toda posibilidad de mimesis" (Sarlo 1983: 14).
} 
De Puig pienso que es el mejor de todos, el mejor después de Arlt. "Después", lo digo cronológicamente. ¿Cuántos novelistas vivos, en actividad, hay tan buenos como él? No llegan a diez: Patricia Highsmith, Joseph Heller, Marguerite Duras, Robbe-Grillet, Nathalie Sarraute (que es viejísima), Grass y Onetti y Copi. (Aira 1982: 3)

Contra la observación de Patiño sobre la continuidad que establecería la revista Sitio respecto a Literal en lo que hace al lugar del intelectual y el tipo de discurso crítico que propone ("es posible encontrar en las ambiciosas páginas de esta publicación [Sitio] los ecos de esa 'flexión literal' que hila los discursos discordantes [...] una voluntad de cruce de textualidades, residuales, coloquiales y eruditas, un trabajo incesante con los significantes"), creemos que se observan importantes cambios entre ambas.

Sitio no practica la política de descentramiento del discurso y el instrumental teórico practicado por Literal, y tampoco presenta influencias teóricas rápidamente discernibles. A diferencia de su antecesora, no causa la impresión de ser una revista codificada, ni escrita “en jerga”. Se trata, claro está, de dos apuestas crítico-discursivas diferentes. Mientras desde su primer número Literal invita programáticamente al “incesto de los géneros" (la expresión es de Ricardo Strafacce), la misma condición de "amalgama intergeneracional" de Sitio parece vedarle la homogeneidad de discurso y método, esto es, la constitución de un "nosotros". Por lo mismo, Sitio no publica editoriales, sino "Entredichos", para dar cuenta precisamente de esta pluralidad. ${ }^{84}$

Un ejemplo: si el número doble 2/ 3 de Literal de mayo de 1975 desplegaba un análisis de Sebregondi retrocede inficionado de psicoanálisis lacaniano y lingüística (el artículo "La palabra fuera de lugar", sin firma, aunque se sabe que fue escrito por Germán García), los firmantes del número 4/ 5 de Sitio de mayo de 1985, destinado a dar un panorama de la literatura y el ensayo locales, lo hacen mediante un registro tanto más llano y accesible para el lector no especializado.

Es precisamente en la sección "Preferencias" de este número doble de Sitio donde Jorge Panesi publica "Puig, las relaciones peligrosas", que insiste sobre el carácter político de la literatura de Manuel Puig, enfrentándose por lo mismo con aquellos que la leen en términos de "una literatura alienada":

\footnotetext{
${ }^{84}$ A título de ejemplo: el staff del número doble 4/ 5 de Sitio de mayo de 1985 mantiene en la dirección a Ramón Alcalde, Eduardo Grüner, Luis Gusmán y Jorge Jinkis. Participan en el número como colaboradores: Luis Chitarroni, Jorge Monteleone y Daniel Link.
} 
Puig, que en sus narraciones siempre ha estado preocupado por insertar la historia política argentina (el centro es el peronismo), a partir de Pubis angelical la hace girar en torno a personajes enfermos, que determinan la trama [...] La escritura se piensa en Puig como un producto material [...] Cumple siempre una función develadora, aclaratoria, desalienante, echa luz sobre la confusión o la ceguera en que se mueven los personajes de clase media. (Panesi 1985: 130-131)

El mismo año, Rodolfo Enrique Fogwill da a conocer Pájaros de la cabeza, homenaje a Manuel Puig. ("Pájaros de la cabeza” era el primitivo título de "el monólogo de las tías" que está en la génesis de La traición de Rita Hayworth.) Escaso año más tarde, Alan Pauls publica su tesis de licenciatura como libro, cuyas conclusiones se apoyan en la idea, tan cara a la época, de la micropolítica:

Allí donde la lectura de la alienación se empeña en localizar los instrumentos de la opresión [...] Puig ve la posibilidad de tomar la palabra y la alternativa de un plan de resistencia. Allí donde esa concepción [...] descubre uno de los principios de homogeneización de la ideología dominante, Puig encuentra el territorio de una experimentación que es política precisamente porque pone en juego heterogeneidades y contradicciones [...] En Puig no existe esa ideología de la "zona franca" donde los sometidos podrían gritar su sumisión, los homosexuales hablar su condición perseguida, las mujeres denunciar su esclavitud: tierra de nadie, al reparo de la dominación ejercida por los medios y el poder [...] Mientras la lectura de la alienación los piensa como medios de manipulación, Puig los trabaja como aparatos de reproducción: no objetos "malos" de los que habría que desprenderse para resistir y luchar, sino escenario y arsenal de toda lucha y resistencia. (Pauls 1986: 82-83)

Babel, revista de libros no sólo adhiere explícitamente a esta "tradición de de literatura política" (Walsh, Lamborghini y Puig) levantada en su momento por determinados "hermanos mayores", sino que coloca en primer plano la pregunta sobre los posibles herederos de estas poéticas, lo que se vuelve patente en las lecturas que hacen Daniel Link sobre Puig ("Cae la noche tropical. Manuel Puig" en el no 6 de Babel de enero de 1989), Alan Pauls sobre Lamborghini, y Christián Ferrer sobre Walsh ("Lengua, ¡sonaste!" y "Rodolfo Walsh: una herencia imposible", ambas en el no 9 de Babel de junio de 1989, que -nada casualmente, pensando la cuestión en términos de "sintaxis de revista"- tiene como "Libro del mes" a Novelas y cuentos de Osvaldo Lamborghini, editado y prologado en 1988 por César Aira para Ediciones del Serbal de Barcelona). ${ }^{85}$ La única voz discrepante que se alza, solitaria, es la de Sergio Chejfec,

${ }^{85}$ En calidad de directores del suplemento "Culturas" de Página/ 12 (que tenía una organización monotemática, con una extensión máxima de seis páginas), Jorge Dorio y Martín Caparrós optan por la 
que en su nota "De la inasible catadura de Osvaldo Lamborghini", publicada en la sección "Opiniones" correspondiente al n 10, no sólo argumenta en contra de la lectura que hace Pauls, sino también discrepa con la lectura laudatoria del albacea y prologuista de Novelas y cuentos, sosteniendo que "afirmar que Lamborghini fue un gran escritor o incluso un genio es [para mí] un chiste" (Cf. Chejfec 1989: 21). No obstante, doce años más tarde, en su ensayo "Fábula política y renovación estética" para el número único de la revista rosarina Nueve perros, Chejfec va a colocar a Osvaldo Lamborghini a la misma altura que Rodolfo Walsh, en tanto practicante de una "apuesta radical" al momento de incluir la política en la representación literaria (Cf. Chejfec 2001: 17-18).

En el caso de Link, la pregunta señala un espacio vacante y a la vez enuncia un programa: "la literatura argentina sólo puede escribirse hoy a partir del espacio que queda entre Puig, Walsh y Lamborghini” (Link 1989a: 8). ${ }^{86}$ Por su parte, Pauls cree encontrar "la descendencia" de Lamborghini en las letras de Sumo, allí donde una música violenta hace "sonar" el lenguaje (en su doble acepción: no sólo como "trabajo sonoro sobre la lengua", sino también como "puesta en jaque de la lengua"), y vuelve a reivindicar a Manuel Puig, aunque esta vez despegándose de la lectura "ideológica" realizada tres años antes:

Las literaturas de Osvaldo Lamborghini y de Manuel Puig se gustaban. Pero, ¿cuál es el secreto de esta confesada afinidad entre el prosista cortado y el zar de la narración, entre el músico abarrocado y el adalid de la sencillez, entre el maldito y la estrella? Tal vez, arriesgo, el estereotipo, ese cristal de lengua que está "en el principio" de ambas literaturas, y que las condujo a una fascinación recíproca. Para Puig y para Lamborghini, el estereotipo no es un oropel kitsch de la lengua ni un objeto parcial del costumbrismo; es esa formación donde la lengua hace oir su poder, su formidable facultad de decir-hacer: un pequeño aparato de estado. Hacer sonar la lengua (lo que los dos hacen acaso como nadie) es lanzar una asonada sobre ese punto, asediar esa ciudadela tan de todos. (Pauls 1989: 5)

publicación barcelonesa de Novelas y cuentos como tema del número publicado el 27 de noviembre de 1988, bajo el provocativo título de tapa (una cita del mismo autor) "Lean, che". A lo largo de cinco páginas (que incluyen tres fotos de Lamborghini) se reproducen partes del prólogo firmado por Aira para Ediciones del Serbal, Miguel Briante cuenta anécdotas que alimentan el mito de "el escritor tan genial como maldito" ("Agarrarlo vivo") y se adelantan fragmentos de La novia del gendarme, Las hijas de Hegel y Sebregondi se excede (en el epígrafe se dice erróneamente que el fragmento pertenece a Las hijas de Hegel). Por último, sin firma, aparece la nota biográfica "Osvaldo Lamborghini".

${ }^{86}$ El trabajo firmado por Link tuvo una primera versión como ponencia, leída en julio de 1986 en el Primer Congreso de Estudios de Literatura Iberoamericana organizado por la Facultad de Filosofía y Letras de la UBA. No hemos encontrado Actas. Con posterioridad a su aparición como reseña en el $n^{\circ} 6$ de Babel, la hipótesis principal fue reproducida en "El boom, Manuel Puig, la realidad: aspectos de una teoría de la representación" incluido en La chancha con cadenas (1994). Con algunas modificaciones (entre ellas, el título) fue incluído en Cómo se lee y otras intervenciones críticas (2003). Volveremos a la producción crítica de Daniel Link en el capítulo cuatro. 
Analizando la viabilidad de la propuesta de Daniel Link sobre que "la literatura argentina solo puede escribirse hoy a partir del espacio que queda entre Puig, Walsh y Lamborghini”, cabría preguntarse ¿es ésta una intersección posible? Si, como afirma Pauls, las literaturas de Lamborghini y Puig se gustaban (algo, incluso, comprobable a nivel anecdótico, si leemos en el $\mathrm{n}^{\circ} 5$ de Los libros que Osvaldo Lamborghini considera a Boquitas pintadas la mejor novela publicada en el año 1969, y las generosas gestiones que hizo Puig para que Lamborghini lograra publicar su poema Die Verneinung completo en la revista Escandalar en diciembre de 1978, narradas en Osvaldo Lamborghini, una biografia: VER Strafacce 2008: 533-549): ¿qué textualidad posible en la intersección entre ambos? Y, la pregunta más difícil: ¿cómo entraría a jugar en esta amalgaba la apuesta de Walsh, que termina subsumiendo la literatura a la eficacia de un discurso que busca por sobre todas las cosas hacer conocer la verdad sobre los hechos a la opinión pública? En otras palabras: ¿qué tipo de "literatura política” posible entre, pongamos, El fiord, ¿Quién mató a Rosendo? y La traición de Rita Hayworth? ${ }^{87}$

Walsh y Lamborghini coincidirían en una misma pregunta acuciante: cómo hacer memoria en la literatura de que -con el líder en exilio- los héroes anónimos de la Resistencia ("las Bases"; "Sebas") están siendo marginados por la burocracia sindical. Sin embargo, las memorias en la literatura que construyen Walsh y Lamborghini sobre el nacimiento del vandorismo y la lucha facciosa dentro del Movimiento son absolutamente disímiles. El fiord, además, no es como ¿Quién mató a Rosendo? la consolidación de una propuesta narrativa ya probada (si pensamos que ¿Quién mató a Rosendo? profundiza el procedimiento de Operación masacre, de la que precisamente en 1969 Jorge Álvarez publica una tercera versión corregida y aumentada), sino un relato inaugural, enmarcado por "dos violentos alumbramientos (uno biológico, el otro político)" (Oubiña 2008: 71). En otras palabras: el nacimiento de "Atilio Tancredo Vacán” (¿Augusto Timoteo Vandor? ¿O la misma "figura de autor” de Osvaldo Lamborghini, de quien también podría predicarse que nació "con una boquita no mayor que el punto de un lápiz"?) con el que se abre el relato y la triunfal salida en manifestación que lo cierra, que también constituye, como ya lo había señalado de manera pionera Germán García en su posfacio "Los nombres de la negación” para

\footnotetext{
${ }^{87}$ Elegimos ex profeso El fiord (fechado por Lamborghini entre "octubre de 1966 y marzo de 1967", pero escrito según Strafacce en marzo de 1968 y publicado por Ediciones Chinatown en 1969); ¿Quién mató a Rosendo? (publicado a mediados de 1968 en el semanario "CGT") y La traición de Rita Hayworth (publicado por Jorge Álvarez en 1968) como posibles componentes de dicha "amalgama", dado que los tres textos se escriben (y publican) en el contexto del Cordobazo.
} 
Ediciones Chinatown, el nacimiento de una voz literaria inaudita, que se manifiesta por primera vez. ${ }^{88}$

Una evaluación más detenida del "programa" enunciado por Daniel Link nos obliga a repensar la posible relación entre Osvaldo Lamborghini y Rodolfo Walsh por la contraria: El fiord como anti ¿Quién mató a Rosendo?, Lamborghini como un antiWalsh. En otras palabras: El fiord se propondría manifestar en términos de alegoría desquiciada lo mismo que denuncia ¿Quién mató a Rosendo? en términos de un discurso eficaz cuyo grado cero es el discurso forense y el informe balístico que -con su correspondiente gráfico- Walsh no duda en incluir para demostrar cabalmente la culpabilidad de Vandor en la muerte de Rosendo García.

Como señala Eduardo Jozami en su biografía Rodolfo Walsh. La palabra y la acción, a partir de 1969 Walsh mantiene una relación culposa con el ejercicio de la ficción. Si bien merodea el proyecto de escribir "la gran novela" hasta el día mismo de su secuestro, la entrada correspondiente al día 21 de enero de 1969 de su diario de escritor da cuenta de un importante bloqueo creativo, alimentado por la creencia de que:

...la Novela es el último avatar de mi personalidad burguesa, al mismo tiempo que el propio género es la última forma del arte burgués en transición hacia otra etapa en que lo documental recupera su primacía. Pero tampoco estoy seguro de esto, que puede ser una excusa para mi momentáneo fracaso. (Walsh [1969] 2007: 126)

Si se piensa el posible vínculo entre Walsh y Lamborghini en términos de trayectorias de escritor y/ o "autoimágenes", las diferencias se vuelven aún más flagrantes. Mientras el primero se obliga así mismo a abandonar el ejercicio de la ficción animado por la creencia de que, para ser eficaz, la denuncia política debe prescindir de la misma y pasa a dedicarse casi exclusivamente a sostener el semanario de la CGT (que ha fundado) y a redactar boletines internos para la Organización Montoneros, el segundo hace un paso casi de comedia por el peronismo revolucionario (del 19 de junio al 21 de agosto de 1973 en la Subsecretaría de Cultura, experiencia que comparte con Lorenzo Quinteros y Germán García) y tiene una epifanía tardía de su propia (e involuntaria) condición subversiva. Se trata, claro está, de una toma de consciencia netamente literaria. En Sebregondi se excede, fechado en 1981, escribe:

88 “... festeja un nacimiento, el de la escritura. Es la escritura quien mata a la autoridad, quien realiza el nacimiento y el festejo [...]" (García [1969] 2003: 16-17) 
"Después del 24 de marzo, ocurrió. Ocurrió, como en El Fiord [...] El 24 de marzo de 1976, yo, que era loco, homosexual, marxista, drogadicto y alcohólico, me volví loco, homosexual, marxista, drogadicto y alcohólico" (2010: 175).

Retomando una distinción que plantea Noé Jitrik en su ensayo "Violencia y literatura" entre una escritura que representa la violencia y una escritura violenta, la poética de Lamborghini exacerbaría la condición violenta que -según Jitrik- es característica de toda literatura. ${ }^{89}$ Nuevamente: contra la creencia en el valor instrumental de la literatura (Walsh), la paradoja del sentido "que no está nunca donde se lo busca" (Literal 1: 11), "la literatura [como] palabra para nada" (Op. Cit. Literal 1: $13)$.

Tal como señala Ariel Idez en Literal. La vanguardia intrigante, "Literal impugna la práctica literaria al servicio de fines políticos” (2010: 64). En este marco, los literalistas tuvieron como uno de sus blancos favoritos el discurso periodístico, al que acusaron de querer arrogarse un plus de valor por su carga informativa de potencial revolucionario. En el trabajo que inaugura la publicación "No matar la palabra, no dejarse matar por ella", que podría ser considerado el manifiesto ideológico-estético del grupo y que (aunque se publica sin firma) sabemos hoy que redactaron Quinteros, García y Lamborghini, los literalistas explicaban que: "La información en un texto es un beneficio secundario que no justifica la existencia de una escritura literaria. A diferencia de una 'noticia', la verdad de un texto no puede someterse a una prueba de realidad" (Literal 1: 5). Dos páginas más adelante, el planteo es expandido en tesitura lacaniana, colocando la literatura del lado del goce, y el periodismo del lado de su imposibilidad. A la figura del escritor (el "gran masturbador", para citar el célebre título de Salvador Dalí) se le contrapone la del periodista, el "gran frígido":

La noticia es una cama donde cualquiera puede acostarse sin que se le mueva el piso. Se entiende que alguien sea periodista porque hay diarios que pagan la función, hay ruinas cotidianas y reuniones de ministros. No se entiende que alguien escriba unas palabras no demandadas por nadie, cuyo valor es siempre dudoso a priori aunque pueda exaltarse a posteriori. Por eso todo escritor es materia dispuesta

\footnotetext{
89 "En cuanto a lo que llamaba lo más complejo para entender el alcance de este tema, se diría, para empezar, que el hecho de escribir -y la literatura es escritura- es violento; pareciera que no lo es y que, a partir de un don o de un saber, se ejecuta pacíficamente porque trabaja sólo con palabras; pero las palabras son signos que, a su vez, provienen de la violencia que el significante ejerce sobre la cosa y le crea un significado. La cosa es lo que es: la designación la pone en otra parte y en esa otra parte nos movemos. Todo lenguaje, en suma, descansa sobre una violencia arcaica, olvidada, que si bien comunica y sirve para comunicar, no es sentida aunque reaparece con toda su fuerza en la escritura." (Jitrik 2010: 37-38)
} 
para cualquier misión que dé un sentido social a esa práctica compulsiva, siempre cercana a los fantasmas de la masturbación; según el tópico que asegura una relación íntima entre este placer solitario y el goce de escribir. El periodista que cambia un sueldo por palabras que remiten a una realidad conocida por otros, pareciera no haberse masturbado nunca. (Literal 1 1973: 7; énfasis en el original)

Contra esto, y desde las páginas de Babel, Christian Ferrer apuntará precisamente a rescatar a Rodolfo Walsh en tanto "gran estilista" (en otras palabras: no en tanto periodista-militante, sino en tanto escritor). Para Ferrer, el estilo de Walsh es inimitable, carece de discípulos y herederos literarios:

... existe más de un periodismo que sugiere mantener la línea de Walsh: en el caso de Horacio Verbitsky, sólo el afán de investigación y la voluntad de denuncia pueden contabilizarse a beneficio de inventario. En el caso de Página/ 12, se practica un abuso en el novelado de los hechos: éstos desaparecen como datos para ser reenviados al boom de la literatura latinoamericana del ' $60[\ldots]$ En el caso de Verbitsky, hay ausencia del trabajo de géneros que hacía Walsh, y en el último caso el periodista se confunde con García Márquez o Vargas Llosa: realismo mágico, puro ademán, libera al dato de su carga explosiva, de su relación conflictiva en el huracán de las relaciones sociales originantes del mismo hecho. En un caso por defecto, en el otro por exceso. (Ferrer 1989: 27)

El realismo mágico, es, entonces, otro de los blancos que los escritores nucleados alrededor de Babel heredan de sus "hermanos mayores". En la sección "Narrativas" del número nueve, Daniel Link reseña El general en su laberinto con una extensa primera frase que parodia el célebre arranque de Cien años de soledad. ${ }^{90}$

Link denuncia la cristalización y el agotamiento de la poética de García Márquez, impugnándolo desde dos frentes. Por un lado, señala que García Márquez escribe para el mercado (repite una fórmula que ya sabe exitosa: en el mismo número de Babel leemos que El general en su laberinto está primero en el ranking de ventas del mes). Por otro, señala la voluntad de García Márquez de "escribir para el Estado" (para la "escuela progresista"), de colocar su literatura "en el siglo XIX" (en tanto aspira a una función didáctica, comunicativa). En este contexto fuertemente contrario al realismo mágico de Babel, se entiende tanto la celebración por parte de Alan Pauls de la poética

\footnotetext{
90 "Muchos años después, frente al jurado que le otorgaría el Premio Nobel de literatura, Gabriel García Márquez habría de recordar aquella mañana remota de 1967, cuando la prestigiosa Editorial Sudamericana de Buenos Aires distribuía los primeros tímidos ejemplares de su novela, que se perderían, años más tarde, en las cifras de vértigo del inventario de libros salido de un delirio de multiplicación bíblica antes que de un plan de producción editorial.” (Link 1989b: 10)
} 
de Juan José Sáer, que opera por fuera de "el latinoamericanismo de los García Márquez, los Fuentes, los Vargas Llosa, los Roa Bastos” (1988: 4), como la necesidad de Carlos E. Feiling de aclarar el "error" de filiar Los fantasmas de César Aira con "las morisquetas del realismo mágico" (1990: 5).

En 1995, en su aporte para el tomo Culturas del Río de la Plata (1973-1995). Transgresión e intercambio, que compila Roland Spiller, Link volverá in extenso a apoyar esta "tradición selectiva":

La década del ochenta nos introdujo en nuevos modos de organización social. Todo comenzó con una separación brutal: Alfonsín separaba la política (entendida como debate cívico) de la violencia [...] Descubríamos lo que habíamos perdido durante todos esos años y aprendíamos a leer la literatura de otro modo. Es más: la literatura cambiaba: ya no había tanto epígono de Onetti dando vuelta por ahí; Walsh, Puig y Lamborghini (Osvaldo) representaban modelos ciertamente escandalosos pero precisamente por el carácter de "modelos" que tenían en la década del ochenta es que hay que interpretar sus obras como ya hechas y leídas: toda la década del ochenta es el trazo de ese ya. (Link 1995: 52)

Unas páginas más tarde:

Nada de representación. Toda la literatura de los setenta se piensa a sí misma en la intersección de dos transgresiones: los modelos clásicos de la representación y los modelos genéricos de la percepción: Puig, Walsh, Lamborghini. Un poco después (y de otro modo), Piglia, Saer y Gusmán. (Op. Cit. Link 1995: 56)

En efecto: la "tríada" suma nombres: Ricardo Piglia, Juan José Saer, Marcelo Cohen, Copi, Rodolfo Fogwill, Alberto Laiseca y César Aira. Con excepción de Piglia y Cohen, todos los ellos tuvieron su espacio en la seción "El libro del mes": Juan José Saer en el $\mathrm{n}^{\circ} 4$, con motivo de la reedición de La ocasión; Alberto Laiseca en el $\mathrm{n}^{\circ} 12$, con motivo de la publicación de La hija de Kheops; Copi en el n 15, con motivo de la traducción al español de La internacional argentina; Rodolfo Fogwill en el $n^{\circ} 20$, con motivo de la publicación de La buena nueva de Los Libros del Caminante, y César Aira en el último número de Babel, con Los fantasmas. No obstante, Piglia fue entrevistado en la sección "La esfinge" correspondiente al $n^{\circ} 21$. Marcelo Cohen tuvo su propia columna como "corresponsal" desde Barcelona ("Batidore Libero": lunfardesco juego de palabras: "batir novedades editoriales internacionales"). En el $n^{\circ} 11$, Cohen escribió sobre Italo Calvino. En el n 12, sobre Paul Auster. En el n 13, sobre Clarice Lispector. 
En el $n^{\circ} 14$, sobre William Gibson. En el $n^{\circ} 16$, sobre Charles Doyle, padre de Arthur Conan Doyle. Su última participación como columnista fue para el $n^{\circ} 19$, donde reseñó novelas de Peter Handke. ${ }^{91}$

A pesar de las indudables diferencias existentes entre ambos en términos de -para usar las categorías de Sarlo en "Política, ideología y figuración literaria" (1987)“órdenes de la representación y de lo representado", Jorge Asís y Osvaldo Soriano son conceptualizados de similar forma (negativa) por los escritores agrupados alrededor de Babel, revista de libros.

Mientras el primero es rabiosamente atacado en la reseña a El cineasta y la partera y (el sociólogo marxista que murió de amor) (1989), que firma Álvaro Fernández Bravo para el $\mathrm{n}^{\circ} 10$ de Babel, el segundo lo es en la correspondiente a Una sombra ya pronto serás (1990), contenida en el n 22 de Babel que escribe Carlos E. Feiling, punto más bajo de esta impugnación, donde se llega a afirmar que Soriano es "el equivalente cultural de la política menemista":

Una sombra ya pronto serás, la quinta y exitosa novela de Osvaldo Soriano (Buenos Aires, Sudamericana, 1990, 256 páginas), le hace a la literatura argentina lo que el excelentísimo Sr. Presidente al país [...] ¿Qué pasa en la novela de Soriano? Simplemente, nada que no sea esperable o se aparte mucho del golpe bajo [...] No hay lugar común ni estereotipo que escape a la máquina narrativa [...] el concentrado populismo de Una sombra ya pronto serás responde a una combinación mortífera de las peores tendencias de cierta izquierda argentina [...] Uno se pregunta si no es hora de ser un poco más frívolo, más pedante o más cínico. Son formas de evitar la idea de que para escribir hay que emborracharse y pelear. De no quedarse, por otra parte, babeando frente a un banderín de Boca Juniors o las estampitas de San Cayetano. (Feiling 1990: 7)

¿Por qué este ataque?

La explicación más fácil es del orden del chisme: a raíz de una reseña negativa a la reedición de La vida entera, de Juan Carlos Martini, firmada por Daniel Link, Soriano habría decidido el despido de Martín Caparrós y Jorge Dorio de Página/ 12, de cuyo Suplemento "Culturas", como ya señalamos, fueron directores entre 1987 y 1989. ${ }^{92}$ Las razones más interesantes serían, no obstante, las que siguen.

Por un lado, el encono contra Soriano estaría relacionado con una disputa por divergentes "imágenes de escritor". Retomando lo desarrollado en el primer parágrafo

\footnotetext{
${ }^{91}$ Las notas de Marcelo Cohen para el $\mathrm{n}^{\circ} 10$ ("El efecto Vonnegut") y $\mathrm{n}^{\circ} 15$ ("Cuando el relato comienza"), si bien enmarcadas dentro de la sección "Batidore Libero" tienen un cariz diferente, puesto que no son reseñas, sino ensayos de carácter más general.

${ }^{92}$ Para una narración detallada de este conflicto, VER Link "Osvaldo y sus amigos" (2012).
} 
del presente capítulo, no parece casual que en su diatriba Feiling vuelva a la vieja acusación de "posmodernos" lanzada en 1984 por Miguel Briante, y repetida años más tarde por, entre otros, Tomás Eloy Martínez en el $n^{\circ} 62$ de Crisis. ${ }^{93}$ Feiling afirma que este supuesto posmodernismo constituiría un rasgo positivo frente al antiintelectualismo militante de Soriano, el escritor que -según su propia leyenda personalpracticaba boxeo, jugaba al fútbol y había aprendido a escribir en Redacciones y bares.

Desde las páginas de Babel, la acusación de "posmodernos" realizada por Tomás Eloy Martínez fue refutada con energía por Alan Pauls en su reseña a La ocasión, de Juan José Saer, ya mencionada. También en el $\mathrm{n}^{\circ} 14$, cuyo un dossier es sobre El fin de la Historia y el último hombre (1992; traducido al castellano y editado por Planeta en 1994), de Francis Fukuyama, que una primera lectura podría considerar la "principal prueba incriminatoria” de esta acusación. (El dossier incluye una traducción de “¿El fin de la Historia?", artículo seminal publicado por Fukuyama en el $\mathrm{n}^{\circ} 16$ de la revista The National Interest.) La publicación de estos materiales, sin embargo, no significa adhesión.

En términos de "sintaxis de revista" (Cf. Op. Cit. Sarlo 1992), es de destacar que el número catorce de Babel se inaugura con sendas reseñas a "El hombre y la democracia”, de György Lukács ("libro del mes”), que firman Horacio González y Horacio Tarcus (seud. de Horacio Pagliani). Al mismo tiempo, el "dossier Fukuyama” consta del apartado "Disparen contra Fukuyama", donde se traducen intervenciones de Irving Kristol, André Fontaine, Gertrude Himmelfarb, Pierre Hassnet y Alan Bloom, que refutan de manera total o parcial las tesis vertidas en El fin de la historia y el último hombre. En este contexto, también es importante la presencia de Claudio Uriarte, ex militante trotskista que hace una evolución matizada del libro de Fukuyama. Por último, no parece casual la inclusión en la página veintinueve de este número de un artículo que se posiciona claramente en contra del discurso político de Menem basado en la “doctrina de la reconciliación nacional" ("Postales argentinas”), que firman Telma Luzzani y, nuevamente, Claudio Uriarte. ${ }^{94}$

\footnotetext{
${ }^{93}$ En su intervención, Martínez diagnostica "tres líneas" para la literatura argentina: la "línea Saer" ("cuya perversiones se están dando en las imitaciones de Thomas Bernhard y del nouveau roman"; la "línea realista" (un espectro amplio que va de Asís a Laiseca, pasando por Fogwill) y "una tercera línea, que podríamos llamar de los posmodernos, que suponen que hay que burlarse de todo, que nada tiene sentido, cuya figura central sería Aira, y donde están Guebel, Dippy, etc. Es en gran medida el terror al referente concreto, a la identificación con la realidad." (Martínez 1988: 35). "Dippy" es Jorge Di Paola, autor de ¡Minga! (1987).

94 Autor de Almirante Cero: biografía no autorizada de Emilio Eduardo Massera (1992), Uriarte terminaría como confeso admirador de George W. Bush.
} 
Volviendo a la reseña de Charlie Feiling a Una sombra ya pronto serás: la prosa utilizada para la misma hace "memoria de la literatura I" del ensayo "La intriga" (sin firma, pero que se sabe escrito por Osvaldo Lamborghini) que cierra el primer número de Literal: "Y a último momento apareció la política como posible máscara para reclamar los beneficios de la escena. La conciencia moral se esforzaba en un doble sacrificio: ¡Por la ciencia! ¡Por los proletarios!” (Literal 1 1973: 121). Por lo mismo, la memoria del tono escandalosamente cínico de Osvaldo Lamborghini que realiza Feiling para fundamentar su repudio a la poética de Soriano pediría ser leída como uno de los momentos de máxima adhesión por parte de determinados miembros de la "generación ausente" a la poética anti-populista de determinados "hermanos mayores". 95

\subsection{Un contexto de publicación adverso y común: la crisis del mercado editorial (1976-1989) y el "alejamiento del lector nativo de la ficción" (1985-1990)}

En la sección "Los nuevos" incluida en el primer número de Pie de Pagina (primavera de 1982), Sergio Bizzio y Daniel Guebel dan a conocer sus primeros textos. El primero publica tres poemas (“I”; "II" y "VI"), extraídos de su poemario inédito Gran salón con piano. La presentación de Bizzio que acompaña los textos pone énfasis en su condición de "inédito":

SERGIO BIZZIO: 1956, Ramallo, Pcia de Buenos Aires.

Colaboró en El Ornitorrinco, Nova y publicaciones en el exterior del país.

OBRA: "El árbol del Cuervo" (inédito) y "Gran Salón con Piano" (inédito) al cual pertenecen estos poemas. (Pie de Página 1 1982: 11)

Daniel Guebel publica el cuento "Flores para Felisberto". Su presentanción, calcada de la de Bizzio, también remite a la crisis de la industria editorial:

DANIEL GUEBEL: 1956, Capital Federal. OBRA: inédito. Dos novelas, en espera de ser publicadas: “Arnulfo o los infortunios de un Príncipe” y "El avestruz que Clamaba en el Desierto". (Pie de Página 1 1982: 13)

La imposibilidad de publicar vuelve a ser subrayada en las micro-biografías incluídas en el $n^{\circ} 8$ de Vuelta de marzo de 1987, dedicado a "ofrecer un panorama de la literatura que escriben en la Argentina de hoy los que tienen entre 25 y 35 años..."

\footnotetext{
95 Para una genealogía de la prédica anti-populista en el campo literario argentino, VER "La injuria 'populista' (episodios literarios de un combate poético", primera parte de La palabra justa. Literatura, crítica y memoria en la Argentina 1960-2002 (2004), de Miguel Dalmaroni.
} 
(Torres Fierro 1987: 6). Doce son los nombres que se incluyen: Daniel Guebel, Luis Thonis, Matilde Sánchez, Sergio Bizzio, Jorge Dorio, Luis Chitarroni, Telma Luzzani, Marcos Lucio Victoria y María Martoccia, entre los cuales "se cuelan" los ya no tan jóvenes Jorge Panesi, Martín Caparrós y Elsa Osorio. En los casos de Guebel, Bizzio, Victoria, Martoccia y Chitarroni, se enfatiza especialmente el hecho de poseer obra inédita.

De manera paradójica, estos escritores eligen hacer de dicha condición un reaseguro de calidad (algo así como "no nos publican porque somos demasiado buenos"). En palabras de Luis Chitarroni, durante su reconstrucción retrospectiva de la época: "Nosotros éramos parcialmente inéditos, y había una identificación con Lamborghini, que era voluntariamente inédito. Lo habíamos tomado como bastión. Había algo putrescible (sic!) en lo que se publicaba en ese momento" (Chitarroni [Entrevistado por Mauro Libertella] 2011: 7).

Es una redundancia señalar que el estado del mercado de libros durante la década del '80 poco tiene que ver con el contexto de de publicación de El fiord (1969). ${ }^{96} \mathrm{La}$ alusión a la condición de "inédito voluntario" de Osvaldo Lamborghini funcionaría entonces no como un término de comparación real, sino como símbolo de un gran estilo que hace caer el sentido (Cf. Op. Cit. Aira 1982). Es, además, el mito fundante de la "mafia neobarroca" (Saavedra 1988), conformada por Héctor Libertella, Arturo Carrera, Néstor Perlongher, Emeterio Cerro, César Roberto Echavarren, Eduardo Milán y Tamara Kamenszain, con la inclusión (algo forzada, como lo admite el mismo Saavedra en su nota publicada sobre dicha "mafia" en el n² 212 de El nuevo periodista) de César Aira, practicante de un estilo límpido que -coincidimos con Saavedra- "es el que peor resiste el sayo neobarroco" (Saavedra 1988: 42). ${ }^{97}$

\footnotetext{
${ }^{96}$ Entre 1960 y 1969, la producción editorial en nuestro país fue de 238 millones de libros, representando el 50\% de todos los libros producidos en idioma castellano en el mundo (Cf. Getino 2008: 66). Recuperada de su caída en el período 1954-1958, la industria del libro argentino creció notablemente durante el período 1962-1968 ("primavera de los años sesenta"). Con el fondo del boom latinoamericano, fueron muchos los editores argentinos que volvieron a apostar por publicar (o reeditar) autores locales. El fenómeno, también llamado "boom del libro argentino" tuvo, por un lado, un apoyo propagandístico en semanarios como Primera Plana, Panorama y Análisis, y, por el otro, encontró un importante impulso en los nuevos métodos de comercialización -fascículos- y líneas de venta -kioscos de revistas-, de los cuales fueron pioneros la editorial Codex y el Centro Editor de América Latina. El fenómeno recién declinó a partir del año 1970 (Cf. Rivera 1980/ 86).

${ }_{97}$ En su trabajo "La barroquización", publicado en marzo de 1988 en la Folha de Sâo Paulo, Néstor Perlongher había señalado que Sebregondi retrocede (1973) "detona por dentro de la literatura argentina, cierto flujo que cabría denominar, antes que neobarroco, 'neobarroso' " ([1988] 2008: 117). Osvaldo Lamborghini resultaría así el co-fundador de la "mafia neobarrosa", si aceptamos la formulación de Perlongher en "Caribe transplatino", según la cual "el neobarroso transplatino tendría, en verdad, dos
} 
De todas formas, si bien la prosa de Aira está lejos del estilo definido por Severo Sarduy en 1972 en términos de "extrema artificialización" con sus mecanismos de la sustitución, la proliferación y la condensación (Cf. Sarduy 1972: 167-184), sí parece andar más próxima a la definición de "barroco" que Sarduy, entrevistado en París por Alicia Dujovne Ortiz para la revista Vigencia, dará ocho años más tarde para caracterizar como "lujo barroco" su propia apuesta narrativa:

Hay un barroco en el sentido más estricto del término, es decir, en ése que adoptó la Contrarreforma y que practicaron con regocijo las saturadas capillas de Churriguera, el arte colonial sudamericano, los sonetos áureos de Góngora y, más recientemente, en la calle Trocadero, Lezama Lima. Quiero decir: lo importante es atraer, fascinar, seducir (Me dice el autor: "Las tres cosas subrayadas". ¡Cuidado, amigo tipógrafo!). Y todo con un simple propósito: convencer. En la India, y valga la anécdota, ante el templo de Khajuraho, que, como es sabido, es una proliferación incontenible y deliciosa de parejas fornicando, los especialistas se plantean con frecuencia el dilema de saber a qué obedece ese despliegue de placer. La respuesta, que me apareció allí, es, por demasiado sencilla, informulable: para atraer. Maitreya [última novela por entonces édita de Sarduy] practica, pues, ese lujo barroco, ese erotismo, esa suave risa, y esa pulsión sin límites de decorados, de escenografías, de fasto, como un biombo chino iluminado con garzas, cofres laqueados de rojo y cerezos de invierno a la luz de la luna. (El autor observa el aspecto kitsch de la cosa). (Sarduy 1980: 31; énfasis del autor)

Así, César Aira operaría para los escritores nucleados alrededor de Babel más como modelo de "novelista exótico" que en tanto miembro de la llamada "mafia neobarroca". Lo más obvio: César Aira nunca publicó poesía, y si bien tanto Sergio Bizzio como Carlos E. Feiling y Jorge Dorio empezaron sus trayectorias de escritor como poetas, los dos primeros se pasarían luego al género novela. ${ }^{98}$ Asimismo, el análisis cuantitativo de la sección "El libro del mes" (considerada el lugar central de la crítica literaria dentro de la revista, tal como se explicita en el editorial del $n^{\circ} 9$ ) arroja como resultado una marcada preferencia por este género frente al lírico. Y aún más: se trata, por holgada mayoría, de escritores argentinos.

nacimientos. Uno, el de El fiord; otro, el de La partera canta" ([1991]: 2008: 99), quedando reservado el término "neobarroco" para Severo Sarduy. En "Ondas en el fiord. Barroco y corporalidad en Osvaldo Lamborghini" (1991), Perlongher explota la idea de "escribir a tajos de gillette" presente en DIÁLOGO CON UN LIBERAL INTELIGENTE incluido en Sebregondi retrocede para oponer Sarduy a Lamborghini, entendiendo que el primero practica una "escritura como tatuaje" mientras el segundo, una "escritura como tajo" ([1991] 2008: 135). Por último, en "Breteles para Puig" (1988), Perlongher inscribe al escritor oriundo de General Villegas en su propia "mafia neobarrosa", en tanto El beso de la mujer araña "evoca $[\ldots]$ cierto clima lamborghiano, cierto fiord, irreductible, si bien decorado, como un livingroom kitsch, con las pavadas de todos los días [...] muy disimulado, sí, muy en el fondo- un dejo desteñido de barroco" ([1988] 2008: 128-129).

${ }_{98}$ También Chejfec incursionó en el género lírico en Tres poemas y una merced (2002) y Gallos y huesos (2003). 
De los 22 títulos seleccionados para los 22 números de Babel, sólo dos pertenecen al género lírico (El ala de la gaviota, de Enrique Molina en el $\mathrm{n}^{\circ} 11$ y Children's corner, de Arturo Carrera, en el $\mathrm{n}^{\circ} 13$ ); dos al género memorias (Peregrinaciones argentinas, de Witold Gombrowicz en el $\mathrm{n}^{\circ} 2$ y El sobrino de Wittgenstein, de Thomas Bernhard en el $n^{\circ} 3$ ); nueve al ensayístico (El arte de la novela, de Milan Kundera en el primer número; De los espejos y otros ensayos, de Umberto Eco en el n ${ }^{\circ} 5$; El género gauchesco. Un tratado sobre la patria, de Josefina Ludmer en el $\mathrm{n}^{\circ} 6$; Michelet, de Roland Barthes en el $\mathrm{n}^{\circ} 7$; Historia social de la literatura argentina, compilada por Graciela Montaldo en el $\mathrm{n}^{\circ}$ 8; Historia del tiempo, de Stephen Hawking en el ${ }^{\circ} 10 ; E l$ hombre y la democracia, de György Lukács en el n 14; Memorias para Paul de Man, de Jacques Derrida en el $\mathrm{n}^{\circ} 16$ y Crítica de la razón cínica, de Peter Sloterdijk en el $\mathrm{n}^{\circ}$ 22), y nueve al género novela (La ocasión, de Juan José Saer en el $n^{\circ} 4$; Novelas y cuentos, de Osvaldo Lamborghini en el n ${ }^{\circ}$ 9; La hija de Kheops, de Alberto Laiseca en el $\mathrm{n}^{\circ} 12$; La internacional argentina, de Copi en el $\mathrm{n}^{\circ} 15$; Lenta biografía, de Sergio Chejfec en el $n^{\circ} 17$; La perla del emperador, de Sergio Guebel en el n 18; El coloquio, de Alan Pauls en el n ${ }^{\circ}$ 19; La buena nueva de Los Libros del Caminante, de Rodolfo Fogwill en el n² 20 y Los fantasmas, de César Aira en el n²1).

Lo primero que salta a la vista sobre las novelas seleccionadas como "libro del mes" es que se trata exclusivamente de novelas argentinas. Dentro de la nómina, es notorio el espacio otorgado a la promoción de la propia obra: de las nueve novelas seleccionadas, tres fueron escritas por miembros del staff de Babel: Lenta biografia, de Chejfec; La perla del emperador, de Guebel y El coloquio, de Pauls. Las dos últimas, a su vez, son exponentes de la muy promocionada "novela exótica", cuya paradójica novedad se despliega en el editorial "Nuevos avances y retrocesos de la nueva novela argentina en lo que va del mes de abril”, firmado por Martín Caparrós y publicado en la sección "Caprichos" correspondiente al n 10 de la revista.

Si decimos "novedad paradójica" de la "novela exótica", es porque Caparrós mismo se encarga de señalar que la "nueva novela argentina" a la que alude el título habría sido concebida bajo la inspiración del ensayo "El escritor argentino y la narración", de J. L. Borges, al mismo tiempo que renuncia explícitamente a la prerrogativa de ser uno de los inventores de la misma cuando señala al "hermano mayor" César Aira como principal precursor de este subgénero novelístico (con Ema, la 
cautiva), cuyos más altos exponentes serían Aira (con Una novela china), Marcelo Cohen (con El oído absoluto) y Alberto Laisea (con La hija de Kheops).

Dos años antes, en una reseña de Daniel García Helder sobre Poemas Chinos (Libros de Tierra Firme, 1987) para el $n^{\circ} 6$ de Diario de Poesía, la apuesta por el exotismo en Laiseca ya había sido puesta en relación con las tesis vertidas en el ensayo “El escritor argentino y la tradición”, de J. L. Borges. ${ }^{99}$ Según Helder, Poemas chinos hace usufructo de las teorizaciones borgianas sobre el apócrifo: el poemario de Laiseca publicado en 1987 se presenta como la compilación realizada por un tal "Lai Ts Chiá" de 103 poemas de autores inexistentes.

En septiembre de 1987, Guillermo Saavedra, en ese entonces parte del staff de $E l$ Porteño, publica "Retrato de artista con novela", donde celebra los "textos tan acabados como inéditos" de Alberto Laiseca (en especial: "una magnífica pesadilla que ocupa varios cajones de incunables, agazapada a la espera de un borgeano Teseo que vaya a redimirla [...] su monumental saga novelística Los Sorias"), señalando que "se sabe, lo esencial es invisible a los editores" (1987: 72). En el marco de esta nota, se publica un adelanto del capítulo 144 de la mítica novela. ${ }^{100}$

Por todo esto, Alberto Laiseca no sería tanto el "escritor secreto del grupo Babel" (Cf. Saítta 2004: 248), sino el "escritor secreto de Fogwill", que en la sección "Bibliográficas" del primer número de Pie de Página había escrito una reseña sumamente elogiosa a Las aventuras de un novelista atonal (Sudamericana 1982) y

\footnotetext{
${ }^{99}$ Diario de Poesía ( ${ }^{\circ} 1$ : julio de 1986 - $\mathrm{n}^{\circ}$ 83: 2011; frecuencia inicial trimestral), tuvo como fundador y director a Daniel Samoilovich, con un Consejo de Redacción integrado por Daniel Freidemberg, Jorge Fondebrider (secretario de redacción), Diana Bellesi, Elvio E. Gandolfo, Daniel García Helder, Mirta Rosenberg y Martín Prieto. En el n 9 se incorporan Ricardo Ibarlucía y Jorge Ricardo Aulicino. De formato tabloide y aproximadamente 40 páginas, tuvo un tiraje de 5000 ejemplares. Fueron encargados de su diseño los artistas plásticos Juan Pablo Renzi y Eduardo Stupia (a partir del nº 23 del año 1992). En el año 2003 tuvo una etapa de "transición". A partir de 2006 mantuvo una periodicidad bianual. En el año 2007 se reorganiza el Consejo de Dirección, siendo integrado por Osvaldo Aguirre, Edgardo Dobry, Pablo Gianera (secretario de redacción), Ricardo Ibarlucía, Mirta Rosenberg, Matías Serra Bradford y Eduardo Stupía (director de arte), manteniéndose Daniel Samoilovich en la Dirección. Sobre Diario de Poesía, VER Porrúa (2004) y Usabiaga (2012)

${ }^{100}$ El Porteño fue fundado en 1981 por Gabriel Levinas, con un staff donde estuvieron Daniel Molina, Enrique Symns, María Eugenia Stenssoro y Ernesto Tiffenberg. Llegó a vender 30.000 ejemplares por número y fue, junto con Humor registrado, uno de los pocos espacios críticos a la dictadura. Tuvo una refundación (con cambio de formato) en febrero de 1982, con la asesoría de Rodolfo Enrique Fogwill (que tenía en la práctica un rol de subdirector, aunque no figuraba en el staff) y publicó su último número 134 en febrero de 1993. Para febrero de 1985 (que es cuando comienza a ser publicado por la Cooperativa de Periodistas Independientes), figuran Jorge Lanata como Jefe de Redacción, Ernesto Tiffenberg como Asesor Editorial y Eduardo Blaustein como Secretario de Redacción. Son sus colaboradores frecuentes César Aira, Horacio González, Jorge Fondebrider, Osvaldo Baigorria, María Moreno (seud. de Cristina Forero), Ricardo Ibarlucía, Jorge Warley, Rolando Graña, Martín Caparrós y Guillermo Saavedra.
} 
afirmado que "Alberto Laiseca ha sido hasta ahora un secreto a voces entre críticos y autores de vanguardia" (Fogwill 1982: 27). ${ }^{101}$ También Ricardo Piglia, desde las páginas del $\mathrm{n}^{\circ} 16$ de Punto de Vista había alertado que "ya es hora de hablar de este libro misterioso y larguísimo [Los Sorias] que es con seguridad uno de los textos fundamentales de la literatura argentina" (1982: 132). En efecto: pensando la cuestión en términos de la tensión "literatura-mercado", Los Sorias es una novela que -por su desmesurada extensión- se coloca tanto en las antípodas de lo publicable, como de lo vendible. Esto es: una respuesta desde la vanguardia a la crisis del mercado editoral.

Resumiendo: en un contexto de crisis editorial y "vuelta a la narración" (Cf. Catelli 1983; 1992), los narradores nucleados alrededor de Babel, revista de libros adoptan dos estrategias, contradictorias entre sí. Por un lado, ponen el acento en la materialidad del libro (como en Los libros, en cada reseña publicada en Babel consta el precio de tapa de los "libros que nadie puede comprar"), convocan a editores, libreros y distribuidores para que relaten de primera mano su experiencia en el rubro, proyectos y visión sobre la crisis editorial en la sección “Tráfico. Una tribuna para mercaderes" (del $\mathrm{n}^{\circ} 1$ al 14 inclusive), dan un "Ranking del mes" (parcial y seguramente algo irónico, dado el escaso número de las librerías consultadas, todas porteñas, excepto Capítulo de La Plata) de los libros "mejor vendidos", y publican en el primer número la columna "El buscón" (relevo de las ofertas disponibles en las librerías de Capital Federal). Por otro lado, coquetean con la idea de ser "inéditos voluntarios" (haciendo una lectura tendenciosa de una condición que Osvaldo Lamborghini intentó revertir por lo menos hasta el año 1980, VER Strafacce 1998 y 2008), enarbolan como modelo de novelista al impublicable Alberto Laiseca y se autopromocionan como "lo nuevo" (novedad paradójica de la "novela exótica").

En otras palabras: plantean la cuestión del mercado editorial en los mismos términos que lo había hecho el "hermano mayor" Juan José Saer en su ensayo "Literatura y crisis argentina" (1982): "populismo o vanguardia" (antinomia que ya para entonces aparecía como anacrónica). Si bien la antinomia "populismo o vanguardia" había sido una problemática central en las revistas Literal o Los libros, de la segunda de

\footnotetext{
${ }^{101}$ En la sección "Los Libros" de Los libros de la guerra ([2008] 2010) se vuelve patente el temprano interés por parte de Fogwill hacia la obra de Alberto Laiseca. A la reseña en el primer número de Pie de Página ya mencionada, cabría agregar los artículos "Las aventuras de la escuela de Viena" (publicado originalmente en la revista Vigencia, también en el año 1982); "Fractal: una lectura de Los Sorias de Alberto Laiseca" (en Tiempo Argentino, septiembre de 1983); "Política pública y literatura confidencial" (en el $n^{\circ} 54$ de Primera Plana de mayo de 1984) y "La otra literatura: los inéditos de Laiseca" (Tiempo Argentino, junio de 1986).
} 
las cuales Saer había sido un frecuente colaborador, ya no era válida para inteligir la literatura de la década del ochenta.

En el "informe especial" que es nota de tapa del n ${ }^{\circ} 30$ de El periodista de Buenos Aires (5 al 11 de abril de 1985) firmado por Jorge Madrazo y titulado "Crisis de la industria editorial" se dan las siguientes cifras:

Mientras en 1974 se editaron 49.640.000 ejemplares, con una exportación de 16.657.011 y una importación de 9.397.158 unidades, en 1981 la producción interna total a duras penas alcanzó los 14.190.401 volúmenes; contrariamente la importación batió ese año todos los récords: 55.086.208 ejemplares; al exterior, en cambio, sólo se enviaron 7.727.494 [...] en 1983 se siguió tocando fondo: se produjeron apenas 13.525.515 ejemplares y se exportó un lote insignificante de 5.302.341. Y como la era de la "plata dulce" y las aduanas abiertas de José Alfredo Martínez de Hoz habían quedado forzosamente atrás, las importaciones también cayeron en picada: sólo 3.754 .253 volúmenes entraron al país. (Madrazo 1985: 29-30)

En El capital de la cultura. Las industrias culturales en la Argentina (2008), Octavio Getino alerta sobre algunas números en materia de exportación de libros bajo dictadura que podrían llevar a confusión, y debilitar la idea de "crisis de la industria". Ejemplos son los "picos exportadores" de los años 1977 (ventas internacionales por más de 103 millones de dólares) y 1980 (por aproximadamente por 43 millones de dólares), cuando el promedio histórico se ubicaba entre 18 y 20 millones. En palabras de Getino:

La explicación de dicho salto radica en la mentalidad especuladora que guió buena parte del empresariado en esos años, estimulada a su vez por la política económica del gobierno de facto. De esa manera, numerosos exportadores locales se aprovecharon del súbito proteccionismo gubernamental que elevó hasta un $25 \%$ el reembolso, en efectivo, de los montos facturados por exportación.

Toneladas de material impreso, o no impreso - guías telefónicas, papel de desecho y todo lo que pudiera ingresar en los contenedores- fueron beneficiadas por dicho porcentaje, en cargas que podían desaparecer en el mar porque no necesitaban llegar a ningún otro punto de destino. Esta realidad era simultánea, además de la sobrefacturación ejercitada por el sector, como manera de contrarrestar los efectos del doble cambio monetario y la inseguridad económica, factores todos ellos que atentaron contra el desarrollo de la industria. (Getino 2008: 68)

La investigación de Daniel Chirom para el n 81 de El periodista de Buenos Aires (28 de marzo al 3 de abril de 1986), titulada "El mercado perdido anda en bicicleta", incluye el cuadro comparativo "Títulos publicados y tiraje durante los últimos 15 años", 
del que extraemos los datos correspondientes a los años 1974, 1976 y 1984. En 1974, los títulos registrados fueron 4.906, con un tiraje de 46.640.619 ejemplares; en 1976, los títulos registrados fueron 6.674, con un tiraje de 31.508.099 ejemplares, y en 1984, los títulos registrados fueron 4.591, con un tiraje de 16.844.220 (Cf. Chirom 1986: 28).

Sobre el tiraje por título (en el caso específico de la novela): en una entrevista para el suplemento “Cultura y Nación”, de Clarín publicada el 15 de abril de 1988, Jorge Naveiro (Presidente de la Cámara Argentina del Libro) redondea cifras para señalar que si en 1974 se editaban 20.000 ejemplares de una novela y hasta 60.000 de un best-seller, en 1984 un best-seller llega a 10.000 ejemplares y un autor argentino a 5.000 ejemplares. Las cifras correspondientes al año 1988 que dan José Luis Reyna y Ernesto Ferrando (de Gráfica Yanina), entrevistados en el mismo Suplemento, son aún más dramáticas: "los pedidos en general rondan los dos mil o tres mil ejemplares [...] en la época del 'Rodrigazo', había tiradas de 20, 30 y 50.000 ejemplares” (1988: 9).

¿Cuáles serían los motivos de esta retracción?

El principal sería el costo del papel: en el informe ya citado "Crisis de la industria editorial" que firma Jorge Madrazo, se señala que el papel nacional es de peor calidad y "hasta dos veces más caro que el traído del exterior": el papel importado tipo "Obra" -usado en la impresión de libros- sufre gravámenes del 38\% cuando su gramaje supera los 60 gramos. A esto se le suma la concentración en pocas manos de la industria papelera local, que hace que ésta pueda presionar a la Cámara Papelera para imponer un determinado precio. ${ }^{102}$ Dado que las editoriales argentinas adquieren en Papelera Sarandí más del $90 \%$ de esta materia prima, las condiciones de pago se vuelven leoninas:

Papelera Sarandí cobra el precio neto del producto si el pago es efectuado precisamente a los veinte días de la fecha de factura; si ésta es pagada a los diez días, hay un descuento del 5\%. Pero pasando los veinte casilleros del calendario la empresa aplica un plus del 20\% mensual, más el 3\% para gastos administrativos. (Op. Cit. Madrazo 1985: 32)

Como resultado (puesto que ninguna editorial está en condiciones de recuperar en diez días la suma equivalente al precio del papel, que a principios de 1984 constituye el $70 \%$ del precio de tapa del libro), se empobrecen los catálogos: nadie "arriesga" un

\footnotetext{
102 "Celulosa Argentina produce, junto con Ledesma y Massuh, el total del papel nacional necesario para cualquier edición; las tres cuartas partes de este lote los distribuye papelera Sarandí, mientras que el 20\% restante lo canalizan Copagra SA y Koch-Polito y Cía." (Madrazo 1985: 32)
} 
tiraje de 3000 o 4000 ejemplares por obras que puedan demorar de ocho o diez meses en venderse, limitándose por lo mismo a la reedición de títulos de salida rápida.

En 1987, los libros más vendidos llegan en promedio a 8000 ejemplares y los más importantes autores argentinos merecen tirajes de 3000 a 4000 ejemplares (en 1988, Sudamericana reedita Respiración artificial con un tiraje de 4000 ejemplares, lo que es ruidosamente celebrado por Daniel Samoilovich en el primer número de Babel). Daniel Divinsky, editor de Ediciones de la Flor, señala que el tiraje para un autor inédito es de apenas 2000 ejemplares. A este contexto, se le suma el auge del libro de auto-ayuda: entre diciembre de 1985 y marzo de 1986, Vivir, amar y aprender, de Leo Buscaglia (editorial Emecé) vende 28.000 ejemplares, lo que da un promedio de venta de 7000 ejemplares por mes (Cf. Op. Cit. Chirom 1986: 28).

El suplemento "Culturas" de Página/12 del 27 de diciembre de 1987 tiene como nota de tapa “Los libros del '87” y gira sobre la pregunta de cuáles fueron los libros más vendidos. Un dato llama la atención: contra el predominio del ensayo político coyuntural y el género testimonial entre los años 1983-1987, se observaría el relativo "repunte" del género novela durante los meses de noviembre-diciembre 1987. En una nota firmada por Norberto Noares, éste recoge el testimonio de Jorge Guiraud, jefe de ventas de Puntosur (que para entonces cuenta con un año y medio de vida) y de Matías Ayerza, jefe de prensa de la editorial Sudamericana, y señala los siguientes "hitos de venta" para la ficción: 35.000 ejemplares vendidos de A sus plantas rendido un león, de Osvaldo Soriano (que edita Sudamericana); 8000 ejemplares agotados de Partes de inteligencia, de Jorge Asís y 3000, también agotados, de Cuentos para tahúres, de Rodolfo Walsh (ambos editados por Puntosur).

Las comillas utilizadas para "hitos de venta" van a cuenta de que -en términos absolutos- la auto-ayuda y el ensayo político siguen ostentado las cifras más altas: Soares señala que Sexualidad femenina, de Luisa Leres lleva 70.000 ejemplares vendidos, mientras que la editorial Contrapunto contabiliza tres ediciones de 3000 ejemplares cada una de Civiles y militares, de Horacio Verbitsky.

Aún más: el "tenue avance de la narrativa" que señala Soares no significa la reversión del fenómeno, observable entre los años 1985 y 1990, del "alejamiento del lector nativo de la ficción [argentina]". Como señalan Alberto Castro y Jorge Warley, firmantes de "La escasez austral y la moda", también incluido en el suplemento "Culturas" de diciembre de 1987: si bien quedan aún lectores para la ficción, éstos se han volcado a los midcult, "una suerte de híbridos que adaptarían ciertos recursos de la 
literatura 'alta' a los gustos de un lector masivo, y que se benefician con un aura prestigiosa que [...] los convierte en los más vendidos" (1987: 3). Los autores señalan que El nombre de la rosa, de Umberto Eco (que es precisamente quien inventa el concepto de "midcult", retomando el concepto de "poshlust" de Vladimir Nabokov), volvió a ser en 1987 la novela extranjera más vendida, a la que le siguen los textos de Milan Kundera La insoportable levedad del ser y El libro de los amores ridículos. ${ }^{103}$

También en 1987, Juan Forn publica la novela Corazones cautivos más arriba por la editorial Emecé, con un tiraje de 2000 ejemplares. Situada en La Cumbre, Córdoba, transcurre en el invierno de 1972 y está protagonizada por un adolescente porteño que, al quedar huérfano de padre, es enviado a la provincia para que viva con su abuelo y una empleada doméstica, que tiene una hija de su misma edad. Las visitas traen noticias del mundo exterior: el hecho más crucial parece ser la inminente vuelta de Perón al país. Lo político, entonces, ingresa por desplazamiento (todo parece ocurrir en Buenos Aires y en el seno del mundo adulto) aunque también está presente en la historia íntima: la fallida historia de amor que une al protagonista con la hija de la mucama.

Como señala el mismo Juan Forn en su "Nota final" para la reedición por la editorial Alfaguara en octubre de 2001 de Corazones cautivos más arriba (que pasa a llamarse solamente Corazones), lo más llamativo en la novela es el uso de la segunda persona para evitar el "apelmazamiento del yo" y la "distancia y falsa imparcialidad de la tercera" (Forn 2001: 227), artificio copiado de Bright lights, big city, novela de Jan McInerney (que el autor había traducido al español para la editorial Emecé). Corazones cautivos más arriba (que toma su título de un verso de Roberto Juarroz) es básicamente una Bildungsroman que se corresponde punto por punto a la poética que, tres años más tarde, entrevistado para El Porteño por Jorge Warley, Forn va a caracterizar (tomando la expresión de Adolfo Bioy Casares) como de gentileza para con el lector:

La novela funciona en dos planos: el del argumento y el de los personajes en sí; uno y otro crecen y se transforman desde la primera a la última página del libro. Si esto funciona, creo que un libro consigue el único objetivo que para mí importa: conmover al lector. (Forn [Entrevistado por Jorge Warley] 1990: 38)

\footnotetext{
${ }^{103}$ En su respuesta a las "Tres preguntas clave a seis editores" planteadas por Juan Jacobo Bajarlía como parte de la investigación para la nota de tapa "La novela y la crisis" en el suplemento "Cultura y Nación" de Clarín del 15 de abril de 1988, el editor de El nombre de la rosa, Daniel Divinsky, señala que entre marzo de 1985 y abril de 1988 ha vendido 100.000 ejemplares de la novela firmada por Umberto Eco, en un área que abarca Argentina, Chile y Uruguay. (Cf. Divinsky [Entrevistado por Juan Jacobo Bajarlía] 1988: 2).
} 
Podría pensarse que este concepto fue el que guió (al menos en sus comienzos) el criterio de selección de autores para la colección "Biblioteca del Sur" de Planeta, que Forn dirigió entre 1990 y 1995, y cuya aparición marcaría precisamente un fugaz "regreso" del lector nativo a la ficción. En el próximo parágrafo precisaremos el contexto de aparición de dicha colección, confrontando su línea editorial con la de "Narrativas argentinas" de Sudamericana (cuyo asesor y editor fue Luis Chitarroni). En segundo lugar, nos detendremos en opiniones vertidas a comienzos de los noventa alrededor del género "novela" por parte de un "hermano mayor": Guillermo Saccomanno, que también ensayó una posible "fórmula" para los narradores argentinos frente a la adversa coyuntura editorial.

\subsection{Escribir, publicar y editar en un contexto de "concentración y polarización de la industria editorial" (1990-2000)}

En "La concentración y la polarización de la industria editorial (1990-2000)", Malena Botto se basa en un informe del Centro de Estudios para la Producción titulado "La industria del libro en la Argentina" (que abarca los años 1990-2004) y su propio trabajo de campo para caracterizar los noventa en términos de "paradoja": un crecimiento matemático de la industria del libro (con un promedio de edición anual de 52 millones de ejemplares), pero que "no se corresponde con una efectiva recuperación y circulación del libro del autor argentino, el que, por el contrario, va a ver agudizada la crisis en la que cayera a fines de los años setenta" (Botto 2006: 209).

En efecto: se observa un crecimiento de la actividad editoral entre 1991 y 1992 con la implementación de algunas medidas gubernamentales como fueron la desregulación económica, que permitía a los editores producir sus libros fuera del país y luego reexportarlos; la exoneración de impuestos a los derechos de autor y la eliminación de gravámenes a la exportación de libros, a lo que se sumaba una mayor estabilidad cambiaria. (Cf. Op. Cit. Getino 2008: 72).

De todas formas, el mayor índice de ventas no significa prosperidad para la ficción argentina, ya que como señala Guillermo Schavelzon en su editorial "Las futuras generaciones, comprometidas" para Clarín, publicado el 7 de marzo de 2002:

En los años '90 subió la venta de libros y eso se consideró crecimiento. El aumento no fue en la venta de libros científicos y técnicos, de enseñanza escolar o de literatura, sino en libros de regalo, en ediciones ilustradas, en títulos de autoayuda y de espiritualidad. Nuevas pautas de consumo y la concentración en centros comerciales sirvieron para aumentar el nivel total de ventas, pero eso no 
significó que se generaran nuevos o más lectores, ni que subiera el nivel cultural de la población. (Schavelzon 2002: 25)

Precisamente, este cambio de perfil del lector durante la década del noventa del siglo pasado (contrastándolo con el de los años '60-'70) es uno de los cuatro rasgos que según Sealtiel Alatriste en "El mercado editorial en lengua española" (1999) caracterizarían al período.

A saber: (1) la desaparición del "mercado homogéneo" de libros en lengua castellana por la concomitante desaparición del sistema de distribución argentino, que durante la época dorada de la industria editorial abastecía de libros tanto al resto de América como a España (el ejemplo por antonomasia es la distribuidora Tres Américas, dirigida por Isay Klasse entre 1958 y 1994); (2) la transformación del lector: del "lector de estirpe proustiana" al "lector consumidor"; (3) la concentración de la producción editorial en grandes Grupos, con la concomitante desaparición de la figura tradicional del editor, que es reemplazado por un consejo editorial donde llevan la voz cantante los expertos en marketing (y la simultánea aparición de una serie de "editoriales independientes", que, ajenas a esta lógica, apuestan a publicar "nueva narrativa"); y (4) el ingreso a fines de los noventa de la moda de las megalibrerías, que son manejadas por los mismos grupos, lo que marca una diferenciación muy importante en el consumo de libros en tanto "se especializan en libros de interés general y sobre todo novedades [...] un sistema que debe mantener altos stocks para responder a una demanda efimera y de ciclo muy corto" (Rama 2003: 128), fenómeno que, a su vez, significa la extinción del la figura del librero tradicional, capaz de proponer lecturas a sus clientes.

Sobre el punto tres, Octavio Getino agrega que, una vez fagocitadas por los grandes Grupos, el prestigio de las editoriales tradicionales deja de depender de su catálogo y selección de autores, pasándose a aplicar la lógica propia de los holdings:

Los holdings exigen que la rentabilidad del negocio de la industria editorial sea parecida o idéntica a la de las otras industrias y medios que maneja, en términos generales, más lucrativos que la industria del libro, por lo cual, sitúan las nuevas tasas de ganancias en una franja comprendida entre $10 \%$ y $15 \%$, o sea, tres o cuatro veces más de lo que era tradicionalmente la actividad editorial. En consecuencia, el libro aparece en sus estrategias económicas como una simple manufactura industrial, a la cual hay que exprimir económicamente, aunque ello no represente ningún aporte significativo al desarrollo de la cultura local y menos aún, de la literatura o de la educación y la cultura en general. (Op. Cit. Getino 2008: 77) 
En este contexto adverso, los narradores argentinos, tanto los nóveles como los ya publicados, se ven constreñidos a ofertar sus manuscritos a los pocos conglomerados que van comprando prácticamente todas las editoriales: el grupo colombiano Carvajal, que desembarca en 1992 través de la editorial Norma y que en 1991 había comprado la editorial Tesis y que, tres años más tarde, comprará Kapelusz; el Grupo Planeta de Barcelona, "pionero" en el proceso de concentración editorial (en 1982 había comprado Seix Barral y Ariel y en 1989, Ediciones Deusto), que en 1991 compra Espasa-Calpe, y el Grupo Bertelsmann, que en abril de 1996 -a través de su división editorial Plaza y Janés- adquiere el 80\% del sello Lumen, una pequeña editorial fundada en 1962 por la escritora catalana Esther Tusquets y en 1997, Random House, la casa más prestigiosa de Estados Unidos, y se asocia en un 50\% para la edición de libros en español con Mondadori, propiedad de Silvio Berlusconi, que controla un tercio del sector editorial italiano (Cf. Op. Cit. Ruiz 2005: 24). Finalmente, el Grupo Bertelsmann adquiere en febrero de 1998 el 60\% de Sudamericana, por 5, 4 millones de dólares. ${ }^{104}$

Entrevistado en 2011 por Silvina Friera con motivo de la celebración de la tercera edición del Festival Internacional de Literatura de Buenos Aires (Filba), Luis Chitarroni resume la supuesta confrontación entre "babélicos" y "planetarios" a una cuestión de editoriales:

Como toda dicotomía, fue más aparente que real. Babel era una revista amplia de criterios; los babélicos éramos internacionalistas, pero tal vez el más babélico de todos era un escritor que no estaba en Babel, Rodrigo Fresán, el mejor lector de lectura anglosajona. En realidad, la pelea fue entre el grupo Planeta y la colección de Sudamericana, entre Juan Forn y yo. Creo que este tipo de dicotomías favorecen mucho. (Chitarroni [Entrevistado por Silvina Friera] 2011: 31)

Con Luis Chitarroni como asesor y editor de la colección "Nuevas narrativas", Sudamericana publicó entre los años 1986 y 1998 los siguientes volúmenes (incluidas reediciones): Enciclopedia secreta de una familia argentina, de Marco Denevi; La lección del maestro y Fe de ratas, de Jorge Asís; Crónica de amor, de locura y de muerte y Serie negra, de Jorge Manzur; A sus plantas rendido un león, Cuarteles de invierno, Cuentos de los años felices, El ojo de la patria, No habrá más penas ni olvido,

\footnotetext{
${ }^{104}$ Quizá el más acabado símbolo de "época de oro" de la industrial editorial en Argentina, que abarca de 1938 a 1953 (Cf. De Diego 2001; 2006), sea, precisamente, la editorial Sudamericana, fundada en diciembre de 1938 por Antonio López (también fundador de Edhasa de Barcelona -la filial española de Sudamericana- y Hermes de México), quien asumió las tareas de gerente ejecutivo y convocó al legendario Francisco "Paco" Porrúa como editor. Durante los años sesenta del siglo pasado, Sudamericana detenta una fuerte presencia en el campo cultural, y la inteligencia de Porrúa hace que en 1967 sea la primera en editar Cien años de soledad, con un visionario tiraje inicial de 8000 ejemplares (altísimo para un escritor desconocido). Ya en Barcelona, Porrúa dirigió Edhasa entre 1977 y 1993.
} 
Triste, solitario y final y Una sombra ya pronto serás, de Osvaldo Soriano; Divertimento y Los reyes, de Julio Cortázar; El sótano, de María Angélica Bosco; La señorita Ordoñez, de Marta Lynch; La fiesta inmóvil, de Federico Moreyra; A las 20:25 la señora entró en la inmortalidad, de Mario Szichman; El ganso parlante, de Fernando López; Ondina y Supertramp, de Emilio Rodrigué; El rey de la torre, de Gabriel Barnes; Viajando se conoce gente y Casa de geishas, de Ana María Shua; La bahía de silencio, de Eduardo Mallea; El basural, de Carlos Gorostiza; La condición efimera, de Néstor Sánchez; Prisión perpetua, Respiración artificial y La ciudad ausente, de Ricardo Piglia; El amante de las películas mudas, de Pablo Torre; El curandero del cuarto oscuro y Paredón, paredón, de Gabriel Báñez; Adán Buenosayres, El banquete de Severo Arcángelo y Megafón o la guerra, de Leopoldo Marechal; El laberinto y La casa, de Manuel Mujica Lainez; El hambre de mi corazón, de Martha Mercader; La noche anterior, de Martín Caparrós; El agua electrizada, Un poeta nacional y Amor a Roma, de Carlos E. Feiling; Infierno Albino, de Sergio Bizzio; El ser querido, de Daniel Guebel; Las invasiones inglesas, de Gloria Pampillo; El amparo y El perdón, de Gustavo Ferreyra; Novela negra con argentinos y Simetrías, de Luisa Valenzuela; Lo más oscuro del río y La música de Frankie, de Luis Gusmán; El náufrago de las estrellas, Fuegia y No se turbe vuestro corazón, de Eduardo Belgrano Rawson; La mancha de luz, de Luisa Axpe; Prólogo anotado, de Federico Jeanmaire; Amores brutales, de Carlos Chernov; Restos diurnos y Los pichiciegos, de Fogwill; Matilde, de Daniel Guebel; Más allá del puente, de Ángel Bonomini; El sexto día, de Néstor Barreiro; Soy paciente, de Ana María Shua; Coney Island, de Damián Tabarovsky; Caravana, de María Martoccia; Las delicias del jardín, de Solange Camauër; El ciudadano de mis zapatos, de Luis María Pescetti, y Planet, de Sergio Bizzio. ${ }^{105}$

La reedición de "autores históricos" de Sudamericana como Osvaldo Soriano y Julio Cortázar dentro de la Colección facilitaría, por arrastre, el ingreso en el mercado de determinados escritores argentinos, que, pertenecientes a la "generación ausente",

\footnotetext{
105 Antes de entrar a trabajar en Sudamericana, Chitarroni escribió la contratapa a El pudor del pornógrafo (Sudamericana 1984), primera novela en ser publicada de Alan Pauls (en momentos en que Enrique Pezzoni era editor de dicha Editorial). En abril de 2014, la novela fue reeditada por Anagrama. A dicha reedición se le dedica un espacio considerable en el "Radarlibros" correspondiente al 27 de abril de 2014, donde Pauls hace una reconstrucción ("30 años después") de los avatares de escritura y publicación de su novela. Allí también confiesa que escribió El pudor del pornógrafo para ganar un premio literario, mencionando una aspiración que fue compartida por todos los escritores de la "generación ausente" en un contexto editorial adverso, donde las únicas posibilidades para lograr la condición de "autor édito" eran un premio, un subsidio o la autoedición. Sobre las desventuras del escritor inédito, Jorge Warley coguionó con Eduardo Berti el cómic "El hombre que quería publicar" para el n 61 de El Porteño (enero de 1987).
} 
mantenían hasta entonces su condición de inéditos. El hecho de que los grandes grupos admitan un pequeño margen de pérdida explica cómo Rodrigué, miembro de la familia fundadora de la primitiva Editorial Sudamericana, haya podido mantener activa hasta 2004 inclusive la deficitaria colección "Narrativas Argentinas", con tirajes que oscilaron entre los 2000 y 3000 ejemplares.

La colección "Biblioteca del Sur" tuvo el financiamiento del grupo Planeta. Bajo la dirección de Juan Forn, se publicaron o reeditaron: La buena nueva de los Libros del Caminante y Muchacha punk, de Fogwill; Maluco, de Napoleón Baccino Ponce de León; Esa maldia lujuria, de Antonio Elvio Brailovsky; La guerra del amor, de Tomás Abraham; La muerte de un hombrecito, de Juan Carlos Martelli; Acerca de Roderer, de Guillermo Martínez; El factor sentimental y La vida brillante, de Rodolfo Rabanal; Polaroids e Historia de Teller, de Jorge Lanata; La mujer en la Muralla y El jardín de las máquinas parlantes, de Alberto Laiseca; Oscuramente fuerte es la vida, Fuego a discreción, Siete de oro, La tierra incomparable y Gente del bajo, de Antonio Dal Masetto; Historia argentina, Vidas de santos y Trabajos manuales, de Rodrigo Fresán; Obra completa, de Roberto Arlt; La mano del amo, La novela de Perón y Santa Evita (1995: con diez ediciones [i.e. reimpr.] el mismo año de su publicación), de Tomás Eloy Martínez; El muchacho peronista, de Marcelo Figueras; Rapado, de Martín Rejtman; Teoría del cielo, de Arturo Carrera y Teresa Arijón; Son cuentos chinos y Urracas de Luisa Futoransky; Konfidenz, de Ariel Dorfman; Los crímenes de Van Gogh, de José Pablo Feinmann; Sucesos Argentinos, de Battista Vicente; Imposible equilibrio, de Mempo Giardinelli; Mujeres de ojos grandes y Puerto libre, de Ángeles Mastretta; Don Galaz de Buenos Aires, El brazalete, Invitados en el paraiso, El viaje de los siete demonios, Los ídolos, El escarabajo, Cuentos inéditos y Cecil, de Manuel Mujica Láinez; Bajo bandera y Animales domésticos, de Guillermo Saccomanno; La patria equivocada, de Dalmiro Saenz; El dock, de Matilde Sánchez; Tigre hotel, de Alejandro Manara; Cárcel de árboles, de Rodrigo Rey Rosa; El jardín de las dudas, de Fernando Savater; Ciudad sin noche, de Ernesto Schoo; Cuando digo Magdalena y Músicos y relojeros, de Alicia Steimberg; El ahijado y Manucho. Una vida de Mújica Lainez, de Oscar Hermes Villordo, y Prontuario y Claudia conversa, de David Viñas. Al abandonar sus funciones, Forn deja aprobados y en prensa Velcro y yo, de Rejtman y El mal menor, de Carlos E. Feiling, que salen en 1996.

Si bien los tres primeros años de existencia de Biblioteca del Sur son realmente exitosos (volviendo a Nadar de noche: su cuarta reedición, fechada en octubre de 1993, 
tiene una tirada de 11.000 ejemplares), en 1994 la colección ve mermar sus ventas y cambia su diseño intentando recuperarse, aunque no lo logra. Finalmente, poco antes de verse forzado a renunciar, Forn republica Santa Evita (1995), de Tomás Eloy Martínez dentro de la Colección, un best-seller "inevitable", habida cuenta del "efecto arrastre" de La novela de Perón (publicada en 1985 y reeditada por Planeta en 1991, traducida a nueve idiomas y también una "mejor vendida").

Según Elsa Drucaroff en Los prisioneros de la torre. Política, relatos y jóvenes en la postdictadura (2011), el fracaso de la colección Biblioteca del Sur se debe a que “defrauda las expectativas del lector" (puesto que no mantendría su promesa de dar a conocer "los nuevos valores de la literatura local"). En efecto: el mismo año en que tiene lugar el primer gran éxito de ventas con Historia argentina, de Fresán (un autor que indudablemente responde a la línea editorial propuesta), Forn publica una biografía (Manucho, una vida de Mujica Láinez, de Oscar Hermes Villordo), coedita las obras completas de Roberto Arlt junto a Ediciones Carlos Lohlé y reedita a Mújica Lainez ("autor histórico" de Seix Barral, lo que explica su fuerte presencia -a primera vista totalmente extemporánea- en la Colección).

Por lo general, la estrategia editorial de los grandes grupos consiste en comprar la segunda o tercera obra de un escritor de éxito probado, sin arriesgarse con autores nuevos. Como señala Getino:

... para las finalidades de los grandes conglomerados, cada título debe ser rentable por sí mismo, dejando atrás los criterios de que un libro pudiera subvencionar a otros libros $[\ldots]$ los concursos y premios literarios [...] suman su cuota de marketing para incrementar la rentabilidad de determinados títulos, aunque muchos de los autores beneficiados desaparezcan luego del mercado, sin que se produzca una verdadera renovación de valores literarios. (Op. Cit. Getino 2008: 77)

Desde dicha lógica, se entiende la creación en 1992 del "Premio Planeta de Argentina", dotado de 40.000 dólares: la versión local del Premio Planeta de Novela, creado por José Manuel Lara Hernández, que se concede en Barcelona desde 1952. En su versión local, el Premio favorece en su primera edición a Alicia Steimberg, por Cuando digo Magdalena. Luego, es otorgado a Carlos Chernov, por Anatomía humana (Edición 1993); a Antonio Dal Masetto, por La tierra incomparable (Edición 1994) y a Vicente Battista, por Sucesos argentinos (Edición 1995). Una vez desvinculado Juan Forn de la colección Biblioteca del Sur, son premiadas las novelas: El general, el pintor y la dama, de María Esther de Miguel; Plata quemada, de Ricardo Piglia (acusación de 
fraude mediante, a la que volveremos en la coda correspondiente al próximo capítulo); Pequeña música nocturna, de Liliana Díaz Mindurry; Vuelan las palomas, de Carlos Gorostiza, y La arquitectura de los ángeles, de Liliana Escliar.

El segundo factor que explicaría el éxito de la colección es la aparición a partir de los noventa de la nueva figura de "escritor-performer", del escritor como personaje público que aparece en los medios. En palabras de Forn:

Todo es culpa de los '90, y me hago cargo de algunas cosas que hice impune y alegremente, con buena voluntad. Esto de vender a los autores, de vender literatura argentina, hacerla trendy, atractiva, y generarle una caja de resonancia, es peligroso, porque empuja a al escritor a la farandulización de sí mismo. Se trabajó mucho con el concepto de éxito en aquellos años, y creo que fue contraproducente. En mi defensa, puedo decir que al menos publicaba buena literatura. (Forn [Entrevistado por Pedro Pablo Guerrero] $2012 \quad$ http://www.letrasdechile.cl/Joomla/index.php/entrevistas/2136-2136, consultado el 12.5.2013)

El tercer factor es el mecanismo de "auto-bombo" que rodea la aparición de cada uno de los best-sellers de Biblioteca del Sur, favorecido por la fuerte presencia de sus autores en los medios. Polaroids (1990) es publicado y alcanza el rango de best-seller local cuando Lanata no sólo es un joven escritor (que ha logrado publicar obra por segunda vez), sino además el fundador del diario Página/ 12 (año 1987), que bajo su dirección llegaría a la cifra récord de 100.000 ejemplares.

En el primer editorial de "Primer Plano", fechado el 9 de junio de 1991 y titulado "La loca de la casa", Tomás Eloy Martínez (editor en funciones hasta agosto de 1995), afirma lo siguiente:

Este suplemento de Página/ 12 tiende a demostrar que, pese a todo, la cultura argentina está más viva que nunca: en estado de efervescencia, de creación. Trata de poner en primer plano los nombres y las ideas que ninguna persona inteligente de este país debiera pasar por alto. Y, sobre todo, pretende reconquistar algo del terreno que los gobiernos y las corporaciones vernáculas han perdido. (Martínez 1991a: 1)

Dos son las instancias en que desde "Primer Plano" se intenta claramente influir en el público lector: desde la sección "Carnets" (definida como "las obras que el lector no se debe perder: libros, films, plástica, espectáculos de teatro o televisión, conciertos [...] no sobra ninguno de los que está") y mediante la "Lista de best-sellers", que se publica acompañada por las "Recomendaciones del editor", que adoptan la forma de breves reseñas. 
A un año de la publicación de Polaroids, Lanata no sólo es entrevistado el 4 de agosto de 1991 (“Cómo revelar polaroids") y su título reseñado en "La literatura de la realidad" que firma Susana Rotker una semana más tarde, sino que -el 18 de agostorecibe el espaldarazo de Martínez, que desde la sección "Recomendaciones del editor" afirma que Polaroids es “... obra mayor de un género rico en antecedentes argentinos: las ficciones de la vida real" (1991c: 4).

El sistema de "auto-bombo" y la figura de amistosa tutela ejercida por los "hermanos mayores" parecen calcados de Babel, revista de libros, aunque lo que cambia en "Primer Plano" es que allí se entremezclan de forma aún más pronunciada no sólo las generaciones, sino también los miembros de los tres grupos culturales que la bibliografía secundaria ha presentado como irreconciliablemente enfrentados entre sí: "planetarios", "babélicos" y los “jóvenes de los '90 nucleados alrededor de $V$ de Vian" (Cf. Berg 1996; Patiño 1997; Saítta 2004 y 2005; Botto 2006; Sager 2007).

En efecto: para "Primer Plano" escriben Tomás Eloy Martínez (su editor), Ricardo Piglia, Beatriz Sarlo, Oscar Terán, Jorge E. Dotti, Nicolás Rosa, Tulio H. Donghi, Miguel Briante, Alberto Laiseca, Daniel Samoilovich, Graciela Speranza, Marcos Mayer, Claudio Zeiger, Karina Galperín, Sergio Olguín, Cecilia Absatz, Gabriela Esquivada, Josefina Delgdo, José Nun, Miguel Russo, María O’ Donnell, Jorge Monteleone, Federico Monjeau, Sergio Wolf, Rodrigo Fresán, Marcelo Figueras, Elvio E. Gandolfo, Luis Chitarroni, Jorge Lanata, Rolando Graña... y publica poemas Néstor Perlongher. Su editor elogia y promociona a diferentes autores de manera plural: quince días antes de recomendar Polaroids, Tomás Eloy Martínez había recomendado La liebre, "uno de los más memorables momentos de toda la obra de César Aira" (Op. Cit. Martínez 1991b: 4).

En "Primer Plano" se observa una constante preocupación por el aspecto material del libro: las reseñas, como en Babel (y en Los libros) aparecen igualmente acompañadas por el precio de tapa. En el n 2 (16 de junio de 1991) "Garganta Profunda" firma una provocativa nota titulada “¿Cuánto vale un escritor?”, donde se revelan las cifras exactas de los anticipos que cobran algunos de los más renombrados escritores argentinos. A saber: Adolfo Bioy Casares (20.000 dólares por la reedición de Una muñeca rusa, vendida a Tusquets); Tomás Eloy Martínez (recibe 25.000 dólares de Alianza de España); Osvaldo Soriano (factura 25.000 por la edición argentina de Una sombra ya pronto serás y 40.000 dólares por su edición italiana); Piglia (recibe 25.000 
dólares por una novela y un libro de ensayos, que vende a Sudamericana). Contra estas cifras, "Garganta Profunda" señala que: "Planeta, por su parte, adelanta contra-entrega de manuscrito -costumbre poco frecuentada en estas latitudes, donde se supone que la edición es suficiente recompensa para el novato- unos 500 dólares a escritores novatos y no tanto".

En este contexto económicamente muy adverso, se vuelve inteligible la preocupación por marcar el deseable derrotero que debería tomar la narrativa nacional, que se vuelve explícita en el desvío que sufre el debate "La Argentina como escenario", inicialmente planteado con eje en la "novela exótica" (tema del $1^{\circ}$ Encuentro de Escritores Argentinos celebrado en Miramar, reseñado en el suplemento "Primer Plano" correspondiente al $1^{\circ}$ de diciembre de 1991). Frente a las tres preguntas que se formulan como punto de partida para el mismo (“¿Qué le resulta más fácil de representar en su literatura: lo conocido o lo desconocido, lo familiar o lo exótico?"; "Si tuviera que establecer una corriente afín o simpática de obras argentinas en las que el país esté representado, ¿qué obras mencionaría?” y “HHay un idioma de los argentinos?”), tanto Martín Caparrós como Luis Gusmán eligen focalizar en el aspecto económico, quedando por lo mismo soslayado el tema de la "novela exótica".

Mientras Caparrós aventura la hipótesis de que "la tensión de la literatura con el mercado reemplaza a la tensión con la política" (ya citada en la "Introducción" a nuestro trabajo), Gusmán vuelve a la vieja antinomia en Literal ("nueva escritura o populismo"), aunque reformulándola en términos económicos:

Cuando surge un idioma que se caracteriza por la homogeneidad y hace que el escritor sea reemplazado por los comunicadores sociales, es necesario que la literatura le devuelva a la palabra ese lugar fundante, que perdió en la economía de la devaluación. (Gusmán 1991: 7)

Un año más tarde, Miguel Russo entrevista nuevamente a Guillermo Saccomanno para La Maga. Noticias de Cultura. ${ }^{106}$ El novelista desarma la ecuación "jóvenes narradores igual a nueva narrativa":

\footnotetext{
${ }^{106}$ La Maga ( ${ }^{\circ}$ 1: septiembre de 1991- $\mathrm{n}^{\circ}$ 249: septiembre de 1998) nació en el seno de la Escuela de Periodismo TEA y tuvo como director a Carlos Ares. Su último dueño, el dirigente racinguista Daniel Lalín, resolvió cerrarla por motivos económicos. Había empezado como un emprendimiento prácticamente dedicado a notas y eventos vinculados con el arte y la cultura, aunque luego se transformaría en una suerte de órgano de denuncia contra los desmanes del menemismo, hecho que seguramente alejó a muchos anunciantes, propiciando el desenlace final. Fue relanzada en octubre de 2011 con un tiraje de 15.000 ejemplares, aunque apenas logró sacar tres números, y cerró definitivamente en enero de 2012.
} 
[Esta falsa opción de escribir o no para el mercado] tiene que ver con aquellos intelectuales que adscribieron al alfonsinismo en el '83. Ahí empezó la truchada [...] Los jóvenes posmodernos adoptaron una actitud dandinistica al afirmar que había llegado una nueva época y por lo tanto una nueva forma de narrar y de usar los artilugios del lenguaje. Por entonces se esperaba que aparecieran sus obras, sus grandes novelas, y resultó que los que aparecieron con obras importantes eran todos veteranos: Fogwill con los Pychy Cyegos (sic!), Tomás Eloy Martínez con La novela de Perón, Andrés Rivera con La revolución es un sueño eterno y Miguel Bonasso con Recuerdos de la muerte. Cuatro novelas paradigmáticas de veteranos y uno se preguntaba dónde estaba la nueva narrativa [...] Están los que cuentan y los que no tienen nada que contar. (Saccomanno 1992: 29; nuestro énfasis)

Saccomanno describe la cuestión en los por él muy queridos términos arltianos de "imponerse por prepotencia de trabajo":

En un principio la división ["escribir para o contra el mercado"] se creó, estúpidamente, entre los que se reunieron alrededor de la revista Babel y los no babélicos. Luego se dividió entre una editorial y otra [...] Lo importante es quiénes están produciendo, quiénes están narrando. (Op. Cit. Saccomanno 1992: 29; énfasis en el original)

Sin embargo, estas afirmaciones no aciertan en lo evidente: la lógica de los grandes grupos ha inficionado las poéticas. Escasos dos años más tarde, La Maga titula "Cómo se vende la cultura" la nota de tapa correspondiente a su $n^{\circ} 121$. El subtítulo no puede ser más elocuente: "El supermercado de los productos artísticos". En el epígrafe de presentación del tema -que no se limita a la literatura, sino que también indaga la utilización de la investigación de mercado en la escena teatral y la industria discográfica- se explica que:

La lógica de la economía de mercado parece haber llegado también al territorio de la cultura. Cada vez es más frecuente la utilización de estrategias comerciales de venta, publicidad de productos culturales que hasta no hace mucho carecían de ese tipo de planteamientos. (La Maga 121 1994: 2)

Entrevistado por Miguel Russo, el gerente de Planeta Ricardo Sabanes explica que "cada producto-libro que se publica tiene un plan de marketing (venta, promoción y publicidad) predefinido" (1994: 2). En concordancia con lo dicho (como mea culpa) por Juan Forn en su reconstrucción retrospectiva del período antes citada, Sabanes señala que "nuestras campañas no se montan en los libros, sino en los autores [...] vendemos al autor y la imagen que tiene ante su público" (Ibid.). En sus palabras:

El marketing tiene, en mundo de la cultura, una fama de segunda. Se cree que cualquier cosa se puede marketinear menos la cultura, ya que todavía se tiene el concepto romántico de cultura. Nosotros en Planeta suponemos que los autores quieren vivir de lo que escriben. Para eso, entre otras cosas, hay 
que vender muchos ejemplares. En el mundo competitivo de hoy, hasta autores como García Márquez, Osvaldo Soriano o Víctor Sueiro, que venden muchísimo, tienen detrás un marketing específico y arrasador. La investigación de mercado no es sólo para gaseosas o pantalones. Un libro también es un producto posible de marketinear. (Sabanes [Entrevistado por Miguel Russo] 1994: 2)

A continuación, el gerente de Planeta se jacta de estar en condiciones de saber -mediante la investigación de mercado- "qué es lo que está esperando la gente hoy en la ficción argentina". Sabanes describe el triunfo de los llamados "creativos de la empresa" y el editing por sobre la figura del editor tradicional:

Hasta que nosotros empezamos, no estaba consolidada la idea de contratar libros anticipados o de trabajar el texto junto al autor en trabajos de edición. Allí innovamos y producimos un cambio. No nos sentamos a esperar que los autores traigan sus originales sino que los incentivamos para que trabajen determinados temas que sabemos están dando vueltas entre el público. Eso hace cualquier editor de un país normal, y Argentina está empezando a serlo. (Sabanes [Entrevistado por Miguel Russo] 1994: 2)

2.6. Diversas acepciones de "lo nuevo". La experiencia cooperativa de Ediciones Tantalia en el contexto del surgimiento de las "nuevas editoriales idependientes" de los años noventa

Contra su utilización durante las décadas del setenta y comienzos de los ochenta como sinónimo de "nueva escritura" o "vanguardia", "lo nuevo" se transforma durante la década del noventa en sinónimo de novedad: "nuevo" es todo libro durante un máximo de seis meses, esto es, mientras se mantenga en exhibición en el sector de novedades. No obstante, las dos acepciones de "lo nuevo" mencionadas continúan conviviendo en tensión, en un sentido también literal (ya adquirió estatuto de mito el enfrentamiento entre Juan Forn y Fogwill, con motivo de que el primero se atreviera a hacerle un editing inconsulto a La buena nueva de los Libros del Caminante). Por último, "lo nuevo" es un concepto passe-partout, utilizado una y otra vez para meramente convocar a la discusión.

Ejemplo de esto último es el "Primer diccionario de la joven narrativa argentina", que el suplemento "Primer Plano" propone como nota de tapa el 7 y 14 de febrero de 1993. Ordenado alfabéticamente y en dos entregas (de la letra "a" a la "f" y de la "g" a la "z"), se propone dar cuenta de un grupo de escritores cuyas edades "van desde los veinticinco a los cuarenta años, publicaron tras el restablecimiento de la democracia en editoriales de primera línea de Buenos Aires”. Es notoria la importancia otorgada a la instancia de publicación, contra el supuesto prestigio de la condición de "inédito voluntario" durante la década del ochenta. 
Los elegidos son: Daniel Ares, Sergio Bizzio, Esteban Buch, Martín Caparrós, Emilio Cócaro, Esther Cross, Sergio Chejfec, Luis Chitarroni, Pablo de Santis, Carlos E. Feiling, Marcelo Figueras, Juan Forn, Rodrigo Fresán, Edgardo González Amer, Daniel Guebel, Daniel Gutman, Federico Jeanmaire, Jorge Lanata, Guillermo Martínez, Alan Pauls, Martín Rejtman, Matilde Sánchez y Miguel Vitagliano. ${ }^{107}$

A estos "hacedores de la nueva narrativa argentina" se les plantean las siguientes preguntas: (1) “¿Qué esperaba de la literatura cuando era lector y qué espera ahora que es, además, escritor?”; (2) “¿Reconoce alguna tradición literaria? ¿Cuál es el libro de autor nacional que más influyó en su escritura? ¿Cuál no querría escribir nunca?”; (3) ¿Leyó a los demás escritores de su generación? ¿Se siente partícipe o al margen de lo que escriben?”; (4) “Cuando escribe, ¿piensa a veces en algún tipo de lector? ¿Y en su editor?”; (5) “¿Establece relaciones entre sus textos y su ideología? ¿Considera necesario ese vínculo?".

Dos "mayores" comentan las respuestas dadas por los "jóvenes escritores": Alicia Steimberg ("Lo bueno, si nuevo": en la primera entrega del "diccionario") y Miguel Briante ("Una visión de mundo": el 14 de febrero de 1993). Ambos coinciden en poner en duda los criterios sobre los que se ha construido el "diccionario".

En su intervención, Briante insiste en señalar que "el escepticismo en general -y esa distancia con el mundo de las pasiones, políticas o de las otras- es una de las constantes de los nuevos narradores" (1993: 8), al mismo tiempo que da un mentís a la idea de que existe una "nueva narrativa argentina" (según Briante, se trataría de una mera maniobra publicitaria del mercado editorial). Del comentario de Steimberg, interesa la explícita puesta en cuestión del (casi naturalizado) vínculo entre los términos “jóvenes narradores” y “nueva narrativa”: “№ sería más lógico esperar que las cosas, literariamente nuevas, las aporten los que tienen más experiencia, más años encima de este menoscabado acto de escribir?" (Steimberg 1993: 8).

En sintonía con esta polémica, Miguel Russo titula "Un debate sobre las nuevas tendencias en literatura argentina" su reseña sobre el $1^{\circ}$ Encuentro Nacional de Narradores, celebrado en Villa Gesell el $1^{\circ}$ de abril de 1993. De la mesa "Nuevas

\footnotetext{
${ }^{107}$ En el apartado "Los más nuevitos" se incorporan ocho nombres más al "diccionario" (aunque éstos no son convocados a responder preguntas ni se les publica fragmentos de obra): Carlos Antognazzi, Marcelo Birjamer, Leopoldo Brizuela, Manuel Lozano, Andrea Nacho, Ingrid Proietto, Damián Tabarovsky y Gustavo Nielsen. La inclusión está motivada porque -junto con Buch, de Santis, Figueras y Martíneztodos ellos han sido invitados a España a participar del seminario de intercambio "Literatura y compromiso: nuevos desafíos, nuevas respuestas", organizado por el Instituto de la Juventud de España y el Instituto Nacional de la Juventud argentino, con el objetivo de "propiciar el encuentro y la cooperación entre jóvenes españoles y jóvenes de otros países de Europa y América Latina".
} 
tendencias de la narrativa contemporánea argentina", que constituye el tema convocante, participan Juan Martini, Carlos E. Feiling, Liliana Heker, Guillermo Martínez, Esther Cross, Daniel Guebel y Rodrigo Fresán. En la misma, Fresán nuevamente propone -en consonancia con Forn y Saccomanno- una estética de "seducción del lector": "Si yo me exijo nombrar o adscribir a alguna tendencia actual, pienso invariablemente en aquella que tiene una nueva consideración para con el lector [...] Esa especie de seducción hacia el lector no debe implicar ninguna culpa" (Fresán [Entrevistado por Miguel Russo] 1993: 45).

Otro de los integrantes de la mesa insiste en plantear la cuestión bajo la antinomia "populismo VS. vanguardia", heredada de determinados "hermanos mayores": “... hoy puede abominarse Rayuela, ya que no hay nada más espantoso que las modas de ayer. Lo que discuto es si los narradores van a inventar una nueva moda sustitutiva o se van a dedicar a escribir literatura" (Guebel [Entrevistado por Miguel Russo] 1993: 45).

Luis Chitarroni vuelve a echar mano de la categoría de "lo nuevo" (entendido ahora en términos de "vanguardia") para construir la argumentación de su trabajo "Narrativa: nuevas tendencias. Relato de los márgenes", que publica también en 1993 en Cuadernos Hispanoamericanos, cuyo n. 517-519 lleva el subtítulo de "La cultura argentina. De la dictadura a la democracia”.

Trazando una genealogía que arranca con Siberia Blues (1968), de Néstor Sánchez, "la novela que inaugura el tránsito hacia lo nuevo" (1993: 437), Chitarroni realiza una selección de autores que publicaron en el mítico año 1973: Osvaldo Lamborghini (Sebregondi retrocede); Manuel Puig (The Buenos Aires-Affair) y Luis Gusmán (El frasquito). ${ }^{108} \mathrm{Si}$ la tradición a reivindicar es "lo nuevo", el ensayista se vuelve magnánimo al momento de definir cuáles serían "los herederos": Alan Pauls (con El pudor del pornógrafo y El coloquio: "Pauls libra su batalla privada contra las influencias y sale victorioso"); Daniel Guebel (de su producción, Chitarroni sólo rescata La perla del emperador: "una de las texturas más ricas del arte de narrar que conozca la literatura de la década del ochenta"); Rodrigo Fresán (Historia argentina: "un punto alto de la nueva narrativa”); Juan Forn (“Memorándum Almazán” y Nadar de noche: "un proyecto riguroso y feliz"); Carlos E. Feiling (El agua electrizada: "una sugestión

\footnotetext{
${ }^{108}$ Chitarroni también señala (aunque muy al pasar) que 1973 fue también el año de publicación de Triste, solitario y final, de Osvaldo Soriano. Por otro lado, éste es también el año de publicación de otro "bestseller": Mal don, de Beatriz Guido (que Chitarroni ni siquiera menciona).
} 
muy convincente"); Matilde Sánchez (La ingratitud); Sergio Chejfec (Lenta biografía, Moral y El aire); Sergio Bizzio (El divino convertible, Infierno albino): "novelas de primera magnitud" (Cf. Op. Cit. Chitarroni 1993: 442-444).

Lo "nuevo" fue, por último, la divisa de las llamadas "editoriales independientes" surgidas en los años noventa. La mayoría de ellas, como señalan Adriana Astutti y Sandra Contreras en "Editoriales independientes, pequeñas... Micropolíticas culturales en la literatura argentina actual" (2001), definieron su "independencia" en relación a los conglomerados de carácter transnacional, fundamentalmente, frente al imperativo de la máxima rentabilidad, otorgándole prioridad a la calidad y el valor cultural del libro. Por otra parte, si la homogeneización del gusto (en el marco de la "globalización cultural") es el principal objetivo de los grandes grupos para obtener el máximo de rendimiento económico, las “editoriales independientes" se esforzarán por garantizar la diversidad y escapar al principio de estandarización. Contra las nuevas figuras del creativo editorial y los investigadores de mercado, aquí se trata de "crear catálogo" con una infraestructura mínima y tirajes que oscilan entre los 700 y 1000 ejemplares. Los principales desafíos son la distribución y el asegurarse una rentabilidad mínima, que permita simplemente recuperar la inversión para continuar publicando nuevos títulos (Cf. Op. Cit. Astutti/ Contreras 2001).

Lo más característico de los años noventa del siglo XX fueron las editoriales autogestionadas de poesía (que tomaron como modelo las revistas de producción artesanal La mineta y Trompa de Falopo: VER Moscardi 2011). ${ }^{109}$ Entre las más representativas se cuentan Editorial Siesta (creada en 1997 y dirigida desde 1998 por Santiago Llach y Mariana Mariasch); Ediciones Deldiego (dirigida entre 1998 y 2003 por Daniel Durand); Colectivo Editorial Vox (surgido en 1997, su principal animador es Gustavo López) y Belleza y felicidad (surgida en 1998, coordinada por Fernanda Laguna, Cecilia Pavón y Gabriela Bejerman). Con una estética de edición tan peculiar

${ }^{109}$ La mineta (1987-1990: periodicidad irregular), fue una publicación dirigida por el poeta Rodolfo Edwards, de distribución gratuita. La publicación consistía en una hoja oficio fotocopiada a doble faz en donde se incluían poemas de distintos autores entre los que se destacan Fabián Casas, Carlos Battilana, Daniel Durand, Darío Rojo, Mario Varela, José Villa y Juan Desiderio. Los poemas eran mecanografiados, recortados y luego pegados en el original, al igual que las imágenes. En algunos números aparecen, además, intervenciones manuscritas. Trompa de Falopo, dirigida por Leandro Gado pero asociada fuertemente a la figura del poeta Juan Desiderio, circuló entre 1989 y 1993, en seis números. Antiguos integrantes de La mineta trasvasaron a Trompa de Falopo: Juan Desiderio, José Villa, Mario Varela, Fabián Casas, Daniel Durand y Darío Rojo, e incorporándose, en ocasiones, David Wapner, Sebastián Bianchi y Néstor Colón. Toma el formato de la plaqueta y no sólo incluye poemas, sino también ensayos, cartas, entrevistas y letras de rock, con similar modalidad artesanal de producción que su antecesora (fotocopias, collage, intervenciones manuscritas). 
como cuidada (formato de $12 \times 12$ ), se destaca dentro del conjunto Editorial Mate (surgida en 1996, su director editorial es Arturo Carrera y sus editores Juan Lagomarsino y Vanesa Viudes). Asimismo, cabría mencionar Zapatos rojos (a partir de 1999 como espacio de lectura de poesía "a micrófono abierto", gestionado por Romina Freschi, Ximena Espeche y Karina Maccio: publican en el año 2001 la Antología Zapatos Rojos 2000, en editorial La Bohemia), tsé-tsé (la revista comienza publicarse en 1995; en 1998 los editores Reynaldo Jiménez y Gabriela Giusti publican el primer libro) y la cooperativa editorial Nusud (a partir de 1994, sus fundadoras son Diana Bellesi, Mónica Efrón y María Cristina Santiago).

El suplemento "Primer Plano" correspondiente al 20 de diciembre de 1992 tiene como nota de tapa "El estado de las cosas", entrevista coral realizada por Marcos Mayer y Miguel Russo a los poetas y editores José Luis Mangieri (editor desde los años ochenta del mítico Libros de Tierra Firme); Daniel Samoilovich (que para entonces publica el n 24 de Diario de Poesía), Víctor Redondo (Último Reino), Carlos Pereiro y Edgardo Pígoli (Ediciones del Dock). Como señala Pígoli: “editar poesía no puede escindirse del hecho de leerla y escribirla". No obstante, frente a la presión de los entrevistadores, los editores se ven obligados a confesar que, la mayor parte de las veces, los poetas pagan la edición de sus obras (como descargo, Redondo puntualiza que editar un libro de poesía cuesta "apenas" 1000 dólares, "el equivalente a diez días en Punta del Este o Mar del Plata”). En todas las intervenciones se percibe cierto (confeso) "resentimiento" contra los novelistas (que, a excepción de Ricardo Piglia, no leen poesía) y la Universidad de Buenos Aires (cuyos referentes en literatura argentina promocionan fundamentalmente la narrativa).

Otras importantes editoriales surgidas a comienzos de los años noventa fueron: Juan Genovese Editor (surgida en 1992, su director es Omar Genovese); Paradiso (surgida en 1991, sus directores son Américo Cristófalo y Cristian Kupchik) y Bajo la Luna (inicia sus actividades en 1992 en Rosario publicando poesía, como editorial de Mirta Rosenberg: en 2002, sus editores Miguel Balaguer y Valentina Rebasa se trasladarán a Buenos Aires y reestructurarán su catálogo, creando varias colecciones).

En el contexto de la primera mitad de los años noventa, Ediciones Tantalia constituyó una verdadera rareza. Fundada en 1993 por los narradores Rubén Mira, Aníbal Jarkowski, Miguel Vitagliano y Martín Kohan, asumió la forma de una “conspiración de escritores" de espaldas al mercado (por lo mismo, su colección de 
narrativa se titulaba irónicamente "Treinta monedas"), proponiéndose como objetivo exclusivo la "auto-edición" de novelas, lo que fue posible gracias al apoyo de Alejandra Glace, que tenía un taller de diseño y composición. Allí publicaron durante 1993 sus primeras novelas Aníbal Jarkowski, Rubén Mira y Martín Kohan: Rojo amor, Guerrilleros (Una salida al mar para Bolivia) y La pérdida de Laura, respectivamente. El tercer título en orden de aparición, El niño perro, es la segunda novela publicada de Miguel Vitagliano. En las presentaciones de sus títulos, con vino patero y lecturas en voz alta, que confluían en crear un peculiar clima de celebración entre amigos, los autores del catálogo practicaron el mismo tipo de sociabilidad que los animadores de las editoriales independientes de poesía.

La novela de Mira (una suerte de reescritura cyber-punk de El Diario de Bolivia de Ernesto "Che" Guevara en amalgama con la "memoria de la literatura I" quizá más lograda en suelo local de la psicodelia del autor de El almuerzo desnudo) alcanzó categoría de mito. ${ }^{110}$ Entre 1996 y 1997 Tantalia pasaría a manos de Florencia Abbate (que también publicaría allí su primer libro, Puntos de fuga: un diario de viajes), incorporado las colecciones "Rarezas" (una serie cuyo objetivo es el rescate de obras atípicas u olvidadas, en cuyo marco se edita poesía en versión bilingüe); “Contemporáneos" (orientada a promover la circulación de nuevos escritores) y “Artes visuales" (dedicada a libros de pintura, fotografía o que combinan palabra e imagen), y manteniéndose activa hasta el año 2011, con Daniela Allerbon como co-editora.

Si repasamos los derroteros editoriales de Jarkowski, Vitagliano y Kohan, Ediciones Tantalia resultó ser una más que exitosa plataforma de lanzamiento. Para el caso de Aníbal Jarkowski: a Rojo amor (Ediciones Tantalia 1993) le seguirían dos títulos en Tusquets Editores: Tres (1998) y El trabajo (2007). También Vitagliano pasaría de Tantalia a Tusquets para publicar en dicho sello las novelas Los ojos así (1996), Cielo suelto (1998) y Vuelo triunfal (2002). Más tarde, en Norma: Golpe de aire (2004). Por último, en Eterna Cadencia Editora: Cuarteto para autos viejos (2008), El otro de mí (2010) y Tratado sobre las manos (2013). El caso de Kohan es el más espectacular: de Tantalia, pasa a publicar en Sudamericana: El informe (1997) y Los cautivos. El exilio de Echeverría (2000); Dos veces junio (2002) y Segundos afuera (2005). En Mondadori: Museo de la Revolución (2006). Luego de ganar el Premio

\footnotetext{
${ }^{110}$ Carlos Gamerro dedicó a Rubén Mira su novela Un yuppie en la columna del Che Guevara (2011), y ya a comienzos del 2000 impulsó la reedición de Guerrilleros desde las páginas de "Radarlibros". La novela de Mira fue finalmente reeditada en 2007 en la editorial independiente Diada.
} 
Herralde de Novela Edición 2007 con Ciencias morales, queda como integrante del catálogo de Anagrama, donde publica Cuentas pendientes (2010) y Bahía Blanca (2012), siempre dentro de la colección "Narrativas hispánicas".

En el marco de nuestro trabajo, que focaliza en algunas incidiencias que determinadas políticas editoriales tuvieron sobre la producción novelística local, interesan las colecciones "Ficciones" (Beatriz Viterbo) y "La lengua/ novela" (Adriana Hidalgo). Por último, creemos necesario contextualizar la concreción en 1998 de la quijotesca empresa de publicar Los Sorias dentro de la colección "Cuadernos de extramuros" de Simurg, lanzada en el año 1995 con Gastón Gallo como editor general.

La rosarina Beatriz Viterbo Editora (fundada en 1990 por las críticas y profesoras de la UNR Adriana Astutti, Sandra Contreras y Marcela Zanín: a partir del año 1994 quedan a cargo sólo las dos primeras) inaugura en 1991 con la publicación de Copi, de César Aira y ¡Por favor: plágienme!, de Alberto Laiseca. Hasta el año 2000 inclusive, su colección "Biblioteca Ficciones” logra editar los siguientes títulos: Los elementales, de Daniel Guebel; Quién, que no era yo, te había marcado el cuello de esa forma, de Alejandro Margulis; 40 watt, de Oscar Taborda; Santo, de Juan José Becerra; Muero contento, de Martín Kohan; Dos obras extraordinarias, de Sergio Bizzio y Daniel Guebel; La resaca, de Hernán López Echagüe; Antes de la ventura, de Rodrigo Lara; Gravedad, de Sergio Bizzio; El alejamiento, de Sergio Delgado; El encuentro, de Mario Herrero; La deriva, de Osvaldo Aguirre; La creciente, de Carlos Dámaso Martínez; El llamado de la especie, de Sergio Chejfec; Bingo y Kafka de vacaciones, de Damián Tabarovsky; El intérprete, de Néstor Ponce; La temporada, de Esteban López Brusa; Millas, de Pedro F. Mouján; El antílope, de Mariano Fiszman; Señor/ Triste como mi país, de Carlos Álvarez Insúa; Juan y la loca por la milonga, de Walter Motto; Los pelados, de Sergio Rigazio; iNítida esa euforia!, de Marcelo Eckhardt; Zaira y el profesor, de Bettina Keizman y El crimen de la negra Reguera, de Ricardo Strafacce. ${ }^{111}$

La observación de lo editado hasta el año 2000 inclusive permite inferir una apuesta fuerte por género novelas (aunque también teatro co-firmado por Bizzio y Guebel, dos nouvèlles de Álvarez Insúa, y el poemario de Taborda), con una presencia importante de autores relativamente jóvenes y una muy modesta de autoras mujeres. La

\footnotetext{
${ }^{111}$ Tomamos el año 2000 como límite, debido a los efectos que tuvo la crisis económica del 2001 sobre el mundo editorial. La crisis no sólo fue ocasión del surgimiento de las llamadas "editoriales artesanales" (o "alternativas"), sino también de una breve "primavera editorial" (2002-2004). Daremos cuenta de esta coyuntura en la coda correspondiente al capítulo cuatro.
} 
ausencia en esta lista de novelas firmadas por Astutti, Contreras o Zanín no debe llevarnos a pensar que Beatriz Viterbo contradice la lógica común a todas las "editoriales independientes", esto es: el armado de una línea editorial que funcione como encuadre óptimo para la publicación de la obra de los mismos editores.

Por recomendación de Ricardo Piglia, el mismo año de su aparición las editoras de Beatriz Viterbo lanzan las colecciones "El escribiente" (donde aparece publicado el título de Laiseca), “Tesis/ Ensayo", "Estudios Culturales” y -en el año 1996- "Ensayos críticos", que inauguran con Lúmpenes peregrinaciones. Ensayos sobre Néstor Perlongher, de Adrián Cangi y Paula Siganevich. En esta última colección, Astutti y Contreras publicarán la versión libro de sus respectivas tesis doctorales: Andares clancos. Fábulas del menor en Osvaldo Lamborghini, Juan Carlos Onetti, Rubén Dario, J. L. Borges, Silvina Ocampo y Manuel Puig (2001) y Las vueltas de César Aira (2002, con un subsidio de la Fundación Antorchas).

Es precisamente en relación a la producción académica de las editoras que cobra sentido la creación de las colecciones diferenciadas "César Aira en Beatriz Viterbo" (con quien Contreras y Astutti mantienen además una relación de amistad y donde éste, además de ficción, publica ensayos que habían sido originalmente seminarios impartidos en el Centro Cultural Ricardo Rojas, departamento de Extensión Universitaria de la Universidad de Buenos Aires: Copi, Alejandra Pizarnik y Las tres fechas) y "Manuel Puig en Beatriz Viterbo Editora" (rescate de textos teatrales, textos originalmente escritos en portugués y guiones hasta el momento inéditos o de circulación prácticamente nula). ${ }^{112}$

Aunque resulte ociosa la aclaración, ninguno de los títulos de la colección "Biblioteca Ficciones" fue un "mejor vendido", aunque encontraron un eco más que favorable en revistas culturales de importancia, como, por ejemplo, Punto de Vista, y varios de ellos tuvieron un rol decisivo en el debate sobre "la literatura de izquierda" lanzado por Damián Tabarovsky en 2004, como veremos en el capítulo cuatro.

El último año de la década del noventa surge Adriana Hidalgo editora, con Edgardo Russo y Fabián Lebenglik como directores editoriales y Adriana Hidalgo como editora general. Bajo el título de "la lengua" Adriana Hidalgo lanza cuatro subcolecciones de narrativa: "la lengua/ cuento", "la lengua/ crónica", "la lengua/ relato" y "la lengua/ novela".

\footnotetext{
${ }^{112}$ También Ezequiel Martínez Estrada ostenta una colección exclusiva dentro de Beatriz Viterbo Editora.
} 
Hasta el año 2000, esta última sólo contaba con los títulos: El silenciero y Los suicidas, de Antonio Di Benedetto; Los pasos previos, de Francisco "Paco" Urondo; Reina Amelia, de la uruguaya Marosa Di Giorgio; La piel del caballo, de Ricardo Zelarayán; Guerra conyugal, de Edgardo Russo y Rutas argentinas, de Carlos Bernatek. Es importante destacar la labor de reedición de la obra de Di Benedetto, que era para entonces -con la excepción de Zama, que fue reeditado en 2001 en formato económico por el Grupo Clarín dentro de la colección "La Biblioteca Argentina. Serie Clásicos" y vendida en kioscos de revistas- un autor que sólo se conseguía en "librerías de viejo".

En el caso de Edgardo Russo, el gesto editor es claro: se trata de exhumar ciertos títulos selectos de fines de los sesenta y comienzos de los setenta para enmarcar la publicación en 2000 de Guerra conyugal, su primera novela. (Russo ya había publicado en el $\mathrm{n}^{\circ} 2 / 3$ de Literal un fragmento de una novela autobiográfica que quedó inconclusa, Tantalia, a partir de lo cual se haría amigo "a distancia" -en ese entonces el futuro editor de Adriana Hidalgo residía en la provincia de Santa Fe- de Germán García y Luis Gusmán.)

Adelantándonos un poco al cambio de coyuntura (al que volveremos en la coda correspondiente al capítulo cuatro), en la edición 2001 de la Feria Internacional de Libro Liber (3 al 6 de octubre de 2001, Madrid), Adriana Hidalgo editora pacta con la española Edhasa la distribución de su catálogo en la Península. La iniciativa cuenta con el patrocinio de la embajada argentina, cuyo consejero cultural es Sergio Baur.

También sobre el cambio de siglo (entre 1999 y 2001) surge en la ciudad de La Plata ediciones el broche (son sus editores Esteban López Brusa y Carlos Ríos). En una primera etapa publican sólo cuatro títulos: Señores chinos, de Sergio Pángaro; El juego de los mundos, de César Aira; Caballo en la catedral, de Horacio Fiebelkorn y Media romana, de Ríos.

En 2012 el sello es relanzado en formato de un cuarto de página A4 $(15 \times 10,5 \mathrm{~cm})$, con una estética que estiliza la de la llamada "literatura de cordel". El relanzamiento consta de ocho títulos: Dos cuentos vulgares, de Juan José Becerra; La marca de la polilla, de María Martoccia; Hacia la ciudad eléctrica, de Sergio Chejfec, El durmiente, de Ulises Cremonte; Palito, de Patricia Suárez; Institucionalizaciones, de Sergio Fitte; Industrial, de López Brusa y A la sombra de Chaki Chan, de Ríos. Los ejemplares, con un aire de literatura clandestina y selecta, tienen un precio simbólico (quince pesos). 
Como ya fue señalado, la condición mítica de Laiseca estuvo estrechamente relacionada con el carácter de inédito de Los Sorias, que circuló entre un círculo restringido de amigos (Rodolfo Fogwill, Ricardo Piglia y César Aira) como manuscrito mecanografiado. ${ }^{113}$ Precisamente, éste último recomendó la novela al editor de Simurg (de cuyo catálogo editorial formaba parte), donde ya se habían publicado para entonces -dentro de la colección "Cuadernos de Extramuros", dirigida por Sylvia Saítta- los títulos El desierto y su semilla, de Jorge Baron Biza; Notas sobre el cinematógrafo y En el país del viento. Viaje a la Patagonia, de Roberto Arlt; Cacerías, de Marcos Herrera; Tanta vida, de Esther Andradi; Cinco, de Sergio Chejfec; Una pena extraordinaria, de Martín Kohan; El perdón, de Gustavo Alejandro Ferreyra; Guiando la hiedra, de Hebe Uhart; Taxol precedido de Duchamp en México y La Broma, de César Aira; Mis queridas se murieron, de Vizconde de Lescano Tegui; El enigma de la calle Arcos, de Sauri Lostal; Oasis en la vida, de Juana Manuela Gorriti; Si yo no hubiera sido así, de Beatriz Abelleira y En breve cárcel, de Sylvia Molloy. La exhumación de textos de Roberto Arlt, como ya lo hemos señalado para el caso de las editoras Astutti y Contreras, tiene relación directa con las inquietudes académicas de Saítta, que en 2000 publicó El escritor en el bosque de ladrillos. De Roberto Arlt, además de En el país del viento (aguafuertes patagónicas), Simurg publica Notas sobre el cinematógrafo, El resorte secreto y otras páginas y Aguafuertes vascas. ${ }^{114}$

Gastón Gallo se encargó de digitalizar con un equipo de colaboradores las mil trescientas páginas de Los Sorias (que supera por 30.000 caracteres el Ulises de James Joyce), que su autor fue llevando a la editorial en sucesivos "tomos" de originales mecanografiados, con el papel ya amarillo por el paso del tiempo. Los Sorias salió finalmente en 1998, con una tirada de 350 ejemplares en papel Chambril importado de Brasil, numerados y firmados por el autor, que se empecinaba en hacerlo con un breve "Lai". La tapa fue un diseño de Guillermo Kuitca: un mapa intervenido digitalmente. La presentación en la Librería Hernández estuvo a cargo de Rodolfo Fogwill. El prólogo, aunque en principio lo iba a redactar Beatriz Sarlo, terminó siendo escrito por Ricardo Piglia. En él se afirma que Los Sorias "es la mejor novela que se ha escrito en Argentina desde Los siete locos".

\footnotetext{
113 También (de manera quizás sorpresiva, dado el carácter de su propia novelística) Osvaldo Soriano cumple funciones de protector y mentor para con Laiseca, como éste lo ha señalado en numerosas entrevistas.

${ }^{114}$ En el año 2010, Laura Juárez publicó en Simurg Roberto Arlt en los años treinta, versión-libro de su tesis doctoral dirigida por Sylvia Saítta.
} 
El 19 de julio de 1998, Daniel Link escribe para "Radar" una nota sobre la aparición de Los Sorias, donde traza un paralelismo entre las apuestas literarias de Héctor Libertella (que en simultáneo a Los Sorias publica en la editorial Perfil Memorias de un semidiós) y Alberto Laiseca. Como señala Link: “... no se trata, nunca, del realismo. Tan lejos de la vanguardia como del realismo 'de almacén', Libertella y Laiseca definen su literatura con palabras como sueño y delirio" (http://www.pagina12.com.ar/1998/suple/libros/98-07/98-07-19/nota1.htm, consultado el 7.5.2013)

En el mes de noviembre del mismo año 1998 y con una tirada excepcional de 1500 ejemplares, Gallo publica Las Islas, de Carlos Gamerro, que, salvando las distancias, puede ser considerada la otra gran apuesta editorial de Simurg. Sobre esta novela volveremos extensamente en el próximo capítulo.

\subsection{Con V de Vian contra Babel, revista de libros. Tres herederas disímiles de Babel: La Giralda, el perseguidor/ revista de letras y Magazín Literario}

En diciembre de 1990 sale a la calle el primer número $V$ de Vian, con el subtítulo de "revista anacrónica". En este primer número, Sergio Olguín figura como Director y Pedro B. Rey, como Secretario de Redacción. Entre los miembros de su Redacción aparecen Karina Galperín y Javier Vandenberg. Tiene como secciones más o menos fijas: "Apertura" (el editorial); "Biografía"; "Inéditos" (donde aparecen no sólo textos literarios de los firmantes de la publicación, sino también de los ganadores del concurso anual que organiza la revista); "Click!"; "Poesía"; "ficción"; "zona crítica"; una entrevista (a veces bajo el rótulo de "testimonio"); y -desde su primer número hasta el n 11 de abril/ mayo de 1993- "Folletín", donde se publica por entregas la novela Que se mueran los feos, de Boris Vian traducida al español por Galperín. Mención aparte merece la sección “¿Cuánto vale tu silencio?” que escribe Sergio Olguín bajo el seudónimo de "Santiago Pazos", espacio de crítica (que muchas veces roza la injuria), que encontrará sus blancos privilegiados en Daniel Guebel y Alan Pauls. ${ }^{115}$ Otros escritores atacados son Luis Chitarroni, Guillermo Saavedra, Juan Martini y César Aira. $^{116}$

\footnotetext{
115 Sergio Olguín mantiene este lugar de enunciación (con una entonación apenas un poco menos escandalosa) como firmante del suplemento "Radar", bajo el título de "Vale decir".

${ }^{116}$ En la sección "Click!" correspondiente al $\mathrm{n}^{\circ} 6$ de la revista (febrero-marzo 1992), se expresa un desagrado tan profundo como jocoso porque el Premio Boris Vian le fue otorgado a Juan Martini por $E l$
} 
En consonancia con la caracterización de Marina Yuszczuk de "los poetas de los noventa propiamente dichos" que hemos reseñado en el capítulo uno, los escritores nucleados alrededor de Con $V$ de Vian publican notas sobre series televisivas de las décadas del sesenta y setenta, estrellas de rock alternativo, "perlas" del cine norteamericano de bajo presupuesto (su primer número especial es sobre Betty Page, estrella del cine erótico clase B). También lanzan su propia editorial: Vian Ediciones, con tirajes de 300 ejemplares (lo que contrasta con el tiraje promedio de la revista de 2000 ejemplares, con un tiraje excepcional de 5000 para el $\mathrm{n}^{\circ} 7$ ), que distribuye TRAPAX, una pequeña distribuidora especializada en textos de psicoanálisis.

En "Malas intenciones", el editorial que inaugura la publicación, se demarca el espacio generacional de pertenencia de manera tajante:

Vian es una excusa para hacer una revista que se relaciona confusamente con la literatura, para hacer literatura y para hablar de literatura. El debate intelectual en la Argentina es inexistente. El único intento en estos años fue un conato de discusión entre algunos integrantes de las llamadas generaciones del '60 y ' 80 . Debate totalmente improductivo porque parecía la discusión entre un grupo de castrados y otro de onanistas. No es inútil marcar que entre las dos generaciones estuvo la dictadura que hizo de los intelectuales un conjunto de incapaces para observar críticamente a la sociedad y, lo que es mucho peor, incapaces para crear una obra de verdadero valor literario. Hay excepciones, pocas. Los escritores más representativos de la década pasada escriben para los profesores de literatura y robándoles ideas ya no a poetas u otros escritores, como antes tan sabiamente se estilaba, sino a teóricos y críticos. Estos escritores, para seguir con las imágenes sexuales, podrán llegar a ser buenos ginecólogos, pero nunca buenos amantes. (Con V de Vian 1: 1990: 3)

La metáfora sexual se pone en serie con las llamativas fotos de desnudos femeninos que ilustran las tapas de Con V de Vian (que a partir del n 14 de marzo-abril de 1994 pasa a llamarse simplemente $V$ de Vian; sus números 4 y 5 adoptan el subtítulo "Una revista casi de literatura"). La profesión de fe antiacademicista encuentra en el escritor Boris Vian la "figura de autor" por antonomasia:

enigma de la realidad y a César Aira por La liebre: “¿¡Cómo puede ser que obras así sean premiadas en el nombre de Boris Vian?! Debemos alertar al jurado (y si quieren pueden tomarlo como una amenaza) que si en la próxima entrega del premio deciden dárselo a libros tan poco significativos, impugnaremos el premio de alguna manera o formaremos el comando Vernen Sullivan encargado de depositar en las puertas de los jurados y premiados un cargamento de materia fecal de origen nacional. Están avisados" (Con V de Vian 6 1992: 5). 
... el destino de Boris Vian es una paradoja: el menos francés de los escritores franceses [...] es el continuador de una literatura que se remonta a François Rabelais, y que continúa en los escritores transgresivos de los dos últimos siglos (los llamados "escritores malditos", Alfred Jarry, los surrealistas) [...] Vian, de alguna manera, empieza a vivir de nuevo después de su muerte, convirtiéndose en referente obligado de otro tiempo explosivo, los '60. (Olguín 1990:4)

En consonancia con lo señalado, el editorial del n 7 de mayo/ junio de 1992 ("Que bufen los eunucos") vuelve a hacer explícito el interés en una literatura "que sintamos latir, respirar, gozar" (Con V de Vian 7 1992: 3). La línea "patafísica" va de Alfred Jarry a Julio Cortázar, pasando por Luis Buñuel y Boris Vian. No obstante, tomados todos juntos, los escritores argentinos reivindicados en las páginas de Con $V$ de Vian aparecen como bastante disímiles entre sí: Julio Cortázar, Ricardo Piglia, David Viñas, Rodolfo Walsh, Fogwill y Elvio E. Gandolfo. (Este último también se incorporaría como miembro del staff, junto a Christián Kupchik, Claudio Ziger -que comienza firmando bajo el seudónimo de "Pablo Zeca"-, Gerardo Laster, Norberto Galzerano, Roberto Herrscher, Fernando Peña, Belén Gaché, Cecilia Szperling y Gisel Picca.)

Dentro de la "tradición selectiva" que hemos mencionado, la coexistencia de Cortázar y Piglia resulta de lo más complicada. Si bien Rolando Graña en "El niño decoroso" en el n 8 de agosto/ septiembre de 1992 de Con V de Vian fuerza una comparación según la cual Piglia y Saer habrían caído en desgracia como antes cayera Cortázar (Cf. 1992: 9), hay que decir que el planteo no se sostiene. Como ya hemos reseñado antes, Cortázar (con su Libro de Manuel) sí había sido objeto de polémica (e impugnación) durante los años setenta y ochenta. Contra esto (y más allá de las eventuales suspicacias que las altas cifras de venta pudieran suscitar entre sus detractores), Piglia logra mantenerse desde Respiración artificial como uno de los "nombres del consenso" (junto con Saer y Puig).

Otro elemento llamativo es el rechazo a César Aira, a quien en el $n^{\circ} 8$ de $C o n V d e$ Vian se acusa de "haber pausterizado todo lo salvaje, lo impresentable que había en Lamborghini” (Op. Cit. Graña 1992: 10). En el mismo número, Karina Galperín escribe una reseña a La prueba, donde acusa a los "fanáticos" de César Aira de no darse cuenta de que "la velocidad, virtud indiscutible en los cien metros llanos, nada tiene que ver con la destreza literaria” (Galperín 1992: 14). 
Por último, cabe señalar que el encono de Con V de Vian contra "la Academia" no encontró demasiado eco. Desaparecida Babel, revista de libros (hecho que es objeto de un sentido lamento en la sección "Click!" del n 3 de Con $V$ de Vian de junio/ julio de 1991) y con una presencia prácticamente nula por parte de sus miembros en la Universidad de Buenos Aires, resulta lógico que los "blancos" elegidos no estuvieran particularmente interesados en responder a los ataques. Como señala Sergio Olguín en una reconstrucción retrospectiva: "Eramos petardistas, pero estábamos solos, no teníamos ninguna vereda de enfrente" (Olguín [Entrevistado por Sebastián Hernaiz y Juan Pablo Liefeld para el interpretador-literatura, arte y pensamiento 32]: 2007). De todas formas, las cabezas principales del staff de Con V de Vian, tal como lo señalamos anteriormente, también pasarían a ser parte de "Primer Plano" y luego, de "Radar".

La revista La Giralda, dirigida por Marcos Herrera y con un Consejo de Redacción integrado por Martín Kohan, David Oubiña, Leandro Araujo, Jorge Consiglio y Gustavo Generani (con intervenciones firmadas por Damián Tabarovsky y Adriana Amante), se presentó como "heredera" del proyecto de Babel, revista de libros. Sacó un único número en abril de 1995, que giró sobre la pregunta de cómo escribir algo nuevo cuando las vanguardias no sólo han fracasado (se han museificado), sino que además se han convertido en puro marketing. El número apareció acampañado de un dossier de textos literarios (firmados por Sergio Chejfec, Matilde Sánchez, Carlos E. Feiling, Daniel Guebel y Federico Jeanmarie). Yendo más atrás en el tiempo que Babel, la tradición en la que buscó inscribirse La Giralda fue la de las vanguardias del veinte: la inclusión bajo el título de "Polémica" de un debate registrado en 1928 entre surrealistas franceses (André Bretón, Antonin Artaud, Jacques Prévert, Raymond Queneau y Marcel Duchamp) en este número único, habla por sí sola. De todas formas, hay un alto grado de consciencia de que el diálogo que se busca establecer con dicha tradición es imposible, puesto que "las vanguardias parecen haber retrocedido, dejando lugar a los reciclajes cosméticos de la posmodernidad [...] a pesar de todo, se sigue escribiendo y se sigue leyendo" (Giralda 11995 [Citado en Hernaiz 2012: 116]).

Otra revista cuyo staff surgio del seno mismo de la Facultad de Filosofía y Letras de la Universidad de Buenos Aires fue el perseguidor/ revista de letras ( $\mathrm{n}^{\circ}$ 1: mayo 1995 - $\mathrm{n}^{\circ}$ 12: Primavera/ Verano 2005), para la cual también escribieron docentes, estudiantes y graduados de la Facultad de Ciencias Sociales. Con una frecuencia trimestral, fue su editor y responsable Diego Viniarsky. Aparecen conformando su 
Consejo de Redacción en el primer número: Jorge Cabezas, Oscar Carísimo, Omar Carpín, Domin Choi, Marcela Domine, Rolando Pérez, Raquel Poblet, Alejandro Rosemberg y Ariel Williams. Entre sus colaboradores frecuentes, estuvieron Jorge Panesi, Graciela Speranza, Horacio González y Martín Kohan.

En el editoral del $n^{\circ} 2$ (Otoño/ Invierno 1996), sus firmantes hacen explícito el deseo de formular "un discurso capaz de tender puentes entre el lenguaje de los medios de comunicación y el de los académicos" (el perseguidor/ revista de letras 2: 1), lo que explicaría las secciones "kultura", "multimedia" y "letra y música" en convivencia con, por ejemplo, "metateoría" y "arte poético".

Los índices de sus doce números muestran la práctica de un ecleticismo notable: para su sección “el sujeto en cuestión” fueron entrevistados David Viñas (para el n²) y Abelardo Castillo (para el $\mathrm{n}^{\circ} 4$ ), pero también Josefina Ludmer (para el $\mathrm{n}^{\circ}$ ) y Beatriz Sarlo (para el n ${ }^{\circ}$ ). La sección "separata" (construida a la manera de un dossier) tuvo como tópicos la llamada "generación beat" (para el $n^{\circ} 2$ ), el neobarroco (para el $n^{\circ} 5$ ) y el "futbolismo" (para el $\mathrm{n}^{\circ}$ 6). Por último, el "número aniversario" (y último) de Primavera/ Verano 2004/ 2005, pensado como homenaje al autor de Rayuela, nuclea firmas disímiles: además de su director, escriben, entre otros: Horacio Salas, Juan Sasturain, Carlos Fuentes, Luisa Valenzuela, Tomás Eloy Martínez, Ovaldo Bayer, Nicolás Casullo, Héctor Schmucler, Nicolás Rosa y Horacio González.

Magazín Literario. Mapa mensual de cultura se lanza en julio de 1997, bajo la dirección de Violeta Weinschelbaum. Se trata de una publicación periódica bastante anómala dentro de la constelación de revistas que hemos relevado hasta ahora, porque no se origina en el deseo de un grupo de amigos de "hacer juntos una revista", sino, como Los inrockuptibles, que le es contemporánea, en la idea de comprar marcas y hacer franchising cultural. También porque plantea un concepto novedoso: "una revista comercial de cultura".

Violeta Weinschelbaum contrata a Daniel Link en calidad de Secretario de Redacción para que se encargue de la parte de producción periodística local, reservándose para sí la selección de dossiers ya aparecidos en Magazine Littéraire (que eran traducidos al español -con algunas modificaciones para el público lector argentinopor Bruno Guerra). 
El primer número consta de las siguientes secciones: "El mes”; “Agenda/ Pliego central" (que firma Daniel Link y que a partir del $\mathrm{n}^{\circ} 2$ se circunscribe a la actualidad literaria); "Dossier" (el tema es "Cine y literatura", con una entrevista de Graciela Speranza a Martín Rejtman para argentinizar el dossier originalmente aparecido en la antecesora francesa); "Libros" (cuya portada se titula "Los libros del mes" y que tiene las siguientes subsecciones de reseñas: "Ficción", "Historia", "Vidas", "Teatro", "Cine", "Ensayo" e "Infantiles") y "Entrevista" (si bien Weinschelbaum es quien entrevista a Julian Barnes -para el primer número- y Antonio Tabucchi -para el segundo-, cede su rol de entrevistadora a Guillermo Saavedra para el $n^{\circ} 4$, donde el diálogo es con Juan José Saer).

La sección "El mes" tiene diferentes subsecciones para las cuales escriben de manera fija las siguientes figuras: Martín Caparrós ("Bibliofilia"); Marita Chambers ("Multimedia"); Luis Chitarroni ("Barras Paralelas"); Sandra de la Fuente ("Música"); Hernán Díaz ("Discos"); Claudia Gilman ("Centenario"); Horacio Guido ("Cine y Video"); Marcelo Pacheco ("Plástica"); Guillermo Saavedra ("Reviata de Revistas": notas sobre publicaciones periódicas contemporáneas a Magazín) y Ariana Vacchieri (“Televisión”).

Ya desde el primer número, el azar (porque se trata de libros publicados en el mes de julio) parece complotarse con los firmantes de Magazín Literario para darle una impronta de "mafia neobarrosa" a la publicación: Delfina Muschietti reseña en la subsección "libros/ poesía” El vespertillo de las parcas, de Arturo Carrera; en la sección "Colecciones" se da cuenta del proyecto editorial Siesta; la subsección de dos páginas (la más extensa) de "Libros" ("libros/ ensayo") queda en manos de Claudia Kozak, que escribe sobre Tratados sobre Néstor Perlongher, de Nicolás Rosa y Prosa plebeya, de Perlongher. Por su parte, en "Reviata a Revistas", Saavedra elige comentar de manera entusiasta (y tanto más extensamente que la publicación del n 64 de El amante) la aparición del $n^{\circ} 41$ de Diario de Poesía.

La presentación oficial de la revista, realizada el 10 de julio de 1997 en la Alianza Francesa, constó de los siguientes eventos: una mesa redonda sobre "Arte y cultura" (de la cual participaron Ricardo Piglia, Felipe Noé, Martín Rejtman y Rafael Spregelburd, con la coordinación de María Iribarren, redactora de la revista); el recitado de una carta apócrifa de Manuel Puig por parte de la actriz Ingrid Pelicori y la exhibición de un video relacionado con el tema del primer dossier de Magazín. En su intervención, 
reproducida en la nueva sección "inéditos" correspondiente al n 2 de Magazín literario, Piglia elige un desvío: en vez de hablar inmediatamente del tema impuesto ("literatura y cine"), comienza hablando de la relación "literatura y revistas". Lo hace, claro está, en calidad de ex redactor de Los libros:

Yo me acuerdo de que cuando nosotros empezamos con Los libros nuestro objetivo era hacer una revista que fuera en contra de los suplementos de los diarios [...] Queríamos hacer una revista en la que el tratamiento de la literatura no fuera tan estrictamente periodístico [...]. Sería muy bueno, también, que el magazín literario (sic!) tuviera como punto de referencia un espacio diferente al espacio de circulación de la cultura y de la literatura de los suplementos literarios que, por una serie de motivos, es un espacio muy degradado desde el punto de vista de lo que serían los debates verdaderos de la literatura argentina, de la literatura contemporánea. (Piglia 1997: 16)

Piglia traza una deseable línea de continuidad entre Los libros, Babel y Magazín

\section{Literario:}

... me parece que todos los escritores esperamos siempre que las revistas ayuden a crear esos espacios donde la cultura puede ser discutida con un sentido más interno, más epecífico. Instantáneamente pienso, porque veo aquí algunos amigos que tuvieron que ver con ese proyecto, en lo que fue la experiencia de Babel, por ejemplo. Una revista que, me parece, también marcó un momento y también dio lugar a la aparición de una serie de nuevas poéticas y nuevas discusiones sobre la cultura y la literatura. (Op. Cit. Piglia 1997: 16-17)

El vínculo de Magazín con Babel no sería sólo de proyecto, sino también afectivo. El segundo número tiene como tapa una cara pop femenina de tres cuartos perfil (una lágrima cae de uno de sus ojos), que parece recortada de un cuadro de Roy Lichtenstein, e incorpora por única vez la sección "Homenaje" para dar cuenta de la prematura muerte de Carlos E. Feiling. En la sentida semblanza que inaugura este número, Guillermo Saavedra señala el valor superior de la poesía (Amor a Roma) de Feiling por sobre su diestro dominio de los géneros (policial, aventuras, terror gótico), demostrado en sus tres novelas publicadas (El agua electrizada, Un poeta nacional y El mal menor, respectivamente):

[Con sus novelas] sacaba la punta al lápiz del estilo, dejaba sospechar allí que, detrás de la voz que ocultaba a fuerza de transparencias, había un poeta. En algún momento permitió que esa presunción fuera certeza de sus lectores: Amor a Roma (1995), un libro de poemas insólito en la literatura argentina. La construcción de una suerte de lingua franca, la búsqueda de una entonación por un temperamento iluminado doblemente por el rencor y la erudición. El resultado es un cruce de ritmos, 
metros y palabras de tradición doble, inglesa y argentina, que confluyen en la ciudad de todos los caminos. (Saavedra 1997: 8)

\section{CODA. Ni "babélicos", ni "planetarios". Memoria en la literatura de la "Operación Raymond Williams"}

La "generación ausente" fue recurrentemente estudiada en términos de dos "grupos culturales" enfrentados, por ser supuestos defensores de estéticas rivales. Según la formulación pionera de Edgardo H. Berg en "La joven narrativa argentina de los '90, ¿nueva o novedad?”:

Haciendo una reducción de la multiplicidad de escrituras emergentes en los últimos '90 en la Argentina, los jóvenes escritores se hallan asociados a dos grupos básicos que mantienen diferentes formas de relación con la tradición literaria, los medios masivos de comunicación y el mercado. Y, a su vez, configuran poéticas en enfrentamiento y disputa. Neotradicionalistas o estéticamente conservadores, experimentalistas o neovanguardistas. Los primeros, Rodrigo Fresán, Juan Forn o Guillermo Saccomanno, entre otros, ante la sospecha del agotamiento de la "experimentación" narrativa visible en ciertos textos de los ' 80 , cultivan un retorno a la narración en los términos más clásicos [...] Textos que intentan reelaborar un pacto de mímesis con el lector, con los deseos imaginarios del público televisivo [...] Textos sin fragmentación y con escasa variación del sistema de enunciación o del punto de vista y que elaboran personajes en muchos casos, estereotipados o adscriptos al imaginario de la tipificación social, acercando de esta manera, los modos estéticos a los conflictos cotidianos $[\ldots]$

Sergio Chejfec y el grupo de los llamados experimentalistas (Daniel Guebel, Alan Pauls, Martín Caparrós, Carlos Eduardo Feiling) se apartan de los moldes clásicos de la narración y hacen del trabajo con la lengua, la problematización de la narración y de lo "real" [...] de la disolución de la temporalidad lineal y de los ensayos o pruebas a partir de los géneros "menores", hoy canonizados y dominantes tanto en el cine como en la literatura -obviamente me refiero al policial o thriller, el relato de viajes o de aventuras y en menor medida el relato epistolar [...] o del uso estratégico de la fábula oriental o de lo exótico como marca posicional de distanciamiento, sus principales políticas de escritura $[\ldots]$ los juegos y descentramientos a nivel de la enunciación que desacralizan al narrador hegemónico de la novela decimonónica, el montaje de citas y la incorporación del discurso ajeno, la autorreflexividad e infiltración teórica, los saltos espacio-temporales, la ruptura con el pacto de mímesis del realismo y con el régimen del relato clásico, con el orden y la lógica causal de la novela decimonónica, son algunas de las estrategias narrativas de distanciamiento. (Berg 1996: 36-37)

De manera casi unánime, se recoge esta descripción del campo realizada tempranamente por Berg, y se le agregan algunos nombres para ejemplificar quiénes serían los "narrativistas" (con mayor frecuencia aludidos bajo el nombre de "planetarios") y los "experimentalistas" (o "babélicos"). Dentro del primer grupo: Juan 
Forn, Guillermo Saccomanno, Marcelo Figueras y Rodrigo Fresán. Dentro del segundo: Martín Caparrós, Jorge Dorio, Guillermo Saavedra, Ricardo Ibarlucía, Matilde Sánchez, Daniel Guebel, Luis Chitarroni, Alan Pauls, Sergio Chejfec, Carlos E. Feiling, Sergio Bizzio, Graciela Speranza y Daniel Link (Cf. Saítta 2004 y 2005; Botto 2006; Patiño 2006 y Sager 2007).

Esta pretendida antinomia fue puesta en cuestión por Hernán Sassi (2006), Diego Molina (2010) y Elsa Drucaroff (2011), que, para mejor atacarla, focalizan en, por un lado, la poética de Rodrigo Fresán, más afín a la descripción que se hace de aquella practicada por los llamados "babélicos", que a la prototípicamente adjudicada a los "planetarios" (en la misma tesitura, desconfían de la "condición babélica" de Martín Caparrós). Por otro lado, se detienen en los cruces entre ambos supuestos grupos a partir del relevo de lo publicado por Juan Forn en la Biblioteca del Sur (no sólo Teoría del cielo, de Arijón/ Carrera y La mujer en la Muralla, de Laiseca, sino también El dock, de Matilde Sánchez). A estas observaciones cabría agregar el hecho de que El mal menor (1996), de Feiling, fue finalista del Premio Planeta Edición 1995, y que la "mezcla" entre "babélicos" y "planetarios" ya se había producido hacia el interior de Babel, revista de libros.

Algunos ejemplos: Rodrigo Fresán ("El hombre que caminaba demasiado") coincide con Arturo Carrera ("La bonne nouvelle de Fogwill”) al momento de comentar elogiosamente La buena nueva de Los Libros del Caminante ("libro del mes" correspondiente al $\mathrm{n}^{\circ} 20$ de Babel), de Fogwill. Los supuestos "narrativistas" internacionales y/ o "neo-dickesianos" Paul Auster, John Irving y Raymond Carver son reseñados de manera positiva por Marcelo Cohen ("Paul Auster y el ciruja que hay en todos nosotros", en el n 12); Guillermo Piro (“Oración por Owen. John Irving”, en el $\mathrm{n}^{\circ}$ 16), Graciela Speranza y Guillermo Saavedra ("La vida es breve, las ficciones también" y "La luz que sucede al trueno", también en el n 16). Por último, en el n 18 de Babel, Adriana Amante escribe una reseña sobre Roberto y Eva (1989), de Guillermo Saccomanno, donde da fe de su "placentera lectura" al mismo tiempo que recuerda "las excelentes" Prohibido escupir sangre y Situación de peligro.

Las notas sobre Julio Cortázar publicadas en el ejemplar de "Primer Plano" correspondiente al 30 de junio de 1991, que tiene como nota de tapa "Cortázar veinte años después", son una prueba temprana de cómo se dio la convivencia pacífica entre sostenedores de opiniones totalmente divergentes. Mientras Jorge Lanata hace una entusiasta defensa de la poética cortazariana en "Ahora dicen que escribía mal", Luis 
Chitarroni afirma en "Los límites de la imitación" que "la literatura de Cortázar no tiene interés para muchos de los que hoy intentamos escribir" (1991:2).

Si bien las tapas con Osvaldo Soriano, el humor malévolo de Sergio Olguín en su sección "Vale decir" y la prédica exaltada de Elvio E. Gandolfo contra César Aira son seguramente los elementos más recordados de "Radar" ( $\mathrm{n}^{\circ}$ 1: 18 de agosto de 1996- $\mathrm{n}^{\circ}$ 65: 9 de noviembre de 1997), tampoco en este caso parece legítimo postular la existencia de un "nosotros" homogéneo. A título de ejemplo: si bien Soriano es tapa del $\mathrm{n}^{\circ} 3$ de noviembre de 1996 con motivo de la publicación de Piratas, fantasmas y dinosaurios, es Copi quien una semana más tarde ostenta las dos páginas de la sección "Reportaje" ("Con Copi en París antes de morir", que firma José Tcherkaski, que en 1998 publicará Habla Copi. Homosexualidad y creación).

El carácter heterogéneo (casi podríamos decir: "pluralista") de "Radar" se torna evidente si leemos la tapa-homenaje a Carlos E. Feiling publicada el 27 de julio de 1997 ("Un poeta nacional") en contrapunto con el número-homenaje del 2 de febrero de 1997 con motivo de la muerte de Osvaldo Soriano, y con la nota de tapa del 23 de julio de 1997, que conmemora el vigésimo aniversario de la muerte de Rodolfo Walsh. De todas formas, es justo señalar que al único escritor al que se le dedicó un número entero fue Osvaldo Soriano. No obstante, en esta decisión también habría pesado la lógica corporativa: Soriano, además de un escritor admirado por algunos de los firmantes de "Radar" (entre ellos, su director: Juan Forn), fue un periodista histórico de Página/ 12 (de hecho, su velatorio se hizo a pocas cuadras de la Redacción).

Sobre los cruces entre "babélicos" y "planetarios" cabría agregar que es en Rodrigo Fresán en quien recae la tarea de escribir el "Prólogo" a Con toda intención (2005), compilación de ensayos y artículos periodísticos de Carlos E. Feiling, el "mito personal" de muchos de los escritores nucleados alrededor de Babel: traductor, poeta, novelista ocasional e indiscutido especialista en literatura anglosajona, muerto de leucemia a los 36 años de edad. En el prólogo, Fresán señala la excepcionalidad "intrigante" del proyecto narrativo de Feiling: "Una especie de regocijado y atípico e internacional -pero al mismo tiempo muy argentino-, polimorfo y perverso paseo por diferentes géneros. Policial, histórico y terror" (Fresán 2005: 8). Nada casualmente, en la cita resuena un título de Héctor Libertella: El paseo internacional del perverso (1990). 
Dos años más tarde, el Grupo Editorial Norma publicará Los cuatro elementos, que reúne las tres novelas éditas (El agua electrizada, Un poeta nacional y El mal menor) de Feiling, y el primer capítulo de una cuarta, que dejó inconclusa. En este caso, Luis Chitarroni y Gabriela Esquivada (quien fuera su mujer) ofician de presentadores del volumen.

Repetimos: prácticamente todos los "críticos-estrategas" que se ganaron la vida como periodistas culturales entre fines de la década del ochenta y los años noventa del siglo XX terminaron trabajando codo a codo en las redacciones de "Radar" (y luego, "Radarlibros"). La coexistencia más o menos pacífica de poéticas dispares en "Radarlibros" se da desde la misma dirección: entre 1998 y 2002 Juan Forn no tiene mayores problemas en compartir el espacio con Daniel Link (editor hasta 2004). Las diferencias de criterio, si alguna vez las hubo, se resolvieron salomónicamente con un sistema de "tapas dobles" (VER Op. Cit. Link [Entrevistado por Sebastián Hernaiz y Diego Cousido] 2007).

Aún más: supuestos sostenedores de estéticas rivales cruzan inesperados elogios. Para dar un ejemplo: en el n 33 de "Radar" publicado en 30 de marzo de 1997, que reproduce las intervenciones realizadas en el marco de las Jornadas del Segundo Encuentro Nacional de Narradores en Villa Gesell, Carlos E. Feiling titula su intervención "El viejo cuento de la narrativa", donde tras una disquisición sobre las diferencias entre "cuento" y "novela corta”, señala que "ejemplo de 'cuento' y 'novela' son algunos de los relatos de Velcro y yo, de Martín Rejtman, y de Animales domésticos, de Guillermo Saccomanno [...] He citado solo libros y relatos que me agradan" (1997: 21).

La oposición "planetarios VS. babélicos" en términos de "políticas de la literatura" tampoco se sostendría si retrocedemos en el tiempo al 14 de enero de 1996, cuando el suplemento de cultura de Página/ 12, aún bajo el nombre "Primer Plano", lanza un interesante debate sobre "el lugar de la actividad literaria en los años sesenta/ setenta y en los noventa", al que son invitados a participar Abelardo Castillo, Carlos E. Feiling, Juan Forn, Rodrigo Fresán, Guillermo Saccomanno y Juan Sasturain. El epígrafe de la nota, titulada "Del compromiso al mercado", hace explícitos el criterio de selección de los autores convocados, así como la cuestión planteada:

El escritor, como figura que durante los años sesenta generaba visiones de la realidad y del futuro se fue diluyendo -dictaduras y caída de utopías mediante- en un aparente objeto comerciable al que no 
se le exigen compromisos políticos. "Primer Plano" pidió la opinión de seis escritores representativos de distintas generaciones y perspectivas estéticas como una forma de abrir un necesario debate sobre el lugar social de la actividad literaria en la Argentina. (s/ firma [en "Primer Plano" 14.1.1996: 2-3])

La respuesta que da Guillermo Saccomanno ("La literatura está en otra parte") es sorprendente, porque pugna por una "tradición selectiva" que es en parte la misma que la promocionada por los escritores agrupados alrededor de Babel:

Walsh en una punta y Puig en la otra tensan el arco de expresiones de lo que se escribía y publicaba en los '60 y los '70. Desde la denuncia política hasta el uso de técnicas provenientes del cine y del folletín, la literatura de esos años no teme arriesgar las teclas de la máquina de escribir en una ansiedad por reflejar lo social. Abelardo Castillo, Miguel Briante, Germán García, y en una complementariedad marginal, Osvaldo Lamborghini [...] daba impresión de que la literatura y la realidad, en el decir de Viñas, se planteaban inseparables [...] se pensaba que la literatura tenía una utilidad [...] Había, sí, compromiso [...] (Saccomanno 1996: 2)

La idea de que Manuel Puig y Abelardo Castillo (para no decir Walsh ni Lamborghini, cuyas incompatibilidades ya hemos analizado) compartirían un afán común de dar cuenta de la "realidad" y la idea sartreana del compromiso es altamente dudosa, pero sintomática de la voluntad por parte de Saccomanno de armar una "tradición selectiva" lo más inclusiva posible. ${ }^{117}$ El gesto de leer desde un mismo lugar a escritores incompatibles se vuelve aún más evidente cuando el escritor hace un veloz paneo sobre el campo literario en los años dictatoriales, y el de la llamada "primavera alfonsinista" (1983/ 86):

En los años del exilio exterior e interior se publican afuera dos textos clave: No habrá más penas ni olvido y Cuarteles de invierno. Por acá la ficción estaba condenada a la alusión de la alusión de la realidad. Más tarde, con la primavera alfonsinista, se aguardaba la aparición de ficciones que dieran cuenta de lo ocurrido en los años negros, textos de "jóvenes" -y la "juventud" es una categoría burguesa-, agazapados en algún ropero. Sólo aparecieron textos de veteranos: La novela de Perón, Los Pichy Ciegos (sic!), Recuerdo de la muerte, Fuego a discreción y La revolución es un sueño eterno. (Op. Cit. Saccomanno 1996: 2)

\footnotetext{
${ }^{117}$ La idea sartreana de compromiso sólo le cabría a Abelardo Castillo, quien la retomó explícitamente en editoriales firmados para El escarabajo de oro ( $\mathrm{n}^{\circ}$ 1: mayo-junio de 1961- $\mathrm{n}^{\circ} 48$ : julio-septiembre de 1974), publicación periódica de la que fue director.
} 
De la cita interesan dos cosas: la deliberada tergiversación de la apuesta de las "poéticas de la negatividad" (Saer y Piglia) con la frase "la alusión de la alusión de la realidad" y -tal como ocurriera en 1992 durante la entrevista con Miguel Russo antes citada- la idea de que los que terminan imponiéndose por "prepotencia de trabajo" son siempre los escritores "veteranos". En otras palabras: si bien Saccomanno elogia inicialmente a Rodrigo Fresán en tanto "[intenta] devolverle a la literatura una mirada nueva [sobre la realidad] ironizando con crueldad" (Op. Cit. Saccomanno 1996: 2), su "tradición selectiva" parece estar integrada exclusivamente por escritores pertenecientes a las generaciones del sesenta y setenta.

Según la perspectiva de Saccomanno, ni "lo nuevo" ni "el mercado" parecen ser categorías válidas para pensar el campo literario de los años noventa:

En los '90, cuando Planeta irrumpe en el mercado -y se empieza a usar la palabra "mercado"- con autores nuevos, se plantea una polémica banal entre lo que se supone una literatura de venta masiva y una literatura de elite. El maniqueísmo de esta discusión de gallinero esconde con su alboroto la ausencia de una actitud que representaba los '60, los '70: la literatura -en términos de Briante- como pasión, como espacio a rodear, a construir, pero también un oficio [...] Literatura y realidad, en estos '90, pasan por otro lado, al igual que la atención de los lectores. (Saccomanno 1996: 2)

Podría afirmarse que la forma que tiene Saccomanno de analizar el campo literario de la primera mitad de los años noventa es tan anacrónica como la utilizada por Luis Gusmán y sus "hermanos menores" Daniel Guebel y Luis Chitarroni, cuando piensan el campo desde la antinomia "populismo o vanguardia".

Por un lado, se trataría de una maniobra defensiva que perseguiría resguardar el propio lugar en tanto escritor "mayor", intentando nuevamente desarmar por lo mismo la ecuación "jóvenes narradores" igual a "nueva narrativa”. Por otro lado, la reivindicación de la "literatura-pasión”. Según Saccomanno, sólo sería posible escapar del contexto adverso de publicación ("crisis de la industria editorial", "alejamiento del lector nativo de la ficción" y auge de la llamada "novela histórica bestsellerista") enarbolando otros valores.

Por último: la persistencia en entender a los llamados "babélicos" y "planetarios" como representantes de propuestas estéticas divergentes y rivales y/ o en términos de grupos culturales enfrentados no sólo se explicaría por la efectividad con que este conflicto fue "puesto en escena" (Cf. Op. Cit. Sassi 2006), sino también a causa de la 
existencia de una serie de novelas, que, escritas en modo autoficcional, construyeron una memoria en la literatura de dicho enfrentamiento. Para ello, retomaron un subgénero novelesco ya practicado por Jorge Luis Borges (en su versión miniaturizada): la "memoria en la literatura" de un "grupo cultural" que se reduce a dos personas en los cuentos “Tlön, Uqbar, Orbis Tertius” y “El Aleph” (Bioy Casares, Borges mismo).

De todas formas (y antes que Borges), Manuel Gálvez había escrito un fresco de su "grupo cultural" de pertenencia en El mal metafísico (1916). También podrían ser leídas en esta clave La buena nueva de Los Libros del Caminante (1990), de Fogwill y La grande (2005), de Juan José Saer. Según nuestra lectura, harían "memoria de la literatura I" de la formulación borgiana mínima de este subgénero novelesco La Internacional Argentina (donde el segundo integrante del "grupo cultural" es Héctor Bianchotti), de Copi; Un novelista atonal y El jardín de las máquinas parlantes (donde el otro integrante es Fogwill), de Alberto Laiseca; Help a él (nuevamente: Laiseca y Fogwill), de Rodolfo Enrique Fogwill y Cómo me hice monja (con la mención al amigo “Arturito Carrera"), de César Aira. También Vivir afuera (con sus envenenados dardos contra Ricardo "Millia” Piglia) se dejaría leer en esta clave.

Mención aparte merece la novela corta Los dos payasos (1995), de César Aira, única vez en que la coartada del modo autoficcional permite al autor compartir una versión tanto más oscura de su vínculo con Osvaldo Lamborghini. Por último, continuando la línea del "ajuste de cuentas en clave autoficcional", Alan Pauls hace "memoria en la literatura" del autor de Los pichiciegos mediante la figura del dandy navegante en El pasado (2003).

En 1990, Sergio Bizzio logra publicar El divino convertible, gracias al financiamiento de la Beca Antorchas. La novela cuenta la historia de un escritor llamado "Sergio Bizzio", y comienza con un larguísimo reportaje que supuestamente le realiza la periodista "Ida Singer" para la revista Bazar, de la editorial neoyorquina H\&H. En contraste con la hasta entonces magra obra publicada por el autor que se enumera en la contratapa del volumen, la obra édita del personaje "Sergio Bizzio" es copiosa, e incluye tanto títulos efectivamente existentes (o que serán publicados por el autor de carne y hueso a lo largo de la década del noventa), como otros que, en una clara "memoria de la literatura I" de los juegos borgianos con la falsa atribución y el apócrifo, nunca saldrán del terreno de la imaginación.

Según la presentación que redacta "Ida Singer": 
En 1981 publicó su primer libro de poemas, “Gran salón con piano" [En verdad, "Gran salón con piano" se publicó en 1982], y en 1988 "Mínimo figurado", nuevo libro de poemas o, como él mismo prefiere, un solo poema fragmentario -pasajes- de aguda belleza y con un error que los recorre: la perfección [En verdad, "Minimo figurado" se publicará un año más tarde]. De más está decir que estos libros pasaron completamente desapercibidos, excepto, en el corto circuito literario de sus amigos, lectores exigentes y malignos que los cerraban abriendo los ojos en señal de aprobación antes de pasar a otra cosa, según refiere Bizzio con una risita. Pero, cuando a fines de 1980 aparece su primera novela, "Más allá del bien y lentamente" [En verdad, la novela recién se publica en 1995], unas voces se alzaron, repitiéndose en revistas y en los suplementos culturales de los diarios (comentarios estúpidos, buenísima propaganda) desviando la atención desde sus maestros -innombrados- hacia él, atención acentuada pocos meses después con la aparición de sus relatos bajo el título singular de "Relato" [Se trata de un volumen de cuentos inexistente, o bien inédito]. El suceso estaba en marcha. Lo traducen al inglés y ocupa rápidamente los primeros puestos de venta y los elogios de los más prestigiosos críticos, que se vuelven a su poesía como a un tesoro oculto. De ahí en más, sus libros se traducen a una decena de idiomas [...] en 1989 publica su segunda novela, "Los tres ministros" [Se trata de una novela inexistente, o bien inédita]. En tanto, poemas suyos, sueltos, que, según dice, piensa reunir en un volumen titulado "Paraguay" [Volumen efectivamente existente, aunque recién se publica en 1991], producen en cierta crítica especializada escándalos de pudor, poniéndolos al derecho y de revés bajo el grueso cristal de sus lupas empañadas. (Bizzio 1990: 17-18)

A lo largo de la entrevista, en cuyo marco "Bizzio" cuenta infidencias de Fogwill, Briante y Guebel, muchas inventadas, algunas reales, la trama se vuelve cada vez más disparatada: "Ida Singer" se enamora del jardinero homosexual de "Bizzio", que a su vez se enreda con unos sujetos de cuidado que comienzan a complicarle la vida al escritor. Se trataría, en verdad, de ajustar cuentas mediante el ejercicio de un humor que va de lo ingenuo a lo cruel con determinados "hermanos mayores".

De "Fogwill", por ejemplo, que siempre detestó el cine, se dice que termina su carrera como realizador cinematográfico. Ofuscado porque "Fogwill" no acepta filmar la adaptación de "Los tres ministros", el célebre "Bizzio" se trenza con él en una pelea a zapatillazos (¿una "memoria en la literatura” de la famosa pelea a chancletazos incluída en Adán Buenosayres?). De todas formas, el aparente conflicto es más bien un homenaje entre pares (y amigos): en el $\mathrm{n}^{\circ} 21$ de Babel de diciembre de 1990, Fogwill escribe la reseña "Sergio y yo", donde afirma que "por fortuna, en El divino convertible, Bizzio no reprimió las fuentes que lo dotaron como el poeta más jugado de su generación" (1990: 8), y reconoce la influencia que -en tanto poeta- Bizzio ejercería sobre él. 
La disputa con "Aira" en El divino convertible posee otro cariz: "También rompí un cuento fantástico titulado 'Escatología de Facundo', y una nouvelle, 'Ocampo', que aún conservo, y que algún día publicaré - para llenar, como hizo Aira con 'Moreira', aunque la mía es evidentemente superior..." (Op. Cit. Bizzio 1990: 34).

En 1992, César Aira publica El volante, novela corta fechada el 17 de diciembre de 1989, claro índice de que el "grupo Shangai", a escaso año de la aparición de su órgano de expresión, ya era lo suficientemente visible en la escena literaria local como para ser ficcionalizado. (Es significativo, además, que Aira publique El volante dos años antes que Los misterios de Rosario, memoria impiadosa en su literatura del "Grupo de Estudios Literarios" de la Universidad Nacional de Rosario: Alberto Giordano, Darío González, Sergio Cueto, Nora Ávaro, Marcela Zanín y Analía Gerbaudo, entre otros.)

El volante ridiculiza la ambición literaria de los “jóvenes del grupo Calcutti” (en clara alusión al autodenominado "Grupo Shangai"). Aira no solo se burla de la idolatría que sienten "Fejfec", "Hitarroney" y "Beguel" (esto es: Chejfec, Chitarroni y Guebel) por el autor "Cedar Pringle", sino que también -en un arranque de modestia- define a dicho autor como "un gran escritor, grande entre los grandes, a la altura de un Henry James, un Flaubert, un Laforgue" (1992: 62).

Esta supuesta idolatría, valga la aclaración, ya había mostrado sus fisuras. En el $\mathrm{n}^{\circ} 20$ de Babel, revista de libros (noviembre de 1990), se publican dos intervenciones en contra de la prédica de César Aira sobre el valor literario de la obra de Emeterio Cerro: "El cencerro y las vacas", de Carlos E. Feiling (en la sección "Polémicas") y una nota de Martín Caparrós en su sección "La Verónica”, donde señala lo siguiente: "César Aira, abanderado-chasco de tan espaciosos bríos, trabaja una literatura de la displicencia: palabras que se proponen como la tradición de los gestos más banales: una estatización de lo vulgar [...] ¿Una literatura entonces, del accidente? (1990: 17). De manera más asordinada, también Matilde Sánchez desconfía del valor literario de otro de los escritores reivindicados por Aira: Copi. ${ }^{118}$

En 1997 Luis Chitarroni publica El Carapálida, donde se narran las aventuras de un adolescente (apodado así por su palidez) y sus compañeros de séptimo grado A-B. Una melancolía ominosa ensombrece los escenarios de esta novela: el abismo entre los

118 "Hace un par de años asistí a una serie de charlas de César Aira sobre Copi en el Centro Cultural Ricardo Rojas. Durante esos encuentros Aira nos convenció [...] de que estábamos ante un autor sencillamente genial, único y extraordinario, juicio con el que hoy yo no coincidiría del todo." (Sánchez 1990: 4) 
intereses de los estudiantes y las estrambóticas propuestas pedagógicas de los directivos de la escuela parece insalvable. Entre los profesores se cuentan "César Quaglia", profesor de Ciencias Sociales con inquietudes literarias, "pasaba por ser el más inteligente", "admirado por todos" (1997: 33), y "Ricardo Neira", el profesor de matemática cuya "mayor virtud como educador era el hecho de anunciar una iluminación inminente y decepcionarlos" (1997: 109). Esto es: Ricardo Piglia (“Quaglia”) y César Aira ("Neira”).

El cruce de los nombres propios reales para armar los seudónimos ("César Quaglia" y "Ricardo Neira", en vez de los más fácilmente descifrables "Ricardo Quaglia" y "César Neria"), habida cuenta del desprecio que Aira siempre profesó por el autor de Respiración artificial, no puede ser tomado más que como una broma maligna. ${ }^{119}$

En 2007 aparece Peripecias del no. Diario de una novela inconclusa: el eco más tardío de la memoria del llamado "grupo Babel" en la literatura de Chitarroni. Prácticamente, todos los seudónimos y anagramas que plagan esta novela esconden identidades reales ("Nicasio Urlihrt" es, para dar un ejemplo, el mismo "Luis Chitarroni"). Por otra parte, abandonando las convenciones de la roman à clef, el autor no se priva de escribir con nombre y apellido:

Escribí "Temprano" para una reunión de La causa, un grupo que no fundamos o una revista que no hicimos, cumpliendo el mandato de constituirnos como grupo de la revista (rencor cacofónico) El periodista (¡me acordé!). ¿Antes?

Creo que esa vez fui el único que hizo los deberes. La reunión fue en el departamento de Charlie de la calle Independencia (el de El mal menor). Charlie, Alan, Chejfec, Guebel, Bizzio, yo. Los recuerdo a

\footnotetext{
119 En agosto de 1981, en su artículo "Novela argentina: nada más que una idea" para Vigencia, Aira afirmaba que: "Ricardo Piglia logra con Respiración Artificial (Pomaire, 1980) una de las peores novelas de su generación gracias, en parte, a esta sordidez profesional, que en él deriva del temor infantil de que no lo comparen con Arlt (la otra cara de esta identificación es la escritura vigilada hasta la aridez, por temor de que sí lo comparen con Arlt). En realidad Piglia no proviene en absoluto de Arlt, que fue un verdadero novelista [...] Su maestro es Sábato" (1981: 58). Contra este juicio de valor va a pronunciarse Fogwill en la nota "Jardín de letras robadas", publicada en diciembre de 1981 en la misma revista (y antologizada en Los libros de la guerra), donde señala que: "Desde las páginas de Vigencia se ha dictaminado que Respiración artificial es la peor novela de su generación, olvidando señalar que es la peor novela del mejor escritor de su generación, lo que hubiese contribuido al diagnóstico de la narrativa actual" [1981] 2010: 97). Durante la entrevista que Castro y Borgna realizan a César Aira para el primer número de Pie de Página ya citada, el escritor oriundo de Pringles vuelve a algunos de los exabruptos presentes en "Novela argentina: nada más que una idea": "La gran influencia de los novelistas recientes, de Asís a Piglia, ida y vuelta, es Sábato: ese gesto de ciudadano responsable, de hombre serio, entre cura y cana. Por supuesto, los leo poco. Me resultan deprimentes a más no poder, lo que seguramente es culpa mía. Pero yo nunca usaría a la literatura para pasar por una buena persona" (Op. Cit. Aira 1982: 3).
} 
todos pasándose las hojas mecanografiadas en la Hermes de metal mientras yo no sé qué hacía. Hasta que el polaco, el primero o el único que terminó de leer, dijo: 'A mí me gusta. Es muy sentimental'.

Veleidad absoluta de mi memoria. No es imaginable siquiera que Sergio y Danny pudieran concentrarse. (Chitarroni 2007: 13)

Un año antes de la aparición de Peripecias del no, Sergio Bizzio y Daniel Guebel habían publicado El día feliz de Charlie Feiling, donde se narra el viaje de tres amigos a la localidad de Ramallo, un asado pantagruélico y la excursión a un arroyo cercano. "Feiling" es aquí Carlos E. Feiling, "Guebel” es Daniel Guebel y "Bizzio" es Sergio Bizzio, y también aparecen los nombres reales de los anfitriones: los padres de Bizzio. El día feliz de Charlie Feiling contiene diatribas contra Mario Benedetti, Osvaldo Soriano y Julio Cortázar; una relectura por parte de Feiling de Rayuela como plagio (fallido) de Pálido Fuego y algunas burlas amables contra la morosidad con que Juan José Saer suele narrar en sus novelas los ritos del asado y la amistad.

Los nombres propios, sin embargo, ya habían aparecido antes. En El coloquio (1990), Alan Pauls había utilizado los nombres de Guebel y Chitarroni para bautizar casos policiales: el "altercado en el Destacamento de Guebel”, el "episodio del presidio de Chitarroni” (1990: 65). En la novela El tercer cuerpo, aparecida el mismo año, Caparrós adjudica a un tal "Jorge Dorio" la autoría de un hit radial que aturde el verano. En El agua electrizada (1992), de Feiling, el personaje ficticio de "Tony" lee la novela Más allá del bien y lentamente.

En resumen: algunos de los autores de nuestro corpus se ocuparon desde muy temprano de autorrepresentarse no sólo en términos de "generación literaria" (como se analizó en el capítulo uno), sino en tanto "grupo cultural", dando pábulo a las lecturas críticas que propusieron la antinomia “ 'babélicos' VS. 'planetarios' ” como un modo de volver inteligible el campo literario entre fines de la década del ochenta del siglo XX y mediados de la década siguiente.

\section{Conclusiones del capítulo}

Más allá de la eficaz puesta en escena de un supuesto conflicto ("narrativistas-queescriben-para-el-mercado VS. experimentalistas-que-escriben-para-una-elite”), los escritores de la "generación ausente" compartieron un contexto de publicación que les fue adverso y hostil, que reconoce tres fases: la "crisis del mercado editorial" (19761989); el llamado "alejamiento del lector nativo de la ficción” (1985-1990) y la 
“concentración y polarización de la industria editorial” (1990-2000). Contra él, en tanto “críticos-estrategas", esgrimieron diferentes armas, que fueron desde un rol muy activo dentro de diferentes revistas culturales y publicaciones de llegada más o menos masiva, una importante labor editora, su vínculo fluido con la Academia (el más notorio: con los docentes y "hermanos mayores" de la Cátedra de Literatura Argentina II de la Universidad de Buenos Aires, cuya Jefa de Cátedra hasta el año 2003 fue Beatriz Sarlo) hasta, incluso, una cierta inserción en radio y televisión. ${ }^{120}$

De todos los medios nombrados, las revistas culturales fueron el espacio privilegiado para la formulación de una deseable "nueva política de la literatura" (Rodolfo Walsh, Osvaldo Lamborghini, Manuel Puig; las comillas van a cuenta de que dicha propuesta por parte de miembros de la "generación ausente", tal como lo hemos visto al desplegar la "red de publicaciones periódicas" en la que se insertaría Babel, revista de libros, no era "nueva", sino heredada de determinados "hermanos mayores", entre ellos, quizá el de mayor gravitación, César Aira) y la instalación de la pregunta por los posibles herederos de dicha "tradición selectiva".

Si hace más veinte años varios de los agentes estudiados se ocuparon de reordenar el sistema literario argentino, lo habrían hecho precisamente para crear un espacio de recepción propicio para sus propias novelas, que varios de ellos recién comenzarían a publicar a fines de la década del '90 del siglo pasado. La correspondencia entre la poética desplegada en las novelas de más reciente publicación de, por ejemplo, Alan Pauls y Carlos Gamerro (que serán analizadas en el marco del próximo capítulo) y la "fórmula" de Daniel Link en el n 6 de Babel, serían indicio de una enorme coherencia de proyecto.

Si bien fue una publicación de duración relativamente breve (sólo 22 números entre abril de 1988 y marzo de 1991), Babel, revista de libros constituyó uno de los puntos de encuentro más intensos de la "generación ausente" y siguió irradiando su influencia muchos años después de que dejara de publicarse.

Los llamados "babélicos" y "planetarios" por la bibliografía secundaria mantuvieron zonas de intersección en lo que hace a sus intereses estéticos y fluidos

${ }^{120}$ Con esto nos estamos refiriendo a los programas televisivos "Cinegrafía" (en Canal 13) y "Cable a tierra" (en ATC), conducidos por Alan Pauls, Marcelo Figueras y Daniel Guebel en los tempranos ochenta; la emisión radial sabatina "Sueños de una noche de Belgrano" (1984) y el programa televisivo "El Monitor Argentino" (1986), que Jorge Dorio co-condujo con Martín Caparrós (el nombre de este último programa pareciera ser un homenaje a El Monitor, jefe máximo de la Tecnocracia en Los Sorias, de Alberto Laiseca) y el espacio "La Biblioteca", conducido por Dorio dentro del programa Badía \& Compañía, de Juan Carlos Badía. 
contactos personales, todo lo cual desmiente el mito de su supuesto "enfrentamiento". O bien volvieron a elegirse a la hora de armar elencos en otras publicaciones ("Radar"; "Radarlibros", Magazín literario), o bien cooperaron entre sí para autopromocionarse como la "nueva narrativa argentina" (asumida como categoría passe-partout), según la lógica de un sólido sistema de lealtades, sobre el cual volveremos en el capítulo cuatro.

Mediante estrategias aprendidas en la lectura de Jorge Luis Borges y César Aira, varios de los escritores de nuestro corpus apostaron a la construcción de una "autoimagen de escritor" colectiva en sus novelas, lo que también demostraría que no sólo la bibliografía secundaria sino también la literatura fue permeable a la "operación Raymond Williams en Punto de Vista" (Cf. Op. Cit. Dalmaroni 1997). Al respecto, podría afirmarse que El coloquio (1990), de Alan Pauls; El tercer cuerpo (1990), de Martín Caparrós; El agua electrizada (1992), de Carlos Feiling; El día feliz de Charlie Feiling (2006), de Sergio Bizzio y Daniel Guebel, y El carapálida (1997) y Peripecias del no. Diario de una novela inconclusa (2007), de Luis Chitarroni son textos de intervención que confluyen con las maniobras de promoción de la propia narrativa desplegadas en la sección "El libro del mes" de Babel, revista de libros, y por medio de las cuales los autores estudiados pretendieron asegurarse un lugar en el campo literario argentino, desde forma muy temprana y cuando todavía no se vislumbraba la trascendencia de ninguno de ellos en particular. 


\section{CAPÍTULO TRES}

LAS NOVELAS

\subsection{Los militantes populares como "víctimas absolutas" en Los planetas, de Sergio Chejfec}

En 1999 se publica Los planetas, de Sergio Chejfec, ejemplo enrarecido de una memoria de la militancia de los "jóvenes menores" que contraría el contexto de recuperación del pasado militante de los detenidos-desaparecidos, y que tiene uno de sus hitos en la publicación en tres tomos de La Voluntad. Una historia de la militancia revolucionaria en la Argentina, de Eduardo Anguita y Martín Caparrós. ${ }^{121}$

La novela de Chejfec narra la historia de $\mathrm{M}$, adolescente secuestrado por las llamadas "fuerzas del orden" sobre cuya posible participación en algún tipo de organización revolucionaria no se da ninguna referencia precisa. Al respecto, el narrador S, su mejor amigo desde la niñez -en diálogo con "Sito", otro amigo del barrio a quien reencuentra de manera casual a comienzos de la década del noventa- sólo expresa lo siguiente:

... mientras tomábamos ese café, advertí el tenor de las dudas de Sito. En su memoria la figura de M, siempre distraído hasta el punto de parecer indiferente, conservaba un aura de inocencia [...] y en este sentido la desaparición constituía, además de una interrogación acerca de su destino, también una incógnita sobre su pasado. El pasado de M, según lo entendía Sito, podía haber sido susceptible de propiciar el secuestro -o todo lo contrario, acaso fuera totalmente ajeno a la política, y por lo tanto víctima de una situación imprevista ni buscada-. [...] Sito entendía que la conducta era capaz de incidir en la fortuna de las personas [...] necesitaba saber si M era absolutamente inocente, o sea, según su criterio, una víctima absoluta. Lo era, dije al responder "No" a su pregunta. (Chejfec 1999a: 119-120)

$\mathrm{M}$ es un detenido-desaparecido sin pasado militante a reivindicar. Aún más: en este caso, la construcción de su condición de "víctima absoluta" no obedece a ningún tipo de estrategia judicial, dado que M nunca fue mencionado en el Juicio a las Juntas y

\footnotetext{
${ }^{121}$ La Voluntad volvió a reeditarse corregida y aumentada en el mes de febrero del año 2006, esta vez por la editorial Booket (sello de bolsillo del Grupo Planeta), en cinco tomos y con un tiraje de 4000 ejemplares. En 2013 se publicó la versión definitiva, nuevamente en tres tomos, y con un tiraje de 5000 ejemplares para el primer volumen (en orden decreciente, el volumen dos tiene un tiraje de 4000 y el tercero y último, de 3000 ejemplares). En el prólogo que Martín Caparrós escribe para la misma, ensaya una "tipología de militantes", que constituye al mismo tiempo un ensayo de periodización y una provocación: "1977-1995: el militante como víctima"; "1996-2003: el militante como militante"; "20042010: el militante como héroe indefinido" y "2010: el militante como monto patotero" (Cf. Caparrós 2013: XIX-XXI).
} 
tampoco está en las listas de detenidos-desaparecidos realizadas por la CONADEP, ni en los listados ampliados posteriores:

Todavía hoy me asombra no haber encontrado el nombre de $\mathrm{M}$ escrito en ningún lugar, en los listados de las organizaciones ni en los avisos de la prensa. Y digo todavía hoy porque, enseguida después del secuestro, me aboqué como muchos otros a leer denuncias y pedidos judiciales, documentos y testimonios de antiguas víctimas, etcétera. Esto duró años; después simplemente continué aguardando su aparición en algún listado o aviso de prensa y ahora termino sintiendo una mezcla de temor y adoración: el efecto se revirtió en causa, el nombre de $\mathrm{M}$ fue aislado por el silencio y de este modo retornó al estado de puro encantamiento en el que flota cualquier nombre hasta que lo rescatamos en el uso, asignándole un individuo. (Chejfec 1999a: 42-43)

¿Qué decir entonces de M, cómo contar la historia de M?

Lo primero es recuperar su voz: reconstruir las historias en forma de parábolas de ribetes kafkianos que gustaba de relatar M mientras caminaba por la ciudad con S. Si, según el narrador, $M$ es un "mártir", lo es (torsión etimológica mediante) en tanto ha dejado una marca (Cf. Chejfec 1999a: 22). Una marca: es decir, una serie de relatos, que $\mathrm{S}$ inserta dentro de la narración marcando su atribución con letras mayúsculas. Pero Chejfec también recupera la etimología de "mártir" que viene del latín clásico martyr (tomado del griego $\mu \alpha \rho \tau \nu \rho \varsigma_{\varsigma}$ que significa "testigo", a partir de la idea de que un mártir continúa dando testimonio de su fe incluso -o aún más- cuando su cuerpo ha sido torturado).

En efecto: S sostiene que "era otro el que podía hablar y no yo" (Chejfec 1999a: 23), señala que testimonia "en lugar del otro", tal como lo sostuvo Primo Levi para los testigos de la Shoah. ${ }^{122}$ La voz del testigo es una voz que habla por delegación, porque los detenidos-desaparecidos (como M) de los cuales ni siquiera se sabe dónde están sus

\footnotetext{
${ }^{122}$ La figura del "testigo" tiene en latín una doble acepción: testis/ superstes. Por un lado, testis alude a que su desempeño tiene que ver con el establecimiento de los hechos con vistas a un proceso judicial; la segunda acepción de testigo, superstes, hace referencia al que ha transitado una determinada experiencia y está en condiciones de ofrecer un testimonio sobre ella. La respuesta a la pregunta sobre el sujeto del testimonio implica sin embargo una paradoja, ya que, como señala Primo Levi en Los hundidos y los salvados (1989), no son los sobrevivientes los verdaderos testigos de la Shoah: "no somos nosotros, los supervivientes, los verdaderos testigos... Los que hemos sobrevivido somos una minoría anómala, además de exigua: somos aquellos que por sus prevaricaciones, o su habilidad, o su suerte, no han tocado fondo. Quien lo ha hecho, quien ha visto a la Gorgona, no ha vuelto para contarlo, o se ha vuelto mudo; son ellos, los 'musulmanes', los hundidos, los testigos integrales, aquellos cuya declaración habría podido tener un significado general. Ellos son la regla, nosotros la excepción... Los que tuvimos suerte hemos intentado, con mayor o menor discreción, contar no solamente nuestro destino sino también el de los demás, precisamente el de los 'hundidos'; pero se ha tratado de una narración 'por cuenta de terceros', el relato de cosas vistas de cerca pero no experimentadas por uno mismo. La demolición terminada, la obra cumplida, no hay quien la haya contado, como no hay nadie que haya vuelto para contar su muerte" (Levi 1989: 72-73).
} 
restos vendrían a ser los "testigos integrales": el equivalente argentino de los musulmanes del Lager según los definió Giorgio Agamben apoyándose en la tipología de Primo Levi en Los hundidos y los salvados (1986). ${ }^{123}$ La condición judía de ambos amigos, que el narrador S subraya más de una vez, entraría así en relación con el trabajo con dicha identidad llevado a cabo por el Chejfec en Lenta biografía, publicada en 1990 (novela también escrita en modo autoficcional). ${ }^{124}$

A la manera del sobreviviente de Auschwitz Jean Améry, S tiene una relación vacilante con la primera persona prototípica del género testimonio. En la rememoración de la amistad (que en el cuerpo de la novela aparece destacada en itálicas), S pasa de la primera a la tercera y se refiere a sí mismo como "uno" (en su uso impersonal) y "el otro". La recuperación de la historia de M significa para S ocupar un espacio de “escritor" que, en verdad, hubiera cuadrado tanto mejor al amigo desaparecido:

Aquella historia de la pareja de nómadas me dejó tan absorto como la del ojo. Comparado conmigo, que carecía de aptitud hasta para describir confusamente lo vivido el día anterior, $M$ se prodigaba en historias e incidentes que no sólo le concernían directamente [...] sino también abarcaban una materia más amplia y difusa, y por eso más opinable y controversial, que provenía de quién sabe dónde para llegar hasta él, adquiriendo un nuevo contorno con su voz. Por ello, es para mí evidente que, de haber continuado con vida, él habría sido el escritor, el novelista. (Chejfec 1999a: 104)

$\mathrm{S}$ escribe porque $\mathrm{M}$ no está: "si hay en mi idioma -el idioma particular- algo plausible de ser dicho, no las palabras, tampoco los hechos, sino la moral de unas y el valor de otros, están de algún modo dictados por la memoria de M" (Op. Cit. Chejfec 1999a: 104), y se transforma en autor por medio de la apropiación de un tono, un sistema de personajes y un repertorio de imágenes oníricas que pertenecían originariamente a M. Pero esta apuesta no continúa más allá de las dos primeras páginas de Los planetas, que es cuando irrumpe la noticia de "cierta explosión en el medio del campo" (Chejfec 1999a: 17). La explosión, que llena el terreno de "miembros regados, repartidos, ordenados en círculos imaginarios" sólo puede remitir -en el contexto

\footnotetext{
${ }^{123}$ Los sobrevivientes viven ocupando el puesto de otro (del que ha muerto en vida o en la cámara de gas), y hablan por el llamado "musulmán" en la jerga de los campos de concentración nazis, en el sentido jurídico técnico de "por cuenta de" o "por delegación". La paradoja de Levi consiste en sostener como "testigos integrales" de la experiencia de la Shoah a los no-hombres, a aquellos cuya humanidad ha sido destruida. A la figura del "musulmán", Giorgio Agamben dedica el tercer capítulo de Lo que queda de Auschwitz. Homo Saccer III (2002: 41-89).

${ }^{124}$ Si bien en "Marcas en el laberinto. Literatura judía y territorios" ([1995] 2005), Sergio Chejfec ha argumentado con fundamento contra la idea de una "literatura judía latinoamericana", consideramos pertinente retomar algunos conceptos vertidos por Primo Levi y Giorgio Agamben para analizar Los planetas. El artículo "Marcas en el laberinto" integra la antología de intervenciones críticas El punto vacilante. Literatura, ideas y mundo privado (2005).
} 
dictatorial en el que S lee esta noticia periodística- a "los cuerpos deshechos después de haber sufrido, separados en trozos y dispersos" (Ibid.), y hace de la "historia de Grino" que inaugura la novela un falso incipit, porque de lo que en verdad se trata, es de recuperar la memoria de la amistad con $\mathrm{M}$.

Hemos señalado que $\mathrm{M}$ es un detenido-desaparecido atípico y -por lo mismo- su identidad es volátil ("M de Miguel, o de Mauricio; también podría decir M de Daniel”). Sin embargo, en el primer relato oral que S recupera ("PRIMERA HISTORIA DE M"), esta identidad parece quedar fijada a la primera posibilidad. En ella se cuenta la broma que dos amigos ("Sergio" y "Miguel") deciden jugarle a sus respectivos padres, intercambiando identidades a la salida del colegio para marchar a casa del otro, y asumir su vida como si fuera la propia. Los burladores finalmente terminan burlados, porque los progenitores ignoran ostentosamente la nueva situación. Esta "primera historia de M” podría ser tomada como pesadilla anticipatoria del trámite que, promediando la década menemista, realiza S en el Registro Nacional de Personas para cambiarse el nombre por el de su amigo desaparecido:

No sé lo que pueda parecer -curioso, ridículo, insensato-, pero sé lo que fue: vano; lo concreto es que durante un tiempo intenté cambiar mi nombre, quise adoptar el de M [...] Ya que él había tenido la desdicha de ser muerto, ya que era él quien había sufrido el martirio, me pareció justo que yo, habiendo quedado vivo, compensara su ausencia volcando su nombre en el mío. (Chejfec 1999a: 213)

En su afán, S se convierte en amante de una empleada del Registro, quien le recomienda que escriba y publique una novela utilizando el nombre de $\mathrm{M}$ como seudónimo, para esgrimir este hecho como "causal" y tener más posibilidades que su pedido de cambio de identidad encuentre eco. Ya sobre el final de la novela, cuando todo parece conducir a una resolución "en abismo" (esto es: el volumen Los planetas que el lector tiene en sus manos como la "causal” solicitada), S desiste de su propósito.

En un contexto donde los detenidos-desaparecidos, habiendo sido presentados inicialmente como "víctimas" por una estrategia judicial, son abiertamente reivindicados en tanto "militantes populares", la voz de Chejfec se elevaría, solitaria, proponiendo otra cosa: resignificarlos como "muertos", y, por lo mismo merecedores de un respeto no ya político, sino antropológico, en el sentido que le da Philippe Ariès en El hombre ante la muerte ([1977] 1999). ${ }^{125}$

\footnotetext{
${ }^{125}$ En una entrevista de Mónica Sifrim publicada por Clarín el 7 del noviembre de 1999 como parte de la campaña de promoción de la novela, Chejfec afirmaba lo siguiente: "Quise trabajar con la idea de que, si algo podemos hacer para recuperar la entidad humana de quienes han desaparecido, es pensar en ellos
} 
La originalidad de Chejfec en lo que hace a la memoria en la literatura de la militancia de los adolescentes y/ o jóvenes menores resulta aún más notoria si la contrastamos con la presente en la novelística de Martín Caparrós.

La contratapa de la primera edición de No velas a tus muertos (publicada en 1986, aunque allí mismo el autor señala que fue escrita antes que Ansay o los infortunios de la gloria) sorprende por la virulencia con que se elige hacer explícito el conflicto entre la conducción y las bases dentro de la Organización Montoneros:

La militancia devota e ingenua de la que alguna vez fue llamada "juventud maravillosa", conducida por un revolucionarismo de salón que terminó masacrado en medio de un delirio de sangre, aparece aquí vista desde adentro, pero con una distancia que sólo los años -aparentemente pocos, pero con virtualidad de años luz- podían conferir.

Narrada en varios planos, con un nivel de escritura poco común y el empleo de un riquísimo idioma, esta novela caricaturesca desmesurada intencionalmente, es la primera aproximación no piadosa al drama argentino de la última década. (Caparrós 1986: s/ n)

No velas a tus muertos ensaya con éxito una modesta experimentación formal. Tres son los puntos de vista que se utilizan para narrar los avatares de una célula montonera que planea realizar un atentado: "Carlos Montana", escritor de treinta y dos años para cuando ocurre el golpe del '76, que luego de la muerte de Perón decidió unirse al Frente Barrial de la Organización Montoneros para -entre otras cosasdesquitarse de no haber participado en el mayo francés; "Hernán", alumno del Nacional Buenos Aires y joven militante de la UES-Montoneros que recibe su bautismo de fuego en la llamada "masacre" de Ezeiza, y "Estela", estudiante universitaria y la responsable de la célula.

La figura de "Hernán" establece un claro paralelismo con la trayectoria política del autor, que también fue alumno del Colegio Nacional de Buenos Aires (entre 1969 y 1974) y miembro de dicho sector de la llamada Tendencia. ${ }^{126}$ En la novela, la voz de

como muertos, más que como desaparecidos. Porque el desaparecido es víctima de una acción: lo secuestran, lo torturan, o ponen una bomba y lo destrozan, y nunca se vuelve a saber de él. Pero en la Argentina, de tanto utilizar la palabra, se perdió un poco la dimensión humana de esa gente. Cuando me puse a pensar cómo tratar a un personaje que es desaparecido, pensé que era más justo con la historia, con la novela, con la literatura y con mi forma de ver las cosas tratarlo como muerto. Y esto vuelve como una mayor responsabilidad sobre los culpables de esa muerte, en tanto no realizaron una operación más o menos ilegal, militar, política: ejecutaron un asesinato" (1999b: http://edant.clarin.com/suplementos/cultura/1999/11/07/e-00501d.htm, consultado el 10.1.2013)

${ }^{126}$ El 18 de abril de 1973 se creó en el Colegio Nacional la agrupación Ateneo Ramón Cesario de la Unión de Estudiantes Secundarios (UES), que inmediatamente después comenzó a funcionar en otros establecimientos educativos. Su responsable político nacional era un ex alumno que había hablado en el acto de asunción del rector Raúl Aragón el 4 de junio de 1973, Claudio "El Barba" Slemenson. Fue una de las organizaciones de masas creadas por Montoneros, que junto con otras organizaciones políticas, 
"Hernán" (nombre de guerra "Santiago") aparece siempre en diálogo imaginario con "Pato", ex compañero de militancia y secundaria de quien el lector puede fácilmente inferir que -ya para el año 1978, que es cuando la célula planifica el ajusticiamiento en No velas a tus muertos- está desaparecido.

El libro de Santiago Garaño y Werner Pertot, La otra juvenilia. Militancia y represión en el Colegio Nacional de Buenos Aires (1971-1986), devela lo siguiente:

Benjamín Isaac Dricas, alias "El Pato Fellini”, era un militante de la UES de Buenos Aires, compañero de Eduardo Bekerman y de Claudio Slemenson. Para evitar ser apresado, se suicidó en noviembre de 1976. Tenía veinte años. El libro No velas a tus muertos de Martín Caparrós toma ciertos aspectos de su militancia y su desaparición. (Garaño/ Pertot [2002] 2008: 69)

Pensada en términos de "auto-imagen de escritor", en No velas a tus muertos el autor prestaría rasgos de su identidad no a una, sino a dos criaturas autoficcionales, parcialmente contradictorias entre sí. Por un lado, su adscripción generacional, la militancia en la UES-Montoneros y su temprano ingreso al periodismo (Caparrós, con apenas 16 años de edad, entra como aprendiz de periodista al diario Noticias, donde trabajaban Rodolfo Walsh y Francisco Urondo, VER Caparrós [Entrevistado por Javier Trímboli] 1998: 51). Por otro lado, su exilio en París, sus ambiciones de escritor y un cinismo casi siempre ostentoso a la figura de "Carlos Montana", que es precisamente el seudónimo que elige Caparrós para firmar la sección "Caprichos” en la contratapa del $\mathrm{n}^{\circ} 1$ de Babel de abril de $1988 .^{127}$

Dentro del conjunto de las novelas que hacen memoria en la literatura del proceso de toma de consciencia político-social de un alumno de escuela media, entre las que cabría mencionar Sinfonía para Ana de Gaby Meik (publicada en 2004) y Noticias del setenta y cinco (2009), de Jan de Jager, la novela de Caparrós sorprende por su

como la Juventud Universitaria Peronista (JUP), formaban parte de la Tendencia Revolucionaria. Buena memoria. Un ensayo fotográfico (1996), de Marcelo Brodsky es al día de la fecha el más sugerente intento de dar cuenta de la militancia estudiantil en el Colegio Nacional, que tuvo 106 alumnos asesinados. La exhibición Buena memoria fue presentada por Martín Caparrós, cuyas palabras se reprodujeron en la publicación de Buena memoria como libro (1997).

${ }^{127}$ El personaje de "Carlos Montana" reaparece en La noche anterior (1990), novela de exilio que empalma temporalmente con No velas a tus muertos y donde se cuenta la deserción de Carlos en 1979 del Frente Barrial, y su huída al extranjero. También "Carlos" es el héroe de A quien corresponda (2008), donde Caparrós denuncia la utilización de la bandera de los DDHH por parte del gobierno kirchnerista y la reificación de la memoria ("La memoria se volvió hoy una obligación moral social"), al mismo tiempo que se propone derribar algunos mitos: "No es que fuéramos mejores que otros, más generosos, más decididos, y por eso nos entregamos a la revolución" (Caparrós 2008: 263). A quien corresponda se abre con tres epígrafes. Dice el último: "Este relato debería ser pura ficción. Sería fantástico", e invitaría a leer la novela como "no ficción" (o mejor: como autoficción). 
temprana reivindicación de ésta en términos de militancia (VER Caparrós 1986: 185186). ${ }^{128}$

Según la CONADEP, el $81 \%$ de las víctimas del terrorismo de Estado tenían entre dieciséis y treinta y un años, y un $21 \%$ del total eran estudiantes. Sin embargo, esta descripción soslaya el hecho de que numerosos individuos dentro del grupo de los perpetradores compartieron la adscripción generacional con sus víctimas. Entre ellos, hubo quienes oficiaron de "segundones" dentro del sistema concentracionario: los que por esos años realizaban la conscripción obligatoria, o bien los llamados "verdes" en la jerga de la Escuela de Mecánica de la Armada, esto es, alumnos de la Institución, que, sin estar directamente implicados en la tortura y exterminio de prisioneros, oficiaron de guardia-cárceles, chóferes y amanuenses de los "capos" pertenecientes a los grupos de tareas, o bien trabajaron como personal de mantenimiento y limpieza (muchas veces, codo a codo con detenidos-desaparecidos que -por ser considerados "recuperables"habían logrado cierto "trato de privilegio" dentro del campo). En el próximo parágrafo nos ocuparemos de aquellas novelas donde la apuesta parece ser asumir el punto de vista de estos "segundones" para narrar-desde el otro lado- la violencia política en la Argentina.

\section{2. ¿Quién de nosotros escribirá el "Deutsches Requiem" de la dictadura? Dos veces junio, de Martín Kohan}

En el momento de la publicación de "Deutsches Requiem" en el número 136 de la revista Sur (febrero de 1946), el Juicio de Nürnberg todavía no había terminado, faltaban dos años para que el llamado "médico de la muerte" Josef Mengele se refugiara en Buenos Aires (donde en 1956 obtendría un pasaporte expedido a su propio nombre por la policía argentina), y unos quince para que la Mossad capturara a Adolf Eichmann en nuestro país y Hannah Arendt enunciara su tesis sobre la banalidad del mal.

Si frente a la palabra del enemigo, las posibilidades son dos (silenciarla o llevarla hasta la estridencia, para provocar asco en el lector), la voz del ignoto sub-director de un campo de concentración en el Este en "Deutsches Requiem" construida por Borges parece apostar a complicar este planteo. ${ }^{129}$ Para la escena política local, Borges repetirá

\footnotetext{
128 En clave tanto más ambigua, Rodrigo Fresán tematiza la opción por las armas de los “jóvenes menores" en Esperanto (1995).

${ }^{129}$ Otto Dietrich zur Linde es melómano y lector de Shakesperare. No admira a Richard Wagner -el compositor del nacionalsocialismo- sino a Johannes Brahms, que fue el oponente musical de Wagner y que en 1868 había compuesto una misa de difuntos llamada, como el cuento argentino, "Deutsches Requiem".
} 
el gesto con "La fiesta del monstruo", cuento escrito un año más tarde en colaboración con Adolfo Bioy Casares bajo el célebre heterónimo de Bustos Domecq, pero recién publicado en el semanario Marcha de Montevideo el 30 de septiembre de 1955.

En "La fiesta del monstruo" narra un miembro de la Alianza Libertadora Nacionalista, que cuenta con alborozo el agravio, tortura y asesinato de un intelectual judío en el marco de una jornada de movilización a la Plaza para escuchar la palabra del líder. ${ }^{130}$ A diferencia de lo que ocurre con la voz de "Deutsches Requiem", es imposible sentir empatía por este narrador, que relata sus atrocidades por medio de un argot en exceso literario. Nunca interpela al lector (como sí lo hacía Otto Dietrich zur Linde), sino que se dirige en exclusiva a su novia, la "gordeta" Nelly, término léxico que bien podría ser una entrada del Breve diccionario del argentino exquisito (1978), de Bioy.

"Deutsches Requiem” y "La fiesta del monstruo", sin embargo, coinciden en el gesto de "ceder la palabra al otro enemigo", que es siempre un segundón de un régimen execrable. La figura del segundón tendría, por un lado, las ventajas de la verosimilitud. (De todas formas, Borges era demasiado inteligente como para proponerse seriamente "hacer hablar" a Hitler o a Perón.) Por otro lado, las bondades del didactismo: hombres ordinarios como ustedes -parecen ser el mensaje para los lectores- también fueron susceptibles de transformarse en seguidores ciegos de una causa equivocada.

Este gesto, en realidad, es parte de la tradición de la mejor literatura política argentina, y Borges mismo se encarga de señalarlo al elegir el verso veintiuno de "La refalosa" de Hilario Ascasubi como epígrafe para "La fiesta del monstruo".

En El género gauchesco (1988), Josefina Ludmer demuestra que es precisamente "La refalosa" -donde un mazorquero anticipa con delectación la ceremonia del degüello- la composición que por primera vez hace hablar en primera persona a los enemigos:

"La refalosa" de Hilario Ascasubi es un texto conocido para los argentinos. No sólo cuenta la primera fiesta del monstruo, sino que deja leer la construcción de una lengua asesina y brutal, la presentación del mal en la lengua [...] La voz del malevo de Hidalgo (el que hacía sacar el cuchillo a Contreras) emerge del silencio, ocupa el espacio entero de la patria, y por primera vez se unen el horror y el escándalo verbal del género (Ludmer [1988] 2000: 145 y 147)

\footnotetext{
130 "La fiesta del monstruo" ficcionaliza un episodio efectivamente ocurrido el 4 de octubre de 1945, cuando "por la noche, en los alrededores de la Facultad de Ingeniería un grupo de aliancistas tiroteó a un grupo democrático y un estudiante, Aaróm Salmún Feijóo, fue asesinado por negarse a vivar a Perón" (Luna [1971] 2005: 222).
} 
Ludmer arma una serie: de "La refalosa" a "La fiesta del monstruo", pasando por "El matadero", de Esteban Echeverría (escrito alrededor de 1839, pero publicado recién en 1871). La culminación de este gesto de "cesión de la palabra al otro enemigo" sería "El niño proletario" incluido en Sebregondi retrocede (1973), de Osvaldo Lamborghini (Cf. Ludmer [1988] 2000: 149-158).

De manera convergente a este planteo, en su ensayo "Echeverría y el lugar del ficción" incluido en La Argentina en pedazos (1993), Ricardo Piglia señala que la excepcionalidad de "El matadero" consistiría en el "registro de la lengua popular", rasgo que haría de él un "acontecimiento histórico" en el corpus de la literatura argentina alta del siglo XIX. Según Piglia, esta apuesta en un texto en prosa marcaría nada menos que el nacimiento de nuestra literatura:

La ficción como tal en la Argentina nace, habría que decir, en el intento de representar el mundo del enemigo, del distinto, del otro (se llame bárbaro, gaucho, indio o inmigrante). Esa representación supone y exige la ficción. Para narrar a su grupo y a su clase desde adentro, para narrar el mundo de la civilización, el gran género de la literatura argentina (el género narrativo por excelencia, habría que decir: que nace, por lo demás, con Sarmiento) es la autobiografía. La clase se cuenta a sí misma bajo la forma de la autobiografía y cuenta al otro con la ficción. (Piglia 1993: 9; énfasis del autor)

Aunque el lector ya sepa que está frente a la "ficción de la reproducción escrita de la palabra oral del otro como palabra del otro y no como la del que escribe" (Ludmer [1988] 2000: 66), la lectura del texto de Echeverría se ve entorpecida además por una abundante "censura a nivel tipográfico": los puntos suspensivos con los que el narrador elige dejar en suspenso la bestialidad de los rosistas, tanto en el plano verbal (elisión de palabras gruesas y obscenidades) como en el de la trama, si coincidimos con David Viñas que lo que allí está ocurriendo es la violación del joven unitario (Cf. Viñas [1964: 2005: 12).

Es sabido que "El matadero" llegó al lector contemporáneo ya mediado por la tarea de exhumación y rescate de Juan María Gutiérrez: al no disponer del manuscrito original, no sabemos si estos silencios fueron obra del propio Echeverría, o del editor de sus obras completas (Cf. Amante 2003: 178). De todas formas, es clara la incomodidad del escritor culto frente a la lengua popular en su apuesta por cederle la palabra, actitud en la que nunca cayeron los autores de la gauchesca. Pensando la cuestión de la cesión de la voz al otro desde este texto precursor, cabría preguntarse cuáles son las tensiones y los límites de hacer hablar en primera persona a los enemigos. 
En 1975 Elvirá Orphée escribió La última conquista de El Ángel. La novela fue publicada dos años más tarde en Caracas, en la editorial Monte Ávila. Fue reeditada en 1984 en Javier Vergara Editor, pero tuvo muy poca circulación, y recién en 2004 ayeshalibros la publicó como libro electrónico. Desde el título (que, contra lo que podría asumirse, no fue pensado en alusión al alias del teniente de fragata Alfredo Ignacio Astiz), toda la novela funciona como pesadilla anticipatoria, y quizá resultaría ilegible de haber sido escrita post Nunca más. Aquí, el que habla es un miembro de la "Sección Especial", en funciones bajo el primer peronismo: la misma voz que rememora el firmamento tachonado de estrellas de su Rioja natal, cuenta cómo se monta sobre el pecho de un prisionero (“aguantándole el sacudón”) en las sesiones de picana. El narrador es un protegido del Oficial Winkel, cuya voz cierra la novela con una apología de la tortura (que parece haber sido traducida directamente del alemán, manteniéndose en la transcripción el uso de las mayúsculas luego de los dos puntos):

Lección número uno del adiestramiento del jefe: A las preguntas dejarlas sin contestación. El que no habla habla mejor. Lección número dos: El hombre es débil. Nosotros somos hombres, y para no creer lo que nos cuentan, mejor cerremos los oídos. Ninguno de los que aquí entran es inocente.

Todos los hombres son iguales ante nosotros; parece álgebra; hombre más hombre igual a cero. Hombre igual a cero ante Sección Especial. Sección Especial igual a Dios. No hay diferencias entre nosotros y Dios en este sector de la vida.

El interrogatorio es un arte y nosotros sus artistas. (Orphée [1977] 1984: 179)

En términos de memoria de la literatura, Orphée no haría más que desdoblar el narrador alemán de "Deutsches Requiem" en dos figuras: el Oficial Winkel (que significa "ángulo" en alemán) y su inferior jerárquico en la Sección Especial oriundo de La Rioja, duplicando por lo mismo el gesto de cesión de la voz al otro enemigo, que, según lo quiere la inflexión borgiana, resulta ser para el lector una figura peligrosamente próxima.

Dada la escasa visibilidad de la novela de Elvira Orphée, podría afirmarse que la línea inaugurada por "La refalosa" tuvo su continuación novelística más resonante en Villa (1995), de Luis Gusmán. Aquí el que habla es "Carlos Villa", correveidiles del Doctor Firpo. Inicialmente afectado a diversas tareas administrativas en el Ministerio de Bienestar Social, en el transcurso de la novela "Villa" devendrá médico auxiliar en la sala de torturas y dócil firmante de numerosas actas de defunción, que, con el eufemismo de "muerte por paro respiratorio", aluden al destino atroz de aquellos que se quedaron en las sesiones de picana. 
Lector avisado de las intervenciones críticas sobre "El matadero" realizadas por David Viñas, Josefina Ludmer y Ricardo Piglia, Luis Gusmán da al lector un importante indicio:

El Robustiano ya no era una tierra de misterio sino de miedo. Habían aparecido algunos cuerpos muertos en la extensión que iba desde el Policlínico hasta los corrales. Los dejaban entre el Matadero y el hospital. "Debe ser para que si alguien los encuentra los lleve al hospital", decían en los Olímpicos. (Gusmán 1995: 49)

Estamos, entonces, en el extremo sur de Avellaneda. Para ser más precisos: en "Villa Perro", el barrio de infancia y juventud de Luis Gusmán (de donde éste toma el nombre para la figura del médico: "Carlos Villa"). A pocas cuadras se levanta el Policlínico. Y también los chalets del llamado "Barrio de los Olímpicos", donde vive el campeón Delfo Cabrera. La topografía de Villa se superpone con la de "El matadero": es el mismo espacio geográfico y aquí también hay cadáveres (como diría Néstor Perlongher). Pero con una importante diferencia: ahora los muertos fueron despojados no sólo de la facultad de la palabra (porque el unitario de Echeverría, prácticamente hasta el momento mismo de morir ahogado en su propia sangre, continuaba increpando con energía a quienes lo atormentan), sino que carecen de nombre. En Villa, como en la novela Los planetas de Sergio Chejfec, los cadáveres NN aparecen regados en el espacio del matadero.

En su ensayo "La ficción calculada" incluido en el libro homónimo (1998), Luis Gusmán afirmaba que el hallazgo de José Mármol en Amalia era el haber encontrado un punto de vista para narrar la dictadura rosista. Lo mismo podría decirse de Villa, aunque con una importante salvedad: "Carlos Villa" no sólo es un punto de vista para narrar la última dictadura militar, sino también una respuesta a la pregunta por la posibilidad de recuperar la dimensión ética, o, aunque más no sea, el mundo problemático de los valores en el mundo de la narración. Precisamente a esta posibilidad se refería Gusmán en un reportaje dado a Jorge Panesi en octubre de 1998 para la revista los inrockuptibles: "Hay algo en Borges que ha sido descuidado en la literatura argentina y es que él se permite hablar en buenos términos de los sentimientos o los valores (el coraje, la cobardía)" (1998b: 132).

Habría una dimensión ética en el universo borgiano que iría más allá del tan mentado "culto al coraje" o de la positividad (siempre sospechada de xenofobia) puesta en el "gaucho viejo" frente al "malevo" de origen migratorio. En "Deutsches Requiem", 
el ejemplo que importa para pensar cómo esta herencia entra en las novelas de nuestro corpus, estaría presente en la figura del editor que, a nota al pie, aparece comentando la narración de Otto Dietrich zur Linde. La voz del editor relativiza el gesto de cesión de la voz al otro enemigo, cumpliendo una función de encuadre análoga a la que tenía el título-subtítulo en "La refalosa", tal como señala Josefina Ludmer para el caso de Ascasubi (Op. Cit. Ludmer 1988: 56-74).

En otras palabras: el editor de "Deutsches Requiem" impide que, en un arranque de empatía por esa voz aviesamente (auto) exculpatoria y refinada, nosotros los lectores olvidemos que Otto Dietrich zur Linde tuvo un rol activo en la máquina de exterminio nazi:

$\mathrm{Ni}$ en los archivos ni en la obra de Soergel figura el nombre de Jerusalem. Tampoco lo registran las historias de la literatura alemana. No creo, sin embargo, que se trate de un personaje falso. Por orden de Otto Dietrich zur Linde fueron torturados en Tarnowitz muchos intelectuales judíos, entre ellos la pianista Emma Rosenzweig. "David Jerusalem" es tal vez un símbolo de varios individuos. Nos dicen que murió el $1^{\circ}$ de marzo de 1943; el $1^{\circ}$ de marzo de 1939, el narrador fue herido en Tilsit. (Nota del editor.) (Borges 1946: 12)

En Villa, la dimensión ética no estaría dada por el sistema de encuadre, sino a nivel de la trama, en términos de lo que Beatriz Sarlo ([1996] 2004) ha llamado las "demasiadas coincidencias", y que terminan habilitando al lector un juicio moral externo al espacio construido por la voz del médico:

Villa es un miserable en un sentido que es exterior a la novela [...] y también es un miserable porque padece la casualidad que lo ha puesto en una red de coincidencias que culminan en la inyección de potasio que le aplica a Elena, para que no siga sufriendo en la tortura, para que los torturadores no se den cuenta de que él conocía a esa mujer, para defenderse primero, para defenderla quizás, aunque jamás la hubiera defendido si en esa defensa no estuviera incluida su propia defensa. (Sarlo [1996] 2004: 156)

Hay, entonces, otro aspecto de la "ficción calculada" en Villa, que consiste -como ocurría en "Deutsches Requiem", pero también en "La refalosa” y "El matadero"- en tomar recaudos para que el lector no quede enteramente subyugado por la voz del otro enemigo. La cesión de la palabra efectivamente se produce, pero manteniendo una instancia de enunciación externa (llámese sistema de título-subtítulo, editor a nota al pie o construcción de la trama), que permite, en definitiva, que el lector esté en condiciones de tomar posición frente a los hechos narrados. 
En 2002, Martín Kohan publicó Dos veces junio, escrita al pie de la novela de Gusmán (algo que, ya desde el epígrafe que la inaugura, el mismo autor se encargó de hacer explícito). El que habla ahora es un colimba: las más de las veces, cumple funciones de chofer para el "Doctor Mesiano", médico en funciones en un centro clandestino de detención.

En la novela de Kohan, el "cálculo matemático" de la ficción no estaría tan sólo a nivel de los algoritmos que dan nombre a los capítulos, sino también en la manera en que se digita la trama, sus resonancias y recurrencias alrededor de la figura de la duplicación: la selección argentina pierde estrepitosamente por dos veces en el mes de junio durante dos mundiales de fútbol celebrados respectivamente en los años 1978 y 1982 (y de allí el título de la obra); dos son las prostitutas que contrata el Doctor Mesiano para salvar la noche; dos las películas pornográficas cuyas tramas se narran; dos las mujeres que le dicen "mi soldadito" al narrador; dos los médicos que realizan tareas en sendos centros clandestinos de detención (los doctores Mesiano y Padilla); dos las ocasiones en que los verdugos a cargo de la prisionera terminan entregándole su bebé recién nacido para que lo calme (con el objetivo de poder ver jugar al seleccionado argentino en paz); dos las veces en que la prisionera, en su desesperado pedido de auxilio, repite al conscripto el teléfono del abogado a quien debe llamar para denunciar su desaparición y dos los abrazos que el narrador recibe por parte del Doctor Mesiano en ocasión de darle el pésame por su hijo caído en Malvinas.

En "La peor conversación argentina", reseña de Miguel Dalmaroni (2002) a la novela de Kohan publicada en BazarAmericano (sitio web de Punto de Vista abierto en agosto de 2001), éste señalaba el momentáneo abandono del punto de vista del conscripto y la asunción de la narración por parte de una voz que podríamos entender como de tipo omnisciente:

Mientas espera, solo en el pasillo de la mazamorra, a que Mesiano resuelva el dilema por el que ha sido consultado, el narrador es interpelado desde el interior de una celda por el murmullo de la voz de la madre secuestrada (cuyo íntimo discurrir ya ha interferido en el texto mediante las intervenciones fragmentarias de otro punto de vista, tan otro que ha cortado el registro predominantemente instalado por el narrador principal; por esa voz marginal y divergente ya sabemos que la madre ha decidido que el niño se llame Guillermo, y que "Casi no le quedaba cuerpo donde pudiesen matarla"). (Dalmaroni 2002 http://bazaramericano.com/buscador.php?cod=276\&tabla $=$ resenas\&que $=$ miguel $\% 20$ dalmaroni, consultado el 2.2.2010) 
Paradójicamente, la asunción de un punto de vista omnisciente evita la narración de hechos atroces, dado que como bien observa Dalmaroni: "las únicas violaciones no fingidas, es decir las que podrá sufrir la secuestrada aún después de las torturas y del parto, se anuncian pero no se narran". El abandono momentáneo de la voz del conscripto en Dos veces junio, entonces, sería una variante de la instancia ética (que asume la forma de una "ficción calculada"), aunque no la única.

Al respecto, en una entrevista de promoción de Ni muerto has perdido tu nombre, Luis Gusmán comentaba lo difícil que le había resultado "hacer hablar" al doctor Firpo (que podría pensarse como la figura con el más alto poder de decisión en la cadena de mandos del cuerpo médico que trabaja codo a codo con los genocidas-torturadores):

En Villa, el personaje más difícil no era Villa, era un coronel [el Doctor Firpo tiene grado de coronel] a quien me costaba hacerlo hablar. Se me hacía demasiado bueno, o demasiado poco comprometido y me costaba mucho, desde el punto de vista ético. (Gusmán [Entrevistado por Jonathan Rovner] 2002: 8)

Repensando esta cuestión a la luz de la línea inaugurada por "La refalosa", la imposibilidad de "hacer hablar al más alto responsable" encontraría su explicación en la ausencia de una tradición literaria de mimesis de la voz de los "grandes enemigos" con la cual dialogar. Más allá de una dificultad de tipo ético, entonces, la ausencia de una "memoria de la literatura I" de este tipo de voces explicaría porqué no hay ninguna novela donde hable el dictador. También, porqué el subgénero "novela de dictador" no tiene ningún exponente local... con la gran excepción de El farmer, de Andrés Rivera.

No obstante, la fecha de publicación de El farmer (año 1996) obligaría a repensar esta novela más como desafío a los protocolos de la "novela histórica bestsellerista" (esto es: escrita para el mercado), que en serie con, para dar el ejemplo por antonomasia, Yo el Supremo (1974).

Por último, dentro del universo novelístico de Rivera, no hay dudas que la "mimesis de la voz del otro" es el recurso más y con mejor fortuna utilizado, en un arco temporal que va desde la novela El viejo soldado (donde habla un viejo soldado franquista, y que -leemos en la "Advertencia"- fue escrita en 1981, poco antes de $L a$ casa y el viento, aunque recién se publicará en 2002) hasta la voz terrible en la novela corta Traslasierra (2007) de "Rebeca Schrader", judía del guetto de Varsovia salvada del exterminio por un coronel de la Wehrmacht, que se ha terminado identificando completamente con el perpetrador. 


\subsection{Volver a contar la guerra de Malvinas: Las Islas, de Carlos Gamerro como "memoria de la literatura I" de Los pichiciegos y "Los pasajeros del tren de la noche"}

En términos de "memoria de la literatura I", la novela Los pichiciegos. Visiones de una batalla subterránea (1983), de Fogwill, escrita en simultáneo con la guerra y terminada antes de la derrota argentina, obtuvo un alto acatamiento a su propuesta de contar el conflicto bélico en el Atlántico Sur vaciado de toda épica y utilizando ciertos elementos tomados de la picaresca. Ejemplos de los dicho son las novelas Historia argentina ("El aprendiz de brujo" y "La soberanía nacional”), de Rodrigo Fresán, publicada en 1991; Latas de cerveza en el Río de la Plata (1995), de Jorge Stamadianos y La flor azteca (1997), de Gustavo Nielsen.

Sobre las llamadas "novelas de Malvinas", que reconocen su piedra fundacional en Los pichiciegos, existiría al día de hoy cierto consenso crítico, resumido ejemplarmente en dos trabajos firmados por el también "novelista de Malvinas": Martín Kohan $(1994 ; 1999)$. Entre los rasgos más repetidos atribuidos a dicha novelística: su carácter antirrealista, su tono muchas veces farsesco, su buscado contraste con el registro glorificante característico del discurso militar, o bien con la entonación conmiserativa presente en las intervenciones de Daniel Kon que rodean los testimonios de ex combatientes en su ya clásico Los chicos de la guerra. Hablan los soldados que estuvieron en Malvinas, publicado en 1982.

A estos rasgos cabría agregar otros dos: la asunción de una perspectiva generacional específica para la narración de la guerra (focalizaciones máximas, o bien narradores en primera persona, o narradores testigo que nunca son militares de carrera, sino conscriptos: la guerra se narra desde la voz de los soldados rasos) y nulas o muy escasas secuencias bélicas propiamente dichas (la "acción" se limita a la espera interminable en los pozos, o se consuma, asordinada, en espacios cerrados: la "pichicera" en la novela de Fogwill; el fondo de los hornos del restaurante Savoy Fair adonde es confinado el narrador por el despótico chef Roderick Shastri en "El aprendiz de brujo", de Fresán; el despacho de Bienestar Social donde un conscripto que nunca es movilizado sirve café en La flor azteca, de Nielsen; los baños del Colegio Nacional de Buenos Aires en Ciencias morales, de Martín Kohan; o, como ejemplo extremo de este rasgo, en la panza del submarino que nunca entra en acciones militares en la novela Trasfondo, de Patricia Ratto, publicada en 2012). ${ }^{131}$

\footnotetext{
${ }^{131}$ Mención aparte merece Acerca de Roderer (1992), de Guillermo Martínez, lograda "memoria de la literatura I" de Demian (1919), de Hermann Hesse, y uno de los "mejor vendidos" de la colección dirigida
} 
De todas formas, cabría problematizar todos los rasgos mencionados poniéndoles como piedra de toque la novela de Malvinas quizás más ambiciosa y monumental publicada al día de hoy: Las Islas (1998), de Carlos Gamerro. ${ }^{132}$ La novela, que ha sido leída con acierto como una feliz conjunción de farsa y drama (Kohan 1999; Vitullo 2012), no sólo remitiría en su registro farsesco a Los pichiciegos, sino también al otro Fogwill, el que -poco antes de escribir su novela más célebre- eligió el género cuento para en "Los pasajeros del tren de la noche" alucinar una guerra por límites entre Chile y Argentina, sólo evitada en el mundo real gracias a la mediación en diciembre de 1978 del papa Juan Pablo II.

El cuento de Fogwill (cuya primera versión dataría de 1980, pero publicado dos años más tarde en la editorial de belgrano como parte del volumen Música japonesa) escenifica el regreso de los soldados argentinos luego de la finalización de un conflicto bélico, con remisiones ostentosas a Cien años de soledad (1967) y Crónica de una muerte anunciada (1981), y quizá constituya la única prueba de que su autor alguna vez sucumbió a la cadencia hipnótica de la prosa del más célebre representante del boom. ${ }^{133}$

Aquí, a diferencia de lo que ocurría en Cien años de soledad, el tren fantasma no trae al pueblo de provincias los cadáveres de los obreros asesinados por la Fruit Company, sino a ex combatientes que habían sido dados por muertos. Entre ellos, un tal “Sergio Guebel”. En este caso, no hay farsa, ni burla, ni voluntad anti-épica, y el tono difiere totalmente del que predominará dos años más tarde en Los pichiciegos:

La guerra tiene esas cosas. Y las madres, que son tan resignadas para traer hijos al mundo y para servir a los hijos de ellas y a los hijos de otras, no saben resignarse cuando les faltan los hijos, y

por Forn. El narrador en primera es destinado a Malvinas, pero su participación en la guerra se resuelve en unas pocas frases: "Nuestro batallón fue asignado a la defensa de Monte Harriet, en la isla Soledad. Son curiosos los registros del tiempo; se supone que estuvimos allí apenas un mes y medio. El día de la rendición, por la noche, caímos prisioneros y durante casi una semana, hasta que terminaron las negociaciones, estuvimos encerrados en la iglesia de Puerto Argentino; luego nos embarcaron en el Canberra con los restos de los demás destacamentos. Allí en cubierta, por primera vez en setenta días pudimos bañarnos, pero tuvimos que ponernos la misma ropa destrozada. Nos desembarcaron a la altura de Puerto Madryn donde nos esperaba un equipo de enfermería con comida caliente y ropa limpia. Recién entonces sentí que todo había terminado. Yo, que no estaba herido, volví por tierra, en uno de los camiones de Gendarmería" (Martínez [1992] 1999: 109-110).

${ }^{132}$ La novela tuvo también su versión teatral en el año 2011, con texto de Carlos Gamerro y dirección de Alejandro Tantanián. Fue representada en la Temporada 2011 del Teatro Presidente Alvear (parte del Complejo Teatral de Buenos Aires). Gamerro escribió una breve presentación para el programa de mano, donde señalaba que: "En su proteica simetría especular, todo lo desdoblan, todo lo reflejan: las Malvinas como el espejo roto y escindido de la Argentina de las últimas décadas, un espejo que nos devuelve el rostro que no queríamos ver, una prolongada pesadilla regida por el número dos".

${ }^{133}$ Fogwill hace dos guiños al lector: menciona "las compras en el almacén de campo de Santiago Nasar" que realizan los pueblerinos (1982: 9) y bautiza a uno de los conscriptos que trae el "tren de la noche" con el nombre de "Márquez" (Fogwill 1982: 14). El cuento fue reeditado en el volumen Restos diurnos (1993). 
siguieron yendo al andén de la estación a esperar y esperar, muchas veces con los maridos, o con los otros hijos civiles o con nueras y nietos, y así los jueves desde temprano se producían montones de gente esperando la llegada del tren de la noche.

Aunque las últimas semanas, para marzo, o abril, cuando vino la época de las lluvias, muy pocas madres esperaban porque ya a casi todas les había vuelto el hijo. (Fogwill 1982: 11)

En términos de "memoria de la literatura I", todo el cuento "Los pasajeros del tren de la noche" se ubicaría en el terreno de una suerte de realismo mágico argentinizado, porque lo que allí se cuenta es la reaparición con vida de conscriptos cuya muerte en el campo de batalla había sido oficialmente comunicada a sus madres, y que -dada la adhesión civil que suscitara en sus inicios la "causa justa" de la guerra contra Chile- son reincorporados al seno familiar y social con secreto escándalo.

Ahora bien: ¿por qué aparecería el otro Fogwill en la novela de Carlos Gamerro? ¿Cómo ingresaría esta inflexión (no farsesca) presente en "Los pasajeros del tren de la noche" en Las Islas? Y, en términos de "memoria de la literatura I" y "memoria de la literatura II”: ¿cómo entender las remisiones a García Márquez, que, tal como señaló Horacio González en "El boom: rastros de una palabra en la narrativa y la crítica argentina", fuera objeto muy tempranamente de un "verdadero programa de rechazo" por parte de algunos "crítico-estrategas", entre ellos, Osvaldo Lamborghini y Fogwill, que lo recusaron por su cualidad comercial (Cf. González 2000: 406)?

Sobre las dos primeras cuestiones: para mejor mitigar la "angustia de las influencias" suscitada por Fogwill, Gamerro optaría por mixturar en su novela la memoria de Los pichiciegos con la de "Los pasajeros del tren de la noche", texto tanto menos célebre. Y lo haría, además, sumando otras "memorias de la literatura I": en el espacio mnemotécnico de Las Islas conviven "El informe de Brodie", de Jorge Luis Borges (en el desopilante "Diario del Mayor X"), con "La causa justa", de Osvaldo Lamborghini, y El almuerzo desnudo, de William S. Burroughs. La inflexión no farsesca de "Los pasajeros del tren de la noche" reaparece tanto en el "sueño de los zulúes" como en el reencuentro final (de carácter onírico) entre el héroe y sus compañeros caídos en las Islas en la calle porteña Malvinas Argentinas (Op. Cit. Gamerro 1998: 102-103 y 575-580, respectivamente). Aquí también, como en "Los pasajeros del tren de la noche", los conscriptos muertos reaparecen, aunque más no sea en el subconsciente de Felipe Félix, que culposamente los sobrevivió. 
Sobre la tercera cuestión: el episodio de las monjas francesas asesinadas que se les aparecen a "los pichis" podría pensarse como una repetición del gesto de aparecer conscriptos en "Los pasajeros del tren de la noche". (Otros que se nos aparecen en Los pichiciegos son "el pichi Dorio" -en alusión a Jorge Dorio- y "el pichi Manuel" -en alusión a Manuel Puig-, dos "reapariciones" que, habida cuenta de que Fogwill se desdobla -para mejor autorrepresentarse- en la figura del sociólogo/ entrevistador y el "Pichi Quiquito", se vincularían en este caso con la problemática de las novelas que escenifican un estado del campo literario a partir de la ficcionalización de un "grupo cultural" efectivamente existente, ya analizada en el capítulo anterior.)

No sólo ocurre la "aparición" de Léonie Henriette Duquet y Alice Domon, sino también, al narrarla, de un tono que no condice con el registro farsesco predominante en la novela:

Los Magos decían que Pugliese se estaba volviendo loco porque una noche, volviendo con Acosta de un viaje a la Intendencia, contaron que mientras esperaban la oscuridad para entrar al tobogán sin delatar el sitio donde lo habían disimulado, cuando estaban todavía enterrados en la sierra, habían sentido voces de mujeres. Que no eran malvineras, dijo Acosta, y que hablaban casi como argentinas, con acento francés. Él no las vio, las escuchó. Pero Pugliese dijo que él corrió a verlas, que se desenterró de la arenilla para verlas porque sintió que estaban cerca, y se asomó entre las piedras y vio dos monjas, vestidas así nomás de monjas, en el frío, repartiendo papeles en medio de las ovejas que les caminaban alrededor. (Op. Cit. Fogwill [1983] 2007: 74)

Al año siguiente de la publicación de Las Islas, Raúl Vieytes gana con Kelper la Primera Mención del Premio Clarín de Novela Edición 1999, con un jurado conformado por Augusto Roa Bastos, Vlady Kociancich y Andrés Rivera. Tampoco esta novela respode a las características atribuidas a las "novelas de Malvinas", aunque podría leerse como una peculiar vuelta de tuerca al gesto de "dar la voz al otro enemigo" desarrollado en el parágrafo anterior, porque el que aquí rememora la guerra dieciséis años después es el kelper Leonard Bresley: xenófobo, misógino y pro imperialista.

A diferencia del trabajo de extrañamiento realizado por Elvira Orphée con el idioma alemán, Vieytes no trata de recrear la sintaxis del inglés, sino que hace hablar a Bresley como traducen los (malos) traductores españoles. Al mismo tiempo, exhibe el artificio de esta "cesión de la voz" cuando el kelper se asombra de que el personaje de "Thriller", en un exceso de confianza, lo llame "compadre" y lo tutee, algo que sería imposible dentro del sistema pronominal del inglés, que no distingue entre "usted" y “tú" (Cf. Vieytes 1999: 126). Es precisamente la voz del otro, desde su misma 
brutalidad simplificadora, la que permite emitir un inequívoco juicio de valor sobre "los asesinos nazifascistas del Continente" que invadieron las Islas en 1982 (esto es: sobre los militares argentinos).

Los premios Clarín de novela favorecieron en tres oportunidades a novelas que hacen memoria en la literatura del pasado reciente argentino: Memorias del río inmóvil, de Cristina Feijóo (ganadora de la Edición 2001); Composición (ganadora de la Edición 2007), de Norma Huidobro; y Sobrevivientes, de Fernando Monacelli (ganadora de la Edición 2012).

Sobrevivientes toma como punto de arranque una noticia periodística ficticia: el hallazgo el 2 de enero de 2007 (de manera coincidente con el 25 aniversario de la guerra) de tres cadáveres quemados por el frío en una balsa a la deriva, que resultan ser tres héroes del Crucero General Belgrano: un oficial, un suboficial y un conscripto. ${ }^{134}$ Este último esconde entre sus ropas congeladas un diario íntimo, gracias al cual su madre entra en conocimiento de que, para la época del conflicto bélico en el Atlántico Sur, la novia adolescente de su hijo estaba embarazada.

A partir de allí, ésta inicia una larga pesquisa para dar con su nieto, con la ayuda del personaje de Celina Figueroa, "periodista estrella" del diario local. A lo largo de la misma, las mujeres descubren que el bebé fue apropiado por el intendente del pueblo, que terminó por abandonarlo al descubrir que padecía de autismo. La búsqueda llega a su fin en España, donde encuentran tanto a la mujer que finalmente lo tomó en adopción (de nacionalidad española y libre por lo mismo de cualquier sospecha de complicidad con el régimen militar argentino), como a "Iñaki", el nieto robado.

Como Carlos Gamerro, Monacelli tampoco se priva de repetir el gesto onettiano de fundar un pueblo -"Mar Calmo”- para su ficción. También, como Manuel Puig, el autor incorpora materiales "en bruto": gran parte de la novela es una transcripción del monólogo-confesión de Figueroa frente a la madre adoptiva española de Iñaki, y de los sucesivos mails que intercambian antes y después del primer encuentro cara a cara para ultimar los detalles de la reunión entre éste y su familia biológica. Sin embargo, Monacelli no logra hacer mimesis de las voces femeninas. Su utilización del "thriller" en alianza con el melodrama para hacer memoria del pasado reciente argentino

\footnotetext{
${ }^{134}$ El ARA General Belgrano fue torpeteado el domingo 2 de mayo de 1982 (a las 15:57 y 16:01 hs) con 1093 tripulantes a bordo. En el naufragio murieron 323 hombres y sobrevivieron 770 . El General Belgrano fue el primer barco hundido durante la guerra de Malvinas por un submarino nuclear de ataque, el "Conqueror". El hundimiento es considerado por muchos un crimen de guerra, porque la nave fue atacada cuando se encontraba fuera del área de exclusión de 150 millas alrededor de las Islas, que había sido impuesta unilateralmente por los británicos.
} 
(sumando a la guerra de Malvinas la temática de la apropiación de bebés) impresiona como fallida. Por último, la trama adolece de un problema lógico grave. Considerando que el parto ocurre en algún momento de 1982, en los estertores del gobierno militar: ¿cómo es que el intendente de "Mar Calmo" pudo apropiarse del bebé de una adolescente que no estaba en cautiverio al momento del dar a luz sin que este hecho desatara un escándalo mayúsculo o, por lo menos, fuera inmediatamente comentado por todos los habitantes del pueblo?

Antes de ganar con Sobrevivientes, Monacelli había sido finalista de la Edición 2005 del Premio Clarín con La mirada del ciervo (publicada por Mondadori en 2008), cuya trama gira sobre la apropiación de niños durante la dictadura. ${ }^{135}$

La premiación de novelas que toman como eje esta temática nos reenviaría a las novelas escritas por los hijos de los militantes populares, entre las que se destaca Los topos (2008), de Félix Bruzzone. A ésta y otras "narrativas de H.I.J.O.S.” está dedicado el próximo parágrafo.

\subsection{Tomar la voz de los "hijos tempranos" de los detenidos-desaparecidos}

Dentro del conjunto de las nuevas organizaciones de derechos humanos que se fundaron durante y luego de la última dictadura militar, varias lo hicieron tomando como marca identitaria los lazos de sangre, como los Familiares de Desaparecidos y Detenidos por Razones Políticas (fundada en 1976, mismo año del golpe militar); las Madres de Plaza de Mayo (abril de 1977); las Abuelas de Plaza de Mayo (octubre de 1977); los Hijos e Hijas por la Identidad y la Justicia Contra el Olvido y el Silencio, que agrupa a los hijos de los desaparecidos, ex presos políticos y exiliados (octubre de 1995) ${ }^{136}$ y los Herman@s de Desaparecidos por la Verdad y la Justicia (marzo de 2003).

En relación a la emergencia de las voces de los hijos de los detenidosdesaparecidos en el escenario político, cabría señalar tres momentos clave. El primero: la presencia el 24 de marzo de 1996 de la agrupación H.I.J.O.S. en la vigésima marcha en conmemoración del golpe militar (24 de marzo de 1976), donde por primera vez ésta

\footnotetext{
${ }^{135}$ La mirada del ciervo también fue finalista del premio La Nación-Sudamericana (Edición 2006).

${ }^{136}$ Se calcula que aproximadamente unos 500 bebés nacieron en los campos clandestinos de detención, a quienes el Estado Terrorista sustrajo su verdadera identidad y dio en adopción de manera irregular. Hasta la fecha, sólo 117 de estos niños fueron encontrados gracias a las muestras existentes en el Banco Nacional de Datos Genéticos, organismo autónomo y autárquico, creado en 1987 por la Ley 23511. Sus objetivos son garantizar la obtención, almacenamiento y análisis de la información genética para el esclarecimiento de delitos de lesa humanidad que se hayan perpetrado en el ámbito del Estado Nacional hasta el 10 de diciembre de 1983. De esta forma, favorece la búsqueda y restitución de la identidad de hijos e hijas de detenidos-desaparecidos, y auxilia a la justicia en la identificación de los restos de personas víctimas de desaparición forzada.
} 
se constituye en columna diferenciada dentro del colectivo de los manifestantes pertenecientes a diferentes organizaciones políticas y organismos de derechos humanos. Segundo: la realización en diciembre de 1996 del primer escrache. ${ }^{137}$ Tercer momento: la entrega de los pañuelos blancos que realizan las Madres de Plaza de Mayo a la Agrupación H.I.J.O.S. para cerrar su XXII Marcha de la Resistencia (4 al 5 de diciembre de 2002), que puede ser interpretada como el momento en que las Madres reconocen en ellos los herederos de su lucha política.

H.I.J.O.S., por otra parte, adquiere visibilidad social a partir de diversas prácticas culturales: el ciclo Teatro por la Identidad, las realizaciones documentales que algunos hijos de detenidos-desaparecidos realizan sobre la desaparición de sus padres (la más debatida pero no la única, Los rubios, de Albertina Carri, ya reseñada en la Introducción), el rescate de la obra poética de los progenitores asesinados en el proyecto editorial Los detectives salvajes de Julián Axat y Juan Aiub, ${ }^{138}$ y, de factura reciente, una producción novelística cada vez más notable, escrita dentro del modo autoficcional. Entre otras novelas, cabe mencionar: Los topos, de Félix Bruzzone y La casa de los conejos, de Laura Alcoba (ambas de 2008); Soy un bravo piloto de la nueva china (2011), de Ernesto Semán; El espíritu de mis padres sigue subiendo la lluvia (2011), de Patricio Pron; Diario de una princesa montonera. 110 \% verdad, de Mariana Eva Pérez y El turno, de Juan Romero (ambas publicadas en 2012); Pequeños combatientes (2013), de Raquel Robles y, nuevamente de Laura Alcoba, El azul de las abejas (2014). Estas "novelas" (y las comillas van a cuenta de que, repetimos, en todas ellas se observan deslizamientos hacia lo autobiográfico y lo testimonial) coincidirían en dos apuestas generacionales.

La primera: una suerte de ajuste de cuentas con la generación de los "padres militantes", que podría resumirse mediante la frase: "Todos dicen que mis padres fueron

\footnotetext{
${ }^{137}$ Cuando los hijos de los detenidos-desaparecidos decidieron agruparse, la Comisión de Escrache fue una de las primeras que organizaron. Tenía entonces otro nombre (Comisión de Reconstrucción Histórica y Condena Moral), pero en la intimidad todos hablaban de escrachar, un término lunfardo que significa "poner en evidencia". El escrache fue el modo que la asociación H.I.J.O.S. encontró para denunciar la impunidad de miembros del aparato represivo, beneficiados por las llamadas "leyes de impunidad" promulgadas en 1986 ("Ley de Obediencia Debida") y 1987 ("Ley de Punto Final") bajo el gobierno de Raúl Alfonsín, y, escasos años más tarde, por los indultos (1989/90), otorgados por el ex presidente Carlos Saúl Menem. El escrache se inicia con la colocación de fotos del genocida-torturador en el espacio público con la leyenda "Aquí vive un genocida", para así lograr el repudio social. Luego, miembros de H.I.J.O.S. manifiestan con un altavoz frente a la casa del ex represor. El escrache culmina cuando varias "bombuchas" (bombitas de carnaval rellenas de pintura roja) son arrojadas contra la fachada, para simbolizar que esa casa está manchada de sangre.

${ }^{138}$ El primer volumen de la colección fue Versos aparecidos, libro de poemas del profesor y militante del MIR-17 Carlos Aiub, secuestrado el 10 de junio de 1977 en la ciudad de La Plata.
} 
militantes excepcionales, pero yo los sufrí como padres ausentes...”. La segunda: una resignificación de la figura del "detenido-desaparecido" que va más allá de la figura del “militante ejemplar", rescatando por lo mismo la dimensión más subjetiva e íntima de los progenitores asesinados. Este cambio de énfasis, que coloca en un segundo plano la trayectoria militante ( $\mathrm{y} /$ o cualquier reivindicación de la misma), toma algunas veces la forma de proyectos de tipo colectivo (algo que se vuelve patente en el Proyecto Tesoros). ${ }^{139}$

En el caso de Los topos, de Félix Bruzzone, el gesto va acompañado por la pregunta sobre la legitimidad de vengar por mano propia estas muertes, cuestión fuertemente tabuizada dentro de la "memoria hegemónica" vigente hasta el día de hoy (aunque esta pregunta surgía ya en 1997, en varios de los testimonios compilados por Juan Gelman y Mara La Madrid para Ni el flaco perdón de Dios. Hijos de desaparecidos). ${ }^{140}$

Sobre la legitimidad de "hacer justicia por mano propia" gira precisamente Calle de las escuelas $N^{\circ} 13$, única novela publicada del poeta rosarino Martín Prieto, que narra la conformación de una "célula" de cuatro integrantes, que en agosto de 1993 se propone entrar en relación amistosa con un ex torturador que ha salido beneficiado por los indultos menemistas para ajusticiarlo. La necesidad de "hacer justicia por mano

${ }^{139}$ El Proyecto Tesoros, una iniciativa del Colectivo de hijos lanzada en 2010 que cuenta con el apoyo del Fondo Nacional de las Artes, tiene por objetivo principal, según el texto de presentación en su página WEB, "la creación de un archivo que contenga los registros de aquellos objetos y documentos que pertenecían a nuestros padres, detenidos-desaparecidos y asesinados por el último genocidio en nuestro país [...] es a través de estos fragmentos que podemos hoy hablar de nuestra propia condición, la de ser huérfanos producidos por el genocidio. El Proyecto intenta dar visibilidad a estas experiencias, y es por eso que elegimos una herramienta virtual para extender lazos hasta donde nos sea posible..." (http://www.proyectotesoros.org/proyecto.html, consultado el 10/8/2013). Al día de la fecha, once son los "tesoros" que constituyen este archivo digital, que se presentan acompañados por una filmación de unos dos minutos de duración en cuyo marco se escuchan los testimonios de hijos e hijas que dan cuenta del origen e historia de cada uno de los objetos seleccionados, al mismo tiempo que se muestra el momento mismo en que éste es fotografiado para pasar a formar parte del Proyecto. La serie parece conformada a partir del deseo casi animista de, por medio de objetos pertenecientes a los padres, "estar un poco más cerca de ellos" (testimonio de la hija María Giuffra). En otras palabras: "hacer hablar a los objetos para acercarse a los que no están" (testimonio de la hija Ana Adjiman) y "[hacer] que la energía [que emana de ellos] no quede estancada, que permanezca en uso" (testimonio de la hija Débora Villanueva).

${ }^{140} \mathrm{Al}$ conocer la identidad del genocida-torturador que asesinara a uno o ambos progenitores (y que ha sido dejado en libertada y circula libremente en la Argentina post indultos), los hijos Fernado, Raquel II y Mariano II afirman no saber qué hacer con esta información: si usar a su vez la violencia contra los perpetradores, o perdonar. Ninguna de las dos posibilidades les resulta satisfactoria. Como señala Mariano II, a quien contacta el genocida-torturador Juan Carlos Solis (alias "Miguel") para hacerle un relato moroso de los últimos días de su madre en Campo de Mayo, "que venga [el perpetrador] y te lo cuente, también forma parte de la impunidad". La condición excepcional de "hijo" hace que -continúa su razonamiento Mariano II- el deseo "normal" de (por lo menos) golpear al hombre que asesinó a tu madre sea "mal visto" por una sociedad que prefirió adherir sin más a la llamada "teoría de los dos demonios" (y/ o al discurso de la "reconciliación nacional" menemista), "porque seríamos los pichones asesinos que nuevamente atacan” (Mariano II [Entrevistado por Juan Gelman/ Mara La Madrid] 1997: 398). 
propia" se propone programáticamente hacia un "afuera del texto", construido como "mise en abîme" (Dällenbach 1991). En diálogo con el único integrante de la célula del cual el lector no sabrá su nombre y que asume el relato en primera persona, el personaje de "David" dice al respecto lo siguiente:

... la sola idea de que te hayas puesto a escribir una novela, me parece como de, por un lado, una pulsión narcisista, hacer alarde de una cosa que, creo yo, estaba para nosotros perfectamente recortada, y por otro, una propuesta de proyecto político, salgan todos, busquen a su torturador... (Prieto 1999: 20)

Dado que ninguno de ellos es hijo de un detenido-desaparecido, la relación que los integrantes de la "célula" mantienen con el pasado reciente es más libresca que autobiográfica. Su motivación al momento de elegir al perpetrador parece obedecer a una fidelidad irónica al nominalismo borgiano: lo eligen por su alias, "Parrillita". Aluden a su proyecto como "la causa", o bien lo nombran utilizando la fórmula "matar al perro" (mientras la primera denominación remite nuevamente a "La causa justa", de Osvaldo Lamborghini, la segunda parece haber sido construida sobre el conocido refrán popular: "Muerto el perro, se acabó la rabia").

El único integrante de sexo femenino de la célula es la cantante de jazz Violeta, que funciona como carnada para atrapar a "Parrillita", que es un gran lector. Si Calle de las escuelas $N^{\circ} 13$-como ya señaló María Teresa Gramuglio en "Políticas del decir y formas de la ficción. Novelas de la dictuadura militar"- se construye (para mejor traicionarlo) sobre el molde de Libro de Manuel, el personaje de Violeta sería la "anti Maga [de Rayuela]": pragmática, arrogante, quizá la más formada política e intelectualmente del grupo, y la mujer que los otros tres miran hacer y deshacer con embeleso. Es, además, una ex poeta objetivista, hecho que reenvía nuevamente a la problemática de la "autoimagen de escritor” (Cf. Op. Cit. Gramuglio 1992).

En efecto: el poema que Prieto atribuye a Violeta ("Detrás, la pared blanca/ de la casa de mis padres/ y en su frente el brillo/ de una bicicleta azul") hace irrisión de los principios constructivos del neobjetivismo poético, que tiene en la mirada su piedra de toque. Si, como señala Samoilovich, el neobjetivismo es "el intento de crear con palabras artefactos que tengan la evidencia y disponibilidad de los objetos" (1990: 18), en Calle de las escuelas $N^{\circ} 13$ el desafío parece estar en crear con palabras efectos que tengan la evidencia de los hechos. 
Contra otras novelas que avanzan sobre los pormenores de la consecución de la fantasía de "castigar por mano propia" al genocida-torturador tales como El agua electrizada (1992), de Carlos E. Feiling; No sé si casarme o comprarme un perro (1995) de Paula Pérez Alonso; El Informante (1998) de Carlos Dámaso Martínez; No te fíes de mí, si el corazón te falla de Eduardo Sguiglia (ambas de 1999) y Memorias del río inmóvil (2001) de Cristina Feijóo, la novela de Prieto defrauda la expectativa del lector desde la primera frase, gracias a la cual éste queda inmediatamente avisado de que, pese al minucioso plan de ajusticiarlo, "Parrillita" aún sigue vivo: "De haberlo matado, a mí me hubiera gustado que lo matáramos en París, en el hotel Minerve..." (Op. Cit. Prieto 1999: 9).

La fantasía de hacer justicia por mano propia también asume una forma esencialmente libresca en El secreto y las voces (2002), de Carlos Gamerro, donde narra nuevamente "Fefe", el héroe de Las Islas, que vuelve a Malihuel para averiguar qué pasó exactamente con su padre, asesinado frente a los ojos de todo el pueblo durante un multitudinario festival de música al que Sandro, su estrella invitada, nunca se presentó. ${ }^{141}$ Apelando a la memoria de aquellas novelas que trabajan "con la responsabilidad grupal ante la violencia y con la construcción social de un victimario colectivo" (Cf. Op. Cit. Reati 1992: 88), cuyo ejemplo paradigmático sería Cuarteles de invierno (1983), de Osvaldo Soriano, Gamerro construye una novela coral, donde cada personalidad de Malihuel, a solicitud de "Fefe", da su propia versión de los hechos.

Para obtener testimonios, "Fefe" oscila entre dos mentiras: afirma que él mismo va a redactar una novela policial situada en el pueblo, o bien que tiene "un amigo novelista" que ya ha escrito una novela (El sueño del señor juez), a quien su trabajo de compilador de testimonios podría llegar a interesarle. El juego por parte de Gamerro de atribuir a una de sus criaturas ficcionales la autoría de El sueño del señor juez, colocaría a El secreto y las voces en fugaz intersección con el conjunto de novelas que tienen por objetivo principal desplegar una determinada "autoimagen de escritor".

En El secreto y las voces el género es otra vez un híbrido. ${ }^{142}$ La novela resulta de la amalgama entre la recopilación por alguien que viene de afuera de diversos

\footnotetext{
${ }^{141}$ Que el ex combatiente y hacker "Fefe" de Las Islas reaparezca en El secreto y sus voces nos reenvia, nuevamente, al universo narrativo de Fogwill, que en Vivir afuera (1998) volvió a Los pichiciegos mediante el personaje de "El pichi" ("Quiquito").

${ }^{142}$ Es la "contra-ley", "ley de impureza o principio de contaminación", que Derrida formula como contrapartida indisoluble a la ley del género ("no mezclar los géneros"). La hipótesis merece ser citada in
} 
testimonios (a la manera de Operación masacre) y la reproducción -aquí directamente onomatopéyica- de los tonos de la conversación. En este sentido, no parece casual que El secreto y las voces aparezca dedicada a la "tía Hilda", cuya voz -como las de "las tías" en el caso de Manuel Puig- parece haber estado en la génesis misma de la ficción.

Nuevamente toma lugar la resemantización política en suelo argentino del realismo mágico: "Dario Ezcurra", el padre de "Fefe", es un don Juan irredimible, a quien en definitiva todos los padres del pueblo tienen sobrados motivos para matar ( $o$ dejar matar), y aparece por lo mismo construido como "memoria de la literatura I" del personaje de Santiago Nasar en Crónica de una muerte anunciada, de Gabriel García Márquez. Pero Ezcurra es también "el monto del pueblo", el único periodista que se atreve a denunciar los abusos del terrateniente Rosas Paz. Si bien, tal como en Crónica de una muerte anunciada, el narrador "que viene de afuera" a indagar esa muerte está emparentado con el difunto y aúna las funciones de cronista con las de fiscal y detective, Gamerro resemantiza el planteo de García Márquez: la muerte en El secreto y las voces no es ya "un crimen de honor" pueblerino, sino un crimen netamente político, cuya resolución denuncia la complicidad de la totalidad de la población civil con los (mal) llamados “crímenes de Estado".

La propuesta de Gamerro apunta a la recuperación del legado de Rodolfo Walsh, creador con Operación masacre de "el policial auténticamente argentino", cuyo planteo absorbe y supera el del policial negro norteamericano. Uno de sus rasgos es el reemplazo del detective o investigador privado (que en Argentina siempre es un ex-policía o un ex-servicio, y por lo mismo imposibilitado de cumplir la regla de "rectitud moral" que exigía Raymond Chandler) por la figura del "periodistajusticiero". ${ }^{143}$ Este último ha renunciado a la ley como instancia válida de justicia y castigo -porque sabe de antemano que el aparato judicial es completamente corrupto- y su única ambición es hacer saber la verdad a la opinión pública. Sobre "el policial

extenso: "un texto no pertenecería a ningún género. Todo texto participa de uno o varios géneros, no hay texto sin género, siempre hay género y géneros, pero esta participación no es jamás una pertenencia. Y esto no ocurre a causa de un desborde de riqueza o libre productividad anárquica o inclasificable, sino a causa del mismo rasgo de participación, del efecto de código y de la marca genérica. Marcándose con la marca de género, un texto se demarca" (Derrida 1980: 186; nuestra traducción). Sobre la hibridez genérica en el caso específico de Rodolfo Walsh, VER Alabarces [en Jorge Lafforge, comp.] 2000.

143 "Por estas calles malignas caminan hombres que no son malignos ni están comprometidos ni asustados. El detective de una historia así tiene que ser un hombre de ésos. Es el protagonista, el héroe, todo. Debe ser un hombre completo, un hombre común y al mismo tiempo extraordinario. Debe ser, para usar una frase remanida, un hombre de honor. Por instinto, por inevitabilidad. Sin pensarlo y por cierto, sin decirlo. Debe ser el mejor hombre del mundo y lo suficientemente bueno para cualquier mundo..." (Chandler 1989: 341) 
auténticamente argentino", Gamerro publica un artículo ("Disparen sobre el policial negro") en el n ${ }^{\circ} 98$ de $\tilde{N}$. Revista de Cultura del 13 de agosto de 2005, donde -a la manera de S. S. Van Dine y Dickson Carr- enuncia una serie de "reglas", a las cuales responden punto por punto los "elementos policiales" presentes en sus novelas Las Islas, El secreto y las voces y La aventura de los bustos de Eva.

Copiamos el decálogo completo: "1. El crimen lo comete la policía. 2. Si lo comete un agente de seguridad privada o -incluso- un delincuente común, es por orden o con permiso de la policía. 3. El propósito de la investigación policial es ocultar la verdad. 4. La misión de la Justicia es encubrir a la policía. 5. Las pistas o indicios materiales nunca son confiables: la policía llegó primero. No hay, por los tanto, base empírica para el ejercicio de la deducción. 6. Frecuentemente, se sabe de entrada la identidad del asesino y hay que averiguar la de la víctima. 7. El principal sospechoso (para la policía) es la víctima. 8. Todo acusado por la policía es inocente. 9. Los detectives privados son indefectiblemente ex-policías o ex-servicios. La investigación, por lo tanto, sólo puede llevarla a cabo un periodista o un particular. 10. El propósito de esta investigación puede ser el de llegar a la verdad y, en el mejor de los casos, hacerla pública; nunca el de obtener justicia" (Gamerro 2005: 8). ${ }^{144}$

El secreto y las voces plantea además otra interesante cuestión: la de los hijos tempranos de los militantes populares, que, como los hijos (tardíos) de los ex combatientes de Malvinas, parecen no haber encontrado todavía un lugar claro de enunciación social. Al descubrir las motivaciones políticas por detrás del asesinato de su padre, "Fefe" se propone lo siguiente:

Voy a ponerme en contacto con HIJOS de Buenos Aires y Rosario. Porai (sic!) le podemos organizar un escrache. Eso para empezar. Si aparece algún resquicio legal para acosarlo, pongo a trabajar a mi abogado. Datos no me faltan, ahora. Haría lo mismo con Neri y Rosas Paz, pero los hijos de puta se murieron antes. En fin. Aprenderé sobre la marcha. No es fácil, a mi edad, enterarte que sos hijo de desaparecidos. Esas son cosas que se hacen a los veinte. (Op. Cit. Gamerro 1998: 260)

Con la novela Historia del pelo, aparecida en 2010, Pauls completó la segunda entrega de su "trilogía sobre los setenta", proyecto -según el autor- "articulado alrededor de tres fósiles: llanto, pelo y dinero" (2010b: 24). Historia del pelo apunta,

\footnotetext{
${ }^{144}$ Gamerro reproducirá este trabajo con muy pocas modificaciones en El nacimiento de la literatura argentina y otros ensayos (2006), bajo el título de "Para una reformulación del género policial argentino". También en su artículo "Policial, peronismo y dictadura", que publica en el $\mathrm{n}^{\circ} 454$ de Ñ. Revista de Cultura correspondiente al 9 de junio de 2012, volverá a insistir con que el policial es el género narrativo que más acusa el impacto de la última dictadura.
} 
desde una mirada sobre lo capilar, a responder a las preguntas: ¿Qué es el "espíritu de época”? ¿Qué fueron "los setenta”? ¿Qué es la historia personal? ¿Qué es la Historia? ¿Qué tipo de relación existe entre la historia personal y la Historia?

Según Historia del pelo, sería legítimo entender la creciente polarización política durante las décadas del sesenta y setenta y su bandera del "hombre Nuevo" como “epidemia del Pelo Nuevo" (cuyo arquetipo platónico sería el afro de los Black Panthers, estilo capilar sobre el cual también se detiene gozosa Agnès Varda en su documental Black Panther Newsreel). También los setenta encuentran su fórmula capilar en "el pelo bueno de los militantes políticos, de los revolucionarios, de los resistentes, de los artistas comprometidos" VS. "el pelo nefasto de los setenta", que no es sólo el de los galanes televisivos como Carlos Calvo, sino también el del genocida Alfredo Astiz, estilo capilar definido en la novela como "el pelo tirando a largo, a dos aguas, fugado hacia los lados en degradé, con raya al costado" (Pauls 2010a: 152-154). Se trata de leer la época en el cuerpo, marcado por señas particulares y huellas. Se trata, en otras palabras, de politizar lo trivial (un largo de cabello, un corte, un peinado). O, en otras palabras, de leer lo político en lo trivial.

Alan Pauls no sólo ofició de guionista-asesor para Los rubios, de Albertina Carri, sino que hizo las veces de presentador de Cartografía de una película:

Hablando de pelucas: lamento que el libro no venga con una peluca rubia y unos playmobils. Sería el perfecto kit Los rubios. Permitiría atenuar la acusación de frivolidad que alguna vez pesó sobre el film -Albertina habría frivolizado la historia- y devolverla sutilmente pervertida: ¿y si hubiera politizado la frivolidad? ¿Y si Los rubios redescubre el extraño nudo que enlaza frivolidad y política? (Pauls [Reproducido en Gustavo Noriega] [2007] 2009: 83)

La cita devela que, tres años antes de publicar su Historia del pelo, Pauls ya estaba pensando en la posibilidad de colocar el eje en la intersección entre política y banalidad. De manera coherente con este planteo, elige contar el asesinato de Aramburu y sus efectos desde la historia de la peluca ("rubia con claritos") utilizada por Norma Arrostito durante el secuestro. ${ }^{145}$ El héroe, construido de manera descaradamente autoficcional como en Historia del llanto, es otra vez alguien descolocado de su tiempo,

${ }^{145}$ La publicidad del negocio "Pelucas y Minipelucas Fontaine", de Felipe Sinópoli, situado en la calle Arenales 1473, que publica por aquel entonces la revista dominical de Clarín, decía lo siguiente: "Prepárese a cambiar de la noche a la mañana, o de la mañana a la noche, o en cualquier momento. Un peinado diferente la transforma... Fontaine es la clave para las travesuras más femeninas y los cambios más amorosos. Vale la pena curiosear la última novedad Fontaine: la peluca que se peina con o sin flequillo...". Fue en Fontaine donde la Organización Montoneros compró la peluca que usaría Arrostito para el secuestro (Cf. Saidón 2005: 10-11). En Historia del pelo, el anuncio publicitario de Pelucas y Minipelucas Fontaine aparece parafraseado en la página 185. 
un "maniático del pelo", obsesionado por "una época que venera y que siente que no vivió, o que hubiera podido vivir de otro modo, con otra edad, o quizás sólo con otro corte de pelo..." (Op. Cit. Pauls 2010a: 146; nuestro énfasis).

En esta segunda entrega de su trilogía, Pauls ensaya la focalización máxima en el llamado "veterano de guerra", un "hijo temprano" al que vemos en el exilio y la postdictadura sacar provecho de su condición de ser hijo de y transformarse en un dealer de poca monta, para luego terminar vendiendo a un coleccionista los escasos objetos personales que le dejara su padre. Entre ellos, la peluca utilizada por Norma Arrostito:

Como le sucede con todo, no sólo con lo que tiene sino con lo que es y hace, la peluca de Arrostito le llega a través de su padre, primero militante montonero, como Arrostito, después, con el correr del tiempo, fanático, mesiánico enfermo, kamikaze sin remedio. La peluca es de hecho la herencia que su padre le deja, la única, aparte de una brújula, un par de botas de montaña y la libreta con las notas que toma en mil novecientos setenta y uno en la selva misionera, mientras encabeza la Operación Ortiga, excursión suicida disfrazada de operativo guerrillero... (Op. Cit. Pauls 2010a: 186)

Contra la reivindicación de la militancia de los padres detenidos-desaparecidos que ha venido realizando desde su fundación la agrupación H.I.J.O.S., el tono de este hijo ficcional para referirse a lo actuado por su padre es escandalosamente cínico. ${ }^{146} \mathrm{Al}$ mismo tiempo, frente al "maniático del pelo" (una "autoimagen de escritor" de rasgos aún más caricaturescos que la presente en Historia del llanto), la figura del "veterano de guerra" se erige como la más potente en la novela.

Una escena en Historia del pelo condensa la opción por la voz de los "hijos tempranos": la reapertura de la ex ESMA, devenida Centro Cultural Haroldo Conti, es referida por Alan Pauls (quien participó en las Jornadas Ficción y memoria histórica de agosto de 2008 en calidad de expositor, junto a Germán García y Martín Kohan, con la coordinación de Claudio Zeiger) desde la mirada del "veterano de guerra", que aparece sentado al fondo del antiguo Casino de Oficiales, aterido de frío:

Una tarde, a instancias del sobrino de una delegada sindical legendaria, un bribón que conoce el ecosistema de los años setenta como la palma de su mano y le oficia a veces de informante, va a una mesa redonda a la Escuela de Mecánica de la Armada. Es la primera vez que pisa ese ex teatro del horror en el que de chico, sin embargo, piensa a menudo, sin duda influido por todo lo que oye que se dice de él en la comunidad de exiliados de París, y que se imagina como una proyección gigantesca,

${ }^{146}$ Una excepción a la casi unánime reivindicación de la militancia de los padres lo constituye Cómo enterrar a un padre desaparecido (2012), de Sebastián Hacher, donde la hija del detenido-desaparecido Manuel Javier Corral afirma que le tiene absolutamente sin cuidado cuál fue exactamente la trayectoria militante de su progenitor. 
una versión a escala ciudad del tren fantasma, su juego preferido del Italpark... (Pauls 2010a: 166167)

Más específicamente, Pauls elige narrar la intervención de Beatriz Sarlo para el panel "El testimonio en cuestión" (conformado además por Alejandro Kaufman, Javier Trímboli y Marta Vasallo, con la coordinación de Lucila Pagliai) desde el punto de vista del "veterano de guerra", para -nuevamente- marcar un distanciamiento de tipo generacional:

No tienen adónde ir. Es la única razón que se le ocurre para explicar por qué, si no escuchan bien, si no terminan de acomodarse en esas sillas de plástico que, al cabo de diez minutos, apenas el cuerpo se relaja, lo martirizan y lo obligan a contraerse, si tiemblan de un frío que saben que no podrán combatir [...] por qué no se van antes de que el frío los seque, los vuelva de piedra, por qué no recogen sus cosas y se levantan de sus sillas y se mandan a mudar de una buena vez, lo antes posible, todos, en estampida, incluidos los dos oradores que esperan su turno en la mesa y la mujer mayor que ahora, para ver si logra hacerse oír mejor, acerca la boca a la cabeza del micrófono, casi besándola, y habla, y lo que hace brotar de los parlantes, tan decrépitos como el micrófono, no es una frase sino una especie de viento atropellado, sombrío, incomprensible. No tienen adónde ir. Tienen techo y familias, departamentos, casas, autos, más de uno, incluso, una casa de fin de semana, una chacra, una isla en el Tigre [...] Una y otra vez, sin embargo, como sonámbulos, dejan la intimidad de sus nidos tibios y vuelven a ese lugar inhóspito, brutal, que sólo los acoge para torturarlos, y ahí se quedan, más huérfanos y a la intemperie que nunca [...] (Op. Cit. Pauls 2010a: 170-171)

El caso de Rodrigo Fresán es aún más anómalo, porque recién en una entrevista dada en el año 1995 a Verónica Chiaravalli para el suplemento "Cultura" de La Nación, se reivindica a sí mismo como hijo de militantes:

... cuando me reprochan mi escasa participación política, yo digo que a mí me secuestraron a los diez años y me canjearon por mi madre. Y con eso ya cumplí. Mis padres eran personajes de la intelligentzia de los setenta. (Fresán 1995 [Citado en Elsa Drucaroff 2011: 95])

Con motivo del estreno en los cines argentinos de la versión reducida del docudrama Carlos (2011) de Oliver Assayas sobre la vida del miembro de la Frente Popular para la Liberación de Palestina Illich Ramírez Sánchez, Fresán vuelve a exhibir su pasado como "hijo temprano [exiliado]":

El pasado es un país extranjero, allí siempre hacen las cosas de manera diferente y, en este caso, el país extranjero en ese pasado se llama Venezuela. Allí voy: rapidito y sin aviso. Malos aires en Buenos Aires, atmósfera irrespirable, mediados de los años '70. Y allí aterrizo junto a mis padres: en la tierra a la que llegó el Corto Maltés y de la que salió Illich Ramírez Sánchez alias Carlos alias El 
Chacal [...] Y Carlos es una de las noticias que marcan el fin de mi infancia. Un titular que permanece impreso en mi memoria. (Fresán 2011: 4)

Fascinación y repulsa por "Carlos". Fascinación y repulsa por "los setenta":

Y la época, la era, claro. Porque: ¿habrá algo más intrigante que el look de los '70? ¿Sus colores? ¿Sus patillas? ¿Sus pantalones? ¿Sus jóvenes? Los jóvenes de los '70 son como un animal liminar, fronterizo. No tienen nada que ver con los de los ' 60 o con los de los '80. Están en el medio, entre hippies y yuppies, como un accidente espacio-temporal que los convierte en ciudadanos del mundo a la vez que habitués de Mau-Mau. (Op. Cit. Fresán 2011: 5)

En verdad, si releemos con atención Historia argentina (1991), de Fresán, la confesión ya estaba allí, contenida en modo atoficcional en el último capítulo de la novela bajo el título de "La vocación literaria", que elige como tema para "cerrar el fin de la historia" el secuestro sufrido a los diez años por "el hijo que, cuando fuera grande, quería ser escritor" (1991: 205). Tomado como rehén en ausencia de sus padres por el Grupo de Tareas donde alistan "Mocasín" y "Cable Pelado", el autor reacciona eligiendo "el cuaderno Rivadavia donde estaba reunida toda su obra literaria" al ofrecimiento de los agentes que lo secuestran de llevarse consigo alguna pertenencia. De manera coincidente con Nicolás Prividera, Laura Alcoba y Patricio Pron (entre otros), este hijo ignora cuál fue el grado de militancia de su madre, pero - a diferencia de aquéllos- no tiene ningún interés en averiguarlo:

... la madre del hijo que, cuando fuera grande, quería ser escritor era, por la época en que Cable Pelado y Mocasín se ofrecieron a revelar los sagrados misterios del fútbol, una dedicada estudiante de psicología [...] Este tipo de disciplina pronto fue considerada por la gente como Cable Pelado y Mocasín como una de las más peligrosas ciencias ocultas y así, una mañana de Navidad, vinieron a buscarla para llevársela. Y así fue.

O no. ¿Quién sabe? También existía la posibilidad de que la madre fuera una experta y peligrosa guerrillera con varias muertes en su haber $[\ldots]$

Nunca volveré a hablar sobre este tema. (Fresán 1991: 205)

De todas formas, Fresán sí retomó el "tema" (aunque de manera desplazada, tanto geográfica como temporalmente) en Jardines de Kensington (2003), que escenifica el abismo generacional entre el narrador en primera y sus padres adoptivos, Sebastian "Darjeeling" Compton-Lowe ("líder de The Beaten Victorians") y Lady Alexandra Swinton (siempre "girando en una espiral lisérgica"), personajes menores de los "Swinging Sixties" británicos: 
¿A qué se refería mi padre cuando caía en esos trances proféticos? [...] ¿O tal vez ya intuía las disonancias del '68, donde los jóvenes dejarían de ser dandies para salir a las calles o quemar sus propias escuelas en las pantallas de los cines? ¿Habrá sido mi padre un torpe Nostradamus de la música pop o un ideólogo que -como suele ocurrir con los ideólogos- tenía más visión que auténtico talento? $[\ldots]$

Siempre hay un instante de encandilante omnisciencia en la caída. El premio consuelo para quien comprende que no alcanzará la línea de llegada. Tal vez mi padre intuyera que toda esa ropa extraña no demoraría en ser canjeada por trajes de Yves Saint-Laurent y Pierre Cardin y que la nueva transgresión pasaría por otros territorios: protestas, guerras, asesinatos, revueltas, revoluciones. Londres no tenía nada de eso. Londres no podía competir. Londres era una ciudad satisfecha. Lo único que le quedaba a Londres eran las drogas y un puñado de películas que habían envejecido demasiado rápido. (Fresán 2003: 134-136)

Aquí sólo se reivindica la lucidez concomitante a la perspectiva del escritor:

Tal vez yo también sea un gastado cliché: el hijo náufrago de un par de ahogados de la revolución eléctrica, salvado de la vorágine de los '60 en nombre de mi capacidad [...] para empapelar con ficciones las habitaciones de hijos verdaderos y siempre ajenos.

No importa. ¿Qué valor puede tener la reconstrucción de las arengas de un padre desesperado por su hijo que, ya entonces, lo escucha y lo lee calibrando su potencia como personaje imaginario? Los padres, se sabe, son inventos de los hijos. (Op. Cit. Fresán 2003: 137)

Mientras en la novela Kamtchatka (2003), de Marcelo Figueras, a la manera de La casa de los conejos, de Laura Alcoba, se elige contar la violencia política desde la construcción de una mirada infantil (si bien con interferencias de una reflexión adulta), Fresán, Gamerro y Pauls perciben el potencial subversivo de la perspectiva de los "hijos tempranos" de los militantes populares asesinados. No habiendo sido testigos de los hechos a tan corta edad como para depender de los compañeros de militancia sobrevivientes y/ o las Abuelas para el trabajo de la posmemoria, estas voces asumen el peligro de confluir con la mirada cínica y desencantada sobre el período de otros agentes históricos, lo que explicaría el pequeño escándalo que rodeó la publicación de Historia del pelo, cuando, desde la sección "cartas de lectores" de la revista $\tilde{N}$ de Clarín, la también escritora Viviana Lysyj acusó a Pauls de "derrape reaccionario". ${ }^{147}$

\footnotetext{
${ }^{147}$ La polémica fue trabajada en mi ponencia “¿Trivialización de la política o politización de lo trivial? Historia del pelo (2010), de Alan Pauls" (ISBN 978-987-544-517-8), presentada en el Cuarto Congreso Internacional CELEHIS (Mar del Plata, 7, 8 y 9 de noviembre de 2011). En términos de "memoria de la literatura I", el personaje del "veterano de guerra" de Pauls recuerda a "la Princesa" de Informe de París (1990), de Paula Wajsman, figura ficcional que también sobrevive en el exilio como dealer. Toda la novela de Wajsman resulta altamente disruptora en tanto no escenifica las penurias del exiliado político,
} 
La asunción por parte de determinados miembros de la "generación ausente" de la perspectiva de los "hijos tempranos" significaría un importante matiz respecto al conjunto de las narrativas de los hijos de los detenidos-desaparecidos, que, como Albertina Carri o Félix Bruzzone, vienen haciendo un trabajo análogo -pero no idéntico, tanto en la adscripción genérica de sus novelas como en los matices que asumen en tanto "textos colectivos" en su función de "circulación" según la terminología de Astrid Erll (2005)- a los fines de inquietar los sentidos que arroja el trabajo de la memoria.

\subsection{Carlos Gamerro, "crítico-estratega": su novelística como confluencia y desvío respecto a las tesis expuestas en "Argentine Literature and its Monsters" y $E l$ nacimiento de la literatura argentina y otros ensayos}

En 2006, Carlos Gamerro publica El nacimiento de la literatura argentina y otros ensayos, una compilación de trabajos sobre literatura argentina y literaturas en lengua inglesa, en su mayoría publicados originalmente entre 2000 y 2005 en Clarín y Página/12. Gamerro reivindica explícitamente su lugar de enunciación en tanto "críticoestratega":

Varios privilegios atienden a la práctica de la crítica de autor: el derecho a la primera persona y, por consiguiente, a hablar desde los sentimientos y las emociones; un relativo derecho a la ignorancia o por lo menos a la irresponsabilidad bibliográfica (el crítico académico, en cambio, es aquel que debe leer toda la literatura anterior sobre determinado tema antes de permitirse decir una palabra propia) y -aquí sutilmente pasamos del terreno de los derechos al de los deberes- la decisión de escribir no en jerga de especialistas o iniciados sino en un lenguaje accesible a los lectores cultos en general. (Gamerro 2006: 11-12)

El volumen está organizado en tres partes interrelacionadas: "Primera parte. Esta orilla"; "Segunda parte. Buenos Aires-Dublín: el puente" y "Tercera parte. La otra orilla", que parecen querer hacer "memoria de la literatura I" de las tres partes de Rayuela ("Del lado de allá"; "Del lado de acá” y "De otros lados").

Gamerro inaugura "Esta orilla" con el ensayo que da título a todo el volumen, donde hipotetiza "un doble origen" para la literatura argentina, recuperable en sendos textos firmados por Esteban Echeverría: La cautiva (el “poema malo") y El matadero (el "cuento bueno"). La formulación de Carlos Gamerro abreva en una hipótesis más general, formulada por David Viñas en Literatura argentina y política. De los jacobinos 
porteños a la bohemia anarquista ([1964] 2005): aquella que sostiene que la literatura argentina emerge alrededor de la violación como metáfora (El matadero, de Esteban Echeverría).

Los autores argentinos seleccionados como objeto diferenciado y exclusivo son Rodolfo Walsh (dos trabajos: "Rodolfo Walsh, escritor" y "Para una reformulación del género policial argentino"); Jorge Luis Borges ("Borges y la tradición mística”) y Juan José Saer ("El hombre que hacía llover”). Esta sección se cierra con un trabajo dedicado al autor español Manuel Vázquez Montalbán, a quien Gamerro define como "uno de los nuestros". También incluye una rareza: un ensayo titulado "14 de junio, 1982", donde afirma que su identidad está marcada por el hecho de -habiendo nacido en 1962- "no haber ido a Malvinas" (en el momento en que la "clase 62" estaba siendo llamada a filas, el autor de Las Islas se encontraba haciendo turismo en México).

"El puente" al que alude el título de la segunda parte no se sostiene desde dos, sino desde tres lados: Jorge Luis Borges, T. S. Eliot ("un americano en Londres que intenta definir su lugar ya no con relación a la literatura americana sino a la inglesa") y James Joyce (que, tal como lo hace Borges, "desplaza el centro a la periferia sin anular su status periférico"). Todo, por supuesto, tiene su razón de ser en el ensayo "El escritor argentino y la tradición" (1932), del que, sin embargo, Gamerro ensaya una lectura "desde el lado de allá", dando cuenta del "factor Joyce" sobre la literatura inglesa. Y también del "factor Joyce" sobre la argentina: entre los joycianos locales, se incluyen no sólo a Rodolfo Walsh, Luis Gusmán y Ricardo Piglia, sino también a Manuel Puig, "quien mejor lee la veta posmoderna del Ulises, su sensibilidad camp y pop hacia lo kitsch, lo cursi y los productos de la cultura de masas" (Op. Cit. Gamerro 2006: 136).

Por último, la sección "la otra orilla" abre con un trabajo sobre la vida y obra de Nathaniel Hawthorne (el formato - con su correspondiente tono y principio adjetivadorparece calcado del de Borges en sus reseñas para El Hogar). La tercera sección, que incluye trabajos sobre determinadas obras firmadas por Truman Capote, J. D. Salinger, John Cheever, William Burroughs y Aldous Huxley, es la menos lograda en su pretensión de tender "puentes" con la literatura argentina.

En la introducción al volumen, Gamerro despliega su historia familiar para justificar su derecho a "hablar como un escritor" sobre estas cuatro literaturas: 
Haber tenido un abuelo en Gibraltar (es decir, de sangre española y cultura inglesa), haber recibido una educación inglesa en un país sudamericano, enseñar una literatura en lengua extranjera, mientras practicaba otra en la propia, nativa (materna, en cambio, para mí fueron ambas), son dones o estigmas que no se borran fácilmente porque resultan tan constitutivos de la identidad cultural como de la física de los genes. (Gamerro Op. Cit. 2006: 12-13).

Las hipótesis principales de los ensayos contenidos en la primera parte de $E l$ nacimiento de la literatura argentina ya estaban in nuce en "Argentine Literature and its Monsters", conferencia dada por Gamerro en junio de 2003 frente a un grupo de editores europeos, y cuyo título alude precisamente a los dos "monstruos" que habrían signado la Historia y la literatura argentinas: Juan Domingo Perón y Jorge Luis Borges.

El autor de Las Islas señala nuevamente el doble nacimiento de la literatura argentina en Esteban Echeverría (con el "poema malo" y el "cuento bueno"), y logra llegar en su exposición a la "generación de los nietos de Borges" (Manuel Puig, Rodolfo Walsh y Juan José Saer) y la "trilogía de los excéntricos" (Copi, Néstor Perlongher y Osvaldo Lamborghini), pasando por Sarmiento, Hernández, Güiraldes, Lugones, Marechal, Cortázar y Sábato (aunque sin olvidar de enfatizar por el camino la importancia de Roberto Arlt, el "padre de la novela argentina tal como la conocemos").

Borges no es sólo y "sin ninguna duda el más grande escritor argentino de todos los tiempos", sino también el "mejor prosista en lengua castellana después de Cervantes" y el único latinoamericano que enseñó a los europeos a leer (de otra forma) a determinados autores de sus propios cánones nacionales.

Sobre Julio Cortázar, Gamerro señala que "fue probablemente el primer escritor en entender a Borges", esto es, en estar en condiciones de mitigar la angustia de las influencias suscitada por él en los términos (creativos) de una "mala lectura" (aquí el conferencista retoma explícitamente los conceptos de Harold Bloom, sobre quien el mismo año 2003 publica el volumen Harold Bloom y el canon literario).

$\mathrm{Si}$ bien frente a un auditorio extranjero resulta imposible pasar por alto la existencia de Rayuela, se profetiza enfáticamente que "ya está claro que [Cortázar] será recordadado por sus cuentos, que nos envuelven en una suerte de siniestro indefinido". De todas formas, es válido aclarar que contra la preeminencia otorgada a los cuentos 
cortazarianos por sobre las novelas, el único cuento del que se elige hacer "memoria de la literatura I" en Las Islas es "Esa mujer", de Rodolfo Walsh. ${ }^{148}$

Un año después de dar su conferencia "Argentine Literature and its Monsters", Gamerro publica La aventura de los bustos de Eva, cuyo héroe parece haber sido construido sobre los ecos del grito de “¡Estropeado!” en El niño proletario. ${ }^{149}$ En verdad, toda la novela -junto con Un yuppie en la columna del Che Guevara, que se publicará recién en 2011- funciona como una precuela (en sentido cinematográfico) de Las Islas y El secreto y las voces.

Otra vez, a la manera de Manuel Puig (Boquitas Pintadas. Un folletín y The Buenos Aires Affair. Novela policial) la adscripción a un género se exhibe ya desde el título: La aventura de los bustos de Eva. Corre el año 1974 y el joven empresario Ernesto Marroné -el héroe de la aventura- queda a cargo de las negociaciones para rescatar a Fausto Tamerlán, que ha sido secuestrado por una célula montonera. Dentro de las condiciones impuestas por los secuestradores, está la de conseguir noventa y dos bustos de Eva Perón y colocarlos en lugares visibles de la Constructora Tamerlán. A los fines de lograr su cometido, Marroné entra en tratativas con la Yesería Sansimón (el carnaval lamborghinesco de los nombres continúa...), en el curso de las cuales ésta es tomada por sus obreros y rebautizada como "Yesería Eva Perón".

Guiándose según los preceptos de interacción social "exitosa” que se explican en los best-sellers Cómo ganar amigos e influir sobre las personas y Cómo hablar bien en público e influir en los hombres de negocios, de Dale Carnegie, y The Use of Lateral Thinking, de Edward De Bono, Marroné logra su cometido, e, incluso, es tomado tanto por los líderes obreros como por los militantes de la Orga que azuzan la expropiación de la fábrica (entre los que se encuentra su ex compañero de escuela Paddy Donovan)

\footnotetext{
${ }^{148}$ La siguiente descripción de Rodolfo Walsh, en "Esa mujer": "Oscurece por grados, como en el teatro. La cara del coronel está casi invisible. Sólo el whisky brilla en su vaso, como un fuego que se apaga despacio. Por la puerta abierta del departamento llegan ruidos remotos. La puerta del ascensor se ha cerrado en la planta baja, se ha abierto más cerca. El enorme edificio cuchichea, respira, gorgotea con sus cañerías, sus incineradores, sus cocinas, sus chicos, sus televisores, sus sirvientas. Y ahora el coronel se ha parado, empuña una metralleta que no lo vi sacar de ninguna parte..." ([1965] 1985: 166-167). Y su memoria en Las Islas: "Miré hacia el patio, a través de la persiana entreabierta: noche cerrada, un cielo de lacre fundido, una delgada película de humedad extendida sobre todo, como si la respiración del edificio -cañerías, elásticos de camas, un perro gruñendo en sueños, un viejo tosiendo, el zumbido de mis máquinas, un teléfono sonando en un departamento vacío- circulara por las habitaciones y pasillos y por el frío se condensara sobre sus paredes, macetas, baldosas, puertas, ventanas..." (Op. Cit. Gamerro 1998: 104).

149 "Marróné", apellido falsamente afrancesado de Ernesto, en verdad alude al color oscuro de su piel de hijo adoptado: el “imarrón caca, marrón villa!” con el que lo torturan sus compañeritos de colegio inglés.
} 
por un importante oficial montonero de la Columna Norte, enviado en misión secreta como veedor de la toma.

Gran parte de los títulos que Marroné lleva en su attaché y consulta obsesivamente (Don Quijote, el ejecutivo andante; Shakespeare The Businessman; El samurai corporativo y Haikus for Managers, que también aparecen citados en el cuerpo de la novela) están construidos à la Borges. Ejemplos: el autor del apócrifo Don Quijote, el ejecutivo andante, "Michael Eggplant", resulta de cruzar la lista de temas del disco "Best of Michael Franks" (donde el título de una de las canciones es precisamente “Eggplant”) con el clásico firmado por Cervantes. ${ }^{150}$ Haikus for Managers y El samurai corporativo, textos que, junto con The Tao of Management, configurarían un subcorpus de "auto-ayuda empresarial" orientalista, son invenciones. The Tao of Management, que en la novela se atribuye a "Dean Tesola", tiene por autor real a Bob Messing. Por otra parte, Small is beautiful, de Ernst Friedrich Schumacher; La gerencia de empresas, de Peter Drucker; The Art of Competition, de Dwight D. Connoly; El vendedor más grande del mundo, de Og Mandino y The Managerial Grid, de Robert Blake y Jane Mouton, son todos textos efectivamente existentes.

Se trata de la exhibición desaforada de una biblioteca (otra), pero construida a la manera borgiana por cruce y superposición de títulos existentes con otros inventados, que ponen a dialogar la más alta literatura (Cervantes, Shakespeare, los haikus japoneses) con el trash de la "auto-ayuda empresarial".

Finalmente, la yesería "Eva Perón” es recuperada a sangre y fuego por la policía: la matanza de los trabajadores rebeldes termina con una invasión de mariposas amarillas. ${ }^{151}$ La repetición de este motivo podría ser leído como "memoria de la literatura I" y homenaje oblicuo a Cien años de soledad, escrita y publicada antes de que la prosa de García Márquez se transformara en una fórmula sin riesgos estéticos y -por lo mismo- tan fácilmente reproducible como comercializable. Así, en La aventura

\footnotetext{
${ }^{150}$ A título anecdótico: Michael Franks fue también profesor en la Universidad de California en Los Ángeles (UCLA), donde Gamerro realizó estudios de cine.

${ }^{151}$ Uno de los micro relatos más bellos de Cien años de soledad es la historia de amor prohibido entre Meme Buendía y Mauricio Babilonia, con su explícito trasfondo social: la niña rica que se enamora de un aprendiz de mecánico, y se le entrega a escondidas en la propia casa paterna. Como se sabe, cada aparición de Mauricio Babilonia es precedida por una nube de mariposas amarillas, las mismas que revolotean por última vez cuando los amantes son descubiertos, y Mauricio abatido de un escopetazo que lo deja paralítico de por vida
} 
de los bustos de Eva, Gamerro eligiría (como Fogwill en "Los pasajeros del tren de la noche") parodiar el realismo mágico, pero no en sentido antiguo, sino bajtiniano. ${ }^{152}$

La última página de la novela, a la manera del folletín, anuncia la pronta aparición de Un yuppie en la columna del Che Guevara (contra esta promesa, al año siguiente Gamerro publicó una compilación de cuentos escritos entre 1987 y 1995, bajo el título de El libro de los afectos raros).

En la última entrega de la saga, que recién aparece en 2011, la principal "memoria de la literatura I" convocada parece ser ¿Quien mató a Rosendo?, de Rodolfo Walsh, aunque con una importante salvedad: "la evidencia disponible" (la expresión es de Walsh) que Gamerro incorpora a su novela está construida a partir de la ficcionalización de documentos históricos efectivamente existentes, como si fueran parte del reservorio de subgéneros de la literatura.

A saber: la transcripción del juicio a Fausto Tamerlán (memoria del "jucio revolucionario" al teniente general Pedro Eugenio Aramburu, secuestrado el 29 de mayo de 1970 y ejecutado el $1^{\circ}$ de junio, del que la Organización publicará su versión titulada “Cómo murió Aramburu", en el n 9 de La Causa Peronista del 3 de septiembre de 1974); el diario que lleva Ernesto Marroné durante su entrenamiento militar en el Delta, mientras, en simultáneo, posa como personaje principal para la fotonovela "Che" (construido como pastische de El diario de Bolivia, de Ernesto "Che" Guevara); "La risa de un montonero", sobre la muerte de Paddy Donovan (memoria de las semblanzas que se publicaban en la prensa montonera en homenaje a los compañeros caídos) y la carta de despedida (finalmente nunca enviada) de Marroné a sus hijos, que hace "memoria de la literatura I" de la "Carta de despedida del Che a sus hijos".

Por último, el apócrifo más escandaloso: el "testimonio del señor EUGENIO PÉREZ GIL. Electricista”, que Gamerro fecha el "día 6 de mayo de 1985" y que simula ser un fragmento de la "Versión Taquigráfica de El Diario del Juicio" correspondiente a los días 6 al 10 de mayo de 1985 (recordemos que el $\mathrm{n}^{\circ} 1$ de El Diario del Juicio

\footnotetext{
${ }^{152}$ Acá retomamos la distinción entre "parodia en sentido antiguo" y "parodia en sentido moderno" que despliega Linda Hutcheon en "Ironie et parodie: stratégie et structure" ["Ironía y parodia: estrategia y estructura"]: "Y el uso moderno de la parodia no parece, en ningún caso, apuntar al ridículo y la destrucción. Dentro de este uso moderno, la parodia implica más bien una distancia crítica entre el texto en segundo plano que es parodiado y el nuevo texto que está cincelándose, una distancia señalada ordinariamente por la ironía. Pero esta ironía es más euforizante que desvalorizante, o más crítica en términos analíticos que destructora" (1978: 468; nuestra traducción).
} 
auténtico se publica el día 27 de mayo de 1985, y recoge los testimonios más importantes escuchados durante la semana anterior).

En el relato del electricista "Pérez Gil" aparecen cinco elementos pertenecientes al testimonio del ex secretario académico de la Facultad de Ciencias Exactas de la Plata, Mario Villani, secuestrado el 18 de noviembre de 1977 y entrevistado bajo el título "El testigo de la semana" para el $n^{\circ} 1$ de El Diario del Juicio correspondiente al 27 de mayo de $1985 .^{153}$

"Pérez Gil" es rebautizado "X-9" (al prisionero Mario Villani le dan la letra "X" el número "96"), cambia numerosas veces de CCDTyE, se le adjudican tareas de mantenimiento en el (inexistente) "Pozo Coto" para, finalmente y a pedido de sus captores, arreglar una picana averiada. En su declaración, pide a los jueces que lo escuchan lo mismo que había pedido Villani durante su testimonio dado el 22 y 23 de mayo de 1985: utilizar el término "mudanza" para referirse a un cambio de CCDTyE y reservar la palabra "traslado" -tal como ocurría en la jerga de los campos- como sinónimo de "asesinato".

La ficcionalización del testimonio de Villani (su transformación en un mero género literario, tramable por lo mismo con otras "memorias de la literatura I"), marcaría el límite de lo que puede ser dicho por la "generación ausente". En este sentido, resulta significativo que sobre el cierre de "Argentine Literature and its Monsters", para mejor posicionarse como autor, Gamerro elija explicar su vínculo con el pasado reciente desde su perspectiva generacional de pertenencia:

Y de este modo llegamos al final de nuestra charla. No voy a decir nada en particular sobre los autores de mi generación, dado que probablemente ustedes los conocerán por sí mismos y no quiero influenciar en su mejor juicio. Pero hay una cosa que me gustaría decir sobre nosotros, considerados como un grupo. Si lo que dije al comienzo no es enteramente falso, entonces los autores de mi edad han de enfrentar el desafío mayor, puesto que no hay monstruos en la historia argentina que se comparen con la mayor campaña del terror que este país conoció jamás. Ricardo Piglia, uno de los críticos y escritores sobresalientes de la actualidad, sostiene en su estimulante primera novela, Respiración artificial, que no podemos decir nada sobre el mundo de Auschwitz - un mundo más allá del lenguaje. Auschwitz, claro está, era su modo de nombrar la última dictadura militar cuando todavía estaba en funciones, en la época en que su novela fue escrita y publicada. La literatura -para no decir sus escritores- se siente impotente frente a la magnitud de esta tarea. Haremos todo lo

${ }^{153}$ En el año 2011, Fernando Reati publicó Desaparecido. Memorias de un cautiverio. Club Atlético, El Banco, El Olimpo, El Pozo de Quilmes y ESMA, conjunto de entrevistas realizadas a Mario Villani, donde éste cuenta su experiencia. 
posible, y ojalá lo poco que podamos lograr sea recogido y continuado por otros que sigan nuestros pasos. (Gamerro 2003: mimeo, mi traducción)

3.6. Memoria del lector y "sobreinterpretación" en El coloquio, de Alan Pauls; Los ojos así, de Miguel Vitagliano; La perla del emperador, El terrorista y El perseguido, de Daniel Guebel

Uno de los procedimientos literarios listados por Andrés Avellaneda en "Lecturas de la historia y lecturas de la literatura en la narrativa argentina de la década del ochenta" (1997) es el "presente en clave alusiva", que continúa siendo practicado durante los años noventa de manera subrepticia por algunos miembros de la "generación ausente" en novelas donde -a diferencia de las escritas bajo dictadura- la puesta en escena de la pasado reciente no parece ser el objetivo más importante. Un ejemplo de lo dicho es Los ojos así (1996), de Miguel Vitagliano, saga familiar donde todos los personajes están animados por el deseo de escribir. En invierno-primavera de 1978, el "tío Nelson" atraviesa la Costa Patagónica y hace escala en diferentes pueblos, que tienen nombres como "Rata", "Pingüino", "Pantera", "Delfín", "Halcón", "Puma” y "Cuervo", desde los cuales remite cartas a su sobrina, contándole sus aventuras de viaje.

Por una única mención, el lector está en condiciones de descubrir que dicha topografía no es aleatoria (no se trata de cualquier animal), sino que remite a los apodos reales del personal perteneciente a la Marina que tuvo responsabilidad directa en la tortura y asesinato de prisioneros en la Escuela de Mecánica de la Armada:

Aquella fue la carta más extensa -León, 5 de agosto de 1979- que el tío Nelson había enviado hasta el momento. Repartió el espacio entre las quejas a su sobrina y los balleneros japoneses: “Ahora que estás por cumplir doce años espero te dignes a hacer a un costado mi olvido [...] y escribirme a Hotel de la Mutual, Contraalmirante Delfin, al parecer ya he perdido por ese motivo cartas de tu madre, si me recuerda...” (Vitagliano 1996: 122; énfasis del autor)

Se trata, claro está, del Contraalmirante Rubén Jacinto Chamorro, director de la ESMA hasta principios de 1979 (alias "Delfín" o "Máximo"). ${ }^{154}$ Estos índices topográficos forman a su vez sistema con otras alusiones al pasado reciente dispersas en la novela: los "hermanos desaparecidos" cuyas voces aturden a "Dedy" y le piden que

\footnotetext{
${ }^{154}$ La topografía de animales ("Puma", "Pingüino", etc.), desplegada en las cartas del tío Nelson que aparece en Los ojos así alude a: el ex Capitán de Corbeta Jorge Perrén (alias "Puma"); el ex Teniente de Navío Raúl Enrique Scheller (alias "Pingüino"); el ex Capitán de Corbeta Jorge Eduardo Acosta (alias "Tigre"); el ex Teniente de Fragata Alfredo Ignacio Astiz (alias "Cuervo"); el ex Teniente de Navío Antonio Pernías (alias "Rata") y el ex Capitán de Fragata Néstor Omar Savio (alias "Halcón" o "Pantera").
} 
recuerde; la enemistad de "Dana", su madre, con el personaje de "el Negro" (que se niega a usar sus influencias para averiguar el paradero de una vecina detenidadesaparecida); la recomendación que recibe una Dedy adolescente de no andar por la calle por las cosas que pasan.

Si uno de los riesgos que corren las novelas que se sirven del procedimiento del "presente en clave de pasado remoto" es que un lector no avisado lea una mera narración ficcional de tipo histórico donde en verdad se le está proponiendo la recuperación de una memoria más acuciante, el riesgo opuesto sería el de la sobreinterpretación. Precisamente, en su columna La Verónica del n 19 de Babel de septiembre de 1990, Caparrós señalaba la posibilidad de leer La perla del emperador en clave política (y en la desaparición del personaje de Li Chi, la cifra de la suerte de los detenidos-desaparecidos de la última dictadura), al mismo tiempo que alertaba sobre lo aventurado de realizar una lectura en dichos términos.

Podría afirmarse que tanto El terrorista (1998) como El perseguido (2001), de Daniel Guebel, optan por hacer del riesgo de la sobreinterpretación un procedimiento literario. La sobreinterpretación es definida por Umberto Eco como:

... la sobreestimación de la importancia de los indicios que nace con frecuencia de una propensión a considerar significativos los elementos más inmediatamente aparentes, cuando el mismo hecho de que son aparentes nos permitiría reconocer que son explicables en términos mucho más económicos. (Eco [1992] 1995: 52-53)

El terrorista cuenta la historia de Daberre, verdulero porteño que un día encuentra un pasquín con la palabra "revolución" entre los papeles de diario que le sirven para envolver la mercadería. A partir de ese momento, Daberre se transforma en, primero, un lector compulsivo de prensa política, y, poco tiempo después, en editor febril de panfletos y materiales "de izquierda". Daberre, sin embargo, sufre esta conversión en un contexto que podríamos inferir como relativamente democrático (en tanto finalmente le hacen un juicio público para condenarlo por "terrorismo").

Entre las páginas 33 a 36 de la novela, se narra una inesperada explosión: Daberre, motejado de "judío bolchevique", es injustamente acusado de haberla provocado. Al respecto, el lector es inducido a leer dicha explosión en clave de otro pasado reciente, casi contemporáneo al de la escritura: el de la Guerra de Bosnia (6 de abril de 1992 al 14 de diciembre de 1995), que reverbera irónicamente en la siguiente 
cita: “... la explosión había destruido un jardín de infantes ligado a una asociación italiana y una mutual de ayuda para ancianos de origen eslavo" (Guebel 1998: 35).

El perseguido, como Las Islas, constituye un ejemplo de las relativamente escasas incursiones locales en el género de la ciencia ficción cyber-punk. Aquí, con el correr de las páginas, la trama política se desquicia: Ferretti, el héroe de la novela, inicialmente perseguido por "los Aparatos de Inteligencia, el Terror", decide recurrir al doctor Hunico para que lo clone, y desandar así su “viaje a la desaparición” (Guebel 2001: 9). Para testear la calidad de las copias, envía sus clones a la casa de cada una de sus numerosas amantes, aunque finalmente entra en competencia con ellos, y los termina cremando.

Luego de las primeras treinta páginas, la trama de El perseguido, a la manera airiana, da un "salto hacia delante" (Cf. Contreras 2002: 20-24). El héroe, como el gaucho Martín Fierro, escapa al desierto para mimetizarse con el indio y evitar que "los Aparatos de Inteligencia, el Terror" logren dar con él. No obstante, el desvío hacia una posible "novela pampeana" no prospera más allá de unas pocas páginas: para mejor camuflarse, Ferretti decide someterse a una operación de cambio de sexo, y se transforma en "Sandra Vonas". Con esta nueva identidad, logra fácilmente seducir a un supuesto agente de los servicios que le estaba dando caza, a quien termina asesinando. Luego de una segunda operación de cambio de sexo, se enamora de una actriz y tiene un hijo con ella. Se transforma a su vez en estrella de cine, descubre que su esposa e hijo son androides, comienza a adquirir rasgos de carácter cada vez más inhumanos y perversos (entre ellos: una obsesión morbosa por los experimentos médicos con hermanos gemelos, que traen a la memoria del lector la figura de Josef Mengele), continúa escapándose de los “Aparatos de Estado", para finalmente ser capturado por ovnis (sic!) y despertar en una celda en diálogo con la voz del misterioso personaje de Hunico (¿El Único? ¿Dios?), que se apresta a detonar la bomba atómica. Por todo lo dicho, el énfasis en El perseguido parece estar más bien en la carnavalización gozosa de ciertos debates bioéticos desatados a partir de la clonación de la oveja Dolly (año 1997), que en la narración críptica de la violencia política en la Argentina.

En efecto: tanto en El terrorista como en El perseguido, el pasado dictatorial se ve reducido a una serie de ítems léxicos: "los Aparatos de Estado, el Terror", "la prensa de izquierda”, etc., que no terminan de armar sistema dentro de la trama total. Si el título, que como señaló Umberto Eco (1986) es la primera clave del contenido del libro y el 
disparador de las primeras conjeturas, operaría para el caso de las novelas de Guebel como catalizador de la sobreinterpretación del lector. ${ }^{155}$

En el capítulo anterior hemos visto que una de las propuestas que traen los narradores nucleados alrededor de la revista Babel es "la novela exótica" (deudora de la formulación de Severo Sarduy), que esgrimen como un posible antídoto contra los excesos de color local y postulan como una paradójica novedad literaria. En el editorial "Nuevos avances y retrocesos de la nueva novela argentina en lo que va del mes de abril", que firma Martín Caparrós y donde son desarrollados estos conceptos, se empalma la imagen del desierto pampeano con la idea de "poblarlo" por medio de ficciones novelescas hipercivilizadas:

Al principio de estos ochenta, escritores cuarentones que nunca trabajaron la narrativa Roger Rabbit intentaron, quizás inadvertidamente, una operación: hacer del desierto, del vacío pampeano, un demasiado lleno, un lugar de la hipercivilización. Están los últimos cuentos de Fin de juego, de Miguel Briante, que hacen de la pampa un campo de la metafísica, o algo así. En El entenado, de Juan José Saer, los indios se lanzan a bebercios y comercios que llenan el espacio con los ecos de una cultura del pacer y el placer. Y, sobre todo, en Ema la cautiva, de César Aira, los indios pampeanos aparecen como refinados mandarines, señores de la guerra que comen pavos braseados en coñac y acicalan cuidadosamente sus dispendiosas sedas.

Revertir el mito. Hacer del vacío un exceso fue una forma de extrañamiento. Ahora, últimamente, el extrañamiento parece tomar características más directas: el mismo Aira con su novela china [Una novela china, 1987], la novela egipcia de Laiseca [La hija de Kheops, 1989], el "Lorelei" de M. Cohen. [El oido absoluto, 1989], el ambiente caballeresco de Daniel Guebel [Arnulfo o los infortunios de un príncipe, 1987], el ligero tinte germano de Alan Pauls [El coloquio, aún inédita para ese entonces], mi novela griega [La noche anterior, también inédita] (Caparrós 1989: 44)

Colocar El coloquio dentro del grupo de "novelas exóticas" es por lo menos discutible. La novela de Pauls parte de una trama policial mínima (Pablo Daniel F. ataca la casa de su ex mujer Dora, lo que da origen a la pesquisa) para enrarecer à la Kafka esta minucia policial (uno de los funcionarios policiales se apellida "Brod", como el amigo y albacea del autor checo; todos los crímenes ocurren en La Ciudad Este; las

\footnotetext{
155 "Por desgracia, un título ya es una clave interpretativa. Es imposible sustraerse a las sugerencias que generan Rojo y negro o La guerra y la paz. Los títulos que más respetan al lector son aquellos que se reducen al nombre del héroe epónimo, como David Copperfield o Robinson Crusoe, pero incluso esa mención puede constituir una injerencia indebida por parte del autor. Papá Goriot centra la atención del lector en la figura del viejo padre, mientras que la novela también es la epopeya de Rastignac o de Vautrin, alias Collin. Quizás habría que ser honestamente deshonestos, como Dumas, porque es evidente que Los tres mosqueteros es, de hecho, la historia del cuarto." (Eco 1986: 10)
} 
calles ostentan el nombre de "Praga" y "Dek"). ${ }^{156}$ Cuando el lector recaba que otro de los policías se llama "Mossalini” (¿Mussolini?) y el médico forense, “doctor Kalewska” (¿por "Galewski”, el personaje de Sebregondi se excede?), comienza a sospechar que toda la novela funciona como una desquiciada alegoría del fascismo.

Pauls no se priva de repetir la pregunta que J. L. Borges había planteado en "Deutsches Requiem” (¿pueden los asesinos ser melómanos y amar la poesía?), deslizando los sentidos de esta supuesta novela policial hacia la historia argentina reciente. Aquí también, como en Respiración artificial, ésta aparece tramada con el pasado nacionalsocialista.

En efecto: los criminales que asolan Ciudad del Este tienen para sus víctimas un tratamiento que mezcla por partes iguales el comportamiento propio de un grupo de tareas (vejaciones, quemaduras con cigarrillos, golpes con cachiporras) y el de los Sonderkommandos de los campos de exterminio nazis (los hombres son incinerados como "una piña de leños secos"). A diferencia de lo que ocurre en las novelas de Guebel antes reseñadas, aquí la clave de lectura que propone el título (El coloquio) sí arma sistema con aquello contenido en el cuerpo de la novela: un intento de reescribir en clave política la "novela exótica".

$\mathrm{Si}$, como hemos expuesto en el capítulo anterior, el modo en que los miembros de la "generación ausente" eligieron para relacionarse con la generación de sus mayores no fue el modelo de conflicto, sino el de un diálogo posible, el título El coloquio de la novela de Pauls aludiría a esa modalidad, aunque ahora en términos de "memoria de la literatura I". Por último: todas las novelas de los autores estudiados se construirían a partir de la "figura del coloquio", por lo que su aspiración a ser encuadradas como "lo nuevo" no estaría relacionada con una cualidad textual constatable, sino con el afán de activar una lógica propia del "mercado de los bienes simbólicos", precisamente en momentos en que éste se encontraba sumido en una profunda crisis.

\subsection{Politizar a César Aira: Auschwitz, de Gustavo Nielsen y Gerardo y Mercedes, de Ricardo Strafacce}

Dentro de las novedades que muestra la escritura airiana, una de las más acusadas sería la ostentosa renuncia a remitir a la escena política contemporánea a la escritura. La gran excepción a la regla es Embalse (con fecha de finalización dada por el autor del 6 de

\footnotetext{
${ }^{156}$ El "Odradek" es una criatura imaginaria que aparece en el cuento "Las Preocupaciones de un padre de familia", incluido en el volumen Un medico rural (1920), de Franz Kafka. También se hace presente en el bestiario El libro de los seres imaginarios (1967), de Jorge Luis Borges.
} 
diciembre de 1987, aunque recién publicada en 1992). En ella, los periódicos traen noticias de "citaciones y procesos a militares", que son leídas obsesivamente por el héroe, Martín. Se aclara sobre el mismo que "era apolítico, la mera idea del totalitarismo lo ponía fuera de sí, le causaba un espanto inimaginable, un pavor que lo asfixiaba" (Op. Cit. Aira 1992: 93 y 204, respectivamente).

Con un arranque taimadamente realista ("Martín”, su esposa "Adriana" y sus dos hijos vacacionan en la provincia de Córdoba, donde conocen -jcuando no!- a "César Aira", un "distinguido escritor" que pronto muestra la hilacha: padre de familia, homosexual reprimido, millonario, cocainómano, comete el peor de los pecados: "le faltaba lo principal: la simplicidad"), la trama de Embalse pronto desvía hacia la ciencia ficción más extrema. El apacible pueblo cordobés se revela como laboratorio de confusos experimentos sobre humanos y animales, cruzas kafkianas que contradicen toda bioética. Frente a la inminente aparición de la "liebre giniebrina", "los generales" (que no precisan más identificación que ésta) desatan una ofensiva nuclear contra la provincia. Sabiéndose condenado por la radioactividad, el héroe reflexiona que:

Había algo peor que morir: que murieran también los únicos que podían llorarlo, los únicos que lo extrañarían, que lo amaban... Era una inmensa nostalgia [...] No es que Martín no hubiese pensado en su muerte, y en "las cosas peores que la muerte", como piensa todo el mundo. Más de una vez, reflexionando sobre el tema, había llegado a la conclusión de que lo peor de todo sería caer en manos de los militares que habían gobernado el país, y sufrir las torturas: la electricidad, las uñas arrancadas, las inmersiones, las mutilaciones. (Op. Cit. Aira 1992: 219).

En las antípodas del trabajo sobre el pasado reciente en los términos adornianos de la negatividad (tal como lo hicieran, por ejemplo, Ricardo Piglia y Juan José Saer), la última frase de Embalse -mientras "Martín" se hunde en las aguas del lago para intentar vanamente aplacar la calvarie de los efectos de la explosión sobre su cuerpo- es directamente estentórea:

El agua le azotó los ojos ciegos. Trató de levantar la cabeza como un último gesto Ya no tenía boca para gritar, y es dudoso que lo hubiera hecho de todos modos, pero algo en él alcanzó a pensar unas palabras todavía: Muero por la Argentina y por el presidente Alfonsín. (Op. Cit. Aira 1992: 222)

La única novela de Aira que podría ser llegada a leer en términos de "la elipsis, la alusión y la figuración como estrategias [para] rodear el núcleo resistente y terrible que se denominaba "lo real"' (Op. Cit. Sarlo 1987: 35) es Los fantasmas, con fecha de escritura el 13 de febrero de 1987, pero publicada por Grupo Editor Latinoamericano en 
1990. De todas formas, se hace imprescindible echar mano al concepto de “sobreinterpretación" de Eco ([1992] 1995), y, como en el caso de Sergio Guebel, poner énfasis en las prevenciones con que necesariamente ha de ser encarada una lectura en tales términos.

En efecto: si "los fantasmas" desnudos y cubiertos de polvillo de cal que pululan alrededor de los albañiles chilenos remiten a los detenidos-desaparecidos, la utilización del tórax de los mismos como método de destilación y/o refrigeración de vino tinto, su sociabilidad ostentosamente homoerótica y la manera cruel en que inducen al personaje de "la Patri" a suicidarse para admitirla en su festejo de fin de año constituirían elementos por demás enigmáticos, que no terminan de ensamblar unos con otros. Como ya hemos analizado para el caso de El terrorista, de Daniel Guebel, los ítems léxicos (en este caso: nombres propios) no arman ningún sistema, o, mejor dicho, invitan al lector a perderse en el callejón sin salida de la sobreinterpretación.

A saber: la familia de chilenos que vive en la obra en construcción se apellida "Los Viñas” (¿por los hermanos Viñas?); el uruguayo que también trabaja allí se llama "Washington Mena” (¿Una remisión al personaje de Juan José Saer? ¿Una alusión al militante popular perteneciente al PRT-ERP José Ricardo Mena?); el obrero al que todos llaman "El Macaneador" lleva el nombre civil de Carlos Soria (¿por Los Sorias?); "el santiagueño" responde al nombre de "Lorenzo Quincata" (¿por el actor y ex literalista Lorenzo Quinteros?) y "la Patri”, el apodo de la heroína de la novela, si bien podría ser leído como alusión a "la Patria", es -como la mayoría de los personajes- de nacionalidad chilena...

Similar trabajo con el sistema onomástico realizaría Gustavo Nielsen en Auschwitz (2004), novela donde se narra la peculiar historia de amor entre la judía "Roxana Auschwitz" y el neonazi "Beto" (Roberto), ambientada en la década del noventa. La novela fue publicada en Alfaguara mediante un subsidio a la creación de la Fundación Antorchas (concurso Edición 2003 de becas y subsidios para las artes), con un Jurado unipersonal conformado por César Aira.

A diferencia de Los fantasmas, la novela de Nielsen sí remite de manera inequívoca al pasado reciente mediante el procedimiento del "presente en clave alusiva" (Op. Cit. Avellaneda 1997). En una larguísima secuencia narrativa, "Beto" atormenta y sodomiza al hijo de diez años de "Roxana", a quien ha secuestrado para extorsionar a su madre (que le ha robado un preservativo con semen). Para dar una idea del tono 
predominante (esforzada "memoria de la literatura I" de El fiord) transcribimos un fragmento:

Le convirtió la nariz en pulpa cortándole la piel en capas finas, como si laminara un ajo sobre el aceite. Tiró del tabique nasal con la pinza pico de loro hasta astillar el cartílago, que quedó expuesto, y como a Beto no le gustaban las exposiciones, se lo volvió a hundir a golpes de martillo. No podía romperle los dientes porque no tenía; se cercioró de que así fuera antes de meter su soldado adentro de esa boca. Durante la meada, Beto había sufrido una erección [...] y se le había ocurrido la feliz idea de metérsela ahí adentro. [...] Ya le había clavado agujas, clavos de vidriero y escarbadientes partidos debajo de las uñas de las manitos, pero era un trabajo enorme y quedaba desprolijo: cada uña no aceptaba más de dos incrustaciones, antes de descamarse o deshacerse en banderines que colgaban desprolijamente de los dedos. Sin contar con que los alfileres se doblaban, los escarbadientes se quebraban y los clavos eran difíciles de maniobrar. Las dificultades provenían de las mismas manos, que presentaban cierta blandura. Intentar arrancarle las uñas era igual de lento y complicado. ¡Y había tanto que disfrutar! (Guebel 2004: 94)

Aburrido del carácter amateur de sus emprendimientos, "Beto" se sienta a estudiar el Nunca más (que lee como un manual de tortura), del cual extrae prolijas notas. Se impone entonces una excursión al Easy del barrio, para hacerse de una picana. De manera quizá en exceso previsible, el encargado de la sección electricidad del centro comercial resulta ser un ex integrante de un Grupo de Tareas, que le explica con gran didactismo cómo puede fabricar una máquina casera.

Ya de regreso en su departamento, "Beto" toma el velador de la mesa de noche, le pela los cables y se aproxima al niño. Es precisamente en ese momento, cuando el lector comienza a hundirse en un perplejo horror, que irrumpe el disparate airiano: el contacto con la carne provoca un cortocircuito masivo, que deja el departamento a oscuras.

La novela pierde entonces todo resabio realista y desbarranca hacia la ciencia ficción: admirado, "Beto" descubre que el hijo de Roxana es un alienígena inmortal y capaz de cicatrizar en tiempo récord cualquier tipo de herida, en alianza con los muerciélagos de hábitos vampíricos que invaden los edificios del barrio de Palermo. El final no es exactamente feliz, pero va en esa dirección: "Roxana Auschwitz" (¿otra alienígena?) recupera a su hijo, devuelve el semen robado, y se promete futuros encuentros con "Beto".

Si bien Strafacce ya se había presentado como un post airiano en su producción narrativa anterior (Crímenes imperceptibles, publicada en 2012, es al día de hoy su novela más lograda), Ricardo y Mercedes es la única que da una novedosa entonación a 
lo ya ensayado por Daniel Guebel y Gustavo Nielsen: hacer del disparate una instancia ética. Lo logra utilizando los procedimientos airianos prototípicos de "la fuga hacia delante" (Cf. Speranza 2001) y "el continuo" (Cf. Contreras 2002) y a los fines de dar una reversión particularmente iconoclasta de un tópico considerado intocable en el plano de la memoria social: la apropiación de niños.

Décima novela de Strafacce en ser publicada, Ricardo y Mercedes (2013) tiene como marco la dictadura de los herederos ideológicos del fallecido general "José Cosmelli Lanzzeta" (una alusión directa a Jorge Rafael Videla). Atravesados por ella desfilan personajes reales -Hebe de Bonafini, Rodolfo Enrique Fogwill, Antonio Carrizo, Susana Jiménez- y figuras de nombres regocijantes -“Mecha", "Gofieguito", la modista 'Puntilla' ", el psicoanalista "Licenciado Tortolo", "los López Pagiola", "Don Bienvenido"-, que dan carnadura a búsquedas identitarias y vocacionales, enredos amorosos y aventurillas sexuales.

La escena donde "Mecha" se entrevista con Hebe con motivo de la desaparición de sus padres, Don Bienvenido y Doña Filomena, y ésta la deriva "con un gesto imperial" a la oficina de H.I.J.O.S. ("una organización rival con la que, sin embargo, mantenía acuerdos”) es una de las más logradas (Cf. Op. Cit. Strafacce 2013: 76-80). Mención aparte merece la descripción de la fiesta (que degenera en "fiesta hiperbórea", en el sentido que le da al término Héctor Libertella) celebrada a raíz del embarazo de "Mecha". Traemos una única y extensa cita para ilustrar el logrado manejo del tono airiano por parte de Strafacce:

Caviar y langosta, cochinillo y centolla, tocino, panceta, ojo de bife, pastel de papa, arroz con pollo, puchero, carbonada, sushi, fetuchini, polenta, mondongo, liebre, cerdo, corderito, bola de lomo, radicheta, milanesa..., en fin: ¿para qué describir (hasta la exótica y deliciosa carne de seso de mono vivo formaba parte del menú) los manjares que los camareros, que surcaban los jardines con las bandejas en ristre y la sonrisa pletórica de eficacia y convicción, depositaban en las mesas?

La noche, para colmo, no podía mostrarse más de acuerdo con la celebración. No hacía ni frío ni calor. O hacía las dos cosas a la vez. Distribuidos por los maîtres en mesas de cinco o seis participantes, según una lista confeccionada de acuerdo a las afinidades existentes entre los invitados (los deportistas con los deportistas, los de la farándula con los de la farándula, los políticos con los militares y los eclesiásticos), todos la pasaban bárbaro. Se departía, se disfrutaba, se comía a cuatro manos y se bebía a lo loco. Los trabajadores de sexo que, oliendo el dinero, se habían infiltrado en la fiesta (chongos, putas, dominatrices... Hasta algunos travestis habían logrado colarse) no estaban, lógicamente, previstos en el protocolo. De todas maneras, se las arreglaron para acomodarse cada uno en alguna mesa donde, discretos y empecinados a la vez, no cesaban de ofrecer sus voluptuosos servicios para el fin de la velada. (Strafacce 2013: 39-40) 
Contra la propensión del autor oriundo de Coronel Pringles a "abandonar" sus novelas (Cf. Sarlo 2006) la frase que clausura Gerardo y Mercedes es fundamental: "De Don Bienvenido y Doña Filomena no se supo nunca nada más" (Strafacce 2013: 134). La desaparición de los padres se constituye así en dique de contención para la suave euforia airiana dominante en las páginas precedentes, y -como en Embalse- invita a releer toda la novela en clave política.

\subsection{La hipótesis de "la tensión literatura-mercado" (Caparrós 1991) usada a favor del trabajo de la memoria}

En el marco del "Primer Encuentro escritores Argentinos en Pinamar" (convocado por la Editorial Sudamericana con el auspicio de Página/ 12), que reseña María O’ Donnell para el suplemento "Primer Plano" correspondiente al domingo $1^{\circ}$ de diciembre de 1991 bajo el título de "La Argentina como escenario", Martín Caparrós enuncia una hipótesis de lectura del campo tan arriesgada como incómoda: la idea de que estaríamos asistiendo al proceso por el cual "la tensión de la literatura con el mercado reemplaza a la tensión con la política" (1991: 7). La formulación de Caparrós pide ser leída en contrapunto con aquella que postula que la tensión entre literatura y política fue la predominante durante la década del setenta (hasta que finalmente la primera habría quedado subsumida en la segunda, Cf. Op. Cit. Sigal 1991: 249 y Gilman 2003: 158187).

Más allá de su carácter ostensiblemente poco riguroso (si la literatura está ahora en tensión con el mercado: ¿de qué "mercado" se puede hablar con propiedad en un contexto de publicación que, partiendo de un estado de crisis editorial, desemboca en un proceso de concentración y polarización -ya desarrolado extensamente en el capítulo dos?), la hipótesis enunciada por Caparrós en diciembre de 1991 resulta altamente sugerente para abordar Los cautivos. El exilio de Echeverría, de Martín Kohan, publicada en el año 2000 en la colección "Narrativas históricas" de Sudamericana.

La Colección fue producto de una investigación de mercado, que demostró que la narrativa histórica era la favorita de las mujeres de alrededor de cincuenta años, que parecían ser el público que más compraba libros (esto también explica el alto número de autoras mujeres convocadas por la colección). Estaba planificada para sacar a la calle un título por mes. Su divisa era "contar lo que la historia oficial no cuenta", centrándose en la intimidad de personajes famosos del siglo XIX, con preferencia por sus mujeres (de Rosas, de Urquiza y de muchos otros). Los libros, que requerían cierta investigación, 
eran encargados y pagados de antemano. Algunos de los títulos publicados fueron: $L a$ amante del restaurador, de María Esther de Miguel; Camila O' Gorman: la historia de un amor inoportuno, de Marta Merkin y Felicitas Guerrero: "la mujer más hermosa de la república", de Ana María Cabrera.

Con las convenciones mismas de la "novela histórica bestsellerista" (para mejor traicionarla) parece estar operando Kohan cuando elige publicar Los cautivos. El exilio de Echeverría en dicha Colección, donde en 1997 ya había aparecido su novela El informe. San Martín y el otro cruce de los Andes (aunque ciñéndose más estrictamente que en el caso de Los cautivos a los lineamientos editoriales). Tal como señala Valeria Sager: "lo que la convierte en un objeto interesante es que su promesa de tapa, el abordaje histórico-ficcional de El exilio de Echeverría, se defrauda desde el interior" (2009: 202-203).

Para Los cautivos, Kohan recupera además la "memoria de la literatura I" de aquellas novelas que se sirven del procedimiento de "el presente en clave de pasado remoto" (Op. Cit. Avellaneda 1997: 153) para escenificar la violencia política. ${ }^{157}$ Al mismo tiempo, parece estar recuperando el legado de César Aira y su particular inflexión del género "novela histórica".

En efecto: en diciembre de 1990, desde las páginas de Babel, revista de libros, Carlos E. Feiling había señalado que una de las apuestas de César Aira desde Ema la cautiva (1981) era demostrar la imposibilidad del naturalismo mediante la paradójica conjunción de un verosimil realista y lo altamente improbable (esto es: diálogos que no se corresponden con el nivel socio-educativo de las personas que los entablan). Las novelas Moreira (1976), Ema la cautiva (1981) y La liebre (1991) constituyen el llamado "ciclo pampeano" de César Aira, al que aplicaría dicha lectura.

Por un lado, cuando el personaje de "Mauro" en Los cautivos denuncia la presencia del poeta en la casa del patrón, el comandante de la patrulla rosista a cargo de su captura anuncia que va a proceder (trayendo a la memoria del lector la jerga represiva típica de los años setenta, utilizada por la institución policial al día de hoy).

Por otro lado, los personajes mezclan en su habla el registro engolado y el repertorio léxico utilizados por el unitario de El matadero con una serie de insultos contemporáneos al autor (y al lector): Luciana, la china que mantiene a escondidas un

${ }^{157}$ En el "triste destino de los restos de Esteban Echeverría", cuyos huesos, durante el sitio de Montevideo, se mezclan en el cementario con los de los otros muertos, resuena el destino de los detenidos-desaparecidos. Al respecto, el autor señala que "Esteban Echeverría nunca fue encontrado. Su cuerpo itinerante, lo que quedó de él, nunca apareció" (Kohan 2000: 170; nuestro énfasis). 
tórrido romance con el poeta, discurre con su padre de esta forma sobre la "pureza" de sus sentimientos para con Echeverría. Dice el padre: “¿De qué espíritu me hablás, puta del orto, si yo veo cada noche como te garcha ese cretino?”. Y así se defiende Luciana: "Gaucho bruto y afiebrado [...] ciego a las delicadas sutilezas del amor bien hecho" (Kohan 2000: 87).

En Los cautivos, Kohan aprovecharía además el auge de la novela histórica bestsellerista (que tuvo su pico máximo en el año 2000, con los 70.000 ejemplares vendidos de Don José, de José Ignacio García Hamilton) para obligar al lector a consumir otra cosa.

Similar amalgama de "memorias de la literatura I" ("novela histórica bestsellerista" en conjunción con "novela histórica a la manera de Aira"), parece estar realizando Carlos Gamerro en El sueño del señor juez (también publicada en el año 2000 en la editorial Sudamericana, aunque en la colección "narrativas argentinas"), donde despliega la (pre)historia del pueblo de Malihuel. (¿Mal y “well”? ¿El mal y el bien?)

Se trata de una verdadera fundación espacio-temporal para su ficción: el eje Buenos Aires-Malihuel y los años 1877 y 1977, años clave en las temporalidades en que se desarrollan, respectivamente, la "dictadura onírica" del Juez en El sueño del señor juez y la dictadura (caracterizada como cívico-militar) que propicia la desaparición de Darío Ezcurra en El secreto y las voces (puestas en sutil paralelo según la lógica del "eterno retorno").

El sueño del señor juez sorprende nuevamente por el uso paródico (en sentido bajtiniano) del tono y los tópicos del realismo mágico. Gamerro, como Kohan en Los cautivos, retrocede hasta el siglo XIX para referir la dictadura en clave de pasado (Cf. Op. Cit. Avellanera 1997). En términos de "memoria de la literatura I", la apuesta de Gamerro parece ser la de amalgamar dicha fórmula con una peculiar inflexión del género "novela de dictador", sumando a todo ello la disparatada torsión perpetrada por César Aira sobre el género de la novela histórica.

De todas formas, Los cautivos avanzaría un poco más allá que la novela de Gamerro, puesto que el contexto mismo de publicación es usado aquí a favor del "trabajo de la memoria". De manera sólo aparentemente paradójica, la "tensión literatura-mercado" que Caparrós denunciaba como una defección, es ganada por Kohan para la política. 
Por todo lo dicho, en Los cautivos, se dejaría leer no sólo una "política de la literatura", sino también una "política de edición", que -de manera subrepticia- socava desde adentro el discurso omnívoro y acrítico del mercado.

\subsection{Memoria y bestsellerismo: Jorge Asís y Jorge Lanata}

En octubre de 2001, Josefina Ludmer, entrevistada por María Moreno (seud. de Cristina Forero) para "Radarlibros", realiza una sorpresiva reivindicación de Jorge Asís en términos de "el maldito total de nuestra literatura" (http://www.pagina12.com.ar/2001/suple/Libros/01-10/01-10-07/nota1.htm, consultado el 12.4.2010). El movimiento crítico de Ludmer pasa por exacerbar el vínculo Jorge Asís-Roberto Arlt, que, muy tímidamente, ya había sido señalado por Antonio Marimón en su reseña (no enteramente negativa) a Flores robadas en los jardines de Quilmes, publicada en el n 14 de Punto de Vista de marzo de 1982.

Se trata de una filiación propiciada desde muy temprano por el mismo autor, tanto en su libro Cuadernos de Oberdán Rocamora (1977), donde la "memoria de la literatura I" convocada es la de las aguafuertes arltianas, como en sucesivas intervenciones públicas. Asimismo, se adjudica la clarivencia que daría el ejercicio del cinismo entendido como posibilidad de volver la mirada de manera desalienada y crítica hacia las miserias de la propia clase social de pertenencia (otra vez: en la línea del autor de $E l$ amor brujo).

La revalorización de Jorge Asís por parte de algunos agentes sobre el cambio de siglo es notoria en el $\mathrm{n}^{\circ} 16$ de El Ojo Mocho. Revista de crítica política y cultural (Verano 2001/ 02). ${ }^{158}$ Además de una muy extensa entrevista a Jorge Asís ("Transfiguraciones literarias de un dandy suburbano"), realizada por las principales firmas de la revista (Horacio González, Christian Ferrer, María Pía López), este número incluye tres artículos sobre el autor de Flores robadas...: "Parodia y sátira en dos poéticas peronistas", de Carlos Belvedere; "Voladuras (Historia, aventura y resignación)", de Esteban Rodríguez y Fernando Alfón Scafati y “Asís presidente”, de Facundo Martínez. También -en la sección “Apostillas”- Horacio González publica "La figura literaria del reventado como teoría picaresca de la política", donde se parte de un

\footnotetext{
${ }^{158}$ El Ojo Mocho. Revista de Cultura y Crítica Cultural (n ${ }^{\circ}$ 1: Verano 1991- $\mathrm{n}^{\circ}$ 20: Invierno/ Primavera 2006) tiene en su Grupo Editor a Emilio Bernini, Christian Ferrer, Horacio González (que en algunos números figura como director), Jung Ha Kang, Guillermo Korn, María Pía López, Facundo Martínez, Eduardo Rinersi y Esteban Vernik. Ya desde el título (pensado según González como una humorada) se coloca en la vereda de enfrente de Punto de Vista.
} 
análisis de la cultura bajo el menemismo para terminar caracterizando la novelística de Asís como anticipación de la misma.

Mientras el artículo de Belvedere contrapone la sátira practicada por Jorge Asís a la parodia practicada por Leónidas Lamborghini, caracterizando a ambos como dos disímiles pero igualmente válidos exponentes de lo que él denomina "poéticas peronistas", Rodríguez y Scafati ponen en duda el paralelismo trazado poco tiempo antes por Ludmer entre Asís y Arlt:

Los crudistas [aquí como sinónimo de "cínicos"] no son una escuela homogénea: un Roberto Arlt, que como aguafuertista dio mucho a esta matriz de pensamiento, no es lo mismo que un Asís, en donde lo que se trata es la carne, la carne sensual, sensible, y tratarla es picarla, carne picada, expuesta al sol. No son lo mismo, pero tampoco están contando el mismo reviente y de la misma manera. A la acidez de Asís no se llega si no es por una vivencia propia del reventismo. (Rodríguez/ Scafati 2001/02: 22)

En su trabajo, los autores enfatizan la importancia del elemento generacional en la composición de "los reventados de Asís". A diferencia de lo que ocurre en el universo arltiano, donde el cínico - a causa de su propia clarividencia- es siempre un individuo solitario, el reviente de Asís: "no es un reviente hogareño sino político, casi generacional $[\ldots]$ los reventados como la sugestión colectiva de una generación urbana, ensimismada y manijeada por diferentes microclimas que se vino a pique" (Rodríguez/ Scafati 2001/ 02: 22).

La reivindicación de Asís por parte de Ludmer tuvo su mentís explícito en la sección "Burrillo" del n 3 de la revista milpalabras, cuyas intervenciones tienen como eje temático "Dinero, ficción, política". ${ }^{159}$ En ella, Gonzalo Aguilar discrepa abiertamente con el rescate que hace Ludmer de la figura de Asís en tanto supuesto "gran desenmascarador de los postulados progresistas", y señala la existencia de dos tipos de cinismo:

Lo escandaloso de Asís radica en enfrentarse a ese limitado sentido común con otros sentidos no menos comunes e ir contra todo postulado progresista, difamándolo o denunciándolo, sin jamás superarlo o develarlo en sus mecanismos [...] Esta posición ha llevado a algunos a definir a Asís como a un cínico y ha acercarlo a otros escritores, como Fogwill y Arlt. Pero esto sería no entender nada de los diferentes tipos de cinismo que han surgido últimamente. Uno hunde sus raíces en el

${ }^{159}$ La revista milpalabras ( ${ }^{\circ} 1$ : otoño $2000-n^{\circ} 5$ : otoño de 2003), que aparece cada tres meses, tiene en su dirección a Alejandra Laera, Graciela Speranza, Marcelo Cohen y Gonzalo Aguilar. Martín Kohan participa de la dirección sólo en los dos primeros números, luego de los cuales se retira del proyecto. Cada número está armado sobre un eje temático. Contra el discurso académico prototípico, los artículos tienen un marcado tono ensayístico y carecen de notas al pie (la bibliografía utilizada se ordena bajo el rótulo "lecturas" y nunca supera los seis títulos). El corpus literario elegido es casi siempre narrativo. Mantiene las secciones: "plástica"; "entrevista"; "burrillo" e "ideas". 
reconocimiento, furioso o entristecido, de que las cosas se degradan y que muy difícilmente la acción humana pueda hacerlas cambiar (en el caso de Fogwill). El otro cinismo, el que practica Asís, hunde sus raíces en el poder y no nada contra la corriente sino que celebra el estado de cosas sosteniendo que es el único posible. Como posee intuiciones certeras, puede fabricar brillantes baratijas (el maldito soy yo), que algunos intelectuales con tal de parecer raros, corren a comprar. (Aguilar 2002: 62)

De manera inmediata a la publicación de su "serie de los canguros", la impugnación de Asís se realizó no sólo a causa de su "cinismo oportunista", sino también por su éxito económico.

Ya desde el $\mathrm{n}^{\circ} 2$ de Pie de página de invierno de 1983, Fogwill se propone desenmascarar lo que él llama la "crítica oficial”, que desde La Nación o Clarín (donde Asís había entrado a trabajar como periodista en 1976) apoya con reseñas elogiosas la propuesta narrativa del autor de Flores robadas en los jardines de Quilmes. Fogwill diferencia entre dos tipos de best-sellers: los “mejor vendidos" involuntarios y los libros escritos meramente para vender: "A diferencia de otras obras (¿acaso El extranjero, de Camus y Celda sin número de Timerman, por ser best-sellers dejan de ser obras maestras de la ficción?) el éxito es, en los best-sellers de Asís, una condición literaria" (Fogwill 1983b: 23; énfasis del autor). ${ }^{160}$

En su aporte "La narrativa argentina (estos diez años: 1975-1984)" contenido en el volumen compilado por Saúl Sosnowski Represión y reconstrucción de una cultura: el caso argentino (1988), Jorge Lafforgue agrupa las narrativas de Enrique Medina, Osvaldo Soriano y Jorge Asís a partir de sus altas cifras de venta y la fluida vinculación con los medios que detentan sus autores:

... Asís, Soriano y Medina son escritores que han roto el circuito de los "interesados", de los hombres de letras y sus adláteres, o sea que han accedido a "otros" lectores: sus obras más difundidas sobrepasaron holgadamente la barrera de los diez mil ejemplares mientras que ellos (escritores convertidos en personajes) fueron "nota" en revistas de gran circulación (así es: antes que los propios textos, ellos: los entretelones de sus vidas, sus fantasías, el horizonte de sus módicas glorias). (Lafforgue 1988: 154-155)

A nota al pie, Lafforgue aclara que Las tumbas (1972), de Enrique Medina "se trata del libro más vendido en el país de un escritor de su generación: sobrepasa los 250.000 ejemplares en 1986" (Op. Cit. Lafforgue 1988: 165). Frente a esto, cabría

\footnotetext{
${ }^{160}$ En Nuestro modo de vida, novela cuya última versión es de 1981, pero que permaneció inédita hasta junio de 2014, el personaje de "Fernando" se entusiasma con la novela La farsa, un best-seller ficticio que remite a Flores robadas en los jardines de Quilmes.
} 
preguntarse por qué el principal objeto de impugnación de la crítica autodefinida como "anti-populista" fue Asís, y no Medina. Creemos que esta situación podría explicarse a partir de la recurrente censura sufrida por Medina, que lo volvería legible en términos de "literatura de la resistencia". ${ }^{161}$

De todas formas, las cifras son por demás contundentes: entre 1980 y 1982 Flores robadas en los jardines de Quilmes alcanzó las veintes reediciones (Cf. Avellaneda 1983). Para el año 2007, cuando Carne picada es reeditada por el Grupo Editorial Planeta S.A.I.C./ Booket, la breve biografía del autor que acompaña el texto enfatiza el número de 350.000 ejemplares vendidos.

Los posibles puntos de cruce que se intentan esbozar en este parágrafo entre Jorge Asís y Jorge Lanata comenzarían a volverse algo menos aventurados si se los piensa en términos de construcción de una similar "autoimagen de escritor".

Ambos han sido o continúan siendo periodistas de alta visibilidad, por lo que reciben un importante apoyo por parte de los medios para los cuales trabajan en la instancia de promocionarse como "escritores". Ambos gozan, en consecuencia, de una considerable popularidad entre el público lector no especializado, hecho que sólo se ve empañado por la nula aceptación que sus proyectos narrativos encuentran en el seno de la Academia. (En términos de Nora Catelli: detentan un considerable éxito editorial contra una prácticamente nula consagración literaria.) Por último, ambos reivindican el ejercicio del cinismo como una forma de aproximación válida para revisitar el pasado reciente.

En el caso de Muertos de amor habría, además, una explícita voluntad por parte de su autor de intervenir desde una posición autoconstruida en términos generacionales en un debate que hasta entonces había sido prácticamente monopolizado por los coetáneos y/ o partícipes directos de la experiencia foquista liderada en la provincia Salta entre los meses de junio de 1963 y abril de 1964 por el Comandante Jorge Ricardo "Segundo" Masetti.

Más allá de la calidad o disvalor de su prosa, la narrativa que Lanata construye sobre el EGP interesa porque en ella se vuelve casi estridente el carácter de

\footnotetext{
${ }^{161}$ Entrevistado por Daniel Molina para El Porteño en febrero de 1985 ("Yo soy un clásico"), Asís había afirmado sobre su condición de "mejor vendido": "Nadie me perdonaba haber tenido éxito. Lo que tendría que haber hecho era no haber existido, haberme callado la boca o haberme exiliado. O haber ido en cana o tendría que haberme hecho matar. Como soy tan pelotudo que no me prendí en ninguna de esas opciones, metí la mano en el tacho de porquería, banqué muchísimas cosas, creo que mantuve la dignidad..." (Asís [Entrevistado por Daniel Molina] 1985: 82).
} 
"intervención generacional" y/o "pronunciamiento generacional", que en los textos analizados en el capítulo anterior se presentaba las más de las veces asordinado.

Ya desde el título, que cita uno de los versos del poema "egepé" de Alberto Spunzberg, publicado originalmente en el apartado "Poemas a los guerrilleros" del n ${ }^{\circ} 4$ de marzo de 1965 de La Rosa Blindada, ${ }^{162}$ en el cual coexisten los homenajes a Raúl González Tuñón por su $60^{\circ}$ aniversario y al EGP (a un año de su aniquilación por parte de la Gendarmería), Lanata elige colocarse en diálogo desafiante con la llamada "generación militante". Lejos de cualquier tono reivindicativo, reduce la experiencia foquista a un delirio sangriento, y utiliza la experiencia fallida del EGP (que no logró el apoyo popular y cuya presencia en el monte -como la del "Che" en Bolivia- terminó siendo denunciada por los mismos campesinos) como parábola del fracaso de toda la izquierda revolucionaria en la Argentina

Que Muertos de amor de Jorge Lanata haya logrado mantenerse en la lista de bestsellers (oscilando entre el segundo y el quinto puesto de los "libros más vendidos") durante todo el invierno de 2007) nos retrotrae a un problema que sobrevolaba todos los interrogantes planteados por Andrés Avellaneda en el artículo que escribe sobre Flores robadas en los jardines de Quilmes para el $\mathrm{n}^{\circ} 125$ de la Revista Iberoamericana, publicado en diciembre de 1983 (" 'Best-seller' y código represivo en la narrativa argentina del ochenta: el caso Asís"): ¿por qué el gran público prefiere leer una versión tergiversada $\mathrm{y} / \mathrm{o}$ tendenciosa (aunque tranquilizadora) de la historia reciente?

\footnotetext{
${ }^{162}$ La aparición de la revista La Rosa Blindada (octubre de 1964 a septiembre de 1966: nueve números en total), es sintomática del conflicto generacional y cultural, pero también político, que enfrentó a la "Nueva Izquierda Intelectual" con la llamada "izquierda tradicional" en el seno del Partido Comunista Argentino. La Rosa Blindada toma el nombre del poemario homónimo de Raúl González Tuñón (19051974) dedicado a la insurrección de los mineros de Asturias. Si bien pretende tener una frecuencia mensual (y lo expresa bajo la forma del subtítulo: "Aparece el primero de cada mes"), sufre interrupciones en los meses de verano (enero-febrero) a partir del cuarto número, volviéndose bimensual a partir del n ${ }^{\circ} 6$ (septiembre-octubre de 1965). En su Dirección aparece como "director de honor" el poeta Raúl González Tuñón (hasta el $\mathrm{n}^{\circ} 5$ inclusive) y los también poetas Carlos Alberto Brocato y José Luis Mangieri. En el rubro "Narrativa", aparecen Andrés Rivera, Horacio Néstor Casal, Estela Canto y Octavio Getino; en "Teatro", Roberto Cossa, Andrés Lizarraga y Susana Vallés; en "Literatura Infantil", Javier Villafañe; en "Poesía", Juan Gelman, Guillermo B. Harispe y Ramón Plaza; en "Historia", León Pomer; en "Cine", Roberto Raschella, Roberto Aizemberg y Nemesio Juárez; en "Plástica", Oscar Díaz, Carlos Gorriarena, Hugo Griffoi y Norberto Onofrio, y en "Diagramación", Oscar Díaz. En el n 6 se incorporan a la revista Oscar Terán y Carlos Olmedo. En el mismo número, Andrés Rivera pasa a formar parte de la Secretaría de Redacción y se agregan en el rubro "Poesía" Julio Huasi, Eduardo Romano, Juana Bignozzi y Alberto Szpunberg. Si bien el grupo La Rosa Blindada no brindó apoyo logístico al EGP, como sí lo hizo el grupo Pasado y Presente, ya desde la portada, todo el ${ }^{\circ} 4$ de La Rosa Blindada es un sentido homenaje a la experiencia foquista liderada por Jorge Ricardo Masetti. En efecto: la ilustración de tapa (en amarillo) es un grabado de Carlos Giambagi que muestra un grupo de tres guerrilleros descansando (¿o muertos?) bajos los árboles. En el $n^{\circ} 4$, además de "egepé, se incluyen "hechos", de Juan Gelman y "Orán", del mismo Alberto Szpunberg en el apartado titulado "Poemas a los guerrilleros".
} 
La respuesta más obvia tiene que ver con cuestiones a las que ya hemos hecho referencia: la exitosa construcción de una "autoimagen de autor" a caballo entre el "periodista estrella" y el escritor novel realizada por Lanata desde Polaroids (1990) e, indudablemente, el publicar Muertos de amor respaldado por todo el aparato de promoción y distribución de Alfaguara (parte entonces del grupo español PRISA). La otra respuesta tiene que ver con que la publicación se presenta por parte de Lanata acompañada de dos certeras operaciones.

La primera apunta a la creación de un supuesto vacío discursivo, que Muertos de amor vendría precisamente a subsanar. En una entrevista de promoción de la novela dada en abril de 2007 para La Nación, Lanata afirma falazmente que: "Falta un debate sobre la violencia política de los 70", simulando desconocer que desde hacía ya dos años y medio, a partir del testimonio de Héctor Jouvé para la revista cordobesa $L a$ Intemperie, dicho debate no había hecho otra cosa que seguir sumando voces. (Cuando decimos "simulando desconocer" es porque, precisamente, el autor de Muertos de amor utiliza -aunque de manera adulterada- el testimonio de Héctor Jouvé dentro del conjunto de las voces tramadas en su novela.) ${ }^{163}$

La segunda operación podría pensarse en términos de "estudio de mercado", y tiene que ver con la percepción por parte de Lanata de que existía un público lector considerable que, a cuatro años de asunción de Néstor Kirchner y del éxito de las políticas de la memoria impulsadas por su gobierno (plasmado fundamentalmente en la derogación de las llamadas "leyes de Impunidad", la reapertura de los Juicios y el cambio de "Prólogo" al Nunca más) estaba deseoso de releer la versión tranquilizadora de la llamada "teoría de los dos demonios", o, aunque más no fuera, su versión "no ficción”. En palabras del mismo autor, el EGP sería entonces:

... metáfora del movimiento guerrillero en el país; un Esperando a Godot, donde se matan entre ellos [Esperando a Godot aparece citado como epígrafe de la segunda parte de la novela] Es una buena metáfora de la guerra en general. La violencia política de aquellos años no fue representativa de la sociedad [...] Me pareció una historia emblemática. En 1964 hubo 40 tipos que, en la selva salteña, querían hacer la revolución y fusilaron por débiles a dos de los suyos [...]. Aquella idea de la creación del hombre nuevo es un delirio. Para mí todo asesinato es sólo asesinato. Y la gente piensa parecido. Hay que ser capaz de secuestrar a un tipo, meterlo en un pozo, darle de comer y después matarlo cuando el tipo está desarmado. No se hace una revolución secuestrando a un empresario ni fusilando a

\footnotetext{
${ }^{163}$ Dos son los testimonios de Héctor Jouvé que aparecen en Muertos de amor: las entrevistas con Daniel Ávalos para su libro La guerrilla del Che y Masetti en Salta, 1964. Ideología y mito en el Ejército Guerrillero del Pueblo. Testimonio de Héctor Jouve ([2003] 2005) y su testimonio para la revista cordobesa La Intemperie.
} 
un colimba en la calle. [Lanata [Entrevistado por Susana Reinoso] http://www.lanacion.com.ar/nota.asp?nota_id=900311 (consultado el 11.5.2009)

En la cita es clara la voluntad por parte del autor de Muertos de amor de apelar al sentido común de la gente, deshistorizando por completo la experiencia foquista liderada por Masetti y la lógica interna del EGP, que podríamos homologar a la de la secta religiosa. Tal como lo señala Horacio Tarcus en "La secta política. Ensayo acerca de la pervivencia de lo sagrado en la modernidad", ésta es "una forma parcialmente secularizada de la secta religiosa", cuya identidad ideal propugna la cuasi disolución del individuo en el todo grupal (Cf. Tarcus 1998: 28-31).

Por lo mismo, las afirmaciones del tipo "No se hace una revolución secuestrando a un empresario ni fusilando a un colimba en la calle" que abundan en las entrevistas de promoción de la novela serían un tiro por elevación contra las organizaciones políticomilitares Montoneros y Partido Revolucionario del Pueblo, que ejercieron estas prácticas en contextos históricos específicos (y que nada tenían que ver con la lógica por detrás de los fusilamientos internos en el EGP). ${ }^{164}$

Como señala Gabriel Rot en una columna de opinión publicada en Ñ. Revista de Cultura el 12 de mayo de 2007:

Lanata no sólo se desinteresa de la historia de los guerrilleros del EGP y su contexto político y cultural, sino que cae en un pseudo historicismo para legitimar una posición política: muerte, autoritarismo, irrealidad son parte indivisible de la revolución. Para ello recurre a episodios tan verídicos como lamentables, manipulándolos para que certifiquen su posición. El atajo que tomó fue ocuparse de los fusilamientos en el monte y extraer a partir de ellos su teoría acerca de la psicopatía de los jefes y la ingenuidad suicida de sus seguidores [...] Así resume Lanata la intrincada trama revolucionaria: una empresa de ilusiones que no encuentra compradores. Y si propios y extraños no compran, algo hay que hacer. Es hora entonces de escarmientos. Todo para demostrar que la revolución se come a sus hijos y que el sueño eterno revolucionario no es más que un peligroso entramado de locura, violencia y soberbia de unos pocos. [Lanata] está en su derecho de hacer lo que más le venga en ganas, pero llamemos las cosas por su nombre: "recuperar" la historia para contar otra no es novela histórica, sino una oportunista ficción o peor aún, amarillismo político-literario. (Rot 2007: 13)

\footnotetext{
${ }^{164}$ Luego de un juicio sumario, Adolfo Gustavo "Pupi" Rotblat fue fusilado por mano del propio Comandante "Segundo" el 5 de noviembre de 1963. Bernardo Groswald, un ex empleado de banco cordobés, fue ejecutado frente a sus compañeros el 19 de febrero de 1964.
} 
En efecto: Lanata afirma falazmente que "[Masetti] terminó cercado por las autoridades del Partido Comunista cubano" (2007: 34), cuando en verdad éste fue fundado recién el 3 de octubre de 1965, cuando ya hacía tiempo que el Comandante "Segundo" había desaparecido en el monte salteño. También se equivoca al dar la adscripción militante del hijo del General Julio Alsogaray (que no era "guerrillero del ERP”, como el autor afirma en la página 136 de la novela, sino oficial de una escuadra de Montoneros).

Más allá de estos y otros errores historiográficos menos flagrantes, lo más dudoso de Muertos de amor es la utilización del recurso pergeñado por Arthur Schnitzler del monólogo interior para que el lector "escuche" los pensamientos de Adolfo Gustavo Rotblat, Bernardo Groswald, Jorge Ricardo Masetti y Ernesto "Che" Guevara. Los monólogos interiores son, indudablemente, el tour de force del Lanata escritor, y donde el fracaso de la ambición literaria es más evidente: Guevara piensa como un cínico, Masetti es un loco sanguinario, Groswald sólo logra pensar algo mientras se masturba, y así siguiendo.

Al respecto, la "memoria de la literatura [de Asís] de tipo I" más explícita que aparece en Muertos de amor es aquella que le da el tono reventado al monólogo interior del Comandante "Segundo" sobre sus propios combatientes:

No saben lo que son, no saben lo que quieren, no saben cómo lograrlo. Son una manga de nenes de mamá y papá, débiles, enfermos y suavecitos. Todo sería distinto de haber traído hombres. El Cubano los mira como si fueran parte de un experimento científico. Yo ya ni los miro. Todo el tiempo quieren estar vivos, no entienden que ya están muertos. Lo dijo el Che: ya estamos muertos. Pero no lo entienden. Creen que, por algún motivo, van a sobrevivir. Nadie sobrevivirá. La manera de sobrevivir es vencer, y la mejor manera de vencer es disponerse a morir. Vivimos tiempo de descuento. No lo entienden. Hay momentos en los que sueño con adelantarme e ir yo solo a enfrentar a las patrullas. Siento realmente que el hecho de que alguien me acompañe no hace demasiada diferencia. Puedo enfrentarlas solo. Y si no pudiera, nadie puede matarme dos veces. (Lanata 2007: 116)

\section{CODA. Memoria y Premios. Algunos notas sobre el Apéndice 1}

El apéndice que incluimos en este capítulo da la nómina de los ganadores de cuatro premios de novela deliberadamente disímiles entre sí con el afán de hacer una primera aproximación a la temática "memoria y premios": el Premio Clarín de Novela (1998hoy); el Premio Planeta Argentina (a partir de 1992, con una interrupción entre los años 2001 y 2004 inclusive y un juicio por fraude en su Edición 1997, que se resuelve en 
contra del Grupo en el año 2005; con motivo de un nuevo escándalo, el Premio se suspende nuevamente por tiempo indeterminado en el año 2007); el Premio Herralde de Novela (1983-hoy) y el Premio Alfaguara de novela (1998-hoy).

Esto es: un premio nacional de prestigio quizá dudoso, pero cuyos ganadores hacen usufructo de una campaña de publicidad y distribución que podríamos caracterizar como muy efectiva (Premio Clarín de Novela); un premio organizado por un grupo español para su filial argentina signado por el escándalo (Premio Planeta Argentina); un premio fundado por un editor español "histórico" que, convocado por Editorial Anagrama, oficia de auspiciosa plataforma de lanzamiento para entrar en el mercado europeo (Premio Herralde de Novela) y un premio que podríamos definir como de lógica transnacional (Alfaguara). ${ }^{165}$

Al día de la fecha el Premio Clarín de Novela tiene una dotación de 150.000 pesos para la novela ganadora, que es publicada por Clarín-Alfaguara. Dentro de sus bases legales está la posibilidad de participar para todos los mayores de 18 años, de cualquier nacionalidad, que presenten obras originales e inéditas en idioma español. No pueden participar del concurso las personas que se desempeñen en relación de dependencia en cualquiera de las empresas que forman parte del Grupo Clarín y Grupo Santillana, ni los escritores que hayan sido ganadores en ediciones anteriores. Como en el resto de los premios, existe una comisión lectora de preselección, que evalúa el total del material recibido y selecciona diez obras finalistas, que envía al Jurado.

Con un inicio muy auspicioso y un Jurado integrado por Adolfo Bioy Casares, Guillermo Cabrera Infante y Augusto Roa Bastos, la primera edición del Premio Clarín de Novela tuvo a Pedro Mairal como ganador con Una noche con Sabrina Love. Inaugurando una relación que se repetiría en los otros premios aquí reseñados, la novela fue llevada al cine tres años más tarde, bajo la dirección de Alejandro Agresti y con el protagónico de Cecilia Roth. ${ }^{166}$

El Premio Clarín de Novela favoreció en cinco ocasiones a novelas que hacen centralmente memoria en la literatura del pasado reciente argentino: Kelper (ganadora

\footnotetext{
${ }^{165}$ Suspendiendo la sospecha sobre su transparencia que envuelve con mayor o menor grado de intensidad a prácticamente todos los premios literarios existentes, en el Apéndice 1 constan los ganadores de cada uno de los cuatro. En el caso de los Premios Herralde y Alfaguara, se repone la nacionalidad de los premiados entre corchetes. Por último, se señalan con asterisco simple las novelas cuyos autores fueron ganadores ex aequo, y con doble asterisco las novelas premiadas que hacen centralmente "memoria en la literatura" del decenio 1973-1983.

${ }^{166}$ Otra novela premiada por el Grupo Clarín (Edición 2005) llevada al cine fue Las viudas de los jueves, de Claudia Piñeiro. La película homónima fue rodada por Marcelo Piñeyro (que escribió el guión junto a Marcelo Figueras) y estrenada en septiembre de 2009.
} 
de la 1era mención en la Edición 1998), de Raúl Vieytes; Memorias del río inmóvil (ganadora de la Edición 2001, con un Jurado integrado por Héctor Tizón, Vlady Kociancich y Andrés Rivera), de Cristina Feijóo; Ojo por diente (ganadora de la 1era mención en la Edición 2005, con un Jurado integrado por José Saramago, Rosa Montero y Eduardo Belgrano Rawson), de Sara Zapata Valeije; Composición (ganadora de la Edición 2007, con un Jurado integrado por José Saramago, Rosa Montero y Alberto Manguel), de Norma Huidobro; y Sobrevivientes (ganadora de la edición 2012, con un Jurado integrado por Claudia Piñeiro, Santiago Roncagliolo y Juan Cruz Ruiz), de Fernando Monacelli. A partir de la Edición 2012 se introducen modificaciones en las bases del concurso, que se reduce a la entrega de una sola distinción para la novela ganadora (esto es: el premio monetario y la publicación).

Ya hemos hecho referencia al afán si se quiere "mercantil" con que se lanza el Premio Planeta Argentina, que contempla la premiación de tres obras (aunque sólo los autores de las novelas que quedan en los primeros dos puestos se hacen acreedores de una recompensa monetaria). A partir del año 1998, el premio principal tiene una dotación de 50.000 pesos (recordemos que en el año inaugural de 1992 tenía una dotación de 40.000 dólares, la más grande entonces para una premio argentino).

Como ya fue señalado, luego de que Juan Forn abandonara la colección Biblioteca del Sur, son premiadas las novelas El general, el pintor y la dama, de María Esther de Miguel (Edición 1996, con un Jurado integrado por el Director General de la editorial Guillermo Schavelzon, Ángeles Mastretta, Mario Benedetti y Tomás Eloy Martínez); Plata quemada, de Ricardo Piglia (Edición 1997, con un Jurado integrado por Guillermo Schavelzon, Augusto Roa Bastos, María Esther de Miguel, Mario Benedetti y Tomás Eloy Martínez); Pequeña música nocturna, de Liliana Díaz Mindurry (Edición 1998, con un Jurado integrado por el editor de Planeta Ricardo J. Sabanes, María Esther de Miguel, Manuel Vázquez Montalbán y Tomás Eloy Martínez); Vuelan las palomas, de Carlos Gorostiza (Edición 1999, con un Jurado integrado por Ricardo J. Sabanes, Abelardo Castillo, María Esther de Miguel y Eduardo Gudiño Kieffer) y La arquitectura de los ángeles, de Liliana Escliar (Edición 2000, con un Jurado integrado por primera vez por ex ganadores del Premio, tanto en su versión local como española: Marcos Aguinis, Antonio Dal Masetto, María Esther de Miguel y Carlos Gorostiza).

De las novelas premiadas al día de hoy, tres hacen memoria en la literatura del pasado reciente: la ya mencionada La arquitectura de los ángeles, de Liliana Escliar; El lago (Edición 2005), de Paola Kaufman y La casa operativa (finalista de la Edición 
2006), de Cristina Feijóo. Luego de la novena edición del Premio que favorece a Escliar, el premio queda suspendido hasta el año 2005, en que vuelve a ser convocado con un Jurado integrado por los escritores Marcos Aguinis, Federico Andahazi, Carmen Posadas y Marcela Serrano, y por Ricardo Sabanes. Finalmente, la versión local del premio es suspendida por tiempo indeterminado a partir del año $2007 .{ }^{167}$

De todos los premios existentes, quizá el Planeta sea el de peor fama en lo que hace a su transparencia.

El primer número del suplemento "Radarlibros", publicado el 16 de noviembre de 1997, tiene como nota de tapa "Plata quemada" y se ocupa con morosidad de dar cuenta del escándalo que suscitara la premiación de la novela de Ricardo Piglia. La nota principal, firmada por Gabriela Esquivada, da dos razones para la desconfianza. Por un lado, la edición de Plata quemada ya había sido anunciada para diciembre de 1996 en Seix Barral (uno de los sellos de Espasa Calpe, integrante del Grupo Planeta). Por otra parte, al momento del concurso, Guillermo Schavelzon estaba empleado como director general de la División de Libros del Grupo Editorial Planeta, lo que constituiría un grave impedimento para cumplir con imparcialidad su rol de Jurado. De las dos, la primera razón se sostiene más que la segunda, puesto que en todos los staffs de los sucesivos Jurados que hemos mencionado hay un integrante que ocupa un puesto gerencial en el Grupo.

Al respecto, Esquivada no gasta tiempo en rodeos: "La clave está en las bases mismas del concurso: un evento hecho a medida de una gran operación de publicidad" (1997: 1). De manera más sutil que la tapa acusatoria de "Radarlibros", el no 6 de Magazín Literario de diciembre de 1997 elige opinar sobre la premiación mediante una serie de fotos. El copete correspondiente a la que retrata el momento mismo de otorgamiento de la distinción al autor de Plata quemada dice lo siguiente: "Ricardo Piglia y el bochornoso cheque gigante que año a año entrega Planeta. Esas cosas no se hacen" (Magazín Literario 6 1997: 5; nuestro énfasis).

Gustavo Nielsen, uno de los diez finalistas de la fraudulenta Edición 1997 del Premio, es el único participante que iniciará acciones legales: en 2005 logra un resarcimiento económico (a pagar por el escritor Ricardo Piglia, el editor Guillermo

\footnotetext{
${ }^{167}$ En la Edición 2006 resulta ganador Federico Andahazi con El conquistador. La premiación de
} Andahazi, un autor "histórico" de Planeta, termina definitivamente con la credibilidad del Premio. 
Schavelzon y la Editorial) de diez mil pesos más intereses. ${ }^{168}$ El descargo realizado por Piglia en el suplemento "Radarlibros" correspondiente al 13 de marzo de 2005, donde denomina a Nielsen el "nuevo Carlos Daneri" en tanto: "como el personaje de Borges [...] piensa que la justicia literaria sólo es justa si es él quien gana el concurso, porque cualquier otro resultado es prueba de una manipulación y de un fraude", encontrará una considerable adhesión.

En marzo de 2005, más de cincuenta intelectuales (entre ellos, Juan José Saer, Héctor Tizón, León Rozitchner, Juan Carlos Romero, Alan Pauls, Luis Felipe Noé, Noé Jitrik, Carlos Altamirano, Aníbal Ford, Horacio González, José Luis Mangieri, Alvaro Abós y Alfredo Prior) firman un texto de apoyo, en el que subrayan que "la infundada acusación contra la probidad de Ricardo Piglia responde a una sola causa: se lo acusa de ser quien es en nuestra literatura, en la cultura nacional y en el plano internacional y académico". 169

Contra esto, interesa recabar en la lectura que realiza Martín Prieto en el marco del debate que inaugura el $\mathrm{n}^{\circ} 66$ de Punto de Vista (abril de 2000), titulado precisamente "Literatura, mercado y crítica", donde expresa su repudio por la cualidad comercial de Plata quemada y desestima por lo mismo la defensa de la novela ensayada por el propio Piglia en la entrevista de promoción (“Crítica y ficción”) publicada en el número de "Radarlibros" correspondiente al 19 de diciembre de 1999 en términos de "cruce entre populismo y vanguardia en la línea de Osvaldo Lamborghini y Ricardo Zelarayán”.

El escándalo alrededor de la premiación de Plata quemada interesa como claro índice de los roces existentes entre determinados agentes del campo pertenecientes a la "generación ausente" y determinados "hermanos mayores", y va en contra de la tersa imagen del coloquio enunciada por Pauls (1983). De todas formas, es justo señalar que ya los dos primeros números de Babel, revista de libros contenían algunas pullas contra el autor de Respiración artificial. ${ }^{170}$

\footnotetext{
168 Sobre los detalles del juicio, VER http://www.pagina12.com.ar/diario/cultura/7-47897.html y http://edant.clarin.com/diario/2005/03/01/sociedad/s-03015.htm (consultados el 12.2.2013). El amor enfermo, la novela finalista de Nielsen, fue publicada en el año 2000 por Alfaguara. El juicio perdido es causa, entre otros efectos, de que Piglia se vea imposibilitado de firmar "Algunas precisiones sobre esta edición" que cierra la edición de La grande (2005), de Juan José Saer, si bien es sabido que no fue "A. D." (Alberto Díaz, editor de Seix Barral) el autor de este posfacio, sino Piglia.

169 Para la versión completa de la polémica, VER la intervención de Ricardo Piglia en http://www.pagina12.com.ar/diario/suplementos/radar/9-2094-2005-03-13.html, consultado el 12.2.2013)

${ }^{170}$ En el $n^{\circ} 1$ de Babel, en medio de una reseña celebratoria a la reedición con un tiraje excepcional de 4000 ejemplares en Sudamericana de Respiración artificial, Daniel Samoilovich afirma que el libro tendría "el san benito del best-seller de prestigio" (Samoilovich 1988: 11). El epígrafe que acompaña la
} 
Con motivo de la premiación de El vuelo de la reina en la Edición 2002 del Premio Alfaguara de novela, vuelve a discutirse no ya la transparencia del Premio Planeta Argentina, sino el valor literario de Plata quemada. En "Apéndice: literatura y mercado" (incluido en su antología Cómo se lee y otras intervenciones críticas, de 2003), Daniel Link señala lo siguiente:

Aún en Plata quemada, Piglia se reconoce como un escritor experimental y asume los riesgos de jugar con los mecanismos del neopopulismo de mercado [...] Del otro lado está Tomás Eloy Martínez, sólidamente apoyado en la cultura industrial. [...] cuando Tomás Eloy Martínez escribe que ese hombre mayor que se masturba ante una ventana, escuchando la sonata de César Franck que Proust hizo famosa, “oye los sordos ciegos ojos del deseo abriéndose en lo más hondo de lo que él es" (pág. 16) está dejándose devorar precisamente por ese estilo medio (bien fait, kitsch hasta la náusea) que la cultura industrial reclama para sí. (Link 2003: 330-331; énfasis del autor)

La novela premiada de Martínez, que Link ya había reseñado de manera harto negativa en "Políticas del género" (en el n 73 de Punto de Vista de agosto de 2002) sería un claro ejemplo de la "alfaguarización de la literatura latinoamericana", definida por Víctor Barrera Enderle como:

... cierta regularización formal y distributiva que la literatura hispanoamericana ha experimentado en los últimos años [...] masificar un producto, a través de la cooptación, dotándolo de ciertas características comunes a lo que entendemos como fenómeno literario [...] Y no hablo aquí de literatura en serie, sino de una estrategia para vender una literatura, que aún en su heterogeneidad y distancia espacio-temporal, se nos presenta con rasgos similares (rasgos, claro, impuestos desde una perspectiva extra-literaria) [...] Los autores de todo el subcontinente $[\ldots]$ entran en la corriente de la "alfaguarización", que bajo sus leyes decidirá qué producto rebasará los límites del país y cuál se quedará con el mercado local y con un tiraje, en el mejor de los casos, de 2000 ejemplares. Esto provoca, entre otras cosas, que el autor elabore, mucho antes de escribir su obra, la mejor manera de

sección "Anticipos" del n ${ }^{\circ}$ 2, que adelanta el relato sobre la hija de Friedrich Nietzsche ("El fluir de la vida") incluido en Prisión perpetua, suena, a su vez, algo irónico: "Mientras las primeras letras del nombre verdadero de Ricardo Piglia empiezan a esculpirse en el bronce aleatorio de suplementos literarios y listas de best-sellers, Sudamericana publica una nueva recopilación de sus relatos, Prisión perpetua" (Babel 2 1988: 42). Por último, también en el n 2, desde la sección "Vanidades", se parodian las principales hipótesis sobre el campo literario argentino del autor de Respiración artificial: "Narrar es como jugar al póker, dijo el padre de Steve. Todo el secreto consiste en fingir que se miente cuando en realidad se está diciendo la verdad. Batista, vestido de blanco, dice que el citado trozo prueba que Piglia segrega más Borges que Arlt: frío, europeo, cerebral y teórico, y no cálido, latino, pasional como Roberto Godofredo Christophersen. Eso, siguiendo a Batista, prueba que es Piglia, y no otro, el último escritor argentino de vanguardia del siglo XIX. Sin embargo, a juzgar por lo leído, eso es literatura norteamericana. ¡Pruebas al canto!” (Babel 2 1988: 6). 
ofrecer el futuro producto para hacerlo atractivo. Un ejemplo claro de ello ha sido la aparición del Crack narrativo mexicano (1996) [...] Hasta ahora, la "alfaguarización" ha "afectado" principalmente a la narrativa (el género masivo por antonomasia); aunque ya el ensayo ha experimentado algunos cambios que empiezan a afectar la producción de conocimiento hecha desde Latinoamérica. (Barrera Enderle 2002: http://sincronia.cucsh.udg.mx/alfaguar.htm, consultado el 3.3.2013)

El Premio Alfaguara de novela, instituido en el año 1998 y con una dotación actual de 175.000 dólares, favoreció en cuatro ocasiones a autores argentinos: la ya mencionada El vuelo de la reina (con un Jurado presidido por Jorge Semprún e integrado por Rosa Regàs -secretaria-, Agustín Díaz Yanes, Rosario Ferré, Juan González, Carlos Monsiváis y Nélida Piñón), de Tomás Eloy Martínez; El turno del escriba (Edición 2005, con un Jurado presidido por José Manuel Caballero Bonald e integrado por Silvia Hopenhayn -secretaria-, Juan González, Fernando León de Aranoa, Ana María Moix, Manuel Rivas e Iván Thays), de Graciela Montes y Ema Wolf; El viajero del siglo (Edición 2009, con un Jurado presidido por Luis Goytisolo y conformado por Ana Clavel, Carlos Franz, Julio Ortega, Gonzalo Suárez y Juan González - con voz pero sin voto-), de Andrés Neuman, y Una misma noche (Edición 2012, con un Jurado presidido por Montxo Armendáriz e integrado por Jürgen Dormagen, Antonio Orejudo, Lluís Morral y Pilar Reyes -con voz pero sin voto-), de Leopoldo Brizuela.

De las novelas argentinas premiadas, Una misma noche es la única que hace "memoria en la literatura" del pasado reciente, focalizando en el tópico de la mayoría silenciosa y su responsabilidad en el terrorismo de Estado. Lo hace de manera coincidente con los últimos debates historiográficos, que plantean la necesidad de evaluar la pertinencia del término "dictadura cívico-militar" para describir lo ocurrido en nuestro país entre 1976 y $1983 .{ }^{171}$

Las características del Premio Herralde de Novela son reseñadas en detalle por Daniel Link en su artículo monográfico "América", incluido en Fantasmas. Imaginación y sociedad (2009). ${ }^{172}$ Aunque escrito a partir de la consigna "una ponencia

\footnotetext{
${ }^{171}$ En clave sociológica, cabría señalar el estudio Los años setenta de la gente común. La naturalización de la violencia (Siglo Veintiuno Editores 2013), de Sebastián Carassai.

${ }^{172}$ Dotado con 18.000 euros, el Premio tiene su primera edición en 1983 y lo concede anualmente la editorial Anagrama a una novela inédita en lengua castellana, pudiendo concurrir a él los escritores de esta lengua, cualquiera sea su nacionalidad.
} 
donde exprese sus puntos de vista en torno al impacto que los Premios Herralde y la reciente designación de los 39 mejores escritores hispanoamericanos menores de 39 años tienen en la difusión de la literatura hispanoamericana en el contexto de la lengua", en su segunda parte arriesga hipótesis que avanzan sobre el espíritu mismo del Premio:

¿Qué política podríamos deducir del Premio de Narrativa Jorge Herralde? En principio, se trata de un premio español cuyo ámbito de eficacia es el mercado europeo del libro, en primer término. Los diferentes jurados del Premio han ido, a lo largo del tiempo, construyendo una figura de la literatura en lengua castellana que la editorial Anagrama gusta de patrocinar $[\ldots]$

Volviendo a la representación de los escritores novomundanos en los Premios Jorge Herralde la nueva tendencia, si se consolida en el tiempo, no implicará sino una reconsideración del campo de actuación de editorial Anagrama, es decir su mercado, cada vez menos "español" y cada vez más "hispanoamericano", o, para evitar palabras cuyos equívocos ya he señalado, cada vez menos nacional y cada vez más global. (Link 2009: 302-303)

Al día de la fecha, tres novelas argentinas han resultado favorecidas por el premio Herralde de Novela: El pasado (Edición 2003, con un Jurado conformado por Salvador Clotas, Juan Cueto, Esther Tusquets, Enrique Vila-Matas y el editor Jorge Herralde), de Alan Pauls; Ciencias morales (Edición 2007, con idéntico Jurado), de Martín Kohan, y Los Living (Edición 2011, con un Jurado conformado por Salvador Clotas, Paloma Díaz-Mas, Marcos Giralt Torrente, Vicente Molina Foix y el editor Jorge Herralde), de Martín Caparrós. Asimismo, en la Edición 2003 Andrés Neuman resulta finalista con Una vez Argentina. Al año siguiente, Eduardo Berti, con Todos los Funes. Las novelas El pasado y Ciencias morales tuvieron sus respectivas adaptaciones cinematográficas, lo que impulsó lógicamente su venta. ${ }^{173}$

Cuatro de las cinco novelas premiadas hacen referencias al pasado reciente. Tanto en El pasado como en Una vez Argentina las mismas son escasas, aunque significativas, y, en el caso de Pauls, El pasado preanunciaría su "trilogía de los setenta". ${ }^{174}$ Mientras

\footnotetext{
${ }^{173}$ El pasado, una producción argentino-brasileña dirigida por Héctor Babenco y protagonizada por Gael García Bernal, Moro Anghileri, Analía Couceyro, Ana Celentano, Mabi Abele y Carlos Portaluppi, fue estrenada el 26 de octubre de 2007 en Brasil. Ciencias morales fue adaptada al cine por Diego Lerman bajo el título de La mirada invisible (estreno: 19 de agosto de 2010), con una activa participación del autor en la escritura del guión. (Kohan también aparece fugazmente como actor.)

${ }^{174}$ Mientras "1976" es el año "hasta donde llegó nuestra juventud", el personaje de Javier de El pasado se queja amargamente al ser acusado de "traidor" con harta liviandad por la gurú "Frida" y su grupo de discípulos, puesto que "él [...] muy joven, secuestrado por las fuerzas de seguridad, había resistido dos meses de interrogatorios y tormentos sin abrir la boca, sin entregar uno solo de los nombres que le reclamaban sus verdugos" (Pauls 2003: 507 y 147, respectivamente). Por último, mientras aguarda que su mujer comience el trabajo de parto, el protagonista fantasea con que "se iba y Carmen era raptada y paría en cautiverio y los secuestradores se apropiaban del bebé para venderlo" (Op. Cit. Pauls 2003: 261). Si bien Rímini baraja otras posibilidades igualmente típicas de un padre primerizo (que su mujer muera durante el parto, que su hijo nazca "muerto o deforme"), no hay dudas que el primero de los terrores
} 
Ciencias morales pediría ser leída como parte de la "novelística de Malvinas", Los Living entraría en diálogo desapacible con la "novelística de hijos", en tanto defrauda las expectativas del lector. El héroe de esta novela nace en 1974, justo el día de la muerte de Perón. Pero este schifter no reenvía a ninguna parte, puesto que: "mi padre no se metía en política, decía, ni quería tener nada que ver con eso: la política es para los que no saben hacer nada bueno, decía -y yo, mucho después, recordaría tantas veces esa frase" (Caparrós 2011: 25).

En "Un premio para Alan Pauls" (con fecha de abril de 2004 y escrito especialmente por Jorge Herralde para la edición de El observatorio editorial en Adriana Hidalgo editora), el editor señala que el Premio Edición 2003 "ha resultado ser el más latinoamericano de nuestra historia [...] Alan Pauls ha ganado por unanimidad, pero Neuman quedó también primer finalista por unanimidad" (Herralde 2004: 207).

El editor no tiene mayor problema en confesar - contra toda fingida imparcialidadque él mismo fue de la idea de "presentar" El pasado al Premio Herralde de Novela, un texto del que ya había leído sus primeros cinco capítulos en el año 2000 y que para abril del 2001 ya había sido aceptado para su publicación (Cf. Op. Cit. Herralde 2004: 208211). De alguna forma, el testimonio de Jorge Herralde no hace más que confirmar la sospecha de que todos los premios funcionan como una precisa operación de marketing orquestada a favor de autores (previamente) aprobados para su publicación por la respectiva casa editorial:

... en abril de 2001, en Buenos Aires, me cité con Alan Pauls en el bar del Hotel Alvear y seguimos hablando de su work in progress. Y a finales de noviembre de 2002 aterrizó en Anagrama la primera versión de la novela, que me pareció deslumbrante, aunque Alan no la dio por definitiva. Después de ciertos retoques menores y del título, que pasó de llamarse Ex a $E l$ pasado, recibimos la versión definitiva con la que concursó el premio que ganó por unanimidad. Elaboración lenta, resultado final, un novelón de 560 páginas, al contrario que sus breves novelas anteriores. (Herralde 2004: 209-210)

mencionados ancla la novela en suelo local. Lo señalado obligaría a revisar la hipótesis de lectura formulada por Beatriz Sarlo desde las páginas de Punto de Vista, según la cual: "Pauls, de modo programático, explora cómo puede ser una ficción sin política y $\sin$ historia, que prescinda de sus alegorías o de sus representaciones. Claro está, no lo hace para suscribir una versión banal de que todo es político (y en consecuencia esa historia del poder del deseo y del amor también lo es). Diría, en cambio, que lo hace porque no encuentra en lo político algo que le resulte narrativamente interesante: no hay una afinidad intelectual entre este narrador y lo político. Quien quiera pensar que esta distancia es radicalmente posmoderna, está en su derecho. También convendría pensar por qué, en una literatura que pasó veinte años mordiendo lo político de diversos modos, un escritor construye un espacio fíccional independiente y una sociedad de personajes que logran sostener esa independencia. La distancia de lo político es una extranjería radical, una decisión en contra" (2004: 18; énfasis en el original). 
De todas formas, la evaluación retrospectiva de su gestión que realiza Herralde a treinta y cinco años de la fundación de Anagrama en el marco de la extensa entrevista que le realiza Nuria Azancot ("El último mohicano"), nos disuade de extraer conclusiones demasiado taxativas sobre su línea editorial a partir de la nómina de los ganadores (argentinos o no) del Premio Herralde de Novela. Al respecto, no podemos menos que coincidir con Daniel Link cuando señala que, por ejemplo, la presencia de un autor como César Aira (que nunca ganó el Premio) en la colección "Narrativas Hispánicas" sería un claro índice de que hay autores que "llegan al catálogo de Anagrama por otras vías [...] resultado de la colisión entre las singulares políticas de publicación de esos [...] autores y los intereses de la editorial Anagrama..." (Op. Cit. Link 2009: 304).

\section{Conclusiones del capítulo}

A lo largo de este capítulo hemos analizado cómo las memorias en la literatura propuestas por la "generación ausente" tienen que ver centralmente con reponer perspectivas generacionales que -hasta el momento- ocupaban un lugar marginal dentro de la memoria colectiva sobre la violencia política en la Argentina durante el decenio 1973-1983. Para ello, los autores del corpus asumen de manera preferencial los llamados "géneros del yo" y el modo autoficcional para dar la voz a los detenidosdesaparecidos que transitaban la adolescencia (con una importante salvedad: en tanto "víctimas absolutas" y contrariando por lo mismo el contexto general de recuperación del pasado militante de los detenidos-desaparecidos, entre ellos, los militantes populares “jóvenes menores"); el otro enemigo, afectado a tareas represivas dentro de los campos clandestinos de detención; el conscripto de Malvinas y los "hijos tempranos" de los detenidos-desaparecidos.

A la luz de la recurrencia con que ciertos tópicos se hacen presentes en las novelas favorecidas por los cuatro premios literarios reseñados, se volverían algo menos anecdóticas las invectivas emitidas por Rodolfo Fogwill poco antes de su muerte contra Martín Kohan, a quien acusó de ser permeable a la presión del editor Herralde que "obliga a poner un desaparecido por novela". ${ }^{175}$ De todas formas, en este diagnóstico no parece nada justa (ni ajustada a la realidad) la homologación explícita entre cierta

\footnotetext{
175 "Herralde es un ser deleznable, es deleznable la editorial y es deleznable lo que hace con los autores argentinos. Les obliga a poner un desaparecido por novela." (Fogwill [entrevistado por Patricio Zunini] http://blog.eternacadencia.com.ar/archives/2010/7627, consultado el 3.5.2013)
} 
sensibilidad epocal y el más craso oportunismo. Tampoco parece legítima la lectura por parte de Fogwill de determinados aportes al trabajo de memoria de sesgo generacional en términos de mero acatamiento a la "presión del mercado editorial" y/o seducción del sistema de premios.

De todas formas, la hipótesis de Martín Caparrós de que "la tensión literaturapolítica propia de los ' 70 es reemplazada a partir de la década siguiente por una nueva tensión: literatura-mercado" (Cf. Op. Cit. Caparrós 1991), ha resultado altamente sugerente para indagar novelas tales como Los cautivos, de Martín Kohan, y Muertos de amor, de Jorge Lanata.

El caso de la novelística de Carlos Gamerro, construida mediante el entramado de "memorias de la literatura I" no completamente coincidentes con la "tradición selectiva" que él mismo coloboró a imponer, alerta sobre la necesidad de pensar las trayectorias de algunos de nuestros "críticos-estrategas" de manera no lineal.

Se ha señalado con acierto que ni siquiera datos tan fuertes como la censura o el exilio (Sarlo 1987; 2006 y De Diego 2001), ni la llegada en 1983 de la Unión Cívica Radical al gobierno (Avellaneda 1997) fueron causales de cambios de poética, ni en el sistema literario en su conjunto, ni en la "trayectoria de escritor" de cada autor en particular (con la excepción, quizás, de Juan Martini: VER De Diego 2007). En efecto: se observa la reutilización en novelas de publicación muy reciente de "formas de representación oblicuas y fragmentarias", que en algún momento se creyeron explicables como resistencia al discurso autoritario monolítico (Cf. Sarlo 1987), o bien en tanto estrategias para "nombrar lo innombrable" en contextos marcados por la censura y la represión física y cultural (Cf. Reati 1992).

La reaparición de textualidades de este tipo (Vitagliano, Pauls, Kohan) en el contexto de una democracia ya consolidada podría esgrimirse como prueba de la pertinencia de pensar esta cuestión en términos de "memoria de la literatura I". Al mismo tiempo, cabría reconsiderar las "memorias de la literatura de tipo I" presentes en las novelas de nuestro corpus en el contexto más amplio de las luchas que los agentes en el campo literario libran por imponer determinadas políticas de la literatura.

Sobre el cambio de milenio, habida cuenta del capital simbólico acumulado por nuestros "críticos-estrategas", éstos apuntarán a imponer una "memoria de la literatura II" específica, con su concomitante y férreo sistema de exclusiones. En otras palabras: no ya una "tradición selectiva", sino un canon. 
Apéndice 1: Ganadores de los premios Clarín de Novela, Planeta de Argentina, Herralde de Novela y Alfaguara de novela

\section{PREMIO CLARÍN DE NOVELA}

\begin{tabular}{cll} 
Año & \multicolumn{1}{c}{ Autor } & \multicolumn{1}{c}{ Novela } \\
1998 & Pedro Mairal & Una noche con Sabrina Love \\
1999 & Leopoldo Brizuela & Inglaterra, una fábula \\
2000 & Pablo Toledo & Se esconde tras los ojos \\
2001 & Cristina Feijóo & Memorias del rio inmóvil (**) \\
2002 & María Henestrosa & Las ingratas \\
2003 & Patricia Suárez & Perdida en el momento \\
2004 & Ángela Pradelli & El lugar del padre \\
2005 & Claudia Piñeiro & Las viudas de los jueves \\
2006 & Betina González & Arte Menor \\
2007 & Norma Huidobro & Composición $(* *)$ \\
2008 & Raquel Robles & Perder \\
2009 & Federico Jeanmaire & Más liviano que el aire \\
2010 & Gustavo Nielsen & La otra playa \\
2011 & Luis Lozano & Lloverá sobre nosotros \\
2012 & Fernando Monacelli & Sobrevivientes $(* *)$ \\
2013 & Fabián Martínez Siccardi & Bestias afuera \\
2014 & Daniel Ferreira & Rebelión de los oficios inútiles
\end{tabular}

\section{PREMIO PLANETA DE ARGENTINA}

\begin{tabular}{rll}
\multicolumn{1}{c}{ Año } & \multicolumn{1}{c}{ Autor } & \multicolumn{1}{c}{ Novela } \\
1992 & Alicia Steimberg & Cuando digo Magdalena \\
1993 & Carlos Chernov & Anatomía humana \\
1994 & Antonio Dal Masetto & La tierra incomparable \\
1995 & Vicente Battista & Sucesos argentinos \\
1996 & María Esther de Miguel & El general, el pintor y la dama \\
1997 & Ricardo Piglia & Plata quemada \\
1998 & Liliana Díaz Mindurry & Pequeña música nocturna \\
1999 & Carlos Gorostiza & Vuelan las palomas \\
2000 & Liliana Escliar & La arquitectura de los ángeles $(* *)$ \\
-- & & \\
2005 & Paola Kaufmann & El lago (**) \\
2006 & Federico Andahazi & El conquistador
\end{tabular}




\section{PREMIO HERRALDE DE NOVELA}

\begin{tabular}{|c|c|c|}
\hline Año & Autor & Novela \\
\hline 1983 & Álvaro Pombo [España] & El héroe de las mansardas \\
\hline 1984 & Sergio Pitol [México] & El desfile del amor \\
\hline 1985 & Adelaida García Morales [España] & El silencio de las sirenas \\
\hline 1986 & Javier Marías [España] & El hombre sentimental \\
\hline 1987 & Félix de Azúa [España] & Diario de un hombre humillado \\
\hline 1988 & Vicente Molina Foix [España] & La quincena soviética \\
\hline 1989 & Miguel Sánchez Ostiz [España] & La gran ilusión \\
\hline 1990 & Justo Navarro [España] & Accidentes intimos \\
\hline 1991 & Álvaro del Amo [España] & La historia más triste \\
\hline 1992 & Paloma Díaz-Mas [España] & El sueño de Venecia \\
\hline 1993 & José María Riera de Leyva [España] & Aves de paso \\
\hline 1994 & $\begin{array}{l}\text { Carlos Perellón [España] } \\
\text { Pedro Zarraluki [España] }\end{array}$ & $\begin{array}{l}\text { La ciudad doble }(*) \\
\text { La historia del silencio }(*)\end{array}$ \\
\hline 1995 & José Ángel González Sainz [España] & Un mundo exasperado \\
\hline 1996 & Antonio Soler [España] & Las bailarinas muertas \\
\hline 1997 & Jaime Bayly [Perú] & La noche es virgen \\
\hline 1998 & Roberto Bolaño [Chile] & Los detectives salvajes \\
\hline 1999 & Marcos Giralt Torrente [España] & París \\
\hline 2000 & Luis Magrinyà [España] & Los dos Luises \\
\hline 2001 & Alejandro Gándara [España] & Últimas noticias de nuestro mundo \\
\hline 2002 & Enrique Vila-Matas [España] & El mal de Montano \\
\hline 2003 & Alan Pauls [Argentina] & El pasado $(* *)$ \\
\hline 2004 & Juan Villoro [México] & El testigo \\
\hline 2005 & Alonso Cueto [Perú] & La hora azul \\
\hline 2006 & Alberto Barrera Tyska [Venezuela] & La enfermedad \\
\hline 2007 & Martín Kohan [Argentina] & Ciencias morales $(* *)$ \\
\hline 2008 & Daniel Sada [México] & Casi nunca \\
\hline 2009 & Manuel Gutiérrez Aragón [España] & La vida después de marzo \\
\hline 2010 & Antonio Ungar [Colombia] & Tres ataúdes blancos \\
\hline 2011 & Martín Caparrós [2011] & Los Living $(* *)$ \\
\hline 2012 & Juan Francisco Ferré [España] & Karnaval \\
\hline 2013 & Álvaro Enrigue [México] & Muerte súbita \\
\hline 2014 & Guadalupe Nettel [México] & Después del invierno \\
\hline
\end{tabular}




\section{PREMIO ALFAGUARA DE NOVELA}

\begin{tabular}{lll} 
Año & \multicolumn{1}{c}{ Autor } & \multicolumn{1}{c}{ Novela } \\
$1998 \begin{array}{l}\text { Eliseo Alberto [Cuba] } \\
\text { Sergio Ramírez [Nicaragua] }\end{array}$ & $\begin{array}{l}\text { Caracol beach }(*) \\
\text { Margarita, está linda la mar }\left(^{*}\right)\end{array}$ \\
1999 Manuel Vicent [España] & Son de mar \\
2000 Clara Sánchez [México] & Últimas noticias del paraíso \\
2001 Elena Poniatowska [México] & La piel del cielo \\
2002 Tomás Eloy Martínez [Argentina] & El vuelo de la reina \\
2003 Xavier Velasco [México] & Diablo Guardián \\
2004 Laura Restrepo [Colombia] & Delirio \\
2005 Ema Wolf y Graciela Montes [Argentina] & El turno del escriba \\
2006 Santiago Roncagliolo [Perú] & Abril rojo \\
2007 Luis Leante [España] & Mira si yo te querré \\
2008 Antonio Orlando Rodríguez [Cuba] & Chiquita \\
2009 Andrés Neuman [Argentina] & El viajero del siglo \\
2010 Hernán Rivera Letelier [Chile] & El arte de la resurrección \\
2011 Juan Gabriel Vásquez [Colombia] & El ruido de las cosas al caer \\
2012 Leopoldo Brizuela [Argentina] & Una misma noche (**) \\
2013 José Ovejero [España] & La invención del amor \\
2014 Jorge Franco Ramos [Colombia] & El mundo de afuera
\end{tabular}




\section{CAPÍTULO CUATRO \\ "MEMORIAS DE LA LITERATURA II": \\ LA FORMULACIÓN DE UN CANON}

\section{1. "Canon de mercado", "canon" y "contra-canon". A modo de mapa: cuatro grandes "ciclos de canonización" de 1985 a hoy}

Entre enero y marzo de 2007, con motivo del décimo aniversario de la muerte del autor de Cuarteles de invierno, Osvaldo Bayer, Beatriz Sarlo y Guillermo Saccomanno vuelven a cruzar versiones sobre el supuesto escarnio público sufrido por Osvaldo Soriano en noviembre de 1991 a manos de la por aquel entonces titular de la Cátedra de Literatura Argentina II de la Universidad de Buenos Aires, Beatriz Sarlo. Según la versión que da el autor en el marco de una entrevista publicada el 27 de mayo de 1992 en La Maga, su inclusión en el ciclo "charlas con escritores" - del que ya habían participado César Aira, Adolfo Bioy Casares y Rodolfo Fogwill- se habría dado frente a "un auditorio hostil".

La descripción tendenciosa de la Facultad de Letras y su estudiantado sirve para continuar edificando una "autoimagen" en terminos de "un sujeto que viene de otro lugar, que no es de la literatura, que no pasó por la facultad [...] que viene del interior, que escribe y que tiene lectores y valores diferentes" (Soriano [Entrevistado por Daniel Ares] 1992: 3; nuestro énfasis).

La anécdota según la cual el público habría estallado en carcajadas frente a la confesión de los estudios secundarios incompletos de Soriano (por demás falaz, según el testimonio de Hinde Pomeraniec, la organizadora del ciclo) sirvió a Marcos Mayer para introducir en "La polémica por el canon" (nota de tapa del n 189 de $\tilde{N}$. Revista de Cultura correspondiente al 12 de mayo de 2007) el concepto de "canon de mercado":

Si bien ésta es una categoría por ahora poco usada, parece en principio como la contracara del canon académico: el criterio de inclusión canónica se conjuga inevitablemente en tiempo presente o, si se quiere, en épocas breves y siempre contemporáneas. Forman parte de esa selección los autores muy leídos, lo cual implicaría el pase a retiro de gran parte de la literatura universal. No habría que escandalizarse ni ante la fórmula ni ante las consecuencias que se derivan de ella. (Mayer 2007: 8)

La pregunta de si cabría recuperar determinados autores como parte de un "canon de mercado" es respondida por Mayer de manera afirmativa, aunque alertando sobre la necesidad de realizar previamente una inversión de valores: donde antes se decía (con 
una fuerte connotación negativa) "el mercado", ahora debería decirse "los lectores". Según su explicación:

La descalificación académica provendría de la idea de que autores como Soriano, Medina o en su momento Jorge Asís escribían para el "mercado". Como suele ocurrir en este tipo de polémicas, se toma la imputación como un valor, y hoy puede leerse o escucharse que, por ejemplo, Federico Andahazi (que se confiesa gran admirador de Soriano) hace equivaler "mercado" a "los lectores", despojando al término de cualquier connotación mercantilista. (Op. Cit. Mayer 2007: 7)

Si bien sería ingenuo pensar que las elecciones de los lectores son impermeables a la influencia del aparato de propaganda que despliegan los grandes Grupos para imponer determinadas "novedades editoriales", el concepto de "canon de mercado" interesa para indagar de manera no mecánica (esto en: siempre en términos inversamente proporcionales) la relación entre valor literario y cifras de venta. $\mathrm{O}$, en términos de Pierre Bourdieu, entre el valor cultural del libro y su valor comercial.

La lógica que rige la conformación del "canon de mercado", además, pediría ser recontextualizada en términos transnacionales, puesto que muchas veces determinados autores circulan de manera más fluida por el mercado extranjero hispanohablante y/ o en traducción que en su país de pertenencia. (Siendo, incluso, mejor recepcionados por determinada Academia extranjera que por la local. Ejemplo de lo dicho sería Luisa Valenzuela, una autora cuya novelística tematiza el pasado reciente.)

De todas formas, no sería "el mercado" (por su misma lógica de la novedad y la obsolescencia) uno de los espacios de sedimentación del canon propiamente dicho. Tal como señala Marcelo Jurisisch en "Lo que yace debajo: para qué sirve el canon literario" (2008), es precisamente bajo las leyes del mercado como agente regulador de la producción editorial a gran escala cuando el canon en sentido tradicional se vuelve paradójicamente indispensable.

Las historias de la literatura constituyen el espacio por excelencia de sedimentación del canon. En menor medida, lo son también los trabajos de edición que dan como resultado el establecimiento de las Obras Completas de un autor determinado, pasando por el lugar que éste ostenta en las "encuestas a la literatura argentina" gestionadas entre pares, los comentarios que merecen sus libros por parte de reseñistas particularmente prestigiosos y/ o colegas ya consagrados, su inclusión en el sistema escolar o el currículo universitario, la aparición de antologías de artículos académicos y/ 
o Jornadas y Congresos que lo tomen como objeto de estudio exclusivo, y la inscripción de su obra en un catálogo editorial determinado y/ o en el sistema de traducciones que le permita circular por fuera de las fronteras de su idioma.

Podrían postularse de modo tentativo cuatro grandes "ciclos de canonización", discernibles desde 1985 a la actualidad, que no se darían de manera consecutiva, sino por adición y superposición temporal. En un primer ciclo, aproximadamente en el decenio que va de 1985 a 1995, entrarían al canon argentino Ricardo Piglia, Manuel Puig y Juan José Saer (de su mano, Antonio Di Benedetto, cuya obra reedita Adriana Hidalgo a partir del año 2000). ${ }^{176}$ En el segundo ciclo, Osvaldo Lamborghini y Rodolfo Walsh (en tanto "maestro de estilo"). En un tercer momento (alrededor del año 2000) César Aira, Alberto Laiseca, Luis Gusmán y Copi. En un cuarto ciclo, se percibiría el ingreso inminente en el canon de Héctor Libertella y Rodolfo Fogwill (2009-hoy).

Mientras, tal como lo hemos desarrollado en el capítulo dos, la "generación ausente" se limitaría en el marco del primer ciclo de canonización a adherir a las estrategias de reconfiguración del canon pergeñadas por determinados "hermanos mayores", su agencia cobraría una importancia capital en los otros tres ciclos. Tal es así que hemos decidido destinar el quinto parágrafo del presente capítulo a analizar en detalle las intervenciones de Daniel Link (en calidad de albacea y editor de Rodolfo Walsh), Martín Kohan (como exégeta de Glosa) y Ricardo Strafacce (como biógrafo y plagiario de Osvaldo Lamborghini).

Sobre el primer ciclo de canonización, que tiene su punto cúlmine en el lugar de privilegio que ostentan Manuel Puig, Juan José Saer y Ricardo Piglia en el onceavo volumen (2000) de la Historia crítica de la literatura argentina compilado por Elsa Drucaroff, faltaría agregar algunas observaciones generales antes de proceder al análisis de cada caso en particular.

Primero: la activa participación de estos tres autores en su propio ciclo de canonización en la fase temprana del mismo y -para el caso de Piglia y Saer- una indestructible alianza personal, plasmada en Diálogo (ed. Sergio Delgado), volumen publicado en 1995 por la editorial de la Universidad de Santa Fe. En segundo término

\footnotetext{
176 También entre 1985 y 1990 Aberlardo Castillo reinscribe a Leopoldo Marechal y Ricardo Piglia suma a Macedonio Fernández. De todas formas, estos dos nombres no tienen especial relevancia en el marco de nuestro trabajo, que focaliza en la producción novelística que hace "memoria en la literatura" del decenio 1973-1983. Sí la tienen los nombres de Andrés Rivera, Juan Carlos Martini y Héctor Tizón, que aunque no ostentan el estatuto de "escritores canónicos", fueron repetidas veces mencionados durante la década del ochenta en relación a las poéticas de la negatividad de Ricardo Piglia y Juan José Saer.
} 
(también para el caso del binomio Saer-Piglia): el importante rol que tuvo la Academia en su proceso de consagración. (Contra esto, el proyecto de Manuel Puig articuló desde muy temprano con la fe anti academicista de los literalistas, encontrando en Severo Sarduy y Emir Rodríguez Monegal dos de sus más importantes propagadores a nivel continental.) Tercero: la importancia de determinados sellos editoriales en la consolidación de la presencia de dichos autores en el campo, o bien de determinados agentes en el proceso de exhumación de materiales que modifican parcialmente su recepción.

Ricardo Piglia es el que logra el ingreso al canon más temprano de los tres, gracias al impacto que causa Respiración artificial (Cf. Sarlo 2006). Tanto en la "Encuesta a la literatura argentina contemporánea" que gestionan Beatriz Sarlo y Carlos Altamirano en 1982 como en la encuesta que lanza la revista Humor registrado y cuyos resultados se publican entre los números 196 y 205 (mayo-septiembre de 1987), la novela publicada en 1980 recibe un amplio reconocimiento de sus pares. Mientras los sesenta y cinco escritores pertenecientes a la "literatura argentina contemporánea" interrogados en el marco de la primera Encuesta mencionan a Piglia tres veces (contra las dieciséis veces en que es nombrado Jorge Luis Borges), los cincuenta escritores y académicos que responden a la pregunta planteada por Humor ubican a Respiración artificial entre las diez mejores novelas de la historia argentina del género.

Otro hito en el proceso de consagración de Piglia estaría dado por la adaptación de la novela La ciudad ausente (1992) como libreto operístico para la ópera homónima compuesta por Gerardo Gandini (cuyo estreno mundial se realizó en 1995 en el Teatro Colón). Dos años más tarde, su prestigio se vio menoscabado con la fraudulenta premiación de Plata quemada (Premio Planeta Edición 1997), a la que ya hemos hecho extensa referencia en la coda correspondiente al capítulo anterior. Por último, la adaptación cinematográfica de la novela realizada por Marcelo Piñeyro (estrenada el 11 de mayo de 2001) gana el Premio Goya Edición 2002 a la mejor película extranjera de habla hispana.

En el año 2000, Piglia ingresa en el catálogo de Anagrama con reediciones de Plata quemada y Formas breves. En agosto del mismo año, el editor André Dimanche publica en Francia Respiración artificial (traducida al francés por Isabelle y Antoine Berman). En Anagrama, la novela se reedita en 2001: en el discurso de presentación del libro (19 de marzo de 2001) Jorge Herralde señala con acierto que su autor se ha 
transformado en un "instant classic, situado entre la plana mayor de la literatura latinoamericana" ([2001] 2004: 217).

En el caso de Juan José Saer, nunca se podrá insistir lo suficiente sobre la importancia de la publicación de El lugar de Saer (1986), de María Teresa Gramuglio, que sienta las bases de la recepción saeriana en consonancia con el propio autor. En efecto: la lectura de María Teresa Gramuglio coincide con la tajante afirmación en "Narrathon" (1973) tantas veces citada (y que precisamente avalaría su lectura en términos de "indagación de lo real"): "No puede saberse, del acontecer, nada" (Saer [1973] 2004: 144).

Mientras que en "Narrathon" esta afirmación aparece -acorde con los tiempos que corrían entonces- inficionada de política (la cultura, entendida por Saer como la suma de nuestras representaciones, sería una construcción arbitraria de la "opresión", que, encarnada bajo la forma de la "narración tradicional", es preciso abandonar), ya para 1979, en "La selva espesa de lo real”, estas convicciones son argumentadas en términos de adhesión a la teoría macedoniana de la novela.

El autor mismo propicia muy tempranamente la lectura de su novelística en conjunto con la de Piglia, en términos de negatividad. Entrevistado por Pie de Página, frente a la pregunta planteada por Mónica Tamborenea y Sergio Racuzzi (“¿Con qué literatura de la que se está produciendo hoy en la Argentina te vincularías?”), Saer afirma lo siguiente:

Respiración Artificial es la única narración argentina de los últimos tiempos que me interesa discutir porque plantea seriamente los problemas narrativos: cómo entrar en relación con lo real, cómo resolver problemas de referente, de tipo gnoseológico, epistemológico, no macanear, no decir "me encontré con fulanita y la quiero mucho y somos guerrilleros los dos". Son todas nociones que hay que poner en tela de juicio. Lo real es espeso. (Saer [Entrevistado por Mónica Tamborenea y Sergio Racuzzi] 1983: 6)

Alrededor de 1995, las poéticas de Saer y Piglia sufren un casi simultáneo punto de inflexión (Piglia con Plata quemada; Saer con La pesquisa, publicada en 1994). Es altamente significativo que Saer dedique La pesquisa a Piglia, y subtitule "novela policial" (a la manera de Manuel Puig) este ejercicio de las convenciones genéricas. Al respecto, podría aventurarse que algo tuvo que ver con este coincidente abandono de la 
“poética de la negatividad" el contexto de publicación: una creciente concentración de sellos editoriales en manos de unos pocos grandes Grupos.

En el año 2010, el Centre de Recherches Latino-Américaines de la Universidad de Poitiers publica el número 61 de la Colección ARCHIVOS, que de manera excepcional reúne en un solo volumen las ediciones críticas de Glosa y El entenado, más un CDROM en donde se pueden visualizar manuscritos. La edición tiene como coordinador general a Julio Premat, que ocho años antes había publicado en Beatriz Viterbo La dicha de Saturno. Escritura y melancolía en la obra de J. J. Saer.

Las secciones "Historia del texto" y "Lectura del texto" de la edición crítica incluyen trabajos del coordinador (en coautoría con Diego Vecchio y Graciela Villanueva), María Bermúdez Martínez, Miguel Dalmaroni, Florencia Abbate, Daniel Balderston (en coautoría con Nicolás Lucero), Sergio Delgado, Florencia Garramuño, María Teresa Gramuglio, Graciela Montaldo, Beatriz Sarlo y Dardo Scavino. La subsección "Testimonios y lecturas de escritores" (dentro de "Dossier de la obra") consta de trabajos firmados por Arturo Carrera, Bernardo Carlvalho, Sergio Chejfec, Milton Hatoum, Martín Kohan, Juan Carlos Mondragón, Alan Pauls y Alain RobbeGrillet.

Del 28 al 30 de junio de 2011 toman lugar las "Jornadas Juan José Saer" en la Biblioteca Nacional. Varias de las intervenciones son reproducidas en el volumen Zona de prólogos (compilador Paulo Ricci), publicado el mismo año. También en 2011, en el $\mathrm{n}^{\circ} 6$ de los cuadernos L.I.R.I.CO. (cuyo director es Julio Premat), se publica una selección de las ponencias leídas durante el coloquio internacional "Juan José Saer: archives, mémoire, critique", celebradas entre el 4 y 5 de junio de 2010, organizadas conjuntamente por la Universidad Paris 8- Vincennes-Saint Denis, la Universidad de Bretagne Sud-Lorient y la Universidad Nacional de La Plata.

Durante el bienio 2012/ 2013 son editados sus "papeles de trabajo" (en dos tomos) y un volumen de sus poemas inéditos, nuevamente bajo el cuidado de Julio Premat (Seix Barral 2012a; 2012b y 2013). La publicación del primer tomo de los "papeles de trabajo" es tema de tapa del n 453 de $\tilde{N}$. Revista de Cultura, para el que escribe una extensa nota Beatriz Sarlo. En ella, define a Saer como el "escritor decisivo de la segunda mitad del siglo XX": 
Los Cuadernos confirman lo que, de algún modo, sabíamos. La literatura de Saer responde a la estética de la resistencia. Sin embargo, no es contorsionada. Es bella y serena, aunque casi siempre desesperada. La misma textura tienen esas páginas preliminares o desechadas, que no son filosóficamente diferentes a las que se publicaron. Las obras "juveniles" de Saer lo son por su cronología, no por torpezas o indecisiones. Hubo cambios, sin duda, y esos cambios tienen que ver con su historia. Pero el gran escritor, el escritor decisivo de la segunda mitad del siglo XX, estaba allí desde el principio (Sarlo 2012: 8)

Por último, Saer -junto con Juan Gelman y Julio Cortázar, del que se cumple el centenario de su nacimiento- es objeto de homenaje en el Salón del Libro en París dedicado a la Argentina (21 al 24 de marzo de 2014). En la sección "Cultura y espectáculos" de Página/ 12 del 23 de marzo de 2014 Silvina Friera (que asiste al evento como corresponsal) reproduce el juicio emitido en este marco por Martín Kohan: "Saer lo hizo de manera perfecta. Él nos plantea un desafío sólo comparable al de Borges, que es el dilema de cómo escribir después de ellos" (Kohan [Entrevistado por Silvina Friera] 2014: 35).

En el caso de Manuel Puig, es indudable el peso que tuvo en su proceso de consagración el éxito obtenido en 1985 por la versión cinematográfica de El beso de la mujer araña, una co-producción entre Estados Unidos y Brasil dirigida por Héctor Babenco, con William Hurt, Raúl Juliá, Sônia Braga, José Lewgoy y Milton Gonçalves en los roles proncipales, que recontextualiza la historia de amor entre Molina y Valentín en una cárcel de la dictadura brasileña. Es importante aclarar que adaptación para cine no fue obra de Puig, sino de Leonard Schrader. La película de Babenco fue candidata a los premios Oscar en las categorías "Mejor Director", "Mejor Película", "Mejor Guión Adaptado" y "Mejor Actor", aunque sólo William Hurt resultaría ganador de una estatuilla.

Dos años antes, Puig había adaptado su novela para la escena teatral, tanto en idioma castellano (el estreno se realizó en 1981, en España) como en inglés, siendo estrenada en dicho idioma en 1985, en el Bush Theatre de Londres. Como musical, Kiss of the Spider Woman (libreto de Terrence McNally; música de John Kander y Fred Ebb; coreografía de Rob Marshall y dirección de Harold Prince, con Mark Rylance y Simon Callow en los roles principales) fue estrenada en Broadway el 3 de Mayo de 1993, donde superó las 900 representaciones y consiguió once nominaciones a los premios 
Tony, de los que obtuvo siete (Mejor Musical, Mejor Libreto, Mejor Partitura, Mejor Actor Principal, Mejor Actriz principal y Mejor Actor Secundario).

Amén de la tesis devenida libro La traición de Rita Hayworth (1986), de Alan Pauls y la importancia de la colección "Manuel Puig en Beatriz Viterbo Editora" para la exhumación de inéditos a las que ya hemos hecho referencia en el capítulo dos, la edición por Beatriz Viterbo en 1998 de las actas del Encuentro Internacional Manuel Puig (comp. José Amícola y Graciela Speranza), organizado por la Universidad Nacional de La Plata entre el 13 y el 15 de agosto de 1997, puede ser considerado el primer gran hito en la recepción académica del autor.

También en 1998, la revista Hispamérica publica un dossier especial sobre Manuel Puig (Hispamérica, $\mathrm{n}^{\circ}$ 80-81, agosto/ diciembre 1998). Por último, es importante aclarar que cinco años antes, la Universidad Nacional de La Plata había recuperado y tomado en guarda los papeles y manuscritos de Manuel Puig (que estaban en depósito en la Universidad de Princeton), lo que posibilitó no sólo el abordaje crítico-genético de obras conocidas del autor, sino también la exhumación y publicación de inéditos. Fueros directores del equipo de investigadores de la UNLP que trabajaron sobre los manuscritos recuperados: José Amícola, Julia Romero y Graciela Goldchluk.

El trienio 2000-2002 es indudablemente el momento de apoteosis definitiva del autor oriundo de General Villegas. El 2 de julio de 2000 Manuel Puig es tapa del suplemento "Cultura y Nación" de Clarín bajo el título de "El escritor traicionado". 177 La "traición" a la que se alude -además de un guiño obvio al título de su primera novela- remite al hecho de que: "en los '70 fue un boom traducido a veinte idiomas, pero murió en 1990 olvidado en su propio país". En el interior del suplemento escriben sendas notas Daniel Molina y Graciela Speranza, quien adelanta un fragmento de su libro Manuel Puig. Después del fin de la literatura, donde señala la radical originalidad de Puig en tanto "la videoteca se impone materialmente como espacio privilegiado de

\footnotetext{
177 Es importante aclarar que Manuel Puig ya había sido tapa (y tema único, dada la lógica de la publicación) del suplemento "Primer Plano" correspondiente al 21 de julio de 1991 bajo el título de "Los últimos días de un expatriado". Sobre Puig escriben el editor Tomás Eloy Martínez ("El que no quería morir") y Tununa Mercado ("No me digas adiós"). También se publica el cuento inédito de Puig "Humedad relativa 95\%" y "La trastienda de una novela", breve texto del autor sobre el proceso escriturario de Maldición eterna a quien lea estas páginas (1981).
} 
aprendizaje e inspiración y reemplaza a la enciclopedia tradicional del escritor, la biblioteca" (Speranza 2000: 131). ${ }^{178}$

Al año siguiente, Puig es tapa de "Radarlibros" bajo el título de "El General Villegas tiene quien le escriba", con motivo de la celebración de las jornadas "Manuel Puig en acción" (18 al 20 de octubre de 2001) en su pueblo de nacimiento. El mismo año, Alberto Giordano publica Manuel Puig. La conversación infinita en Beatriz Viterbo editora. En 2002, el Centre de Recherches Latino-Américaines realiza la edición crítico-genética de El beso de la mujer araña bajo la dirección de José Amícola y Jorge Panesi. El volumen, que tiene el n ${ }^{\circ} 42$ de la Colección Archivos, es claro índice del importante lugar logrado por Manuel Puig no ya en el canon argentino, sino latinoamericano.

La crítica genética permite arrojar nueva luz sobre la "política de la literatura" a la que adhiere Puig, y alerta sobre el cambio más espectacular introducido por el autor en el proceso de textualización de El beso de la mujer araña, que es el del tiempo narrado: de 1971/ 72 a 1974/ 75. Como consecuencia de esta modificación, el personaje de "Valentín Aguirre" pasa de ser un preso político del gobierno de facto de Alejandro Agustín Lanusse (y susceptible por lo mismo de ser liberado durante el llamado "Devotazo"), a ser construido en tanto combatiente del PRT-ERP, en prisión durante el gobierno de María Estela Martínez de Perón. El cambio es atribuido por Graciela Goldchluk y Julia Romero a la situación de exilio de Puig, que fue amenazado de muerte por la organización parapolicial "Triple A" luego de la publicación de The Buenos Aires Affair (cuya edición se secuestró), todo lo cual, ya para septiembre de 1973, motiva su exilio en México (Cf. Goldchluk/ Romero 1997; Goldchluk 1998; Romero 1999; Goldchluk 2002; Romero 2002). También -y siempre según Goldchluk“implica una toma de posición con respecto al avance de la represión dentro de un gobierno que había comenzado su ciclo liberando a todos los presos políticos" (Op. Cit. 2002: LXXI). ${ }^{179}$

\footnotetext{
178 Otra importante lectura que plantea Graciela Speranza en Manuel Puig. Después del fin de la literatura es que el autor de La traición de Rita Hayworth se erige en la "condición de posibilidad de las escrituras-sin-estilo de las fícciones de los noventa", aunque de allí extrae la conclusión de que "su escritura es inimitable" (Op. Cit. 2000: 224-225), lo que desestimaría a Alejandro López (La asesina de Lady Di), Daniel Link (Los años noventa y La ansiedad) y/ o Ricardo Strafacce (El crímen de la negra Reguera) como posibles herederos de Puig.

${ }^{179}$ A pesar de esto, Manuel Puig mantiene la primitiva fecha de detención de "Valentín Aguirre" (esto es: el año 1972), lo que -según coinciden Graciela Goldchluk y Julia Romero en "El contorno del fantasma. Las huellas de la historia en El beso de la mujer araña de Manuel Puig" (1997)- se trataría de un error
} 
En El beso de la mujer araña, se buscaría desestabilizar, al mismo tiempo, dos figuras: la del homosexual que persigue su visibilización y termina auto-confinándose en el "guetto gay" (crítica por demás presente en el ensayo publicado por Puig en 1990, "El error gay"), y la de los (por el escritor bautizados como) "reaccionarios de izquierda", esto es, los militantes populares que permanecen ciegos frente a la paradoja de que, en las sociedades patriarcales que pretenden "revolucionar", ellos mismos están colocados, en tanto varones heterosexuales, en el lugar del opresor. ${ }^{180}$

Todo lo dicho permite inferir que Puig se propuso señalar la contradicción existente entre el discurso revolucionario de determinadas organizaciones políticomilitares de la época y su adhesión en la práctica a una concepción falocéntrica y héteronormativa de la sexualidad. Es altamente significativo que el escritor no haya elegido como objeto de crítica la homofobia en abstracto, sino aquella que anidaba en el seno mismo de las organizaciones que sostenían tener como horizonte la subversión de todos los valores burgueses.

Al tomar como objeto tanto los pretextos de la etapa prerredacional (apuntes, registros, anotaciones realizadas por el escritor, materiales de investigación), como las diferentes etapas redaccionales de El beso de la mujer araña (manuscritos, dactiloescrito y reconstrucción de las correcciones realizadas sobre las pruebas de galera, que se han perdido), la crítica genética permite recuperar la complejidad del proceso de textualización, dando un mentís a dos de los principales "mitos de autor": tanto el que hacía de Puig un mero transcriptor de voces ("un escritor sin estilo"), resumido magistralmente en el comentario de Juan Carlos Onetti luego de leer Boquitas pintadas, como aquel que quiso hacer de él un escritor intuitivo e ingenuo. ${ }^{181}$

\footnotetext{
voluntario, que apuntaría a la inteligencia de un lector capaz -más allá del anacronismo- de leer entre líneas una crítica a las políticas de seguridad interior del último gobierno peronista.

${ }^{180}$ Sobre esta última cuestión: Puig tampoco adhiere sin más al discurso feminista entonces vigente, sino que, como señala Graciela Goldchluk en "La travesía de Valentín: de la vida real a El beso de la mujer araña", está particularmente interesado en investigar "qué ventajas podía tener para la mujer (y para los románticos incurables como Molina) el rol de oprimida" (Goldchluk 1998: 52).

${ }^{181}$ En su aporte para la edición crítico-genética de El beso de la mujer araña (“ 'Los posibles narrativos'. Estudio crítico genético de la fase prerredaccional"), Julia Romero trabaja, entre otras cuestiones, las "Anotaciones de la cárcel" (once páginas manuscritas que registran entrevistas mantenidas en Buenos Aires por Puig con presos políticos, liberados por el presidente Cámpora en 1973 durante el llamado "Devotazo") en vínculo con el proceso de textualización, a lo largo del cual se observa la estilización de la primitiva transcripción de la oralidad, hasta la casi supresión del lunfardo carcelario. También Graciela Goldchluk en “ 'Distancia y contaminación'. Estudio crítico genético de la fase redaccional” (2002) da ejemplos puntuales del proceso por el cual Puig modifica en dos sentidos el habla del cuadro del PRTERP: menor frecuencia de aparición de lexemas propios del argot carcelario y mayor pacatería a la hora
} 
Durante el bienio 2005-2006, Editorial Entropía da a conocer dos volúmenes de cartas personales, bajo la coordinación de Graciela Goldchluk: Querida familia. Tomo 1. Cartas europeas (1956-1962) y Querida familia. Tomo 2. Cartas americanas. New York-Río (1963-1983). Según Daniel Link en Clases. Literatura y disidencia (2005), es precisamente en las "cartas europeas" donde se percibe "la construcción de una voz a la vez íntima e impersonal (la voz que sostendrán, cada una a su modo, todas las novelas de Puig)" (2005: 337-338; nuestro énfasis). Esta hipótesis crítica se opondría nuevamente a la idea de Puig como un mero "transcriptor de voces".

En 2009, Entropía publica Teatro reunido, que consta de la adaptación firmada por Puig de su novela El beso de la mujer araña, y de Bajo un manto de estrellas, El misterio del ramo de rosas, Triste golondrina macho y Un espía en mi corazón. Es de destacar que, finalizando los años noventa -bajo el cuidado de Julia Romero y Graciela Goldchluk- ya se habían editado en Beatriz Viterbo Bajo un manto de estrellas y El misterio del ramo de rosas (1997); Triste golondrina macho, Amor del bueno y Muy señor mío (1998), y la comedia Gardel, uma lembrança (que aparece acompañada por el guión cinematográfico La tajada, escrito por Puig en 1960).

En diciembre de 2012, con motivo del $80^{\circ}$ aniversario del nacimiento de Puig, el grupo Planeta comienza a reeditar la totalidad de su obra narrativa, en formato booket y con un tiraje de 10.000 ejemplares por título, a cargo de Jorge Álvarez. Se produce un auge sin precedentes de las puestas en escena de sus obras: Bajo un manto de estrellas (estrenada en enero de 2013 en el Teatro de la Comedia bajo la dirección de Manuel Ledvabni: ya había sido preestrenada en el marco de las jornadas "Manuel Puig, escritor de varios mundos", organizadas por la Municipalidad de General Villegas los días 6, 7, 8 y 9 de diciembre de 2012); Impalpable (reestrenada en marzo de 2013 con puesta renovada en el teatro off "El Extranjero", bajo la dirección de Sergio Calvo e Ignacio de Santis) y Triste golondrina macho (estrenada en agosto en el Teatro Regio -parte del Complejo Teatral de Buenos Aires- bajo la dirección de Guillermo Arengo y Blas Arrese Igor).

Así como el grupo Punto de Vista resultó fundamental para la canonización de Juan José Saer, lo fue César Aira para la de Osvaldo Lamborghini en el marco de lo que hemos delimitado aquí como "segundo ciclo de canonización". A la fijación de unas

de refererirse a la sexualidad (lo que Puig denomina en anotaciones metaescriturarias de la etapa redaccional "más asepsia, mayor puritanismo"). 
primeras e hipotéticas “obras completas" (edición en 1988 de Novelas y cuentos de Osvaldo Lamborghini en Ediciones del Serbal de Barcelona), se le sumarían las sucesivas reediciones corregidas y aumentadas en Sudamericana (2003a; 2003b; 2004; 2005) y Mondadori (2010; 2011; 2012a y 2012b), siempre prologadas y/ o epilogadas por Aira.

La idea de "unas hipotéticas obras completas" es particularmente pertinente en este caso, habida cuenta de que, en vida, el autor, además de artículos y poemas sueltos en revistas, sólo publicó tres libros: El fiord (1969), Sebregondi retrocede (1973) y Poemas (1980). ${ }^{182}$

Osvaldo Lamborghini vivió en hoteles y cuartos prestados, diseminó obra (en revistas, en carpetas, en hojas sueltas, en cartas privadas), fue el "mito" de sus amigos y discípulos, y fue construido por otros (y se autoconstruyó) como autor póstumo y genial. Como Macedonio Fernández, levantó una "figura de autor" para la cual el acto de prometer obra (antes de tenerla publicada) y el afán por suscitar en los otros el deseo de la propia obra (incluso antes de tenerla escrita) resultarían constitutivos. ${ }^{183}$

Los cuatro escritores que se han ocupado hasta el momento de ordenar el archivo Osvaldo Lamborghini a los fines de establecer sus "obras completas" (en orden de aparición: César Aira, Rodolfo Enrique Fogwill, Ricardo Strafacce y Oscar Steimberg) compartirían el designo de hacer obra de la dispersión. Para ello, clasifican los textos según claras adscripciones genéricas ("novelas", “cuentos", "poemas”, “obra teatral”, "epistolario", "cómic"), a los fines de situar a su autor dentro de una deseable "memoria de la literatura II". Coinciden, asimismo, en la práctica de una crítica genética de tipo artesanal: no realizan edición diplomática de los manuscritos de manera consecuente, ni los publican en facsímil (hasta el día de hoy, la única excepción a lo señalado es la edición facsimilar de Teatro proletario de cámara, publicada en Barcelona en 2008).

El darle una adscripción genérica fija a los manuscritos no sólo escamotea el uso siempre rayano con lo lúdico o lo abusivo (un uso macedoniano) que hizo Osvaldo

\footnotetext{
${ }^{182}$ Para la nómina completa de lo publicado en vida por Lamborghini, VER Strafacce (2008: 829-830).

${ }^{183}$ Por lo mismo, en el caso de Osvaldo Lamborghini hemos elegido como mojones de su proceso de canonización las sucesivas versiones de sus "obras completas", más allá del impacto que hayan tenido algunas exégesis críticas. Para una lista de las intervenciones críticas sobre Osvaldo Lamborghini realizadas hasta el año 2001, VER Andares clancos. Fábulas de menor en Osvaldo Lamborghini, J. C. Onetti, Rubén Darío, J. L. Borges, Silvina Ocampo y Manuel Puig, de Adriana Astutti (2001: 86-87). Con posterioridad a esta fecha, cabe mencionar la aproximación al autor de El fiord desde las sexualidades disidentes en Sueños de exterminio. Homosexualidad y representación en la literatura argentina contemporánea (Beatriz Viterbo 2004), de Gabriel Giorgi.
} 
Lamborghini de los conceptos de "novela" y "capítulos" -por ejemplo: en Sebregondi se excede- sino también la importancia de la instancia de edición en las relaciones (siempre irreverentes) que el autor mantuvo con las convenciones genéricas. Al respecto, cabe recordar que Sebregondi retrocede fue prosificado por Lamborghini, animado del deseo de, a la sombra del éxito obtenido por El frasquito, hacer de "El niño proletario" un "tercer capítulo" de esta "novela". Asimismo, para su publicación en octubre de 1981 en la revista Feeling, el texto Sonia (o el final) fue subtitulado como "Fragmento de la novela Las frases del ayer tramposo".

En su "Prólogo" a Novelas y cuentos, César Aira presenta al autor como una figura modélica: Osvaldo Lamborghini es "el Maestro", tan erudito como el mismo Jorge Luis Borges y escribe sin esfuerzo, en continuo. Al mismo tiempo, dado que ofició muchas veces de secretario, Aira se sirve del "Prólogo" para cimentar su propio lugar de albacea mediante el señalamiento (de memoria, porque el manuscrito se ha perdido) de una supuesta errata en ambas versiones publicadas en vida del autor de Sonia (o el final) (Cf. Aira 1988: 13-14).

En verdad, la idea presente en el "Prólogo" a Novelas y cuentos de que Lamborghini escribía en continuo ("una suerte de 'escritura automática' [...] lo perfecto de verdad, que escapa al trabajo") es menos una descripción de la textura de la escritura lamborghiniana que una clave de lectura que el albacea-escritor desearía ver aplicada a su propio proyecto creador. En efecto: también en Copi (1991) Aira se sirve de la descripción de la literatura de un otro a los fines de facilitar el entendimiento de su propia apuesta literaria, y, en este sentido, sería el ejemplo por antonomasia (junto con J. L. Borges y Ricardo Piglia) del "crítico-estratega". ${ }^{184}$

En 2002, Fogwill epiloga Palacio de los Aplausos (o el suelo del sentido) para Beatriz Viterbo, experimento teatral escrito a cuatro manos por Osvaldo Lamborghini y Arturo Carrera el 25 de abril de 1981, en Pringles. A la manera de Aira, Fogwill hace valer sus credenciales de amigo, pero recoloca a Lamborghini dentro de un "grupo cultural" del que él mismo sería parte (“OL, Carrera, Néstor Perlongher, Emeterio Cerro, Alfredo Prior y yo"). Fogwill, además, es el único que publicó a Osvaldo Lamborghini en vida: Poemas (1980), en Ediciones Tierra Baldía.

\footnotetext{
${ }^{184}$ En Copi reaparecen la idea de escribir en continuo en términos de la "necesidad de la continuación" (Aira [1991] 2003: 36) y a la de "escritura automática", se le suma la idea de "trama" (concepto siempre caro para el escritor oriundo de Pringles): "basta imaginarse un posible desarrollo de la novela para que ya esté sucediendo. Es su aproximación a la escritura automática. Salvo que él [Copi] la precede de una historia" (Aira [1991] 2003: 55; énfasis del autor).
} 
En julio de 2008 aparece en las librerías Y todo el resto es literatura, conjunto de doce trabajos que los profesores argentinos radicados en Estados Unidos Juan Pablo Davobe (Universidad de Colorado) y Natalia Brizuela (Universidad de California) compilan y publican en la colección ensayos de InterZona Editora. En septiembre del mismo año, Ricardo Strafacce publica Osvaldo Lamborghini: una biografía en Mansalva, de la cual se habían adelantado fragmentos en el n 9 de El rodaballo (1998), el $\mathrm{n}^{\circ} 8$ de Boletín (2000) y el $\mathrm{n}^{\circ} 7$ de El niño Stanton (2007). Antes, en enero del mismo año, AR Publicaciones de Barcelona había presentado Teatro proletario de cámara bajo la supervisión de Hanna Muck y con prólogo de César Aira: 529 páginas color en papel ilustración, con formato $17 \times 23 \mathrm{~cm}$ y un tiraje de 300 ejemplares numerados y cosidos, con una tapa borravino en Pvc serigrafiado.

Si bien no compartimos la sospecha de Diego Peller de que la coincidencia en el año 2008 de estos tres hitos editoriales no sería fortuita, sino que obedecería a "una 'operación Lamborghini' estratégicamente programada" (Peller 2010: 2), sí es de destacar que con ella es la primera vez que tanto el archivo Lamborghini como su "imagen de escritor" dejan de estar en manos de sus amigos y/ o compañeros de gesta generacional para pasar a ser disputados por otros agentes.

O bien de aquel que se ufana de su no pertenencia al mundo académico ni al círculo íntimo del escritor (Ricardo Strafacce), o bien de aquellos que articulan como doctorados, profesores $\mathrm{y} / \mathrm{o}$ becarios con la "academia norteamericana" (todos los firmantes de $Y$ todo el resto es literatura, con excepción de Julio Premat, que enseña en de la Universidad de París 8; Luis Gusmán, cuya intervención de tipo testimonial resulta totalmente extemporánea al tono dominante en el volumen, y Luis Chitarroni, que hace ostentación de antiacademicismo, renunciando a las notas al pie y volviendo a lo ya dicho en su artículo "Tipos de guerra", publicado en junio de 1989 en la sección "El libro del mes" en el n 9 de Babel, revista de libros).

$Y$ todo el resto es literatura, más allá de su heterogeneidad, parece tener como principal objetivo universalizar a Osvaldo Lamborghini. En otras palabras: sin negar su interlocución con determinados autores locales (José Hernández, Oliverio Girondo, Roberto Arlt, Macedonio Fernández, Witold Gombrowicz, Alejandra Pizarnik, Rodolfo Walsh), recolocar su escritura en diálogo con el pensamiento y la teoría europeas, no sólo con los autores que legítimamente podemos suponer que el Lamborghini leyó en traducción (el marqués de Sade, Pierre Klossowsi, Antonin Artaud, Jean Genet, Georges Bataille, Sigmund Freud, Jacques Lacan, Félix Guattari/ Gilles Deleuze y Elias Canetti), 
sino ya como "precursora" de algunas conceptualizaciones de Toni Negri, Michael Hardt, Alain Badiou y Jacques Rancière.

Como si quisieran dar un mentís a la afirmación de los compiladores de que Osvaldo Lamborghini "parece confinado, o exaltado, de momento, al sistema literario argentino" (Dabove/ Brizuela 2008: 13), las intervenciones muchas veces fuerzan los vínculos con determinados autores extranjeros (el ensayo "La detención de la escritura: Samuel Beckett en Osvaldo Lamborghini”, de Reinaldo Laddaga es, al respecto, el ejemplo más ilustrativo). ${ }^{185}$

La importancia de Osvaldo Lamborghini, una biografia es insoslayable. Los aportes de Strafacce, tanto en lo que hace a la datación de textos ya publicados (el ejemplo más espectacular es su señalamiento de que El fiord debió haber sido escrito "alrededor de marzo de 1968", reinterpretando para ello la fecha "octubre 1966-marzo 1967” dada de puño y letra por el autor al pie del texto en términos simbólicos), como también en la exhumación de inéditos (el primer poema adolescente de Lamborghini; su primera colaboración firmada el 11 de noviembre de 1969 para Periscopio sobre El amhor, los orsinis y la muerte, de Néstor Sánchez; sus cartas personales; su trabajo como guionista de historietas) y la adjudicación de un lugar determinado a manuscritos que hasta el momento aparecían como papeles sueltos, fueron destacados por César Aira en sus sucesivas "notas del compilador", escritas con motivo de la reedición de las “obras completas” de Osvaldo Lamborghini entre los años 2003 y 2005 por Sudamericana (esto es: cinco años antes de que Osvaldo Lamborghini: una biografía fuera publicada).

Por último, la edición en junio de 2013 de la historieta ;Marc! (publicada originalmente en la revista Top entre julio de 1971 y mayo de 1972), con guión de Osvaldo Lamborghini y dibujos de Gustavo Trigo por la pequeña editorial marplatense Puente Aéreo y con prólogo de Oscar Steimberg, constituye el intento más reciente de reunir la dispersión y fijar los contornos definitivos de las obras completas del autor de El fiord.

\footnotetext{
${ }^{185}$ En este marco, interesa recabar en la relativamente temprana traducción al francés (año 2005) de los dos textos más célebres de Osvaldo Lamborghini en una edición conjunta de Sudamericana con Éditions du Rocher (Le Fjord suivi de Sebregondi recule, traductores Isabelle Gugnon y Laurence Viallet). La contratapa del volumen es compartida por el cineasta franco-argentino Gaspard Noé y César Aira, de quien se traduce un fragmento al francés de su "Prólogo" a Novelas y cuentos (1988). Como contraste, recién en enero de 2013 la editorial italiana Libri Schweiwiller publicó una antología poética titulada $I l$ ritorno di Hartz e altre poesie (versión bilingüe, con traducción al italiano de Massimo Rizzante).
} 
Los editores Esteban Prado y Esteban Quirós de Puente Aéreo eligen la última viñeta del último episodio de ;Marc! (sin reproducir la frase del personaje de Blanche “¿Y a mí qué me contás?”) para darle una tapa (amarilla, de estética pop) a la reedición del cómic en formato libro. Si bien no reproducen las publicidades (por lo que se ven obligados a cambiar la composición de página), sí se ocupan de señalar y reproducir el cambio de disposición (de vertical a apaisada) a partir del episodio de "Lina Luna, mártir" ( $\mathrm{n}^{\circ} 10$ de abril de 1972). No obstante, el cambio de formato (de un preponderante $20 \times 28 \mathrm{~cm}$ en la historieta original, los editores eligen darle a todo ;Marc! un formato 20x14, que es el que tiene la Top entre los números 10 y 15, apaisados) encoge sensiblemente las viñetas reproducidas como libro.

En verdad, si comparamos la edición original (esto es: las quebradizas Top en las que Lamborghini/ Trigo publican los once episodios de ;Marc!) con el libro sacado por Puente Aéreo, este último impresiona como lujoso (papel alto gramaje, tapa a color, con solapas). Por lo mismo, aparece como perfectamente capaz de incorporarse a las "obras completas", y de articular con el resto de la hasta el momento obra édita de Lamborghini.

Las arbitrariedades con las que fue encarado el pasaje de ;Marc! a formato libro ( $\sin$ capitalizar para el mismo el cambio de criterio editorial que significó la aparición en 2012 de El Eternauta Vintage de Oesterheld y Solano López en Doedytores, que incluyó por primera vez no sólo las viñetas capitulares con el título de la serie y el resumen de los episodios anteriores, sino también el pie de imprenta editorial y las publicidades) son -si se quiere- una "puesta en abismo" de todo el trabajo editor realizado hasta el momento. ${ }^{186}$ Contra el deseo de Osvaldo Lamborghini de ser "un Macedonio de los setenta" y proliferar en libros indigentes (pero que hacen de dicha condición una paradójica fuente de contrapoder), la obra de edición realizada hasta el momento deja traslucir un carácter marcadamente monumentalista, algo que ya fue observado por Alan Pauls en "Maldito mito" (2003).

\footnotetext{
${ }^{186}$ Se ha señalado repetidas veces que la historieta es el género que pone en mayor evidencia el problema de la materialidad de la edición (en otras palabras: en qué medida la instancia de edición modifica el manuscrito original). En efecto: si bien este hecho está prácticamente naturalizado, la historieta que compramos difiere notablemente de la "obra" que salió del tablero del dibujante y el escritorio del guionista: mientras la disposición original de la página fue modificada por la inclusión de las viñetas capitulares con el título de la serie, el pie de imprenta editorial y/o las publicidades, se han producido además importantes cambios a nivel del color ("grisados" y/ o reducción de la paleta por motivos de economía).
} 
Para el caso de Rodolfo Walsh, importa recuperar la producción crítica alrededor de ciertas efemérides.

El domingo 23 de marzo de 1997, el n 32 de "Radar" tiene como nota de tapa "Rodolfo Walsh, veinte años después". La foto que ilustra la portada muestra al autor de Operación masacre con un grabador a cinta en la mano, semiinclinado sobre un chimpancé. En el interior escriben sendas semblanzas biográficas su amigo y compañero en la Agencia de Noticias Clandestinas, Horacio Verbitsky ("La revelación de lo escondido") y quien fuera su última pareja, Lilia Ferreyra ("Los caballos de Walsh"). Ambos enfatizan el carácter militante de la escritura de Walsh ("el mejor periodista del país, que era también uno de sus mejores escritores", dice Verbitsky; "la coherencia entre sus palabras y sus actos de la que fui testigo en los diez años de nuestra unión hasta que nos separó la muerte", subraya Ferreyra). Además, ésta última describe de memoria el cuento "El 27", secuestrado en la casa de San Vicente por el grupo de tareas 3.3.2. de la Escuela de Mecánica de la Armada la noche del 25 de marzo de 1977.

Precisamente por la "aparición con vida" de su autor, pero también de este cuento y otros manuscritos secuestrados, Luisa Valenzuela, León Rozitchner, Rodrigo Fresán, Sylvia Iparraguirre, Luis Bruschtein, Leónidas Lamborghini, Liliana Herrero, Eduardo Blaustein, Osvaldo Bayer, Liliana Heker, Martín Caparrós, Arturo Carrera, David Viñas, Jorge Torres Zabaleta, Carlos Chernov, Gloria Pampillo, Guillermo Saccomanno, Juan Forn, Claudio Uriarte, Antonio Dal Masetto, Beatriz Sarlo, David Blaustein, Abelardo Castillo, Liliana Heer, Sergio Bizzio, Rogelio García Lupo, Paula Pérez Alonso, José Pablo Feinmann y Horacio Verbitsky acompañan el 22 de mayo de 1997 a Lilia Ferreyra en su presentación judicial a la Cámara Federal de Comodoro Py. La nómina de la delegación interesa porque en ella es patente la comunión generacional y estética lograda alrededor de Walsh y su literatura. Sobre este acto de apoyo corporativo el 23 de mayo de 1997 Carlos E. Feiling publica una breve reseña en "Radar", que será reproducida en Con toda intención ("Literatura militante").

El 21 de marzo de 1999, el n 136 de "Radar" tiene nuevamente como imagen de tapa una foto de Rodolfo Walsh, en la que éste aparece en traje de baño sentado en el muelle de "Lorelei" (la casa del Río Carapachay), con el cuerpo y el cabello chorreantes, fumando y mirando el río. El tema excluyente es la "Carta de un Escritor a la Junta Militar", y nuevamente es Lilia Ferreyra quien toma la palabra, en tanto testigo privilegiada del proceso de escritura. No obstante, se percibe un cambio de énfasis: 
Pocas semanas antes de cumplir los cincuenta años -había nacido el 9 de enero del '27- quiso definir dos apuestas para el 24 de marzo del '77, aniversario del primer año de gobierno de la Junta Militar: terminar el cuento "Juan se iba por el río" y difundir un documento que denunciara los crímenes de la dictadura $[\ldots]$

Pero esa carta, ¿debía tener un autor? [...] Rodolfo era un militante revolucionario, pero elige escribir la carta desde su lugar como intelectual y con su propia identidad. "Vuelvo a ser Rodolfo Walsh", dice. Y titula el texto “Carta de un Escritor a la Junta Militar”. (Ferreyra 1999: 5-6)

Por primera vez, Ferreyra se permite insistir sobre el carácter literario de "la escritura militante" de Walsh:

Después de varios borradores, fue encontrando el tono, el ritmo, la tensión de las frases. Con el café de la mañana o la ginebra de la tarde, declamaba en latín frases de las Catilinarias que había traducido minuciosamente en un cuaderno Avon. Quería trabajar ese estilo: "Como las invectivas latinas, la palabra escrita con la contundencia de la palabra oral”. (Op. Cit. Ferreyra 1999: 6)

Al año siguiente, se publica en Alianza Editorial Textos de y sobre Rodolfo Walsh, bajo la coordinación de Jorge Lafforgue. La antología de trabajos críticos reproduce las intervenciones publicadas originalmente en el número 12/ 13 (julio 1993-junio 1994) de Nuevo Texto Crítico (director Jorge Ruffinelli). La sección "Evocaciones y ubicaciones" contiene textos de Eduardo Galeano, Ricardo Piglia, David Viñas, Rogelio García Lupo y Horacio Verbitsky. ${ }^{187}$

En el apartado "Estudios, lecturas" aparecen como firmantes de trabajos especialmente escritos para la ocasión Pablo Alabarces, Víctor Pesce, Gonzalo Moisés Aguilar, Eduardo Romano, Elena Braceras, Cristina Leytour (en colaboración con Susana Pittella), John Kraniauskas, Martín Kohan, Bárbara Crespo, Roberto Ferro, Gloria Pampillo, Marta Urtasum y Rita de Grandis (en colaboración con Ana María Amar Sánchez). De las intervenciones, interesa especialmente la de Kohan (“Saer, Walsh: una discusión política en la literatura"), donde plantea -a partir de la publicación simultánea de Cicatrices y ¿Quién mató a Rosendo? en 1969- la relación entre ambos autores en términos antitéticos:

\footnotetext{
${ }^{187}$ Ya en 1985, Verbitsky había sentado las bases de una lectura política en Rodolfo Walsh y la prensa clandestina: 1976-1978, publicado en Ediciones de la Urraca. En 1992, Ana María Amar Sánchez publica en Beatriz Viterbo su tesis doctoral El relato de los hechos: Rodolfo Walsh: testimonio y escritura, indagación de la obra narrativa walshiana en términos de "experimentación con los géneros", con eje en la "novela de no ficción".
} 
De tal manera, Leto va constituyendo la contracara del periodista que narra en el texto de Walsh. Y por lo tanto, ampliando la perspectiva, todo Cicatrices puede ser pensado como sosteniendo un debate con ¿Quién mato a Rosendo? Es evidente que Juan José Saer tiende a cerrar a los textos sobre sí mismos y a situar a la literatura en una zona de autosuficiencia; no menos evidente, claro está, es que Rodolfo Walsh se vuelca al registro político. Pero ser dócil con la lectura que los textos desean y prefiguran implica postergar uno de los órdenes, el político o el literario, o bien someter a uno a la determinación vertical y unidireccional del otro. Se lee política o se lee literatura, y en la disyuntiva excluyente que así se plantea se diluye la posibilidad de leer el diálogo, horizontal, entrecruzado, múltiple, de doble circulación, de literatura y política. La categoría de representación es el punto de cruce o de pasaje de ambas lógicas: Saer aplica al cuestionamiento de la representación literaria para elaborar el cuestionamiento de la representación sindical; Walsh, en cambio, necesita ratificar toda certeza en lo que hace a la representación del discurso, para otorgarse una voz eficaz en la denuncia de la ilegitimidad de la representación de los sindicalistas. Uno y otro, dialogando entre sí, se plantean una misma cuestión: cómo discutir la política desde la literatura. (Kohan 2000: 128)

Contra la reivindicación de la escritura militante y/ o el "trabajo con lo géneros" que predomina en los Textos de y sobre Rodolfo Walsh, cuatro años más tarde David Viñas insistirá sobre el valor estético de la prosa walshiana. Entrevistado por Jorge Aulicino y Vicente Muleiro para la N. Revista de Cultura del sábado 26 de junio de 2004, aprovecha la ocasión para denunciar "el borgismo" en términos de "una sociedad anónima [...] señoras aseñoradas, que se encargan sistemáticamente de subrayar, que no sería tan grave como congelar, cristalizar, ese canon que tiene como epicentro la figura de Borges" (Viñas [2004]: 2013: 27).

Según Viñas, "el borgismo" tendría por objetivo "obliterar, congelar toda la situación de la producción literaria y cultural" y una de sus "víctimas" sería Rodolfo Walsh, rescatado únicamente por "ciertas zonas, desde lo que podríamos llamar frente cultural, popular, fundamentalmente peronista" (Ibid.). Contra esto, afirma provocativamente que "Walsh [...] trasciende a Borges [...] hasta le diría: es mejor que Borges" (Op. Cit. Viñas 2004 [2013]: 27). La oposición Borges-Walsh, resuelta en términos de calidad literaria a favor del segundo, será desarrollada por Ricardo Piglia en "El escritor como crítico", conferencia de cierre al VII Congreso Internacional Orbis Tertius "Estados de la cuestión" (18, 19 y 20 de mayo de 2009), organizado por el Centro de Estudios de Teoría y Crítica Literaria de la FAHCE/ UNLP.

En 2012 Ediciones de la Flor reedita La granada y La batalla (la primera edición en dicha editorial es de 1988), dos piezas que Walsh había publicado originalmente en 
1965 en la editorial Jorge Álvarez. (Es importante señalar que las obras también habían sido incluidas en el volumen Obra literaria completa, publicado en 1981 por Siglo XXI.) Por último, en el marco de la $39^{\circ}$ Feria del Libro de abril de 2013, se presenta una edición corregida y aumentada de los "Cuentos completos" de Walsh, con prólogo de Ricardo Piglia. Esta reedición rescata (hasta superar las 500 páginas) no sólo cuentos publicados en prensa periódica y nunca antes antologizados, sino también incluye el cuento inédito "Quiromancia", una carta a Donald Yates y dos entrevistas al autor, realizadas en la década del ' 70 .

La aparición de esta nueva versión de los "cuentos completos" es nota del tapa del $\mathrm{n}^{\circ} 498$ de $\tilde{N}$. Revista de Cultura correspondiente al 13 de abril de 2013. En su prólogo, Piglia termina de cerrar la lectura literaria de Walsh, subsumiendo la idea walshiana de eficacia a un imperativo de época:

Este volumen incluye los cuentos publicados por Rodolfo Walsh entre 1950 y 1968 . Permite por lo tanto seguir el itinerario de un escritor cuyas decisiones políticas (y en esto, su caso se parece al de Borges) han sido usadas muchas veces como marco demagógico de lecturas distorsionadas o triviales. Walsh era demasiado consciente de la particularidad de la ficción como para intentar definir su eficacia de un modo directo y explícito. Pero a la vez su conciencia de las exigencias sociales y la urgencia de la intervención política lo hicieron poner en cuestión rápidamente la autonomía del mundo literario y la figura del hombre de letras. (Piglia 2013: 9)

Hemos señalado el comienzo del segundo milenio como momento clave para delimitar el "tercer ciclo de canonización”, que involucra a César Aira, Alberto Laiseca, Luis Gusmán y Copi.

En el caso de Aira, la publicación en 2002 en Beatriz Viterbo de Las vueltas de César Aira significa la consolidación definitiva de la lectura en clave vanguardista de la poética airiana (y un límite argumentado y erudito frente a sus detractores, que gustaban de acusar al autor oriundo de Pringles de "posmoderno", como lo hace paradigmáticamente Tomás Eloy Martínez en el $\mathrm{n}^{\circ} 62$ de Crisis ya reseñado en el capítulo dos). Como también ya ha sido desarrollado en dicho capítulo, Contreras suma a su tarea exegética la labor editora: lanza en Beatriz Viterbo la "colección César Aira".

El coloquio internacional César Aira: un episodio en la literatura argentina del fin de siglo celebrado en Francia entre el 14 y 17 de mayo de 2004 y organizado conjuntamente por el grupo L.I.R.I.CO. (Julio Premat, Diego Vecchio, Graciela Villanueva, de la Universidad de París 8) y la Universidad Stendhal de Grenoble (donde 
trabaja el especialista en literatura argentina Michel Lafon, héroe de Fragmento de un diario en los Alpes, que Aira publica en Beatriz Viterbo en 2002), constituye indudablemente el hito en lo que hace a su proyección internacional. El coloquio es nota de tapa del n 345 de "Radarlibros" (13 de junio de 2004), que lleva el vanguardista título -que se lee a primera vista como un error tipográfico- de "MáquinAira". ${ }^{188}$

La reseña sobre lo ocurrido en el Coloquio que firma Alan Pauls se inaugura desestimando explícitamente la acusación de apresurado que podría hacérsele a este proceso de canonización:

¿Por qué Aira, a esta altura temprana del partido? Muchos blandieron la pregunta para neutralizar esos colores póstumos que suelen contraer los escritores tan pronto los roza la institución coloquio [...] A los 55 años, con la usina literaria funcionando a pleno y un contagio internacional que crece a pasos agigantados, Aira parece muy lejos del estado más o menos taxidérmico que exigen los coloquios para ser unipersonales. (Pauls 2004: 3)

Al mismo tiempo, Pauls alerta contra los peligros del epigonismo:

Aira está $[\ldots]$ en ese punto crítico en que el escritor empieza a confundirse con sus efectos, un punto inestable, ambivalente, en que los síntomas de la vitalidad [...] pueden volverse indistinguibles de peligros como la irradiación epigónica o la consolidación de un nuevo sentido común, excéntrico, problablemente, y saludablemente esquizo, pero tan homogéneo y omnívoro como cualquier otro. (Pauls 2004: 3)

A partir de 2008, Aira comienza a ser reeditado en la colección "Cruz del Sur" de Emecé/ Grupo Planeta (el primer título es La abeja, cuya primera edición en Emecé data de 1996). En 2012, es lanzada en Alfaguara (también parte del Grupo Planeta) la "Biblioteca César Aira", que se anuncia como la reedición de su obra narrativa completa (con excepción de La luz argentina). Si bien esto no es óbice para que Aira continue publicando en editoriales independientes (para dar un ejemplo: Yo era una mujer casada, publicada en Blatt y Ríos en 2010), interesa como índice del límite que habría

\footnotetext{
${ }^{188}$ Las actas de César Aira: un episodio en la literatura argentina del fin de siglo son publicadas en 2005 en la revista Tigre ( $\mathrm{n}^{\circ}$ 1: 1984-hoy) del Centre d' Études et de Recherches Hispaniques, dependiente de la Universidad Stendhal de Grenoble - Grenoble III. Dentro del conjunto destacan los aportes de Luis Chitarroni y Martín Kohan, que fueron antologizados respectivamente en los volúmenes Mil tazas de té (2008) y Fuga de materiales (2013), a los que volveremos a referirnos en el parágrafo 4.4.
} 
alcanzado su "colocación desviada -irónica- con la industria cultural cuando ésta ocupa un lugar central en la organización ficcional” (Montaldo 1998: 13).

El 16 de agosto de 2012 el diario Perfil publica las respuestas de Gabriela Bejerman, Mariano Blatt, Rafael Spregelburd, Quintín, Leandro Ávalos Blacha, Patricio Pron, Selva Almada, Inés Acevedo, Virginia Cosin, Luis Chitarroni, Carlos Ríos, Damián Tabarovsky, Juan Terranova, Rafael Cippolini, Ariel Idez, Ricardo Strafacce, Cucurto y Ramiro Quintana a la pregunta planteada por la publicación de "cuál es, según criterios estéticos, la mejor novela de Aira y por qué”. El arranque del copete que presenta los resultados de la encuesta no deja lugar a ambigüedades: "César Aira está considerado el mejor escritor de la actual escena literaria en Argentina".

Más allá de algún resultado inesperado (Cucurto y Chitarroni coinciden en señalar -por razones harto diferentes- Los fantasmas como la mejor novela airiana), interesa reparar en algunas ausencias notorias: no responden (¿no fueron convocados?) Sandra Contreras, Graciela Speranza y Alan Pauls, de indudable peso en la recepción del autor oriundo de Coronel Pringles.

El sábado 15 de junio de 2013, con motivo de la publicación simultánea en Mondadori de sus Relatos reunidos (selección de cuentos escritos entre 1996 y 2001) y Los fantasmas, Aira es nota de tapa del $\mathrm{n}^{\circ} 507$ de $\tilde{N}$. Revista de Cultura. El título elegido no puede ser más explícito: “Un nuevo clásico argentino. César Aira, la máquina de escribir". Sobre el significado de la publicación de los Relatos reunidos escriben sendas notas Martín Kohan ("Fuga y misterio de César Aira”), Maximiliano Crespi (“La era de la dispersión”) y Flavio Lo Presti (“El destino insular”. De las tres, la de Kohan es la nota más extensa y la que plantea la canonización del autor como una cuestión cerrada:

Sus novelas hacen eso: comienzan en lo cualquiera y derivan hacia lo excepcional. Hasta fundir una cosa con la otra: esas novelas, contingentes, tocan a la vez algo del orden de lo imprescindible; al disponerse en forma de serie, derivan hacia lo fuera de serie. Cada una de esas novelas puede gustar o no gustar, leerse o saltearse, atesorarse u olvidarse; la desmesura de la obra genial hace de cualquiera de ellas una obra maestra eventual. (Kohan 2013b: 7)

Por último, en agosto de 2014, Leila Guerriero, editora de la colección "Huellas" de Ediciones Universidad Diego Portales de Chile, publica Continuación de ideas diversas (a cuidado de Andrés Braithwaite), que -en palabras de Aira- pretende ser "un 
volumen facetado, un 'cadáver exquisito' 3D, que también quiere ser un tablero de juego, y un retrato". El libro, construido mediante la aleación de fragmentos breves que giran sobre una determinada intuición crítica, exhibe entre sus preocupaciones recurrentes la pregunta por la factibilidad de un arte vanguardista y el género novela. Esta compilación confirma lo que ya sospechábamos: bajo la fachada de sus "novelitas", Aira es el más borgiano de sus contemporáneos, un artista con un grado altísimo de autoconsciencia en lo que hace a su proyecto escriturario y a su (posible) lugar en la tradición literaria.

El año 2011 puede ser considerado clave en el proceso de canonización del autor de Los Sorias, porque es entonces cuando se publican en Simurg sus Cuentos completos, que superan las 600 páginas.

La publicación es nota de tapa del n 399 de $\tilde{N}$. Revista de Cultura (21 de mayo de 2011), bajo el título general de "El delirio serio de Laiseca". Los materiales incluyen una entrevista al autor realizada por Gabriela Cabezón Cámara ("El alquimista del delirio"); las columnas de opinión "El milagro Laiseca", que firma César Aira y "Un inédito en pantalla" (sobre su relación con el cine), de Ezequiel Boetti, y "La historia de un libro legendario" (sobre Los Sorias), de Alejandra Zina. Esta última intervención hipotetiza sobre el destino de "long seller" de Laiseca, en tanto "tiene una cantidad de lectores creciente, ocultos quizá para la prensa y los críticos especializados [...] lecturas silenciosas que erosionan el tiempo exprés de las novedades" (Zina 2011: 9). También en mayo de 2011 se estrena la película Querida, voy a comprar cigarrillos y vuelvo (adaptación cinematográfica de un cuento inédito del autor, co-dirigida por Gastón Duprat y Mariano Cohn: el primero oficia de guionista), en la cual Laiseca asume un rol preponderante como narrador en off. ${ }^{189}$

En 2013 Le nouvel Attila publica la traducción al francés -por Antonio Werli- de Aventuras de un novelista atonal. (Vale destacar que, hasta el momento, Laiseca sólo había sido traducido al francés por La Guêpe Cartonnière -editorial francesa que toma como inspiración nuestra Eloísa Cartonera-. ${ }^{190}$ ) La traducción francesa de Aventuras de

\footnotetext{
${ }^{189}$ El 28 de mayo de 2009, Gastón Duprat y Mariano Cohn habían estrenado El artista, donde Laiseca -junto a Fogwill, Horacio González y León Ferrari- asumía funciones como actor. Un año más tarde, el autor de Los Sorias publicaría en Mondadori El artista, adaptación libre de la película homónima.

${ }^{190}$ La Guêpe Cartonnière, fundada en abril de 2010 por los escritores Guillermo Bravo, Jorge Harmodio y Mailyn Baudeneau, publica en su primer año de vida a los autores Pedro Mairal (Consumidor final: poemas en edición bilingüe), Jorge Harmodio (Musophobie: novelas cortas), Dani Umpi (Niño rico:
} 
un novelista atonal ostentará un lugar importante en el Salón del Libro de París Edición 2014, que ya hemos señalado tiene como invitada de honor a la Argentina.

En octubre de 2013, la revista El Ansia (director: José María Brindisi) dedica su número inaugural a Marcelo Cohen, Hernán Ronsino y Alberto Laiseca. El 15 de marzo de 2014, el autor de Los Sorias vuelve a ser tapa de N. Revista de Cultura con una extensa entrevista realizada por Diego Erlán (“El desparpajo sin límites”). En la misma, Laiseca continúa perfeccionándose en la enunciación de un nuevo mito: su novela en obra sobre la guerra de Vietnam, titulada La puerta del viento. Por último, el 5 de junio del mismo año, Simurg presenta su segunda edición de Los Sorias, con un tiraje de 1500 ejemplares, lo que representa un interesante contraste respecto a la primera edición-arte realizada en 1998, con un tiraje de apenas 350.

(Si bien destacamos la labor editora de Gastón Gallo, no es menor la importancia de Gárgola Ediciones, que en el año 2004 había sacado a la calle una reedición corregida de la monumental obra con un tiraje de 1500 ejemplares, y en 2006 publicado Sí soy mala poeta, pero... Entre 2004 y 2013 se reeditaron en Gárgola: Matando enanos a garrotazos, Poemas chinos y El jardín de las máquinas parlantes.)

Tal como lo afirma en la entrevista que le realiza Javier Alemián con motivo de la publicación de La casa del dios oculto (que es tema de tapa de la N. Revista de Cultura correspondiente al 31 de marzo de 2012) Luis Gusmán había participado de la “circulación prestigiosa" de Nanina y El fiord (Gusmán [Entrevistado por Javier Alemián] 2012: 6). No obstante, su impacto siempre fue más módico que el de -para decir una obviedad- Osvaldo Lamborghini. O bien se lo consideró como parte de un colectivo (los literalistas), o bien se lo leyó a la sombra de otro escritor más prestigioso, como es el caso en el artículo académico "El significado latente en Respiración artificial de Ricardo Piglia y En el corazón de junio de Luis Gumán” que publica Daniel Balderston en la antología Ficción y política. La narrativa argentina durante el proceso militar.

No obstante lo dicho, la centralidad que ostenta Villa (1995) en las lecturas de las memorias en y de la literatura que realizan María Teresa Gramuglio (2002) y Dalmaroni ([2003] 2004) a las que ya hemos referencia en el marco del capítulo uno, podría pensarse como un primer punto de inflexión en la recepción académica de la obra de 
Gusmán, que tiene su hito en el año 2004 con la publicación de Escrito por otros. Ensayos sobre los libros de Luis Gusmán, compilación de reseñas críticas y artículos académicos que abarcan tres décadas: desde la reseña a El frasquito firmada por Oscar Steimberg en marzo-abril de 1973 para Los libros hasta tres trabajos redactados especialmente para el volumen: "Antes y después de Frankie”, de Fernando Fagnani; “Luis Gusmán. Trágicos clamores”, de Antonio Oviedo y “ 'A ver si nos entendemos...' Política(s) de la poética en La ficción calculada (sin otros ensayos)", de Eduardo Grüner. Es de destacar que los trabajos que constituyen Escrito por los otros no están ordenados cronológicamente (si bien a pie de página se aclara su primitivo lugar y fecha de edición) y que Daniel Link es el único de los firmantes que ostenta dos aportes: la reproducción de "Luis Gusmán, la realidad y sus parientes" (resultado de una amalgama de tres artículos diferentes: dos de ellos publicados en 1985, que a su vez habían confluido en una tercera versión para el libro La chancha con cadenas, antología de viejos trabajos críticos que aparece en 1994) y una nota publicada originariamente el 12 de julio de 1999 en "Radarlibros", que toma las funciones de epílogo ("La soledad").

En esta última nota Link señala la necesidad de "trazar un mapa" de la literatura argentina, donde se le otorgue a Gusmán (confinado -según sus palabras- a "la soledad del estilista, la soledad del tímido") el lugar que se merece.

El 9 de marzo de 2003, la reedición de El frasquito en Norma es nota de tapa de "Radarlibros". El comentario (firmado por Luis Chitarroni y reproducido en Escrito por otros) enfatiza "la juventud del libro, su candor e irreverencia inimitables" (Chitarroni [2003] 2004: 23). Al año siguiente, Norma reedita Hotel Edén (la primera edición, también en Norma, es de 1999). En 2005, Gusmán publica en Norma Epitafios: el derecho a la muerte escrita, donde da la clave de lectura de Ni muerto has perdido tu nombre (publicado en 2002 en Sudamericana, será reeditado diez años después en Edhasa). En 2006 Gusmán "se muda" a Edhasa, donde comienza reeditando Villa. Es también en Edhasa donde en 2013 se reedita El frasquito (con prólogo de Chitarroni y contratapa de Oscar Masotta) con una portada que reproduce, en miniatura, la tapa de la primera edición en Ediciones Noé. En 2014, Gusmán reedita Brillos en el nuevo sello editorial Cienvolando, que se inaugura precisamente con la reedición de este título y de Variaciones de la luz, de Diana Bellesi. El mismo año, Gusmán publica los libros de ensayo Kafkas y La valija de Frankenstein, en Edhasa. 
Por último, la elección del autor de El frasquito para inaugurar la $38^{\circ}$ edición de la Feria Internacional del Libro de Buenos Aires (19 de abril de 2012) podría considerarse también como un importante índice -en términos institucionales- de su consagración.

Raúl Natalio Roque Damonte Botana (Copi), como Gusmán, tendría un primer ingreso en el canon por efecto arrastre, acoplado al "mito Laiseca". En su reseña "Las aventuras de la Escuela de Viena" publicada en Vigencia en 1982, Rodolfo Fogwill evalúa El uruguayo en los mismos términos ensalzatorios que Aventuras de un Novelista Atonal, para terminar hipotetizando que tanto Laiseca como Copi participarían de una idéntica "revolución vienesa de la literatura" (Fogwill [1982] 2010: 105). (El adjetivo "vienesa" remite aquí al dodecafonismo del compositor nacido en la capital de Austria Arnold Schönberg, y pide ser entendido como sinónimo de "vanguardista".)

Con motivo de su muerte el 15 de diciembre de 1987, Copi es objeto del suplemento "Culturas" correspondiente al 20 de diciembre de 1987, entonces bajo la dirección de Martín Caparrós y Jorge Dorio. (La nota, titulada "Locas por Copi”, lleva la firma de María Moreno, y también se publican viñetas de La mujer sentada y un fragmento del cuento "Virginia Wolf ataca de nuevo".) César Aira tiene un rol destacado en este proceso de consagración con su libro Copi, originalmente una serie de cuatro clases impartidas durante el mes de junio de 1988 en el Centro Cultural Ricardo Rojas (“Como leer a Copi”), que publica Beatriz Viterbo Editora en 1991.

A comienzos de los noventa se realizan las primeras puestas porteñas de sus obras teatrales: La noche de la rata (año 1991 en el Teatro Payró, con la dirección de Maricarmen Arnó); Una visita inoportuna (año 1992 en el Teatro San Martín, con la misma directora) y Las viejas putas (1994 en el Centro Cultural Ricardo Rojas, con la dirección de Miguel Pittier). En el año 2000, Adriana Hidalgo da a conocer Eva Perón, con traducción de Jorge Monteleone. De 2004 son las puestas en escena de dos versiones de Eva Perón en Buenos Aires (hubo una anterior en Tandil) presentadas en el marco del encuentro Tintas Frescas: la versión "nacional" (en castellano), dirigida por Gabo Correa y con la actriz Alejandra Flechner en el protagónico, y la versión francesa, dirigida e interpretada por Marcial di Fonzo Bo, argentino residente en París desde 1987 y sobrino de Facundo Bo, integrante del mítico grupo TSE liderado por Alfredo Arias, 
que había realizado el estreno mundial de la obra en 1970 en el Théâtre de L' Épée de Bois, de París.

Otro hito en la historia de las puestas en escena de las obras de Copi es la representación en septiembre de 2001 de Una visita inoportuna en La Comédie Fançaise. (Copi se constituye así en el primer dramaturgo argentino en formar parte del repertorio de la emblemática compañía.) En suelo local, sobresale el estreno en noviembre de 2012 de la versión operística de Cachafaz. Tragedia bárbara (con música de Oscar Strasnoy) en el Teatro San Martín de Buenos Aires: la puesta es de Pablo Maritano y la dirección musical, de Pierre Roullier. ${ }^{191}$

Tal como señala Daniel Link en su artículo “1988”, antologizado dentro del volumen Fantasmas, imaginación y sociedad (2009), Copi no es "un argentino en París", sino "un argentino de París" (énfasis en el original), por lo que la labor editora -aunque por razones diferentes a las esgrimidas en el caso de Osvaldo Lamborghiniresulta fundamental para explicar el lugar que ocuparía hoy Damonte Botana en el canon literario. Puesto que Copi escribió -excepto las obras teatrales Cachafaz y La sombra de Wenceslao y, y la novela La vida es un tango- en francés, la instancia de la traducción se presenta como decisiva.

En 1978, la editorial Anagrama publica en su colección "Contraseñas" El baile de las locas y Las viejas travestis y otras infamias seguido de El Uruguayo. En 1981, La vida es un tango. En 1982, Las viejas putas. En 1984, el volumen de cuentos Virginia Wolf ataca de nuevo. En 1989, La Internacional Argentina. Las traducciones son realizadas al español peninsular, por -entre otros- los escritores Enrique Vila-Matas y Alberto Cardín. En 2010, ahora en la colección “Otra vuelta de tuerca”, Anagrama saca el primer tomo de sus Obras, con prólogo de María Moreno, donde se recogen tres novelas: El uruguayo, La vida es un tango y La Internacional Argentina, a las que suma un texto autobiográfico inédito de Copi: "Río de la Plata". En su "Prólogo", Moreno enfatiza el carácter marginal de su literatura:

Copi es considerado un autor de elite. Habrá que escucharlo recitar las marcas populares que declara: Oski, cronista de una fantástica fundación de Buenos Aires dibujada; Carlos Warnes, el irreverente autor de otro autor; César Bruto, a su vez autor de textos como Esplicasiones de una Señora que

${ }^{191}$ Cachafaz ya había sido estrenada en Quimper, Francia, el 5 de noviembre de 2010, con puesta de Benjamin Lazar y dirección musical de Geoffroy Jourdain. 
sescapa con otro (“¡Adiós negro, no mechés la culpa de nada y pensá que todo lo hago para que triunfés con una canción en contra mía..! ¡Ha, y apurate que te van a desalojar antes del 30!”), y donde la incorrección ortográfica es sólo la forma de una incorrección de sentido. (Moreno 2010: 10)

En 2002, Adriana Hidalgo saca en un mismo volumen Cachafaz y La sombra de Wenceslao. En 2009, la editorial El Cuenco de Plata publica La ciudad de las ratas, haciendo accesible en castellano rioplatense la única novela de Copi que quedaba por traducir. La traducción es realizada por Guadalupe Marando, Eduardo Muslip y María Silva. Al año siguiente, publica La guerra de las mariconas. En 2011, Teatro 1, que reúne cuatro piezas de Copi en traducciones argentinas: El día de una soñadora, La torre de la Defensa, La noche de Madame Lucienne y Una visita inoportuna. En el año 2012 confluyen varias inicitativas editoriales: El Cuenco de Plata publica Teatro 2 (con Loretta Strong, ;La pirámide!, La heladera y Las escaleras del Sacré-Coeur) y la editorial Mansalva, junto a Santiago Arcos, hace lo propio con Tango-Charter (escrita en italiano por Copi y en supuesta coautoría con Ricardo Reim). Finalizando el año, El Cuenco de Plata reedita el cómic Los pollos no tienen sillas, que ya había sido traducido al español por el propio autor para la edición en 1968 en la editorial de Jorge Álvarez. En 2013, también en El Cuenco de Plata, aparece La mujer sentada.

Si la publicación de un tomo que tenga a un autor determinado como objeto de estudio exclusivo es uno de los posibles índices de su consagración, en el caso de Copi los estudios publicados en nuestro país son escasos y de extensión breve. En 1998 José Tcherkaski publica en Galerna Habla Copi: homosexualidad y creación. En 2001, El pase del testigo, de Edgardo Cozarinsky, incluye la evocación "Copi: tres instantáneas y una posdata", también fechado en 1998. Dos años más tarde, aparece Copi: sexo y teatralidad, de Marcos Rosenzvaig. Entre 2010 y 2014, Daniel Link (que tiene un importante rol como divulgador de la obra y figura de Copi en la prensa escrita) imparte seminarios de doctorado sobre Copi: en la Universidad de Buenos Aires ("Copi: modos de la acción literaria") y en la Universidad Nacional de Rosario ("La vida según Copi”), y anuncia la pronta publicación de un estudio de largo aliento sobre el autor. Si bien parece exagerado afirmar que Copi es aún hoy más reconocido en Francia e Italia que 
en Argentina, la publicación en 2008 del tomo monográfico Il teatro inopportuno di Copi (comp. Stefano Casi), es por demás destacable. ${ }^{192}$

En el caso de Rodolfo Fogwill, su rol pionero en los procesos de divulgación y/ o canonización de deteminados escritores fue esgrimido por él mismo como uno de sus principales méritos literarios. En 1998, en el "Retrato" que escribe con motivo de la publicación por Mondadori en España de su obra reunida, señala que "publicar a Leónidas Lamborghini, dar a conocer las obras de Néstor Perlongher y Osvaldo Lamborghini como editor y haber orientado como comentarista la lectura de Viel Temperley y Carrera entre los poetas [...] son los únicos aportes a la literatura argentina que reivindico" ([1998] 2010: 28). Sobre su papel a comienzos de los ochenta como reseñista del manuscrito inédito de Los Sorias y principal constructor de "el mito Laiseca" ya hemos hecho referencia en el capítulo dos.

Al respecto, constituye un hito consagratorio indudable la publicación en 2008 de Los libros de la guerra, antología que consta de "la mitad de mis intervenciones de prensa [...] a lo largo de veinticinco años" (Fogwill [2008] 2010: 7). ${ }^{193}$ El volumen, realizado bajo el cuidado del editor Francisco Garamona, Javier Barilaro y Laura Crespi, presenta el material según un ordenamiento temático, aunque de cada artículo se especifica fecha y lugar de su primera publicación. Los artículos reunidos en la sección "Los libros" apoyan la idea de una importante participación por parte del autor de Los pichiciegos en los cuatro procesos de canonización aquí hipotetizados (porque Fogwill, además, fue el principal agente de su propia consagración).

Sobre los hitos editoriales en lo que hace a la divulgación de su obra narrativa, cabe destacar el año 2006, cuando InterZona reedita Los pichiciegos. (La primera reedición, en Sudamericana, data de 1994.) El acontecimiento es nota de tapa del $n^{\circ} 130$ de $\tilde{N}$. Revista de Cultura correspondiente al sábado 25 de marzo de 2006, con una entrevista exclusiva realizada por Martín Kohan que lleva el significativo (y malévolo, por su alusión a Roa Bastos) título de Yo el supremo, y en cuyo marco Fogwill se

\footnotetext{
${ }^{192}$ El interés por Copi tiene su correlato lógico en la temprana traducción del autor al italiano. En 1988, la editorial Ubulibri de Milán publica el extenso tomo Teatro/ Copi, que consta de: La giornata di una sognatrice, Eva Peron, L'omosessuale o la difficolta di esprimersi, Le quattro gemelle, Loretta Strong, La Piramide, La Torre della Defense, Il frigo, La notte di madame Lucienne, Le scale del Sacre Cuore y Una visita inopportuna.

${ }^{193}$ Los libros de la guerra es reeditado en 2010, con un segundo prólogo firmado por el autor donde éste señala que ha agregado catorce textos a la compilación original.
} 
despacha contra El pasado, de Alan Pauls (“yo escribo mejor que él”) y "el lobby del Holocausto" (su entrevistador, recordemos, es judío).

En el año 2009, Alfaguara publica Cuentos Completos, que compila veintiún cuentos escritos por Fogwill entre la década del setenta y la primera década del siglo XXI, con un muy breve prólogo de Elvio. E. Gandolfo. El mismo año, la editorial El Ateneo (parte del Grupo ILHSA S. A., propietario de Librerías Yenny, Librerías El Ateneo y Tematika.com) reedita por primera vez (a una década de su pimera edición) Vivir afuera. Al año siguiente, Los pichiciegos.

Fogwill muere el 21 de agosto de 2010, y sus restos son velados en la Biblioteca Nacional. El conjunto de sus manuscritos, notas y papeles personales, y los volúmenes de su biblioteca personal son tomados en guarda para su catalogación por el Museo de Arte Latinoamericano de Buenos Aires (MALBA), cuyo director, Eduardo Constantini, era amigo personal del escritor. En septiembre, la editorial alemana Rowohlt publica Los pichiciegos bajo el título de Die unterirdische Schlacht [La batalla subterránea], con traducción de Dagmar Ploetz. ${ }^{194}$

A tres años de su muerte, en septiembre de 2013, se celebran en Biblioteca Nacional las "Jornadas Fogwill”, que pueden considerarse un hito en lo que hace a la consagración académica del autor. En la sección "Música y poesía”, que rescata al Fogwill poeta y editor de poesía, leen trabajos Martín Gambarotta, Silvio Mattoni, Damián Ríos y Pablo Gianera. Los integrantes de las mesas "El efecto de realidad" (el miércoles 18 de septiembre, conformada por Hernán Vanoli, Gustavo Ferreya y María Pía López) y "Sobre el arte de la novela" (el jueves 19, conformada por Graciela Speranza, Carlos Gamerro, Cecilia Sperzling y -aunque finalmente no concurre- Alan Pauls) se dedican a dilucidar la importancia de su legado como novelista, con la excepción de Sperzling, que realiza una aproximación a La ventana de los sueños, publicada en abril por Alfaguara (entonces parte del grupo PRISA).

Del conjunto de las intervenciones sobresalen la de María Pía López ("La novela de clases"), que intenta dilucidar en términos no anecdóticos la gravitación de la formación sociológica del autor en su universo narrativo, y la de Graciela Speranza ("Fogwill en Las Vegas: La experiencia sensible"), que a partir del señalamiento de una

\footnotetext{
${ }^{194}$ En 2007, la novela había sido traducida al inglés por Nick Caistor y Amanda Hopkinson y publicada en la editorial Serpent's Tail con el título de Malvinas Requiem.
} 
“cita gráfica" entre la tapa de la primera edición de El fiord (1969) y la de la primera edición de La experiencia sensible (2001), continúa hipotetizando sobre la peculiar relación de Fogwill con la estética realista presente en la trilogía novelesca $L a$ experiencia sensible, En otro orden de cosas y Urbana. ${ }^{195}$

La ventana de los sueños, libro que organiza una serie de cuadernos con registros oníricos que el autor había entregado en vida al colectivo de artistas plásticos Mondongo, es la punta de lanza del proceso de reedición de la totalidad de la obra de Fogwill en Alfaguara. En agosto de 2013, este sello reedita La buena nueva de los Libros del Caminante. En noviembre del mismo año, Una pálida historia de amor. En mayo de 2014, la misma editorial (ya para entonces parte de Penguin Random House del Grupo Bertelsmann) publica Nuestro modo de vida, novela inédita cuyo manuscrito data del año 1981. Por último, el 26 de mayo de 2014 se presenta en la Biblioteca Nacional Fogwill, una memoria coral, conjunto de testimonios de amigos, colegas, editores y discípulos de Fogwill, compilados por Patricio Zunini (administrador del blog de Eterna Cadencia) y que publica Mansalva. En dicho marco, también se anuncian dos biografías, encomendadas a María Moreno y Diego Erlán, y la pronta publicación de una segunda novela inédita, La introducción.

La autobiografía hiperliteraria La arquitectura del fantasma, de Héctor Libertella, publicada post mortem en octubre de 2006 en Santiago Arcos, impresiona como un abandono parcial por parte de su autor de la práctica estricta de la "pasión hermética" (la expresión es de Martín Kohan) para faciliar -mediante una serie de "claves de lectura"- el abordaje de la propia producción. En el mismo sentido de la traducibilidad, el mismo año aparecen Diario de la rabia (Beatriz Viterbo) y El lugar que no está ahí (Losada), reescrituras de relatos contenidos en ;Cavernícolas! (1985). La publicación de la autobiografía fimada por Libertella es nota de tapa del suplemento "Radarlibros" correspondiente al 25 de febrero de 2007, que firma Osvaldo Aguirre y que lleva el título de "Memorias de un escritor raro". En la reseña que escribe Alan Pauls sobre La arquitectura del fantasma para el $\mathrm{n}^{\mathrm{o}} 12$ de Otra Parte (primavera de 2007), se la describe $-\mathrm{y}$ no podemos menor que coincidir- como espacio de sedimentación de una autoimagen novedosa: el "autor precoz" (http://www.revistaotraparte.com/n\%C2\%BA12-primavera-2007/incorregible, consultado el 23.5.2013). En el mismo número de Otra

\footnotetext{
${ }^{195}$ Sobre esta relación, Speranza ya había publicado el trabajo "Magias parciales del realismo" en el no 2 de la revista milpalabras (Verano de 2001).
} 
Parte, se publica el texto "La firma", de Tamara Kamenszain, que será parte del volumen El efecto Libertella, compilado por Marcelo Damiani y publicado en Beatriz Viterbo tres años más tarde. También se reproducirá allí la reseña de Pauls.

Soslayando la publicación de Mis escritores muertos (Mansalva 2008), de Daniel Guebel, una intervención más sentimental que académica sobre Jorge Di Paola Levín y Héctor Libertella, los firmantes de El efecto Libertella -con excepción de las semblanzas de la amistad que firman César Aira (sin título) y Ricardo Strafacce ("Arena de verdad”), el relato de Ariel Idez (“Crónica de un instante”), el texto de Kamenszain y el relato sobre los avatares del pasaje al inglés de "Nínive" del traductor Jeremy Munray-, persiguen dar razones objetivas para defender el importante lugar que tendría el autor de El camino de los hiperbóreos en las letras argentinas. Tal como señala Damiani en el "Prólogo":

... durante bastante tiempo (alrededor de veinte o treinta años), Libertella fue una suerte de código o clave secreta del sentido y del afán literario argentino. No obstante, como suele pasar en estos casos, muy pocos sabían realmente cuáles eran los algoritmos de ese código misterioso, y menos aún los que podían explicarlos, aunque muchos insinuaran conocerlos. Este libro es un intento de reunir a algunos de ellos en torno de este fantasma literario. (Damiani 2010: 14)

El aporte de Martín Kohan ("La pasión hermética del crítico a destiempo") es el que con mayor afán didáctico pretende dilucidar la poética libertelliana. Lo hace aclarando cuál sería el concepto de "vanguardia" propugnado por el autor. Dentro de la antología, sorprende que sólo en un trabajo ("Teoría de la caverna. Los restos de un futuro que vuelve”, que firma Raúl Antelo) se mencione el vínculo de Libertella con la llamada "generación literal". 196

En el año 2011, Mansalva publica los relatos de A la santidad de los juegos de azar, que es elegido "libro del año" en la categoría "narrativa argentina" en la encuesta "Los libros que marcaron el año" que realiza la redacción de $\tilde{N}$. Revista de Cultura y cuyos resultados son nota de tapa del $n^{\circ} 431$ de la publicación. El comentario de Maximiliano Crespi sobre este resultado contrapone -a favor de la primera- la poética libertelliana a la de Manuel Puig dando las siguientes razones:

... en la literatura libertelliana el objeto a desmitificar no son los discursos sino el lenguaje mismo. La literatura libertelliana empieza donde termina la de Puig. De allí el desencuentro irremediable con la ilusión que ciñe la imaginación etnográfica actual, apoyada en una lectura sesgada y pobretona de

\footnotetext{
${ }^{196}$ Recordemos que en 2002 Libertella había prologado y anotado la antología Literal (1973-1977) para Santiago Arcos editor.
} 
Puig donde los discursos sociales adquieren raudamente la testarudez del referente. Libertella no denuncia la cristalización ideológica, la costra sedimentada de los discursos [...] Los textos que componen este libro dan cuenta de una escritura cuyo deseo es plenamente paragramatical: burlar el significado de la ley, el padre, lo reprimido; es decir: escribir a merced de lo múltiple, de lo plural, de lo ambiguo. (Crespi 2011:6)

Los días 29 y 30 octubre de 2013, por iniciativa del Instituto de Literatura Latinoamericana de la Universidad de Buenos Aires, son objeto de discusión los legados literarios de Héctor Libertella y Osvaldo Lamborghini en la Biblioteca Nacional y en el Museo MALBA en el marco de las Jornadas Libertella/ Lamborghini. De los expositores, sólo Luis Gusmán se atreve a objetar con energía la pertinencia de analizar ambos autores en paralelo (algo que parecía estar implícito en el título mismo del evento, pero que sólo llevan a cabo Laura Estrín y Esteban Prado en el marco de la mesa de discusión "Libertella, Lamborghini, la vida y la literatura", y Germán García en su conferencia -de fuertes tintes autobiográficos- "Libertella, Lamborghini, en el mar de los nombres propios"). Tanto Damián Tabarovsky (en "La vanguardia del caballo de Troya") como Ricardo Strafacce (en "Nueva escritura en Latinoamérica: la doble pasión de Lamborghini”) aprovechan este espacio institucional de enunciación para volver a hipótesis de lectura ya presentes en, respectivamente, Literatura de izquierda y Osvaldo Lamborghini. Una biografía.

Del conjunto se destaca la ponencia de Rafael Cippolini (albacea del escritor), que incluye la exhibición del "plan general" de la obra libertelliana y de algunos de los míticos ejemplares blancos autoeditados por Libertella en su permanente proceso de reescritura y cedidos como "don" a sus amigos, porque precisamente alerta sobre la existencia de una masa textual que superaría por amplio margen la obra hasta el momento publicada.

En 2013, Mauro Libertella publica en Mansalva Mi libro enterrado, testimonio del deterioro de su padre a causa del alcoholismo y largo relato de su agonía, suerte de reverso de La arquitectura del fantasma y mentís a aquéllos que, como Aira en El efecto Libertella, quisieron edificar un mito de autor en términos de "el último bohemio".

En marzo del año siguiente, Ricardo Piglia incluye ¡Cavernícolas! en la Serie de Recienvenido (cuyas características generales y línea editorial son reseñadas en el marco del parágrafo 4.6.), en cuyo prólogo propone otra imagen de escritor: "Como 
Borges o Calvino, Libertella es un escritor conceptual; no distingue crítica y ficción, escribe para pensar; entrevera lo que sabe con lo que sueña y postula una intensa poética de la literatura" (2014: 12).

Esta analogía con Jorge Luis Borges en boca de Piglia podría ser tomada como otro hito en el proceso de consagración del autor de El camino de los hiperbóreos, sobre cuya "poética de la literatura" volveremos en detalle en el parágrafo 4.3.

\subsection{Divergentes "memorias de la literatura II": tres historias recientes de la literatura}

En el año 2000, Elsa Drucaroff firma como compiladora del onceavo tomo de la Historia Crítica de la Literatura Argentina, anteúltimo de los doce volúmenes que conforman la serie, aunque el segundo en ser publicado. Coherentemente con el planteo general de la obra, que intenta despegarse de un ordenamiento cronológico y organizar los tomos alrededor de problemas (y no ya según cortes temporales), el volumen once gira alrededor del "triunfo de la narración". En el prólogo, Drucaroff justifica el título del volumen (La narración gana la partida) de la siguiente forma:

Hay un período, entonces, que habría comenzado hacia la segunda mitad de los sesenta, se volvió intenso durante los setenta y sin duda mantiene efectos fuertes hasta ahora, en el que la narración se impuso con una legitimidad particular, adquirió un prestigio específico en un imaginario de expectativas ligadas a una gran expansión de la escritura y a una no menos fuerte problematización de la lectura [...] Hacer "la" novela, no "una" novela (y no por ejemplo poesía), fue durante los setenta casi una cifra de lo que definía a un “(verdadero) gran escritor”. (Drucaroff 2000: 8)

La compiladora da dos razones para explicar por qué la narración ganaría la partida: el prestigio intrínseco al género novelístico (que tendría su punto cúlmine en los años setenta) y la presión del mercado editorial. El punto más alto de confluencia de ambos factores se habría dado con el "Boom" latinoamericano: a ésta y otras cuestiones dedica Horacio González su trabajo "El boom: Rastros de una palabra en la narrativa y la crítica argentina", también incluido en el tomo.

Dentro de La narración gana la partida, los únicos tres autores que son merecedores de artículos extensos son Manuel Puig ("Manuel Puig y la narración infinita”, que firma José Amícola); Juan José Saer (“ 'Un azar convertido en don'. Juan José Saer y el relato de la perecepción”, que firman Miguel Dalmaroni y Margarita 
Merbilháa) y Ricardo Piglia (“Un debate de poéticas. Las narraciones de Ricardo Piglia”, que firma el cubano Jorge Fornet).

Si bien hay otros dos artículos que toman como corpus de análisis las novelísticas de Osvaldo Soriano y Tomás Eloy Martínez (“Absurdo y derrota. Literatura y política en la narrativa de Osvaldo Soriano y Tomás Eloy Martínez”, que firman Claudia Román y Silvia Santamaría) y las narrativas de Luisa Valenzuela, Elvio E. Gandolfo y Angélica Gorodischer ("Típicas atracciones genéricas: fantástico y ciencia ficción”, que firma Sandra Gasparini), es importante destacar que los tres únicos autores que son objeto de estudio exclusivo y de los que se da cuenta de la totalidad de su obra hasta entonces édita, son Manuel Puig, Juan José Saer y Ricardo Piglia. ${ }^{197}$

En su artículo sobre Puig incluido en La narración gana la partida, José Amícola centra su análisis en una política de la diferencia sexual, tomando como eje la figura de la doctora de origen dinamarqués “Anneli Taube", que Puig inventaría para mejor desestabilizar los discursos médicos sobre la homosexualidad desplegados a nota al pie en El beso de la mujer araña. La lectura que hace Amícola de Manuel Puig en términos de "lo personal es político" se terminará de consolidar cinco años después en su aporte para la edición crítico-genética de El beso de la mujer araña ya mencionada.

El artículo que firman Miguel Dalmaroni y Margarita Merbilháa sobre Juan José Saer para el onceavo tomo compilado por Drucaroff coincide en colocar el foco en la peculiar manera en que "lo político" ingresa en la obra del autor santafesino. De manera concordante con los lineamientos generales desarrollados por María Teresa Gramuglio en su pionero "El lugar de Saer" (1986), los autores sostienen que:

... su tratamiento de la historia política, o su actitud frente a ella, consiste en un modo de significar los hechos desde un borramiento de los límites entre sujeto y mundo. Lo histórico, entonces, puede entenderse como un "detalle" o una "contingencia" más de la "selva espesa de lo real", que si reaparece con insistencia, produce una oscilación entre la incertidumbre y el reconocimiento de significados socialmente estabilizados, entre la multiplicación del sentido y su fijación [...] (Dalmaroni/ Merbilháa 2000: 338)

Según los autores, la historia política ingresaría en la obra saeriana sin alterar su condición básica de "indagación obsesiva [...] sobre las posibilidades de la percepción

\footnotetext{
${ }^{197}$ En el tomo diez, publicado en 1999 y cuyo recorte cronológico es 1955-1976, también Rodolfo Walsh es merecedor de un trabajo que lo tiene como objeto exclusivo: "La literatura en el banquillo. Walsh y la fuerza del testimonio", que firma Roberto Ferro.
} 
para aprehender lo real" (Op. Cit. Dalmaroni/ Merbilháa 2000: 321). Lo dicho es ejemplificado mediante el pasaje en Glosa (1985) donde se hace alusión a la delegación de exiliados argentinos que es recibida por los diputados socialistas franceses para hablar de "el asunto" (sic) de "las masacres, las desapariciones, las torturas, los asesinatos en plena calle y en pleno día, etc., etc., en fin, como decíamos..." (Saer 1986: 153-154). Según la lectura que se propone en el artículo:

... tales hechos han sido apropiados por la escritura, que los vuelve funcionales a su lógica interna. En este sentido, lo político se torna tan fragmentario como cualquier otro "estímulo" -el término es de Saer- proveniente de la realidad. Además, su materia se subjetiviza en la medida en que adquiere la forma de la memoria [...] Dicho de otro modo, la referencia a la historia política, en la medida en que otorga función y sentido, se narra menos como suceso que como reconstrucción de la memoria de la experiencia. (Op. Cit. Dalmaroni/ Merbilháa 2000: 339)

En su trabajo sobre la producción crítico-ficcional de Ricardo Piglia incluido en el onceavo tomo que compila Drucaroff, Jorge Fornet coloca Respiración artificial en el centro, entendiendo que es un punto de inflexión dentro de la "trayectoria de escritor" de Piglia. Al mismo tiempo, señala que esta novela publicada en 1980 por Pomaire contiene in nuce todas las obsesiones piglianas: desde cuál tradición narrar; qué hacer con la angustia de las influencias suscitada por Jorge Luis Borges, la ficionalización de la teoría y la utilización enrarecida de las convenciones genéricas (el relato policial, siempre asociado en Piglia a una "consciencia paranoica"). En el marco de su análisis, que gira alrededor de la pregunta “¿Desde qué tradición narrar?”, Fornet no se pronuncia sobre la controvertida recepción de Respiración artificial en términos de "best-seller de prestigio" (tampoco lo hará en El escritor y la tradición. Ricardo Piglia y la literatura argentina, publicado en 2007).

Dos son las colaboraciones escritas por miembros de la "generación ausente" para el tomo compilado por Drucaroff, en las que nuevamente se lee la voluntad de intervenir en la reorganización de las jerarquías del sistema literario desde su doble rol de académicos y escritores ("críticos-estrategas"): "Continuidad de los parques, relato de los límites", que firma Luis Chitarroni e "Historia y literatura: la verdad de la narración", de Martín Kohan.

En su aporte, Chitarroni ajusta las hipótesis desplegadas en su artículo "Narrativa: nuevas tendencias. Relato de los márgenes”, publicado en 1993 en el n. 517-519 de 
Cuadernos Hispanoamericanos. Lo hace mediante la introducción de una nueva categoría: no ya "lo nuevo", sino "los límites" para, dentro del conjunto de los escritores de los setenta, demarcar un grupo específico de narradores:

... en cuyos textos se observaba una resistencia que, sin acuartelarlos en una vanguardia [...] ni
amotinarlos dentro de una mentida marginalidad (ya que algunos publicaban en editoriales
importantes y eran tratados con generosidad por los medios), los ponía en una situación que
designamos "de límite", porque se ubicaban precisamente allí, en los bordes, los lindes, las fronteras
[...] El límite $[\ldots]$ no tiene que ver con la ilegibilidad, sino con la "tensión", con "un llevar hasta un
extremo" las posibilidades del lenguaje. (Chitarroni 2000: 161)

Según Chitarroni, cabrían dentro de esta caracterización Néstor Sánchez (de quien se señala la superioridad literaria por sobre su "precursor", Julio Cortázar); Alejandro Losada; Horacio "Pepe" Romeu; Héctor Libertella; Oscar Steimberg; Ricardo Zelarayán; Osvaldo Lamborghini; Luis Gusmán y Manuel Puig. Todos ellos serían autores de "obras en proceso de desarrollo", que "pasan por alto los modelos y antinomias vigentes en el tiempo de su tiempo", en otras palabras: el boom (Op. Cit. Chitarroni 2000: 171 y 172). Los autores más sobresalientes de esta lista son Lamborghini y Gusmán: "no hay en la literatura argentina de la década del setenta un texto más pleno (exceptuando Sebregondi), más rico que El frasquito" (Chitarroni 2000: 177). Sobre el final de su artículo, al comparar la década del setenta con la del ochenta, Chitarroni afirma que "Todas las definiciones exitosas a las que llegarían los ochenta se probaron y experimentaron en los setenta" (2000: 181).

En otras palabras: la década del setenta es para Chitarroni "la" década, quedando para las décadas del sesenta y ochenta los deslucidos roles de "la caducidad" (la del sesenta) y "la redundancia" (la del ochenta). Por último, también se reivindica a Juan José Saer, cuyo "oficio y artesanía" estarían a la misma altura de los demostrados por Zelarayán en La piel del caballo (Cf. Chitarroni 2000: 171).

La colaboración de Martín Kohan para el tomo compilado por Drucaroff tiene como eje la indagación de la relación entre discurso histórico y narrativa ficcional en la llamada "novela histórica", aunque casi inmediatamente la pregunta se desliza hacia la cuestión de "la representación literaria de lo real bajo condiciones de represión cultural" (2000: 246). Se trata, entonces, de un corpus de textos ("novelas históricas en sentido irrestricto"), que vuelven al siglo XIX para contar de manera cifrada la última dictadura. 
Dentro del conjunto, destacaría la novela Respiración artificial, en tanto en ella se elige volver explícito el interrogante de "cómo narrar los hechos reales". Kohan insiste en la paradoja de que la Historia (el siglo XIX) entraría en estas novelas "no para intensificar sus posibilidades de contruir una representanción más inmediata de lo real, sino, por el contrario, como una forma de acentuar la mediación" (2000: 245).

Que la literatura se pregunte por sus posibilidades de "escribir la verdad" tendría para Kohan dos explicaciones. La primera sería coyuntural (las condiciones de producción y circulación de los textos bajo dictadura). La segunda se relacionaría con la lógica intrínseca de la serie literaria (lo que explicaría -siempre según Kohan- que escritores como Juan José Saer y Andrés Rivera hayan mantenido idéntica poética en el exilio, bajo terrorismo de Estado y en la transición democrática). Precisamente sobre la novela En esta dulce tierra (1984) que firma el segundo, Kohan señala que:

Los términos con los que Rivera caracteriza el absolutismo rosista pretenden proyectarse en el futuro hasta tocar el presente de la escritura, como se evidencia ya en el cruce que proponen los epígrafes de la novela $[\ldots]$ Otras marcas, no tan explícitas, se diseminan en el texto; por ejemplo, al definir a la represión como "aniquilamiento del terrorismo", o a los opositores a Rosas como "imberbes", remite a ciertas expresiones reconocibles en discursos políticos más o menos cercanos. (Op. Cit. Kohan 2000: 249; nuestro énfasis)

Kohan señala similares "marcas, no tan explícitas" en su análisis de Ansay o los infortunios de la gloria (1984), de Martín Caparrós y Río de las congojas (1981), de Libertad Demitrópulos. ${ }^{198}$ Mientras el primero denomina "campo de concentración" al lugar de cautiverio del representante colonial en Mendoza, la segunda narra cómo "esos jueces de paja”, al declarar muerta a María Muratore, lo hacen afirmando que fue “muerta en acción” (Demitrópulos 1981: 84), algo que "dispara esa muerte al presente [dictatorial]" (Cf. Op. Cit. Kohan 251-254). ${ }^{199}$

\footnotetext{
${ }^{198}$ Río de las congojas fue ganadora del Primer Premio Municipal de la Ciudad de Buenos Aires (edición 1981) y del Premio Boris Vian (edición 1997).

${ }^{199}$ Si bien Kohan no lo señala, Demitrópulos también afirma que el odio de las mujeres decentes contra las prostitutas María Muratore y Ana Rodríguez es todavía más enconado que "el odio contra la subversión" (Demitrópulos 1981: 38). Asimismo, el poema de Yannis Ritsos (perteneciente al poemario Grecidad y otros poemas) que sirve de epígrafe a la novela remite de forma diáfana a la última dictadura (específicamente, a la figura del "desaparecido"): "Conviene que guardemos a nuestros muertos y su fuerza,/ no sea que alguna vez/ nuestros enemigos los desentierren y se los lleven/ consigo [...] Tal como se han puesto las cosas en nuestros tiempos/ -quien sabe-,/ puede que hasta nosotros mismos los desenterráramos/y los tiráramos algún día".
} 
Todo el análisis, punto por punto, reenvía a su propio trabajo de "diseminación" en su novela Los cautivos. El exilio de Echeverría, que Kohan publica el mismo año, y a la que ya nos hemos referido en términos de "politización de la novela histórica bestsellerista" en el capítulo anterior.

En otras palabras: mientras lee a Caparrós y Demitrópulos, Kohan prepara la recepción de su propia novela. Esta operación, típica de un "crítico-estratega", también es la que prevalece en la Breve historia de la literatura argentina (2006), concebida por Martín Prieto como un manual de divulgación. Al mismo tiempo que nombra los escritores que reivindica, Prieto formula constantemente la pregunta por los herederos de estas poéticas. Así, la "memoria de la literatura II" que esta Historia propone, operaría como mera excusa para comenzar a perfilar el canon futuro.

La "memoria de la literatura II" formulada en la Breve historia... coincide casi totalmente con la que enuncia Luis Chitarroni $(1993 ; 2000)$, aunque Prieto caracteriza a sus (según él) figuras más descollantes, Osvaldo Lamborghini y Ricardo Zelarayán, en términos de "negatividad y autoexclusión" (Prieto 2006: 432). En el caso de Zelarayán, son señalados como sus posibles sucesores Washington Cucurto, Miguel Ángel Petrecca, Juan Desiderio, Lucía Bianco, Guillermo Daghero y Fernando Cantamutto (Cf. Prieto 2006: 233). En el caso de Lamborghini, los supuestos legatarios no alcanzarían el nivel de su modelo:

... sus más entusiastas prosélitos, César Aira y Alan Pauls, si lo siguen, lo hacen en sentido opuesto. Aira, convirtiendo lo simultáneo y yuxtapuesto -marca registrada de la prosa de Lamborghini- en sucesivo y lineal, y Pauls vaciando de política y contexto el mismo escenario que en Lamborghini se estremecía alrededor de sus claves política y contextual. (Prieto 2006: 436)

En el capítulo dos ya hicimos referencia a las dificultades que presenta el incluir la prosa airiana en el conjunto heterogéneo de las voces "neobarrosas", por lo que no podemos menos que coincidir con la primera parte del diagnóstico de Prieto. Aira es más un creyente que un practicante de esta fe: su labor como albacea y editor de Osvaldo Lamborghini no significó la práctica de la contaminatio. ${ }^{200}$

\footnotetext{
${ }^{200}$ Las excepciones a la regla serían dos fragmentos muy breves. El primero se encuentra en $L a$ luz argentina, donde Aira cita Die Verneinung: "Si había algo que odiaba era la música" (1983: 48). El segundo, en su novela El bautismo: "Lo malo es el clima, pero de eso siempre se puede hacer abstracción, si estamos de acuerdo en que lo importante es el alma. Tan importante es, que para esta gente sencilla será
} 
En la Breve historia de la literatura argentina, ni Piglia, ni Puig ostentan el mismo peso que tenían en el onceavo tomo compilado por Drucaroff, aunque su autor coincide con la apreciación de que Juan José Saer "ocupa hoy en la literatura argentina un lugar central" (Op. Cit. Prieto 2006: 418).

Ricardo Piglia es rescatado en calidad de crítico: en el capítulo cuatro, por ejemplo, la Breve historia de la literatura argentina adhiere punto por punto el análisis desplegado en las ya clásicas "Notas sobre el Facundo", publicadas por Piglia en marzojunio de 1980 en Punto de Vista. La evaluación del valor estrictamente literario de Respiración artificial, que Prieto describe como "[la novela] emblema del período" (2006: 440) es, sin embargo, algo tibia:

... como señala Tulio Halperín Donghi, la complejidad de los asuntos tratados "parecería requerir tratamientos más sistemáticos que el propio de una conversación nerviosa entre intelectuales" [...] la enunciación de esas ideas, a partir de una fórmula contra-determinante cuyo efecto es siempre la sorpresa o el asombro y donde el ingenio funciona como un eficaz reforzador de la verdad del enunciado, ha intensificado su perduración, de modo que, desarrolladas después en ensayos o en escritos de crítica literaria, tuvieron mayores consecuencias en la literatura argentina que la misma novela de Piglia, la cual paulatinamente, y a medida que se congela su valor novelesco, va adquiriendo una importancia sobre todo ensayística, histórica y testimonial, con relación a los temas tratados y a sus hipótesis políticas y literarias. (Op. Cit. Prieto 2006: 443)

Prieto elige concluir su Breve historia... con dos extensos parágrafos que dan cuenta, respectivamente, de la "poesía neobarroca" en suelo local y la experiencia poética de los llamados “objetivistas".

Sobre la primera, señala con acierto que contradice la expectativa de la transición democrática, que "parecía estar dirigida hacia la aparición de una nueva poesía comprometida, un renovado coloquialismo realista y militante [...] entroncado con la tradición emblemáticamente representada por Raúl González Tuñón” (Op. Cit. Prieto 2006: 447). Carlos E. Feiling, con su poemario Amor a Roma (1995), es señalado como “el heredero" de Héctor Piccoli, el "más radical” de los neobarrocos (Prieto 2006: 449). Sobre la segunda, Prieto no se identifica a sí mismo como parte del colectivo de objetivistas que tuvo en Diario de Poesía su principal órgano de difusión. No obstante, la general preponderancia otorgada al género lírico por sobre la narrativa en esta historia 
de la literatura, lo posicionaría como una de las figuras más originales dentro del colectivo de los "críticos-estrategas".

Cuatro años más tarde (y uno antes del fallecimiento de su director, David Viñas) se publica el VII tomo de la Literatura Argentina Siglo XX con el título de De Alfonsín al menemato (1983-2001). Son sus compiladores Roco Carbone y Ana Ojeda. El enfoque sociológico persiste y ya alcanza ribetes problemáticos, porque aquí la literatura parece ser entendida como mero epifenómeno de la serie político-social:

No se puede arrancar el producto literario de la historia como si fuera un yuyo [...] Porque el producto literario surge de ella. Y porque se nutre de su materia. Entonces, si bien es posible leer un texto literario "aisladamente", como mera construcción lingüística [..] es imposible soslayar la representatividad histórica que todo texto literario tiene. (Op. Cit. Carbone/ Ojeda 2010: 12)

En verdad, el trabajo que firman Carbone y Ojeda para introducir De Alfonsín al menemato (1983-2001) adolece de cierta falta de equilibrio: si bien ésta es una "historia social de la literatura argentino del siglo XX”, prima aquí la descripción socio-política de lo acontecido en Argentina entre 1983 y 2001 por sobre el registro de lo ocurrido en la serie literaria. Tal como lo había objetado María Teresa Gramuglio en su reseña al primer tomo de esta Historia ... dirigida por David Viñas, también publicada en 1989: "lo político [opera] como instancia mediadora de la relación literatura-sociedad, y aún como pauta explicativa de algo que suele reconocerse como resistente a la explicación: el cambio literario" (1989: 27).

Y aún más: en "Estallidos: de la democracia a la depresión", la entonación adoptada es propia del discurso militante, con lexemas fuertemente valorativos. A título de ejemplo, el ex presidente Carlos Saúl Menem es "el califa" y se alude a su doble mandato de diez años como "el califato" (Op. Cit. Carbone/ Ojeda 2010: 39; 45 y 42).

De todas formas, este prólogo no da el tono a la totalidad del volumen, donde los autores que resultan merecedores de artículos extensos que los tienen como objeto de análisis exclusivo son Griselda Gambaro, Juan José Saer, César Aira, Miguel Bonasso, Tomás Eloy Martínez, Sergio Chejfec, Angélica Gorodischer... y Federico Andahazi.

En "El vacío, las nubes y la lengua. Una introducción a Glosa de Saer", Dardo Scavino utiliza una matriz en parte psicoanalítica y en parte joyceana para la caracterización de "lo real" en Saer. Partiendo de la célebre sentencia de Friedrich 
Hegel según la cual "el lenguaje es la desaparición del mundo sensible en su presencia inmediata", popularizada por Jacques Lacan a mediados de los años cincuenta en términos de que "la palabra asesina a la cosa" (sacrificio inaugural que -siempre según Lacan- estaría vinculado con la pulsión de muerte de Freud), Scavino explica su contrapartida positiva dentro del universo saeriano, dado que allí: "La palabra -glôssa en griego- destituye entonces la cosa en su realidad corporal inmediata, en su multiplicidad sensible, y al mismo tiempo la instituye como mismidad imaginaria, esto es: como una cosa" (Scavino 2010: 73; énfasis en el original).

En efecto: en "Freud o la glorificación del poeta" (1973), Juan José Saer explicaba la deferencia de éste por la poesía en tanto “... del mismo modo que la psicosis, la poesía, con su poder de concentración significante, muestra [...] ciertos procesos de la psiquis que son universales, pero que en el contexto de la normalidad e incluso de la neurosis, pasan desapercibidos" (Saer [1973] 2004: 152-153). E insistía, más adelante: "La literatura, al trabajar en la dimensión de los afectos y de las emociones, no ha hecho más que adelantarse, según Freud, al psicoanálisis: toda la imaginería conceptual de la ciencia naciente está implícita en la obra de los grandes poetas” (Ibid.).

Es válido aclarar que no sólo el psicoanálisis freudiano hace usufructuo de la mitología griega (mejor dicho: de su "poder de concentración significante"), sino también la literatura del Alto Modernismo para dirimir su peculiar vínculo con la "materia histórica". Ejemplo por antonomasia de lo dicho es el Ulises, de James Joyce. En otras palabras: el objetivo del narrador o del poeta (y para Saer no habría ninguna diferencia entre ambos) no es restituir la historia, sino crear una dimensión mítica que tenga valor en todo tiempo y lugar.

$\mathrm{Si}$, adhiriendo a la postura de Joyce, para Saer el camino de la ficción es salirse de la historia para dirigirse al mito, se comprenden tanto mejor las razones por las cuales Scavino propone leer el suicidio de Leto en términos de "mitema". En tanto "mitema", el suicidio es susceptible de ser colocado en serie con otras muertes por mano propia, y de adquirir una resonancia metafórica (propia del mito) en la sucesión de la trama de Glosa en particular, y, a su vez, de seguir resonando en la serie mayor del conjunto de las novelas saerianas (Cf. Op. Cit. Scavino 2010: 87).

En su trabajo "Aira: un arte basado en la incorrección. El cuestionamiento de las instituciones en una vanguardia finisecular", Graciela Montaldo parte de los lineamientos de lectura trazados por Sandra Contreras en Las vueltas de César Aira para 
reivindicar al escritor oriundo de Pringles, en tanto éste se propondría escribir una "nueva vanguardia" en un contexto de globalización económica y posmodernidad cultural. Para Montaldo, lo destacable consistiría en "su radicalidad: afirmar aquello en lo que ya, socialmente, no se cree; volver a cargar de problematicidad a la escritura, en vías de sucumbir al mercado" (2010: 95). La antinomia "literatura-mercado" es una de las principales categorías de análisis en De Alfonsín al menemato (1983-2001), y explicaría la -sólo a primera vista extemporánea- inclusión de Federico Andahazi en términos de "el anti-Aira".

Si Juan José Saer es señalado como precursor de Sergio Chejfec (Cf. Op. Cit. Carbone/ Ojeda 2010: 26), en el fragmento "El abandono de la trama: entre Aira y Guebel”, extraído del n 86 de Punto de Vista que firma Beatriz Sarlo (y que, según el efecto collage perseguido en esta Historia, sucede al artículo de Montaldo), Sergio Guebel es nombrado "heredero literario" de César Aira, en tanto lo igualaría en su pericia para abandonar la trama (Cf. Sarlo [2006] 2010: 107).

A su vez, en su aporte "Soldados, testigos y escritores”, María Pía López lee la novela Las Islas de Carlos Gamerro en términos de "relato opuesto" de la fundacional Los pichiciegos (2010: 158), para proceder a un análisis contrastado de ambos textos, cuyos puntos sobresalientes son: (1) el reemplazo de "la experiencia" (en Los pichiciegos) por "un abanico -o carnaval- de imágenes que los años proveyeron para pensar Malvinas", esto es, extraídas del repertorio desarrollado durante los quince años que separan la publicación de ambas novelas, y dentro del cual también se contaría la novela publicada en 1983 por Fogwill (López 2010: 159 y nota al pie 17); (2) el reemplazo del drama de la creencia en la palabra del testigo-sobreviviente (el personaje de "Quiquito" de Pichiciegos) por "el drama anterior: quién podrá narrar y con qué lengua" (Ibid.); y (3) la sustitución de la reflexión sobre la guerra desde el conocimiento de la experiencia concentracionaria (Fogwill) por la instancia mediadora del relato policial en Las Islas, género que en los noventa oficiaría de matriz también para inteligir la escena política contemporánea a la escritura. ${ }^{201}$

En el apartado "La herencia de Contorno: Punto de Vista y El Ojo Mocho" contenido en su Breve historia de la literatura argentina, Martín Prieto saludaba la

201 "Los años noventa hicieron pensar la política como hechos policiales: como si la conspiración delictiva fuera el fondo verdadero de las palabras, su razón última, pero también aquello que las volvía cuentos. El policial es la gramática que organiza los cuentos de Las Islas, al tiempo que fue la gramática de la política de la época." (Op. Cit. López 2010: 163) 
emergencia de una "nueva generación de críticos" auspiciada por los "hermanos mayores" de Punto de Vista, y dentro de cuya nómina se encuentran varios de los “críticos-estrategas" de la "generación ausente", cuyos aportes hemos reseñado:

A partir de la segunda mitad de la década del ochenta, Punto de Vista comenzó a publicar a una nueva generación de críticos literarios: Graciela Montaldo, Alberto Giordano, Gonzalo Aguilar, Sergio Chejfec, Sergio Delgado, Graciela Speranza, Renata Rocco-Cuzzi, D. G. Helder, Aníbal Jarkowski, Marcos Mayer, Carlos Mangone, Delfina Muschietti, Jorge Warley, Matilde Sánchez, Sylvia Saítta, Sergio Pastormerlo, Daniel Link y, más adelante, Miguel Dalmaroni y Ana Porrúa, quienes aunque no siempre compartieron el instrumental teórico ni el recorte de la literatura argentina propiciados por la publicación, contribuyeron sin embargo a su vigencia. (Op. Cit. Prieto 2006: 438)

Entre los listados es notoria la ausencia de Damián Tabarovsky, que si bien como novelista parece haber sido afectado por la "irradación epigónica" originada en César Aira (Op. Cit. Pauls 2004: 3), tiene peso propio como editor y animador cultural. Mientras el segundo de estos roles es central para el desarrollo del próximo parágrafo, su labor editora será someramente analizada en la coda que clausura el presente capítulo.

\subsection{Por una Literatura de izquierda: un contra-canon sin Juan José Saer. La polémica por el canon (2005)}

Habiendo publicado las novelas Coney Island (1996), Bingo (1997) y Kafka de vacaciones (1998), en 2004 Damián Tabarovsky da a conocer un pequeño volumen titulado Literatura de izquierda, donde propone un deseable rumbo para las letras argentinas: la "literatura de izquierda", que sería precisamente una "tercera opción" superadora frente a la (para él falaz) antinomia "mercado/ Academia". Tabarovsky da sus razones:

Mientras que el mercado y la academia escriben a favor de sus convenciones, la literatura que me interesa -la literatura de izquierda- sospecha de toda convención, incluidas las propias. No busca inaugurar un nuevo paradigma, sino poner en cuestión la idea misma de paradigma [...] Es una literatura que escribe siempre pensando en el afuera, pero en un afuera que no es real [...] Ese afuera ni siquiera es la tradición, la angustia de las influencias, otros libros [...] la literatura de izquierda está escrita por el escritor sin público, por el escritor que escribe para nadie, en nombre de nadie, sin más red que el deseo loco de novedad. (Tabarovsky 2004: 15) 
Contra la oposición "mercado VS. Academia" para inteligir el campo literario, Tabarovsky señala que ambos polos atractores son "lugares a salvo", "no necesariamente antagónicos", en tanto "escriben a favor de la reproducción del orden, de su supervivencia, a favor de sus convenciones, escriben en positivo" (2004: 13; énfasis en el original). Retomando lo dicho por Roland Barthes en su Lección Inaugural (1977), de la cual el polemista propone hacer "una traducción a nuestro aquí y ahora" (2004: 17), la "literatura de izquierda" sería aquélla que se niega a ser meramente una reproducción lingüística del poder.

El lugar de la llamada "literatura de izquierda" es según Tabarovsky un "no-lugar" (el lugar de la utopía):

Ese lugar en el que se escribe y se inscribe la literatura de izquierda, ese otro lugar que no es la academia ni el mercado, no existe. O mejor dicho: existe, pero no es visible, ni nunca lo será. Instalado en la pura negatividad, la visibilidad es su atributo ausente. Fuera del mercado, lejos de la academia, en otro mundo, en el mundo del buceo del lenguaje, en su balbuceo, se instituye una comunidad imaginaria, una comunidad negativa, la comunidad inoperante de la literatura. (Op. Cit. Tabarovsky 2004: 17)

Literatura de izquierda retoma y expande lo esbozado en el artículo homónimo publicado en el número de otoño de 2002 de milpalabras (cuyo subtítulo temático era “dinero, ficción, política”), donde Tabarovsky describía la apuesta literaria de Copi (el único "post-borgeano" digno de ser llamado como tal) en términos de "izquierdismo literario", y, de manera consecuente, definía la validez de la literatura contemporánea en tanto estuviera "escrita en el espacio de imposibilidad abierto por Copi" (Tabarovsky 2002: 38-39). El contraste planteado por Tabarovsky desde las páginas de milpalabras entre "la gran parte de la literatura contemporánea, que no conoce el fracaso porque no conoce el riesgo" y "las novelas que hacen del riesgo del fracaso su arte [...] que llevan tan lejos su fracaso, su estrepitosa caída, que al hacerlo triunfan" (2002: 38), ejemplifica su segundo término mediante El perseguido y El terrorista, de Daniel Guebel; El amor enfermo, de Gustavo Nielsen; Atlántida, de Juan Becerra; Versiones del Niágara, de Guillermo Piro; Cinco, de Sergio Chejfec; ¡Nítida esa euforia!, de Marcelo Eckhardt; En esa época, de Sergio Bizzio y El informe, de Martín Kohan.

Dicho planteo está en (casi) perfecta consonancia con la propuesta de Héctor Libertella en El árbol de Saussure. Una utopía (2000), prueba de la coherencia crítica a 
lo largo del tiempo de su autor, quien fuera firmante de títulos como Nueva escritura en Latinomérica (1977), Ensayos o pruebas sobre una red hermética (1990), Pathografeia. Los juegos desviados de la literatura (1991) y Las sagradas escrituras (1993). El otro "hermano mayor" que resuena en los planteos de Tabarovsky es Josefina Ludmer, que en octubre de 2000 había sido invitada por el Centro de Estudios de Teoría y Crítica Literaria de la Universidad Nacional de Rosario a inaugurar el II Congreso Internacional de Teoría y Crítica Literaria. De todas formas, la piedra fundacional de las intervenciones de Tabarovsky que hemos reseñado es, indudablemente, Héctor Libertella.

El volumen Nueva escritura en Latinomérica, publicado por Libertella en Caracas en 1977, fue pensada como réplica a La nueva novela hispanoamericana (1969), de Carlos Fuentes (que ejemplificaba "lo hispanoamericano", "lo nuevo" y "la novela" con Julio Vargas Llosa, Gabriel García Márquez, Julio Cortázar y Juan Goytisolo). En poco más de cien páginas, Libertella cubre dos objetivos.

Por un lado, proponer un contra-canon conformado por Sebregondi retrocede, de Osvaldo Lamborghini; Farebeuf, de Salvador Elizondo; Cobra, de Severo Sarduy; The Buenos Aires Affair, de Manuel Puig; Un mundo alucinante, de Reynaldo Arenas y La orquesta de cristal, de Enrique Lihn.

Estos textos son ejemplos de la por él bautizada como "nueva escritura" (siguiendo a Roland Barthes), cuya definición echa por tierra tres lugares comunes. Primero: la idea de que la "nueva escritura" es la que escriben "los jóvenes" (Op. Cit. Libertella 1977: 10). Segundo: contra la idea de que la vanguardia está delante de todo, Libertella la definirá en términos de "lectura activa de la tradición" y como "proyecto cavernícola": "hacer cosas nuevas con cosas viejas" (1977: 10 y 34-38), de manera coincidente con la definición de "vanguardia" de Giorgio Agamben en "Programa para una revista" (incluido en Infancia e historia). Tercero: contra la idea "heroica" de colocarse fuera del mercado -y ya advertido de la capacidad omnívora de ésteLibertella propondrá "sobrevivir en el mercado" (1977: 24-25), lo que se conecta con su idea de una "vanguardia en el caballo de Troya". ${ }^{202}$

\footnotetext{
${ }^{202}$ La "vanguardia en el caballo de Troya" es definida como aquella "que mientras espera el momento ilusorio de estallar se va comprendiendo en su disfraz, reinstaura el mito griego de la astucia, hace $s u$ negocio, incluyéndose en un campo convencional de posibles negocios, invierte a largo plazo indiferente al mecanismo de las pérdidas o las ganancias, y que ajena a la conquista de rápidos efectos en el mercado,
} 
Por el otro lado, Nueva escritura en Latinoamérica busca constituirse en ejemplo por antonomasia de lo que su autor denomina indistintamente una "historia poética de la escritura" o una "Ciencia de la Escritura" (mayúsculas en el original), esto es, "otro tipo de productividad dado por la pesquisa teórica", que, definida en términos de "actividad compulsiva", tiende a volverse indistinguible de la ficción (Libertella 1977: 10 y 37). Se trata, otra vez, de la propuesta (sin firma, pero que se sabe fue escrita por Osvaldo Lamborghini) en el primer número de Literal, que volvemos a traer aquí: “el juego donde el texto teórico podrá ser portador de la ficción, y la reflexión semiótica tejerá la trama del poema", y en cuyo epígrafe se señalaba humorísticamente que "Es verdad que nos falta una ciencia de la escritura, y también es verdadera la posibilidad de que no la tengamos nunca. -Pero somos lo bastante descreídos como para fingir sus efectos" (Literal 1 1973: 121-122 y 119, respectivamente).

Oponiéndose (esta vez de manera implícita) a la crítica sociológica que tenía su exponente local más resonante en Literatura Argentina y realidad política (1964), de David Viñas, Libertella propone volverse en un primer momento a "la escritura", dejando de lado los conceptos de "autor", "obra" y "datos contextuales" (Cf. 1977: 5960). La desestimación del modelo local (Viñas) no significa sin embargo la adopción acrítica de teorías foráneas (formalismo ruso, noción barthesiana de "escritura", noción de intertextualidad de Julia Kristeva). Al respecto, de manera coherente con la flexión literal del discurso anti-imperialista que permea toda su intervención, Libertella propone "una lectura de los textos críticos de la tradición inmediata, una mirada sobre sus síntomas históricos y productivos, y un registro del Orden, Sistema de Conocimiento o Ideología que los sostiene" (1977: 56). ${ }^{203}$

Si bien El árbol de Saussure es el libro que con mayor éxito logra volver indiscernibles el discurso teórico del literario, el árbol ya había sido plantado como clave de lectura en El camino de los hiperbóreos (1968), que lo utiliza tanto como "signo" (en vez de los clásicos asteriscos) para separar secciones, como para cerrar la última parte de la novela, titulada premonitoriamente "LLEGADA DEL ARTISTA A BUENOS AIRES", y que se inaugura con el aforismo "El estilo es el árbol" (Libertella 1968: 300). A esto se le suma que el árbol es el ejemplo aducido por Ferdinand de

sólo funciona -pica, graba, talla- compulsivamente en las cuevas" (Op. Cit. Libertella 1977: 28; énfasis en el original).

${ }^{203}$ Con esto nos referimos al epígrafe que acompaña la nota "La flexión literal" con que se cierra el $\mathrm{n}^{\circ}$ doble $2 / 3$ de Literal: "La apología del ojo que ve y refleja el mundo funda el imperialismo de la representación realista" (Literal 2/ 3 1975: 145). 
Saussure en su Curso de Lingüistica General para explicar el signo lingüístico. Así, El camino de los hiperbóreos se constituiría en temprano ejemplo de la "vanguardia en el caballo de Troya" y modelo (por demás exitoso) de cómo se puede sobrevivir en el mercado. ${ }^{204}$

La conferencia que da Josefina Ludmer para inaugurar el II Congreso Internacional de Teoría y Crítica Literaria en Rosario tiene una primera versión escrita fechada en julio de 2002 y otra (con modificaciones) en el año 2010, como parte de Aquí América Latina. Una especulación. Está organizada en dos ejes. El primero se dispara a partir de los interrogantes "¿Cómo pensar un presente en el que estamos incluidos?” y “Qué es lo que en el presente tiene sentido para una reflexión crítica?” (Cf. Ludmer [2000] 2002: 91-92). Para responderlos, Ludmer toma "el tiempo" como "instrumento crítico" apoyándose fundamentalmente en tres teóricos: Norbert Elias (Time. An Essay, cuya primera edición en alemán es de 1987); Gilles Deleuze ("Prólogo" a Les Temps Capitaux. Récits de la conquête du temps, de Eric Alliez, publicado en 1991) y Paolo Virno (Il ricordo del presente. Saggio sul tempo storico, 1999). En adhesión a las hipótesis de Norbert Elias, Ludmer señala que "el tiempo era el instrumento crítico ideal porque en el año 2000 recorría una frontera temporal y el símbolo del tiempo borra fronteras y no conoce límites entre lo privado y lo subjetivo, y lo público y social" ([2000] 2002: 93).

El segundo eje (que Ludmer afirma que "apenas va a esbozar", pero termina ocupando un espacio considerable en la argumentación) es "la relación entre los 'códigos literarios' de las ficciones -es decir, qué ideas sobre la literatura exhibían- y el mercado. Y las posiciones diferentes de esos 'códigos' en el mercado literario" (Op. Cit. Ludmer [2000] 2002: 95).

Ludmer confiesa haber llevado durante todo el año 2000 un (doble) "diario de lecturas": de la prensa periódica y de las novelas que iban siendo publicadas, desde la creencia de que:

Publicadas y leídas en presente, esas ficciones parecían configurar diferentes versiones del tiempo, y giraban alrededor de ciertos sujetos y posiciones en los diagramas temporales. El camino hacia la

\footnotetext{
204 El camino de los hiperbóreos fue ganadora del Premio Novela Paidós, edición 1968, dotado con 500.000 pesos, por veredicto de un Jurado conformado por Leopoldo Marechal, Bernardo Verbitsky y David Viñas. Al momento de ganar el Premio (que le valió una fama instantánea), el autor contaba con apenas 22 años de edad.
} 
literatura era el deseo de poder ver "en ficción" las temporalidades del presente vividas por algunas subjetividades. (Op. Cit. Ludmer [2000] 2002: 94)

El resultado es una tipología de las ficciones, que ejemplificarían seis temporalidades con sus correspondientes "formaciones culturales" (en este último sintagma resuena tan inconvenientemente uno de los conceptos fundamentales pertenecientes al universo teórico del "materialismo cultural", que será alternado por Ludmer con el de "formante cultural" en la versión de 2002, y reemplazado por "forma" en la versión de 2010). A saber: (1) la "temporalidad histórica de la nación o siglo XIX" y la "formación 'civilización o barbarie'", presentes en las novelas Los cautivos. El exilio de Echeverría, de Martín Kohan y Don José, de José García Hamilton; (2) la "temporalidad de la dictadura y los años '70" y la "formación de la memoria y la filiación", ejemplificadas mediante las novelas El teatro de la memoria, de Pablo de Santis y Un secreto para Julia, de Patricia Sagastizábal; (3) la "temporalidad del fascismo" y la "formación cultural del mal" en las novelas El Mandato, de José Pablo Feinmann y Lesca, el fascista irreductible, de Jorge Asís (que, a su vez, al hacer -ambas- "memoria en la literatura I" del golpe de estado de 1930 y al plantear -la segunda- la oposición "comunismo/ fascismo" en términos de "teoría de los dos demonios", también participarían de la "temporalidad de la dictadura y los años '70"); (4) la "temporalidad de la fábrica y el suburbio" y la "formación cultural de la relación entre los escritores y la clase obrera", presentes en Boca de lobo, de Sergio Chejfec; (5) la "temporalidad pura del presente de la utopía" con su "formación cultural anti mercado" en El árbol de Saussure. Una utopía, de Héctor Libertella, y (6) la "temporalidad futura de la ciencia ficción" en El juego de los mundos. Novela de ciencia ficción, de César Aira con su "formación realidad total". 205

De las seis temporalidades (que serán rebautizadas como "teorías del tiempo" en la versión de 2010), Ludmer señala que:

La utopía del 2000 es una formación cultural y literaria contra el mercado (la única utopía posible hoy) y aparece en El árbol de Saussure. Una utopía de Héctor Libertella [...]. Se trata de "una utopía hermética" (tradición que el mismo Libertella ha instaurado, la de la red hermética) que pasa por la Cábala y el trovar clus y por las vanguardias de los ' 60 y ' 70 ; un texto difícil y enigmático que es un

${ }^{205}$ Ludmer opta por dejar afuera de su argumentación Un episodio en la vida del pintor viajero, publicado por Aira en junio de 2000 en Beatriz Viterbo, donde se observa la voluntad de edificar una auto-imagen de escritor por medio del anacronismo, el desplazamiento y la tergiversación de la "biografía real" del pintor fisonomista alemán del siglo XIX Johann Moritz Rugendas. 
manifiesto antimercado sobre el signo lingüístico (representado por el árbol), ante la amenaza de su desaparición en el océano de redes, puntos y vacíos. Está escrita en presente, con citas falsas, traducidas de varias lenguas, escritores apócrifos, descripciones, reflexiones teóricas, preguntas en futuro. Tiene gráficos y dibujos. No narra sino que, como en toda utopía, inventa y describe un mundo desde cero [...] (Op. Cit. Ludmer [2000] 2002: 105; énfasis en el original)

Los valores que Ludmer rescata de El árbol de Saussure son dos. Por un lado, su carácter autorreferencial, "marca de toda literatura que se postula como autónoma", rasgo que -señala Ludmer- compartiría con Boca de lobo y El juego de los mundos, escritas por autores que estarían en el límite entre autonomía y postautonomía (Cf. Ludmer [2000] 2002: 90-93). Por otro lado, la coherencia entre la "utopia lingüística" que propone Libertella y la editorial elegida para hacerla circular: "Esta formación cultural de una comunidad hermética como resistencia al mercado cultural [...] apareció en una editorial culta y exquisita, nacional...” (Op. Cit. Ludmer [2000] 2002: 106), esto es: Adriana Hidalgo.

Si bien Ludmer no menciona explícitamente la antinomia "literatura VS. mercado", ésta pareciera estar operando por detrás de su argumentación cuando enfatiza el tipo de sello en el que tanto Héctor Libertella (Adriana Hidalgo) como César Aira (ediciones el broche) eligen publicar, en total correspondencia con el tipo de escritura propuesta. ${ }^{206}$ No obstante, también se reivindica la calidad literaria de Boca de lobo, de Sergio Chejfec y Versiones del Niágara, de Guillermo Piro, publicadas respectivamente por Alfaguara (que en marzo de 2000 había pasado a ser parte del Grupo Prisa) y Tusquets (que en 1998 había recuperado su independencia, luego de recuperar acciones vendidas en 1995 al grupo Planeta, y, en marzo de 2000, vuelto a comprar las acciones vendidas en 1998 a RBA).

Para no caer en la mera glosa de "el Proyecto" (mayúsculas en el original) enunciado en 1977 en Nueva escritura en Latinoamérica por Libertella y vuelto a reivindicar en el año 2000 por Ludmer, Tabarovsky se ve en la necesidad de subir la apuesta:

¿Pero qué hacer con el nuevo canon? ¿Qué hacer con Libertella, Fogwill, Aira? Hay que correrlos por izquierda. Se trata de una literatura que escribe con Lamborghini contra Lamborghini, con Puig contra

\footnotetext{
${ }^{206}$ Sobre el texto de Aira, Ludmer señala que "se pone totalmente al margen del mercado [...] porque fue editado por un grupo de estudiantes y jóvenes escritores de La Plata y no circulaba en las librerías de Buenos Aires ni tuvo reseñas" ([2000] 2002: 106).
} 
Puig, con Néstor Sánchez contra Néstor Sánchez. Hay que demostrar que la literatura de Libertella es poco hermética, que la de Fogwill es poco sociológica, que la de Aira es demasiado lenta. (Op. Cit. Tabarovsky 2004: 35)

El "contra-canon" que se propone en Literatura de izquierda incluye a "O. Lamborghini, Néstor Sánchez, Puig, Copi, Zelarayán, Perlongher, Viel Temperley, Saer (“con mucha buena voluntad") y "a la desdichada Pizarnik" (Cf. Op. Cit. Tabarovsky 2004: 26). El "work in progress" (la expresión es de Tabarovksy) de la "literatura de izquierda" estaría integrado por: Daniel Guebel (El terrorista y El perseguido); Gustavo Nielsen (El amor enfermo); Juan Becerra (Santo); Guillermo Piro (Versiones del Niágara); Sergio Chejfec (Cinco y El llamado de la especie); Marcelo Eckhardt (;Nítida esa euforia!); Sergio Bizzio (En esa época); Martín Kohan (Los cautivos); Sebastián Bianchi (El resorte de novia); Ezequiel Alemian (Ruptura) y Oscar Taborda (40 watt).

Así, la "literatura de izquierda" es ejemplificada mediante una mayoría de novelistas: sólo escapan a esta regla el autor del libro de cuentos El resorte de la novia y los poetas firmantes de Ruptura y 40 watt, con lo que la discusión queda otra vez circunscrita a la novela. Por otra parte, se observa cierta incoherencia entre la caracterización de la llamada "literatura de izquierda", conformada supuestamente por "textos diversos y muchas veces contradictorios, pero escritos todos en el espacio del riesgo del fracaso, como desafío a esa imposibilidad" (Op. Cit. Tabarovsky 2004: 47) y las “trayectorias de escritor" ya para el año 2004 muy exitosas de Daniel Guebel, Sergio Chejfec y Martín Kohan. Por último, también en 2004, Tabarovsky publica Las hernias, que fracasaría en su afán de "correr por la izquierda" a César Aira.

Guillermo Martínez, uno de los autores impugnados en Literatura de izquierda en tanto representante de los "jóvenes serios” (VER Tabarovsky 2004: 32-33), responde a los ataques en su ensayo "Un ejercicio de esgrima", incluido en La fórmula de la inmortalidad (2005). Las críticas principales al planteo de Tabarovsky son: (1) la utilización de un concepto de "mercado" poco claro; (2) la no diferenciación de los distintos "segmentos" dentro del público lector que consume literatura, que nunca es homogéneo (habría -según Martínez- una diferencia cualitativa entre aquel lector que elige una novela de Federico Andahazi y este otro que se inclina por una firmada por Tomás Eloy Martínez, aunque ambas sean igualmente “mejor vendidas”) y (3) el 
soslayar la tupida red de alianzas interpersonales y relaciones de simpatía personal (pero, agregamos, también estética) de tipo inter- y transgeneracional que permea toda intervención crítica.

Este último aspecto, que Martínez resuelve de manera bastante mezquina aludiendo a la relación marital de Saítta y Kohan para explicar por qué la primera colocaría al segundo dentro de su nómina de "nueva narrativa", se volvería operativo para trazar genealogías críticas. ${ }^{207}$ En otras palabras: la línea que va de Libertella (1977; $1990 ; 1991 ; 1993 ; 2000 ; 2003)$ y llega a Tabarovsky $(2002 ; 2004)$, encontrando su eco en Ludmer ([2000] 2002) que hemos intentado recuperar aquí.

La polémica Tabarovsky/ Martínez es nota de tapa de Ñ. Revista de Cultura del sábado 11 de junio de 2005 que se titula "Escritores en pugna" (la ilustración elegida -dos gallos de pelea- da una idea cabal del ánimo entre belicoso y lúdico con que se elige abordar la cuestión). Son invitados a pronunciarse los periodistas, profesores de la Universidad de Buenos Aires y/o escritores Álvaro Abós, Juan Forn, Carlos Gamerro, Eduardo Quintín, Florencia Abbate, Gonzalo Garcés y Martín Kohan. De todos ellos, sólo Abós y Kohan detentan una columna de opinión exclusiva. Mientras el primero (“Obras son amores") hace una rápida historia de las más resonantes polémicas entre escritores de la literatura universal y aboga por escribir en vez de "perder tiempo" en polémicas, el segundo ("Los mejores libros se escriben sin fórmulas") plantea una nueva antinomia: "los escritores que fabrican una literatura-que-gusta-a-todo-el-mundo (el tiro por elevación es contra Martínez) VS. "los escritores que admiten la posibilidad

\footnotetext{
${ }^{207}$ En el artículo "Después de Borges: apuntes sobre la nueva narrativa", publicado por Sylvia Saítta en 2002, se plantea una antinomia entre la "nueva narrativa" y "la narrativa que tiene como consigna escribir para el mercado". La primera es definida por en términos de: “... una literatura que circula de un modo casi secreto y cuyos libros son poco reseñados en los diarios de circulación masiva o se publican en pequeñas editoriales alternativas [...] comparte la preocupación por el lenguaje, la desconfianza ante las diversas modalidades de la representación realista y la prevención frente a las reglas del mercado". La segunda: "una literatura que no cuestiona ni altera presupuestos estéticos ya probados, que busca el impacto y la venta masiva a través de temas escandalosos, que parece poco preocupada por los riesgos de la experimentación formal que implica (que debería implicar) la literatura". Los ejemplos aducidos pertenecen exclusivamente al género novela. Bajo la "nueva narrativa" alistan: Atlántida, de Juan José Becerra; El amparo y Gineceo, de Gustavo Ferreyra; Ropa de Fuego, de Marcos Herrera; La temporada, de Esteban López Brusa; Tres, de Aníbal Jarkowski; Inglaterra, de Leopoldo Brizuela; Montevideo, de Federico Jeanmaire; Los cautivos. El exilio de Echeverría, de Martín Kohan; Las Islas, de Carlos Gamerro; Nadie alzaba la voz, de Paula Varsavsky; La asesina de Lady Di, de Alejandro López y La laguna, de Sergio Delgado. Bajo la "narrativa que tiene como consigna escribir para el mercado": $E l$ Anatomista, de Federico Andahazi; Historias de hombres casados, de Marcelo Birmajer; "las novelas de Rodrigo Fresán" (sic!) y Una noche con Sabrina Love, de Pedro Mairal (http://www.revistatodavia.com.ar/notas2/Saitta/textosaitta.htm; consultado el 7.2.2007).
} 
de no gustar y no prometen una satisfacción garantizada" (para ejemplificar, Kohan nombra a Sergio Chejfec, Alan Pauls, Juan José Becerra y Gustavo Ferreyra).

La antinomia planteada por Kohan tiene como antecedente "los libros que cualquiera puede escribir" (en el ensayo "Tres respuestas sin preguntas", publicado en el $\mathrm{n}^{\circ} 1$ de milpalabras de primavera de 2001) y su continuación en el concepto de "lo poco escrito" (en el artículo "Más acá del bien y del mal. La novela hoy", publicado en Punto de Vista en diciembre de 2005). ${ }^{208}$

En el primer número de milpalabras, Kohan señalaba que había tres respuestas naturalizadas a la pregunta de “PPara qué escribir?”: “... que hay que escribir para entretener a los lectores, que hay que escribir para que los lectores compren, que hay que escribir para que los lectores entiendan" (2001: 35). Estas respuestas serían "falsas" en tanto (1) como parte de la "industria del entretenimientos", la literatura corre el peligro de ser sometida a gravámenes (y aquí Kohan trae a colación la "Ley de Competitividad", enviada como proyecto al Congreso por el entonces Ministro de Economía Domingo Cavallo a comienzos de 2001); (2) la literatura argentina, por lo menos desde los años noventa, se habría visto "liberada" (o "despojada") del factor mercado, por lo que no tendría mayor sentido pensar en escribir "para que los lectores compren"; (3) a partir de la tergiversación de la prédica de Bertold Brecht sobre que incluso los receptores menos cultivados están en condiciones de entender las formas más vanguardistas del arte teatral, "ahora es el burro el que ha tomado la pluma", lo que da como resultado "libros que cualquiera puede comprender, pero también que cualquiera puede escribir" (Kohan 2001: 39).

Este último punto será central en "Más acá del bien y del mal. La novela hoy", donde Kohan denuncia la neutralización del aforismo "Primero, publicar; después, escribir" de Osvaldo Lamborghini: "hoy podría decirse de veras que ha llegado a ser preferible publicar que escribir" (Kohan 2005: 7). ${ }^{209}$ Contra los "libros que asumen la apariencia de lo poco escrito", Kohan va a proponer "la ecualización Borges-Puig":

\footnotetext{
${ }^{208}$ La intervención "Más acá del bien y del mal. La novela hoy" está antologizada en Fuga de materiales (2013).

${ }^{209}$ La primera lectura del conocido aforismo de "primero, publicar; después escribir" lo interpreta en términos del sueño utópico de un arte capaz de encontrar resultados con prescindencia de las fatigas del trabajo creador. La segunda, como inversión de la máxima borgiana "hay que publicar para dejar de escribir" (en el sentido de "dejar de corregir") que Jorge Luis Borges toma prestada de Alfonso Reyes. Que Lamborghini invierta dicha máxima podría ser interpretado como un abierto desafío al indiscutido "maestro de estilo" de nuestra tradición literaria: porque yo (Osvaldo Lamborghini) no necesito (como sí lo necesitaba Borges) corregir, puedo pasar directamente a la instancia de publicación. Según la tercera
} 
Esa especie de ecualización Borges-Puig permite crear un nuevo lugar para el estilo (haciendo chocar la plenitud del estilo de Borges con el vaciamiento del estilo de Puig), un nuevo horizonte cultural para la escritura (haciendo chocar el prestigio de las referencias de Borges con el desprestigio de las referencias de Puig), un nuevo criterio del buen gusto y el mal gusto (haciendo chocar los materiales del mal gusto de Puig, que la operación camp salva del kitsch, con la altisonancia de cierta solemnidad cultural de Borges, que la comicidad y la falsificación salvan de un efecto que también sería kitsch).

(Op. Cit. Kohan 2005: 8)

El problema se presentaría en el momento en que "se interrumpe la conexión sincrónica de Borges y Puig”, con dos resultados igualmente nefastos:

... del polo Puig es que se desprende el autor como reproductor, el que corta y pega materiales sin prestigio; sólo que ahora lo hace bajo el amparo de un prestigio garantido que obtiene justamente de la preexistencia de Puig. Y del polo Borges es que se deprende el autor como redactor, con novelas tramitadas en una medianía sin sobresaltos, que sin embargo aspiran, en la impostación de un borgismo apocado, al aura de la alta cultura, la hondura del pensamiento filosófico y una austera seriedad que se quiere sesuda. (Op. Cit. Kohan 2005: 9)

La observación sobre "el borgismo apocado" es, claro está, un tiro por elevación para Guillermo Martínez, al que se alude (sin nombrarlo) como productor de "textos de la más neta midcult [que] se camuflan de cultura 'alta', y a menudo logran ser tomados como tal (siguiendo esa línea de bestsellerismo donde Umberto Eco acertó)" (Kohan 2005: 9). En efecto: dos años antes, Martínez había publicado Crímenes imperceptibles, que fue un best-seller, se tradujo (entre otros idiomas) al alemán, inglés, francés y polaco, y que en 2008 tendría su versión cinematográfica bajo el título Los crímenes de

\footnotetext{
lectura, se trataría en verdad de una inversión del principio macedoniano: "No escribir para publicar", lo que empalmaría directamente con la cuarta interpretación de la fórmula, que focaliza en la contradicción entre el discurso de Lamborghini y sus actos, y señala que, por lo menos en los inicios de su trayectoria como escritor, otro habría sido el vínculo con la instancia de publicación y los mecanismos del reconocimiento literario (Cf. Strafacce 1998). Según esta última lectura, el desatenderse de la publicación y/ o difusión de la obra habría sido una decisión tomada luego de la publicación del poema Die Verneinung (diciembre de 1978, en el $\mathrm{n}^{\circ} 4$ de la neoyorquina Escandalar), que significa no sólo la recuperación de la capacidad de escribir luego de un importante bloqueo creativo, sino también la negación a sucumbir a la tentación mundana del prestigio, y la apuesta final (a la manera de Macedonio) por el reconocimiento póstumo. A la luz del epistolario que Lamborghini mantiene entre junio de 1976 y diciembre de 1978 con sus amigos Tamara Kamenszain, Héctor Libertella, Paula Wajsman y César Aira, donde fabula continuamente una productividad frenética para encubrir su imposibilidad de escribir, cabría agregar a las posibles interpretaciones del "primero publicar; después escribir" una quinta, del orden de la auto ironía: porque siempre me fue (casi) imposible publicar, encubro con esta imposibilidad la incapacidad (tanto más aterradora) de escribir.
} 
Oxford, con la dirección de Alex de la Iglesia, y Elijah Wood, John Hurt y Leonor Watling en los roles principales.

La última voz que se pronunció sobre la "literatura de izquierda" fue, como no podía ser de otra manera, la de Damián Tabarovsky en su aporte para el libro El efecto Libertella (2010). Allí, además de enfatizar la actualidad "asombrosa" de Nueva escritura en Latinoamérica, "[que] casi puede leerse como una intervención crítica acerca de los debates literarios más recientes" (2010: 42), Tabarovsky señala otro peligro: la canonización de la "vanguardia en el caballo de Troya". Al respecto, ésta ya habría sido prevista por Libertella (que sería, por lo mismo, el único autor capaz de resistir a la misma):

En el momento de armar el canon, en el grano de su lucidez [...] el texto ya está sospechando de sus propios efectos: la constitución de ese canon como nueva escritura normal, lo raro vuelto presentable, la novedad convertida en valor de cambio. [...] Ocurre que treinta años después, ese movimiento se ha vuelto instituido, y lo que era contra-canon hoy es tapa de los suplementos culturales [...]

Sin embargo [...] Libertella no fue atrapado por esa ola ascendente. Su literatura ocupó siempre un lugar lateral, descentrado, inadmisible. (Tabarovsky 2010: 44-45)

Si en Literatura de izquierda el principal problema al que se enfrentaba el "contracanon" era "la reacción" (2004: 29), ahora el peligro residiría en su posible neutralización por medio de un dispositivo consagratorio.

No obstante, habría algo que "protege" a determinados nombres del "canon de izquierda" de este derrotero, y es precisamente su intraducibilidad (en todas las acepciones del término). El caso paradigmático sería Héctor Libertella, que no tiene epígonos ni continuadores. Contra "lo poco escrito" ("lo meramente redactado"), Libertella resistiría en su condición hermética. No se dejaría decodificar por la Academia, ni cooptar por la zona más prestigiosa del mercado (la editorial Herralde, para poner un ejemplo). En el sentido laxo de "lo imposible de traducir", es por demás significativa la anécdota que cuenta el traductor Jeremy Munday en El efecto Libertella sobre las inmensas dificultades que tuvo, no para ya traducir el relato "Nínive" (originalmente incluido en ¡Cavernícolas!) al inglés, sino meramente para entenderlo, lo que da como resultado que Libertella redacte Diario de la rabia, una suerte de auto traducción del texto base a la misma lengua de origen.

Si, como lo fue Federico Andahazi en los noventa, Guillermo Martínez es hoy el escritor argentino que más traducciones a lenguas extranjeras ostenta y mejor posicionado en el "mercado de libros transnacional" se halla, el criterio de "lo 
intraducible/ "lo no-exportable" se erige para algunos como piedra de toque para dirimir el valor de una apuesta literaria (y al respecto, los ejemplos por antonomasia son Osvaldo Lamborghini y Héctor Libertella). El otro criterio es la capacidad para sabotear el mercado. O bien ignorando su demanda constante de novedad -como lo hizo Miguel Briante, con su también célebre aforismo "Yo no escribo, reedito"- o bien fingiendo responder a dicha demanda para hacer estallar el mercado por saturación -y el ejemplo paradigmático es César Aira-.

Al respecto, no parece casual que estos cuatro nombres tengan un espacio privilegiado en las antologías de intervenciones críticas de las que se dará cuenta en el próximo parágrafo.

4.4. Algunas notas sobre el canon argentino en las antologías La tierra elegida, de Juan Forn; El punto vacilante, de Sergio Chejfec; Con toda intención, de Carlos E. Feiling; Leyenda, de Daniel Link; Mil tazas de té, de Luis Chitarroni; Temas lentos, de Alan Pauls y Fuga de materiales, de Martín Kohan

$\mathrm{Si}$ bien tanto Luis Chitarroni como Daniel Link son "pioneros" en el gesto antologizador que hace libro de materiales que inicialmente habían sido pensados para soportes menos duraderos (artículos y reseñas en revistas culturales y prensa, conferencias, clases, ponencias en congresos e intervenciones en blogs), el resto de los libros que, firmados por algunos integrantes de la "generación ausente", reseñamos en este marco, aparecen luego del cambio de siglo. ${ }^{210}$

El primero es La tierra elegida, de Juan Forn, que consta de veintisiete textos escritos a partir de fines de 2001 y publicados “en su primera versión” en el suplemento "Radar" de Página/ 12. Son, en principio, crónicas suscitadas por hechos coyunturales: la publicación de un libro -en la mayoría de los casos-, un aniversario, el estreno de una

\footnotetext{
${ }^{210}$ Siluetas, el conjunto de las notas publicadas por Chitarroni en la sección homónima de Babel, revista de libros, aparece en Juan Genovese Editor en 1992 (hay reedición en 2010 en La Bestia Equilátera, editorial dirigida por el autor). El volumen La chancha con cadenas (compilación de clases, ponencias en congresos y artículos producidos por Daniel Link entre los años 1985 y los tempranos noventa, parcialmente reescritos para el formato libro) es publicado en 1994 en Ediciones Del Eclipse. Tal como lo señala su autor, La chancha con cadenas "nombra un conjunto de hipótesis sobre la cultura argentina precisamente en una etapa de la historia intelectual en la que las totalizaciones parecen haber perdido toda su antigua fuerza. Nombra, también, una serie de 'lecturas' relacionadas con las anteriores hipótesis sobre la cultura argentina y con la literatura tal y cómo se la podría imaginar para hoy y para el futuro. En ese sentido este libro es programático y hasta normativo. Nombra, finalmente, una de las relaciones que suelo entablar con la literatura, la del crítico, es decir: la del profesor. En este punto, someto mi capricho y mis arbitrariedades a ciertos protocolos, no por cálculo sino por convicción: la crítica puede definirse, todavía, como un sistema regional de lucha y el crítico como un estratega en el combate literario" (Op. Cit. Link 1994: 7). Con esto último, Link vuelve explícita la principal característica que hemos adjudicado a la totalidad de la "generación ausente": la idea benjaminiana de la crítica como una práctica estratégica, para -en definitiva- facilitar el ingreso de la propia obra ficcional en una hipotética y deseable "memoria de la literatura II" futura.
} 
película, la inauguración de una muestra de pintura. Sin embargo, con el libro, la adscripción el género de la crónica cultural se desdibuja: los textos se colocan en un territorio intermedio entre el ensayo, el diario de escritor y la ficción narrativa. ${ }^{211}$

Se observa, no obstante, una unidad lograda a partir del tono, que se mantiene homogéneo a pesar de la heterogeneidad de los motivos que disparan la escritura. También la unidad está dada por la "construcción en secreto" que asumen muchos de estos veintisiete textos ("El misterio de la piedra líquida" es un ejemplo claro de cómo la promesa de una develación sostiene la lectura desde la primera frase).

Mientras algunos se construyen como micro biografías, que apuntan al rescate de una figura injustamente olvidada (por ejemplo, Soma Morgenstern en "Kaddish para Joseph Roth”), otros piden ser leídos en la estela de Ricardo Piglia, que afirma que la crítica es una de las formas de la autobiografía. En este sentido, el primer texto ("Bushido"), que termina con la frase "Yo no soy japonés" encontraría su verdadero final en el último texto compilado ("La malquerida"), que narra no sólo los avatares por los cuales "una pequeñísima historia de la vida real se convirtió en [...] gran ópera italiana comme il faut", esto es, la ópera Madame Butterfly de Giacomo Puccini (Forn 2005: 244), sino que devela los hilos misteriosos que unen al autor de Nadar de noche con el Japón (su bisabuelo, designado obervador internacional en el conflicto rusojaponés, tiene allí un hijo natural, que aparece de manera inesperada en Argentina en ocasión de su funeral, para ser inmediatamente repudiado por la hija legítima del muerto: con este tío-abuelo "medio japonés" se promete hacer justicia Forn, "en la vida real o en esa vida paralela que son las novelas para los novelistas").

Al analizar el total, sorprende la ausencia de trabajos sobre literatura norteamericana, lo que fue explicado por Forn en una entrevista de promoción del libro dada a Claudio Zeiger para "Radar" en términos de "rechazo al imperialismo" luego de la crisis económica y política de diciembre de 2001 (Cf. Forn 2005 http://www.pagina12.com.ar/diario/suplementos/libros/10-1488-2005-04-02.html, consultado el 3.3.2010). ${ }^{212}$ A la literatura latinoamericana, sin embargo, se le destinan apenas tres ensayos: "Espiando debajo de la alfombra mágica" (reflexión sobre el

\footnotetext{
${ }^{211}$ En 2010, Forn publica una segunda antología de textos publicados los días viernes en la contratapa de Página/ 12 bajo el título de Ningún hombre es una isla, donde subraya la veta narrativa ya presente en $L a$ tierra elegida.

${ }^{212}$ La entrevista, titulada "Intimidad", es nota de tapa del suplemento "Radarlibros" correspondiente al 27 de marzo de 2005.
} 
"encanto infeccioso" del estilo de Gabriel García Márquez, donde Forn aprovecha para ajustar cuentas -aunque sin siquiera mencionar su nombre- con Fogwill); "La parábola del cuchillo" (sobre la edición como libro-arte -imposible de conseguir entonces- de La puñadadal El tango de la vuelta, de Julio Cortázar y Pat Andrea) y "Sueño con serpiente" (semblanza de Miguel Briante -“su extraordinaria respiración narrativa [...] es uno de los milagros de la literatura argentina del último medio siglo"- con motivo de la reedición en agosto de 2002 en Sudamericana de Ley de juego). ${ }^{213}$

También en 2005 Chejfec publica en Norma El punto vacilante. Literatura, ideas y mundo privado, compilación de trabajos escritos entre 1994 y 2004 que el autor dedica a la memoria de Juan José Saer. El volumen está organizado en cuatro secciones: "Espacios del relato", "Libros y peripecias", "Lectura y representación" y "Línea directa". Dentro del total, es notoria la importancia otorgada al escritor alemán Winfried Georg Sebald, al cual Chejfec dedica los trabajos "Breves opiniones sobre relatos con imágenes" y "La historia como representación y condena" (recordemos que en el último número de Punto de Vista, Beatriz Sarlo reivindicaba como uno de los principales aportes de la publicación el haber introducido a Sebald en la escena local).

Sobre los procesos de canonización y la polémica sobre el canon antes reseñados, importan los trabajos: "Un sueño de ser. El sueño público de la literatura argentina" (ponencia leída en la Librería Monte Ávila de Caracas en el año 2000), "La organización de las apariencias" (artículo publicado en abril de 1994 en el nº 64 de la revista Hispamérica de la Universidad de Maryland), "Fábula política y renovación estética" (publicado en la antología de artículos académicos Cultural Politics in Latin America compilada por Burnsbank Jones y Ronaldo Munck en el año 2000, vuelto a editar en noviembre de 2001 en el número único de la revista Nueve perros de Rosario) y “Sísifo en Buenos Aires” (publicado en el n 72 de Punto de Vista en abril de 2002).

En el primero de estos tres trabajos Chejfec aboga por la "nueva legibilidad", que define en términos cercanos a la "literatura de izquierda" de Tabarovksy como "obras resistentes a la lectura", ejemplificando mediante los "recientes casos notorios" de Oscar Taborda, Esteban López Brusa y Emeterio Cerro (Chejfec [2000] 2005: 17-18).

\footnotetext{
${ }^{213}$ La puñalada/ El tango de la vuelta, el libro póstumo de Julio Cortázar y el artista Pat Andrea, fue publicado un día después del entierro del escritor, el 15 de febrero de 1984. La galerista belga Elisabeth Franck, a cargo de la edición en castellano e inglés, nunca se ocupó de su distribución. Recién en el año 2000, fueron descubiertos 240 ejemplares de la edición en castellano en muy malas condiciones de conservación en un almacén de Miami. En septiembre de 2014, Libros del Zorro Rojo reeditó el libro respetando el formato original, con un epílogo de Enrique Vila-Matas.
} 
En el segundo, adhiere a la lectura pionera de María Teresa Gramuglio en El lugar de Saer al señalar que "Saer tiende a una organización verdadera de las apariencias, o sea, a prodigar conjeturas indecisas acerca de nuestro mundo real" (Chejfec [1994] 2005: 85). En el tercero, como ya ha sido comentado en el capítulo dos del presente trabajo, corrige su lectura negativa de Novelas y cuentos de Osvaldo Lamborghini publicada en el $\mathrm{n}^{\circ} 10$ de Babel, revista de libros y postula ahora una "estética radical" (que habría sido abortada por la dictadura), cuyos representantes serían Osvaldo Lamborghini, Rodolfo Walsh, Manuel Puig y Copi (Cf. Chejfec [2000] 2005: 111-112). Por último, en "Sísifo en Buenos Aires" señala la excepcionalidad de Aira en tanto no sólo renuncia a la contrucción de una obra, sino también somete a un tratamiento excéntrico la categoría de autor (Op. Cit. Chejfec [2002] 2005: 154).

Con toda intención (Sudamericana 2005) es una compilación de artículos periodísticos, reseñas e intervenciones firmadas por Carlos E. Feiling, publicada como homenaje post mortem por sus amigos. Incluye cuatro trabajos especialmente significativos para pensar su participación en los procesos de canonización aquí hipotetizados.

El primero es "La letra intermitente", reseña publicada originalmente a comienzos de 1992 en "Radar" con motivo de la aparición en Grupo Editor Latinoamericano de Pathografeia: los juegos desviados de la literatura (1991), de Héctor Libertella, donde Feiling celebra el "borramiento de los límites intergenéricos". Contra la adhesión por parte de algunos de sus coetáneos y amigos al axioma lamborghiniano de "Primero, publicar; después escribir", Feiling declara su preferencia por el "Escribir es reescribir", acuñado por el autor de ¡Cavernícolas! (Cf. [1992] 2005: 57).

El segundo ("Por qué escribo tan mal") es una feroz diatriba contra la "nueva historia oficial de la literatura argentina" instaurada en la transición democrática por, principalmente, Ricardo Piglia (con la ayuda de Beatriz Sarlo y Carlos Altamirano), que -siempre según Feiling- adolecería de dos grandes defectos: "no sólo deja afuera a autores como José Bianco, Miguel Briante, Fogwill y Ezequiel Martínez Estrada [...] sino que prescinde por completo del placer y del gusto" (Feiling 2005: 66-65). La perspectiva del "crítico-estratega" se hace explícita al final, cuando señala que "tengo toda la intención de seguir escribiendo mal [...] a contrapelo de la versión dominante de la literatura argentina [...] Luis Chitarroni y Rodrigo Fresán, no me dejan hacerlo completamente solo" (Feiling [1994] 2005: 66). Que el título de esta antología 
(prologada por Rodrigo Fresán) se titule precisamente Con toda intención es muestra cabal no sólo del fuerte sistema de lealtades interpersonales que motorizaron la publicación, sino también de cómo se sirven de ella algunos agentes para plantarse como un colectivo generacional frente a determinados "hermanos mayores", cuya gravitación en el campo comienza a volverse agobiante.

El tercer trabajo es la reproducción facsimilar de una hoja de la libreta de apuntes perteneciente a Feiling que éste llevó a la $1^{\circ}$ Feria del Libro de La Paz (Bolivia), que los compiladores fechan por lo tanto en el año 1996. La anotación fue numerada por Feiling con el número trece y resulta tan sugerente que merece ser transcrita por entero:

Néstor Perlongher, "Cadáveres"

$\rightarrow$ su importancia, junto con

O. $\mathrm{L} \rightarrow$ editados por Rodolfo

Fogwill, otro grande-

$\rightarrow$ junto con "la larga risa"

el mejor texto sobre el proceso.

$\rightarrow$ no hace falta tener faltas de

ortografía o ser populista

para escribir un texto político. (Feiling [1996] 2005: 68)

La última de las frases remite indudablemente a su virulenta reseña a Una sombra ya pronto serás, de Osvaldo Soriano ("El culto de San Cayetano"), publicada en el último número de Babel, revista de libros, que también es reproducida en Con toda intención.

El cuarto trabajo, "La zona incandescente", es una muy célebre broma realizada por Feiling, "memoria de la literatura I" de "El acercamiento a Almotásim" (1936), de Jorge Luis Borges. Este trabajo, fechado en 1990, enfatiza la importancia para las letras argentinas de "la edición del primer tomo de la Obra completa de Jorge Washington Noriega" (que es, como sabemos, una de las principales figuras del sistema de personajes del universo saeriano). Feiling consigue imitar, parodiándola, la respiración de la prosa borgiana (con inclusión del procedimiento de la falsa atribución y un manuscrito apócrifo final):

Decir que Washington Noriega "eligió un mal momento para morir" es una afectación del estilo. Pronosticar que esta Obra completa marca el comienzo de una merecida y tardía fama es conducta de astrólogo (sobre todo en un país que se jacta de haber ganado dos campeonatos de fútbol). Afirmar, en 
cambio, que los poemas y la prosa de Noriega constituyen uno de los proyectos estéticos de mayor densidad filosófica de la literatura argentina, es simplemente informar al público de un hecho. La justificación de este aserto puede obtenerse leyendo "Colastiné, Mississippi", ensayo sobre Faulkner en que Noriega argumenta que sólo la fidelidad a una zona, el registro puntual de sus objetos (animales, minerales, plantas, personas, instituciones), garantiza que la escritura no se vuelva un quehacer inmoral. "Sin esa fidelidad", dice Noriega, "más vale administrar un burdel o poner un supermercado". (Feiling [1990] 2005: 72-73)

Mención aparte merece la sección "Sin Miguel Briante", que agrupa tres trabajos publicados en Página/ 12 luego de la muerte el 25 de enero de 1995 del autor de Kincón: los dos primeros con fecha de 1995 y el tercero, de 1996. En "El fin” Feiling afirma que Briante "era para mí el último de la familia Hernández-Lugones-Borges, el sobrino que dilapida la herencia porque para eso están las herencias" (Feiling [1995] 2005: 130). En "Este milagro pobrecito" se insiste nuevamente sobre la importancia del legado literario de Briante. Por último, "El chancho en el cuadro" es una reseña sobre la muestra-homenaje a Briante "El ojo en la palabra" (con la curaduría de Michèlle Guillemont, Fabián Lebenglik, Omar Stela, Liliana Piñeiro, León Ferrari, Luis Felipe Noé y Oscar Smoje), que se expuso entre el 21 de noviembre de 1996 y el 20 de enero de 1997 en la Sala Cronopios del Centro Cultural Recoleta. Que tanto Forn como Feiling coloquen a Briante en un lugar de privilegio -en tanto escritor- dentro del conjunto de sus intervenciones críticas es también una nueva razón para desestimar la existencia de dos "grupos culturales" enfrentados (VER coda correspondiente al capítulo dos).

Leyenda. Literatura argentina: cuatro cortes (2006), reorganiza trabajos publicados por Daniel Link entre 1998 y 2005 en cuatro bloques temporales: “Peronismo y misterio (1942-1953)"; “Crítica y política (1955-1966)"; “Crisis de la literatura (1968-1983)" y “Milenio (1968-1983)". Contra lo que podría pensarse a partir del análisis del índice, Link no se propone escribir una historia de la literatura (de aliento ensayístico), sino que los tres primeros cortes funcionan como "retombée (eco anticiapado, causalidad acrónica) del presente" (2006: 15). En palabras del autor:

... lo importante es el punto de llegada, el milenio: es decir, la literatura producida, agónicamente, hacia finales del siglo XX y comienzos del XXI (aproximadamente entre 1995 y 2010, cuando la carrera por decidir cómo y cuál es la literatura del segundo centenario y quiénes integran esa generación estará ya, por fuerza, decidida). Así, los capítulos anteriores al "Milenio" deben entenderse 
como cortes retrospectivos: parto del presente para entender de dónde nos viene $[\ldots]$ una determinada relación (una relación actual) entre literatura y cultura industrial, crítica y verdad, arte y política. (Link 2006: 16)

El "tercer corte (1968-1983)", originalmente un texto escrito como catálogo para la muestra Entre el silencio y la violencia. Arte contemporáneo argentino, organizada por la Fundación ArteBA y Espacio Fundación Telefónica (Buenos Aires: 26 de noviembre de 2004 al 13 de marzo de 2005), insiste en los nombres de Manuel Puig, Rodolfo Walsh y Osvaldo Lamborghini en tanto "escritores emblemáticos" de los años setenta (que, según la periodización que propone Link, comenzarían en 1968 y finalizarían con la transición democrática). Las poéticas de los tres autores compartirían cuatro rasgos: (1) la "postulación de un estilo y un tono" para responder a la pregunta de ¿cómo representar la violencia?, que -siempre según Link- signaría "los setenta" (2) la "transgresión genérica" como estrategia para el "desmoronamiento de la cultura burguesa" ("Walsh y el periodismo popular, Puig y el folletín, Lamborghini y la escatología heterosexista"); (3) una "confianza permanente [...] respecto del 'control' que la cultura alta (letrada) podría ejercer sobre los medios" (Op. Cit. Link 2006: 112114).

De manera coherente con lo propuesto desde las páginas de Babel, Link propone los siguientes "herederos de dicha 'poética de la transgresión" ": "un poco después (y de otro modo), Piglia, Saer, Gusmán, Fogwill” (Op. Cit. 2006: 112), a quienes se les dedican trabajos en la sección "Milenio". 214

Todo el "cuarto corte" está fundamentalmente destinado a dilucidar una importante cuestión: cómo ciertos escritores dirimen "el conflicto entre imaginación literaria e imaginación de mercado", esto es: la creación de una obra en un contexto de globalización cultural, cuyo inicio Link fecha en 1995 (Cf. 2006: 152). En este sentido, no parece casual que el segundo trabajo incluido en la sección "Milenio" sea una reseña sobre lo discutido en el marco del Encuentro Nacional de Narradores edición 1999, cuyo tema fue "Literatura y globalización".

Según Link, los que mejor han resuelto su relación con la cultura industrial son Manuel Puig, Rodolfo Walsh, Juan José Saer, Fogwill, Ricardo Piglia y César Aira (Cf.

\footnotetext{
${ }^{214}$ Sobre Luis Gusmán no hay ningún texto en Leyenda, pero recordemos que Link había participado dos años antes en el tomo Escrito por otros.
} 
2006: 151-152). El contra-ejemplo es El vuelo de la reina, cuyo autor "está dejándose devorar precisamente por ese estilo medio (bien fait, kitsch) que la cultura industrial reclama para sí" (Op. Cit. Link 2006: 151). La formulación, como observamos, es prácticamente idéntica a la de "Apéndice: literatura y mercado" (incluido en su antología Cómo se lee y otras intervenciones críticas, de 2003), y constituye un ejemplo de la técnica de trasvasamiento y reescritura obsesiva de las mismas hipótesis críticas que es casi la marca de fábrica de este "crítico-estratega".

Mil tazas de té (2008), de Luis Chitarroni es la más breve de las antologías que aquí comentamos, aunque su brevedad no es impedimento para que resulte elegida como "libro del año" sobre un total de 19.219 títulos publicados en 2008. La Encuesta, gestionada por $\tilde{N}$. Revista de Cultura y cuyos resultados son nota de tapa del $\mathrm{n}^{\circ} 273$ correspondiente al 20 de diciembre de 2008, invita a quince intelectuales (Edgardo Cozarinsky, Fogwill, Fernando Savater, Elvio Gandolfo, Pablo Ramos, Diana Bellesi, Luis Chitarroni, Angela Pradelli, Sergio Wolf, José Emilio Burucúa, Juan José Becerra, Oliverio Coelho, Pablo de Santis, Luis Gumán y Tamara Kamenszain) a elegir un único libro como "libro del año", en cualquier categoría, dando razones para su elección.

Mil tazas de té incluye gestos borgianos (“Accidentes inseparables", donde Chitarroni -dando una vuelta de tuerca a lo planteado por J. L. Borges en "Pierre Menard, autor del Quijote"- juega a confundir al lector induciéndolo a creer que las primeras líneas de La gitanilla, de Miguel de Cervantes - en traducción francesa- son el arranque de El fiord, traducido a la misma lengua), un panegírico a César Aira ("Los extranjeros definitivos"), un diario de viaje a Cuba (“Cinco días”) y una reseña sumamente elogiosa a Sierra Padre (Emecé 2006), de María Martoccia. ${ }^{215}$

En junio de 2012, Ediciones de la Universidad Diego Portales de Santiago de Chile publica Temas lentos, de Alan Pauls, volumen de más de 300 páginas conteniendo una selección de cuarenta y cinco trabajos entre notas sobre literatura, arte y cine; conferencias; prólogos, crónicas, columnas y fragmentos de diarios de viaje, publicados en medios de España y América Latina. Lo hace dentro de su colección "Huellas", que, lanzada en 2004, hace libro de materiales dispersos, no sólo de escritores, sino también de periodistas y críticos latinoamericanos. Hasta la publicación de Temas lentos (al

\footnotetext{
${ }^{215}$ Aprovechamos para señalar una errata en "Nota del autor", donde Chitarroni da fecha y lugar de publicación originales de los cinco textos que constituyen Mil tazas de té: "Los extranjeros definitivos" debió ser publicado en la revista Tigre de Grenoble en 2005 (no en el año 2000), puesto que es en ese año que se realiza la traducción al francés de Osvaldo Lamborghini por Sudamericana/ Éditions du Rocher.
} 
cuidado de Leila Guerriero), la única argentina en la Colección era María Moreno. En octubre de 2013, se publica allí Fuga de materiales, de Martín Kohan, antología de trabajos aparecidos originalmente en diversos medios (también en soporte digital, en el blog de Eterna Cadencia) durante los últimos quince años.

Ambos libros, aunque adolecen de una distribución prácticamente nula en la Argentina, tienen una acogida entre sus pares por demás entusiasta: mientras Temas lentos es elegido “libro del año 2012" en la categoría ensayo según la encuesta gestionada por $\tilde{N}$. Revista de Cultura, la publicación de Fuga de materiales amerita una nota de dos páginas en el n 899 de "Radarlibros" del $1^{\circ}$ de diciembre de 2013, donde también se reproducen algunos fragmentos del texto. ${ }^{216}$

El libro, que compila varias de las intervenciones críticas de Alan Pauls a lo largo de las últimas tres décadas, está organizado en los apartados "Arte", "Literatura", "Viajes", "Intervenciones", “Cine”, "Monedas" y "Mi vida y yo". Es notorio el interés de Pauls por la fotografía, las artes plásticas y, por sobre todas las cosas, el lenguaje del cine. (Pauls, como leemos en "Yo como actor" es, además de crítico de cine, ocasional intérprete.) En "Literatura" e "Intervenciones", Temas lentos incluye lecturas sobre César Aira, Manuel Puig, Roberto Bolaño, Roland Barthes, Sigmund Freud, Robert Walter, Fernando Vallejo, Samuel Beckett, Ricardo Piglia, Fogwill, Jorge Luis Borges, Mario Bellatin y Héctor Libertella.

El 30 de septiembre de 2012, María Moreno reseña Temas lentos para "Radarlibros", donde señala que:

... en la aparente variedad taxonómica de Temas lentos hay una insistencia, una idea fija que parasita el libro entero: la relación entre literatura y experiencia, entre hechos y obra artística, anécdota ejemplar y texto, a condición de que se dinamite la conjunción copulativa en nombre de lo que Pauls $\begin{array}{llll}\text { bautiza como } & \text { literatura } & \text { (Moreno }\end{array}$ http://www.pagina12.com.ar/diario/suplementos/libros/10-4809-2012-10-06.html, consultado el 2.11.2012)

\footnotetext{
${ }^{216}$ La encuesta sobre los "libros del año" gestionada por $\tilde{N}$. Revista de Cultura, interroga en su Edición 2012 a un total de 100 críticos, académicos y escritores, pidiéndoles esta vez que elijan tres novedades editoriales, en cualquier género y de cualquier nacionalidad. Los resultados son nota de tapa del $n^{\circ} 481$ de la revista correspondiente al 15 de diciembre de 2012, y arrojan como ganador en la categoría ensayo a Temas lentos, junto a la traducción al español que publica Eterna Cadencia de El absoluto literario, de Philippe Lacou-Labarthe y Jean-Luc Nancy; Textos de ocasión, de Daniel Link y Rebeldes y confabulados, de Dardo Scavino
} 
Precisamente sobre el concepto de "literatura expandida" (que remite al concepto de "arte expandido" de las artes plásticas) gira el trabajo "El arte de vivir en arte" (una ponencia presentada originalmente en francés en el coloquio sobre literatura latinoamericana del siglo XXI organizado entre el 11 y el 18 de julio de 2008 por el Centro Cultural Internacional de Cerisy), donde Mario Bellatin, César Aira y Héctor Libertella son definidos por Pauls como artistas de la actitud, en la línea abierta por los artistas conceptuales y los performers. En ellos "ya no es tan fácil distinguir el interior del exterior, lo central de lo secundario, lo significativo de lo insignificante", y sus vidas son "la continuación de la obra por otros medios" (Pauls 2012: 173). El concepto señala el proyecto narrativo del propio autor de Historia del llanto, y excede en sus implicancias últimas al mero gesto de "escribir en modo autoficional".

En relación a la "literatura expandida", es significativo que en "Retrato del artista doble" Pauls haga del espacio físico donde escribía Manuel Puig (la cocina) un elemento esencial para comprender su poética. Si bien dedica un artículo a la omnipresencia todopoderosa de J. L. Borges ("La herencia Borges"), Puig constituye una lectura clave, cuyos efectos superarían las fronteras de la literatura nacional. En una entrevista de promoción de Temas lentos dada a Marcela Fuentealba en junio de 2012, Pauls afirmaba que:

Hay un antes y un después de Puig para mí y para la literatura latinoamericana. Después de Puig (gracias a él) dejamos de creer en ciertos valores literarios, como la imaginación, el estilo (o buen escribir) y la importancia (es decir: la trascendencia, el compromiso, los temas de peso), y descubrimos y nos entusiasmamos con otros: lo trivial como música y campo de batalla; la productividad de toda forma de parasitismo (ventriloquia, playback, karaoke); las potencias del montaje (contra las continuidades narrativas, el arte de la transición, etc.); la posibilidad de hacer todo con nada (lo que él llama la cocina del pobre). El único que tuvo (y tiene) en mí un efecto parecido es Borges. (Pauls [Entrevistado por Marcela Fuentealba] 2012 http://www.paula.cl/tendencia/los-temaslentos-de-alan-pauls/, consultado el 16.7.2012)

También Martín Kohan haría de Borges la piedra de toque del "nuevo canon", según lo que podría inferirse de la lectura conjunta de las intervenciones que constituyen el volumen Fuga de materiales. En "Lo que entiendo por Borges" (publicado originalmente en 2010, en el $\mathrm{n}^{\circ} 4$ de Agora. Journal for metafysisk spekulasjon, de Oslo), termina afirmando que: "Lo que entiendo por Borges es lo que tuvieron que escribir Manuel Puig, Juan José Saer, Ricardo Piglia, Rodolfo Fogwill, 
César Aira, y etcétera, etcétera, etcétera, etcétera, etcétera, para que se pudiese seguir escribiendo en Argentina después de Borges” (Kohan 2013: 64).

De todas formas, los trabajos que tienen como objeto exclusivo la poética de un autor antologizados en Fuga de materiales son únicamente dos: "Héctor Libertella, sigiloso y a destiempo" (originalmente el prólogo a la reedición de Nueva escritura en Latinoamérica que realiza en 2008 Ediciones El Andariego) y "Lo más breve de los breve: las novelas ínfimas de César Aira" (ponencia presentada en el coloquio internacional César Aira: un episodio en la literatura argentina del fin de siglo). Si bien hay otros trabajos que giran sobre un autor determinado, en ellos se procede -más que a dar cuenta de un proyecto estético- a sopesar los efectos producidos por una determinada figura de escritor ("Una cosa más sobre Fogwill”). Un texto de inclusión enigmática es "Cortázar inesperado", que Kohan leyó por primera vez en la Feria del Libro de Buenos Aires Edición 2009, con motivo de la presentación del volumen homónimo que -bajo el cuidado de Aurora Bernárdez y Carles Álvarez Garriga- edita ese año Alfaguara. En el marco de la misma, Kohan invita (¿irónicamente?) a "preguntarse por la actualidad de la inactualidad [de Cortázar]” (2013: 159).

Contra el "borgismo" (definido en consonancia con David Viñas en "Lo que entiendo por Borges" como un movimento ensalzatorio vacío, que tiende a aniquilar todo lo que la poética borgiana tiene de reactivo) y el "cortazarismo" (definido en “Cortázar inesperado" como "su impiadosa reducción a fórmula para los activistas infatigables del tallerismo literario"), Kohan reivindica el concepto de "vanguardia" de Libertella y "la profusa descolocación" de Aira.

En el resumen correspondiente al capítulo dos hemos hecho mención al "sistema de lealtades" que muchos miembros de la "generación ausente" mantuvieron a lo largo de décadas. En efecto: también en las antologías reseñadas se deslizan elogiosos comentarios a determinados coetáneos y/ o escritores más jóvenes, con la única excepción de La tierra elegida, de Forn.

En El punto vacilante se reproducen los trabajos "La parte por el todo" (publicado en el $n^{\circ} 60$ de Diario de Poesía de verano 2001/2002, donde, en el marco de una constelación de escritores que escriben desde el Uruguay y que incluye los nombres de Copi y Juan Carlos Onetti, Chejfec hace una admirativa mención a El dock, de Matilde Sánchez) y "Viaje y sufrimiento" (escrito en 1997, incluye un paralelismo entre El llanto, de César Aira y Wasabi, de Alan Pauls, en tanto ambas novelas “intentan planear 
sobre respuestas a la pregunta que formulan ¿cuál es el sitio del escritor?”: Chejfec [1997] 2005: 65). En Con toda intención, se reproducen dos reseñas encomiásticas, ambas fechadas en 1990: "La novela, la amistad" (sobre Lenta biografía, de Sergio Chejfec: "tan sutil como un soneto de Wilcock") y "El escritor como personaje" (sobre El divino convertible, de Sergio Bizzio: demasiado "maravillosa" -siempre según Feiling- para ser una primera novela).

Contra la promesa de arriesgar los nombres de la "literatura del segundo centenario" presente en la "Introducción" a Literatura argentina. Cuatro cortes antes citada, Link sólo reivindica tres autores "nuevos": Matilde Sánchez (una reseña planteada en términos de "crítica a la novela de género" para La canción de las ciudades); Alejandro López ("Hope over all”: traducción del posfacio escrito por Link a la traducción al inglés de La asesina de Lady Di, publicada en la editorial norteamericana Alisform Publishing en 2005 bajo el título de Die, Lady, Die) y Gabriela Bejerman (con motivo de reseñar las dos novelas cortas que constituyen Presente perfecto).

En la reseña a Sierra Padre con que se clausura Mil tazas de té, Chitarroni utiliza esta novela como un acabado mentís a la coartada del "sólo quise contar una historia" utilizada por "escritores, periodistas, cineastas -y hasta filósofos- en el momento en que tienen que defender la insuficiencia de su desempeño con la escasez de sus argumentos" (2008: 82). Contra esto, destaca el "aticismo de la prosa de María Martoccia”. El "principio de ingenuidad" y la "artesanía ejercitada con las ambiciones -y los poderesdel arte" presentes en Sierra Padre son incluso comparados (a favor de la autora) con los de Manuel Puig (Cf. Chitarroni 2008: 83-85).

Por último, en el artículo "La novela argentina: más allá del bien y del mal” ya citado en el parágrafo 4.3. en el marco de la indagación sobre la "literatura de izquierda", Martín Kohan hermana a Pauls y Chejfec en tanto ejemplos de cómo "frente a las condiciones impuestas por la publicación de lo poco escrito [...] recuperan y validan, para la literatura argentina del presente, la centralidad de la escritura” ([2005] 2013: 70).

De la "auto-promoción" a fines de los ochenta de las propias novelas presente de manera paradigmática en la sección "El libro del mes" de Babel, revista de libros (ya analizada en el capítulo dos) a conatos de "auto-canonización" luego del cambio de milenio: es indudable que el tiempo juega a favor de determinados miembros de la "generación ausente". Sin embargo, hay algunos "hermanos mayores" que al parecer 
siguen resultando indispensables para refrendar estos avances. Entre ellos, la más visible es Beatriz Sarlo, que también hace libro de intervenciones dispersas: en 2007 publica en Siglo XXI Editores Argentina Escritos sobre literatura argentina, y, en 2012, en mardulce, Ficcciones argentinas. 33 ensayos. ${ }^{217}$

El cuarto y último apartado de Escritos sobre literatura argentina, titulado "Leer en presente", incluye tres trabajos sobre Sergio Chejfec, dos sobre Alan Pauls y uno sobre Matilde Sánchez (que es leída en contrapunto con Martín Caparrós). Es interesante contrastar estos números con los de "Clásicos del siglo XX", el apartado precedente, que incluye un trabajo sobre Ezequiel Martínez Estrada, dos sobre Silvina Ocampo, siete sobre Jorge Luis Borges, cinco sobre Roberto Arlt, cuatro sobre Julio Cortázar, uno sobre Juan L. Ortiz, nueve sobre Juan José Saer y uno sobre Manuel Puig.

(Si nos detenemos en dar estos números es porque en estas cantidades no sólo es posible reponer el eje Borges-Saer, que sin duda preside el sistema de lecturas de Beatriz Sarlo, sino también el espacio de consagración que comparten Chejfec y Pauls.)

En el prólogo a Ficciones argentinas, la autora explica que los treinta y tres ensayos responden a la consigna de Maximiliano Torres (director del suplemento literario del diario Perfil) de escribir sobre "libros que se estén editando" en un formato algo más ambicioso que la reseña. Se trata de "notas sobre literatura del presente" que "traen noticias de lo nuevo", aunque "no de todo lo nuevo; ni siquiera podría afirmar que de lo más importante, sino de lo que me interesó o provocó [...] libros que me gustaron" (Sarlo 2012: 12). A saber:

Leí, por supuesto, novelas de escritores cuya obra conozco desde el principio: Matilde Sánchez, Daniel Guebel, Sergio Chejfec, Martín Kohan, César Aira, Luis Gusmán, Marcelo Cohen. Y tuve la sensación de descubrir las líneas casi invisibles de algunas continuidades literarias, de algún nexo entre el pasado y la actualidad. No escribí sobre otros escritores que me gustan: Daniel Link, Aníbal Jarkowski. Cuando miro los nombres de las treinta y tres notas que forman el volumen, me produce alguna tristeza que ellos no estén. (Op. Cit. Sarlo 2012: 17)

Otro "hermano mayor", que con generosidad y obstinación se dedicó a promocionar determinados nombres de la "generación ausente" fue Héctor Libertella. En el arco de la década que va desde la publicación de Las sagradas escrituras (1993) a

\footnotetext{
${ }^{217}$ Mientras Escritos sobre literatura argentina compila no sólo trabajos publicados en diversos medios sino también ponencias en congresos (y hasta un inédito fechado en 1989 sobre La hija de Kheops, de Laiseca) abarcando un arco temporal amplísimo (de 1980 a diciembre de 2006), Ficciones argentinas antologiza todas las notas publicadas por Sarlo en el suplemento cultural del diario Perfil entre octubre de 2007 y mayo de 2012.
} 
La librería argentina (2003), apoyó insistentemente las apuestas escriturarias de Daniel Guebel, Sergio Bizzio, Luis Chitarroni, Gustavo Nielsen, Alan Pauls, Carlos E. Feiling, Esther Cross, Matilde Sánchez, Martín Kohan, Damián Tabarovsky y Marcelo Damiani.

\section{5. "Críticos-estrategas": editores, exegetas y plagiarios}

En el marco del segundo "ciclo de canonización" hipotetizado al comienzo de este capítulo resulta central el trabajo realizado por Daniel Link como editor (y luego geneticista ad hoc) sobre la obra de Rodolfo Walsh a partir del año 1983, que es cuando es designado por Daniel Divinsky de Ediciones de la Flor para organizar la reedición de Operación masacre.

Más de diez años más tarde, Link exhuma material publicado originalmente por Walsh en prensa en el volumen El violento oficio de escribir. Obra periodística (19531977) (Planeta 1995 y 2da ed. [i.e. reimpr.] 1998; edición corregida y aumentada en Ediciones de la Flor en el año 2008) y publica diversos “papeles personales" (fechados entre 1957 y 1976) en Rodolfo Walsh. Ese hombre y otros papeles personales $\left(1^{\circ}\right.$ edición en Ediciones de la Flor en el año 1995; reimpresión en Seix Barral en el año 1996 bajo el título Ese hombre y otros escritos personales; reedición con el título original en Ediciones de la Flor en el año 2007). Mientras que en el caso de El violento oficio de escribir el "Prólogo" queda a cargo del ex compañero de Walsh en ANCLA Rogelio García Lupo y el papel de Link se reduce a redactar breves textos para contextualizar histórica y biográficamente los materiales (que son presentados en orden cronológico), en Rodolfo Walsh. Ese hombre y otros papeles personales es él quien firma como prologuista.

En el caso de la primera edición de Rodolfo Walsh. Ese hombre y otros papeles, su decisión editora por lejos más controversial fue el borramiento de los nombres propios "de las personas vivas", que es explicada en el "Prólogo" como gesto para no herir susceptibilidades. La virulencia con que Horacio Verbitsky ataca este "detalle" en su aporte "La revelación de lo escondido" ya citado (“... su Diario, censurado en la primera edición argentina, donde el nombre de Lilia fue sustituido por una siniestra letra N...”) se vuelve comprensible si recabamos en que la publicación de la compilación de Roberto Baschetti, Rodolfo Walsh, vivo, que justamente apunta a resaltar el carácter militante de la escritura walshiana, es simultánea a la de Rodolfo Walsh. Ese hombre y otros papeles. 
Un contrito Daniel Link enmienda esta falta para la reedición de 2007, y admite lo siguiente:

Lo que yo no había entendido todavía es que la obra de un escritor ("de un escritor de verdad", como en este caso) nunca es palabra muerta: por eso es difícil (y peligroso) pretender apoderarse de la palabra de los escritores a los que amamos $[\ldots]$

Cuando edité el Diario de Walsh cometí varios errores [...] Pero cometí, sobre todo, éste [...] Pensé que "la literatura" era una cosa separada de "la vida". Olvidé - ¿hace falta decirlo?- un fundamento y una tensión constitutiva de la literatura de Walsh: que no hay separación posible entre literatura y vida. (Link 2007: 6)

La lectura (que ahora se define como errada) de Rodolfo Walsh en términos estrictamente literarios ya era la predominante en su producción crítica sobre el autor. Desde La chancha con cadenas (que incluye el trabajo "Los setenta, Walsh y la novela en crisis", donde Link lo proclama "inventor de la novela sin libro", aunque inmediatamente después pasa a adjudicar la autoría de este "género" a J. L. Borges), pasando por el volumen Cómo se lee y otras intervenciones críticas (donde reproduce con ligeros cambios esta hipótesis sobre Walsh, aunque ahora bajo el título de "Rodolfo Walsh y la crisis de la literatura", con el agregado de una coda donde la no concreción por parte del autor de Operación masacre de su "gran novela" es leída como gesto deliberado y programa estético), hasta llegar al volumen Clases. Literatura y disidencia (que incluye "Negatividad", donde se arriesga una -altamente dudosa- lectura de la “Carta abierta de un escritor a La Junta Militar" en términos de “invitación a la revolución ascética").

En 2014, El Cuenco de Plata reedita los cuatro tomos de Antología del cuento extraño (seleccionados, traducidos y anotados por Rodolfo Walsh en el año 1956 para la editorial Hachette: hay una reedición en 1976), con prólogo de Daniel Link. Allí se enfatiza que "1956 no es sólo el año de publicación de esta antología: es el encuentro de Walsh con el que será su destino literario y político [...] Operación masacre" (Link 2014: ...). No obstante, el prologuista cierra ahora su intervención afirmando que, hasta el mismo día de su muerte, Walsh quiso "volver encarnizadamente" a la práctica de la ficción.

Siete años antes, en la entrada del blog Linkillo. Cosas mías correspondiente al 6 de agosto de 2007 ("Leyendo Operación masacre") y antologizada en Textos de 
ocasión (2012), que también publica en el El Cuenco de Plata, Link había logrado una formulación más ajustada:

El modo en que se resiste a toda clasificación (es decir: a toda normalización) es lo más característico de Operación masacre y de quienes insistimos en su participación respecto de las grandes líneas de debate que atraviesan la literatura contemporánea. Leer Operación masacre como literatura es violentar las ideas que hemos heredado de la antigua cultura burguesa (y que la prensa cotidiana reproduce todavía hoy con un cinismo apabullante) sobre el ejercicio con pretensiones artísticas de la escritura.

En nuestra perspectiva, Operación masacre representa ese momento (necesario para la existencia de algo así como "la literatura") en que lo literario se vuelve en su contra, incluyendo lo que al mismo tiempo excluye. Dicho de otro modo: Operación masacre demuestra, como pocos otros textos, que la literatura sobrevive solamente en un instante de peligro, es ese instante de peligro en que todas las certezas se deshacen. (Link [2007] 2012: 172; énfasis del autor)

Si la lectura "como literatura" de Operación masacre es una forma de violencia productiva sobre un texto "en el que toda definición estética se subordina a la eficacia política" (Link [1995] 1998: 85), en el marco de las "Jornadas Saer" celebradas entre el 28 y 30 de junio de 2011 en la Biblioteca Nacional, Martín Kohan ejercerá el mismo gesto en negativo (en el sentido del negativo fotográfico) sobre la novela Glosa, al leer "como política" un texto en el que toda definición política parece subordinarse a la eficacia estética.

Las “Jornadas Saer", que culminan con la colocación de una placa conmemorativa en el hall de entrada de la Biblioteca Nacional, a seis años del fallecimiento del autor de La grande, son tema de tapa del suplemento "Cultura y espectáculos" de Página/12 correspondiente al martes 28 de junio de 2011 (día en el que Saer, de no haber muerto el 5 de junio de 2005, hubiera cumplido 74 años). La periodista Silvina Friera entrevista a Paulo Ricci (organizador de las Jornadas) y Hernán Ronsino (uno de los expositores de la mesa "La política"). Ambos coinciden en señalar la peculiar forma de relacionar literatura y política en Saer ("narrar lo político sin estridencias", en la fórmula de Ronsino), aunque es Martín Kohan, desde la columna de opinión "Otra forma de contar lo político" que acompaña la entrevista, el que se finalmente se explayará sobre esta cuestión:

Saer apostó, sobre una tradición que podría provenir de Macedonio Fernández, a liberar la novela argentina del mandato de ceder al realismo, a la referencialidad documental, al testimonialismo 
vivencial o a las certezas ideológicas, para poder así decir lo político o narrar lo político [...] Se abren así nuevas posibilidades para la novela. Y al mismo tiempo se establece la exigencia implícita de leer de otra manera. Sin tener que leer "mensaje" ni "realidad" para poder leer política. Y declinando esa tan arraigada antinomia que tiende a desconfiar, en función de lo político, de la esmerada perfección moral que pueda perseguir un texto. Porque Saer ha revelado justamente eso: que la literatura puede decir lo político mucho mejor cuando se sabe lenguaje, mejor aún cuando se vale de la potencia del cuidado de la forma. (Kohan [Entrevistado por Silvina Friera] 2011: 28)

En el marco de la mesa de debate "El universo saeriano a través de sus obras" (que comparte con Beatriz Sarlo, Aníbal Jarkowski y Paulo Ricci), Kohan propone una lectura de Glosa como “ 'la' novela política”. La hipótesis de "la indagación de lo real” es reemplazada por su contraria. Según Kohan, en Glosa existiría "un trabajo narrativo muy concreto con distintos grados de intensidad referencial" (2011: 158), y a "lo político" le correspondería el grado más alto. La ponencia es reproducida en el volumen Zona de prólogos, que Ricci editará a fin de año. Allí, Kohan explica que:

El relato político se consuma en Glosa (o, dicho de otro modo, Glosa se consuma como novela política) mediante esta producción narrativa de diferentes intensidades. No se trata de una ilusión referencial, no se trata de apelar a una serie de deixis eficaces, no se trata de un efecto de realidad por los detalles que parecen no significar nada, no se trata de desplegar el poder de representación de la literatura para aprehender el mundo: se trata de lograr, mediante un juego de debilitamientos y contrastes, un aumento de intensidad en ciertos pasajes del texto, secuencias más intensas que por serlo sugieren un "grado de realidad" más acentuado, para, en los tramos así producidos, contar lo político. (Op. Cit. Kohan 2011: 159)

Dos son las secuencias narrativas con las que Kohan ejemplifica este "grado de realidad" más alto: el suicidio de Leto con la pastilla de cianuro y el comienzo del exilio en París en 1979 de El Matemático luego de que su mujer cayera en manos de las llamadas "fuerzas de seguridad", que irrumpen en el tiempo narrado (año 1961) "como futuro". No hay duda, sostiene Kohan, de que Leto eligió suicidarse con la pastilla. El grado máximo de referencialidad (podríamos decir: de certeza) que se le da a este hecho, escaparía a la lógica general de la "indagación de lo real".

Y aún más: su lectura no sólo se aparta de la línea crítica trazada por María Teresa Gramuglio (y a la que Dalmaroni/ Merbilháa en su aporte para el onceavo tomo de la Historia crítica de la literatura argentina adhieren explícitamente), sino también contraría los términos en los que el propio autor santafesino pretendió ser leído. Esta 
nueva lectura de Glosa como "novela política" constituiría por todo lo dicho el más importante índice de la libertad de criterio (e inventiva crítica) que determinados miembros de la "generación ausente" comenzarían a ganar frente a la tutela de sus "hermanos mayores".

Otro exponente de esta inventiva y libertad críticas es sin duda Ricardo Strafacce, autor de Osvaldo Lamborghini, una biografia.

Por un lado, el gesto demitificador por parte del biógrafo de darle un contexto histórico, político y cultural preciso al biografiado va en contra de las construcciones -iniciadas inmediatamente luego de su muerte- de "El Maestro" (César Aira, Fogwill) o el "escritor maldito" (Germán García). Por otro lado, Strafacce no sólo recontextualiza las supuestas lecturas excepcionales a las que aludiera Aira en su prólogo para Ediciones del Serbal dentro de la típica biblioteca de los setenta, sino que también muestra los baches en la formación del autor de Sebregondi retrocede (y alterna la transcripción de algunos de sus míticos "subrayados perfectos" en los ejemplares conservados en la casa natal de Mar del Plata de su Biblioteca Personal con los que hiciera en Barcelona sobre ignotas novelitas pornográficas españolas). Por último, se observa la práctica una crítica genética que podríamos definir como de tipo biograficista: las fechaciones de los manuscritos aparecen las más de las veces justificadas por su vínculo directo con los avatares familiares, domiciliarios, psíquicos y sexuales del biografiado.

La publicación de Osvaldo Lamborghini, una biografia es tapa de adnCULTURA. La revista cultural de los sábados del diario La Nación correspondiente al 23 de agosto de 2008, que incluye como "anticipo exclusivo" cuatro fragmentos del texto firmado por Strafacce. También, las notas "Un genio exasperado", de Pedro B. Rey; una entrevista al biógrafo ("La literatura de verdad no es cosa de este mundo"), que también realiza Rey, y el trabajo "Sintaxis mayor", de Fogwill, que no solamente comenta la publicación conjunta de $Y$ todo el resto es literatura y Osvaldo Lamborghini, una biografía, sino que toma la segunda como reaseguro para la inclusión definitiva de Osvaldo Lamborghini en una "Antología de los Mayores":

Durante cada una de las once décadas que que sucedieron al siglo XIX, la Argentina tuvo una masa crítica de poco más de un centenar de escritores y, en cada década, tres o cuatro de ellos, entonces considerados los mejores, pudieron distinguirse por una gran virtud o un gran defecto, $\mathrm{y}$, entre ambos, por su estilo particular que hoy permite identificar su autoría teniendo a la vista unos pocos renglones de cualquier página de esa plausible e imaginaria Antología de los Mayores. En ella el poeta Leónidas 
y el polígrafo Osvaldo Lamborghini convivirán con Aira, Arlt, Bioy, Borges, Copi, Fijman, Gelman, Manucho, Juan L. Ortiz, Puig, Saer, Silvina y una veintena más que quedará librada al azar de los antólogos y de los vientos de la época. (Fogwill 2008: 8)

De manera consecuente con esto, Fogwill cierra su aporte lamentando la inexistencia en $Y$ todo el resto es literatura de un trabajo crítico que indague la relación entre las poéticas de los hermanos Lamborghini.

La suave ironía con la que Fogwill evalúa el conjunto de los nueve trabajos que constituyen $Y$ todo el resto es literatura ("lucen impecablemente escritos y ricamente documentados pero -cuestión de gustos- ninguno apuesta a dar cuenta de la obra”), contrasta con el entusiasmo con que celebra la aparición de la biografía firmada por Strafacce, que "por sus transcripciones de cartas, textos y manuscritos puede ser leída como altísima literatura, pero es también legible como la novela de la pasión de un biógrafo" (Op. Cit. Fogwill 2008: 9 y 8, respectivamente). ${ }^{218}$

En septiembre de 2013, esta "pasión de biógrafo" tiene una manifestación compleja: la publicación de La novelita triste de Osvaldo Lamborghini, en una edición conjunta en pequeño formato de milena caserola y El 8vo loco. La mención de La novelita triste "en obra" por parte de Osvaldo Lamborghini entre noviembre de 1976 y enero de 1977 en tres cartas a César Aira y una cuarta que tuvo como destinatario a Héctor Libertella, no sería -según Strafacce- otra de sus fabulaciones para esconder la imposibilidad de escribir, sino prueba fehaciente de su existencia:

Una especie de nostalgia por esa novelita perdida nos llevó a plantearnos la posibilidad de escribir una versión apócrifa. En última instancia, pensamos, la imitación descarada y confesa no de una obra particular sino de un estilo podría considerarse una de las armas -lícitas- de la crítica literaria. El crítico, en lugar de describir los procedimientos e inventariar los temas de un autor, se limitaría, simplemente, a remedarlos. En cualquier caso, este juego en el que nos entretuvimos hace ya algunos años no es nuevo, aunque ha tenido ejecutores seguramente más afortunados. (Strafacce 2013: 6-7)

Si bien el apócrifo adolece de algunos quiebres de registro, importa fundamentalmente como síntoma: el biógrafo que, en su pasión por exhumar inéditos,

\footnotetext{
${ }^{218}$ Osvaldo Lamborghini: una biografia cuenta con el espaldarazo de Fogwill, que junto a Patricio B. Rey es uno de los oradores de la presentación, realizada el 25 de noviembre de 2008 en el Centro Cultural Recoleta. En el marco de la misma, el autor de Los pichiciegos cita a Walt Whitman para señalar que "quien lea la biografía de Strafacce, tocará a un hombre". Contra esto, tanto la nota "Maldito mito" que Alan Pauls firma el 4 de mayo de 2003 para "Radarlibros" celebrando la aparición del primer tomo de Novelas y cuentos en Sudamericana, como las intervenciones de Julio Premat y Luis Chitarroni en Y todo el resto es literatura pasan por alto el rol principal que tuvo Strafacce en la reedición corregida y aumentada de las Obras Completas que aparecen en Sudamericana a partir de 2003.
} 
deviene plagiario. La novelita triste de Osvaldo Lamborghini se constituiría así en puesta en abismo de la acción básica de los "críticos-estrategas": escribir sobre otros para, en verdad, lograr ser mejor leídos.

4.6. "Nueva encuesta a la literatura argentina (2000-2009)". "200 años, 200 libros. Recorridos por la cultura argentina": ingreso de tres miembros de la "generación ausente" en el "Canon del Bicentenario"

El n 325 de $\tilde{N}$. Revista de Cultura tiene como nota de tapa los resultados de la "Nueva encuesta a la literatura argentina" (gestionada por Alejandra R. Ballester y Jorgelina Núñez, de la Redacción de Clarín), que, a partir de una muestra de sesenta casos entre escritores y críticos, apunta a responder "qué nos dejó esta primera década del siglo" mediante un cuestionario fijo de cinco preguntas: “¿Cuáles son, para usted, los libros de autores argentinos más significativos de la década? (Mencione cinco títulos en orden de prioridad)”; “QQué autores, argentinos y extranjeros, tienen gravitación en su obra?”; "Para usted, ¿qué es hoy lo actual y lo caduco en la literatura argentina?”; “Cómo percibe las relaciones entre literatura y mercado?” y “¿Cuáles considera que son las principales instancias de legitimación literaria: la publicación en determinada editorial, el aval de escritores de prestigio, la universidad, la crítica periodística o académica, los suplementos literarios, los blogs, los premios, la presencia en mesas redondas y eventos culturales, la aceptación de los lectores?” (Núñez/ Rodríguez Ballester 2009: 12).

Los 61 encuestados (de los cuales se reproduce su respuesta in extenso) son: Griselda Gambaro, Luis Chitarroni, Alberto Laiseca, Hebe Uhart, Angélica Gorodischer, Diana Bellesi, Beatriz Vignoli, Rodolfo Alonso, Santiago Sylvester, María Moreno, Martín Kohan, Washington Cucurto, Luis Gusmán, Sergio Chejfec, Santiago Llach, Irene Gruss, Pablo Ramos, Félix Bruzzone, Claudia Piñeiro, Gonzalo Garcés, Elvio Gandolfo, Sylvia Saítta, Delfina Muschietti, Patricia Suárez, Aníbal Jarkowski, Martín Prieto, Gonzalo Aguilar, Carlos Busqued, Fabián Casas, Leonardo Oyola, Ana Manzzoni, Oliverio Coelho, Florencia Abbate, Reinaldo Laddaga, Alberto Giordano, Daniel Freidemberg, Marcelo Cohen, Gisela Antonuccio, Leonor Silvestri, Anahí Mallol, Ana María Shua, Gustavo Ferreyra, Rodolfo Edwards, Jorge Boccanera, Jorge Aulicino, Andrés Neuman, Ángel Faretta, Angela Pradelli, Federico Jeanmaire, María Martoccia, Joge Fondebrider, Daniel Link, Guillermo Martínez, Claudia Gilman, Damián Tabarovsky, Mempo Giardinelli, Juan Martini, Adriana Astutti, Osvaldo Aguirre, Miguel Dalmaroni y Matías Capelli. 
El escritor más votado resulta ser César Aira (con 12 votos por Cumpleaños). A él le siguen: Juan José Saer (11 votos por La grande), Diana Bellesi (8 votos por Tener lo que se tiene. Poesía reunida), Arturo Carrera (8 votos por Potlach), Sergio Chejfec (7 votos por Boca de lobo), Ricardo Piglia (7 votos por El último lector), Fogwill (6 votos por Cuentos completos), Alan Pauls (6 votos por El pasado), Irene Gruss (5 votos por La mitad de la verdad), Marcelo Cohen (cinco votos por Donde yo no estaba), Joaquín Gianuzzi (cinco votos por Un arte callado), Juan Gelman (cinco votos por Mundar), Washington Cucurto (cinco votos por Cosa de negros), Félix Bruzzone (cinco votos por Los topos) y Aníbal Jarkowski (cinco votos por El trabajo).

De la nómina es altamente significativo el consenso logrado alrededor de Aira. Con la excepción de Santiago Llach, que afirma provocativamente que "Lo caduco es César Aira”, practicantes y/o defensores de poéticas tan disímiles entre sí como Chitarroni, Laiseca, Chejfec, Garcés, Gandolfo, Saítta, Laddaga, Giordano, Martoccia, Link, Astutti y Dalmaroni mencionan al autor en sus respuestas. ${ }^{219}$

Sobre las instancias de legitimación: Laiseca, Cucurto, Bellesi, Gruss, Ramos, Bruzzone, Prieto, Casas, Oyola, Abatte, Pradelli, Fondebrider, Martínez, Giardinelli, Martini, Astutti y Aguirre coinciden en señalar a los "buenos lectores" (sin mayores precisiones) como la principal. Dentro del colectivo de los "buenos lectores", hay algunos (Sylvester, Chejfec, Saítta, Casas, Giordano, Ferreyra, Boccanera, Aulicino, Gilman y nuevamente Martini) que recortan a los "escritores consagrados" y/ o los "lectores legitimados". Contra su demonización por parte de algunos agentes que ya hemos reseñado, Gusmán elige la Academia como instancia legitimadora:

El destino de los escritores que admiro es inexorablemente la universidad, que necesita siempre de un marginal, un maldito para estar a la vanguardia. Y no me refiero a personas en particular, las hay muy talentosas que trabajan de profesores y con su lectura han sido correas transmisoras muy importantes. Me refiero a un funcionamiento discursivo. Podría nombrar autores que admiro y que han corrido ese destino: Osvaldo Lamborghini, Ricardo Zelarayán, Néstor Perlongher. (Gusmán 2009: 16)

Sólo Santiago Llach y Patricia Sánchez se ocupan en sus respuestas de demonizar la "legitimación mediática", aunque el primero afirma que "ésta es una época de transición esperanzadora y alienante", puesto que se estaría perfilando una

\footnotetext{
${ }^{219}$ Vale aclarar que Giordano elige en verdad un libro sobre Aira (no de Aira): Las vueltas de César Aira, de Sandra Contreras. Como "destacados de no fícción", Ballester y Núñez señalan como más votados a Borges, de Adolfo Bioy Casares y Osvaldo Lamborghini, una biografia, de Ricardo Strafacce.
} 
"tribalización" - vía Internet- de la escritura y un deslizamiento hacia lo performático (Cf. Llach 2009: 16). Su diagnóstico intersecta con el Ricardo Laddaga, aunque éste pone además el énfasis en la "proliferación de editoriales anómalas" (independientes) para postular la existencia de "un sistema con varios centros", harto diferente al de los años '90.

Como parte de los festejos del Bicentenario, fue lanzada el cinco de mayo de 2010 en EUDEBA la colección Serie de los Dos Siglos (bajo la dirección de Sylvia Saítta y José Luis de Diego y con un Consejo Asesor integrado por Jorge Lafforgue, Luis Alberto Romero y Beatriz Sarlo), con el objetivo de proseguir el camino iniciado por la propia editorial en 1960, con la Serie del Siglo y Medio. El catálogo editorial trasunta el deseo de hacer circular no sólo clásicos aparecidos originalmente en los primeros doscientos años de la Nación, sino también, mediante lo que podríamos entender como un movimiento canonizador, incluir textos literarios o ensayísticos que podrían aspirar a serlo.

En el marco de la Feria Internacional del Libro de Buenos Aires Edición 2010 (que tiene como lema "Festejar con libros 200 años de historias"), la Colección presenta sus primeros cuatro títulos, con tapas ilustradas por Hermenegildo Sábat y Huadi: Facundo, de Domingo F. Sarmiento y con prólogo de Carlos Altamirano; Radiografía de la Pampa, de Ezequiel Martínez Estrada y con prólogo de Liliana Weinberg; La cautiva y El matadero, de Esteban Echeverría y con prólogo de Carlos Gamerro y Ema, la cautiva, de César Aira y con prólogo de Sandra Contreras.

Además de señalar la inclusión definitivamente consagratoria de Aira en este primer envío, interesa el prólogo firmado por Gamerro, que repite a las mismas hipótesis sobre Echeverría desarrolladas en El nacimiento de la literatura argentina y otros ensayos, aunque con un registro deliberadamente informal:

La literatura argentina empezó muy bien y muy mal al mismo tiempo, y en manos de la misma persona. El matadero es un buen candidato a ser considerado uno de nuestros mejores relatos de ficción, y es sin duda el primero que vale la pena. El poema narrativo La cautiva, en cambio, a pesar del encono de pedagogos e historiadores de la literatura por promover o imponer su lectura, es tan malo que el único goce que puede producir es el de la risotada incrédula. (Gamerro 2010: 8)

En esta Colección es clara la voluntad de aunar los saberes de la generación de los "hermanos mayores" con los de la "nueva generación de críticos", cuya emergencia 
saludaba Martín Prieto en su Breve historia de la literatura argentina. Los prólogos de los siguientes cuatro títulos, que aparecen los primeros días de noviembre de 2011, se reparten así: Un dios cotidiano, de David Viñas y con prólogo de Aníbal Jarkowski; Realismo y realidad en la narrativa argentina, de Juan Carlos Portantiero y con prólogo de María Teresa Gramuglio; Gotán, de Juan Gelman y con prólogo de Miguel Dalmaroni, y La calle del agujero en la media, de Raúl González Tuñón y con prólogo de Martín Prieto. Para la discusión sobre la "memoria de la literatura II" eje de este capítulo, es importante consignar la aparición en septiembre de 2013 de Por favor, iplágienme!, de Alberto Laiseca (prologado por Hernán Bergara).

El 20 de octubre de 2011 se inaugura la muestra "200 años, 200 libros. Recorridos por la cultura argentina" en el Centro Cultural de la Memoria Haroldo Conti, en curaduría conjunta con la Biblioteca Nacional. La exhibición se plantea como una red ferroviaria de siete líneas (David Viñas, Ricardo Piglia, Ezequiel Martínez Estrada, Jorge Luis Borges, Raúl Scalabrini Ortiz, Rodolfo Walsh y Néstor Perlongher), un río (Haroldo Conti) y seis ramales ("En primera persona", "Ficciones de la vida literaria", "Pasiones", "El peronismo como drama personal", "Poder resistencia y tragedia" y "La lengua en cuestión”) para dar cuenta de los primeros dos siglos de literatura argentina.

Un ejemplo: la "línea Viñas" (una de las más extensas) tiene paradas en Una excursión a los indios ranqueles (Lucio V. Mansilla), Carta a mi madre (Juan Gelman) y La razón de mi vida (Eva Perón). También se destaca en su recorrido el apeadero destinado a "Crítica y Contorno", con libros como Sexo y traición en Roberto Arlt (Oscar Masotta) y Operación Masotta (Carlos Correas).

Para llegar a esta "red", se pidió a Juana Bignozzi, José Emilio Burucúa, Arturo Carrera, José Carlos Chiaramonte, Ángela Di Tullio, Leonora Djament, Jorge Dotti, José Pablo Feinmann, Norberto Galasso, Griselda Gambaro, Germán García, Noé Jitrik, Jorge Lafforgue, Laura Malosetti Costa, Alan Pauls, Eduardo Rinesi, Andrés Rivera, León Rozitchner, Beatriz Sarlo, Alberto Szpunzberg, David Viñas, Eduardo Jozami y Horacio González que eligieran diez títulos incluyendo poesía, ensayo, narrativa e historia.

En lo que hace a los resultados sobre literatura argentina del siglo XX, éstos se dividen entre los previsibles (siete títulos de Borges, cuatro de Arlt, cuatro de Piglia, tres de Cortázar, tres de Walsh, tres de Saer, tres de Gelman, dos de Puig, dos de Viñas, dos de Conti, uno de Gusmán, uno de Aira, uno de Fogwill, uno de Gombrowicz) y los 
inesperados (dos de Leónidas Lamborghini, pero ninguno de su hermano menor). Dentro de las sorpresas, se cuenta la presencia dentro de la nómina de los "200 libros" de las novelas Las Islas, de Carlos Gamerro, El pasado, de Alan Pauls y Ciencias morales, de Martín Kohan. También, la inclusión de Cuando me muera quiero que me toquen cumbia (2003), de Cristián Alarcón.

Más allá de su calidad literaria, las novelas firmadas por Gamerro, Kohan y Pauls tienen tres importantes puntos en común. En primer lugar, fueron bendecidas casi al momento mismo de su publicación tanto por la crítica académica como por la periodística. En segundo lugar, son novelas premiadas (Premio Herralde para El pasado y Ciencias morales). En tercer lugar, han traspasado las fronteras de su lengua de origen: o bien ya han sido traducidas a lenguas extranjeras (El pasado, Ciencias morales), o bien su traducción (aún en proceso) se anuncia como inminente (Las Islas). Por último, para el caso específico de El pasado, es de destacar el rol que jugó la adaptación cinematográfica (y la alta visibilidad de su protagonista, Gael García Bernal, que forma parte del star-system latino de Hollywood) en su proyección internacional. Para octubre de 2005, ya se habían vendido en suelo local 9500 ejemplares de El pasado.

Previamente a su inclusión en "El Canon del Bicentenario", El pasado había sido traducido al francés por André Gabastou (Éditions Christian Bourgois 2005), al inglés por Nick Caistor (Harvill Secker 2007; la edición de bolsillo, aparecida al año siguiente en Random House, tiene un fotograma del film de Babenco como imagen de tapa) y al alemán por Christian Hansen (Klett-Cotta 2009). ${ }^{220}$

Dentro de las múltiples actividades por la participación de la Argentina como País Invitado de Honor en la Feria Internacional del Libro de Fráncfort 2010, el Subcomité de Selección de Traducciones del Comité Organizador para la participación argentina en dicha Feria aprueba en el marco del "Programa Sur" veinticinco propuestas para traducir obras de autores argentinos, entre las que se cuenta Ciencias morales (para ser traducido al alemán por la editorial Suhrkamp de Alemania). ${ }^{221}$ La traducción al inglés

\footnotetext{
${ }^{220}$ A partir de la traducción de El pasado, la editorial Klett-Cotta encomienda a Christian Hansen los siguientes títulos: Historia del llanto (aparece en 2010 como "Historia de las lágrimas") e Historia del pelo (2012). Es interesante detenerse en cómo se acorta cada vez más el intervalo de tiempo entre la publicación del original castellano y su traducción al alemán.

${ }^{221}$ Dentro de la nómina de novelas a ser traducidas que la Cancillería informa a Prensa con el $\mathrm{n}^{\circ}$ de despacho 194/ 09, destacan algunos títulos: Operación Masacre, para ser traducido al francés (por la editorial Christian Bourgois) y al alemán (por la editorial Rotpunktverlag); El entenado y Los pichiciegos,
} 
de la primera novela de Gamerro aparecerá finalmente en el año 2012, en la editorial londinense And Other Stories (en rigor de verdad, fue producto de un trabajo en colaboración entre el autor -que es también traductor profesional- y el traductor contratado por la editorial, Ian Barnett).

Entre marzo y mayo de 2012, la Serie del Recienvenido (dirigida por Ricardo Piglia para Fondo de Cultura Económica) se presenta en sociedad con los títulos Nanina, de Germán García y En breve cárcel, de Sylvia Molloy. Según su editor, "esta es una colección que incluye libros que me parecen importantes, y que por motivos que obedecen a una lógica hermética -que también es la del mercado- tardan en ser reeditados 0 no se reeditan nunca" (Piglia 2012a http://elliberal.com.ar/ampliada.php?ID=41047, consultado el 9.12.2012). El título de la colección es, claro está, un homenaje a Macedonio Fernández, autor de Papeles de recienvenido (1929). Entrevistado el 31 de marzo de 2012 para el diario Perfil, Piglia señala al respecto que:

... hay que leer lo que no se ve en la superficie y eso no quiere decir buscar los textos en las profundidades... En la circulación rápida del mercado, la arqueología podría entenderse como una pausa, un cambio de velocidad. La crítica de por sí es un cambio de marcha en la lectura, uno pasa mucho tiempo trabajando sobre algunos libros. En la edición imagino que la arqueología consiste en aspirar a que los libros encuentren un tiempo propio, cierta persistencia y que los eventuales lectores sigan, o se interesen, en la continuidad. [...] Ya sabemos que Macedonio reaparece siempre como si fuera la primera vez. Un clásico imposible, podríamos decir, nunca está fijo. Es el anticanon, es como si todos sus libros fueran primeros libros. (Piglia 2012b http://www.perfil.com/ediciones/cultura/20124-664-0005.html, consultado el 9.12.2012)

Hasta febrero de 2015, la Colección lleva publicados Nanina, de Germán García; En breve cárcel, de Sylvia Molloy, Oldsmobile 1962, de Ana Basualdo; El mal menor, de Carlos E. Feiling; ¡Minga!, de Jorge Di Paola; El hombre en la orilla, de Miguel Briante; La educación sentimental de la señorita Sonia, de Susana Constante; Gente que baila, de Norberto Soares; La muerte baja en el ascensor, de María Angélica Bosco; ¡Cavernícolas!, de Héctor Libertella; Vudú urbano, de Edgardo Cozarinsky y Río de las congojas, de Libertad Demitrópulos.

para ser traducidos al hebreo (por la Editorial Carmel); y Auschwitz, para ser traducido al polaco (por la editorial Muchaniesiada). 
¿Cuál sería la "línea editorial”? Por un lado, se trata recuperar ciertos textos: o bien aquellos que estaban prácticamente fuera de circulación (por ejemplo, ¡Cavernícolas!, que hasta su reedición en 2014 se mantenía inconseguible en la primera y única edición en Editorial Per Abbat, de 1985), o bien aquellos que permanecían en la periferia del canon (;Minga!, de Di Paola). Por otro lado, se trata de propiciar la relectura de determinados autores en un horizonte interpretativo diferente al de su contexto de recepción original. Un ejemplo: hacer colisionar en la misma serie una correcta novela policial publicada por primera vez en la Colección Séptimo Círculo dirigida por Borges y Bioy (La muerte baja en el ascensor, de María Angélica Bosco) con cierta zona de la vanguardia setentista (García, Libertella). Respecto al segundo punto, son fundamentales los prólogos firmados por Piglia, que consigue leer apuestas escriturarias y/ o operaciones vanguardistas en los textos más insospechados.

Dentro los títulos que conforman la Colección, destaca El mal menor, único título firmado por un miembro de la "generación ausente". En su prólogo, Piglia afirma que: "El mal menor es una novela memorable no sólo por su elaboración de la temática del género o la intensidad de su intriga sino por la calidad de su prosa" (2012c: 11). A continuación, traza una filiación que impresiona como algo forzada (porque, en rigor de verdad, esta "novela de terror" parece más próxima a la imaginería espiritista de Luis Gusmán que al trabajo con el registro de la doxa de Manuel Puig):

Escrita en una prosa cuya precisión y serenidad garantiza la verdad de cualquier escena (o situación extrema) que se narre, en El mal menor los detalles, los matices, los tonos, las resonancias verbales son la materia en la que se teje la trama apasionante de la novela. El cruce entre un clásico narrador en tercera persona, irónico y mordaz, con el relato escrito por una mujer cuya lucidez creciente le permite visiones y registros múltiples hace recordar las inolvidables iluminaciones de la prosa de Manuel Puig. (Op. Cit. Piglia 2012c: 11)

Quizá el punto más claro de contacto entre Feiling y Puig no sea la más o menos feliz mimesis de la voz femenina, sino el trabajo dentro de las más férreas restricciones genéricas como (paradójica) vía para la experimentación formal. Si de perder el distingo entre alta y baja cultura se trata, es altamente significativo que Feiling haya elegido hacer coincidir en el sistema de epígrafes de El mal menor una cita de Apuleyo con otra de Stephen King, ambas en lengua original. 
Sobre el "género de terror", Feiling impartió en octubre/ noviembre de 1996 un seminario en el Centro Cultural Ricardo Rojas (departamento de extensión universitaria de la UBA) y escribió dos trabajos, ambos antologizados en Con toda intención: "Monstruos y cirugías" y "La pesadilla lúcida (Apuntes sobre el género de terror, prólogo a una antología)". La antología a la que se alude es Los mejores cuentos de terror, que publica la editorial rosarina Ameghino en 1997, mismo año de la muerte del autor.

En "La pesadilla lúcida", Feiling parte de una definición general del género ("pretende, entre otras cosas, producir miedo en el lector mediante [...] elementos sobrenaturales, por lo común presentados como hostiles o dañinos para los seres humanos" ([1997] 2005: 255) para avanzar sobre un ensayo de tipología, que diferencia entre "el terror gótico", "el terror burgués"; "el terror fantástico" y "el terror cinematográfico". Precisamente, El mal menor se inscribiría en este último. Como segundo punto de intersección con Puig, podría señalarse la autoconstrucción de un "mito de autor" por parte de Feiling, que prescinde de la biblioteca como insumo del laboratorio de la ficción.

En efecto: en el texto sobre El mal menor que Feiling publica el 25 de abril de 1996 en el suplemento "Cultura y Nación" de Clarín ("El terror de los inocentes") para promocionar su novela, éste señala las películas de zombis y de vampiros como sus principales intertextos, al mismo tiempo que -en comunión con Puig- hace de la asunción del punto de vista femenino uno de los logros políticos de su novela, puesto que -siempre según Feiling- el "género de terror cinematográfico", como la pornografía, cosificaría a la mujer (Feiling 1996: 7).

Aunque cronológicamente preceda a todo lo expuesto en este apartado, hemos dejado para el final algunas notas sobre la colección Libros del Bicentenario que dirige Ezequiel Grimson, porque su formato (similar al de un atado de cigarrillos) y costo (una moneda de un peso al momento de su lanzamiento, en octubre de 2007) la aproximan a algunas apuestas de las llamadas "editoriales artesanales" surgidas luego de la crisis de diciembre de 2001, que serán tema del próximo parágrafo.

El material coeditado por la Biblioteca Nacional y Ediciones del Zorzal impresiona como fuertemente heteróclito: en la colección conviven Mariano Moreno con Flora Tristán, César Aira con Ernesto "Che" Guevara". Hay poemas de Juan L. Ortiz y Leónidas Lamborghini; cuentos de Diego Tatián, H. G. Oesterheld, J. L. Borges, 
Eduarda Mansilla, Fogwill, Eduardo Wernicke y Benito Lynch; crónicas de Guillermo Enrique Hudson y textos políticos de John William Cook (y un largo etcétera). Todos los géneros se hacen presentes: cuento, crónica, novela, teatro, ensayo político, poesía, manifiesto, documentos historiográficos. La inclusión de Correo argentino (Apuntes Urbanos), de Martín Kohan y La mala suerte de los animales, de Christian Ferrer en este mar de títulos no parece tener por lo mismo demasiada explicación.

La política editorial termina de enrarecerse cuando recabamos en el tiraje (2000 ejemplares por título) y la distribución (una vieja máquina expendedora de cigarrillos, pero que se ubica en el hall de entrada de la Biblioteca Nacional, uno de los espacios más institucionales e institucionalizadores que existen).

Inspirada según el testimonio del director de la Biblioteca en el famosísimo verso de Raúl González Tuñón ("si quiere ver la vida color de rosa/ eche veinte centavos en la ranura"), la Colección interesa como síntoma de la importancia que reviste la construcción de un catálogo editorial. Su carácter fallido también alerta sobre la centralidad de la instancia de la distribución (porque prácticamente ninguno de los lectores que frecuenta la Biblioteca se siente seducido por el juego vanguardista de la "máquina expendedora de libros", que no sólo está situada al lado de los ascensores de acceso, sino al costado de la librería que vende al público todo el material serio que publica Ediciones Biblioteca Nacional)

Materialidad del libro, construcción de una línea editorial y distribución: sobre la correcta evaluación de la importancia de estos tres factores se edificaron numerosos proyectos editoriales luego del llamado "Argentinazo" (diciembre 2001) y alrededor de la crisis económica mundial del año 2008.

CODA. Crisis de 2001: "nuevas editoriales artesanales" y "primavera editorial" (2002-2004). Surgimiento de los "pequeños sellos editoriales" alrededor de la crisis económica de 2008

En La sociedad excluyente. La Argentina bajo el signo del neoliberalismo (2005), la historiadora Maristella Svampa enmarca el surgimiento de las llamadas "nuevas editoriales editoriales" dentro de un "conjunto heterogéneo de actores sociales movilizados" (2005: 263). Luego de la larga década de neoliberalismo se observaría la proliferación de "formas autoorganizadas de lo social" (asambleas barriales, fábricas recuperadas por sus trabajadores, expansión de los colectivos culturales y de información alternativa), algo que "puso de manifiesto hasta qué punto la cultura 
constituye un eje de reconstrucción de la experiencia individual, y, a la vez, una expresión de resistencia colectiva, sobre todo para las clases medias movilizadas" (Svampa 2005: 265).

Según datos recabados por la Cámara Argentina del Libro, en el año 2000 se registraron 13.149 títulos, de los cuales 11.717 fueron novedades y 1432, reimpresiones. Al año siguiente, hubo 18.651 títulos registrados (920 reimpresiones). El sábado 12 de enero de 2002, el suplemento "Cultura y Nación" de Clarín tiene como nota de tapa "El libro en coma". Jugando con la jerga económica que ya para entonces era parte de la vida cotidiana del desesperado argentino medio, Raquel Garzón titula su intervención "Las librerías se declaran en default", y da las siguientes cifras del derrumbe:

A la lista de especies en peligro de extinción, la recesión sumó las librerías argentinas [...] Con una cadena de comercialización quebrada -librerías que no venden y por ende no pagan a editoriales que no cobran y retienen títulos o declinan importar debido a la incertidumbre cambiaria-, el mercado editorial entró en terapia intensiva [...] Desde 1999 las ventas cayeron un 50\%. Entre 2000 y fines de 2001, 250 librerías cerraron sus puertas. Muchas de las que aún sobreviven, trabajan por debajo del punto de equilibrio, esto es, a pérdida, cancelando sólo gastos fijos y financiándose con una "bicicleta" a las editoriales: algunas están pagando recién hoy libros vendidos en el 2000. Muchas ya tienen el crédito cortado y no reciben libros nuevos [...] El panorama en el Interior es de una desculturización vertiginosa: en la provincia de La Rioja quedan 4 librerías; 3, en toda Catamarca [...] Las librerías de calle Corrientes ya registran alzas de hasta un 35\% en el precio de libros traídos de España, y las nuevas listas de algunas editoriales prometen aumentos promedio del $20 \%$ en los argentinos, originados en la suba de la tinta y el papel extranjeros. (Garzón 2002: 3)

En su nota "El futuro del mercado editorial” para el mismo Suplemento, Ana Laura Pérez señala que todas las editoriales (también los "mégaholdings") están embarcadas en planes de ajuste. Random-House-Mondadori-Sudamericana, que despidió empleados en diciembre, ocultaría un sobrante de devolución en sus depósitos de tres millones de ejemplares. El Grupo Planeta anuncia que durante enero-febrero no distribuirá ningún libro en nuestro país, y que, a partir de marzo de 2002, sólo editará por mes un máximo de diez nuevos títulos, reduciendo las tiradas de 5000 a 3000 ejemplares para los libros de narrativa y ensayo firmados por autores argentinos. Todo esto, por supuesto, impacta sobre la calidad de la oferta, que se simplifica al máximo en aras de recuperar una mínima rentabilidad mediante la reedición de autores europeos ya consagrados en ediciones bolsillo (que entre julio y diciembre de 2001 ha visto crecer en un $100 \%$ su 
aceptación), o la apuesta a los best-sellers clásicos con el aventón de sus adaptaciones cinematográficas (El señor de los anillos y la saga Harry Potter).

Precisamente sobre el empobrecimiento de la oferta en términos cualitativos versa la nota “¿Quiénes deciden hoy qué libros se leen en la Argentina?”, que firma Patricia Kolesnikov (de la redacción de Clarín) en el ejemplar del diario correspondiente al jueves 5 de diciembre de 2002. En el marco de su investigación, la periodista dialoga con Fernando Estévez, gerente editorial de Alfaguara (entonces parte del Grupo Prisa), que no tiene mayor empacho en confesar que "en nuestra editorial va sobre seguro la contratación de un autor que viene con nombre y con un piso de ventas asegurado" (Estévez [Entrevistado por Patricia Kolesnikov] 2002: 30). Dicho "piso" se fija en tres mil ejemplares vendidos en un lapso máximo de un año, lo que explica al cartelito de "No se reciben orginales" en la entrada de la editorial Sudamericana (parte entonces del Grupo Bertelsmann, en sociedad con Random House-Mondadori). ${ }^{222}$

No obstante, tanto los editores de las llamadas "editoriales independientes" como los de las que fueron obsorbidas por los grandes grupos, esperan que la crisis termine impactando de manera positiva en el sector. Por un lado, se cree posible compensar con exportaciones las escasas ventas locales, dado que los libros argentinos comienzan a ser comparativamente más baratos luego de la devaluación. Por otro lado, habida cuenta de la capacidad ociosa de las imprentas y la posibilidad de disponer por un menor costo de personal altamente calificado, se cree factible que los Grupos comiencen a editar en el país. En palabras de Guillermo Bargna, gerente comercial de Alfaguara: "probablemente las grandes tiradas del Grupo Santillana, como por ejemplo los libros del Premio Nobel José Saramago, podrán hacerse aquí y distribuirse hasta en la ultra cerrada plaza española" (Bargna [Citado en Ana Laura Pérez] 2002: 1). Por último, la cautela de los grandes Grupos al momento de editar material nuevo es vista como una oportunidad inédita para los sellos más chicos, que podrían así lograr la visibilización de sus títulos en las grandes librerías o los suplementos culturales de los medios masivos, asociarse y buscar nuevas estrategias en lo que hace a la distribución.

\footnotetext{
${ }^{222}$ Entre febrero y marzo de 2001, el grupo Bertelsmann termina de adquirir el $100 \%$ de Sudamericana mediante su compañía editorial Random House y de su brazo en América Latina, Plaza \& Janés. En diciembre de 2012, Bertelsmann finalizará la adquisición del 100\% del capital social del sello Random House-Mondadori (formado en julio de 2001), tras haber recibido la aprobación de las autoridades españolas de defensa de la competencia. De este modo, se autoriza a Bertelsmann a comprar la participación de Mondadori en la antigua joint-venture española participada al 50\% por Random House y la italiana Mondadori.
} 
Luego de la crisis del año 2001 que lleva a la salida de la convertibilidad y que produce una fuerte caída (de alrededor de un 25\%) en la producción editorial, se observa la aparición de las llamadas "editoriales artesanales", entre las cuales Eloísa Cartonera ("editorial cartonera" y cooperativa de trabajo gestionada a partir de 2002 por Washington Cucurto junto al artista plástico Javier Barilaro) es la más visible. Según Malena Botto en "Esos raros proyectos nuevos. Reflexiones para la conceptualización de las nuevas prácticas editoriales", su característica principal es "la vuelta sobre el libro en tanto objeto estético, que es texto pero también textura, que lleva en sí todas las marcas de su producción, pero también otra serie de marcas que lo vuelven portador de ideología tanto, y en muchos textos más, que los textos mismos” (2011: 3).

Como segunda característica principal, estas editoriales sostienen la idea de que "un autor es un editor", y que la instancia material de la edición (la publicación mediante impresoras caseras, la fabricación artesanal de tapas con materiales de desecho que, paradójicamente, hacen de cada libro un objeto-arte irrepetible, el enhebrado o cosido manual de cada uno de los ejemplares que se editan) es tan importante como el proyecto literario mismo. Al respecto, se observa una marcada desdiferenciación entre los roles del escritor, el editor, el diseñador gráfico y el imprentero, proceso que -más allá de la lectura positiva de Svampa- podría también ser interpretado en términos de “desprofesionalización”. 223

Ya en la instancia de "distribución y venta" (las comillas van a cuenta de que estas categorías resultan extemporáneas a este tipo de proyectos), prevalece por último la idea de que un autor debe ser necesariamente también un performer y un "agitador cultural" (también en la modalidad blogger). Asimismo, cambian de naturaleza los lectores: dejan de ser pensados como anónimos y pasan a ser cooptados en encuentros "cara-a-cara" (recitales de poesía, performances de lectura con música), o bien se los interpela de manera personalizada -valga la paradoja- a través de Internet.

Otras editoriales que, aunque aparecidas años más tarde, adhirieron al espíritu de Eloísa Cartonera son: Clase Turista (a partir de 2005, gestionada por Esteban Castromán, Lorena Iglesias e Iván Moiseeff, con tirajes excepcionales -como Eloísa Cartonera- de 500 ejemplares por título); Colección Chapita (a partir de 2006, gestionada por Daniel Durand -pionero durante los años noventa en esta modalidad artesanal de edición con Ediciones DelDiego, que cerró debido a la crisis en el año

${ }^{223}$ La única de estas "editoriales artesanales” que tiene personal rentado es Eloísa Cartonera. 
2001-, con tirajes de 50 ejemplares); Funesiana (surgida en 2007, gestionada por Lucas Oliveira, con tirajes de 40 ejemplares); Editorial Mancha de Aceite (a partir de septiembre de 2009, "la primera editorial independiente de San Francisco Solano", gestionada por Walter Lezcano y Patricia Jiménez con tirajes de 20 ejemplares); La Gota (a partir de 2009, gestionada por Gonzalo Geller, Cande Rivero y Pablo Escudero, se jacta de ser "la editorial más chica de Sudamérica", con tirajes de 12 ejemplares).

En su trabajo "Los nuevos desafíos de la resistencia cultural" (2008), Sonia Budassi caracteriza el período 2002-2004 como una "efímera primavera" para la edición llamada independiente. ${ }^{224}$ En efecto: es entonces que se observa la aparición de una segunda camada de pequeños sellos, de características más tradicionales que las arriba descritas en lo que hace a la materialidad de sus volúmenes (no hay, en este caso, tapas hechas de cartón ni forradas en plush, ni "intervenidas" con chapitas de gaseosa), y números de tirada (entre 1000 y 2000 ejemplares por título).

Entre las "editoriales independientes" que le dedican un importante espacio a la publicación de narrativa, cabría mencionar la editorial InterZona (co-fundada en 2002 por Damián Ríos, de la cual fue director editorial hasta mediados de 2006; desde entonces y hasta su cierre en 2008, realizó dicha función Damián Tabarovsky); Santiago Arcos Editor (surgida en 2002, su editor es Miguel Villafañe, con la importante participación inicial de Laura Estrín en el diseño de la política editorial); El Cuenco de Plata (a partir de 2004, su director es Edgardo Russo) y Editorial Entropía (también surgida en el año 2004, sus editores son Valeria Castro, Sebastián Martínez Daniell, Gonzalo Castro y Juan Manuel Nadalini). Poco después se sumarán, entre las más destacables: Mansalva (a partir de 2005, dirigida por Francisco Garamona), Editoral Tamarisco (surgida en 2006, sus editores son Hernán Vanoli, Félix Bruzzone, Sonia Budasi y Violeta Gorodischer) y Milena Caserola (a partir de 2005, dirigida por Mariano Quiroga, con libros de pequeño formato).

En el año 2008, una nueva crisis económica (esta vez de alcance mundial), explicaría la menguante cifra de 20.038 títulos registrados (frente a 22.245 en el 2007). En 2008, además, se contrajo el número de tiradas de 5000/6000 a 2600/ 2900

\footnotetext{
${ }^{224}$ Luego del derrumbe económico de diciembre 2001-febrero 2002, entre los años 2002 y 2004 se da un incremento relativo acumulado del $86 \%$. Si bien éste se halla sostenido por los números de los grandes grupos editoriales, que rediseñan sus estrategias para el nuevo escenario, el informe del Centro de Estudios para la Producción del año 2005 sobre la industria editorial señala que fueron las firmas que facturan menos de 500.000 pesos anuales las que registraron, en promedio, un mayor aumento en la productividad (de un $47,7 \%$, frente al $25 \%$ en el caso de las grandes editoriales).
} 
promedio. De las 2.285 editoriales inscritas en el ISBN, el $83 \%$ publicó menos de 10 títulos. La contribución de libros al PBI fue del 0, 025\%, aunque ya finalizando el 2008 había crecido por quinto año consecutivo, confirmando que la industria editorial es la primera en caer en contextos de crisis, pero también la primera en recuperarse tan pronto éste mejora. Nuevamente, el proceso se ve acompañado por el surgimiento de una tercera camada de "editoriales independientes" (la primera, recordemos, se había producido en la década del noventa).

Entre las más comprometidas con la edición de ficción, se cuentan: Eterna Cadencia (desde agosto de 2008: sus editores son Pablo Braun y Leonora Djament); La Bestia Equilátera (surgida en 2008, su director editorial es Luis Chitarroni); Mil Botellas (surgida en 2008, sus directores son Ramón Taruella y Sofía Silva); Editorial 17 Grises (surgida en 2009, sus editores son Guillermo Goicochea y Maximiliano Crespi); Pánico al Pánico (surgida en 2009, sus editores son Marina Gersberg y Luciano Lutereau, con un Comité Editorial integrado por Ariel Idez, Matías Pailos, Pablo Farrés y Sebastián Robles); Factotum Ediciones (a partir de 2009, su directora es Andrea Stefanoni); la ya mencionada InterZona (refundada en noviembre de 2010 bajo la dirección de Guido Indij); Ediciones Outsider (surgida en 2010, sus directores son Valeria Iglesias y Enzo Maqueira); Mardulce Editora (a partir de 2011, su director editoral es Damián Tabarovksy y sus directores generales, Juan Zorraquín y Gabriela Massuh) y Wuwei Editorial (creada en 2011, su director es Luis Mazzarello). ${ }^{225}$

En la mesa redonda "Boom editorial. Pasado, presente y futuro" en el marco de la $39^{\circ}$ Feria Internacional del Libro de Buenos Aires "Libros como puentes" (25 de abril al 13 de mayo de 2013), los editores Maximiliano Crespi, Hernán Vanoli y Enzo Maqueira comparten experiencias y evalúan los límites y potencialidades de la llamada "edición independiente".

En su intervención, Crespi señala que el decidirse por fundar una editorial independiente tiene muchas veces que ver con una sensación de "incomodidad" o "extrajería respecto a la matriz ideológica del campo editorial de la época" (Crespi 2013, mimeo). En el caso de 17 Grises, se trata de apostar por autores "verdaderamente nuevos" ("no editar a Guebel, Bizzio, Cucurto como si fuesen novedad"), que no sólo

\footnotetext{
${ }^{225}$ El 18 de julio de 2013, el Museo del Libro y de la Lengua de la Biblioteca Nacional lanzó el "Mapa Celeste de Editoriales Argentinas", inmenso trabajo de relevamiento de todos los sellos editoriales activos en el país, desde 1764 a la actualidad. La búsqueda puede realizarse por orden alfabético o por categorías, a través de una pantalla táctil instalada en el primer piso de Av. Las Heras 2555. De dicho banco de datos hemos seleccionado algunas de las editoriales más relevantes para el planteamiento de nuestras hipótesis.
} 
sean firmantes de libros de calidad, sino sostenedores de proyectos escriturarios interesantes, y que detenten algún tipo de visibilidad en la escena cultural (como es el ejemplo de Sebastián Hernaiz, parte del grupo editor de la revista digital el interpretador, a quien por aquel entonces 17 Grises acababa de publicarle Rodolfo Walsh no escribió Operación Masacre y otros ensayos ).

Según Crespi, las editoriales pequeñas muchas veces funcionan como "laboratorios baratos para las grandes editoriales". Esto es: un escritor novel publica allí un primer título y es "descubierto" gracias a esta primera edición por un editor que trabaja para un Grupo, por lo que rápidamente "migra" a una editorial grande para la edición de su segundo o tercer libro. Dentro de los ejemplos aducidos, se menciona paradójicamente a Félix Bruzzone (por ser uno de los fundadores de Tamarisco), cuya obra está siendo reeditada por Mondadori.

Los problemas que enfrentan las más pequeñas entre las llamadas "editoriales independientes" (esto es: las que sacan dos o tres libros por año) son: (1) el financiamiento: del "éxito de ventas" de un título depende la posibilidad de publicar el próximo; (2) la distribución, señalada como el principal escollo a superar; (3) la no profesionalización del staff: editores que son también diseñadores gráficos ad hoc, lo que repercute en la calidad del arte de tapa. Puesto que el libro es un "bien simbólico" inmerso en una cultura de la imagen y el packaging, que sea poco atractivo visualmente lo volvería inmediatamente un objeto "no vendible".

Por su parte, Vanoli comienza su exposición afirmando provocativamente que ser "independiente" no es un valor en sí. Asimismo, señala la necesidad de historizar la llamada "edición independiente", puesto que habría considerables diferencias entre, citando su ejemplo, InterZona o Entropía y su propia editorial (Tamarisco), especialmente en lo que hace a recursos y "políticas editoriales" (aquí coincide con Crespi en que su editorial apunta a publicar "gente con un proyecto intelectual, no sólo a gente que le gusta escribir"). Otro punto interesante para nuestro análisis es que Vanoli destaque como un valor excepcional de Tamarisco el no cobrarle a los escritores noveles por la publicación, lo que nos alerta de la delgada línea que separa la publicación en un sello independiente de la llamada "edición de autor".

Por último, Enzo Maqueira elige autodefinirse menos como "editor" que como “agitador cultural". En su testimonio, describe el proyecto de Ediciones Outsider en términos de un colectivo cultural y performático. De los tres editores, Maqueira es el 
que más enfatiza la importancia de las nuevas tecnologías (Facebook, Twitter) para darle visibilidad a la edición independiente. En el caso específico de Ediciones Outsider, las nuevas tecnologías son también un espacio posible para la creación: el lanzamiento en 2010 del "concurso de micro relatos en twitter", que son publicados en la página WEB de la editorial.

Si los tres editores cuyos posicionamientos hemos reseñado dirigen proyectos que bien podrían ser caracterizados como los "más chicos entre los independientes", en la nota de investigación "Los nuevos audaces" que realiza Carolina Menéndez Trucco para ADNCultura de La Nación (publicada el 9 de agosto de 2008) se dan las características de cinco editoriales cuyos tirajes oscilan entre 1000 y 2000 ejemplares. Para ello, Menéndez Trucco entrevista a los editores de Eterna Cadencia (Leonora Djament y Pablo Braun), Ediciones Winograd (Alejando Winograd), La Bestia Equilátera (Diego D’Onofrio, Natalia Meta y Luis Chitarroni), La Compañía (Eduardo Berti), y Negro Absoluto (Juan Sasturain).

Como primera característica, tanto en el caso de Djament (ex empleada de Alfaguara y Norma) como en el de Chitarroni (que trabajó durante veinticinco años para Sudamericana) se percibe la voluntad de reaprovechar el savoir fair adquirido para “editar los libros que nos gustaría leer" (Cf. Djament y Chitarroni [Entrevistados por Carolina Menéndez Trucco] 2008: 13).

En segundo lugar, el principal problema a vencer es nuevamente la distribución. En el caso de Eterna Cadencia (como, agregamos, en el de Mansalva), los editores han solucionado el problema fundando, además de la editorial, una librería, que funciona además como distribuidora para otras editioriales independientes que no disponen de un espacio propio de venta directa al público. En el caso de Ediciones Winograd, la cuestión se resolvió (de manera excepcional para este tipo de emprendimientos) aliándose con Cúspide, una de las más grandes distribuidoras del país. En el caso de La Bestia Equilátera, al momento de la entrevista la editorial mantenía su página WEB cómo único método de difusión del material editado y canal de compra. ${ }^{226}$

En tercer lugar, los editores coinciden en que la especificad y calidad del material es el único método fiable para asegurarse la supervivencia económica. O bien se dedican a un género específico (el policial en Negro Absoluto, que además tiene la

\footnotetext{
${ }^{226} \mathrm{Al}$ día de la fecha, Eterna Cadencia y La Bestia Equilátera son distribuidas por Waldhutter.
} 
particularidad de editar tres títulos por autor, brindándole a éste -según el testimonio de Sasturain- una "autonomía absoluta" en lo relativo a los contenidos y el estilo), o bien se dedican a exhumar rarezas en cuidadísimas traducciones al español realizadas por escritores argentinos (La Compañía, La Bestia Equilátera), o bien proponen catálogos que giran alrededor de determinados "escritores de culto" (la escocesa Muriel Spark en el caso de La Bestia Equilátera).

En cuarto lugar, la imposibilidad de sacar más de ocho títulos por año es vista paradójicamente como una ventaja. En palabras de Diego D’Onofrio: “Una editorial muy grande, que saca al mercado una gran cantidad de libros por año, no puede hacer ese seguimiento; pero nosotros [...] podemos realizar una perfecta selección y cuidar cada libro" (D’Onofrio [Entrevistado por Carolina Menéndez Trucco] 2008: 13).

En este marco, la impronta que Luis Chitarroni le da a la línea editorial de La Bestia Equilátera podría ser tomada como muestra cabal de las correspondencias entre el proyecto literario (como "crítico-estratega") y el trabajo como editor. Por lo mismo, no es casual que como lanzamiento se publiquen en septiembre de 2008 conjuntamente Los encubridores, de Muriel Spark y Mil tazas de té, del propio editor. Además de fiscalizar la calidad de las traducciones (vale destacar que entre los miembros del staff de traductores de La Bestia Equilatera se cuenta César Aira), Chitarroni toma las funciones de compilador y prologuista. En la solapa de Mil tazas de té, se anuncian los siguientes títulos en preparación: Tostadas de jabón y Veneno de Tarántula, de Julian Maclaren-Ross; La muerte de los filósofos en manos de los escritores (Prólogo y selección de Luis Chitarroni); Memento mori, de Muriel Spark; Ha entrado un camello, de Lord Berners y Consideraciones acerca del honor, el duelo y otros temas del siglo XIX (Prólogo y selección de Luis Chitarroni).

Al respecto, vale recordar las "Siluetas", que Chitarroni publicaba en Babel, revista de libros, y el volumen Los escritores de los escritores, publicado por él en la editorial Perfil en 1997, donde lo que precisamente interesa es rescatar determinadas lecturas realizadas por determinados escritores sobre sus pares, poniendo a los exégetas al mismo nivel de importancia que los autores comentados.

Si para los editores responsables de los proyectos "artesanales" surgidos alrededor de 2001 y para los que -surgidos más tarde- toman su inspiración del proyecto Eloísa Cartonera ser escritor es ser un "agitador cultura" y un editor (poniendo énfasis en la dimensión material del proceso de la edición de libros), muchos de los proyectos 
surgidos alrededor de la crisis económica del año 2008 se colocan bajo la divisa borgiana de que ser editor es, fundamentalmente, ser un lector de calidad.

La compra el 20 de marzo de 2014 de Alfaguara por parte del Grupo Penguin Random House (a través de su filial Santillana de Ediciones Generales, S. L.) al Grupo Prisa por un monto de 72 millones de euros (algo más de 100 millones de dólares) podría ser considerada el hito final en lo que hace al proceso de concentración editorial que se iniciara en la década del noventa. Además de Alfaguara, el Grupo Penguin adquiere los sellos de Taurus, Aguilar, Suma de Letras, Objetiva, Punto de Lectura, Altea y Fontanar, quedando excluidas de la venta el segmento de obras y actividad que realizan Alfaguara Infantil y Juvenil dirigidas al mercado educativo.

Tal como lo señala Bárbara Álvarez Plá en "Hiperconcentración: Penguin Random House compró Alfaguara", el resultado de esta operación es "un monstruo editorial compuesto por 250 sellos, con unos ingresos que superarán los 4.200 millones de dólares al año" (Álvarez Plá 2014 http://www.clarin.com/sociedad/HiperconcentracionPenguin-Random-House-Alfaguara 0 1105089549.html, consultado el 25.3.2014)

Uno de los sellos más poderosos dentro de los adquiridos por el Grupo Penguin es, sin lugar a dudas, Alfaguara, que ese año celebra el $50^{\circ}$ aniversario de su fundación, y que publica -entre otros- a Mario Vargas Llosa, José Saramago, Carlos Fuentes o Günter Grass, además de a los autores ganadores del Premio Clarín de Novela, algunos de los cuales (como Claudia Piñeiro) terminan siendo parte del catálogo editorial.

Las consecuencias de haber entrado (o no) en el catálogo de un Grupo son insoslayables, tanto en lo que hace a la visibilidad como al tipo de circulación de los narradores de la "generación ausente". De todas formas $-\mathrm{y}$ la estrategia parece haber sido aprendida de César Aira- varios de los autores estudiados persiguen al mismo tiempo ingresar en catálogos de prestigio, ser parte de la nómina de los "autores secretos" de pequeñas pero prestigiosas "editoriales independientes" y/ o ganar visibilidad y asegurarse algún tipo de rentabilidad económica mediante la firma de jugosos contratos con los grandes Grupos.

El caso paradigmático de lo señalado es Martín Caparrós, que comenzó publicando en editoriales pequeñas como Ada Korn (Ansay o los infortunios de la gloria, año 1984), De La Flor (No velas a tus muertos, año 1986) y Puntosur (El tercer cuerpo, año 1990), ingresó al prestigioso catálogo de Sudamericana (La noche anterior, 
año 1990) y sorprendió luego con una edición de lujo de su monumental La historia (1999) en el Grupo editorial colombiano Norma. Escasos dos años más tarde publicó Un día en la vida de dios en Tusquets, fue favorecido con el Premio Planeta Latinoamérica con su novela Valfierno (Edición 2004) y pasó a integrar el catálogo del Grupo homónimo, para terminar recalando -premiación de Los Living mediante- en la editorial Anagrama, donde continúa publicando hasta el día de hoy. En el marco de este derrotero "ascendente", cabe destacar la reedición en 2012 de El tercer cuerpo en editorial debolsillo (parte del grupo Penguin Random House).

De todas formas, es importante señalar que ninguno de los integrantes de la “generación ausente” aquí reseñados -con la excepción, quizá, de Rodrigo Fresán y Guillermo Martínez- articula de manera enteramente exitosa con el mercado de libros.

En un contexto de uniformidad creciente de la oferta, el rol del colectivo de editoriales englobadas - pese a las importantes diferencias que mantienen entre sí- como "independientes", cobra especial relevancia. Sus mentores coinciden en sostener su independencia no respecto al "mercado" (puesto que, como cualquier empresa, su objetivo de mínima es generar algún tipo de ganancia), sino respecto a la rentabilidad a cualquier precio que caracteriza a los conglomerados. La fuerte presencia de los escritores pertenecientes a la "generación ausente" en sus catálogos (VER Apéndice 2) también nos alerta sobre que toda política de la literatura es también una política de la edición.

Contra este vínculo con el mercado de libros por momentos errático, el análisis del tercer apéndice de este trabajo ("Traducciones a lenguas extranjeras de las novelas escritas por la 'generación ausente' reseñadas en el marco de la presente tesis") llevaría a inducir una muy temprana (y, a partir de la diversidad de lenguas en que son vertidas las novelas escritas por determinados miembros de "la generación ausente", ya casi podríamos decir diversificada) inserción en la escena literaria internacional.

Si bien la traducción al inglés es la condición sine qua non para que un libro efectivamente circule por fuera de las fronteras de su país y/ o idioma, son por lo mismo particularmente llamativas la traducción al polaco de la novela Auschwitz, de Gustavo Nielsen (aunque aquí cabría sospechar que fueron las ominosas resonancias del título el factor que más pesó a la hora de tomar la decisión de verter a una lengua tan exótica un texto que ni siquiera había sido traducido previamente al, contradiciendo lo dicho anteriormente, idioma inglés) y las traducciones al chino, francés, portugués, griego, 
holandés, macedonio, noruego, polaco, rumano, serbio, alemán e inglés de Acerca de Roderer, de Guillermo Martínez (cuya primera edición argentina, recordemos, aparece en la colección "Biblioteca del Sur" dirigida por Juan Forn). En el caso de Martínez, las fechas en que estas traducciones son publicadas contituyen un dato fundamental: casi todas ellas son posteriores a la adaptación cinematográfica de su novela Crímenes imperceptibles.

Las traducciones se realizan fundamentalmente por tres motivos. O bien porque determinado texto es tomado como parte de una política estatal de subsidio a la traducción y/ o difusión de la literatura local en el mundo (por ejemplo: el ya mencionado Subcomité de Selección de Traducciones del Comité Organizador para la participación argentina en la Feria Internacional del Libro de Fráncfort 2010). O bien porque el texto en cuestión ha gozado de un éxito considerable en su país o ámbito lingüístico de influencia, que se cree factible replicar en otras geografías y/ o lenguas (y se trata entonces las más de las veces de un texto perteneciente al género novela y construido sobre el molde del mid cult: todas las novelas de Guillermo Martínez, por ejemplo). O bien porque su autor ha ganado un premio literario con cierta proyección continental y / o internacional (lo que explicaría la traducción al alemán en el año 2004 de la novela Los ojos así, de Miguel Vitagliano, luego de que ésta fuera galardonada por el Premio Anna Seghers, distinción con que la fundación homónima distingue anualmente la obra de un escritor latinoamericano).

De todas formas, constatar el mero hecho de que una novela ha sido publicada en una lengua extranjera determinada no dice nada sobre sus efectos de lectura y recepción allende sus fronteras nacionales y/ o lingüísticas. A dicha constatación le faltaría precisar qué tipo de editorial se hizo cargo de la traducción (como siempre: es muy distinto aparecer publicado -también en traducción- en una "editorial independiente", o en una editorial que es parte de un Grupo) y con qué campaña promocional fue acompañada dicha traducción en su lanzamiento.

Estos puntos, que por falta de espacio no desarrollaremos en este apartado, deberían ser contemplados para que el Apéndice 3 adquiera algo más de espesor en tanto herramienta heurística para colaborar en la puesta en común de las razones por las cuales determinados nombres de la "generación ausente" ocupan hoy posiciones privilegiadas en el campo literario, perfilándose ya como la "memoria de la literatura II" futura. 


\section{Conclusiones del capítulo}

A lo largo del capítulo hemos intentado precisar la participación de determinados nombres de la "generación ausente" en cuatro grandes "ciclos de canonización" que habrían tomado lugar de 1985 a hoy. Habiendo firmado trabajos en diversas publicaciones periódicas, expuesto sus puntos de vista como conferencistas y/ o participado como ponentes en congresos y jornadas, luego del cambio de siglo muchos de ellos coinciden en el gesto de "hacer libro" de dichas intervenciones. El gesto de "hacer libro" no es menor, sino que daría cuenta de un veloz proceso de visibilización y adquisición de capital simbólico por parte de los agentes estudiados.

Recuperando argumentos publicados dos años antes en la revista milpalabras, Damián Tabarovsky lanza en 2004 un breve volumen que funciona como disparador de la discusión sobre la "literatura de izquierda", donde resuena el viejo ideal de Héctor Libertella de la "nueva escritura". La discusión, además de su interés intrínseco, tiene su importancia en tanto resulta sintomática del persistente sistema de lealtades (personales, pero fundamentalmente estéticas) de tipo intergeneracional que vincula a determinados miembros de la "generación ausente" con determinados "hermanos mayores". Por otra parte, tanto el sistema de lecturas que plantea el libro de Beatriz Sarlo publicado en 2012, Ficciones argentinas, como la inclusión por parte de Ricardo Piglia de El mal menor, de Carlos E. Feiling en la Serie del Recienvenido, darían cuenta de la reciprocidad de esta relación.

En efecto: en su rol de "crítico-estrategas" los miembros de la "generación ausente" operan las más de las veces de forma mancomunada con sus "hermanos mayores", repitiendo antinomias usadas durante los setenta para volver inteligible el campo ("vanguardia VS. populismo"), o bien reivindicando las poéticas de escritores como Osvaldo Lamborghini, Alberto Laiseca o Héctor Libertella (que ya habían sido promocionados por César Aira y/ o Fogwill en los tempranos ochenta). Con determinados "hermanos mayores", comparten además espacios de enunciación que, en contraste con el predominio otorgado a la prensa periódica durante las décadas del ochenta y noventa como tribuna desde la cual pronunciarse, aparecen como fuertemente institucionalizados. La participación de los agentes estudiados en la Historia crítica de la literatura argentina (dirigida por Noé Jitrik) y la colección Serie de los Dos Siglos en EUDEBA son buenos ejemplos de lo dicho. 
De todas formas, bien vale destacar algunas lecturas recientes que escapan a la prédica de los "hermanos mayores": la lectura de Glosa en tanto "novela política" realizada por Martín Kohan y la lectura fuertemente epocal y contextualista (en el buen sentido del término) que propone Ricardo Strafacce de la supuesta excepcionalidad de la figura y escritura de Osvaldo Lamborghini (que, a su vez, el estilo del biografiado sea "plagiable" -tal como se pretende demostrar La novelita triste de Osvaldo Lamborghini- sería precisamente un argumento extra en contra del mito impulsado por César Aira de su supuesta genialidad).

Si hay algo "nuevo" en los escritores de la "generación ausente", es la inteligencia estratégica con la que operan en un "mercado de libros" no sólo crecientemente polarizado, sino también cada vez más transnacional. Al respecto, la trayectoria de Martín Kohan (de publicar su primer libro en la vieja Sudamericana a fundar la editorial independiente Tantalia Ediciones, para luego reeditar sus primeras novelas en la editorial barcelonesa - parte del Grupo Random House Mondadori- debolsillo, al mismo tiempo que integra el catálogo de Anagrama y es traducido al inglés, alemán, italiano y francés) sería un ejemplo paradigmático de cómo sobrevivir en el mercado, tal como solía recomendar Héctor Libertella. 


\section{Apéndice 2: Nómina de las novelas escritas por la "generación ausente" reseñadas en el marco de la presente tesis con sus primeras ediciones y reediciones}

Bizzio, Sergio. El divino convertible (Catálogo Editora 1990)

Bizzio, Sergio y Daniel Guebel. El día feliz de Charlie Feiling (Beatriz Viterbo 2006)

Brizuela, Leopoldo. Una misma noche (Alfaguara 2012)

* Caparrós, Martín. Ansay o los infortunios de la gloria (Ada Korn Editora 1984; Seix Barral 2005)

* Caparrós, Martín. La noche anterior (Sudamericana 1990)

* Caparrós, Martín. El tercer cuerpo (Puntosur, 1990; debolsillo 2012)

* Caparrós, Martín. No velas a tus muertos (De la Flor 1986)

* Caparrós, Martín. A quien corresponda (Anagrama 2008)

* Caparrós, Martín. Los Living (Anagrama 2011)

Chejfec, Segio. Lenta biografía (Puntosur 1990; Alfaguara 2007)

Chejfec, Segio. Los planetas (Alfaguara 1999; Alfaguara 2010)

Chitarroni, Luis. El carapálida (Tusquets 1997; InterZona 2013)

Chitarroni, Luis. Peripecias del no. Diario de una novela inconclusa (InterZona 2007; La Bestia Equilátera 2013)

de Jager, Jan. Noticias del setenta y cinco (Grupo Editor Latinoamericano 2009)

Feiling, Carlos E. El agua electrizada (Sudamericana 1992; Norma 2007)

Feiling, Carlos E. El mal menor (Planeta 1996; Norma 2007; Fondo de Cultura Económica 2012)

Figueras, Marcelo. Kamchatka (Alfaguara 2003; Punto de Lectura 2013)

Forn, Juan. Corazones cautivos más arriba (Emecé 1987; Alfaguara 2001)

Fresán, Rodrigo. Historia Argentina (Planeta 1991; Anagrama 2009)

Fresán, Rodrigo. Esperanto (Tusquets 1995; Mondadori 2011)

Fresán, Rodrigo. Jardines de Kensington (Mondadori 2003; debolsillo 2006)

Gamerro, Carlos. Las Islas (Simurg 1998; Norma 2007)

Gamerro, Carlos. El sueño del señor juez (Sudamericana 2000; veintisiete letras 2008)

Gamerro, Carlos. El secreto y las voces (Norma 2002; Edhasa 2011)

Gamerro, Carlos. La aventura de los bustos de Eva (Norma 2004; Norma 2009)

Gamerro, Carlos. Un yuppie en la columna del Che Guevara (Edhasa 2011)

Guebel, Daniel. La perla del emperador (Emecé 1990; La Bestia Equilátera 2010)

Guebel, Daniel. El terrorista (Sudamericana 1998)

Guebel, Daniel. El perseguido (Norma 2001)

Kohan, Martín. El informe. San Martín y el otro cruce de los Andes (Sudamericana 1997; Sudamericana pocket 1999; debolsillo 2014)

Kohan, Martín. Los cautivos. El exilio de Echeverría (Sudamericana 2000)

Kohan, Martín. Dos veces junio (Sudamericana 2002; debolsillo 2007; debolsillo 2008)

Kohan, Martín. Ciencias morales (Anagrama 2007)

Kohan, Martín. Cuentas pendientes (Anagrama 2010)

Lanata, Jorge. Muertos de amor (Alfaguara 2007)

Martínez, Guillermo. Acerca de Roderer (Planeta 1992; Planeta 1999; Planeta 2002; Planeta 2006; Planeta 2007)

Meik, Gaby. Sinfonía para Ana (Corregidor 2004)

Mira, Rubén. Guerrilleros (Una salida al mar para Bolivia) (Tantalia 1993; Diada 2007)

Monacelli, Fernado. La mirada del ciervo (Mondadori 2008)

Monacelli, Fernando. Sobrevivientes (Alfaguara 2012)

Nielsen, Gustavo. La flor azteca (Planeta 1997) 
Nielsen, Gustavo. Auschwitz (Alfaguara 2004)

Pauls, Alan. El coloquio (Emecé 1990)

Pauls, Alan. El pasado (Anagrama 2003)

Pauls, Alan. Historia del llanto. Un testimonio (Anagrama 2007)

Pauls, Alan. Historia del pelo (Anagrama 2010)

Pauls, Alan. Historia del dinero (Anagrama 2013)

Prieto, Martín. Calle de las escuelas $N^{o} 13$ (Libros Perfil 1999)

Ratto, Patricia. Trasfondo (Adriana Hidalgo 2012)

Sánchez, Matilde. El desperdicio (Alfaguara 2007)

Stamadianos, Jorge. Latas de cerveza en el Río de La Plata (Emecé 1995)

Strafacce, Ricardo. Gerardo y Mercedes (WuWei 2013)

Vieytes, Raúl. Kelper (Aguilar 1999)

Vitagliano, Miguel. Posdata para las flores (Último Reino 1991)

Vitagliano, Miguel. Los ojos así (Tusquets, 1996) 


\section{Apéndice 3: Traducciones a lenguas extranjeras de las novelas escritas por la "generación ausente" reseñadas en el marco de la presente tesis}

*Caparrós, Martín. A quien corresponda (al alemán: Berlin Verlag 2014)

*Caparrós, Martín. Los Living (al frances: éditions Buchet-Chastel 2013)

Chejfec, Sergio. Los planetas (al inglés: Open Letter Books 2012)

Figueras, Marcelo. Kamchatka (al francés: éditions du Panamá 2007; al alemán: Verlag Nagel \& Kimche AG 2006 y pb dtv 2008; al hebreo: Yedioth 2012; al italiano: L'Asino d'Oro 2014; al holandés: Signatuur 2007; al polaco: Muza 2005; al rumano: Allfa 2013; al ruso: Inostranka 2007; al serbio: Dereta 2007; al turco: Dogan 2014; al inglés: Atlantic 2010 y Grove Atlantic 2011)

Fresán, Rodrigo. Esperanto (al francés: Gallimard 1999)

Fresán, Rodrigo. Jardines de Kensington (al francés: éditions du Seuil 2004; al inglés: Faber \& Faber Ltd 2005 y Farrar, Straus and Giróux 2006; al griego: Papyros Graphic Arts 2010)

Gamerro, Carlos. Las Islas (al inglés: An Other Stories 2012)

Gamerro, Carlos. La aventura de los bustos de Eva (al inglés: An Other Stories 2015)

Kohan Martín. Ciencias morales (al inglés: Serpent's Tail 2012)

Kohan, Martín. Dos veces junio (al alemán: Suhrkamp 2009; al francés: éditions du Seuil 2012)

Kohan, Martín. Segundos afuera (al alemán: Suhrkamp 2007; al inglés: Serpent's Tail 2010)

Kohan, Martín. Ciencias morales (al alemán: Suhrkamp 2010)

Martínez, Guillermo. Acerca de Roderer (al ingles: St Martin's Press 1994; al alemán: Eichborn Verlag 2009 y Ficher Taschenbuch Verlag 2011; al chino: Ed. Shangai 99 2010; al francés: Pavillons Poche 2008 y Nil 2011; al portugués: Sextante Editora 2010; al griego: Ekdoseis Pakate 2008; al neerlandés: Sgnatuur 2010; al macedonio: Antolog 2010; al polaco: Swiat Ksiazki 2010; al rumano: Humanitas 2008; al serbio: Laguna 2005; al noruego?)

Nielsen, Gustavo. Auschwitz (al polaco: Muchaniesiada 2010)

Pauls, Alan. El coloquio (al francés: L' Instruction 1992; al portugués?)

Pauls, Alan. El pasado (al inglés: Harvill Secker 2007; al alemán: Klett-Cotta 2009; al francés Cristian Bourgois éditeur 2005; al ruso: Publishing Group "Azbooka-Klassika" LLC 2010; al portugués: Publicaçoes Dom Quixote 2010; al italiano: Feltrinelli 2007; al griego?)

Pauls, Alan. Historia del llanto (al francés: Christian Bourgois éditeur 2009; al alemán: Klett-Cotta 2010; al italiano: Fazi 2009)

Pauls, Alan. Historia del pelo (al alemán: Klett-Cotta 2012; al francés: Christian Bourgois éditeur 2010; al italiano: Sur 2012)

Pauls, Alan. Historia del dinero (al alemán: Klett-Cotta 2014; al francés: Cristian Bourgois éditeur 2013; al portugués: Cosac \& Naify Ediçoes 2008; al italiano: Sur 2014)

Vitagliano, Miguel. Posdata para las flores (al alemán: Lateinamerika Verlag 2005) 


\section{CONCLUSIONES GENERALES}

El 11 de agosto de 2012, Luis Chitarroni firma el principal aporte al dossier de tapa "Nuevas ficciones argentinas. Panorama de la narrativa joven" correspondiente al número 463 de $\tilde{N}$. Revista de Cultura. Chitarroni aparece ahora ocupando el lugar de "hermano mayor" para promocionar las narrativas de veintiséis "escritores sub cuarenta", que son definidos por él como las "figuras de la literatura del siglo XXI", entre las que se contarían: Natalia Moret, Alejandra Zina, Matías Capelli, Oliverio Coelho, Pola Oloixarac, Ariel Magnus, Gonzalo Garcés, Pablo Katchadjian, Leandro Ávalos Blacha, Javier Sinay, Rodolfo Palacios, Gabriela Cabezón Cámara, Ariel Idez, Féliz Bruzzone, Sebastián Robles, Josi Havilio, Luciano Lamberti, Buddy Glass, Selva Almada, Hernán Vanoli, Violeta Gorodischer, Alejandro López, Ignacio Molina, Marina Mariasch, Mariana Enríquez y Leonardo Oyola.

En su aporte, Chitarroni caracteriza a los "sub cuarenta" en contraste con su propia generación de pertenencia (Cf. Chitarroni 2012: 8-9). Contra la "tradición de la ruptura" que habrían mantenido las generaciones del setenta y ochenta, los representantes de la narrativa joven "simplifican y aplanan los linajes, las líneas de parentesco" (lo que da como extraño resultado que César Aira y Julio Cortázar resulten -al mismo tiempo- los más votados como sus máximos inspiradores). Contra la creencia de "los mayores" (entre los cuales Chitarroni se permite ahora incluirse) en el "arte como factura, logro, técnica", se observaría un corrimiento hacia el "dialecto de la experiencia" (Los topos, de Félix Bruzzone), pero también hacia la "artesanía y la facilidad maquínica, relojismos, prestidigitación y cirugía" (El aleph engordado y El Martín Fierro ordenado alfabéticamente, de Pablo Katchadjian). ${ }^{227}$

Si bien afirma que esta "narrativa joven" se habría liberado de "la Angustia de las influencias" (mayúsculas en el original), Chitarroni se ocupa de subrayar la existencia de precursores. Según su lectura, El miedo, de Gonzalo Garcés, sólo habría sido posible luego de Derrumbe, de Daniel Guebel. Asimismo, se distinguiría una línea de continuidad entre la novelística de Marcelo Cohen y la "genialidad sintáctica" del autor

\footnotetext{
${ }^{227}$ En "Conversando con Freud y Dostoievski", Pola Oloixarac coincide en la primera parte de este diagnóstico, al afirmar que "mis contemporáneos están preocupados por documentar la realidad. Bucean sus clases sociales, sus géneros sexuales, para dar con el diamante de su expresión verbal. Son etnógrafos de su tiempo, son (¿somos?) testigos de lo real [...] En este reverso del canon, los diálogos tendrían un rol preeminente: son una garantía de un oído para el conurbano y la ciudad” (2012: 12).
} 
de La perla del emperador, y la fe exotista presente en Los invertebrados y Borneo, de Oliverio Coelho. En resumen: determinados miembros de la "generación ausente" ocuparían ahora-siempre según Chitarroni- el espacio de prestigio y tutela detentado en los tempranos ochenta por Ricardo Piglia y Juan José Saer.

En su intervención, "Fantasías de la era digital", Daniel Link agrega dos características para la "narrativa joven" (a la que coincide con Chitarroni en oponer un "nosotros, los mayores"): su relación fluida con las nuevas tecnologías digitales (que posibilitarían nuevos mecanismos de publicación, distribución y lectura) y -de manera paradójica- la práctica limitada de las ciberediciones. De forma anacrónica (acusa Link) la máxima aspiración de los más jóvenes sigue siendo la publicación en papel, y, en lo posible, formando parte del catálogo editorial de un Grupo. ${ }^{228}$ Así, las nuevas tecnologías digitales estarían siendo usadas como mero trampolín para cumplir un viejo anhelo, y no alterarían la vieja lógica de la propiedad intelectual (domiciliada, en su origen, en el soporte libro).

Sobre ésta y otras cuestiones se detiene Damián Tabarovsky en sus respuestas a Mauro Libertella en el contexto de la entrevista grupal que comparte con Mariana Mariasch y Hernán Vanoli ("Nuevas formas de vida para la literatura"). Tabarovsky señala tres grandes características para la "literatura argentina de la última década" (la expresión es del entrevistador): (1) la posibilidad -tanto más próxima en comparación con lo que ocurría en las décadas del ' 80 y '90- para un joven escritor de publicar un primer libro y/ o de llegar a "ser tomado por un medio mainstream, como puede ser $\tilde{N}$ " gracias a la visibilidad que otorga Internet y el auge y la consolidación de las llamadas "editoriales independientes"; (2) "cierto desapego" -que deplora- "de lo intelectual" y (3) la incomprensión de la apuesta escrituraria de César Aira, que -siempre según Tabarovsky- es leído en la actualidad en los reductores términos de una literatura pop. $^{229}$

\footnotetext{
228 "Eso sí: la 'nueva crítica', los 'nuevos narradores' y los 'nuevos poetas' siguen dando entrevistas a los suplementos de los diarios y aspirando a publicar sus libritos en las multinacionales de turno, una vez que la visibilidad lograda gracias a algún blog afortunado consiguió llamar la atención de los asesores literarios de los grandes medios editoriales.” (Link 2012: 18)

229 "Lo que pasa también con la intelectualización que yo reclamo es que se lee de un modo muy vago y parcial la tradición. Me molesta por ejemplo cierta literatura contemporánea que lee a Aira entendiéndolo sólo como el escritor pop, Yo era una chica de siete años, sin ver que detrás de Aira está toda la literatura latinoamericana, todo Mansilla, una gran lectura política, etc... Ahí los efectos de recepción son triviales." (Tabarovsky [Entrevistado por Mauro Libertella] 2012: 26)
} 
En el marco de esta entrevista grupal, son de destacar las diferencias de opinión y evaluación entre Tabarovsky y Vanoli respecto a la calidad y circulación de la "literatura argentina de la última década". Contra la melancólica reivindicación que hace el primero de "la lengua de la literatura que politiza zonas del discurso que parecen a priori despolitizadas o neutras [...] la literatura como algo que te excluye, el idiota de la familia" (Cf. Op. Cit. Tabarovsky [Entrevistado por Mauro Libertella] 2012: 26-27), el segundo afirma con desenfado que "esa ambición de que la literatura horade posiciones de poder es muy utópica y dio como producto libros que me parecieron francamente aburridos" (Vanoli [Entrevistado por Mauro Libertella] 2012: 26). Otro punto poblemático es la pregunta por (la ausencia de) una "nueva crítica". Tabarovsky lamenta que sea siempre Beatriz Sarlo quien, reivindicando el lugar del "crítico puro", deba ocuparse de dar cuenta de la "nueva narrativa" (en alusión a sus intervenciones publicadas en el suplemento literario del diario Perfil dirigido por Maximiliano Tomas, que, como ya señalamos, escasos tres meses más tarde serán antologizadas y publicadas como libro bajo el título de Ficciones argentinas. 33 Ensayos). Contra esto, Vanoli reivindica una "crítica más sociológica" (la línea David Viñas), y celebra el "montón de críticos" (la mayor parte de las veces: desconocidos) que se pronuncian desde el espacio de los blogs. ${ }^{230}$

De todas formas, es de destacar la cautela con la que tanto Tabarovsky como Vanoli eligen exhibir sus diferencias. Se trata, nuevamente, de una relación de coloquio, donde nunca termina de hacer eclosión la disputa generacional.

Que determinados miembros de la "generación ausente" comiencen a postularse en la actualidad ocupando la posición de "hermanos mayores" respecto a otros agentes sería un indicio del largo (y exitoso) camino recorrido de fines de los años ochenta del siglo XX a hoy. También lo sería el ingreso de tres de sus miembros (Martín Kohan, Alan Pauls y Carlos Gamerro) al "canon del Bicentenario" y/ o "canon de mercado [transnacional]" (ejemplificamos este segundo derrotero con las trayectorias de Guillermo Martínez y Rodrigo Fresán).

En este proceso de consagración serían fundamentales tanto el férreo sistema de alianzas -tanto intergeneracionales como intrageneracionales- mantenidas a lo largo del

\footnotetext{
230 "Yo leo muchos blogs y ahí encuentro un montón de críticos, voces que hablan de libros que están siendo publicados, cosas mejores y peores. Muchas veces no sé quiénes son los que escriben, y eso también me parece seductor." (Vanoli [Entrevistado por Mauro Libertella] 2012: 27)
} 
tiempo, como el sostenido desempeño del rol del "crítico-estratega", que se desplegó inicialmente desde las páginas de determinadas revistas literarias y suplementos culturales en términos de adhesión a una "tradición selectiva" ya en disponibilidad, hasta llegar a la participación directa en la conformación de la "memoria de la literatura II", pasando por la fundación y sostenimiento de proyectos editoriales de distinto tenor.

Pensada desde acá, la novela $D A F$ (por la sigla "Deficiente Aptitud Física", que equivalía hasta su derogación en enero de 1995 por la Ley 24.429 a la exención del Servicio Militar Obligatorio), de Beatriz Vignoli podría ser tomada como una puesta en abismo de los derroteros personales y editoriales de la "generación ausente". Ambientada entre 1981 y 1999 y situada en la ciudad imaginaria de Atopia, la novela fue publicada como folletín entre 1992 y 1999 en la contratapa del suplemento Rosario/ 12 de Página/ 12 dirigido por Pablo Feldman (para el cual trabajó como colaboradora Vignoli entre 1998 y 2000). De ella se publicaron además tres fragmentos en El Litoral de Santa Fe y uno en El ciudadano (la escena "en tiempo real" fechada el 31 de diciembre de 1999, que terminaría clausurando la novela).

Recién en el año 2014, DAF fue publicada como libro por la editorial Bajo La Luna -en una versión harto diferente a la que estuvo "colgada" del sitio WEB poesia.com entre los años 2000 y 2002-. $D A F$, por último, contituye una "memoria en la literatura" de la "generación ausente" (que la autora bautiza como "generación inútil" en el primer capítulo publicado el 29 de enero de 1992 en Rosario/ 12), que, por lo mismo, entraría tardíamente a armar sistema con las narrativas de Miguel Vitagliano, Juan Forn, Daniel Link, Alan Pauls y Matilde Sánchez que hemos reseñado en la coda correspondiente al capítulo uno.

Si a fines de la década del ochenta y durante toda la década del noventa las revistas literarias y suplementos culturales fueron la tribuna privilegiada para apuntalar proyectos narrativos aún incipientes, la revista Otra parte podría ser tomada como el último intento de conformar un "nosotros" estético y generacional. ${ }^{231}$ Al respecto,

\footnotetext{
${ }^{231}$ Otra parte ( ${ }^{\circ} 1$ : primavera-verano $2003-\mathrm{n}^{\circ}$ 30: otoño-invierno 2014) tuvo en su dirección a Graciela Speranza y Marcelo Cohen. Integraban el Consejo Asesor del primer número: Damián Tabarovsky, Alan Pauls, Alejandra López, Guillermo Kuitca, Inés Katzenstein y Fabián Casas. En la contratapa del último número anuncian la disolución de la publicación en los siguientes términos: "Lectores: al cabo de doce años, los que hacemos OTRA PARTE queremos acordar con la impermanencia de todas las cosas, despedir una etapa y ponernos a trabajar en otra. Este número es el último con el formato al que ya estábamos habituados. OTRA PARTE Semanal, nuestra revista virtual de reseñas, seguirá publicándose en la web todos los jueves, como prueba de que el espacio de disidencias que compartimos con ustedes
} 
repetimos la importancia del gesto de hacer libro por parte de varios miembros de la "generación ausente" al antologizar trabajos pensados en su origen para soportes más efímeros (artículos y reseñas de libros en la prensa periódica, ponencias en congresos, conferencias).

Si, como señalábamos en la Introducción de este trabajo, las últimas tres décadas estuvieron signadas por cuatro grandes debates (la acusación a los sobrevivientes de los campos clandestinos de detención y exterminio de haber salvado sus vidas convirtiéndose en "traidores"; la aparición disruptora del discurso de H.I.J.O.S; la resignificación de los detenidos-desaparecidos en términos de "combatientes" y la polémica sobre los efectos que el uso de la violencia tuvo sobre las prácticas y valores sostenidos por las organizaciones político-militares de los años '60 y '70), finalizando la primera década del siglo XXI se percibirían nuevos nudos problemáticos.

En primer término, la reconsideración de la violencia represiva de Estado en términos de continuidades, $\mathrm{y}$, de manera interrelacionada, la redefinición de la dictadura en términos de "dictadura cívico-militar" (con el concomitante debate sobre los llamados "cómplices civiles").

En otras palabras: la puesta en duda de la visión instaurada en 1983, que parte de una lógica binaria de "dictadura-actor militar VS. democracia-actor civil". Al respecto, es importante destacar el amplio espectro en que el sintagma "dictadura cívico-militar" circula hoy: desde los libros de divulgación 1976. El golpe civil. Una historia del mal en la Argentina (2011), del periodista Vicente Muleiro, hasta el activismo cultural de la agrupación H.I.J.O.S. (que el 23 de mayo de este año realizaron un escrache contra los empresarios Vicente Massot y Carlos Blaquier, para denunciarlos públicamente como ejemplares de "genocidas civiles"), pasando por documentadas indagaciones de corte académico, como, por ejemplo, Un enemigo para la nación. Orden Interno, violencia y “subversión”, 1973-1976 de la historiadora Marina Franco que hemos reseñado al comienzo de este trabajo, y Cuentas pendientes. Los cómplices económicos de la dictadura (2013), que compilan Horacio Verbistsky y Juan Pablo Bohoslavsky.

Lejos del facilismo del nuevo prólogo del Nunca más, que, persiguiendo dar un mentís definitivo a la "teoría de los dos demonios", termina postulando la relación de la sociedad con el horror desde una mirada perfectamente inversa a la del prólogo original (pero igual de totalizante, según la cual el pueblo, sin fisuras, habría enfrentado el terror

sigue activo. Sabemos que en el deseo de diferentes formas de vida y la atención a la época ya se esbozan formatos nuevos". 
dictatorial), comienza a indagarse la responsabilidad civil en términos de complicidad civil activa (militantes populares capturados por denuncias de vecinos, por ejemplo). De manera convergente, Sebastián Carassai socava en Los años noventa de la gente común. La naturalización de la violencia (2013) la extendida hipótesis de la "simpatía con la guerrilla por parte de la sociedad civil” entre, para fecharla con escaso margen de error, los años 1966 y 1973.

En tercer término, comienza a hablarse de los bautizados como "muertos por la guerrilla" por los líderes de la asociación Argentinos por la Memoria Completa, en espacios que exceden los círculos castrenses y eclesiásticos más recalcitrantes. Si bien los relatos militantes que reivindican la víctimas del terrorismo estatal y condenan a los genocidas son hoy parte de la memoria hegemónica, algunos jóvenes historiadores (como Vera Carnovale en una ponencia de 2014: "Verdades, mentiras y silencios en las memorias de la 'guerra revolucionaria' ") comienzan a postular la necesidad de reconsiderar de manera crítica los casos de personas ejecutadas selectivamente por la guerrilla entre 1969 y 1979.

En cuarto y último término, se enuncia muy tímidamente la necesidad de ajustar la cifra de "30.000 detenidos-desaparecidos", sin por ello ser acusado inmediatamente de negacionista. Un temprano ejemplo es el ensayo La historia íntima de los derechos humanos en la Argentina, publicado en 2009 por Graciela Fernández Meijide.

Si bien, tal como lo hemos expuesto en el capítulo tres, los autores de la "generación ausente" demostraron tener un oído avezado para captar los debates que se iban dando de manera contemporánea a la escritura, en sus posicionamientos mediados por la literatura no se arriesgaron a formular contra-relatos que resultaran políticamente inaceptables, o que no tuvieran su eco garantido en amplios sectores de la sociedad civil. Incluso -como en el caso de A quien corresponda, de Martín Caparrós- en su búsqueda de incomodar no fueron más allá de la repetición de cierta zona de la doxa progresista.

En otras palabras: el gesto de volver a narrar el decenio 1973-1983 por parte de los miembros de la "generación ausente" fue acompañado, fundamentalmente, de la apuesta por hacer de la literatura un modo de circulación (en términos de Astrid Erll) de algunas voces soslayadas (los conscriptos de Malvinas, los "segundones" del aparato represivo, los "hijos tempranos"), pero no del intento de hacer estallar el relato de la memoria hegemónica. 
Donde sí los autores estudiados se revelaron como fuertemente originales fue en su cuidadosa -por momentos también imprevisible- aleación de poéticas "en disponibilidad", lo que dio como resultado una peculiar "política de la literatura". También, en su gran inteligencia estratégica para comparecer-como autores, pero también como editores- tanto en los espacios "anárquicos" del mercado como en los más inficionados por las leyes de la oferta y la demanda. Por último, el "canon argentino" al día de la fecha no se comprendería sin recabar en la sostenida participación de varios de los novelistas estudiados en su edificación.

Hay, sin embargo, algo del orden del resto (del desecho) que no pudo ser incorporado luego de los "cuatro grandes ciclos de canonización" que hemos descrito. Haciendo nombres: ni la "política de la literatura" de cuño más lumpen que la de Jorge Asís (aunque en su momento igualmente exitosa en términos editoriales) de Enrique Medina, ni la vanguardia irrisoria de Emeterio Cerro, ni la apuesta estético-vital de Néstor Sánchez, tanto más intransigente que la patafísica lúdica de Julio Cortázar.

Estos y otros nombres (cabría agregar, por ejemplo, el de Jorge Barón Biza, leído recientemente por Alan Pauls para la antología Los malditos como el último -el único"maldito" de nuestra tradición literaria) nos alertan sobre dos hechos. ${ }^{232}$

El primero: que no siempre los miembros de "la generación ausente" fueron permeables a la prédica de sus "hermanos mayores" respectivos (ilustramos esto último con la pequeña polémica alrededor de Emeterio Cerro -que Aira intentó infructuosamente promocionar en Babel, revista de libros). Lo segundo: que no toda marginalidad es susceptible de ser transformada en canon. En otras palabras: que no debería inferirse la calidad reversible de la condición complementaria de "lo marginal" y "lo canónico", tal como lo explica Noé Jitrik en su trabajo "Canónica, regulatoria y transgresiva" (1998). El caso donde indudablemente esta reversión sí tuvo lugar, fue el de Osvaldo Lamborghini, cuya obra gráfica fue expuesta en su totalidad en el Museo Museo de Arte Contemporáneo de Barcelona a comienzos de este año, con el título de "El sexo que habla", bajo la curaduría de Valentín Roma (y aportes de Alan Pauls y César Aira en la edición del catálogo-libro).

\footnotetext{
${ }^{232}$ La antología Los malditos (compilada y prologada por Leila Guerriero) incluye un perfil de diecisiete autores latinoamericanos, que, por razones tanto de índole personal como literaria, son englobados bajo la categoría de "malditos". Ellos son: Jorge Barón Biza, Alejandra Pizarnik e Ignacio Anzoátegui, de Argentina; Teresa Wilms Montt, Rodrigo Lira y Joaquín Edwards Bello, de Chile; Bernardo Arias Trujillo y Porfirio Barba Jacob, de Colombia; Jaime Saenz, de Bolivia; Samuel Rawet, polaco radicado en Brasil; Pablo Palacio, de Ecuador; Jorge Cuesta, de México; Calvet Cassey, nacido en EEUU pero cubano por elección; Rafael José Muñóz, de Venezuela; César Moro, de Perú y Gustavo Escanlar, de Uruguay.
} 
En la Introducción a este trabajo sosteníamos la necesidad de mantener cierta vigilancia epistemológica, para no confundir categorías nativas (o visión emic) con puntos de partida válidos para nuestra investigación.

Si bien por una cuestión de adscripción disciplinar, a lo largo de este trabajo se ha enfatizado más la necesidad de no confundir expresiones como "nueva narrativa" o "editoriales independientes" con supuestos datos objetivos del campo, ya sería justo admitir que buena parte del instrumental sobre la historia reciente muestra estas características. Porque "terrorismo de estado" también es una categoría nativa y la utilizamos como si fuera un dato, un concepto, fundado, absoluto e indiscutible (simplemente porque hoy forma parte de nuestro sentido común deseable).

A este recaudo metodológico inicial cabría explicitar otro: el intento de recuperar, más allá de las expresiones verbales sobre su quehacer por parte de determinados "crítico-estrategas" que se autodefinieron como pertenecientes a la "generación ausente", las cambiantes condiciones materiales en el marco de las cuales su producción novelística fue efectivamente escrita, publicada, traducida, reeditada y/ o premiada. Por lo mismo, los parágrafos cuatro a seis inclusive del capítulos dos, la coda correspondiente al capítulo cuatro y los tres apéndices a este trabajo piden ser leídos como un contrapunto necesario a la hipótesis en exceso general (aunque por demás atrayente en su simplicidad) de Martín Caparrós, enunciada el $1^{\circ}$ de diciembre de 1991 desde las páginas del suplemento "Primer Plano": la idea de que "la tensión de la literatura con el mercado" habría reemplazado, finalizando los años ochenta, "la tensión con la política" (prototípica de la década anterior).

El 24 de marzo de 2013, en su discurso de cierre del acto de conmemoración por el $37^{\circ}$ aniversario del golpe militar, Estela de Carlotto afirmaba que:

Reivindicamos la lucha inmensa que dieron esos 30.000 hombres y mujeres para cambiar la Historia. Y a pesar de que hoy no están, creemos que pudieron, que no nos han vencido porque estamos acá, porque podemos decir que lo que ellos hicieron fue hermoso: se comprometieron y lucharon por lo que creían justo. Reivindicarlos, poder decir en qué organizaciones políticas, sindicales, estudiantiles y sociales militaron nos llena de orgullo [...] Eran militantes del pueblo... (Carlotto 2013, mimeo)

Escasos dos años antes de este reposicionamiento, en el marco de una entrevista dada a Silvina Friera con motivo de la inauguración del III Festival Internacional de Literatura de Buenos Aires, Luis Chitarroni recordaba que tuvo la "mala suerte" de ser conscripto en 1976, y que vivió la experiencia en estado de "paranoia redundante". Al pasar, 
menciona además que escondió “un bono contribución a la lucha armada" y el último volante que se había animado a repartir en la primera edición de La trama celeste, de Adolfo Bioy Casares (Cf. Chitarroni [Entrevistado por Silvina Friera] 2011: 35).

La tardía confesión en sordina de esta acción "militante" (aunque de carácter tan literario que casi parece ficticia) por parte de Chitarroni nos alerta una vez más sobre la necesidad de no soslayar en nuestro análisis la cuestión de que los agentes analizados continúan al día de hoy reposicionándose en el campo literario, tanto en términos de “crítico-estrategas" como de sujetos sociales.

Al respecto, que los integrantes de la "generación ausente" hayan elegido a fines de los ochenta autoconstruirse identitariamente como apolíticos frente a otros colectivos de coetáneos que aparecen claramente posicionados (como los ex combatientes de Malvinas, los militantes del activismo cultural o de las identidades sexuales disidentes), no significa que -vistas al detalle- las biografias individuales de algunos de ellos no contengan minucias que escapen en parte de dicha construcción.

Por todo lo analizado, podría concluirse que los autores estudiados, a partir de una muy acertada lectura del estado del campo literario de fines de la década del ochenta del siglo XX, lograron en un tiempo récord revertir su lugar inicial de carencia. Lo hicieron percibiendo el lugar central que, tanto en términos de "memoria en la literatura" y “memorias de la literatura I y II" tenía el decenio 1973-1983, con un alto nivel de consciencia del potencial estratégico que tenía el comparecer como generación, y haciendo un uso deliberadamente laxo de la etiqueta de la "nueva narrativa".

Si bien resulta excesivamente prematuro hipotetizar quiénes de entre ellos pasarán a la "memoria de la literatura II" del siglo XXI, hay indicios que permiten postular que esta "generación ausente" fue la última que reflexionó sobre qué hacer con el "factor Borges" (la expresión es de Alan Pauls) y cómo inscribirse en una "política de la literatura" que tenía nombres tan amenazantes -por motivos harto diferentes- como Rodolfo Walsh, Osvaldo Lamborghini, Manuel Puig, Osvaldo Soriano, César Aira, Juan José Saer, Ricardo Piglia, Fogwill y Jorge Asís.

Casi finalizando la escritura de la quinta versión de este trabajo, se produjeron dos hechos que tuvieron una incidencia no académica sino vital en mi investigación: la muerte del ex dictador Jorge Rafael Videla el 17 de mayo de 2013 y la restitución en agosto de 2014 de la identidad del 114 nieto recuperado: Ignacio Guido Montoya Carlotto. Ambos acontecimientos, sumados al boom memorialístico en el campo académico y el perceptible cambio de rumbo observable en proyectos literarios que 
-como en los casos de Martín Kohan y Juan Forn, para dar dos ejemplos deliberadamente disímiles- habían sabido mostrar desde sus orígenes una acusada tendencia a hacer memoria del decenio 1973-1983- comenzaron a darme un sentido de final. Sin soslayar que esta tesis es también un producto memorial de la sociedad en que fue producida, he intentado en el marco de la misma repensar determinadas cuestiones de manera crítica, complejizando nuestra comprensión de lo ocurrido en cierta zona del campo literario argentino durante los últimos treinta años.

\footnotetext{
*n su quinta versión, esta tesis doctoral fue registrada el 12 de septiembre de 2014 en la Dirección Nacional del Derechos de Autor (Expediente $\mathrm{N}^{\circ}$ 5193005). Fue ingresada para su Defensa por mesa de entrada al Doctorado de la FAHCE/ UNLP el 7/7/2015 y defendida el 10/11/2015 ante un Jurado conformado por los doctores José Luis de Diego (UNLP), Marina Franco (UNSAM) y Martín Kohan (UBA), que la calificaron con "diez sobresaliente con recomendación de publicación". Agradezco nuevamente la lectura erudita y exigente de mis tres Jurados, algunas de cuyas sugerencias he conseguido incorporar a esta nueva versión, destinada al repositorio digital de Memoria Académica administrado por la FAHCE/ UNLP.
} 


\section{BIBLIOGRAFÍA GENERAL}

Fuentes Primarias*

Aira, César. Moreira. Buenos Aires: Achaval Solo, 1975.

Aira, César. Ema la cautiva. Buenos Aires: De Belgrano, 1981.

Aira, César. La luz argentina. Buenos Aires: CEAL, 1983.

Aira, César. Una novela china. Buenos Aires: Javier Vergara Editor, 1987.

Aira, César. Los fantasmas. Buenos Aires: GEL, 1990.

Aira, César. El bautismo. Buenos Aires: GEL, 1991.

Aira, César. La liebre. Buenos Aires: Emecé, 1991.

Aira, César. El coloquio. Rosario: Beatriz Viterbo Editora, 1992.

Aira, César. El volante. Rosario: Beatriz Viterbo Editora, 1992.

Aira, César. Embalse. Buenos Aires: Emecé, 1992.

Aira, César. Cómo me hice monja. Rosario: Beatriz Viterbo Editora, 1993.

Aira, César. Los misterios de Rosario. Buenos Aires: Emecé, 1994

Aira, César. Los dos payasos. Rosario: Beatriz Viterbo Editora, 1995.

Aira, César. La abeja. Buenos Aires: Emecé, 1996.

Aira, César. El juego de los mundos. La Plata: Ediciones El Broche, 2000.

Aira, César. Un episodio en la vida del pintor viajero. Rosario: Beatriz Viterbo Editora, 2000 .

Aira, César. Fragmento de un diario en los Alpes. Rosario: Beatriz Viterbo Editora, 2002.

Aira, César. Yo era una mujer casada. Buenos Aires: Blatt y Ríos, 2010.

Aira, César. Relatos reunidos. Buenos Aires/ Barcelona: Mondadori, 2013.

Alarcón, Cristián. Cuando me muera, quiero que me toquen cumbia. Buenos Aires: Norma, 2003.

Alcoba, Laura. La casa de los conejos. Buenos Aires: Edhasa, 2008.

Alcoba, Laura. Los pasajeros del Anna C. Buenos Aires: Edhasa, 2012.

Alcoba, Laura. El azul de las abejas. Buenos Aires: Edhasa, 2014.

Alemián, Ezequiel. La ruptura. Buenos Aires: Libros de Tierra Firme, 1997.

Andruetto, María Teresa. Lengua madre. Buenos Aires: Mondadori, 2010.

Asís, Jorge. Los reventados. Buenos Aires: Crisis, 1974.

\footnotetext{
* Se consignan sólo primeras ediciones. Las reediciones, solamente cuando fueron destacadas a fines de la argumentación en el marco de la presente tesis doctoral.
} 
Asís, Jorge. Cuadernos de Oberdán Rocamora. Buenos Aires: Editorial R. Alonso, 1977.

Asís, Jorge. Flores robadas en los jardines de Quilmes. Buenos Aires: Losada, 1980.

Asís, Jorge. Carne picada. Madrid/ Buenos Aires/ México D. F.: Legasa, 1981.

Asís, Jorge. Carne picada. Buenos Aires: Booket, 2007.

Asís, Jorge. La calle de los caballos muertos. Buenos Aires: Legasa Literaria, 1982.

Asís, Jorge. Cazadores de canguros. Buenos Aires: Legasa, 1983.

Asís. Jorge. El cineasta y la partera (y el sociólogo marxista que murió de amor). Buenos Aires: Planeta, 1989.

Asís, Jorge. Lesca, el fascista irreductible. Buenos Aires: Sudamericana, 2000.

Becerra, Juan José. Santo. Rosario: Beatriz Viterbo Editora, 1994.

Berti, Eduardo. Todos los Funes. Barcelona: Anagrama, 2004.

Bianchi, Sebastián. El resorte de la novia y otros cuentos. Buenos Aires: Paradiso, 2002.

Bioy Casares, Adolfo. Breve diccionario del argentino exquisito. Buenos Aires: Emecé, 1978.

Bizzio, Sergio. El divino convertible. Buenos Aires: Catálogo Editora, 1990.

Bizzio, Sergio. Infierno albino. Buenos Aires: Sudamericana, 1991.

Bizzio, Sergio. Más allá del bien y lentamente. Buenos Aires: Sudamericana, 1995.

Bizzio, Sergio. En esa época. Buenos Aires: Emecé, 2001.

Bizzio, Sergio y Daniel Guebel. El día feliz de Charlie Feiling. Rosario: Beatriz Viterbo Editora, 2006.

Borges, Jorge Luis. "Deutsches Réquiem”. Sur 136 (1946): 7-14.

Borges, Jorge Luis y Adolfo Bioy Casares. "La fiesta del monstruo". Marcha (Montevideo, 30 sept. 1955): C-20-21, 23.

Borges, Jorge Luis. El libro de los seres imaginarios. Buenos Aires: Kier, 1967.

Borges, Jorge Luis. Obras Completas. Buenos Aires: Emecé, 1974.

Briante, Miguel. Ley de juego. Buenos Aires: Folios, 1983.

Brizuela, Leopoldo. Una misma noche. Buenos Aires: Alfaguara, 2012.

Bruzzone, Félix. Los topos. Buenos Aires: Mondadori, 2008.

Burroughs, William S. El almuerzo desnudo. Barcelona: Bruguera, 1980.

Caparrós, Martín. Ansay o los infortunios de la gloria. Buenos Aires: Ada Korn Editora, 1984.

Caparrós, Martín. No velas a tus muertos. Buenos Aires: De la Flor, 1986.

Caparrós, Martín. El tercer cuerpo. Buenos Aires: Puntosur, 1990

Caparrós, Martín. La noche anterior. Buenos Aires: Sudamericana, 1990

Caparrós, Martín. La Historia. Buenos Aires: Norma, 1999. 
Caparrós, Martín. Un día en la vida de dios. Buenos Aires: Tusquets, 2001.

Caparrós, Martín. Valfierno. Buenos Aires: Planeta, 2004.

Caparrós, Martín. A quien corresponda. Barcelona: Anagrama, 2008.

Caparrós, Martín. Los Living. Barcelona: Anagrama, 2011

Chejfec, Segio. Lenta biografía. Buenos Aires: Puntosur, 1990.

Chejfec, Sergio. Moral. Buenos Aires: Puntosur, 1990.

Chejfec, Sergio. El aire. Buenos Aires: Alfaguara, 1992.

Chejfec, Sergio. Cinco. Saint-Nazaire: M.E.E.T., 1996.

Chejfec, Sergio. El llamado de la especie. Rosario: Beatriz Viterbo Editora, 1997.

Chejfec, Segio. Los planetas. Buenos Aires: Alfaguara, 1999a.

Chejfec, Sergio. Boca de lobo. Buenos Aires: Alfaguara, 2000.

Chitarroni, Luis. El carapálida. Buenos Aires: Tusquets, 1997.

Chitarroni, Luis. Peripecias del no. Diario de una novela inconclusa. Buenos Aires: InterZona, 2007.

Codina, Iverna. Los guerrilleros. Buenos Aires: De la Flor, 1968.

Coelho, Oliverio. Los invertebrados. Rosario: Beatriz Viterbo Editora, 2003.

Coelho, Oliverio. Borneo. Beatriz Viterbo Editora, 2004.

Cohen, Marcelo. El oído absoluto. Barcelona: Muchnik Editores, 1989.

Copi. Los pollos no tienen sillas. Buenos Aires: Jorge Álvarez, 1968.

Copi. El baile de las locas. Barcelona: Anagrama, 1978

Copi. Las viejas travestis y otras infamias seguido de El Uruguayo. Barcelona: Anagrama, 1978.

Copi. La vida es un tango. Barcelona: Anagrama, 1981.

Copi. Las viejas putas. Barcelona: Anagrama, 1981.

Copi. Virginia Wolf ataca de nuevo. Barcelona: Anagrama, 1984.

Copi. La Internacional Argentina. Barcelona: Anagrama, 1989.

Copi. Eva Perón. Buenos Aires: Adriana Hidalgo, 2000.

Copi. Cachafaz. La sombra de Wenceslao. Buenos Aires: Adriana Hidalgo, 2002.

Copi. La ciudad de las ratas. Buenos Aires: El Cuenco de Plata, 2009.

Copi. La guerra de las mariconas. Buenos Aires: El Cuenco de Plata, 2010.

Copi. Obra completa. Tomo 1. Barcelona, Anagrama, 2010.

Copi. Teatro 1. Buenos Aires: El Cuenco de Plata, 2011.

Copi. Teatro 2. Buenos Aires: Cuenco de Plata, 2012.

Copi. Tango-Charter. Buenos Aires: Mansalva/ Santiago Arcos, 2012.

Copi. La mujer sentada. Buenos Aires: El Cuenco de Plata, 2013.

Cortázar, Julio. Rayuela. Buenos Aires: Sudamericana, 1963. 
Cortázar, Julio. Libro de Manuel. Buenos Aires: Sudamericana, 1972.

Cortázar, Julio. Queremos tanto a Glenda. Buenos Aires: Sudamericana, 1980.

Cortázar, Julio y Pat Andrea. La puñalada. El tango de la vuelta. Buenos Aires: Libros del Zorro Rojo, 2014.

Dal Masetto, Antonio. Fuego a discreción. Buenos Aires: Planeta, 1991.

Dámaso Martínez, Carlos. El informante. Buenos Aires: Losada, 1998.

Damonte Taborda, Raúl. La guerrilla. Buenos Aires: Falco Editor, 1967.

de Jager, Jan. Noticias del setenta y cinco. Buenos Aires: Grupo Editor Latinoamericano, 2009.

De Santis, Pablo. El teatro de la memoria. Buenos Aires: Editorial Destino, 2000.

Demitrópulos, Libertad. Río de las congojas. Buenos Aires: Sudamericana, 1981.

Demitrópulos, Libertad. Río de las congojas. Buenos Aires: FCE, 2015.

Diez, Rolando. Los compañeros. La Plata: de la campana, 2000.

Echeverría, Esteban. La cautiva. El matadero. Buenos Aires: Eudeba, 2011.

Eckhardt, Marcelo ;Nitida esa euforia! Rosario: Beatriz Viterbo Editora, 1999.

Escliar, Liliana. La arquitectura de los ángeles. Buenos Aires: Planeta, 2000.

Feijóo, María Cristina. Memorias del río inmóvil. Buenos Aires: Clarín Aguilar, 2001.

Feijóo, María Cristina, La casa operativa. Buenos Aires: Planeta, 2007.

Feiling, Carlos Eduardo. El agua electrizada. Buenos Aires: Sudamericana, 1992.

Feiling, Carlos Eduardo. Un poeta nacional. Buenos Aires: Sudamericana, 1993.

Feiling, Carlos Eduardo. Amor a Roma. Buenos Aires: Sudamericana, 1995.

Feiling, Carlos. El mal menor. Buenos Aires: Planeta, 1996.

Feiling, Carlos Eduardo. El mal menor. Buenos Aires: FCE, 2012.

Feiling, Carlos Eduardo. Los cuatro elementos. Buenos Aires: Norma, 2007.

Feinmann, José Pablo. El Mandato. Buenos Aires: Norma, 2000.

Figueras, Marcelo. Kamchatka. Buenos Aires: Alfaguara, 2003.

Fogwill, Rodolfo Enrique. Música japonesa. Buenos Aires: De Belgrano, 1982.

Fogwill, Rodolfo Enrique. Los Pychi-Ciegos. Visiones de una batalla subterránea. Buenos Aires: De la Flor, 1983.

Fogwill, Rodolfo Enrique. Pájaros de la cabeza. Buenos Aires: Catálogos, 1985.

Fogwill, Rodolfo Enrique. La buena nueva de Los Libros del Caminante. Buenos Aires: Planeta, 1990.

Fogwill, Rodolfo Enrique. Una pálida historia de amor. Buenos Aires: Planeta, 1991.

Fogwill, Rodolfo Enrique. Restos diurnos. Buenos Aires: Sudamericana, 1993.

Fogwill, Rodolfo Enrique. Vivir afuera. Buenos Aires: Sudamericana, 1999.

Fogwill, Rodolfo Enrique. La experiencia sensible. Barcelona: Mondadori, 2001. 
Fogwill, Rodolfo Enrique. Urbana. Barcelona: Mondadori, 2003.

Fogwill, Rodolfo Enrique. Cuentos Completos. Buenos Aires / Madrid: Alfaguara, 2009.

Fgowill, Rodolfo Enrique. La gran ventana de los sueños. Buenos Aires/ Madrid: Alfaguara, 2013.

Fogwill, Rodolfo Enrique. Nuestro modo de vida. Buenos Aires/ Madrid: Alfaguara, 2014.

Forn, Juan. Corazones cautivos más arriba. Buenos Aires: Emecé, 1987.

Forn, Juan. Corazones. Buenos Aires: Alfaguara, 2001.

Forn, Juan. Nadar de noche. Buenos Aires: Planeta, 1991.

Fresán, Rodrigo. Historia Argentina. Buenos Aires: Planeta, 1991

Fresán, Rodrigo. Esperanto. Buenos Aires: Tusquets, 1995.

Fresán, Rodrigo. Jardines de Kensington. Barcelona: Mondadori, 2003.

Gálvez, Manuel. El mal metafísico. Buenos Aires: Sociedad Cooperativa limitada Nosotros, 1916.

Kafka, Franz. Ein Landarzt. Kleine Erzählungen. Múnich/Leipzig: Kurt Wolff Verlag, 1919 [recte: mayo 1920].

Gamerro, Carlos. Las Islas. Buenos Aires: Simurg, 1998.

Gamerro, Carlos. El sueño del señor juez. Buenos Aires: Sudamericana, 2000.

Gamerro, Carlos. El secreto y las voces. Buenos Aires: Norma, 2002.

Gamerro, Carlos. La aventura de los bustos de Eva. Buenos Aires: Norma, 2004.

Gamerro, Carlos. El libro de los afectos raros. Buenos Aires: Norma, 2005.

Gamerro, Carlos. Un yuppie en la columna del Che Guevara. Buenos Aires: Edhasa, 2011.

Garcés, Gonzalo. El miedo. Buenos Aires: Mondadori, 2012.

García, Germán. Nanina. Buenos Aires: Jorge Álvarez, 1968.

García, Germán. Cancha rayada. Buenos Aires: Jorge Álvarez, 1970.

García, Germán. Nanina. Buenos Aires: FCE, 2012.

García Hamilton, José. Don José. La vida de San Martín. Buenos Aires: Sudamericana, 2000 .

García Márquez, Gabriel. El coronel no tiene quien le escriba. Medellín: Aguirre, 1961.

García Márquez, Gabriel. Cien años de soledad. Buenos Aires: Sudamericana, 1967.

García Márquez, Gabriel. Crónica de una muerte anunciada. Buenos Aires: Sudamericana, 1981.

Guebel, Daniel. Arnulfo o los infortunios de un príncipe. Buenos Aires: De la Flor, 1987.

Guebel, Daniel. La perla del emperador. Buenos Aires: Emecé, 1990.

Guebel, Daniel. El terrorista. Buenos Aires: Sudamericana, 1998. 
Guebel, Daniel. El perseguido. Buenos Aires: Norma, 2001.

Guebel, Daniel. Derrumbe. Buenos Aires: Mondadori, 2007.

Guido, Beatriz. Mal don. Buenos Aires: Emecé, 1973.

Gusmán, Luis. El frasquito. Buenos Aires, Noé, 1973.

Gusmán, Luis. Brillos. Buenos Aires: Sudamericana, 1975.

Gusmán, Luis. En el corazón de junio. Buenos Aires: Sudamericana, 1983.

Gusmán, Luis. En el corazón de junio. Buenos Aires: Norma, 1999.

Gusmán, Luis. Villa. Buenos Aires: Alfaguara, 1995.

Gusmán, Luis. La ficción calculada. Buenos Aires: Edhasa, 1998.

Gusmán, Luis. Hotel Edén. Buenos Aires: Norma, 1999.

Gusmán, Luis. Ni muerto has perdido tu nombre. Buenos Aires: Sudamericana, 2002.

Gusmán, Luis. La casa del dios oculto. Buenos Aires: Edhasa, 2012.

Hascher, Sebastián. Cómo enterrar un padre desaparecido. Buenos Aires: Marea, 2012.

Heker, Liliana. El fin de la historia. Buenos Aires: Alfaguara, 1996.

Hesse, Hermann. Demian. Berlín: S. Fischer, 1919.

Huidobro, Norma. Composición. Buenos Aires: Clarín, 2007.

Jarkowski, Aníbal. Rojo amor. Buenos Aires: Tantalia, 1993.

Jarkowski, Aníbal. Tres. Buenos Aires: Tusquets 1998.

Jarkowski, Aníbal. El trabajo. Buenos Aires: Tusquets, 2007.

Katchadjian, Pablo. El martín fierro ordenado alfabéticamente. Buenos Aires: Imprenta Argentina de Poesía, 2009.

Katchadjian, Pablo. El aleph engordado. Buenos Aires: Imprenta Argentina de Poesía, 2010.

Kaufman, Paula. El lago. Buenos Aires: Planeta, 2005.

Kohan, Martín. La pérdida de Laura. Buenos Aires: Tantalia, 1993.

Kohan, Martín. El informe. San Martín y el otro cruce de los Andes. Buenos Aires: Sudamericana, 1997.

Kohan, Martín. Los cautivos. El exilio de Echeverría. Buenos Aires: Sudamericana, 2000 .

Kohan, Martín. Dos veces junio. Buenos Aires: Sudamericana, 2002.

Kohan, Martín. Segundos afuera. Buenos Aires: Sudamericana 2005.

Kohan, Martín. Museo de la Revolución. Buenos Aires: Mondadori, 2006.

Kohan, Martín. Ciencias morales. Barcelona: Anagrama, 2007.

Kohan, Martín. Cuentas pendientes. Barcelona: Anagrama, 2010.

Kohan, Martín. Bahía Blanca. Barcelona: Anagrama, 2012.

Laiseca, Alberto. Aventuras de un novelista atonal. Buenos Aires: Sudamericana, 1982.

Laiseca, Alberto. Matando enanos a garrotazos. Buenos Aires: Sudamericana, 1982. 
Laiseca, Alberto. Poemas chinos. Buenos Aires: Libros de Tierra Firme, 1987.

Laiseca, Alberto. La hija de Kheops. Buenos Aires: Emecé, 1989.

Laiseca, Alberto. Por favor, iplágienme! Rosario: Beatriz Viterbo Editora, 1991.

Laiseca, Alberto. El jardín de las máquinas parlantes. Buenos Aires: Planeta, 1993.

Laiseca, Alberto. Los Sorias. Buenos Aires: Simurg, 1998.

Laiseca, Alberto El artista. Buenos Aires: Simurg, 2010.

Laiseca, Alberto. Cuentos Completos. Buenos Aires: Simurg, 2011.

Lamborghini, Osvaldo. El fiord. Buenos Aires: Ediciones Chinatown, 1969.

Lamborghini, Osvaldo. Sebregondi retrocede. Buenos Aires: Ediciones Noé, 1973.

Lamborghini, Osvaldo. “Die Verneinung”. Escandalar 4 (1978): 14.

Lamborghini, Osvaldo. Poemas. Buenos Aires: Ediciones Tierra Baldía, 1980.

Lamborghini, Osvaldo. Novelas y cuentos. Barcelona: Ediciones del Serbal, 1988.

Lamborghini, Osvaldo. "Sonia (o el final)". Feeling 1 (1981): 56-61.

Lamborghini, Osvaldo. "Sonia (o el final)". Sitio 1: (1981): 114-118.

Lamborghini, Osvaldo. Novelas y cuentos I. Buenos Aires: Sudamericana, 2003a.

Lamborghini, Osvaldo. Novelas y cuentos II. Buenos Aires: Sudamericana, 2003b.

Lamborghini, Osvaldo. Poemas 1969-1985. Buenos Aires: Sudamericana, 2004.

Lamborghini, Osvaldo. Tadeys. Buenos Aires: Sudamericana, 2005.

Lamborghini, Osvaldo. Teatro proletario de cámara. Barcelona: ARPublicatións, 2008.

Lamborghini, Osvaldo. Novelas y cuentos I. Buenos Aires: Mondadori, 2010.

Lamborghini, Osvaldo. Novelas y cuentos II. Buenos Aires, Mondadori, 2011.

Lamborghini, Osvaldo. Tadeys. Buenos Aires: Mondadori, 2012a.

Lamborghini, Osvaldo. Poemas 1969-1985. Buenos Aires, Mondadori, 2012b.

Lamborghini Osvaldo y Gustavo Trigo [1971/ 72]. ;Marc! Mar del Plata: Puente Aéreo Ediciones, 2013.

Lanata, Jorge. Polaroids. Buenos Aires: Planeta, 1990.

Lanata, Jorge. Muertos de amor. Buenos Aires: Alfaguara, 2007.

Libertella, Héctor. El camino de los hiperbóreos. Buenos Aires: Paidós, 1968.

Libertella, Héctor. ¡Cavernícolas! Buenos Aires: Per Abbat, 1985.

Libertella, Héctor. ¡Cavernícolas! Buenos Aires: FCE, 2014.

Libertella, Héctor. El paseo internacional del perverso. Buenos Aires: GEL, 1991.

Libertella, Héctor. El árbol de Saussure: una utopía. Buenos Aires: Adriana Hidalgo, 2000 .

Libertella, Héctor. La arquitectura del fantasma. Buenos Aires: Santiago Arcos, 2006.

Libertella, Héctor. Diario de la rabia. Rosario: Beatriz Viterbo Editora, 2006.

Libertella, Héctor. El lugar que no está ahí. Buenos Aires: Losada, 2006. 
Libertella, Héctor. A la santidad del jugador de juegos de azar. Buenos Aires: Mansalva, 2010.

Libertella, Mauro. Mi libro enterrado. Buenos Aires: Mansalva 2013.

Link, Daniel. La mafia rusa. Buenos Aires: Emecé, 2008.

Link, Daniel. Los años noventa. Buenos Aires: Adriana Hidalgo, 2001.

Link, Daniel. La ansiedad. Novela trash. Buenos Aires: El Cuenco de Plata, 2004.

López, Alejando. La asesina de Lady Di. Buenos Aires: Adriana Hidalgo, 2002.

Marechal, Leopoldo. Adán Buenosayres. Buenos Aires: Sudamericana, 1948.

Martínez, Guillermo. Acerca de Roderer. Buenos Aires: Planeta, 1992.

Martínez, Guillermo. Crímenes imperceptibles. Buenos Aires: Planeta, 2003.

Martínez, Tomás Eloy. La novela de Perón. Buenos Aires: Legasa, 1985.

Martínez, Tomás Eloy. Santa Evita. Buenos Aires: Planeta, 1995

Martínez, Tomás Eloy. El vuelo de la reina. Buenos Aires: Alfaguara, 2002.

Martoccia, María. Sierra Padre. Buenos Aires: Emecé, 2006.

Medina, Enrique. Las Tumbas. Buenos Aires: De la Flor, 1972.

Medina, Enrique. Con el trapo en la boca. Buenos Aires: Galerna, 1983.

Meik, Gaby. Sinfonía para Ana. Buenos Aires: Corregidor, 2004.

Mira, Rubén. Guerrilleros (Una salida al mar para Bolivia). Buenos Aires: Tantalia 1993.

Monacelli, Fernando. La mirada del ciervo. Buenos Aires: Mondadori, 2008.

Monacelli, Fernando. Sobrevivientes. Buenos Aires: Alfaguara, 2012.

Montes, Graciela y Ema Wolf. El turno del escriba. Buenos Aires: Alfaguara, 2005.

Neuman, Andrés. El viajero del siglo. Buenos Aires: Alfaguara, 2009.

Neuman, Andrés. Una vez argentina. Barcelona: Anagrama, 2003.

Nielsen, Gustavo. La flor azteca. Buenos Aires: Planeta, 1997.

Nielsen, Gustavo. El amor enfermo. Buenos Aires: Alfaguara, 2003.

Nielsen, Gustavo. Auschwitz. Buenos Aires: Alfaguara, 2004.

Orphée, Elvira [1977]. La última conquista de El Ángel. Buenos Aires: Javier Vergara Editor, 1984.

Osorio, Elsa. A veinte años luz. Buenos Aires: Planeta, 2006.

Pauls, Alan. El pudor del pornógrafo. Buenos Aires: Sudamericana, 1987.

Pauls, Alan. El coloquio. Buenos Aires: Emecé, 1991.

Pauls, Alan. Wasabi. Buenos Aires: Alfaguara, 1994.

Pauls, Alan. El pasado. Barcelona: Anagrama, 2003.

Pauls, Alan. La vida descalzo. Buenos Aires: Sudamericana, 2006.

Pauls, Alan et al. Idea crónica. Literatura de no ficción iberoamericana. Rosario: Beatriz Viterbo Editora, 2006.

Pauls, Alan et al. Confesionario. Historia de mi vida privada. Buenos Aires: Libros del Rojas, 2006. 
Pauls, Alan. Historia del llanto. Un testimonio. Barcelona: Anagrama, 2007.

Pauls, Alan. Historia del pelo. Barcelona: Anagrama, 2010a.

Pauls, Alan. Historia del dinero. Barcelona: Anagrama, 2013.

Pérez, Mariana Eva. Diario de una princesa montonera. 110\% verdad. Buenos Aires: Editorial Capital Intelectual, 2012.

Pérez Alonso, Paula. No sé si casarme o comprarme un perro. Buenos Aires: Tusquets, 1995.

Piglia, Ricardo. Respiración artificial. Buenos Aires: Pomaire, 1980.

Piglia, Ricardo. Formas breves. Buenos Aires: Alfaguara, 2000.

Piglia, Ricardo. La ciudad ausente. Buenos Aires: Seix Barral, 1992

Piglia, Ricardo. Plata quemada. Buenos Aires: Planeta, 1997.

Piro, Guillermo. Versiones del Niágara. Buenos Aires: Tusquets, 2000.

Posse, Abel. Los cuadernos de Praga. Buenos Aires: Atlántida, 1998.

Prieto, Martín. Calle de las escuelas N 13. Buenos Aires: Libros Perfil, 1999.

Pron, Patricio. El espíritu de mis padres sigue subiendo la lluvia. Buenos Aires/ Barcelona: Mondadori, 2011.

Puig, Manuel. La traición de Rita Hayworth. Buenos Aires: Jorge Álvarez, 1968.

Puig, Manuel. Boquitas pintadas. Buenos Aires: Jorge Álvarez, 1968.

Puig, Manuel. The Buenos Aires-Affair. Barcelona: Seix Barral, 1973

Puig, Manuel. El beso de la mujer araña. Barcelona: Seix Barral, 1976.

Puig, Manuel. El beso de la mujer araña. Poitiers -CNRLA y FCE, 2002.

Puig, Manuel. Pubis angelical. Barcelona: Seix Barral, 1979.

Puig, Manuel. Maldición eterna a quien lea estas páginas. Barcelona: Seix Barral, 1981.

Puig, Manuel. Cae la noche tropical. Barcelona: Seix Barral, 1988.

Puig, Manuel. Bajo un manto de estrellas. El misterio del ramo de rosas. Rosario: Beatriz Viterbo Editora, 1997.

Puig, Manuel. Triste golondrina macho. Amor del bueno Muy señor mío. Rosario: Beatriz Viterbo Editora, 1998.

Puig, Manuel. La tajada. Gardel, uma lembrança. Rosario: Beatriz Viterbo Editora, 1998.

Puig, Manuel. Querida Familia. Tomo 1. Cartas europeas (1956-1962). Buenos Aires: Entropía, 2005.

Puig, Manuel. Querida familia. Tomo 2. Cartas americanas. New York - Río (19631983). Buenos Aires: Entropía, 2006.

Ratto, Patricia. Trasfondo. Buenos Aires: Adriana Hidalgo, 2012.

Rivera, Andrés. En esta dulce tierra. Buenos Aires: Folios, 1984.

Rivera, Andrés. La revolución es un sueño eterno. Buenos Aires: GEL, 1987. 
Rivera, Andrés. El viejo soldado. Buenos Aires: Alfaguara, 2002.

Rivera, Andrés. Traslasierra. Buenos Aires: Seix Barral, 2007.

Robles, Raquel. Pequeños combatientes. Buenos Aires: Alfaguara, 2013.

Rozenmacher, Germán. Los ojos del tigre. Buenos Aires: Galerna, 1967.

Saer, Juan José. Cicatrices. Buenos Aires: Sudamericana, 1969.

Saer, Juan José. Nadie nada nunca. México: Siglo Veintiuno, 1980.

Saer, Juan José. El entenado. Buenos Aires: Folios, 1983.

Saer, Juan José. Glosa. Buenos Aires/ Madrid: Alianza Editorial, 1986.

Saer, Juan José. Lo imborrable. Buenos Aires: Alianza Literatura, 1992.

Saer, Juan José. La pesquisa. Buenos Aires: Seix Barral, 1994

Saer, Juan José. La Grande. Buenos Aires: Seix Barral, 2005.

Sagastizabal, Patricia. Un secreto para Julia. Buenos Aires: Sudamericana, 2000.

Sánchez, Matilde. La ingratitud. Buenos Aires: Ada Korn Editora, 1990.

Sánchez, Matilde. La canción de las ciudades. Buenos Aires: Planeta, 2000.

Sánchez, Matilde. El desperdicio. Buenos Aires: Alfaguara, 2007.

Sánchez, Néstor. Nosotros dos. Buenos Aires: Sudamericana, 1966.

Sánchez, Néstor. Siberia Blues. Buenos Aires: Sudamericana, 1967.

Sánchez, Néstor. El amhor, los orsinis y la muerte. Buenos Aires: Sudamericana, 1969.

Semán, Ernesto. Soy un bravo piloto de la nueva china. Buenos Aires: Mondadori, 2011.

Sguiglia, Eduardo. No te fíes de mí si el corazón te falla. Buenos Aires: Norma, 1999.

Sguiglia, Eduardo. Los cuerpos y las sombras. Buenos Aires: Edhasa, 2014.

Shua, Ana María. Soy paciente. Buenos Aires: Losada, 1980.

Soriano, Osvaldo. No habrá más penas ni olvidos. Barcelona: Bruguera, 1980.

Soriano, Osvaldo. Una sombra ya pronto serás. Buenos Aires: Sudamericana, 1990.

Soriano, Osvaldo. Cuarteles de invierno. Barcelona: Bruguera, 1983.

Soriano, Osvaldo. A sus plantas rendido un león. Buenos Aires: Sudamericana, 1985.

Stamadianos, Jorge. Latas de cerveza en el Río de la Plata. Buenos Aires: Emecé, 1995.

Strafacce, Ricardo. El crimen de la negra Reguera. Rosario: Beatriz Viterbo Editora, 1999.

Strafacce, Ricardo. Crímenes perfectos. Buenos Aires: Mansalva, 2012.

Strafacce, Ricardo. Gerardo y Mercedes. Buenos Aires: WuWei, 2013.

Strafacce, Ricardo. La novelita triste de Osvaldo Lamborghini. Buenos Aires: milena caserola/ el 8vo loco, 2013.

Tabarovsky, Damián. Fotos movidas. Buenos Aires: Grupo Editor Latinoamericano, 1992. 
Tabarovsky, Damián. Coney Island. Buenos Aires: Sudamericana, 1996.

Tabarovsky, Damián. Bingo. Rosario: Beatriz Viterbo Editora, 1997.

Tabarovsky, Damián. Kafka de vacaciones. Rosario: Beatriz Viterbo Editora, 1998.

Taborda, Oscar. 40 watts. Rosario: Beatriz Viterbo Editora, 1993.

Vanoli, Beatriz. DAF. Buenos Aires: Bajo La Luna, 2014.

Vieytes, Raúl. Kelper. Buenos Aires: Clarín Aguilar, 1999.

Viñas, David. Dar la cara. Buenos Aires: JAMCANA, 1962.

Viñas, David. Buenos Aires: de la fundación a la angustia. Buenos Aires: De la Flor, 1968.

Viñas, David. Cosas concretas. Buenos Aires: Editorial Tiempo Contemporáneo, 1969.

Viñas, David. Prontuario. Buenos Aires: Planeta, 1993.

Viñas, David. Tartabul. O los últimos argentinos del siglo XX. Novela. Buenos Aires: Sudamericana, 2006.

Vitagliano, Miguel. Posdata para las flores. Buenos Aires: Último Reino, 1991. Vitagliano, Miguel. El niño perro. Buenos Aires: Tantalia, 1993.

Vitagliano, Miguel. Los ojos así. Buenos Aires: Tusquets, 1996.

Vitagliano, Miguel. Cielo suelto. Buenos Aires: Tusquets, 1998.

Vitagliano, Miguel. Vuelo triunfal. Buenos Aires: Tusquets, 2002.

Vitagliano, Miguel. Golpe de aire. Buenos Aires: Norma, 2004.

Vitagliano, Miguel Cuarteto para autos viejos. Buenos Aires: Eterna Cadencia, 2008.

Vitagliano, Miguel. El otro de mí. Buenos Aires: Eterna Cadencia, 2010

Vitagliano, Miguel. Tratado sobre la manos. Buenos Aires: Eterna Cadencia, 2013.

Wajsman, Paula. Informe de París. Buenos Aires: De la Flor, 1990.

Walsh, Rodolfo. La batalla. La granada. Buenos Aires: Jorge Álvarez, 1965.

Walsh, Rodolfo. Los oficios terrestres.. Buenos Aires: Jorge Álvarez, 1965.

Walsh, Rodolfo. Un kilo de oro. Buenos Aires: Jorge Álvarez, 1967.

Walsh, Rodolfo ¿Quién mató a Rosendo? Buenos Aires: Tiempo Contemporáneo, 1969.

Walsh, Rodolfo. Un oscuro día de justicia. Buenos Aires: Siglo XXI Editores, 1973.

Walsh, Rodolfo. Caso Satanowsky. Buenos Aires: De la Flor, 1973.

Walsh, Rodolfo [1957]. Operación masacre. Buenos Aires: De la Flor, 1984.

Walsh, Rodolfo. Obra literaria completa. México D. F./ Madrid/ Bogotá: siglo veintiuno editores, 1985.

Walsh, Rodolfo. El violento oficio de escribir. Obra periodística (1953-1977). Buenos Aires: Planeta, 1995.

Walsh, Rodolfo. El violento oficio de escribir. Obra periodística (1953-1977). Buenos Aires: De la Flor, 2008

Walsh, Rodolfo. Ese hombre y otros papeles personales. Buenos Aires: Seix Barral, 1997.

Walsh, Rodolfo. Ese hombre y otros papeles personales. Buenos Aires: De la Flor, 2007.

Walsh, Rodolfo (comp.). Antología del cuento extraño. Buenos Aires: Hachette, 1965. 
Walsh, Rodolfo (comp.). Antología del cuento extraño. Buenos Aires: El Cuenco de Plata, 2014.

Walsh, Rodolfo. Cuentos completos. Buenos Aires: De la Flor, 2013.

\section{Fuentes secundarias}

Agamben, Giorgio. Homo Sacer. El poder soberano y la nuda vida. España: Pre-Textos, 1998.

Agamben, Giorgio. Estado de excepción. Buenos Aires: Adriana Hidalgo, 2006.

Agamben, Giorgio. Infancia e historia. Buenos Aires: Adriana Hidalgo, 2007.

Aguilar, Gonzalo. "Malditos pero nuestros". milpalabras 3 (2002): 61-62.

Aguilar, Gonzalo. Otros mundos. Un ensayo sobre el nuevo cine argentino. Santiago Arcos editor, 2009.

Aira, César. "Novela argentina, nada más que una idea”. Vigencia 51 (1981): 55-58.

Aira, César. "Yo nunca usaría la literatura para pasar por una buena persona" [Entrevista de Alberto Castro y Graciela Bogna]. Pie de Página 1 (1982): 2-3.

Aira, César. Copi. Rosario: Beatriz Viterbo Editora, 1991.

Aira, César. Alejandra Pizarnik. Rosario: Beatriz Viterbo Editora, 1998.

Aira, César. Las tres fechas. Rosario: Beatriz Viterbo Editora, 2001.

Aira, César. Continuación de ideas diversas. Santiago de Chile: Ediciones Universidad Diego Portales, 2014.

Aira, César. "El milagro Laiseca”. Ñ. Revista de Cultura 399 (2011): 8.

Alatriste, Sealtiel. "El mercado editorial en lengua española". Néstor García Canclini y Carlos Moneta, compiladores. Las industrias culturales en la integración latinoamericana. Buenos Aires: Eudeba, 1999. 207-226.

Altamirano, Carlos. "Raymond Williams: proposiciones para una teoría social de la cultura". Punto de Vista 11 (1981). 21-23.

Altamirano, Carlos y Beatriz Sarlo. Conceptos de sociología literaria. Buenos Aires: CEAL, 1980.

Altamirano, Carlos y Beatriz Sarlo. Literatura/ Sociedad. Buenos Aires: Edicial, 1993.

Altamirano, Carlos (director). Términos críticos de sociología de la cultura. Buenos Aires: Paidós, 2002.

Altamirano, Carlos et al. Argentina 1976. Estudios en torno al golpe de Estado. Buenos Aires: Fondo de Cultura Económica, 2007.

Álvarez Plá, Bárbara (2014) "Hiperconcentración: Penguin Random House compró Alfaguara" Recuperado en: http:/www.clarin.com/sociedad/HiperconcentracionPenguin-Random-House-Alfaguara 0 1105089549.html.

Amante, Adriana [Reseña de Roberto y Eva]. Babel, revista de libros 16 (1990): 8.

Amante, Adriana. "La crítica como proyecto. Juan María Gutiérrez". Julio Schvartzman, director del tomo. Historia crítica de la literatura argentina, vol. 2. La lucha de los lenguajes. Buenos Aires: Emecé, 2003. 164-177. 
Amar Sánchez, Ana María. El relato de los hechos. Rodolfo Walsh: testimonio y escritura. Rosario: Beatriz Viterbo Editora, 1993.

Améry, Jean [1977]. Más allá de la culpa y la expiación. Tentativas de superación de una víctima de la violencia. España: Pre-textos, 2004.

Amícola, José y Graciela Speranza. Encuentro Internacional Manuel Puig. Rosario: Beatriz Viterbo Editora, 1998.

Amícola, José. "Manuel Puig y la narración infinita". Elsa Drucaroff, directora del tomo. Historia crítica de la literatura argentina, vol. 11. La narración gana la partida. Buenos Aires: Emecé, 2000. 295-319.

Amícola, José y Jorge Panesi (directores). El beso de la mujer araña. Poitiers: CNRLA/ y FCE, 2002.

Amícola, José. La batalla de los géneros Novela gótica versus novela de educación. Rosario: Beatriz Viterbo Editora, 2003.

Amícola, José. Autobiografía como autofiguración. Rosario: Beatriz Viterbo, 2007.

Amícola, José. "Autoficción, una polémica literaria vista desde los márgenes (Borges, Gombrowicz, Copi, Aira)". Olivar 12 (2009): 181-197.

Anguita, Eduardo y Martín Caparrós. La voluntad. Una historia de la militancia revolucionaria en la Argentina. Tomo 3. La patria socialista 1973-1974. Buenos Aires: Booket, 2006.

Anguita, Eduardo y Martín Caparrós. La voluntad. Una historia de la militancia revolucionaria en la Argentina. Tomo 4. La patria peronista 1974-1976. Buenos Aires: Booket, 2006.

Anguita, Eduardo y Martín Caparrós. La voluntad. Una historia de la militancia revolucionaria en la Argentina. Tomo 5. La caída 1976-1978. Buenos Aires: Booket, 2006.

Antín, Eduardo. "Progreso". Los días del viaje 1 (1988): 11-14.

Ariès, Phillipe [1977]. El hombre ante la muerte. Madrid: Taurus, 1999.

Aricó, José M. "Pasado y presente". Pasado y presente 1 (1963): 1-17.

Arico, José M. La cola del diablo. Itinerario de Gramsci en América Latina. Buenos Aires: Puntosur, 1988.

Arrieta, Rafael Alberto (dir.). Historia de la literatura argentina. Buenos Aires: Ediciones Peuser, 1958/ 60.

Arrom, José Juan. Esquema generacional de letras hispanoamericanas. Bogotá: Inst. Caro y Cuervo, 1963.

Ascasubi, Hilario. Paulino Lucero o Los gauchos del Río de la Plata cantando y combatiendo contra los tiranos de la República Argentina y oriental del Uruguay (1839 a 1851). París: Paul Dupont, 1872.

Asís, Jorge. "Yo soy un clásico" [Entrevista de Daniel Molina]. El Porteño (Buenos Aires, febrero 1985): C-81-83.

Asís, Jorge. "Transfiguraciones literarias de un dandy suburbano" [Entrevista de Horacio González et al]. El Ojo Mocho 16 (2001/ 2002): 9-15, 18-21, 24-35.

Asmann, Aleida. „Was sind kulturelle Texte?“. Andreas Poltermann, editor. Literaturkanon, Medienergebnis- kultureller Text: Formen interkultureller Kommunikation und Übersetzung. Berlín: Erich Schmidt, 1995. 232-244. 
Asmann, Jan. Das kulturelle Gedächtnis. Schrift, Erinnerung und politische Identität in frühen Hochkulturen. Múnich: Beck, 1992.

Assmann, Jan. “¿Qué es la memoria cultural?”. Confines 21 (2007): 197-216.

Astutti, Adriana y Sandra Contreras. "Editoriales independientes, pequeñas... Micropolíticas culturales en la literatura argentina actual". Revista Iberoamericana 197 (2001): 767-580.

Astutti, Adriana. “Mientras ‘yo’ agoniza”. Tramas 10 (1999): 66-82.

Astutti, Adriana. Andares clancos. Fábulas del menor en Osvaldo Lamborghini, Juan Carlos Onetti, Rubén Dario, J. L. Borges, Silvina Ocampo y Manuel Puig. Rosario: Beatriz Viterbo Editora, 2001.

Ávalos, Daniel. La guerrilla del Che y Masetti en Salta, 1964. Ideología y mito en el Ejército Guerrillero del Pueblo. Testimonio de Héctor Jouvé. Córdoba: Ediciones La Intemperie, 2005.

Avaro, Nora y Analía Capdevila. Denuncialistas. Literatura y polémica en los '50. Buenos Aires: Santiago Arcos Editor, 2004.

Avellaneda, Andrés. "Literatura argentina: diez años en el sube y baja". Todo es Historia 120 (1977): 105-120.

Avellaneda, Andrés. "Best-seller y código represivo en la narrativa argentina de los ochenta: el caso Asís". Revista Iberoamericana 125 (1983): 982-996.

Avellaneda, Andrés. "Realismo, antirrealismo, territorios canónicos. Argentina literaria después de los militares". Hernán Vidal, editor. Fascismo y experiencia literaria: reflexiones para una recanonización. Minneapolis/ Minesotta: Institute for the Study of Ideologies and Literature, 1985. 578-588.

Avellaneda, Andrés. "Estrategias de la resistencia cultural: La Maga. Noticias de la cultura". Roland Spiller, editor. Lateinamerika-Studien 36. Culturas del Río de la Plata (1973-1995). Fráncfort del Meno: Vervuert, 1995. 269-285.

Avellaneda, Andrés. "Lecturas de la historia y lecturas de la literatura en la narrativa argentina de la década del ochenta". Memoria colectiva y políticas de olvido. Adriana Bergero y Fernando Reati, compiladores. Rosario: Beatriz Viterbo Editora, 1997. 141184.

Baigorria, Osvaldo. Sobre Sánchez. Buenos Aires: Mansalva, 2012.

Bajarlía, Juan Jacobo. "Tres preguntas clave a seis editores". Clarín (Buenos Aires, 15 abril 1988): C-2-3.

Bajtin, Mijaíl [1975]. Estética y teoría de la novela. Barcelona: Taurus Humanidades, 1989.

Bajtin, Mijaíl [1978]. Problemas de la poética de Dostoievski. Buenos Aires: FCE, 1993.

Balcarce, Horacio. "Bibliografía anotada del impreciso futuro". Tiempo Argentino (Buenos Aires, 6 nov. 1983): C-2.

Balderston, Daniel (comp.). Ficción y política. La narrativa argentina durante el proceso militar. Buenos Aires/ Madrid: Alianza Editorial/ Institute for the Study of Ideologies \& Literature -University of Minnesota, 1987. 
Balderston, Daniel et al. Escrito por otros. Ensayos sobre los libros de Luis Gusmán. Buenos Aires: Norma, 2004.

Barrera Enderle, Víctor. "Entradas y salidas del fenómeno editorial actual o la 'alfaguarización' de la literatura latinoamericana". Sincronía 22 (2002). Recuperado en: http://sincronia.cucsh.udg.mx/alfaguar.htm

Barth, John. "La literatura posmoderna". Espacios 4-5 (1986): 23-28.

Barthes, Roland [1977] El placer del texto y Lección Inaugural. Buenos Aires: Siglo XXI Editores Argentina, 2003.

Basualdo, Eduardo. Estudios de historia económica argentina. Buenos Aires: Siglo XXI, 2005.

Basualdo, Victoria. "Derivaciones posibles de la polémica iniciada por Oscar del Barco: reflexiones para una agenda de investigación”. Políticas de la Memoria 6/7 (2006/ 2007): 9-13.

Belvedere, Carlos. "Parodia y sátira en dos poéticas peronistas". El Ojo Mocho 16 (2001/ 2002): 16-17.

Belzagui, Pablo René (comp.). Sobre la responsabilidad: no matar. Córdoba: Del Cíclope/ Universidad de Córdoba, 2008.

Benjamin, Walter. Einbahnstrasse. Kleine Prosa Baudelaire-Übertragungen. Gesammelte Schriften. Band IV-1. Fráncfort del Meno: Suhrkamp, 1991. 83-148.

Benzecry, Claudio. “Transformaciones del campo literario en la década del '90”. Mario Margulis y Marcelo Urresti, compiladores. La cultura en la Argentina de fin de siglo. Ensayos sobre la dimensión cultural. Buenos Aires: Oficina de Publicaciones del CBC, 1997. 555-566.

Berg, Edgardo H. "La joven narrativa argentina de los '90: ¿nueva o novedad? Letras 45 (1996): 31-40.

Bloom, Harold. The Anxiety of Influence. A Theory of Poetry. Nueva York: Oxford University Press, 1973.

Bloom, Harold. A Map of Misreading. Nueva York: Oxford University Press, 1975.

Bloom, Harold. El canon occidental. La escuela y los libros de todas las épocas. Barcelona: Anagrama, 2005.

Boetti, Ezequiel. "Un inédito en pantalla". N. Revista de Cultura 399 (2011): 8.

Bosteels, Wouter y Luz Rodríguez-Carranza. "El objeto Sade. Genealogía de un discurso crítico: de Babel, revista de libros (1989-1991) a Los libros (1969-1971)". Roland Spiller, editor. Lateinamerika-Studien 36. Culturas del Río de la Plata (19731995). Fráncfort del Meno: Vervuert, 1995. 313-338.

Botto, Malena. “1990-2000. La concentración y la polarización de la industria cultural”. José Luis De Diego, editor. Editores y políticas editoriales en Argentina, 1880-2000. Buenos Aires: Fondo de Cultura Económica, 2006. 209-247.

Botto, Malena (2011) "Desbordes de la literatura: las pequeñas editoriales y la noción de postautonomía". Recuperado en: http://www.mdp.edu.ar/humanidades/letras/celehis/congreso/2011/actas/ponencias/botto .htm 
Botto, Malena (2012) "Esos raros proyectos nuevos. Reflexiones para la conceptualización de las nuevas prácticas editoriales”. Recuperado en: http://citclot.fahce.unlp.edu.ar/actas-2012/Botto-\%20Malena.pdf

Bourdieu, Pierre. Campo de poder, campo intelectual. Itinerario de un concepto. Buenos Aires: Quadrata Editorial, 2003.

Bourdieu, Pierre. Cosas dichas. Barcelona: Gedisa, 1988.

Bourdieu, Pierre. Sociología y cultura. México: Grijalbo, 1990.

Bourdieu, Pierre. Las Reglas del arte. Génesis y estructura del campo literario. Barcelona: Anagrama, 1995.

Briante, Miguel. "Ya no es lo mismo ser inédito que olvidarse". Tiempo Argentino (Buenos Aires, 13 junio 1984): C- 8 .

Briante, Miguel. "Encuesta”. "Primer Plano". Página/ 12 (Buenos Aires, 14 febrero 1993): C- 8 .

Brizuela, Natalia y Juan Pablo Dabove, compiladores. $Y$ todo el resto es literatura. Ensayos sobre Osvaldo Lamborghini. Buenos Aires: InterZona 2008.

Brodsky, Marcelo. Buena memoria. Un ensayo fotográfico. Buenos Aires: La Marca Editora, 1997.

Brunner, José Joaquín. La cultura autoritaria de Chile. Santiago de Chile: FLACSO, 1982.

Budassi, Sonia (2008) "Los nuevos desafíos de la resistencia editorial”. Recuperado en: https:/groups.google.com/forum/\#!topic/bibliotecologos-cr/4h6gy8Y1wM8

Burgos, Nidia. Jorge Asís. Los límites del canon. Buenos Aires: Catálogos, 2001.

Burgos, Nidia (2003). "La fracturación del campo intelectual argentino. Un caso emblemático: Jorge Asís". Mimeo.

Burgos, Raúl. Los Gramscianos argentinos. Buenos Aires: Siglo XXI, 2004.

Bustos, Emiliano. “Generación poética del '90, una aproximación. Hablar de poesía 3 (2000). 98-103.

Cabezón Cámara, Gabriela. "El alquimista del delirio". N. Revista de Cultura 399 (2011): 6-9.

Calabrese, Elisa y Luciano Martínez. Miguel Briante: genealogía de un olvido. Rosario: Beatriz Viterbo Editora, 2001.

Calveiro, Pilar. Poder y desaparición. Los campos de concentración en la Argentina. Buenos Aires: Colihue, 1998.

Calveiro, Pilar. Política y/o violencia. Una aproximación a la guerrilla de los años '70. Buenos Aires: Norma, 2005.

Cambours Ocampo, Arturo. Indagaciones sobre literatura argentina. Buenos Aires: Albatros, 1952.

Cambours Ocampo, Arturo. Lugones, el escritor y su lenguaje. Buenos Aires: Theoria, 1957.

Cambours Ocampo, Arturo. El problema de las generaciones literarias. Buenos Aires: Editorial A. Peña Lillo, 1963.

Candau, Joël. Memoria e identidad. Buenos Aires: Ediciones del Sol SRL, 2001.

Canelo, Paula. "Consideraciones sobre la subordinación de las Fuerzas Armadas argentinas durante los años noventa". Alfredo Pucciarelli, coordinador. Los años de 
Menem. La construcción del orden neoliberal. Buenos Aires: Siglo Veintiuno Editores, 2011. 143-176.

Canto, Patricio. El caso Ortega y Gasset. Buenos Aires: Ediciones Leviatán, 1958.

Caparrós, Martín. "Dos, tres, muchos Guevaras". "Culturas”. Página/ 12 (Buenos Aires, 4 octubre 1987): C- 6 .

Caparrós, Martín y Jorge Dorio. "Léan, che”. "Culturas". Página/12 (Buenos Aires, 27 nov. 1988): C-1-5.

Caparrós, Martín. "Nuevos avances y retrocesos de la nueva novela argentina en lo que va del mes de abril". Babel, revista de libros 10 (1989): 43-45.

Caparrós, Martín, “La Verónica”. Babel, revista de libros 19 (1990): 18.

Caparrós, Martín. “La Verónica”. Babel, revista de libros 20 (1990): 17.

Caparrós, Martín. "Mientras Babel”. Cuadernos Hispanoamericanos 517-519: "La cultura argentina. De la dictadura a la democracia" (1993): 525-528.

Caparrós, Martín. "Vamos a la playa" [Entrevista de María O' Donnell]. "Primer Plano". Página/12 (Buenos Aires, 1 dic. 1991): C-7.

Caparrós, Martín. "Martín Caparrós". Javier Trímboli, (entrevistador). La izquierda en la Argentina. Buenos Aires: Ediciones Manantial, 1998. 43-76.

Caparrós, Martín, Sergio Chejfec, Luis Chitarroni, Daniel Guebel y Alan Pauls. "Hablando de mi generación". N. Revista de Cultura 403 (2011): 9.

Caparrós, Martín. "Prólogo". La Voluntad, vol. 1. Buenos Aires: Planeta, 2013. XIXXXI.

Carassai, Sebastián. Los años setenta de la gente común. La naturalización de la violencia. Buenos Aires: Siglo XXI, 2013.

Carbone, Rocco y Ana Ojeda. "Estallidos: de la democracia a la depresión". Rocco Carbone y Ana Ojeda, compiladores. De Alfonsín al menemato 1983-2001: literatura argentina siglo $X X$. Buenos Aires: Paradiso, 2010. 11-56.

Carnovale, Vera. Los combatientes. Historia del PRT-ERP. Buenos Aires: Siglo Veintiuno Editores, 2011.

Carnovale, Vera. "Verdades, mentiras y silencios en las memorias de la 'guerra revolucionaria'". Ponencia presentada en el Congreso 2014 de la Asociación de Estudios Latinoamericanos, Chicago, IL, del 21 al 24 de mayo de 2014. Mimeo.

Carri, Albertina. Los rubios. Cartografía de una película. Buenos Aires: Ediciones del BAFICI, 2007.

Carrilla, Emilio. Literatura Argentina, 1800-1950 (Esquema generacional). Tucumán: Facultad de Filosofía y Letras de Tucumán, 1954.

Casi, Stefano (comp.). Il teatro inopportuno di Copi. Milán: Edizioni Titivillus, 2008.

Castillo, Abelardo. "La década vacía". El Ornitorrinco 6 (1979): s/ n.

Castro, Alberto. "Los nuevos tecnócratas (o el círculo de tiza)". Pie de Página 3 (1984/ 85): 4.

Castro, Alberto y Jorge Warley "La escasez austral y la moda". Los libros del '87". "Culturas". Página/12 (Buenos Aires, 27 dic. 1987): C-3.

Catelli, Nora. "La vuelta a la narración". Punto de Vista 18 (1983): 38-40.

Catelli, Nora. “¿Ya no hay invitados a la mesa de Orlando?”. Letra Internacional 27 (1992): 57-61. 
Catelli, Nora. "Circuitos de consagración en castellano: mercado y valor". Boletín/ 15 del Centro de Estudios de Teoría y Crítica Literaria de Rosario (2010): 1-13.

Cavarozzi, Marcelo. Autoritarismo y democracia (1955-1976). Buenos Aires: CEAL, 1983.

Cella, Susana (dir.). La irrupción de la crítica. Buenos Aires: Emecé, 1999.

Cerruti, Gabriela. "El estado de la memoria". Puentes 11 (2004): 4-7.

Chandler, Raymond. El simple arte de matar. Buenos Aires: Emecé, 1989.

Charle, Christophe. El nacimiento de los intelectuales: 1880-1900. Buenos Aires: Nueva Visión, 2009.

Chejfec, Segio. "Sergio Chejfec" [Respuesta al cuestionario "Narrativa: el capítulo que se viene"]. Tiempo Argentino (Buenos Aires, 6 nov. 1983): C-5.

Chejfec, Sergio. "Una gran obra sin preceptivas" [Reseña de La ocasión]. Babel, revista de libros 4 (1988): 5.

Chejfec, Sergio. "Mirada retrospectiva". Los dias del viaje 1 (1988): 9-10.

Chejfec, Sergio "De la inasible catadura de Osvaldo Lamborghini". Babel, revista de libros 10 (1989): 21.

Chejfec, Sergio. [Entrevista de Mónica Sifrim]. Clarín (Buenos Aires, 7 de noviembre de 1999b). Recuperado en: http://edant.clarin.com/suplementos/cultura/1999/11/07/e$\underline{00501 \mathrm{~d} . h \mathrm{tm}}$

Chejfec, Sergio. "Fábula política y renovación literaria”. Nueve Perros 1 (2001): 14-19.

Chejfec, Sergio "El argentino reticente" [Entrevista de Martín de Ambrosio]. Rocco Carbone y Ana Ojeda, comps. De Alfonsín al menemato (1983-2001). Buenos Aires: Paradiso; Fundación Crónica General, 2010. 174-175.

Chejfec, Sergio. El punto vacilante. Buenos Aires: Norma, 2005

Chirom, Daniel. "El mercado anda perdido en bicicleta". El periodista de Buenos Aires (Buenos Aires, 28 marzo-3 abril 1986): C-27-29.

Chitarroni, Luis. Siluetas. Buenos Aires: Juan Genovese Editor, 1992.

Chitarroni, Luis. "Los límites de la imitación". "Primer Plano". Página /12 (Buenos Aires, 30 junio 1991): C- 2.

Chitarroni, Luis. "Narrativa: nuevas tendencias. Relato de los márgenes". Cuadernos Hispanoamericanos 517-519: "La cultura argentina. De la dictadura a la democracia" (1993): 437-444.

Chitarroni, Luis. "Continuidad de las partes, relato de los límites". Elsa Drucaroff, directora del tomo. Historia crítica de la literatura argentina, vol. 11. La narración gana la partida. Buenos Aires: Emecé, 2000. 161-182.

Chitarroni, Luis. Mil tazas de té. Buenos Aires: La Bestia Equilátera, 2008.

Chitarroni, Luis. "Un camino de conversación" [Entrevista de Mauro Libertella]. $\tilde{N}$. Revista de Cultura 403 (2011): 6-8.

Chitarroni, Luis. "Soy un enfermo de la lectura, pero no sé si es una virtud" [Entrevista de Silvina Friera]. Página/ 12 (Buenos Aires, 9 sept. 2011): C-30-31.

Chitarroni, Luis. "Conversaciones que resultaron un lujo" [Entrevista de Silvina Friera]. Página/ 12 (Buenos Aires, 10 sept. 2011): C-35. 
Chitarroni, Luis. "Las figuras de la literatura del siglo XXI". Ñ. Revista de Cultura 463 (2012): 8-9.

Colonna, Vincent. Autofiction et autres mythomanies littéraires. París: Tristram, 2004.

CONADEP. Nunca más. Informe de la Comisión Nacional sobre la Desaparición de Personas. Buenos Aires: Eudeba, 1984.

CONADEP. Nunca más. Informe de la Comisión Nacional sobre la Desaparición de Personas. Buenos Aires: Secretaría de Derechos Humanos/ Eudeba, 2006.

Contreras, Sandra. Las vueltas de César Aira. Rosario: Beatriz Viterbo, 2002.

Corbatta. Jorgelina. Narrativas de la guerra sucia en la Argentina. Buenos Aires: Corregidor, 1999.

Cozarinsky, Edgardo. El pase del testigo. Buenos Aires: Sudamericana, 2001.

Cozarinsky, Edgardo et al. "La elección del mejor libro del año". Ñ. Revista de Cultura 273 (2008): 6-13.

Crenzel, Emilio: "Prólogo". Emilio Crenzel, compilador. Los desaparecidos en la Argentina. Memorias, representaciones e ideas (1983-2008). Buenos Aires: Biblos, 2010. 11-24.

Crenzel, Emilio. La historia política del Nunca más: la memoria de las desapariciones en la Argentina. Buenos Aires: Siglo XXI Editores Argentina, 2008.

Crespi, Maximiliano. "La era de la dispersión". N. Revista de Cultura 507 (2013): 8-9.

Crespi, Maximiliano. "El lenguaje desmitificado" [Respuesta a la Encuesta "Los libros que marcaron el año"]. N. Revista de Cultura 431 (2011): 6.

Dällenbach, Lucien. El relato especular. Madrid: Antonio Machado, 1991.

Damill, Mario. "La economía y la política económica: del viejo al nuevo endeudamiento". José Suriano, director. Dictadura y democracia (1976-2001), tomo 10. Nueva historia argentina. Buenos Aires: Sudamericana, 2005. 146-165.

Dalmaroni, Miguel. La palabra justa: literatura, crítica y memoria en la Argentina (1960-2002). Santiago de Chile, RIL Editores, 2004.

Dalmaroni, Miguel. "La moda y 'la trampa del sentido común'. Sobre la operación Raymond Williams en Punto de Vista". Orbis Tertius 5 (1997): 13-21.

Dalmaroni, Miguel (2002) [Reseña a Villa, de Luis Gusmán] Recuperado en: http://bazaramericano.com/buscador.php?cod $=276 \&$ tabla $=$ resenas $\& q u e=$ miguel $\% 20 \mathrm{dal}$ $\underline{\text { maroni }}$

Dalmaroni, Miguel y Margarita Merbilháa. “ 'Un azar convertido en don'. Juan José Saer y el relato de la percepción”. Elsa Drucaroff, directora del tomo. Historia crítica de la literatura argentina, vol. 11. La narración gana la partida. Buenos Aires: Emecé, 2000. 321-343.

Dalmaroni, Miguel. "Historia literaria y corpus crítico". Boletín/ 12 del Centro de Estudios de Teoría y Crítica Literaria de Rosario (2005): 109-128.

Damiani, Marcelo (comp.). El efecto Libertella. Rosario: Beatriz Viterbo, 2010.

De Diego, José Luis. ¿Quién de nosotros escribirá el Facundo? Intelectuales y escritores en Argentina (1970-1986). La Plata: Al Margen, 2001. 
De Diego, José Luis. "Novela y representación en el discurso crítico de la posdictadura". CELEHIS. Revista del Centro de Letras Hispanoamericanas 14 (2002): 177-195.

De Diego, José Luis. "1976-1989. Dictadura y democracia: la crisis de la industria editorial”. José Luis De Diego, director. Editores y políticas editoriales en Argentina (1880-2000). Buenos Aires: FCE, 2006. 163-208.

De Diego, José Luis. "La transición democrática: intelectuales y escritores". Antonio Camou, María Cristina Tortti y Aníbal Viguera, compiladores. La Argentina democrática: los años y los libros. Buenos Aires: Prometeo Libros, 2007. 49-82.

Delgado, Verónica. "Babel. Revista de libros en los '80. Una relectura". Orbis Tertius 2/ 3 (1996): 275-302.

Demarchi, José Luis. De la crítica de la ficción a la ficción de la crítica. Córdoba: Editorial de la Municipalidad de Córdoba, 2003.

Derrida, Jacques. "La Loi du genre”. Glyph: Textual Studies 7 (1980): 176-201.

Domínguez, Nora et al. "Estimado Lucas" [Réplica a "Retrato de una generación ausente", de Lucas Rubinich]. Punto de Vista 25 (1985): 45.

Drucaroff, Elsa (dir.). La narración gana la partida. Buenos Aires: Emecé, 2000.

Drucaroff, Elsa. Los prisioneros de la torre. Buenos Aires: Emecé, 2011.

Eco, Umberto. Apostillas a El nombre de la rosa. Buenos Aires: De la Flor, 1986.

Eco, Umberto. Interpretación y sobreinterpretacion. Cambridge: Cambridge University Press, 1995.

Elías, Norbert. Los alemanes. México: Instituto José María Luis Mora, 1999.

Erll, Astrid, Marion Gymnich y Ansgar Nünning. ,Einleitung: Literatur als Medium der Repräsentation und Konstruktion von Erinnerung und Identität“. Literatur- ErinnerungIdentität. Theoriekonzepte und Fallstudien. Trier: Wissenschaftlicher Verlag Trier (wtv), 2003. iii-ix.

Erll, Astrid y Ansgar Nünning. „Gedächtniskonzepte der Literaturwissenschaft: Ein Überblick“. Literatur- Erinnerung- Identität. Theoriekonzepte und Fallstudien. Tréveris: Wissenschaftlicher Verlag Trier (wtv), 2003. 3-27.

Erll, Astrid y Ansgar Nünning. "Literaturwissenschaftliche Konzepte von Gedächtnis: Ein einführender Überblick". Gedächtniskonzepte der Literaturwissenschaft. Theoretische Grundlegung und Anwendungsperspektiven. Berlín/ Nueva York: Walter de Gruyter 2005. 1-9.

Erll, Astrid. „Literatur al Medium des kollektiven Gedächtnisses“. Gedächtniskonzepte der Literaturwissenschaft. Theoretische Grundlegung und Anwendungsperspektiven. Berlín/ Nueva York: Walter de Gruyter 2005. 249-276.

Esquivada, Gabriela. “iPlata quemada!”. "Radarlibros”. Página /12 (Buenos Aires, 16 nov. 1997): C- 1-2

Estévez, Fernando. “Quiénes deciden hoy qué libros se leen en la Argentina?" [Entrevista de Patricia Kolesnikov]. Clarín (Buenos Aires, 5 dic. 2002): C- 30.

Evita Montonera. Recuperado en: http://www.ruinasdigitales.com/blog/revista-evitamontonera-coleccion-completa/

Falcone, Héctor. Memorial de la guerralarga. Un pibe entre cientos de miles. La Plata: de la campana, 2001.

Feiling, Carlos Eduardo. "El cencerro y las vacas. Reflexiones de un bienpensante". Babel, revista de libros 20 (1990): 7. 
Feiling, Carlos Eduardo "El culto de San Cayetano" [Reseña a Una sombra ya pronto serás]. Babel, revista de libros 22 (1990): 7.

Feiling, Carlos Eduardo. "Esa clase de sed" [Reseña a Los fantasmas]. Babel, revista de libros 21 (1990): 5.

Feiling, Carlos Eduardo. "El viejo cuento de la narrativa". "Radar". Página/12 (Buenos Aires, 30 marzo 1997): C- 21.

Feiling, Carlos Eduardo. Con toda intención. Buenos Aires: Sudamericana, 2005.

Feiling, Carlos. "El terror de los inocentes". "Cultura y Nación”. Clarín (Buenos Aires, 25 abril 1996): C- 6-7.

Feld, Claudia y Mariela Govea: "Literatura del ochenta. El avestruz que clama en el desierto". El Porteño (Buenos Aires, dic. 1987): C-74.

Feld, Claudia. "La representación de los desaparecidos en la prensa de la transición: el 'show del horror'". Emilio Crenzel, comp. Los desaparecidos en la Argentina. Memorias, representaciones e ideas (1983-2008). Buenos Aires: Editorial Biblos, 2010. $25-41$.

Fernández Meijide, Graciela. La historia íntima de los derechos humanos en la Argentina. Buenos Aires, 2009.

Ferrando, Ernesto y José Luis Reyna. "El problema de imprimir". Clarín (Buenos Aires, 15 abril 1988): C-9.

Ferrer, Christián. "Rodolfo Walsh: una herencia imposible". Babel, revista de libros 9 (1989): 27.

Ferreyra, Lilia. "Los caballos de Walsh". "Radar". Página/ 12 (Buenos Aires, 23 marzo 1997): C-4-7.

Ferreyra, Lilia. "Esa carta". "Radar". Página/ 12 (Buenos Aires, 21 marzo 1999): C- 56.

Ferro, Roberto. "La literatura en el banquillo. Walsh y la prensa clandestina". Susana Cella, directora del tomo. Historia crítica de la literatura argentina, vol. 10. La irrupción de la crítica. Buenos Aires: Emecé, 1999. 125-146.

Fogwill, Rodolfo Enrique. "Las aventuras de la escuela de Viena" [Reseña a Las aventuras de un novelista atonal]. Pie de Página 1 (1982): 27-28.

Fogwill, Rodolfo Enrique. "Asís y los buenos servicio". Pie de Página 2 (1983b): 2124.

Fogwill, Rodolfo Enrique. "Sergio y yo" [Reseña a El divino convertible]. Babel, revista de libros 21 (1990): 8.

Fogwill, Rodolfo Enrique. "La instalación de Arturo Carrera". Osvaldo Lamborghini y Arturo Carrera. Palacio de los aplausos (o el suelo del sentido). Rosario: Beatriz Viterbo Editora, 2002. 59-62

Fogwill, Rodolfo Enrique "Sintaxis mayor". adnCULTURA. La revista cultural de los sábados. La Nación (Buenos Aires, 23 agosto 2008): C- 8-9.

Fogwill, Rodolfo Enrique. Los libros de la guerra. Buenos Aires: Mansalva, 2010.

Fogwill, Rodolfo Enrique (2010) "Fogwill” [Entrevista de Patricio Zunini]. Recuperado en: http://blog.eternacadencia.com.ar/archives/2010/7627

Fogwill, Rodolfo Enrique. "Yo, el supremo" [Entrevista de Martín Kohan]. N. Revista de Cultura 130 (2006): 6-9.

Forn, Juan. La tierra elegida. Buenos Aires: Emecé, 2005. 
Forn, Juan. Ningún hombre es una isla. Buenos Aires: Emecé, 2010.

Forn, Juan "Los de treinta y pico. Abran cancha" [Entrevista de Jorge Warley]. El Porteño (Buenos Aires, sept. 1990): C-37-39.

Forn, Juan (2005) [Entrevista de Claudio Zeiger]. Recuperado en: http://www.pagina12.com.ar/diario/suplementos/libros/10-1488-2005-04-02.html

Forn, Juan (2012) [Entrevista de Pedro Pablo Guerrero]. Recuperado en: http://www.letrasdechile.cl/Joomla/index.php/entrevistas/2136-2136

Fornet, Jorge. "Un debate de poéticas. Las narraciones de Ricardo Piglia". Elsa Drucaroff, directora del tomo. Historia crítica de la literatura argentina, vol. 11. La narración gana la partida. Buenos Aires: Emecé, 2000. 345-360.

Fornet, Jorge. El escritor y la tradición. Ricardo Piglia y la literatura argentina. Rosario: Beatriz Viterbo Editora, 2007.

Forster, Ricardo. "De batallas y olvidos: el retorno de los setenta". Pensamiento de los Confines 14 (2004): 35-49.

Fowler, Alastair [1982]. Kinds of Literature. An Introduction to the Theory of Genres and Models. Oxford: Clarendon Press, 1997.

Franco, Marina y Florencia Levin. "El pasado cercano en clave historiográfica". Marina Franco y Florencia Levin, compiladoras. Historia reciente. Perspectivas y desafios para un campo en construcción. Buenos Aires: Paidós, 2007. 31-65.

Franco, Marina. Un enemigo para la nación. Orden interno, violencia y "subversión", 1973-1976. Buenos Aires: Fondo de Cultura Económica, 2012.

Franco, Marina y Vera Carnovale. "Reflexiones sobre la investigación en Historia Reciente: entrevistas a Marina Franco y Vera Carnovale". PolHis 13 (2014): 196-207.

Fresán, Rodrigo. "El hombre que caminaba demasiado" [Reseña a La buena nueva de Los libros del Caminante]. Babel, revista de libros 20: 5.

Fresán, Rodrigo. "Entrevista a Rodrigo Fresán. Si Mitre viviera..." [Entrevista de Sergio Olguín y P. B. Rey]. Con V de Vian 3 (1991): 20-21

Fresán, Rodrigo. "Tiros, líos y cosa golda". "Radar". Página /12 (Buenos Aires, 19 junio 2011): C-4-5.

Fuentes, Carlos. La nueva novela hispanoamericana. México: Editorial Joaquín Mortiz, 1969.

Fukuyama, Francis. El fin de la historia. Buenos Aires: Planeta, 1994.

Galperín, Karina "Ya no cautiva" [Reseña a La prueba] Con V de Vian 8 (1992): 14-15.

Gamerro, Carlos (2003). “Argentine Literature and its Monsters”. Mimeo.

Gamerro, Carlos. Harold Bloom y el canon literario. Buenos Aires: Norma, 2003.

Gamerro, Carlos. "Disparen contra el policial negro". N. Revista de Cultura 98 (2005): 6-8.

Gamerro, Carlos. El nacimiento de la literatura argentina y otros ensayos. Buenos Aires: Norma, 2006.

Gamerro, Carlos. "Policial, peronismo y dictadura". N. Revista de Cultura 454 (2012): 20-21.

Garaño, Santiago y Werner Pertot. La otra juvenilia. Militancia y represión en el Colegio Nacional de Buenos Aires (1971-1886). Buenos Aires: Biblos, 2008. 
García Canclini, Néstor. La producción simbólica: teoría y método en sociología del arte. México: Siglo XXI, 1979.

García Canclini, Néstor. "Introducción: La sociología del arte de Pierre Bourdieu". Sociología y cultura. México: Grijalbo, 1990. 9-50.

García, Germán. Fuego amigo. Buenos Aires: grama ediciones, 2003.

García Helder, Daniel. "El neobarroco en la Argentina”. Diario de Poesía 4 (1987): 2425 .

García Helder, Daniel [Reseña a Poemas Chinos] Diario de Poesía 6 (1987): 31.

"Garganta profunda” [s/ firma]. “Cuánto vale un escritor?”. "Primer Plano”. Página /12 (Buenos Aires, 16 junio 1991): C-7.

Garzón, Raquel. "Las librerías se declaran en default". "Cultura y Nación". Clarín (Buenos Aires, 12 enero 2002): -3.

Gelman, Juan y Mara La Madrid. Ni el flaco perdón de Dios. Hijos de desaparecidos. Buenos Aires: Planeta, 1997.

Getino, Octavio. El capital de la cultura. Las industrias culturales en la Argentina. Buenos Aires: CICCUS, 2008.

Gilman, Claudia. Entre la pluma y el fusil. Debates y dilemas del escritor revolucionario en América Latina. Buenos Aires: Siglo Veintiuno Editores, 2003.

Gillespie, Richard. Soldados de Perón. Los montoneros. Buenos Aires: Grijalbo, 1997.

Ginzberg, Victoria. "Una presentación inédita por Malvinas". Página/12 (14 junio 2012): C-6-7.

Giordano, Alberto. Manuel Puig, la conversación infinita. Rosario: Beatriz Viterbo, 2002.

Giordano, Alberto. "Cultura de la intimidad y giro autobiográfico en la literatura argentina actual”. Pensamiento de los Confines 21 (2007): 157-167.

Giordano, Alberto. El giro autobiográfico de la literatura argentina actual. Buenos Aires: Mansalva, 2008.

Giordano, Alberto. Vida y obra. Otra vuelta al giro autobiográfico. Rosario: Beatriz Viterbo Editora, 2011.

Giorgi, Gabriel. Sueños de exterminio. Homosexualidad y represión en la literatura argentina contemporánea. Rosario: Beatriz Viterbo, 2004.

Goic, Cedomil. Historia de la novela hispanoamericana. Valparaíso: Ediciones Universitarias, 1972.

Gómez, José María. "Eclipse de la memoria, política del olvido: la cuestión de los derechos humanos en una democracia no consolidada". Punto de Vista 36 (1989): 1-21.

Goldchluk, Graciela y Julia Romero. "El contorno del fantasma. Las huellas de la historia en El beso de la mujer araña de Manuel Puig". Orbis Tertius 4 (1997): 35-50.

Goldchluk, Graciela. "La travesía de Valentín: de la vida real a El beso de la mujer araña". Hispamérica. Revista de literatura 80/81 (1998): 47-80.

Goldchluk, Graciela. "Distancia y contaminación. Estudio crítico genético de la fase redaccional". Amícola, José y Jorge Panesi (directores). El beso de la mujer araña. Poitiers: CNRLA, Archivos; Córdoba: Alción Editora, 2002. LIX-LXXIV. 
González Bombal, Inés y Oscar Landi. "Los derechos en la cultura política". Carlos Acuña et al. Juicios, castigos y memorias. Buenos Aires: Nueva Visión, 1995. 193-216.

González Bombal, Inés. "La Figura de la Desaparición en la re-fundación del Estado de Derecho". Marcos Novaro y Vicente Palermo, compiladores. La historia reciente: Argentina en democracia. Buenos Aires: Edhasa, 2004. 115-131.

González, Horacio. "El boom: rastros de una palabra en la narrativa y la crítica argentina". Elsa Drucaroff, directora del tomo. Historia crítica de la literatura argentina, vol. 11. La narración gana la partida. Buenos Aires: Emecé, 2000. 405-430.

González, Horacio. "La figura literaria del reventado como teoría picaresca de la política”. El Ojo Mocho 16 (2001/ 2002): 36-38.

Gorbato, Viviana. "El grupo Shangai da la cara". El periodista de Buenos Aires (Buenos Aires, 26 feb.-3 marzo 1988): C-24-25.

Gramuglio, María Teresa. "El canon del crítico fuerte". Susana Cella, compiladora. Dominios de la literatura. Acerca del canon. Buenos Aires, Losada, 1998. 43-57.

Gramuglio, María Teresa "El lugar de Saer". Jorge Lafforgue, editor. Juan José Saer por Juan José Saer. Buenos Aires: Celtia, 1986. 261-299.

Gramuglio, María Teresa. "La construcción de la imagen". Revista de Lengua y Literatura 4 (1988): 3-16.

Gramuglio María Teresa. "La construcción de la imagen". La escritura argentina. Santa Fe: Universidad Nacional del Litoral Ediciones de la Cortada, 1992. 37-64.

Gramuglio, María Teresa. "Políticas del decir y formas de la ficción. Novelas de la dictadura militar". Punto de Vista 74 (2002): 9-14.

Graña, Rolando. "El niño decoroso". Con V de Vian 8 (1992): 10.

Gramuglio, María Teresa [Reseña sobre Pubis angelical] Punto de Vista 8 (1980): 33.

Gramuglio, María Teresa. “Genealogía de lo nuevo”. Punto de Vista 39 (1990): 5-10.

Gramuglio, María Teresa. "Genealogía de lo nuevo". Roland Spiller, editor, Lateinamerika-Studien 29. La novela argentina de los años '80. Francfort del Meno: Vervuert, 1991. 239-256.

Gregorich, Luis. "Desarollo de la narrativa: la generación intermedia". Adolfo Prieto, director. Historia de la literatura argentina. Buenos Aires: CEAL, 1968. 1201-1224.

Gregorich, Luis. "La generación del '55: los narradores". Adolfo Prieto, director. Historia de la literatura argentina. Buenos Aires: CEAL, 1968. 1201-1224.

Gregorich, Luis y Josefina Delgado. "Los nuevos. Selección de cuentistas y poetas". Buenos Aires, CEAL, 1968.

Gregorich, Luis y Josefina Delgado. "Las nuevas promociones: la narrativa y la poesía". Prieto Adolfo, director. Historia de la literatura argentina. Buenos Aires: CEAL, 1968. 1297-1320.

Guebel, Daniel. Mis escritores muertos. Buenos Aires: Mansalva, 2008.

Guerriero, Leila (comp.). Los malditos. Santiago de Chile: Ediciones Universidad Diego Portales, 2012.

Guevara, Ernesto. El Diario del Che en Bolivia. Buenos Aires: Siglo veintiuno editores, 1970. 
Gundermann, Christian. Actos melancólicos. Formas de la resistencia en la postdictadura argentina. Rosario: Beatriz Viterbo Editora, 2007.

Gusmán, Luis [Entrevista de Alberto Castro, Daniel Link y Carlos Mangone] Pie de Página 3 (1984/ 85): 15-17.

Gusmán, Luis. "Vamos a la playa" [Entrevista de María O' Donnell]. "Primer Plano". Página/12 (Buenos Aires, $1^{\circ}$ dic. 1991): C- 7.

Gusmán, Luis. "El hombre de los gansos" [Entrevista de Jorge Panesi]. los inrockuptibles, 27 (1998): 30-32.

Gusmán, Luis. "Dr. Jekll y Mr. Hyde" [Entrevista de Jonathan Rovner]. "Radarlibros" Página /12 (Buenos Aires, 10 nov. 2002): 8.

Gusmán, Luis. "Hoy un joven escritor sorprende mucho menos" [Entrevista de Javier Alemián]. N. Revista de Cultura 444 (2012): 6-8.

Gusmán, Luis. Epitafios. El derecho a la muerte escrita. Buenos Aires: Norma, 2005.

Gusmán, Luis. "Respuesta a la 'Nueva encuesta a la literatura argentina' ". N. Revista de Cultura 325 (2009): 16.

Halbwachs, Maurice [1925]. On collective memory. Lewis A. Coser, editor. Chicago/ Londres: The University of Chicago Press, 1992.

Helbling, Carlos Conrado. Derecho a la esperanza. Buenos Aires: Sudamericana, 1978.

Hernáiz, Sebastián. "Revistas literarias y lugar social de la literatura en los '90". Rodolfo Walsh no escribió Operación Masacre y otros ensayos. Buenos Aires: 17 grises editora, 2012. 99-128.

Herralde, Jorge. El observatorio editorial. Buenos Aires: Adriana Hidalgo, 2004.

H.I.J.O.S. Situaciones 5. Mesa de Escrache Popular. Documento de la Comisión de Escarches de H.I.J.O.S. Buenos Aires: Ediciones de Mano en Mano, 2002.

Hilb, Claudia y Daniel Lutzky. La nueva izquierda argentina. Buenos Aires: CEAL, 1984.

Hirsch, Marinne: "Family Pictures: Maus, Mourning, and Post-Memory". Discourse: Theoretical Studies in Media and Culture 15 (1992/ 93): 3-29.

Hirsch, Marianne. Family Frames. Photography, Narrative and Postmemory. Cambridge/ Massachusetts/ Londres: Harvard University Press, 1997.

Hirsch, Marianne. "Family Pictures: Maus, Mourning and Post-Memory". Discourse: Journal for Theoretical Sudies in Media and Culture 15 (1992/ 93): 3-29.

Hutcheon, Linda. "Ironie et parodie: stratégie et structure". Poétique 36 (1978) : 467477.

Huyssen, Andreas. "Guía del posmodernismo". Punto de Vista 29 (1987): i-xli.

Huyssen, Andreas. En busca del futuro perdido. Cultura y memoria en tiempos de globalización. México D. F.: FCE, 2002.

Idez, Ariel. Literal: La vanguardia intrigante. Buenos Aires: Prometeo, 2010.

Izaguirre, Inés et al. Lucha de clases, guerra civil y genocidio en la Argentina (19731983). Antecedentes. Desarrollo. Complicidades. Buenos Aires: Eudeba, 2009.

Jaeger, Hans. „Generationen in der Geschichte. Überlegungen zu einer umstrittenen Konzeption". Geschichte und Gesellschaft 3 (1977): 429-452.

Jelin, Elizabeth "Memorias en conflicto". Puentes 1 (2000): 6-13.

Jelin, Elizabeth. Los trabajos de la memoria. Buenos Aires: Siglo Veintiuno Editores, 2002. 
Jitrik, Noé. Seis novelistas argentinos de la nueva promoción. Mendoza: ediciones bilioteca san martín, 1959.

Jitrik, Noé. "Canónica, regulatoria y transgresiva". Susana Cella, compiladora. Dominios de la literatura. Acerca del canon. Buenos Aires, Losada, 1998. 19-41.

Jitrik, Noé. "Epílogo". Susana Cella, directora del tomo. Historia crítica de la literatura argentina, vol. 10. La irrupción de la crítica. Buenos Aires: Emecé, 1999. 501-503.

Jitrik, Noé. "Violencia y literatura". Verde es toda teoría. Buenos Aires: 2010. 35-38.

Jozami, Eduardo. Rodolfo Walsh. La palabra y la acción. Buenos Aires: Norma, 2006.

Jureit, Ulrike y Michael Wildt. „Generationen“. Jureit, Ulrike y Michael Wildt, compiladores. Generationen. Zur Relevanz eines wissenschaftlichen Grundbegriffs. Hamburgo: Hamburger Edition, 2005. 7-26.

Jurisisch, Marcelo. "Lo que yace debajo: para qué sirve el canon literario". Espéculo. Revista de estudios literarios (2008) http://www.ucm.es/info/especulo/numero38/canonli.html

King, John. "Las revistas culturales de la dictadura a la democracia: el caso de 'Punto de Vista'". Karl Kahut y Andrea Pagni, editores. Literatura Argentina hoy. De la dictadura a la democracia. Fráncfort del Meno: Vervuert, 1989. 87-94.

Kohan, Martín. "Trashumantes de neblina, no las hemos de encontrar". Espacios de crítica y producción 13 (1994): 82-86.

Kohan, Martín. "El fin de una épica". Punto de Vista 64 (1999): 6-11.

Kohan, Martín. "Saer, Walsh: una discusión política en la literatura". Textos de y sobre Rodolfo Walsh. Jorge Lafforgue, compilador. Madrid: Alianza, 2000. 121-129.

Kohan, Martín. "Historia y literatura: la verdad de la narración". Elsa Drucaroff, directora del tomo. Historia crítica de la literatura argentina, vol. 11. La narración gana la partida. Buenos Aires: Emecé, 2000. 245-259.

Kohan, Martín. “Tres respuestas sin preguntas”. milpalabras 1 (2001): 35-40.

Kohan, Martín. "La apariencia celebrada". Punto de Vista 78 (2004a): 24-30.

Kohan, Martín. "Una crítica en general y una película en particular". Punto de Vista 80 (2004b): 47-48.

Kohan, Martín: "Más acá del bien y del mal. La novela hoy". Punto de Vista 83 (2005a): 8-10.

Kohan, Martín. "Los mejores libros se escriben sin fórmulas". N Revista de Cultura 89 (2005b): 8 .

Kohan, Martín. “De Echeverría a Juan José Saer”. N. Revista de Cultura 189 (2007): 8.

Kohan, Martín. "Glosa, novela política”. Paulo Ricci, compilador. Zona de prólogos. Buenos Aires: Seix Barral, 2011. 147-160.

Kohan, Martín. "Otra forma de contar lo político". "Cultura y espectáculos”. Página/ 12 (Buenos Aires, 28 junio 2011): C-28.

Kohan, Martín. Fuga de materiales. Santiago de Chile: Ediciones Universidad Diego Portales, 2013.

Kohan, Martín. "Fuga y misterio de César Aira". N. Revista de Cultura 507 (2013): 6-7. 
Kohan, Martín [Entrevista de Silvina Friera]. "Cultura y espectáculos". Página/ 12 (Buenos Aires, 23 marzo 2014): C- 35.

Kohut, Karl y Andrea Pagni (editores). Literatura argentina hoy. De la dictadura a la democracia. Fráncfort del Meno: Vervuert, 1989.

Kolesnicov, Patricia. “QQuiénes deciden qué libros se leen hoy en la Argentina?”. Clarín (Buenos Aires, 5 diciembre 2002): C- 30.

Kon, Daniel. Los chicos de la guerra. Hablan los soldados que estuvieron en Malvinas. Buenos Aires: Galerna, 1982.

Koselleck, Reinhart. Futuro pasado. Para una semántica de los tiempos modernos. Barcelona: Paidós, 1993.

Koselleck, Reinhart. Zeitschichten. Studien zur Historik. Fráncfort del Meno: Suhrkamp Taschenbuch Verlag, 2000.

Kristeva, Julia. Semiótica I y II. Madrid: Fundamentos, 1981.

Kristeva, Julia. El texto de la novela. Barcelona: Lumen, 1974

La Causa Peronista. Recuperado en: http://www.ruinasdigitales.com/causaperonista/

Lach, Santiago. "Respuesta a la 'Nueva encuesta a la literatura argentina'". N. Revista de Cultura 325 (2009): 16.

Lachmann, Renate. Gedächtnis und Literatur. Intertextualität in der russischen Moderne. Fráncfort del Meno: Suhrkamp, 1990.

Lachmann, Renate. „Kultursemiotischer Prospekt“. Anselm Haverkamp y Renate Lachmann, editores. Memoria: Vergessen und Erinnern. Múnich: Fink, 1993. XVIIXXVII.

Lafleur, Héctor, Sergio Provenzano y Fernando Alonso. Las revistas literarias argentinas: 1893-1967. Buenos Aires: CEAL, 1968.

Lafforgue, Jorge. "El eje de la narrativa argentina" [Comentario al resultado de la encuesta organizada por la revista Humor sobre las diez novelas más importantes de la literatura argentina]. Humor 204 (1987): 113.

Lafforgue, Jorge. "La narrativa argentina". Represión y reconstrucción de una cultura: el caso argentino. Saúl Sosnowski, compilador. Buenos Aires: Eudeba, 1988. 149-166.

Lafforgue, Jorge (comp.) Textos de y sobre Rodolfo Walsh. Madrid: Alianza, 2000.

Lagache, Diego. “Feria No 12: ¿Hasta dónde es posible el cambio?”. El periodista de Buenos Aires (Buenos Aires, 28 marzo- 3 abril 1986): C- 30.

Laiseca, Alberto. "El desparpajo sin límites” [Entrevista de Diego Erlán]. N. Revista de Cultura 546 (2014): 4-6.

Lanata, Jorge "Ahora dicen que escribía mal". "Primer Plano". Página /12 (Buenos Aires, 30 junio 1991): C-2-3.

Lanata, Jorge. "Cómo revelar polaroids" [Entrevista]. "Primer Plano". Página /12 (Buenos Aires, 4 agosto 1991): C- 8.

Lanata, Jorge (2007) "Entrevista". Recuperado en: http://www.lanacion.com.ar/900311falta-un-debate-sobre-la-violencia-politica-de-los-70

Lanata, Jorge (2009) [Entrevista de Susana Reinoso]. Recuperado en: http://www.lanacion.com.ar/nota.asp?nota_id=900311

La Rosa Blindada. Edición facsimilar. Buenos Aires: Biblioteca Nacional, 2014. 
Lesgart, Cecilia. "Luchas por los sentidos del pasado y el presente". Hugo Quiroga y César Tcach, compiladores. Argentina 1976-2006. Entre la sombra de la dictadura y el futuro de la democracia. Rosario: Homo Sapiens Ediciones, 2006. 167-198.

Levín, Florencia. "Arqueología de la memoria. Algunas reflexiones a propósito de Los vecinos del horror. Los otros testigos". Entrepasados 28 (2005): 47-64.

Levi, Primo. Los hundidos y los salvados. Barcelona: Muchnik Editores, 1989.

Libertella, Héctor. Nueva escritura en Latinoamérica. Caracas: Monte Ávila, 1977.

Libertella, Héctor. Ensayos o pruebas sobre una red hermética. Buenos Aires: GEL, 1990.

Libertella, Héctor. Pathografeia. Los juegos desviados de la literatura. Buenos Aires: GEL, 1991.

Libertella, Héctor. Las sagradas escrituras. Buenos Aires: Sudamericana, 1993.

Libertella, Héctor (comp.) Literal 1973-1977. Buenos Aires: Santiago Arcos Editor, 2002.

Libertella, Héctor. La librería argentina. Córdoba: Alción, 2003.

Lida, Clara E., Horacio Crespo y Pablo Yankelevich (comps.). Estudios en torno al golpe de Estado. Buenos Aires: FCE/ El Colegio de México, 2008.

Link, Daniel "Meditaciones de lo real en El entenado de Juan José Saer [Reseña a El entenado] Pie de Página 3 (1984/ 85): 29-30

Link, Daniel. “Cae la noche tropical. Manuel Puig”. Babel, revista de libros 6 (1989a): 8.

Link, Daniel. "El general en su laberinto" [Reseña a El general en su laberinto]. Babel, revista de libros 9 (1989b): 10.

Link, Daniel. La chancha con cadenas. Doce ensayos de literatura argentina. Buenos Aires: Ediciones del Eclipse, 1994.

Link, Daniel. "Ein Bericht für eine Akademie: violencia, escritura y representación en el Río de la Plata (1973-1995)". Lateinamerika-Studien 36. Culturas del Río de la Plata. Roland Spiller, editor. Fráncfort del Meno: Vervuert, 1995. 51-67.

Link, Danie.l. "Políticas del género" [Reseña a El vuelo de la reina]. Punto de Vista 73 (2002): 10-14.

Link, Daniel. Cómo se lee. Buenos Aires: Norma 2003.

Link, Daniel [1999] "Epílogo: la soledad”. Daniel Balderston et al. Escrito por otros. Ensayos sobre los libros de Luis Gusmán. Buenos Aires: Norma, 2004. 213-217.

Link, Daniel Clases. Literatura y disidencia. Buenos Aires: Norma, 2005

Link, Daniel. Leyenda. Literatura argentina: cuatro cortes. Buenos Aires: Entropía, 2006.

Link, Daniel. "Pasado y futuro". Linkillo (2006). Recuperado en: http://linkillo.blogspot.com.ar/2006_01_01_archive.html

Link, Daniel [Reseña a la edición de Los Sorias, "Radarlibros", 19.7.1998]. Recuperado en: $\quad$ http://www.pagina12.com.ar/1998/suple/libros/98-07/98-0719/nota1.htm

Link, Daniel. "Prólogo a la segunda edición" y "Prólogo a la primera edición". Rodolfo Walsh. Ese hombre y otros papeles personales. Buenos Aires: Ediciones de la Flor, 2007. 5-7 y 9-12. 
Link, Daniel (2007) [Entrevista de Sebastián Hernáiz y Diego Cousido] Recuperado en: http://www. elinterpetador.net/32EntrevistaADanielLink.html

Link, Daniel. Fantasmas. Imaginación y sociedad. Buenos Aires: Eterna Cadencia, 2009.

Link, Daniel. Textos de ocasión. Buenos Aires: El Cuenco de Plata, 2012.

Link, Daniel. "Fantasías de la era digital”. N. Revista de Cultura 463 (2012): 18.

Literal (1973-1977). Edición facsimilar. Buenos Aires: Biblioteca Nacional, 2011.

Longoni, Ana. Traiciones. La figura del traidor en los relatos acerca de los sobrevivientes de la represión. Buenos Aires: Siglo Veintiuno, 2007.

López, María Pía. "Soldados, testigos y escritores". Rocco Carbone y Ana Ojeda, comps. De Alfonsín al menemato (1983-2001). Buenos Aires: Paradiso, 2010. 150-163.

Lo Presti, Flavio. "El destino insular”. N. Revista de Cultura 507 (2013): 9.

Lorenz, Federico. "Las conmemoraciones del golpe militar de 1976. Memorias de aquel 24". Todo es historia 404 (2001): 6-26.

Lorenz, Federico. Las Guerras por Malvinas. Buenos Aires: Edhasa, 2006.

Lorenz, Federico. Malvinas. Una guerra argentina. Buenos Aires: Sudamericana, 2009.

Los libros. Edición Facsimilar. Buenos Aires: Biblioteca Nacional, 2011.

Lüscher, Kurt. „Ambivalenz -Eine Annährung an das Problem der Generationen“. Ulrike Jureit y Michael Wildt, editores. Generationen. Zur Relevanz eines wissenschaftlichen Grundbegriffs. Hamburgo: Hamburger Edition, 2005. 53-78.

Ludmer, Josefina. El género gauchesco. Un tratado sobre la patria. Buenos Aires: Libros Perfil, 2000.

Ludmer, Josefina. "Temporalidades del presente". Boletín/ 10 del Grupo de Estudios de $\begin{array}{lllll}\text { Teoría } & \text { y } & \text { Crítica } & \text { Literaria, }\end{array}$ http://www.celarg.org/boletines/articulos.php?idb=21

Ludmer, Josefina (2001). "El lugar de la resistencia" [Entrevista de María Moreno, seud. de Cristina Forero] Recuperado http://www.pagina12.com.ar/2001/suple/Libros/01-10/01-10-07/nota1.htm

Ludmer, Josefina. Aquí América Latina. Una especulación. Buenos Aires: Eterna Cadencia, 2010.

Luna, Félix. El 45. Crónica de un año decisivo. Buenos Aires: Delbolsillo, 2005.

Madrazo, Jorge. "Crisis de la industria editorial". El periodista de Buenos Aires (Buenos Aires, 5-11 abril 1985): C-29-33.

Macón, Cecilia. “ 'Los rubios' o del trauma como presencia”. Punto de Vista 80 (2004): 44-47.

Mangieri, José Luis, Daniel Samoilovich, Victorio Redondo, Carlos Pereiro y Edgardo Pícoli "No todo son musas" [Entrevista de Marcos Mayer y Miguel Russo]. "Primer Plano". Página/ 12 (Buenos Aires 20 de diciembre de 1992): C-2-3.

Mangone, Carlos y Jorge Warley. El manifiesto. Un género entre el arte y la política. Buenos Aires: Editorial Biblos, 1994.

Mannheim, Karl [1928]. „Das Problem der Generationen“. Kurt Wolff, editor. Wissenssoziologie. Auswahl aus dem Werk. Berlín: Luchterhand, 1964. 
Margulis, Mario y Marcelo Urresti. "La juventud es más que una palabra”. Mario Margulis, editor. La juventud es más que una palabra. Ensayos sobre cultura y juventud. Buenos Aires: Biblos, 1996. 13-30.

Marías, Julián. El método histórico de las generaciones. Madrid: Revista de Occidente, 1949.

Marimón, Antonio. "Un best-seller argentino: las mil caras de un pícaro". Punto de Vista 14 (1982). 24-27.

Marín, Juan Carlos. Los hechos armados. Buenos Aires: La Rosa Blindada/ P.I.C.A.S.O., 2007

Martínez, Facundo. “Asís presidente”. El Ojo Mocho 16 (2001/ 2002): 29.

Martínez, Guillermo. "Un ejercicio de esgrima". La fórmula de la inmortalidad. Buenos Aires: Seix Barral, 2005. 157-208.

Martínez, Tomás Eloy. "El poder escribe la historia". Crisis 62 (1988): 35.

Martínez, Tomás Eloy. "La loca de la casa". "Primer Plano". Página /12 (Buenos Aires, 9 junio 1991): C- 1.

Martínez, Tomás Eloy. "Recomendaciones del editor". "Primer Plano". Página /12 (Buenos Aires, 3 agosto 1991): C- 4 .

Martínez, Tomás Eloy. "Recomendaciones del editor". "Primer Plano". Página /12 (Buenos Aires, 18 agosto 1991): C- 4.

Martini, Juan Carlos y Rubén Ríos. "Las 10 novelas más importantes de la literatura argentina”. Humor registrado 196 (1987): 97.

Marx, Karl. Die deutsche Ideologie. Kritik der neuesten deutschen Philosophie in ihren Repräsentanten Feuerbach, B. Bauer und Stirner und des deutschen Sozialismus in seinen verschiedenen Propheten. Obras, vol. 3. Berlín: Dietz Verlag, 1969.

Mayer, Marcos. “¿Qué es el canon?”. Ñ. Revista de Cultura 189 (2007): 8.

Mayer, Marcos. "La cultura va al mercado". Ñ. Revista de Cultura 400 (2011): 6-7.

Menéndez Trucco, Carolina. "Los nuevos audaces". adnREVISTA DE CULTURA. La Nación (Buenos Aires, 9 agosto 2008): 12-13.

Minelli, María Alejandra. Con el aura al margen (Cultura argentina en los años '80 y '90). Córdoba: Alción Editora, 2006.

Molina, Diego. "Babélicos versus planetarios. Puro grupo". Rocco Carbone y Ana Ojeda, compiladores. De Alfonsín al menemato 1983-2001: literatura argentina siglo $X X$. Buenos Aires: Paradiso, 2010. 205-213.

Montaldo, Graciela. "Introducción. El origen de la historia". David Viñas, director. Historia social de la literatura argentina. Irigoyen, entre Borges y Arlt (1916-1930). Buenos Aires: Contrapunto, 1989. 23-30.

Montaldo, Graciela. "La invención del artificio. La aventura de la historia". Lateinamerika-Studien 29. La novela argentina de los años 80. Roland Spiller, editor. Fráncfort del Meno: Vervuert, 1991. 257-269.

Montaldo, Graciela. "Borges, Aira y la literatura para multitudes". Boletín / 6. Centro de Estudios de Teoría Literaria, Rosario (1998): 7-17.

Montaldo, Graciela. "Aira: un arte basado en la incorrección. El cuestionamiento de las instituciones en una vanguardia finisecular". Rocco Carbone y Ana Ojeda, compiladores. De Alfonsín al menemato 1983-2001: literatura argentina siglo XX. Buenos Aires: Paradiso, 2010. 94-106. 
Montergous, Gabriel. La generación del 80 y el proceso militar. Buenos Aires: CEAL, 1985.

Moreno, María. "Locas por Copi”. "Culturas”. Página/ 12 (Buenos Aires, 20 de dic. 1987): C-2-3.

Moreno, María (2012) [Reseña sobre Temas lentos] Recuperado en: http://www.pagina12.com.ar/diario/suplementos/libros/10-4809-2012-10-06.html

Morero, Liliana. "El libro argentino: nunca estuvo peor desde que existe". El nuevo periodista (Buenos Aires, 30 sept. - 6 oct. 1988): C-40-42.

Morresi, Santiago. "La democracia de los muertos. Algunos apuntes sobre el liberalismo conservador, el neoliberalismo y la ideología del Proceso de Reorganización Nacional. Actas en CD-ROM de las XI Jornadas Interescuelas de Historia, Tucumán, 19 al 21 de sept. de 2007. Mimeo.

Moscardi, Matías (2011). "Presente e inactualidad: la construcción de la temporalidad en las primera publicaciones independientes de poesía argentina en los noventa. Sobre las revistas La mineta y Trompa de Falopo". Recuperado de: http://www.mdp.edu.ar/humanidades/letras/celehis/congreso/2011/actas/ponencias/mos cardi.htm

Muleiro, Vicente. 1976. El golpe civil. Una historia del mal en la Argentina. Buenos Aires: Planera, 2011.

Mundo, Daniel. "La generación perdida". Lucha Armada en la Argentina 10 (2008): 4045.

Narrativa argentina. Segundo Encuentro de Escritores Dr. Roberto Noble. Buenos Aires: Fundación Dr. Roberto Noble, 1989.

Narrativa argentina. Quinto Encuentro de Escritores Dr. Roberto Noble. "Narrativa argentina, hoy. ¿Entre la tradición, la vanguardia y la 'post-modernidad'?”. Buenos Aires: Fundación Dr. Roberto Noble, 1992.

Narrativa argentina. Noveno Encuentro de Escritores Dr. Roberto Noble. "La Historia en literatura”. Buenos Aires: Fundación Dr. Roberto Noble, 1996.

Naveiro, Jorge "El deterioro de nuestra industria" [Entrevista de Juan Jacobo Bajarlía]. Clarin (Buenos Aires, 15 abril 1988): C- 4.

Noares, Norberto. "Los libros del '87. Entre la ficción y el narcisismo". "Culturas". Página/12 (27 dic. 1987): C-2-3.

Noriega, Gustavo. Estudio crítico sobre Los rubios. Buenos Aires: Picnic, 2009.

Novaro, Marcos y Vicente Palermo. "Las ideas de la época entre la invención de una tradición y el eterno retorno de la crisis". Marcos Novaro y Vicente Palermo, compiladores. La historia reciente: Argentina en democracia. Buenos Aires: Edhasa, 2004. 11-50.

Novaro, Marcos y Vicente Palermo. Historia Argentina. La dictadura militar 19761983. Tomo 9. Buenos Aires: Paidós, 2003.

Novaro, Marcos. Sal en las heridas. Las Malvinas en la cultura argentina contemporánea. Buenos Aires: Sudamericana, 2007.

Nuñez, Jorgelina y Alejandra R. Ballester. "Una galaxia de estrellas solitarias. Nueva encuesta a la literatura argentina". N. Revista de Cultura 325 (2009): 8-30. 
O’ Donell, María. "Encuentro de escritores argentinos en Pinamar. Vamos a la playa". "Primer Plano". Página/12 (Buenos Aires, 1º dic. 1991): C- 7.

Oesterheld, Héctor Germán/ Francisco Solano López. El Eternauta Vintage, Buenos Aires, Doedytores, 2012.

Olguín, Sergio. “Que bufen los eunucos”. Con V de Vian 7 (1992): 3.

Olguín, Sergio. "Malas intenciones". Con V de Vian 1 (1990): 3.

Ollier, María Matilde y Andrés Thompson. "Trascendente... Intrascendente". Punto de Vista 25 (1985): 42-44.

Ordaz, Luis. "Teatro: desde la generación intermedia a la actualidad". Adolfo Prieto, director. Historia de la literatura argentina. Buenos Aires: CEAL, 1968. 1225-1248.

Ortega y Gasset, José. El tema de nuestro tiempo. Madrid: Espasa Calpe, 2003.

Ortega y Gasset, José. En torno a Galileo. Madrid: Revista de Occidente, 1958.

Oubiña, David. "De la literatura entendida como delirium tremenda". Juan Pablo Dabove y Natalia Brizuela, comps. Y todo el resto es literatura. Ensayos sobre Osvaldo Lamborghini. Buenos Aires: InterZona 2008. 71-93.

Panesi, Jorge. "El peligroso juego de la literatura" [Reseña sobre Cicatrices] Pie de Página 2 (1983): 28-29.

Panesi, Jorge. "Puig, las relaciones peligrosas". Sitio 4/ 5 (1985): 124-131.

Panesi, Jorge. "La crítica argentina y el discurso de la dependencia". Filología 20 (1985): 171-195.

Panesi, Jorge. "Villa, el médico de la memoria". Ana María Barrenechea, comp. Archivos de la memoria. Rosario: Beatriz Viterbo, 2003. 13-25.

Parnes, Ohad, Ulrike Vedder y Stefan Willer. Das Konzept der Generation. Fráncfort del Meno: Suhrkamp, 2008.

Pasado y Presente. Edición facsimilar. Buenos Aires: Biblioteca Nacional, 2014.

Patiño, Roxana "Intelectuales en transición. Las revistas culturales argentinas (19811987)". Cuadernos de Recienvenido 4. San Pablo: Universidad de San Pablo (1997): 534.

Patiño, Roxana. "Revistas literarias y culturales argentinas de los 80". Insula 715-716 (2006): 137-149.

Pauls, Alan. "Alan Pauls" [Respuesta al cuestionario "Narrativa: el capítulo que se viene"]. Tiempo Argentino (Buenos Aires, 6 nov. 1983): C- 4.

Pauls, Alan. Manuel Puig: La traición de Rita Hayworth. Buenos Aires: Hachette, 1986.

Pauls, Alan. "La primera novela realista sobre el azar" [Reseña sobre La ocasión de J. J. Saer]. Babel, revista de libros 4 (1988): 4.

Pauls, Alan. "Lengua, ¡sonaste!". Babel, revista de libros 9 (1989): 5.

Pauls, Alan "Los de treinta y pico. Abran cancha" [Entrevista de Jorge Warley]. El Porteño (Buenos Aires, sept. 1990): C-37-39.

Pauls, Alan. "Corte y confección" [Entrevista de Matías Capelli y Oliverio Coelho]. los inrockuptibles 44 (2010b): 23-27. 
Pauls, Alan. "La primera novela realista sobre el azar" [Reseña sobre La ocasión] Babel, revista de libros 4 (1988): 4.

Pauls, Alan. "Maldito mito". "Radar". Página /12 (Buenos Aires, 4 mayo 2003) http://www.pagina12.com.ar/diario/suplementos/libros/10-550-2003-05-04.html

Pauls, Alan. "MaquinAira". "Radarlibros". Página /12 (Buenos Aires, 13 junio de 2004): C-3.

Pauls, Alan. Temas lentos. Santiago de Chile: Ediciones Universidad Diego Portales, 2012.

Pauls, Alan (2012) [Entrevista de Marcela Fuentealba]. Recuperado en: http://www.paula.cl/tendencia/los-temas-lentos-de-alan-pauls/

Pauls, Alan. "Treinta años después" [A propósito de la reedición de El coloquio]. "Radarlibros". Página /12 (Buenos Aires, 27 abril 2014): C- 25-28.

Pauls, Alan (2007) [Reseña sobre La arquitectura del fantasma para Otra Parte]. Recuperado en: http://www.revistaotraparte.com/n\%C2\%BA-12-primavera-2007/incorregible Peller, Diego (2011) "Osvaldo Lamborghini: dentro y fuera". Recuperado en: http://citclot.fahce.unlp.edu.ar/vii-congreso/actas-2009/Peller.pdf

Perelstein, Berta. "La teoría generacional y sus fuentes irracionales". Cuadernos de Cultura 66 (1964): 97-119.

Pérez, Ana Laura. "El futuro del mercado editorial". "Cultura y Nación". Clarín (12 enero 2002): C- 2.

Perlongher, Néstor. Prosa plebeya. Buenos Aires: Colihue, 2008.

Perriaux, Jaime. Las generaciones argentinas. Buenos Aires: Eudeba, 1970.

Petersen, Julius. "Las generaciones literarias". Emil Ermatinger, editor. Filosofia de la ciencia literaria. México: Fondo de Cultura Económica, 1946. 137-193.

Peyre, Hénri. Les générations littéraires. París: Boivin et Cle, 1948.

Pezzoni, Enrique. "Tres obras singulares”. Clarín (Buenos Aires, 27 nov. 1973): C- 3.

Piglia, Ricardo. "Notas sobre Facundo". Punto de Vista 8 (1980): 15-18.

Piglia, Ricardo. “A. Laiseca”. Punto de Vista 16 (1982): 132.

Piglia, Ricardo "Borges como crítico". Crítica y ficción. Buenos Aires: Planeta, 2000. 155-175.

Piglia, Ricardo. "Ficción y política en la literatura argentina". Karl Kohut y Andrea Pagni, editores. Literatura argentina hoy. De la dictadura a la democracia. Fráncfort del Meno: Vervuert, 1989. 97-103.

Piglia, Ricardo. La Argentina en pedazos. Buenos Aires: Ediciones de la Urraca, 1993.

Piglia, Ricardo. "Literatura en revista" [Conferencia de presentación de Magazín Literario]. Magazín Literario 2 (1997): 16-17.

Piglia (2012a) [Sobre la Colección Recienvenido] Recuperado en: http://elliberal.com.ar/ampliada.php?ID $=41047$

Piglia, Ricardo. "Los cuentos salvajes de Rodolfo Walsh". N. Revista de Cultura 498 (2013): 7-8.

Piña, Cristina. "La narrativa argentina de los años setenta y ochenta". Cuadernos Hispanoamericanos 517-519: "La cultura argentina. De la dictadura a la democracia" (1993): 121-138. 
Piro, Guillermo. “Oración por Owen. John Irving” [Reseña sobre Oración por Owen]. Babel, revista de libros 16 (1990): 8.

Pittaluga, Roberto y Alejandra Oberti. Memorias en montaje. Escrituras de la militancia y pensamientos sobre la historia. Buenos Aires: El Cielo Por Asalto, 2006.

Pittaluga, Roberto. "El pasado reciente argentino: interrogaciones en torno a dos problemáticas". Ernesto Bohoslavsky, Marina Franco, Mariana Iglesias y Daniel Lvovich, editores. Problemas de historia reciente en el Cono Sur. Buenos Aires, UNSAM-UNGS, 2010.

Porrúa, Ana (2004) "Una polémica a media voz: objetivistas y neo-barrocos en el Diario de Poesía". Recuperado en: http://www.celarg.org/boletines/articulos.php?idb=19

Porrúa, Ana. "La novedad en las revistas de poesía: relatos de una tensión especular". Orbis Tertius. Revista de Teoría y Crítica Literaria 10 (11) (2005). 57-72.

Porrúa, Ana. Caligrafía tonal. Ensayos sobre poesía. Buenos Aires: Entropía, 2011.

Portantiero, Juan Carlos. "La joven generación literaria". Cuadernos de Cultura 29 (1957): 27-44.

Pozzi, Pablo. Por las sendas argentinas. El PRT-ERP, la guerrilla marxista. Buenos Aires: Eudeba, 2001.

Premat, Julio. Héroes sin atributos. Figuras de autor en la literatura argentina. Buenos Aires: FCE, 2007.

Premat, Julio (coordinador). Glosa y El entenado. Poitiers: CNRLA-Archivos; Córdoba: Alción Editora, 2010.

Premat, Julio. La dicha de Saturno. Escritura y melancolía en Juan José Saer. Rosario: Beatriz Viterbo, 2007.

Prieto, Adolfo. Borges y la nueva generación. Buenos Aires: Letras Universitarias, 1954.

Prieto, Adolfo. “Conflictos de generaciones”. César Fernández Moreno, comp. América Latina en su literatura. México: siglo XXI editores, 1972. 406-423.

Prieto Adolfo (dir.). Historia de la literatura argentina. Buenos Aires: CEAL, 1968.

Prieto, Martín, Matilde Sánchez et al. "Literatura, mercado y crítica. Un debate". Punto de Vista 66 (2000): 1-9.

Prieto, Martín. Breve historia de la literatura argentina. Buenos Aires: Taurus, 2006.

Pujol, Sergio. Rock y dictadura. Crónica de una generación (1976-1983). Buenos Aires: Emecé, 2005.

Quiroga, Hugo. El tiempo del 'Proceso'. Conflictos y coincidencias entre políticos y militares 1976-1983. Rosario: Homo Sapiens Ediciones, 2004.

Rafecas, Daniel Eduardo. "La reapertura de los procesos judiciales por crímenes contra la humanidad en argentina". Gabriele Andreozzi, coord. Juicios por crímenes de lesa humanidad en Argentina. Buenos Aires: Atuel, 2011. 155-176.

Raggio, Sandra. "La construcción de un relato emblemático de la represión: la 'noche de los lápices'". Emilio Crenzel, coordinador. Los desaparecidos en la Argentina. Memorias, representaciones e ideas (1983-2008). Buenos Aires: Biblos, 2010. 137-160. Rama, Claudio. Economía de las industrias culturales. Buenos Aires: Eudeba, 2003

Rancière, Jacques. "La política de la estética". Cuaderno de Otra parte 9 (2006): 1-15.

Ranciere, Jacques. Política de la literatura. Buenos Aires: Libros del Zorzal, 2010.

Rancière, Jacques. El espectador emancipado. Buenos Aires: Manatial, 2010. 
Reati, Fernando. Nombrar lo innombrable. Violencia politica y literatura argentina 1975-1985. Buenos Aires: Legasa, 1992.

Reati, Fernando. Desaparecido. Memorias de un cautiverio. Club Atlético, El Banco, El Olimpo, El Pozo de Quilmes y ESMA. Buenos Aires: Biblos, 2011.

Rey, Pedro B. "Un genio exasperado". adnCULTURA. La revista cultural de los sábados. La Nación (Buenos Aires, 23 agosto 2008): C-4-5.

Ricci, Paulo. "Narrar la zona. Vanguardias literarias en una ciudad de provincia. Escenas, recorridos y autores en la Santa Fe de la década del setenta". Paulo Ricci, compilador. Cuando los sesenta fueron jóvenes. Literatura y política en la década del '60. Santa Fe: Facultad de Ciencias de la Educación- Universidad Nacional de Entre Ríos, 2006. 7-74.

Ricci, Paulo y Hernán Ronsino. "Una vuelta completa sobre la obra de un clásico" [Entrevista de Silvina Friera]. "Cultura y espectáculos". Página/ 12 (Buenos Aires, 28 de junio de 2011): C- 28-29.

Ricci, Paulo (comp.). Zona de prólogos. Buenos Aires: Seix Barral, 2011.

Ricoeur, Paul. Tiempo y narración: Configuración del tiempo en el relato histórico. México: Siglo XXI, 1983.

Ricoeur, Paul. "Para una teoría del discurso narrativo". Historia y narratividad. Barcelona: Paidós, 1999.

Ricoeur, Paul. Tiempo y narración I. Configuración del tiempo en el relato histórico. México: siglo veintiuno editores, 1998.

Ricoeur, Paul. Tiempo y narración III. El tiempo narrado. México: siglo veintiuno editores, 1996.

Rivera, Andrés, Carlos Dámaso Martínez, Syria Poletti, Pedro Orgambide, Juan Carlos Martín, Abelardo Castillo, Rodolfo Rabanal, Reina Roffe, Liliana Heker, Juan Forn y Angélica Gorodischer. "La novela argentina". Clarín (Buenos Aires, 15 abril 1988): C$4-5 ; 7 ; 10$ y 12 .

Rivera, Jorge B. "Apogeo y crisis de la industria del libro". Susana Zanetti, directora. Historia de la literatura argentina, vol. 4. Los proyectos de la vanguardia. Buenos Aires: CEAL, 1980/ 86. 625-648.

Rodríguez, Esteban y Fernando Alfón Scafati. "Voladuras (Historia, aventura y resignación)". El Ojo Mocho 16 (2001/ 2002): 22-23.

Rodríguez-Carranza, Luz. "Discursos literarios, prácticas sociales (Babel, revista de libros, 1988-1991)”. Hispamérica 61 (1992): 23-40.

Rodríguez Monegal, Emir. El juicio de los parricidas. La nueva generación argentina y sus maestros. Buenos Aires: Deucalión, 1956.

Rodríguez Santamaría, Mónica. "Una zona editorial en peligro". Clarín (Buenos Aires, 15 abril 1988): C-6-7.

Roffo, Analía. "La cultura nacional, ¿existe?" [Entrevista con Alcalde, Gusmán, Gorostiza y Goldar]. Tiempo Argentino (Buenos Aires, 24 abril 1983): C- 1-3.

Romero, José Luis (1997) "Nos falta una buena historia de los años setenta". Recuperado en: http://edant.clarin.com/diario/1997/05/15/rome00.htm

Romero, Luis Alberto. "La democracia y la sombra del Proceso". Hugo Quiroga y César Tcach, compiladores. Argentina 1976-2006. Entre la sombra de la dictadura y el futuro de la democracia. Rosario: Homo Sapiens Ediciones, 2006. 15-30.

Rojas, Ricardo. Historia de la literatura argentina. Buenos Aires; Kraft, 1917/ 22. 
Romero, Julia. "Manuel Puig: del delito de la escritura al error gay". Revista Iberoamericana 187 "Erotismo y escritura" (1999): 306-318.

Romero, Julia. “ 'Los posibles narrativos'. Estudio crítico genético de la fase prerredaccional”. Amícola, José y Jorge Panesi, directores). El beso de la mujer araña. Poitiers: CNRLA/ y FCE, 2002. XXXIII-LI.

Rosa, Nicolás. "Liturgias y profanaciones". Susana Cella, compiladora. Dominios de la literatura. Acerca del canon. Buenos Aires: Losada, 1998. 59-83.

Rosanvallon, Pierre. Por una historia conceptual de lo politico. Buenos Aires: FCE, 2003.

Rosenzvaig, Marcos. Copi: sexo, teatralidad y escritura. Buenos Aires: Biblos, 2003.

Rot, Gabriel. Los orígenes perdidos de la guerrilla en la Argentina. Buenos Aires: Waldhuter Editores, 2010.

Rot, Gabriel "Oportunismo y amarillismo político-literario". Ñ. Revista de Cultura 189 (2007): 13.

Rotker, Susana. "La literatura de la realidad" [Reseña a Polaroids]. "Primer Plano". Página /12 (Buenos Aires, 11 agosto 1991): C-6.

Rubinich, Lucas. "Retrato de una generación ausente". Punto de Vista 23 (1985): 44-46.

Rubinich, Lucas. "Notas grises sobre la esperanza". Los dias del viaje 1 (1988): 19-23.

Ruiz, Laura. Voces ásperas. Las narrativas argentinas de los '90. Buenos Aires: Biblos, 2005

Russo, Edgardo. "Los escritores argentinos debaten acerca de la relación entre la literatura y el mercado". La Maga 71 (1993): 47.

Russo, Edgardo. "Un debate sobre las nuevas tendencias en la literatura argentinas". $L a$ Maga 73 (1993): 44-45.

Saavedra, Guillermo. "Juan José Saer. El arte de narrar la incertidumbre”. La Razón (Buenos Aires, 21 dic. 1986): C- 1-5.

Saavedra, Guillermo. "Retrato de un artista con novela". El Porteño (Buenos Aires, sept. 1987): C- 72-74.

Saavedra, Guillermo. "La 'mafia' neobarroca". El nuevo periodista (Buenos Aires, 14 al 20 oct. 1988): C-40-42.

Saavedra, Guillermo. "C. E. Feiling: el arte de la hospitalidad" [Homenaje a Carlos Eduardo Feiling]. Magazín Literario 2 (1997): 8.

Sabanes, Ricardo "La investigación de mercado no es sólo para gasesosas y pantalones" [Entrevista de Miguel Russo] La Maga 121 (1994): 2.

Sábato, Hilda. “Olvidar la memoria”. Punto de Vista 36 (1989): 8-10.

Sábato, Hilda. "Historia reciente y memoria colectiva". Punto de Vista 49 (1994): 3034.

Saccomanno, Guillermo. "La crítica generalmente es miope, mezquina e interesada" [Entrevista de Miguel Russo]. La Maga 29 (1992): 29.

Saccomanno, Guillermo. "La literatura está en otra parte". "Primer Plano". Página/ 12 (Buenos Aires, 14 enero 1996): C- 2.

Saer, Juan José [1973]. “Narrathon”. El concepto de ficción. Buenos Aires: Seix Barral, 2004. 139-151. 
Saer, Juan José [1973]. "Freud o la glorificación del poeta". El concepto de ficción. Buenos Aires: Seix Barral, 2004. 152-156.

Saer, Juan [1982] "Literatura y crisis argentina". El concepto de ficción. Buenos Aires: Seix Barral, 2004. 94-120.

Saer, Juan José "Poder decirlo todo" [Entrevista de Sergio Racuzzi y Mónica Tamborenea]. Pie de Página 2 (1983): 4-5.

Sager, Valeria. "Destellos de la memoria entre la ciudad y el campo en algunas ficciones argentinas (1980-2005)". Miguel Dalmaroni y Geraldine Rogers, compiladores. Contratiempos de la memoria en la literatura argentina. La Plata: EDULP, 2009. 189-212.

Sager, Valeria. "Reflexiones para una historia de la narrativa argentina de los años 1990". Antonio Camou, María Cristina Tortti y Aníbal Viguera, compiladores. La Argentina democrática: los años y los libros. Buenos Aires: Prometeo Libros, 2007. 8396.

Saidón, Gabriela. La montonera. Buenos Aires: Sudamericana, 2005.

Saítta, Sylvia (2002) "Después de Borges. Apuntes sobre la nueva narrativa". Recuperado en: http://www.revistatodavia.com.ar/notas2/Saitta/textosaitta.htm

Saítta, Sylvia. "La narrativa argentina: entre la innovación y el mercado (1983-2003)". Marcos Novaro y Vicente Palermo, compiladores. La historia reciente: Argentina en democracia. Buenos Aires: Edhasa, 2004. 239-256.

Saítta, Sylvia. "Un mapa casi literario: crítica literaria y crítica cultural en $V$ de Vian (1990-2001)". El Matadero 4. "Revistas argentinas del siglo XX”. Buenos Aires: Corregidor, 2005. 287-298.

Salas, Horacio. Generación poética del '60. Buenos Aires: Ediciones Culturales Argentinas, 1975.

Samoilovich, Daniel. "Respiración artificial. Ricardo Piglia”. Babel, revista de libros 1 (1988): 11.

Samoilovich, Daniel. "Barroco y neo-barroco”. Diario de Poesía 14 (1990): 18.

Sánchez, Matilde. "Entre la imaginación y la práctica". Babel, revista de libros 15 (1990): 4-5.

Sanguineti, Edoardo. Vanguardia, ideología y lenguaje. Monte Ávila Editores: Caracas 1969.

Sarduy, Severo. "El barroco y el neobarroco". César Fernández Moreno, comp. América Latina en su literatura. México: siglo XXI editores, 1972. 167-184

Sarduy, Severo. "Dios detrás de la seducción" [Entrevista de Alicia Dujovne Ortiz]. Vigencia 43 (1980): 31.

Sarlo, Beatriz. "Novela argentina actual: códigos de los verosímil". Los libros 25 (1972): 18-19.

Sarlo, Beatriz. “Cortázar, Sábato y Puig: ¿parodia o reportaje?”. Los libros 36 (1974): 32-33.

Sarlo, Beatriz. "Raymond Williams y Richard Hoggart: sobre cultura y sociedad". Punto de Vista 6 (1979). 9-18. 
Sarlo, Beatriz. "Literatura y política". Punto de Vista 19 (1983): 8-11.

Sarlo, Beatriz [Respuesta a la encuesta "Literatura y situación nacional”]. Pie de Página 2 (1983): 14.

Sarlo, Beatriz. "El saber del texto". Punto de Vista 26 (1986): 6-7.

Sarlo, Beatriz. "Política, ideología y figuración literaria" [1987]. Daniel Balderston, compilador. Ficción y política: La narrativa argentina durante el proceso militar. Buenos Aires: Alianza, 1987. 30-59.

Sarlo, Beatriz. "Strategies of the Literary Imagination". Patricia Weiss Fagen y Manuel Carretón, editores. Fear at the Edge. State Terror and Resistance in Latin America. California/ Oxford: University of California Press, 1992. 236-249.

Sarlo, Beatriz. "Intelectuales y revistas: razones de una práctica". Cahiers du CRICCAL. Le discours culturel. Dans les revues latino-américains (1940-1970) n. 9/ 10 (1992): 916.

Sarlo, Beatriz. "Prólogo a la edición en español de Raymond Williams: del campo a la ciudad". Raymond Williams. El campo y la ciudad. Buenos Aires: Paidós, 2001. 11-22.

Sarlo, Beatriz "La extensión” [Sobre El pasado] Punto de Vista 78 (2004): 12-18.

Sarlo, Beatriz. "Campo intelectual" [Entrevista de Daniel Link]. "Radarlibros". Página/ 12 (Buenos Aires, 21 dic. 2003): C- 1-3.

Sarlo, Beatriz [1996]. “Coincidencias: Villa, de Luis Gusmán”. Daniel Balderston et al. Escrito por otros. Ensayos sobre los libros de Luis Gusmán. Buenos Aires: Norma, 2004. 149-160.

Sarlo, Beatriz. Tiempo pasado. Cultura de la memoria y giro subjetivo. Una discusión. Buenos Aires: Siglo Veintiuno Editores, 2005.

Sarlo, Beatriz. "La ficción, antes y después de 1976". N. Revista de Cultura 129 (2006): 16-17.

Sarlo, Beatriz. "Sujetos y tecnologías. La novela después de la historia". Punto de Vista 86 (2006): 1-6.

Sarlo, Beatriz. Escritos sobre literatura argentina. Buenos Aires: Siglo XXI Editores Argentina, 2007.

Sarlo, Beatriz. "El abandono de la trama: entre Aira y Guebel". Rocco Carbone y Ana Ojeda, comps. De Alfonsín al menemato 1983-2001: literatura argentina siglo XX. Buenos Aires: Paradiso, 2010. 107.

Sarlo, Beatriz. "El sueño de una utopía estética" [Reseña a Papeles de trabajo I]. N. Revista de Cultura 453 (2012): 6-8.

Sarlo, Beatriz Ficciones argentinas. 33 ensayos. Buenos Aires: mardulce, 2012.

Sassi, Hernán. "A pesar de Shangai, a pesar de Babel". Pensamiento de los Confines 18 (2006): 205-212.

Sasturain, Juan. "Boquetes frustrados" [Reseña sobre Maldición eterna a quien lea estas páginas]. Humor Registrado 136 (1981): 130-132.

Scavino, Dardo. Saer y los nombres. Buenos Aires: El Cielo por Asalto, 2004. 
Scavino, Dardo. "El vacío, las nubes y la lengua. Una introducción a Glosa, de Saer". Rocco Carbone y Ana Ojeda, comps. De Alfonsín al menemato 1983-2001: literatura argentina siglo XX. Buenos Aires: Paradiso, 2010. 73-90.

Schavelzon, Guillermo. "Las futuras generaciones, comprometidas". Clarín (Buenos Aires, 7 marzo 2002): C- 25.

Schmidt, Siegfried J. Kalte Faszination: Medien, Kultur, Wissenschaft in der Mediengesellschaft. Weilerswist: Velbrück, 2000.

Schmucler, Héctor. "Los silencios significativos" [Reseña sobre Boquitas pintadas]. Los libros 4 (1969): 8-9.

Schmucler, Héctor. "Las exigencias de la memoria". Punto de Vista 68 (2000): 5-9.

Schulz, Andreas y Gundula Grebner. „Zur Renaissance eines umstrittenen Forschungskonzepts". Andrea Schulz y Gundula Grebner, editores. Generationswechsel und historischer Wandel (Historische Zeitschrift, vol. 36). Múnich: R. Oldenbourg Verlag, 2003. 1-23.

Schwarzberg, Lucio. "Elogio de la prosodia del maestro". Los días del viaje 1 (1988) 15-18.

Scolnik, Sebastián. Catálogo, Ediciones Biblioteca Nacional 2014. Buenos Aires: Biblioteca Nacional, 2014.

Seoane, María y Héctor Ruiz. La noche de los lápices. Buenos Aires: Contrapunto, 1986.

Sidicaro, Ricardo. Los tres peronismos. Estado y poder económico. 1946-55, 1973-76, 1989-99. Buenos Aires: Siglo Veintiuno Editores, 2002.

Sigal, Silvia. Intelectuales y poder en la década de los sesenta. Buenos Aires: Puntosur, 1991.

Sigal, Silvia. "La polémica sobre el genocidio". Puentes 5 (2001): 62-63.

Soares, Norberto. "Dificultades y resonancias del libro argentino". Página/12 (Buenos Aires, 27 dic. 1987): C-2-3.

Soriano, Osvaldo. "La revolución de mayo todavía está pendiente" [Entrevista de Daniel Ares]. La Maga 20 (1992): 1-3.

Speranza, Graciela. Manuel Puig. Después del fin de la literatura. Buenos Aires: Norma, 2000.

Speranza, Graciela. "Magias parciales del realismo". milpalabras 2 (2001): 57-64.

Speranza, Graciela. Fuera de campo: literatura y arte argentinos después de Duchamp. Barcelona: Anagrama, 2006.

Speranza, Graciela. “DDónde está el autor?”. Otra parte 14 (2008): 7-12.

Steimberg, Alicia "Primer Plano". Página/ 12 (Buenos Aires, 7 febrero 1993): C- 8.

Strafacce, Ricardo. "La literatura de verdad no es cosa de este mundo". [Entrevista de Pedro B. Rey]. adnCULTURA. La revista cultural de los sábados. La Nación (23 agosto 2008): C- 7 .

Strafacce, Ricardo. Osvaldo Lamborghini: una biografia. Buenos Aires: Mansalva, 2008.

Svampa, Maristella. La sociedad excluyente. La Argentina bajo el signo del neoliberalismo. Buenos Aires: Taurus, 2005. 
Sverdlick, Laura. “¿Pueden editar los argentinos?” [Entrevistas a José Luis Retes; Jorge Zicollillo; Daniel Divinsky: Jorge Naviero y Enrique Pezzoni]. Clarín (Buenos Aires, 19 nov. 1987): C-1-3.

Tabarovsky, Damián. “Literatura de izquierda”. milpalabras 3 (2002): 34-40.

Tabarovsky, Damián. Literatura de izquierda. Rosario: Beatriz Viterbo Editora, 2004.

Tabarovsky, Damián. "Los atributos del loro". Marcelo Damiani, comp. El efecto Libertella. Buenos Aires: Beatriz Viterbo Editora, 2010. 41-47.

Tabarovsky, Damián, Mariana Mariasch y Hernán Vanoli. "Nuevas formas de vida para la literatura" [Entrevista de Mauro Libertella]. N. Revista de Cultura 463 (2012): 26-27.

Tarcus, Horacio "La secta política. Ensayo acerca de la pervivencia de lo sagrado en la modernidad". El Rodaballo 9 (1998/ 1999): 23-33.

Tarcus, Horacio. "Notas para una crítica de la razón instrumental. A propósito del debate en torno a la carta de Oscar del Barco". Políticas de la Memoria 6/ 7 (2006/ 2007): 14-25.

Tcherkaski, José. Habla Copi. Homosexualidad y escritura. Buenos Aires: Galerna, 1998.

Terán, Oscar. "Tiempo de memoria". Punto de Vista 68 (2000): 10-12.

Terán, Oscar. "Violencia, dictadura y cultura en la década de 1970". Oscar Terán, coordinador. Ideas en el siglo. Intelectuales y cultura en el siglo XX latinoamericano. Buenos Aires: Siglo Veintiuno Editores, 2004. 81-92.

Terán, Oscar. Nuestros años sesenta: la formación de la nueva izquierda. Buenos Aires: Puntosur, 1991.

Todorov, Tzvetan. Los abusos de la memoria. Buenos Aires: Paidós, 2000.

Torre, Juan Carlos. "Los intelectuales y la experiencia democrática". Marcos Novaro y Vicente Palermo, compiladores. La historia reciente: Argentina en democracia. Buenos Aires: Edhasa, 2004. 193-197.

Torres Fierro, Danubio (coordinador). "Literatura Argentina actual: un panorama", Vuelta Sudamericana 8 (1987): 8-55.

Tortti, María Cristina: "Debates y rupturas en los partidos Comunista y Socialista durante el frondizismo". Prismas. Revista de historia Intelectual 6 (2002): 265-274.

Tortti, María Cristina. "Debates sobre la historia argentina reciente". Camou, María Cristina Tortti y Aníbal Viguera, compiladores. La Argentina democrática: los años y los libros. Buenos Aires: Prometeo Libros, 2007. 114-126.

Uriarte, Claudio. Almirante Cero. Buenos Aires: Planeta, 1992.

Urresti, Marcelo. "Generaciones". Carlos Altamirano, director. Términos críticos de sociología de la cultura. Buenos Aires: Paidós, 2002. 93-95.

Usubiaga, Viviana (2012) "Un poco de prosa sobre el Diario de Poesía”. Exposición 25 años de Diario de Poesía. Espacio Arte Fundación OSDE, 9/2 al 31/3 de 2012. Recuperado en: http://www.fundacionosde.com.ar/backend/upload/files/img_\$218.pdf

Vattimo, Gianni. Poesía y Ontología. Valencia: Universitat de Valencia, 1993.

Verbitsky, Horacio. Rodolfo Walsh y la prensa clandestina: 1976-1978. Buenos Aires: Ediciones de la Urraca, 1985. 
Verbitsky, Horacio. Civiles y militares. Memoria secreta de la transición. Buenos Aires: Contrapunto, 1987.

Verbitsky, Horacio. El vuelo. Buenos Aires: Planeta, 1995.

Verbitsky, Horacio. "La revelación de lo escondido". "Radar". Página/ 12 (Buenos Aires, 23 marzo 1997): C- 4.

Verbitsky, Horacio. Doble juego. La Argentina católica y militar. Buenos Aires, Sudamericana, 2006.

Verbitsky, Horacio y Juan Pablo Bohoslavsky (comps.). Cuentas pendientes. Los cómplices económicos de la dictadura. Buenos Aires: siglo XXI editores, 2103.

Vezzetti, Hugo. "La memoria y los muertos". Punto de Vista 49 (1994): 1-4.

Vezzetti, Hugo. "Representaciones de los campos de concentración en la Argentina". Punto de Vista 68 (2000): 13-17.

Vezzetti, Hugo. Pasado y presente. Guerra, dictadura y sociedad en la Argentina. Buenos Aires: Siglo Veintiuno Editores, 2002.

Vezzetti, Hugo. Sobre la violencia revolucionaria. Buenos Aires: Siglo XXI, 2009.

Viniarsky, Diego. “Historia de un número dos”. Magazín Literario 2 (1996): 1.

Viñas, David. Literatura argentina y realidad política. Buenos Aires: Jorge Álvarez, 1964.

Viñas, David. "Una generación traicionada. A mis camaradas de Contorno". Marcha 992 (1959): 12-15, 20.

Viñas, David. "Una generación traicionada. A mis camaradas de Contorno". Marcha 993 (1960): 22-23.

Viñas, David. De los jacobinos porteños a la bohemia anarquista. Buenos Aires: Santiago Arcos Editor, 2008

Viñas, David [2004] "Viñas de ira" [Entrevista de Jorge Aulicino y Vicente Muleiro]. "500 Ñ. Revista de Cultura. Breve Antología". Clarín (Buenos Aires, 27 abril 2013): C26-29.

Vitullo, Julieta. Islas imaginadas. Buenos Aires: Corregidor, 2012.

Warley, Jorge y Alberto Castro. "La escasez austral y la moda". "Culturas". Página/ 12 (Buenos Aires, 27 dic. 1987): C-2-3.

Warley, Jorge. "Revistas culturales de dos décadas (1970-1990)". Cuadernos Hispanoamericanos 517-519. "La cultura argentina. De la dictadura a la democracia" (1993): 195-207.

Weigel, Sigrid. „Familienbande, Phantome und die Vergangenheitspolitik des Generationsdiskurses“. Jureit, Ulrike y Michael Wildt. Generationen. Zur Relevanz eines wissenschaftlichen Grundbegriffs. Hamburgo: Hamburger Edition, 2005. 108-126.

Williams, Raymond. La larga revolución. Buenos Aires: Nueva Visión, 2003.

Williams, Raymond. Marxismo y literatura. Buenos Aires: Las cuarenta, 2009.

Williams, Raymond. Palabras clave. Un vocabulario de la cultura y la sociedad. Buenos Aires: Nueva Visión, 2000.

Williams, Raymond. Problems in Materialism and Culture. Londres: Verso, 1980. 
Williams, Raymond. Cultura. Sociología de la comunicación y del arte Barcelona: Paidós, 1982.

Yerushalmi, Yosef, Nicole Loraux, Hans Mommsen, Jean-Claude Milner y Gianni Vattimo. Usos del olvido. Buenos Aires: Nueva Visión, 1998.

Yuszczuk, Marina (2011) Lecturas de la tradición en la poesía argentina de los noventa. Recuperado en: http://www.memoria.fahce.unlp.edu.ar/tesis/te.742/te.742.pdf

Zanetti, Susana. Historia de la literatura argentina. Buenos Aires: CEAL, 1980/ 86.

Zanetti, Susana. Encuesta a la literatura argentina contemporánea. Buenos Aires: CEAL, 1982.

Zina, Alejandra. "Babel: un modo de nombrar el comienzo". El Matadero 3. Literatura argentina contemporánea (1984-2004). Buenos Aires: Corregidor, 2004. 11-22.

Zina, Alejandra. "La historia de un libro legendario" (sobre Los Sorias)". N. Revista de Cultura 399 (2011): 9.

Zinn, Ricardo. La segunda fundación de la República. Buenos Aires: Pleamar, 1976.

Zubietta, Ana María (2009) "Formarse en dictadura: los grupos de estudio como universidad paralela". Recuperado en: http://conti.derhuman.jus.gov.ar/_pdf/seminario2-09/programa.pdf Zunini, Patricio. Fogwill, una memoria coral. Buenos Aires: Mansalva, 2014. 